
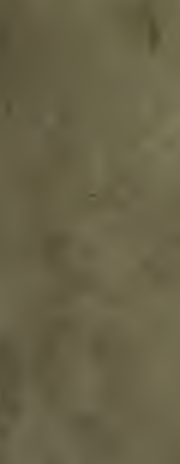
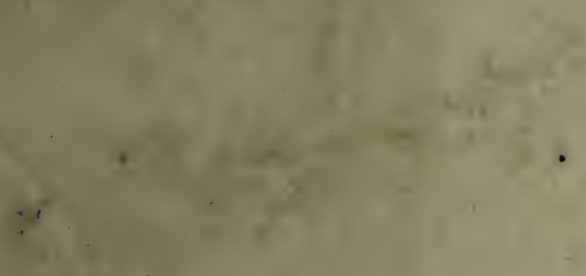

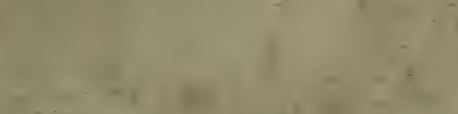

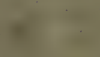

$-1$

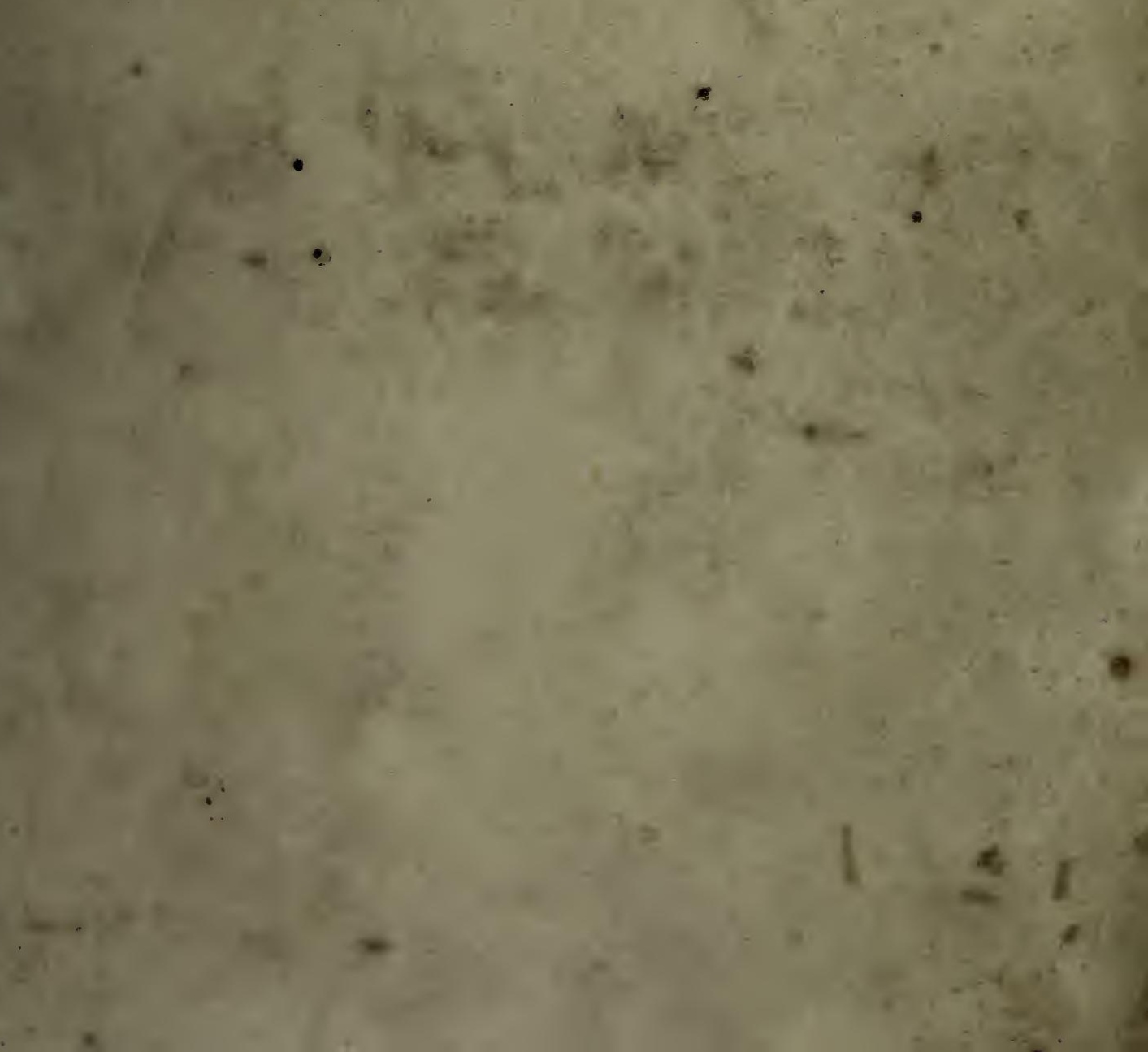







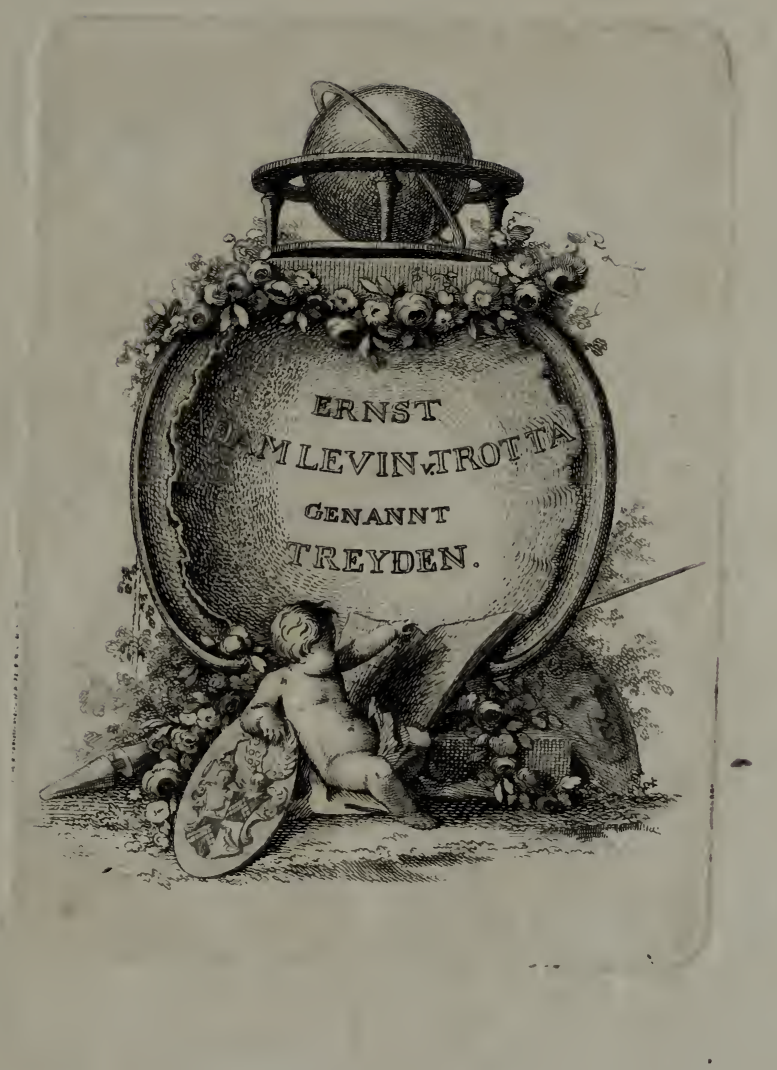




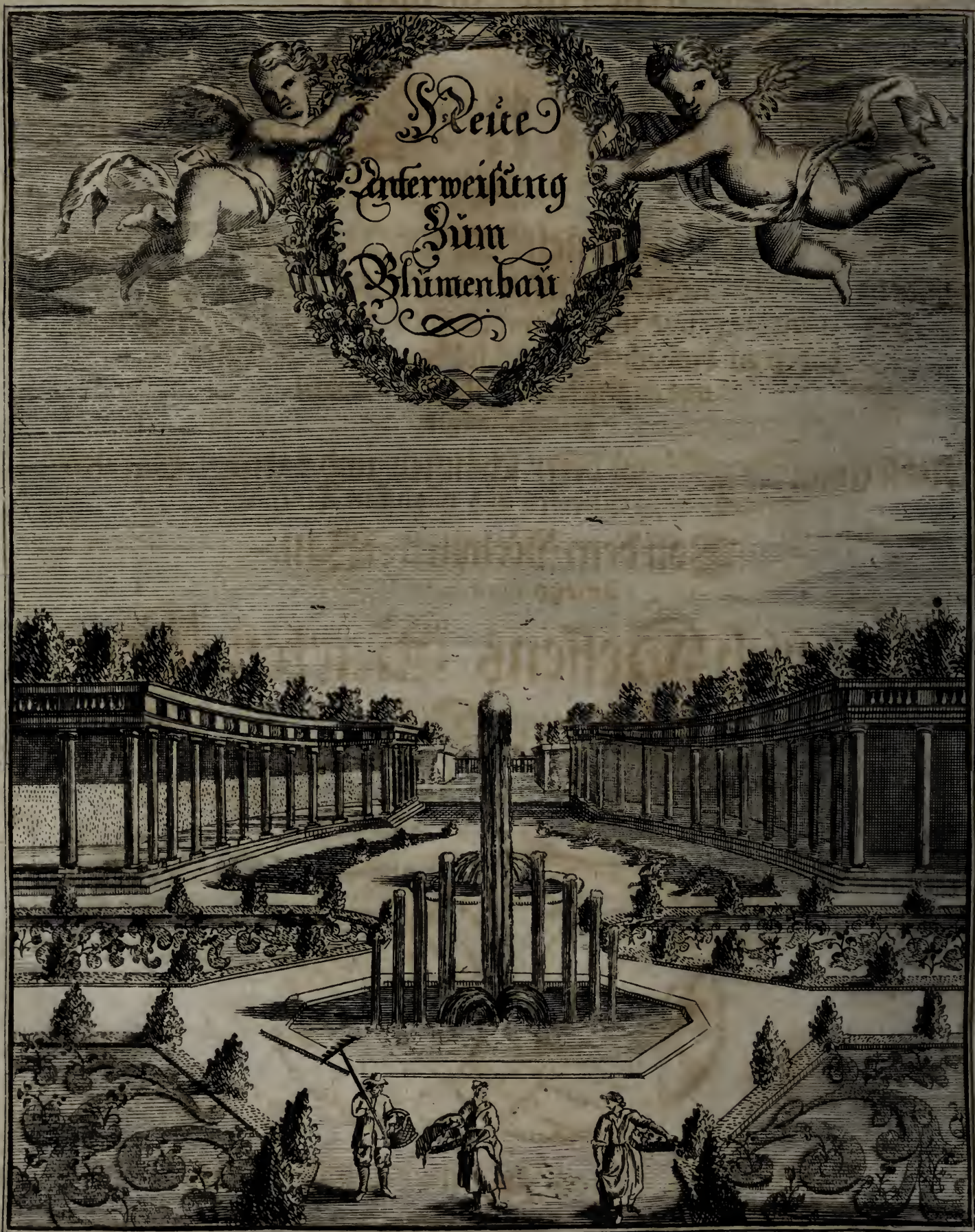




\section{Nene Unterfweifutg \\ 9. \\ morintret}

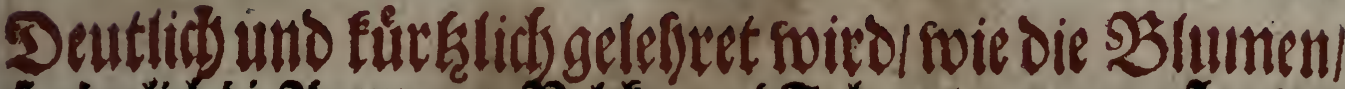

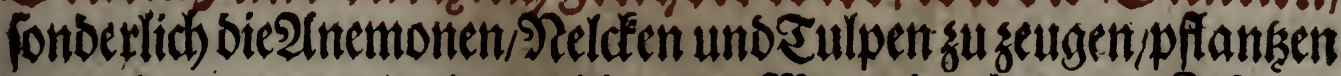
und zu warten/ und was iedweden Monat Durds gankese Jabr Dabev) zu beobadten I Daß fold)e zu ibrer fdjonften und angenebmften $\mathfrak{B}$ odfommenbeit gelangen mógen.

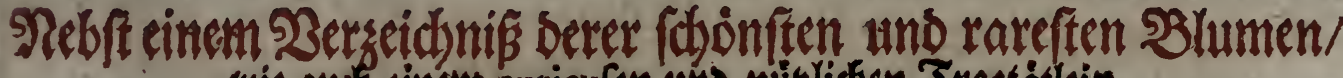
wie auct einem curieufen uno nüblidjen stactảtlein

\section{3ison Dem s) felonet = 2nieso sls ein $3 a$}

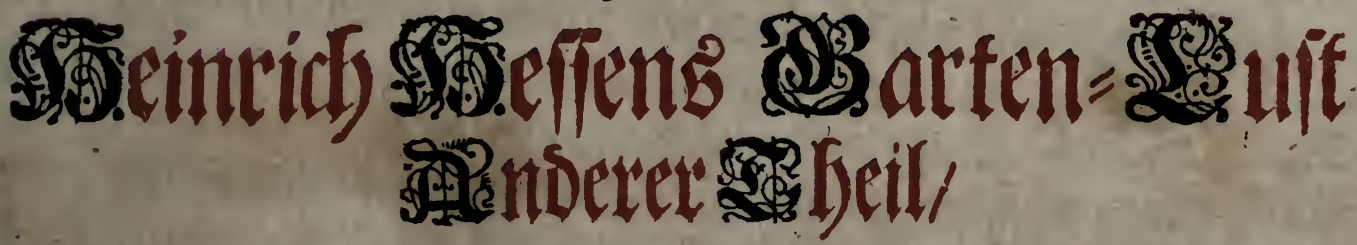

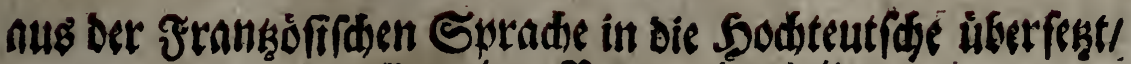
und zu allgemeinen $\mathfrak{R u g} e n$ mitgetbeilet.

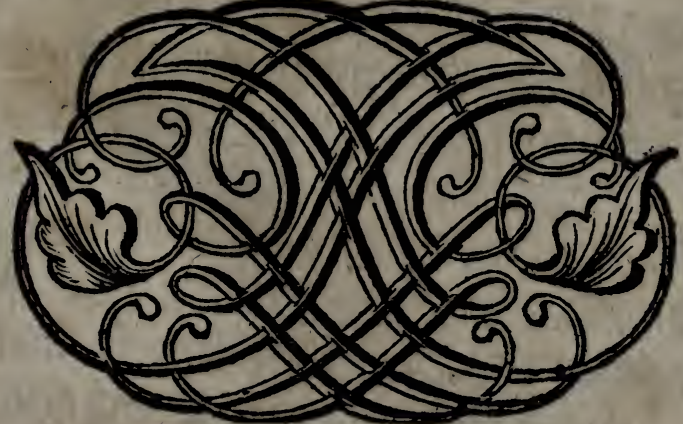

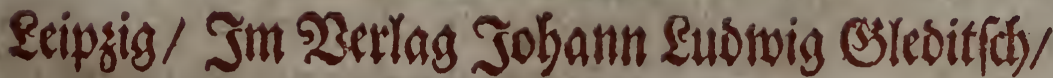
As No 1705. 


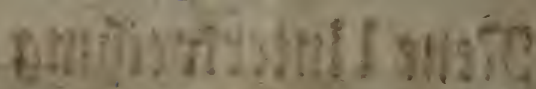

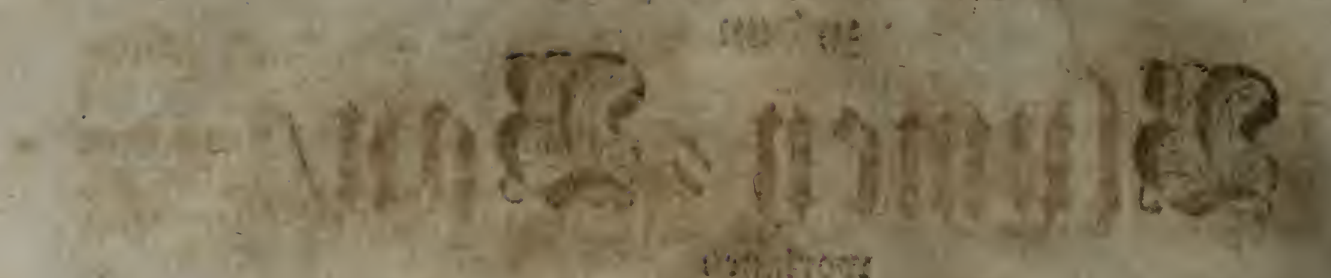

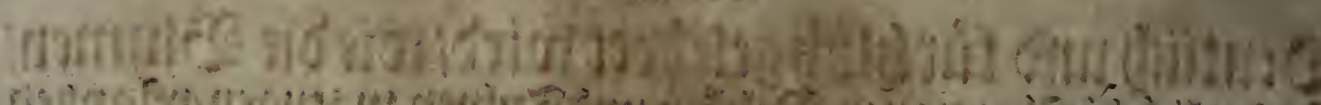

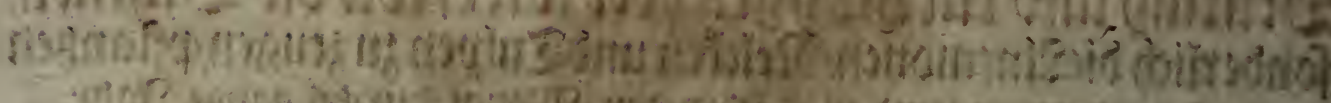

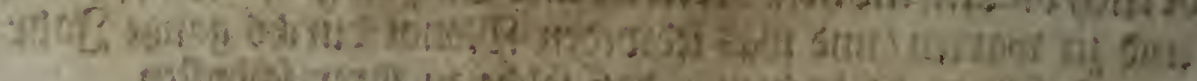

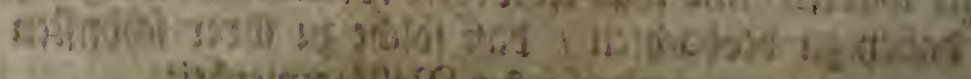

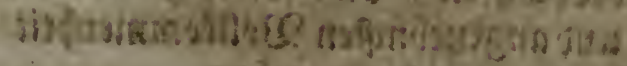

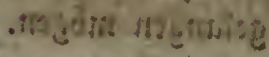

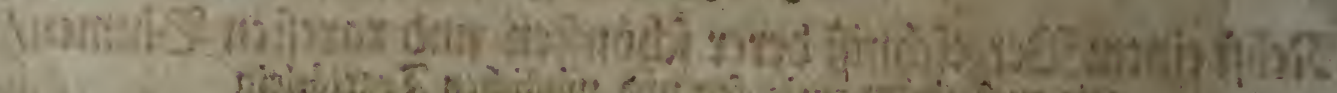

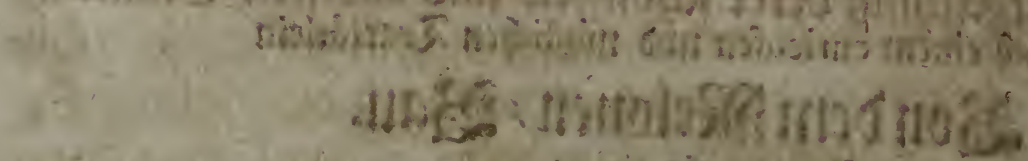

\section{uf}

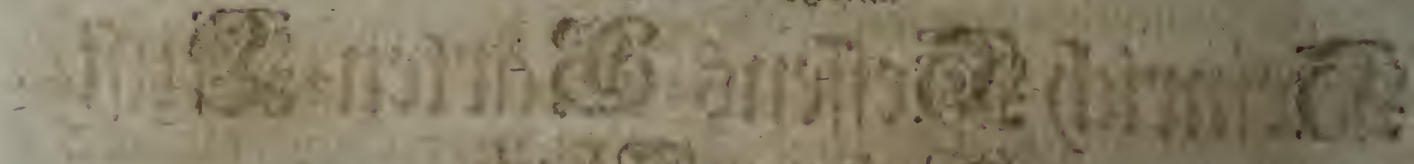

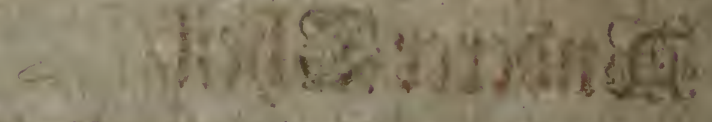

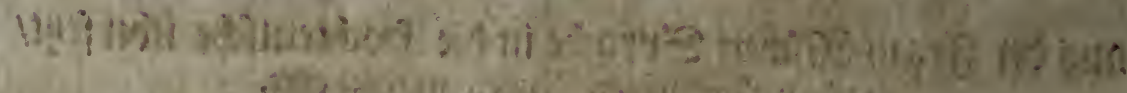

$4 x^{2}$

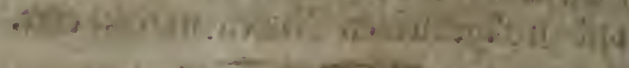

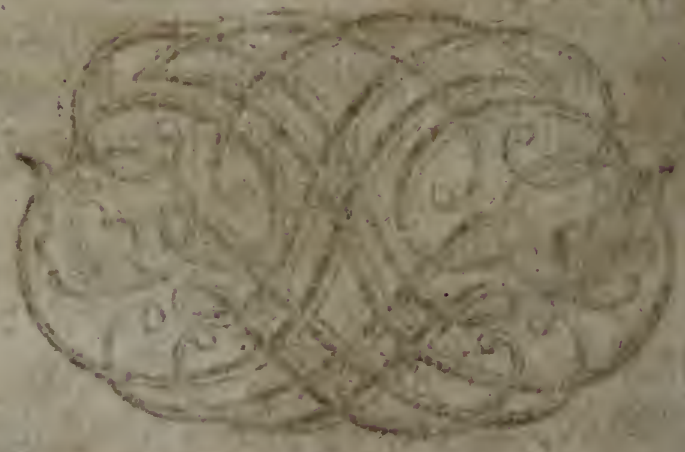

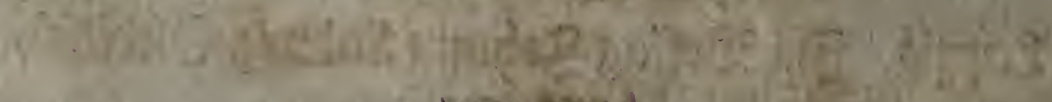

$$
\text { ince seras }
$$




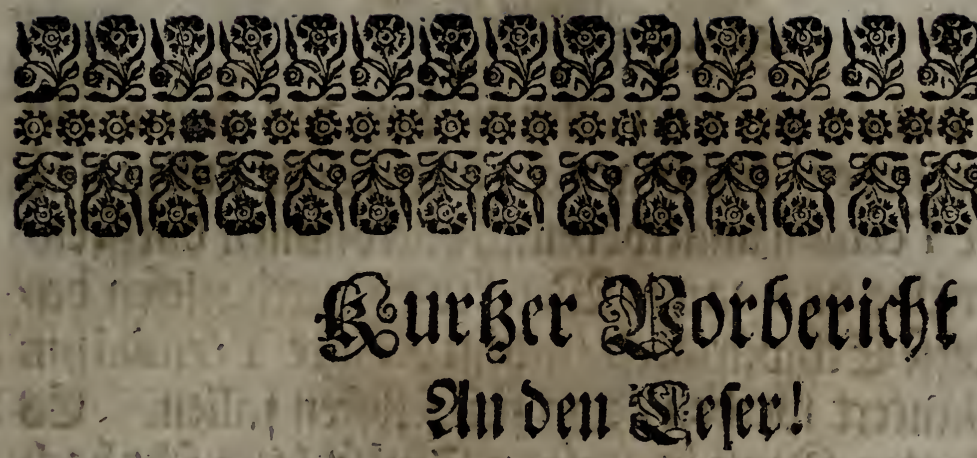

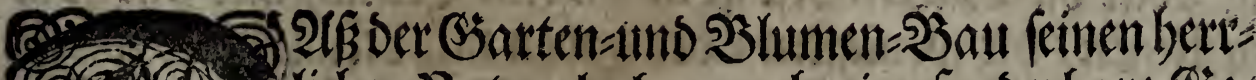

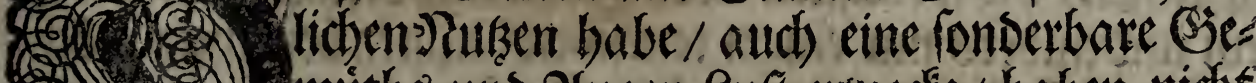

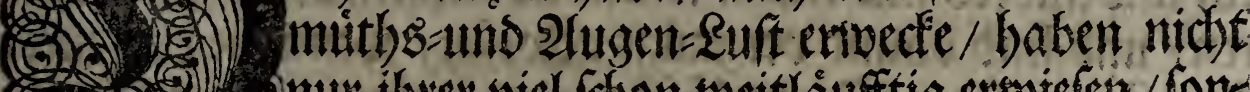
(2) mur ibser viel fobon tocitláufftig errwiefen / fonfalsumis/ Daßs Dannenbero cin mebrers allfier Dawon sures Den unnotbig fernn mird; 2 ielmebe iff man berwogen morden/

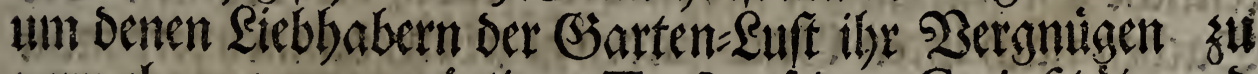
vermebern/gegentwaittigen Tractat feiner Curiofitat und

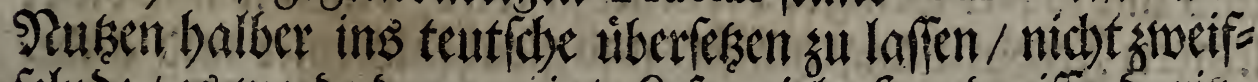
felnde / es werde ber geneigte \&efer vilie Sandgriffe barin= wen finden / Dic ibme bishero nods ganis unbefandt ges

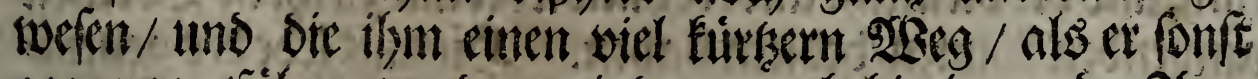

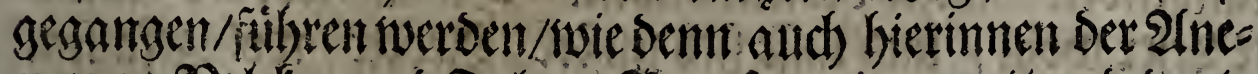

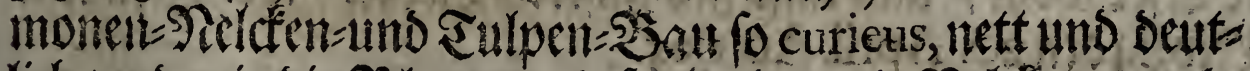

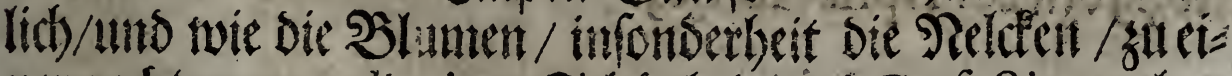
ner red)t extraordinairen Sthonbeit into Perfection gefan gen mógen/ tractiret wito / als mod) niemals in cinem teuts

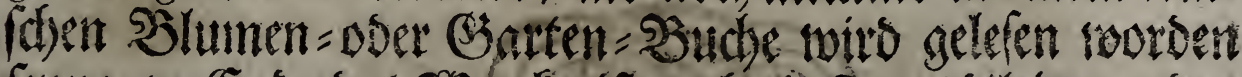

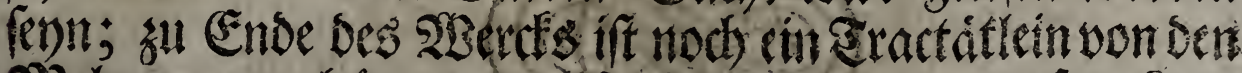

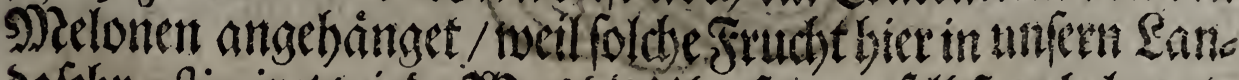

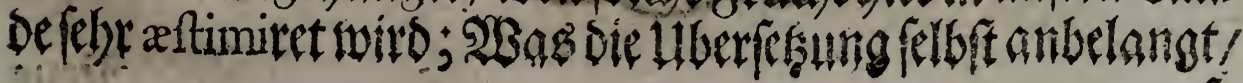




\section{Borrede.}

To ift man / fo viel es bat fennt foimeen/ ben. Des Autoris fei

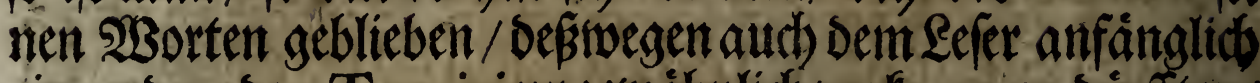

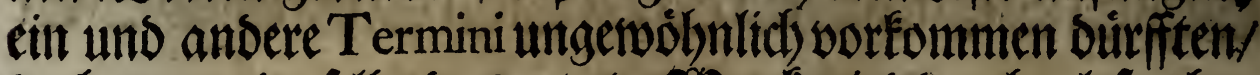
Dod) wann berfelbe bas gant3e $923 e r d f$ wiro burch gelefen ha: ben / fo wirb Diefe Sthiwirigkeit/ indem befagte Termini biit und wieber erláutert werben / won fidb felbiften fallen. EE if stwar bie Garten= Fiunft in unferm Seutfolano febr hod geftiegen / bie wenigften aber baben fich befuimmert / wie fie ein und anders mit einem teutifden ? ?amen benennen mód)= ten / und find Damit vergmigt getweren/ weenn fie bas mei-

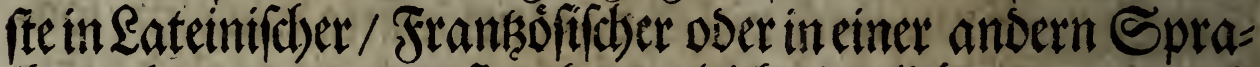
d) zu benennen getwulf / ob es gleid siemlich corrupt und gerftummelt beraus gefommen; 2Andere aber haben swar

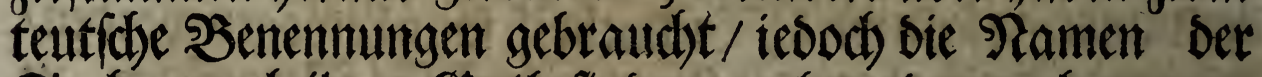
Sadhen nadb ibren Guttbefinden gegeben / Dannenbero man uns um fo viel iweniger verdendten wird/ Dafis wir uns diefer lestern Stenleit antgemaffet/und gleidffals einer und andes ret / (obgleid) unbefanter / Dods verftänolicher Terminorum, und bie vielleicht anderebinwiederum su ihren 20 ortheil antwenden fómen/beoient baben. Siermit lebeder geneig= te eferer wobl / uno laffe fich uniere 2lrbeit woblgefallen. Seipśtg den 20. April.Ao.1705.

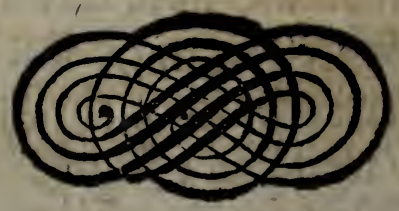




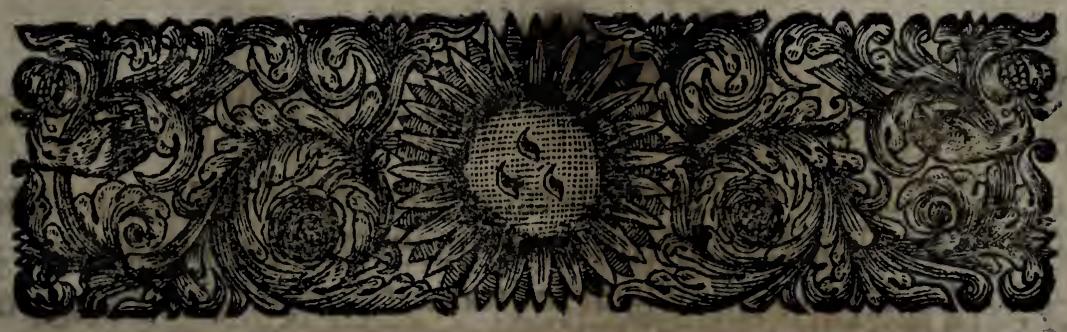

\section{Seuc Lluterneifung zu Dem
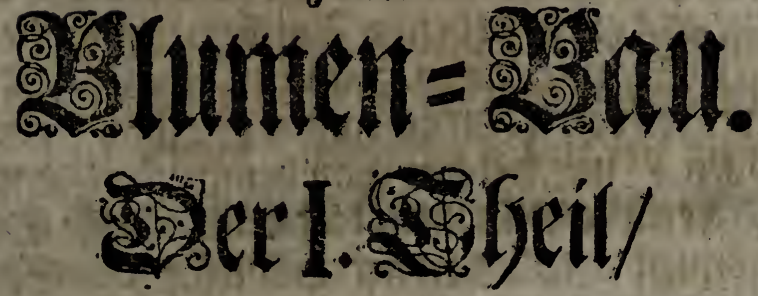

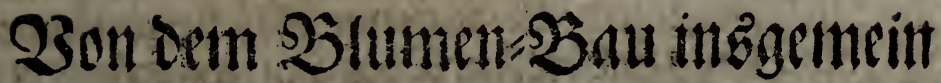

\section{2aร 1. Capitel}

2Bon oem Gintrne/ uno senen ant ifme erfor: Derten Cigenichafiften.

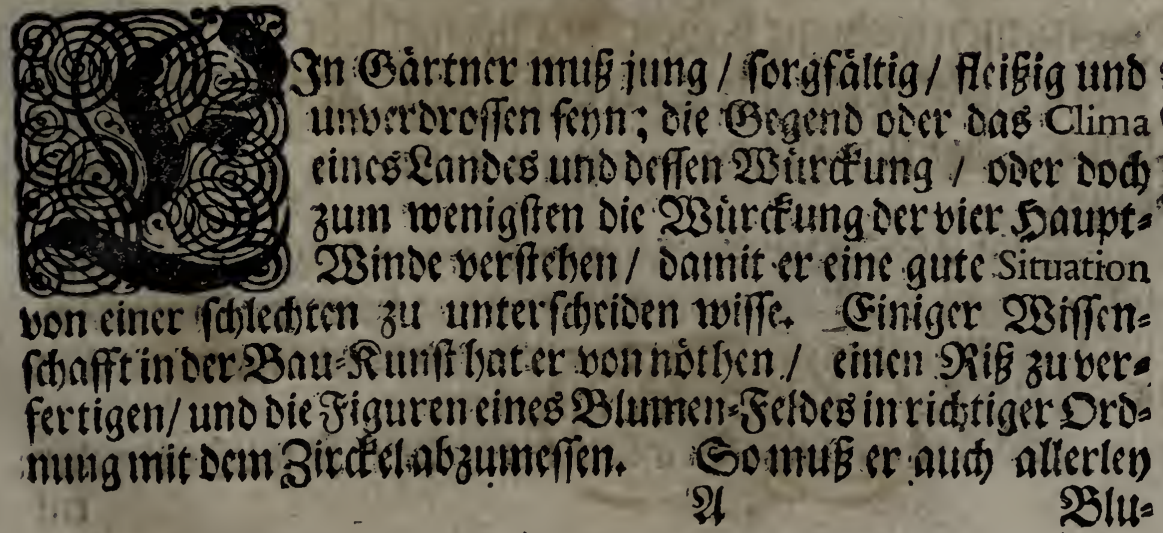




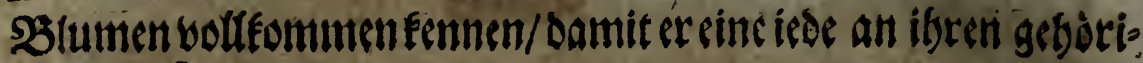
gen Drt feger.

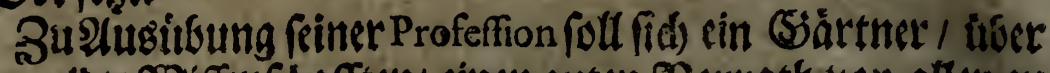

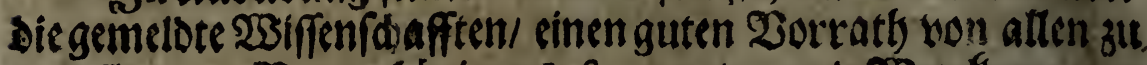

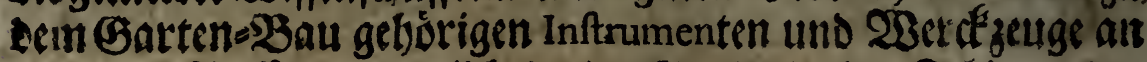

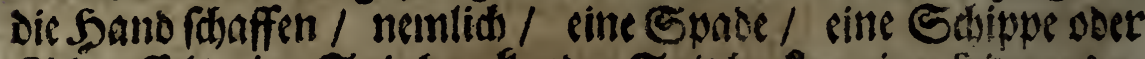

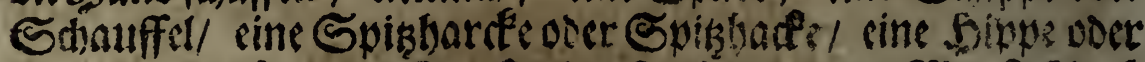
Garten=Meffer/ cine SarcPe voer Bieden / cinen MinaE:-Stab

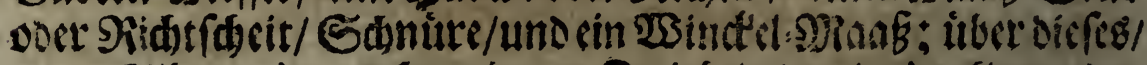

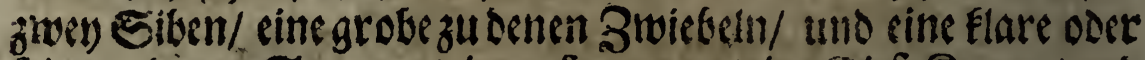

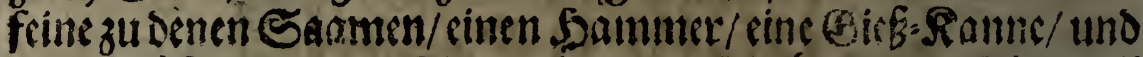
etlide glafere oder bon Thon getrannte Glodien/acten Dbretbeil

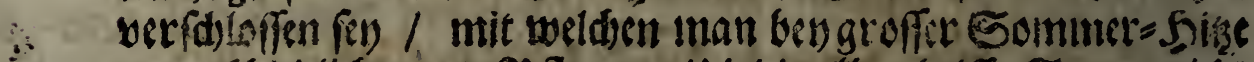
unter rd) icolide zarte Poflankzen/ Die dic allzu beiffe Sonne nidit

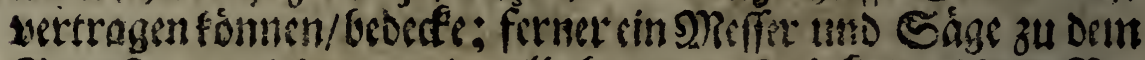

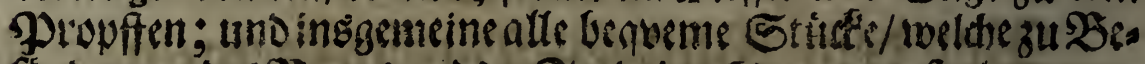

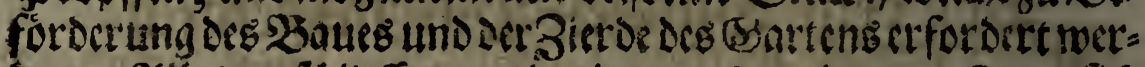
sen. Altes verfotlieffer mant in einen nabe gelegenen Drt/ fids. Deffen im?otbfallbedenen zแ foumen.

\section{2ng II. Cnpifel \\ 3on Det Situation Deร Ğanteng.}

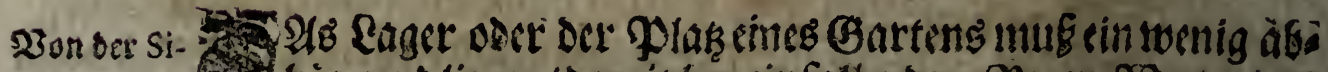
tuation dec שartens.

$23 a$ forme.

bàngend liegen/ damit bencinfallendem SRegen-23etter das 23arfer nidte frelsen bleise und faule I foubern frow atlaufion

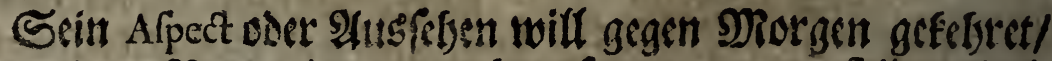

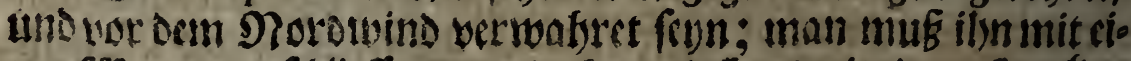

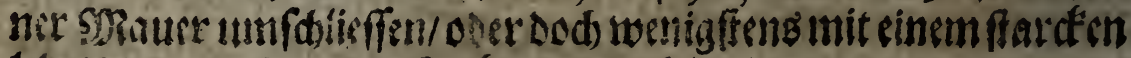
Jhbivigen Spalier oder f fedten umgetern.

Soltecsancinemizrumersmangsin 7 fo mus entrweder 


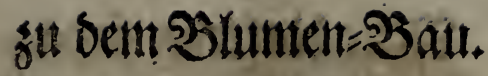

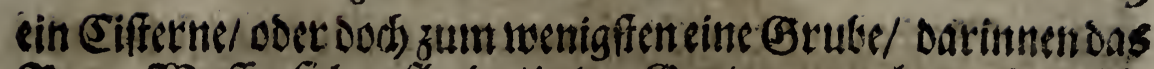

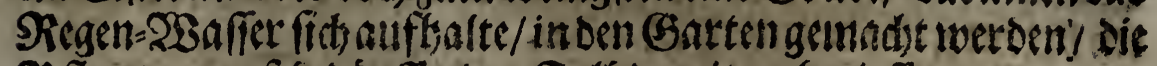

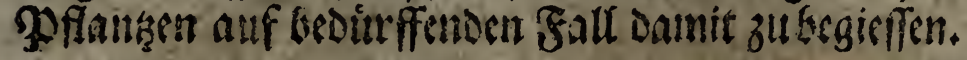

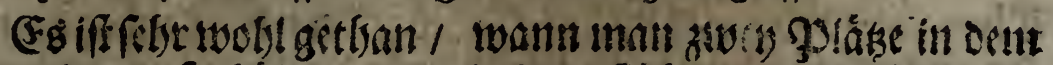

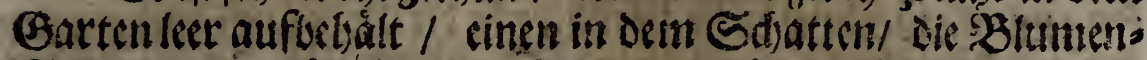

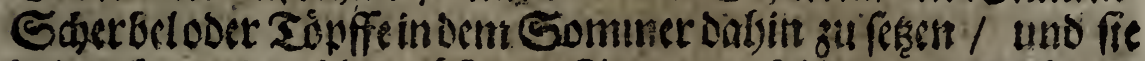

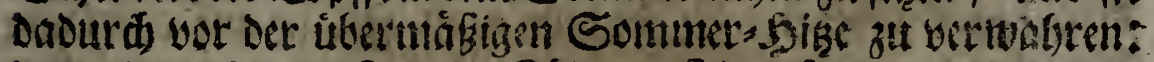

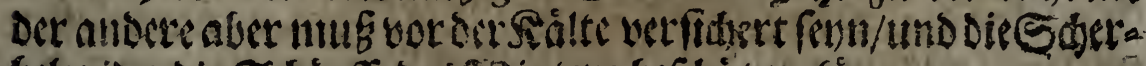

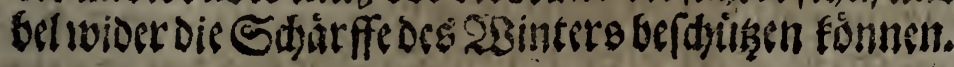

\section{Ong III. Enpitel \\ 3on bet figut und slotbeilung oez.}

Gartens.

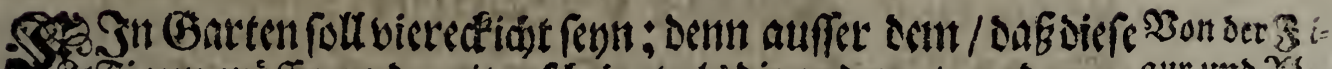

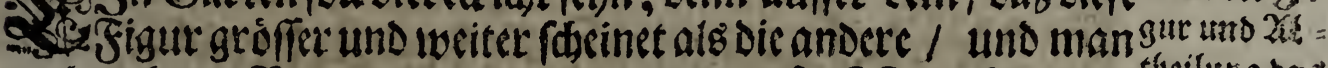
aud) mebrere $\mathfrak{B}$ lumen Darcin p flanksen fan/ fo iff fie aud) leidter theilung bas oumadienumb absutbeilen als dic anderc.

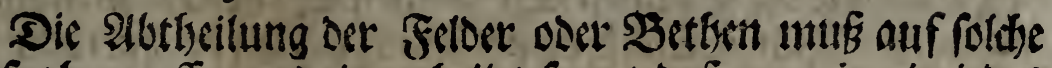
WBeifeabgemeffen und eingctbeilet feun / daf man in cin ictis unterfdicolid) Oattungens

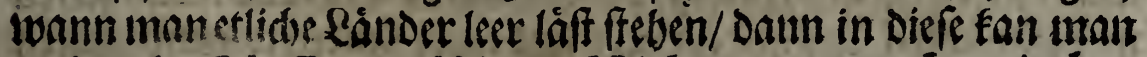

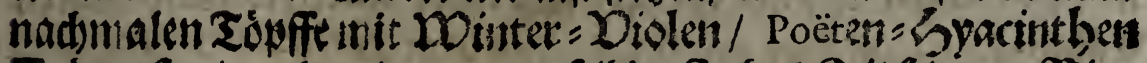

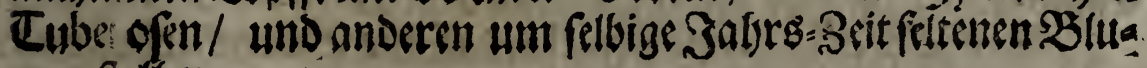
men ficluen.

Sn Denen Elcinen Gárten fittbret man/ fratt Der Einfaffun:

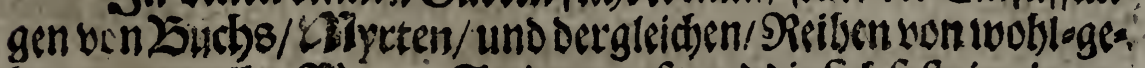

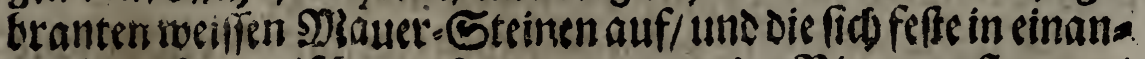

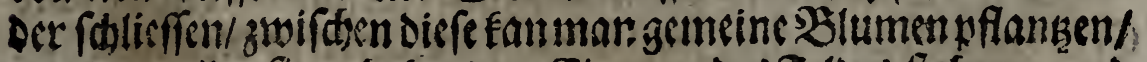

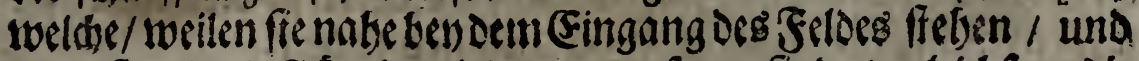
Dererften Curioftáteineşicoen auggefsket fino / gleidfaum sie $\mathfrak{A}_{2}$

Sd)usa 


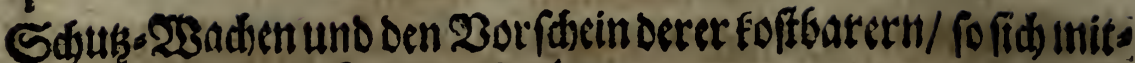
ten in bem Sclbe befindern/ abgeben.

Die Einfaffungen muiffen nidit won $E_{\text {tab }}=50$ urbi

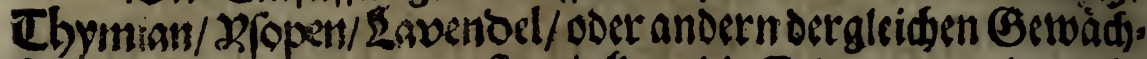

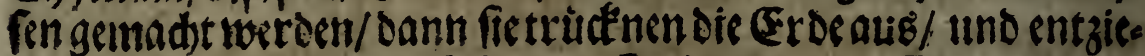
ben denen nafse berumffeteneneen Zlwiebelur uno 28 urbelln die Frudt oder Feudtigfeit; ; fontern inan foed fie auf ob befagte

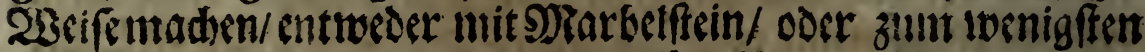

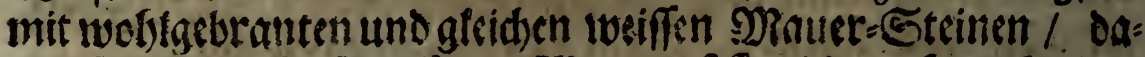

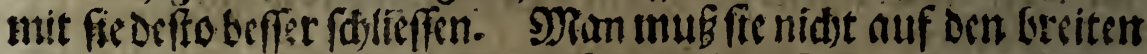

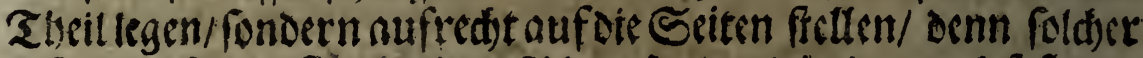
geffalt nelymen fie weeniger Polas ein / the balten aud feffer in

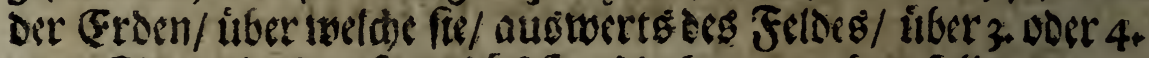
quer

\section{2nฮีIV. Cnpitel| \\ Gonder Sigenffonff tes Groteifbz.}

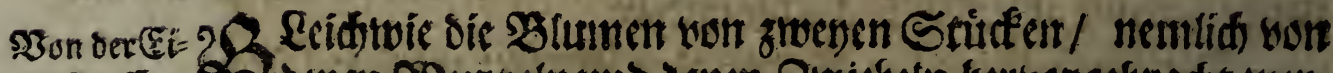
gen:forafift

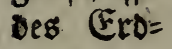
reict) 5 .

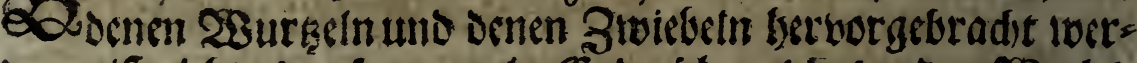

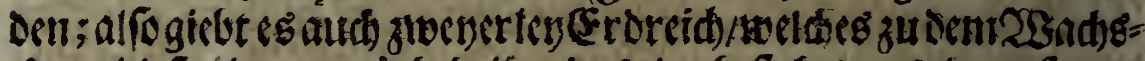

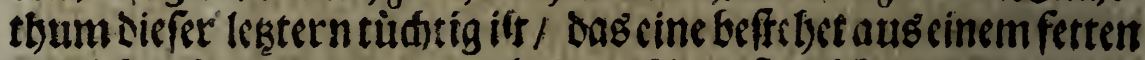

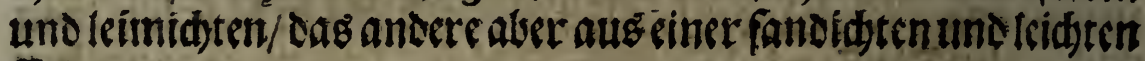
Eroen.

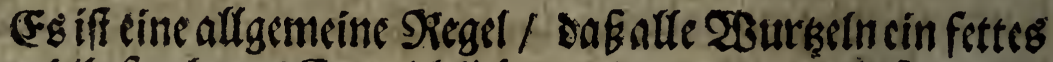

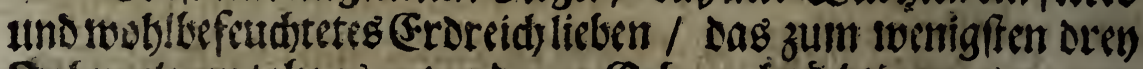

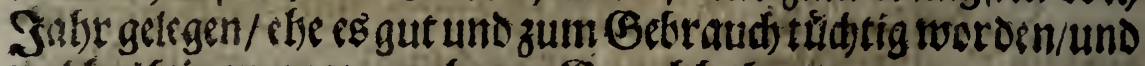

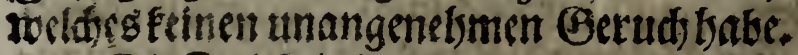

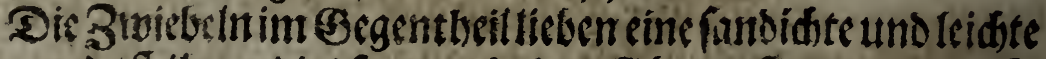
Frese; und iff itsnen Die/ fouman in ben Gärten findect/ waannfie

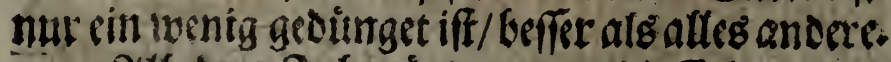

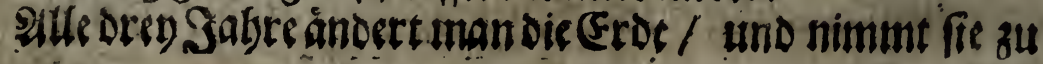




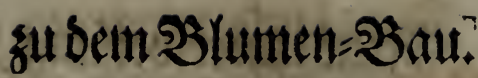

5

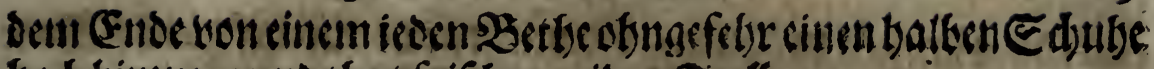
bod binweg/ und thut frifor an ibre Strlie.

\section{खå V. Enpitel/}

28 fiefolf tennen lernen.

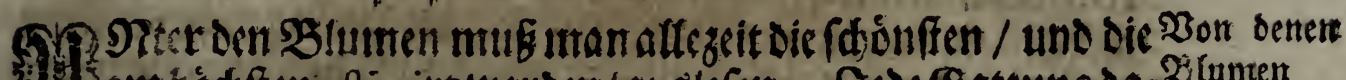

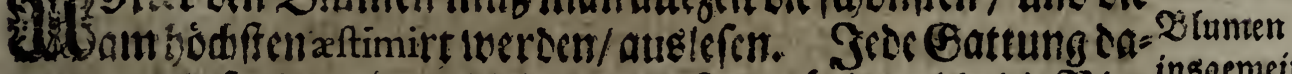

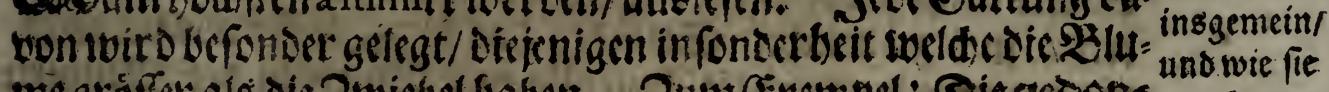

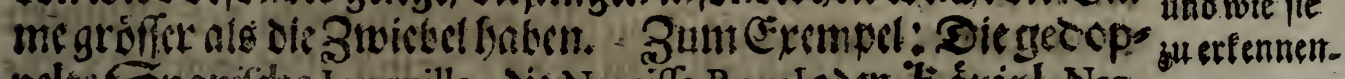

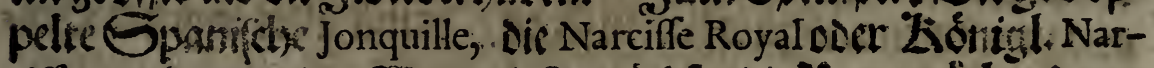

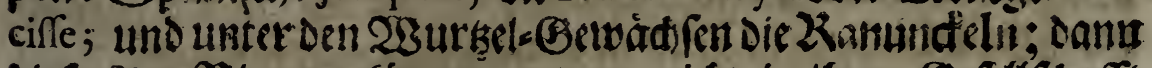

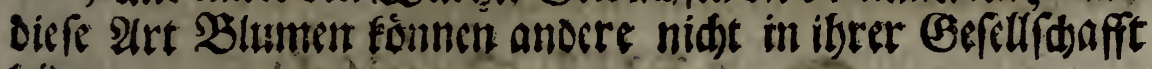
livert.

Dir Tultppen uns sie 'Zthemonet fónnen rings um díe

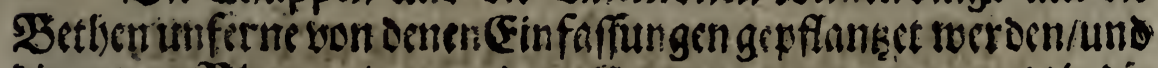
Dic andere $B$ lumen/ won andern Gattungen untremenget/ indie mitten ; folder geffalt twirs in eincmi iseen Feltes die Luntermie

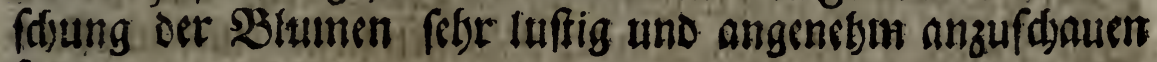
fron.

Daf inandic Gattungen Dicfer B/tumen fenne/ if saruut

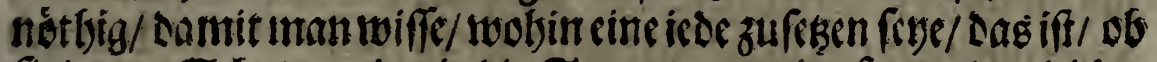
fie inder Sdattendoer in die Sonne : in cine fette decr leidte

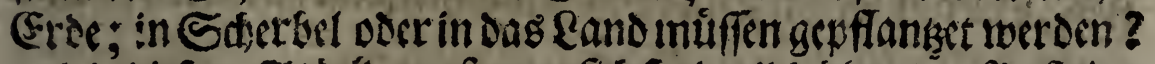

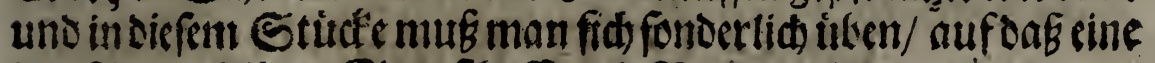

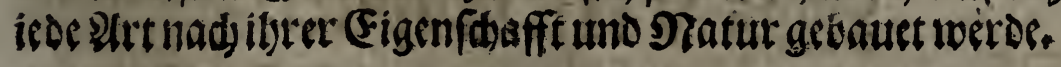

\section{2nธ่VI. Capitel}

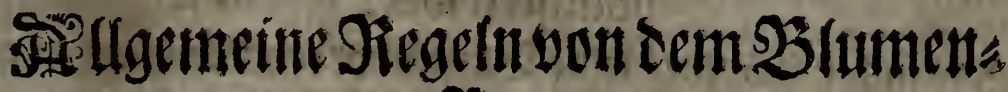
כืau.

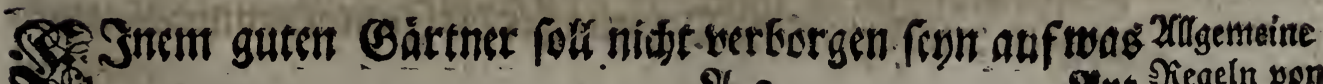

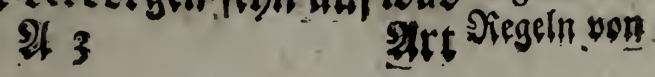




\section{6 \\ Neite untertueifung}

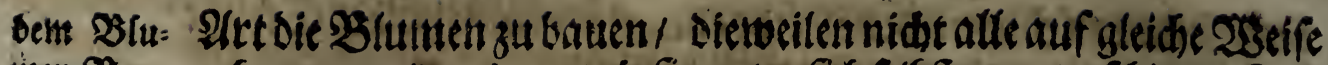

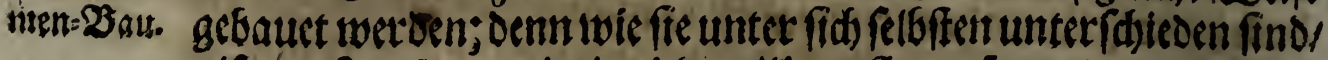
alfo inubaud / wiecime iese will gepfleget fonn / unterfudbet werden.

Dirofialsen mus man die Beit wiffen/anderman in dem Garten arbeiten folfe/ weldse Siegel man in Sp flansen bcobadb. tenmúfe/ insweld)er Dronung sie Saamen zu fammlen; tvels d)er geffalt Diefe zu fáen/in weld)er' Zeit diepplangen zu ver ferzen/

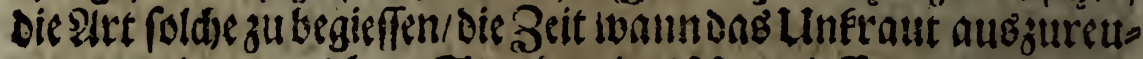
ten / uno zu Leclden Stumben dos Lingezieffer auszurottesu

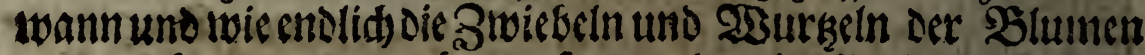
auszunchmen und zuerbaiten foysu/ Damit alles in guter Dros vung geforthe.

\section{2aż VII. Eapitell \\ WBann indem Garten zu arbeitut.}

Bann in 9 Sebenbemffe Beit in Dem Garten zuarbeiten/ Das ift/ bie

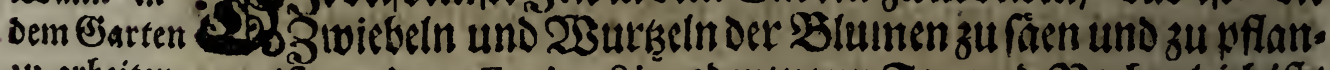

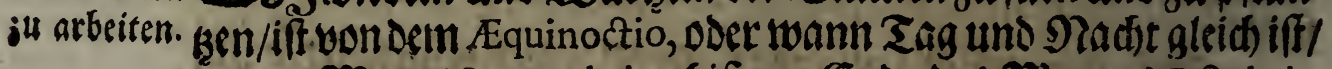
indem DRenat Septembri, bif Zแ Ende DCE Mronats Octobris, Dann meilencsum folde. Beit viel regnet)/ fo wiro Dns (Erorcid

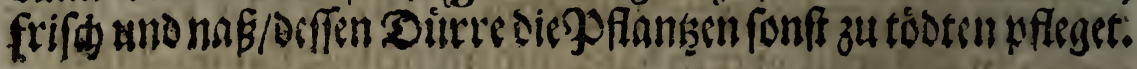

\section{2å VIII. Capifell}

Die Siegel welläie mant in Dem Pflanfigen bes obadten folle.

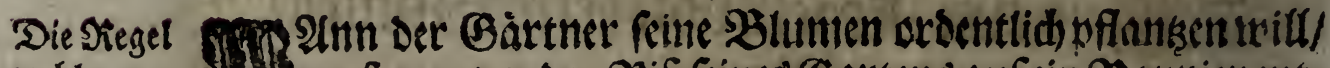

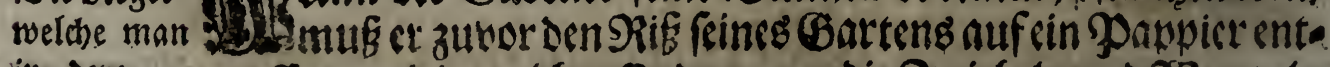
in $\mathrm{Dem}$

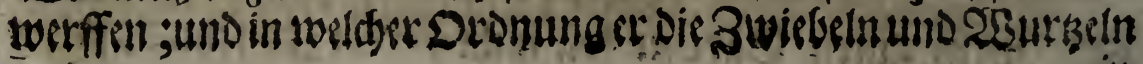




\section{కubem Şlument=:Batt.}

\section{7}

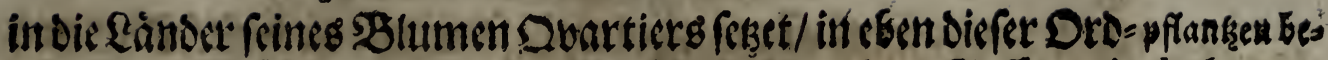

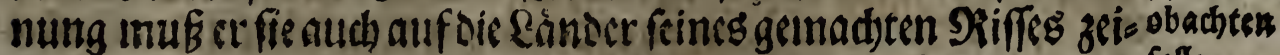

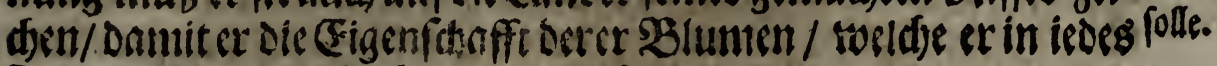
Rand gefeset/ Deffo beffer Eenuten móge.

Ben icdent Eand Docr 'Betbe iff siefs / wann man mobl pflanken will / zu mertfen : SRan grábet die (Froe bes nabe cinen Gaube tieff aus/ uno twitfft fie in den Bangoier an fonffen sis ten gelegenen Ort; traun than aber aut oen Grund foinme /

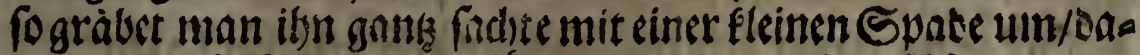

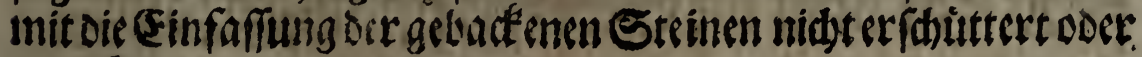
wandelno gemadst werde.

$23 a n n$ diefes gefdelien / fo fibet man wieder Eroe auf ins

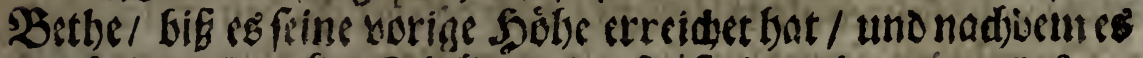
Durch sinen Sarte'en-Siviteen / oder forift einem bequeimen Inftrument, wieber gleid gentedt warden / fo feset man alshann Die \$twielseln in eincr yleidsen 23eite barein.

Damit fie aber in guter Dronung bon cimander ftetsen/.

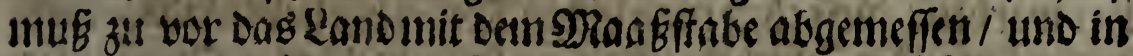

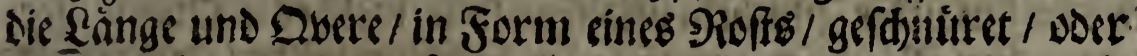
Die Stride mit einem fpisigen Solse gezogen werden; in die

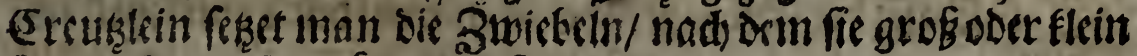
fino: Sormad) Derfert man firmit eben biefer (FrDen wieder zul his fie zwet) Finger hed itber bie (Finfaffung bervorgebe/ als Doun twird fie mit einer $23 a l$ lsen derfelben gleid gemad)t. (Ge

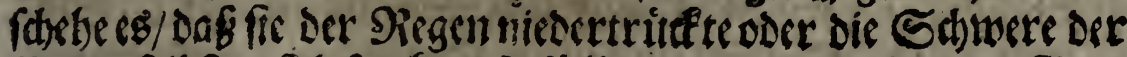
Eerden felbeten fid fendete/ fo fittlet man die sieffe mit gefibter fantiditer und leidter Ertoen soieder aus.

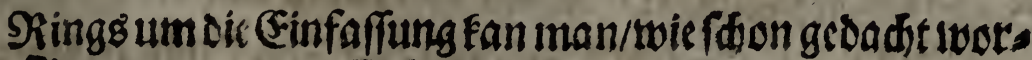

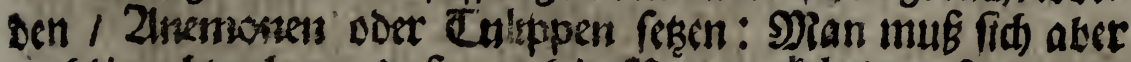
wobl in adt nelsmen/saf man feinez

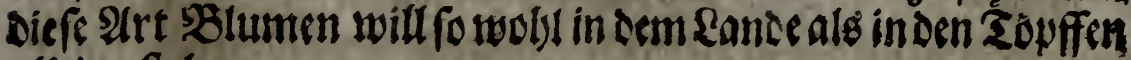
alleine fectien.

wann Der Garten in diefer Dronung gewflanget iff / mus

man 
unan un bie Einfaffiurg aftes wobli faubern/audibie 23 ege uno

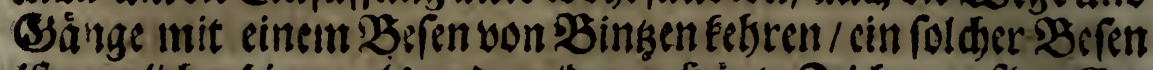

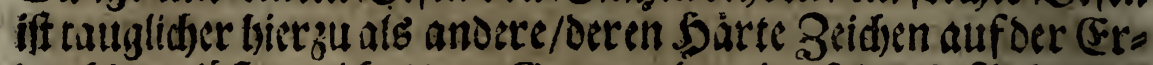

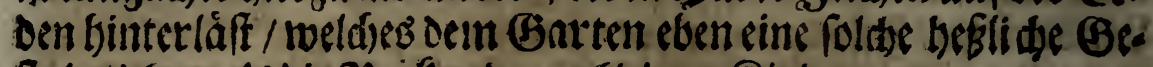
ftalt gieber / als Dic Poodén Senen Eleinen Rindern.

\section{2aì IX. Eapitel/ \\ ¿sie manin die Siferbel pflanfert folle.}

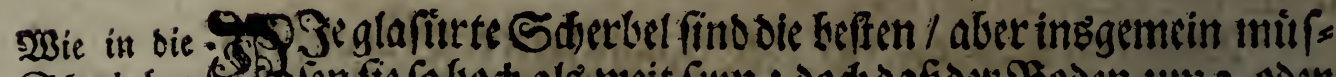
Ederbel $3 \mathrm{u}$ pflamįen:

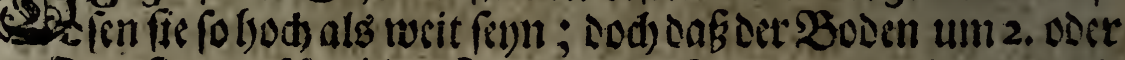
3. Querfinger famaler fin als ocr Rand / Damit Iman sic Pflanken zufamt oer (srde oefto leid)ter lyeraus nebmen moge.

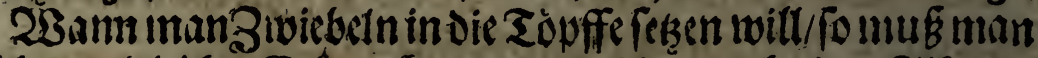
fandidbte und leidste (Fetbe nelymen I lveld)e ourds cine Sibe ge fibet worden/ dicfe thut man in Den Sopff / bif fie die Sobe errei. det daf man die 3 twiebeln pflanken folle/wollates 4. Dverfinger

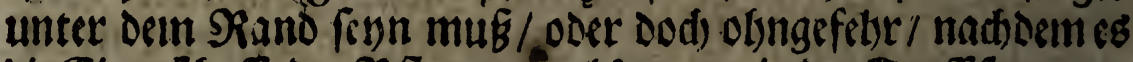

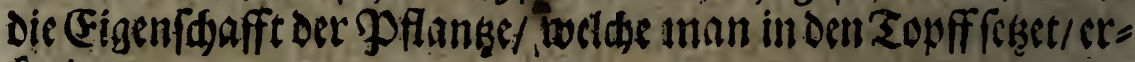
forbert.

Sn cinen ieden Sonffwiro nur eine 3wiebel ooer 251 thel gepfanket/uno wann Deten metbr Datein giengen/ fo mus man/ Unoronung zu vermsiben / nur von ciner Gattung burcinfes

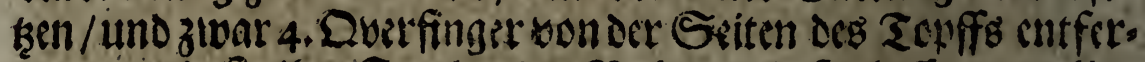
net / Damit fe iffe Frude oda Dabrumg Defto biffer bou allen Eriten ziebon fónne.

Wann bic (Erde ordentlich in octl sopff und in die redite Sobe gebradt/ aud auf oben. befagte 25 tif gleid gemadt t toor.

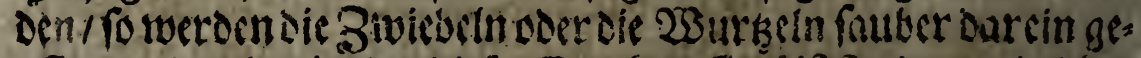

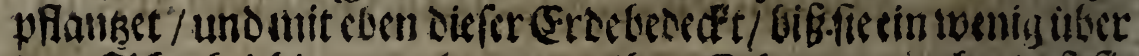

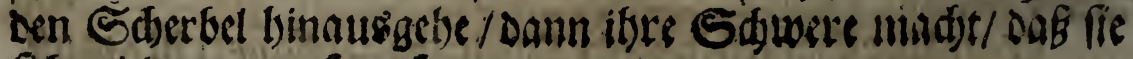
fid toicoer genugfam fage. 


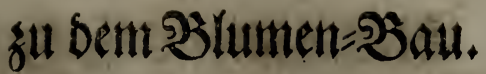

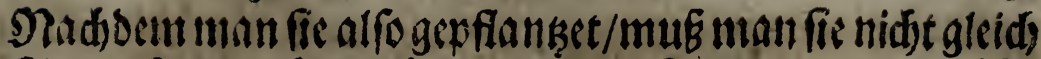

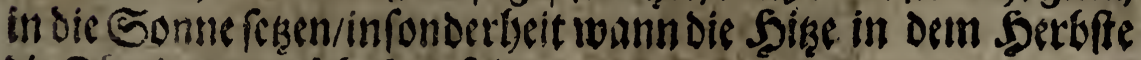
Die Doserband ned fasen folts.

Sind cs 3 miebeln / fo mus man fie in einam fonattidten

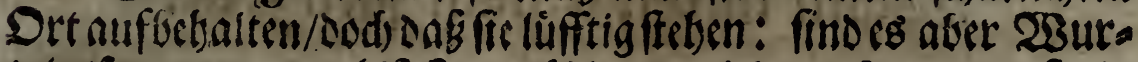

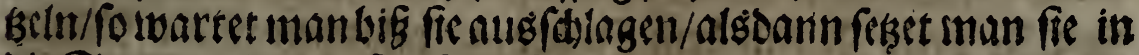
Die Sonne und in die\&ufr / in folder Dronung als simen iesenbse. liefet / und cres zur Bierde des Gartene yor gut befindect.

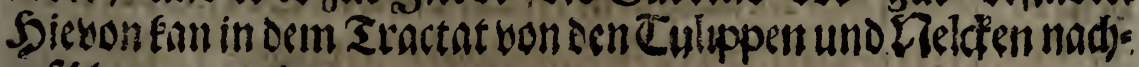
gefdlagen werden.

\section{Q)av. X. Sapifel/}

Wir man die a namen cinjammlen folle.

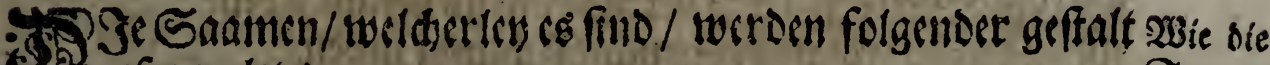
Serammitet:

Gaamen:

DRanláfet einer ieden goflanke cine oder auf oas bodgfe einjufamm:

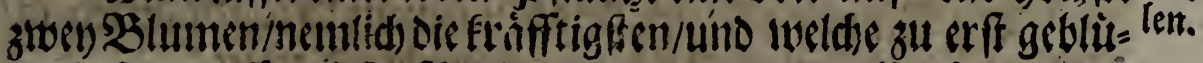
bet baben/auffer siefen fanciset man bie andern alle ab.

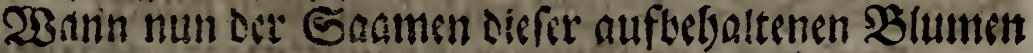

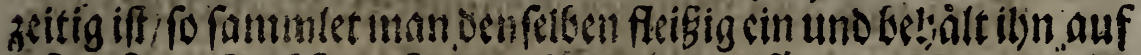

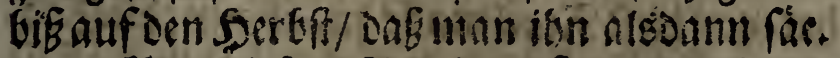

Zon tiefer Siget mis man Lods sen Winter. Dio"

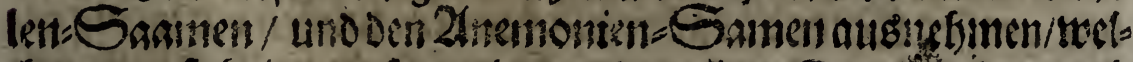

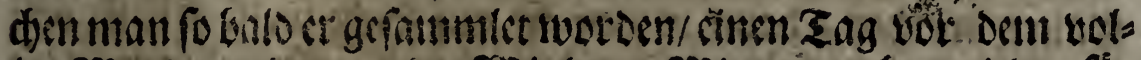

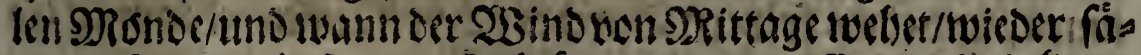

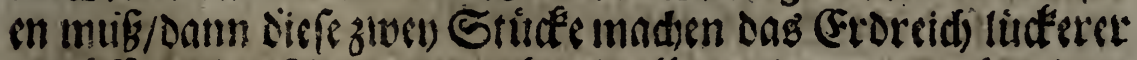
und sffnen itum feine Poros mebr als alles andere/und geben beun Gaumen aude Fraffe; Drrowegen wann Der WBind um Diefe Zcit nid)t von Mittage fáme / oder die \&ufft ourde cincu

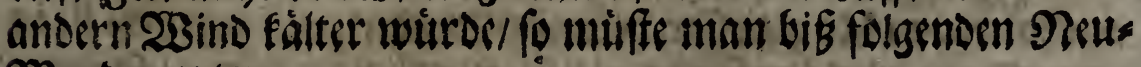
Mono warten. 


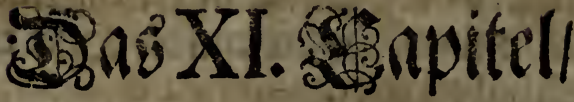 \\ Dalitin und wie man faen folle.}

Wann uno wie man

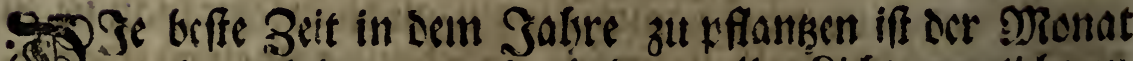
6.2. Martius, und Der September in Dim vollen Ridste/nemilid) von fäen folle.

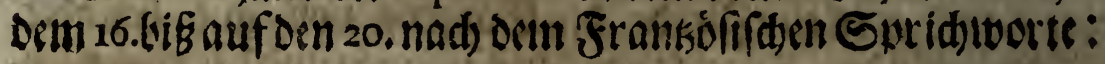

Dansla nouvelle Lune il faut planter des Fleurs:

Lesfemer en decours; \& par cette obfervance

On leur procure l' excellene,

Et la vivacitédes brillantes couleurs. oer Sntyalt ean auf Teut fols olngefely biefer fersn:

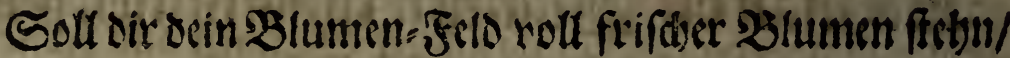
Dis yon 2 ertriffligfit oce Farten gleidf fam lecen/ Miff ou auf Folgeners genaur 2ldtung grbin/

Solviro (e Brociffele: frel) nad) Deinem 23 un fa ergetn:

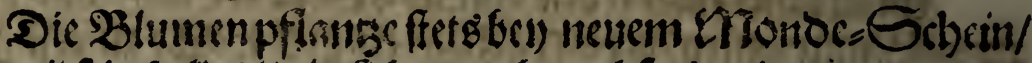

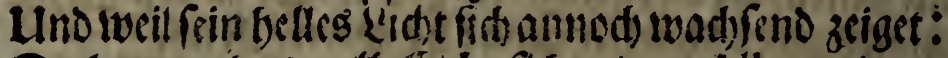
Dod wainn Dag velf: Licht fid zu bem fällest neiget/

STuE aud) Dein SBlumen-Seld mit Saat befreuset fenn. Bey dem Săen bat men diefe Riegel in adt zunelymen; Die Sar=

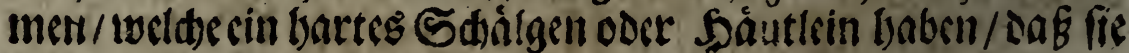

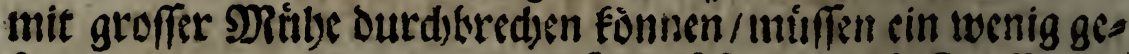
fpalten swerten / Dann Iweilen fie auf folde meife Rraffe bon innen / uns einen freseen Durds brud, von auffen tefoumen / fo werben fec leidttlid aufgeben.

Die Saatmen wobl a Eennen / mus tman fie in das $\mathfrak{T S a f}$ fer werffen / Die jenige woldbe binunter firlen / frito die beften.

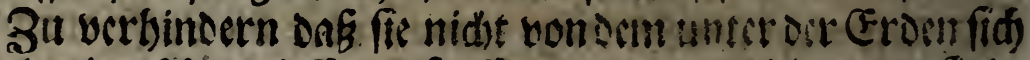
aufbaltenden Lingezieffer gefreffin twercen/widsstmsm fie in

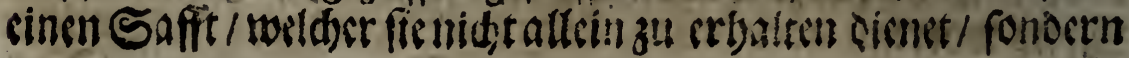




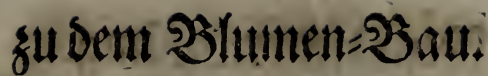

II

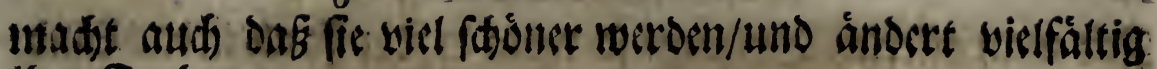
ibre Farben

Vratsocm man die cingetwcidfte Stamen wieter aus bcm Saff beraus gendinmen / fäet inan fie in gute / aber leidste / tmo: Dura) ein flar Sitie grfibte (FrDe / torldse Iman zu Dem Ende in Starbeln oder Ribeln zured) gemed) ljat.

Uno toann fee gefaet fino / fo weroen fie nit efen diefer (St.

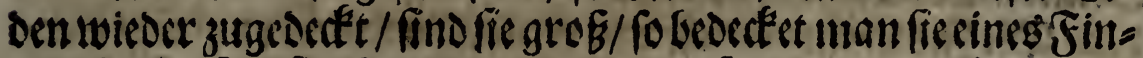
gers bod ; find fic aber elein / folverden fie zum loenigften sincs: balben fingers bod zugedect.

2ud) freflet mtan fie 2. biß 3. Stunden Des Tages an die

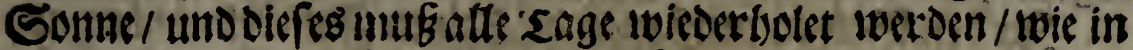
gleidgen das Begieffen / (tavon im folgenden XIII. Sapitel gee:

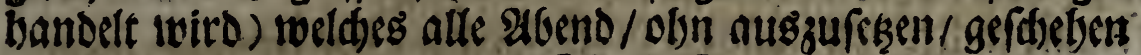
Imug; uno nad Proportion als fid) Die Saamen aus Der (Froen iver ben bervor tbun / nads efen diefer Proportion twer oen fie aud unter die (stoe toads fen / uno fid cinfendern.

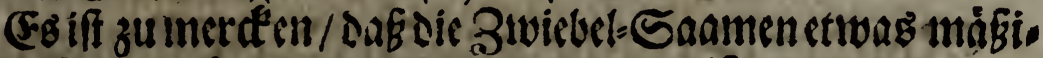
ger mitfen begoffentoerden als andere / und ift es genug wann

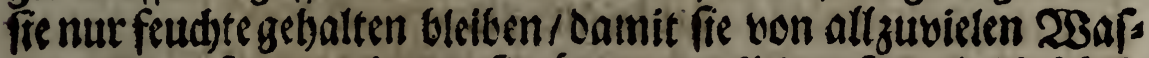
fer nidit verfaulen/ indem fie zarter und fleiner fins als die itbri: ge Saamen.

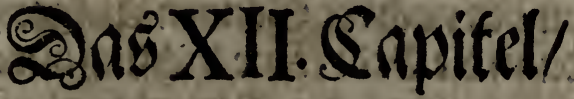

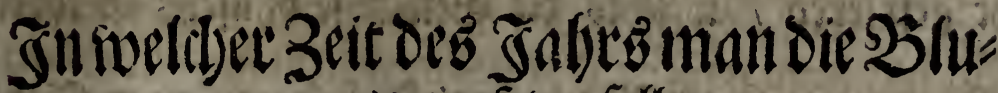 men ver ferectifolle:}

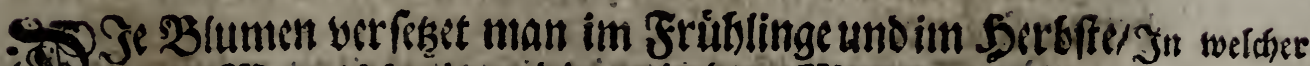

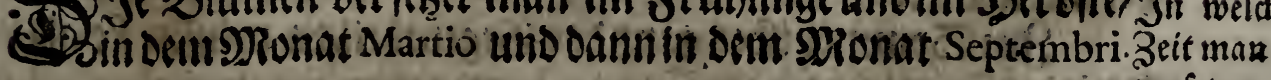

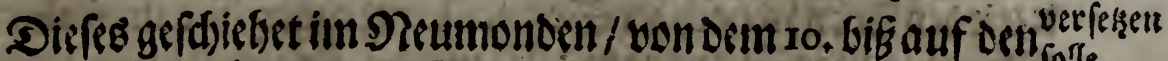
14. infondertbeit aleer Den 12, Zage Des Neumends/an weidsec $\mathfrak{B}=$ Beit 


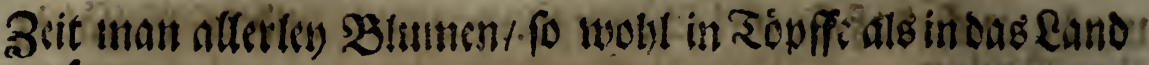
verfeset.

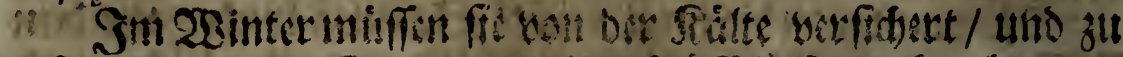

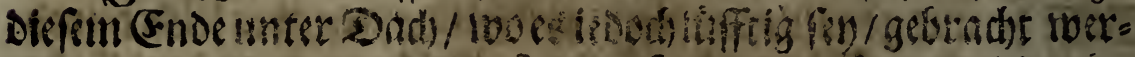
Den: Und im Sommer mus mam fo voroer Eonmentiat be

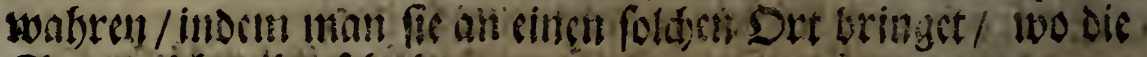
Sonte niditatzu febrerentre.

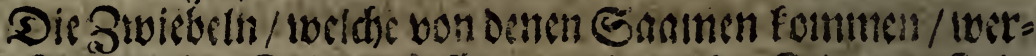

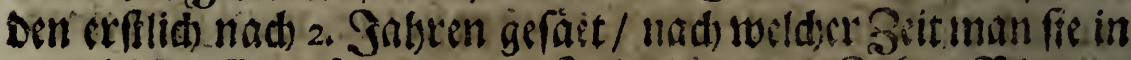
gute leidte Eroe fiket / Dannit fie in bin sten Saise פBlunten rtaigen.

dte Ga Den Betten nitus man sie fleinen Bivietetn nidst gar tieff/Dod) nate bey fammen fesen / Da bingegendic Groffen tisfs fer und weiter bon sinander muffien gefieger werben.

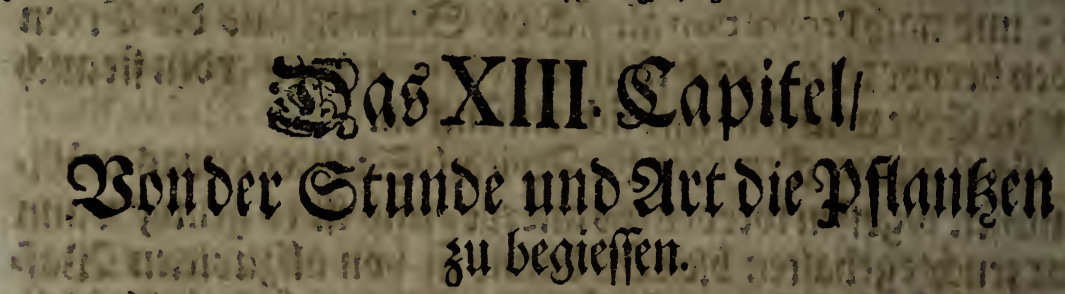

Dou der Etunde

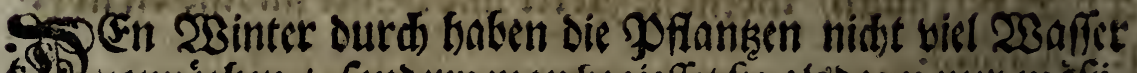
So vonnotben / fondern manbegieffet fie alsbann nur mábiund $2(r$ bie glid) 2.DDer 3. Stunden nad) der Sonnen \&ufgang / niemals $a=$ gof zu begieffern.

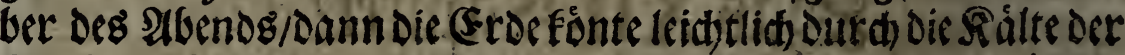

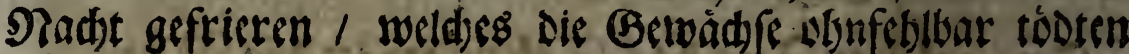
muiroe.

Wann man fie aum 23 inter begic Bt / fo mus iman Sorge

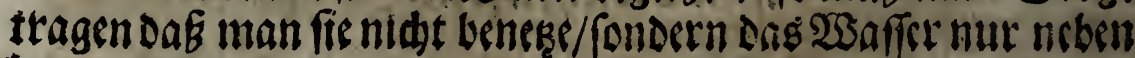
berum fobitte:

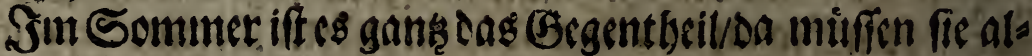
Meseit Der Abenos nad) der Sornen Lntergang/niemals aber des

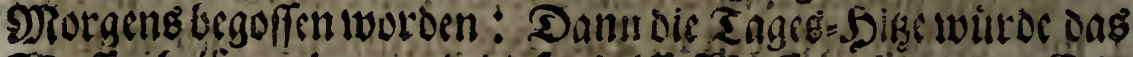

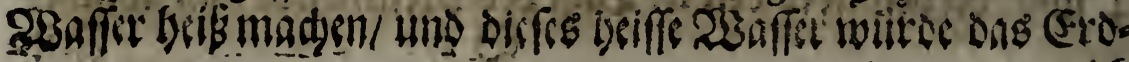




\section{รแ Dem 2 lumen=:Sau.}

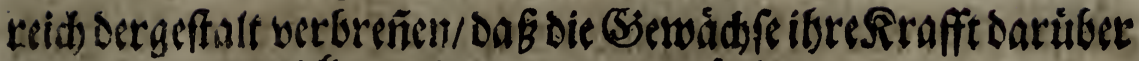
verlieren/vertwelden und augidorren witrden.

Einguter Särtner mußs wiffen/ Dą twann Die Poflankęn nod) fectin und jung find/fie weniser 23 affer sraud)en / als wann

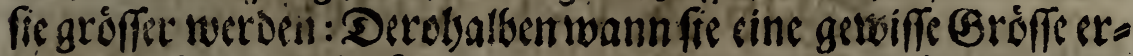
langet haben/mirfen fie aud meth als zuvor begoffen werden/.

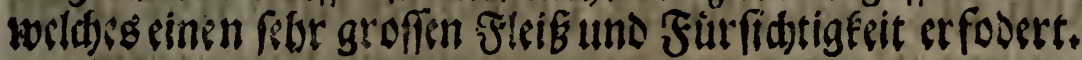

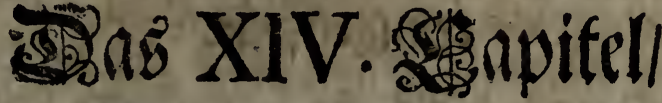

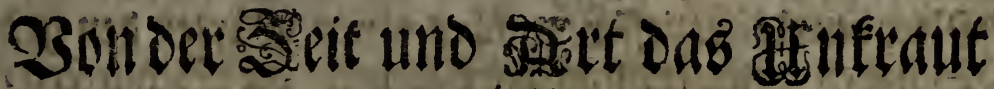
aussujetten.

- Je Bierligfeit uno Sauferterit cinte Gartens dienet nidt Bon der

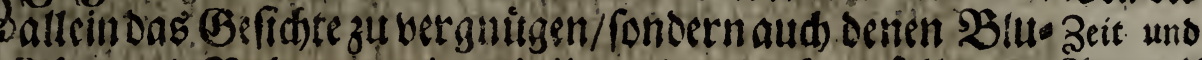

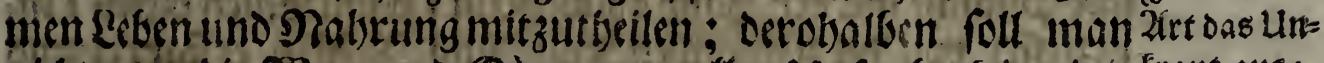

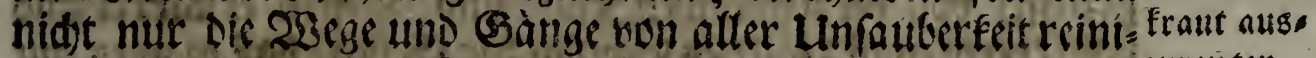
ger tho das tonitse Siraut aubthuffen; forbern man mus zuresten. aud) Die Betle felloften fleibig von nllem Linfernut fáubern.

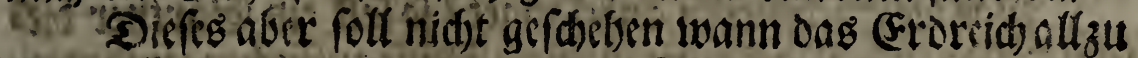

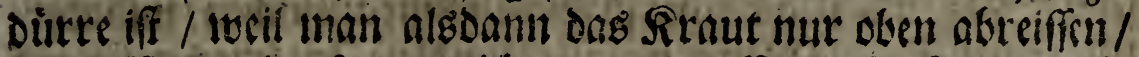
benen 2Burkelin afer / tweldse unter Der Erden bleifen/ un fo viel medor Sinfft gebent wirto / das neue Sirnut defto leidter bervor zu bringen.

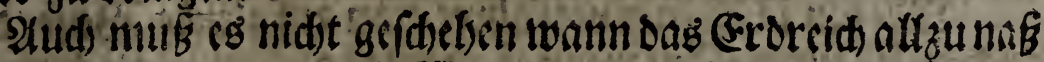

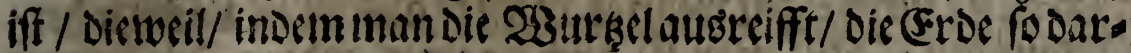

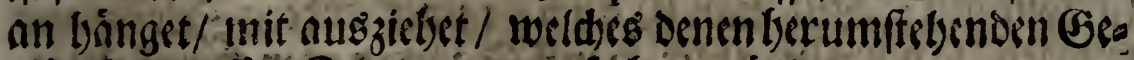

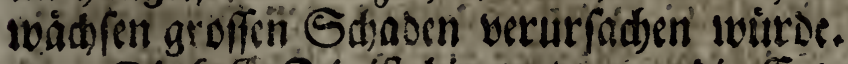

Dic feffe Beit if bierzu/ wann die Croe weder zu trus: ("en nod) zul frudgete ift/ fondern wann fie ourd gemieffigte Feuditigefit und 2 ärme mitrbe getworden / und al fo beffer ant zugreiffon uno sanit unzugelsen iff; nud twann das fraut

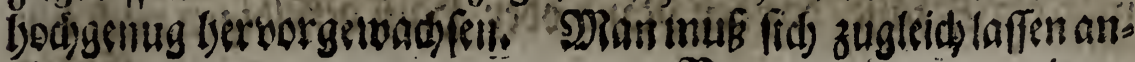




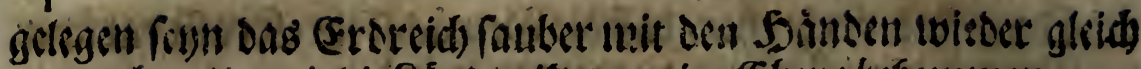
bu maden / Damit die \&änecr itgre vorige Ebene befommen.

\section{2ง XV XV. Capifell}

\section{Bon Det Beit uno Strt / wann und wie mant einen Sarten von ben fidáblicten Ungesieffer}

\section{reinigenfolle.}

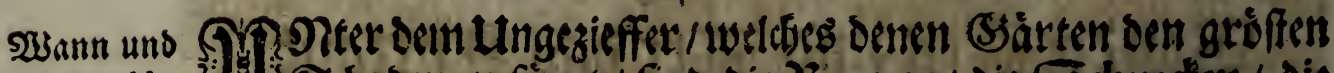

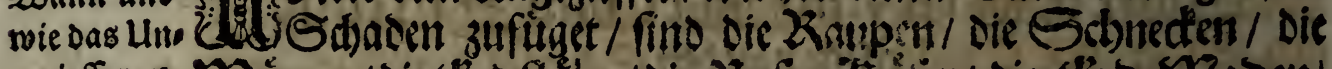

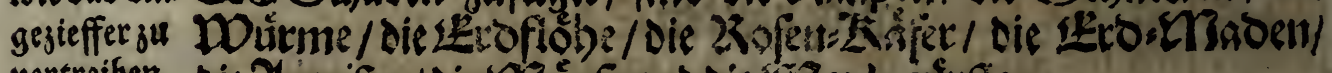

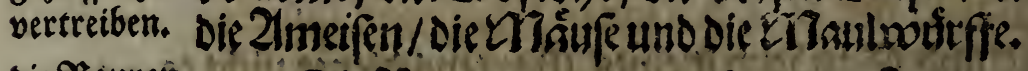

bie PRaupen.

Die Zlaupen zu bertreiben / muk inan alfe Neorgen eine

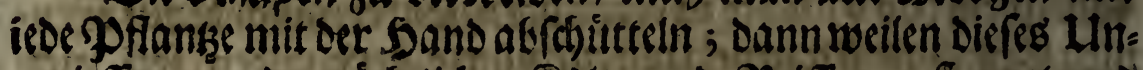
gezieffer von Der nádhtliden Sialte uno Reiffen erftartet uno balb crfroren ift / fattl cs leid)tlid) zur (Erden / Dak man cs mit Denfinfen zu treten fan.

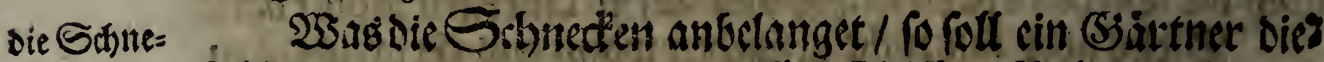
der.

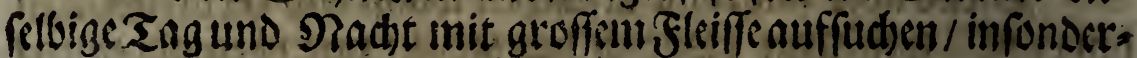

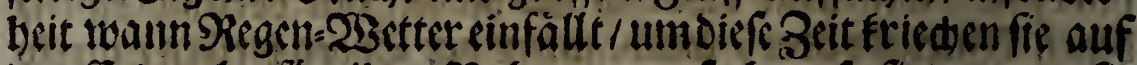
Der Eroen lerfitr ibe gabrung zu fuden/ fo finder man fie - Dann/uns fanfie leid)tlid unbringen.

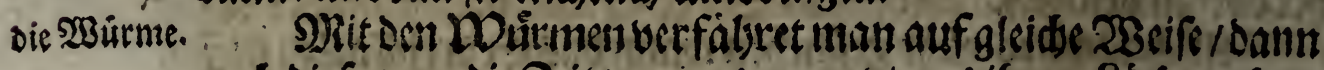
aud Diefe / umbie Zcit wennes regnet / aub ibren gódjern ber= furfommen: 2Sill man fie aud zu ciner andern Beit beraus

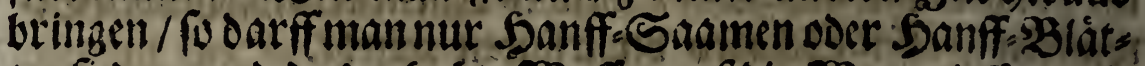
ter fieden / und Das gceddite 2Baffer auf dic 23ege gieffen / fo werden fie bald zum 20 orfacin fommen.

Die Erb= flolite.

Die Exoflobe betreffeno/poffectetmancinen ciunnenSte. den cines balben Satubes bod) in die Ercen/Daruber fturbet mancin Befáfle/ Daf der siano doer SalB deffelbigen nad der 


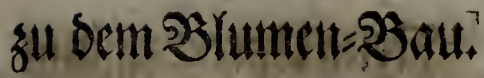

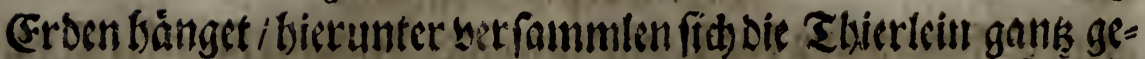

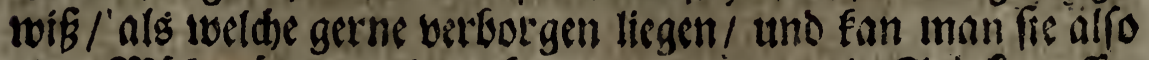

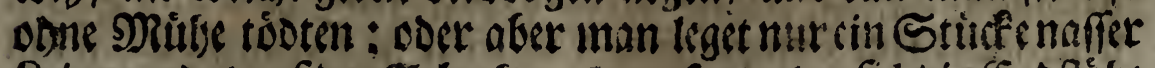

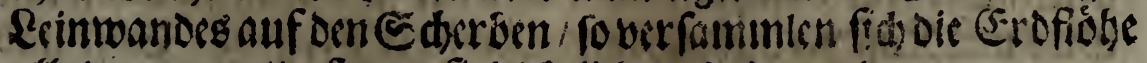

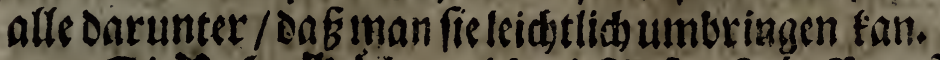

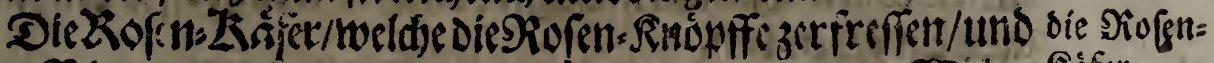

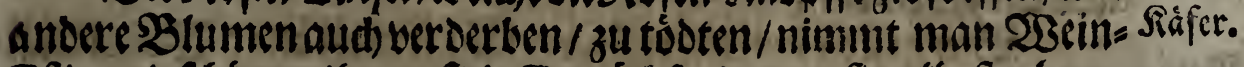

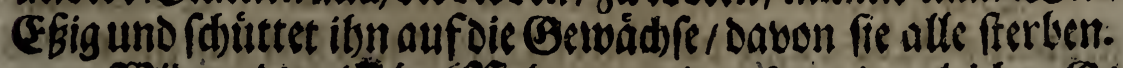

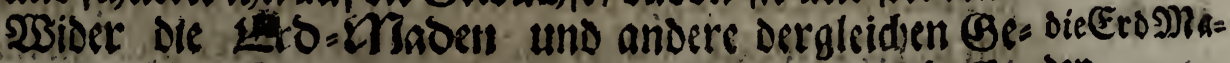

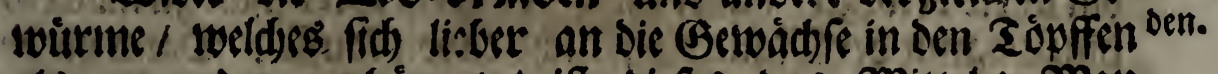
als an andere anbainget / iff Diefes das Mittel: MRan

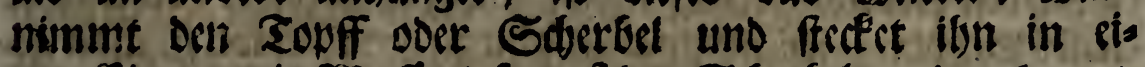
nen Eitater imit 23affer/ fo DaB Der Edjerteel 5. oDer 6; quer Singertieff im 28 affer bänge / Datinnen lâfer man ibn eine biertel Stunde ffethen/teann nun diefes fleine. Ungezicffer wo Dem 23affer ibet fatweenmet wird/ fo getset es alfobald hernor.

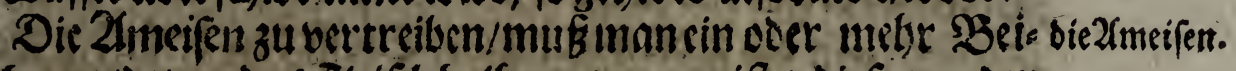

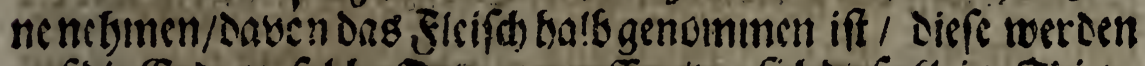

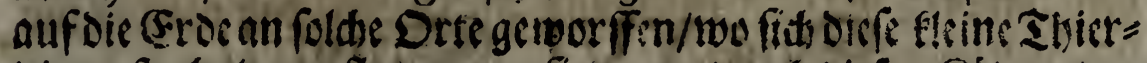

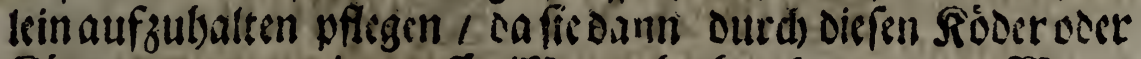

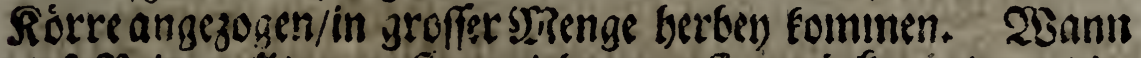

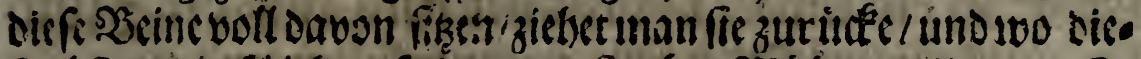

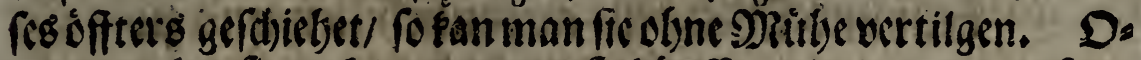
oer unan fan fie alld//wann man fithäuffig mit cinander auf oert

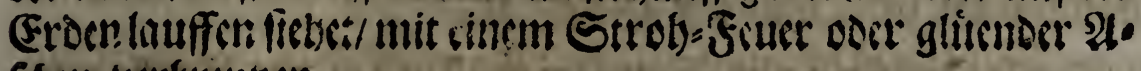
fidin verbercnner.

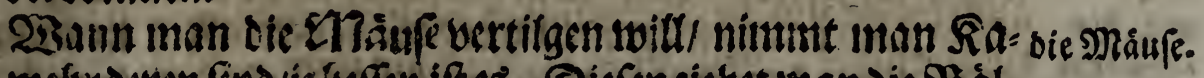

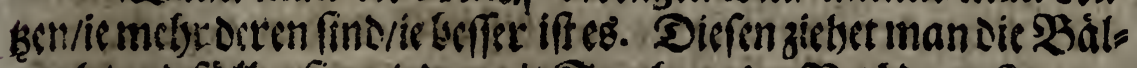
geab/und fittet fie wiescrnit Strob aus: Nadjoen fie nun

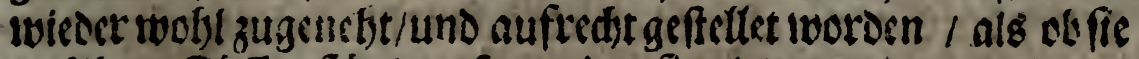

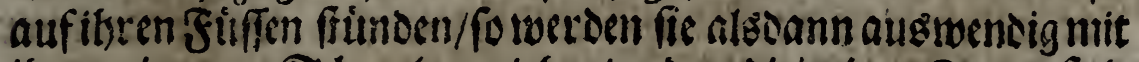

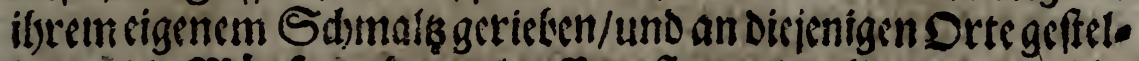

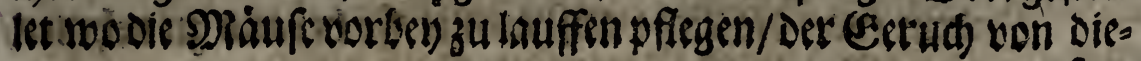




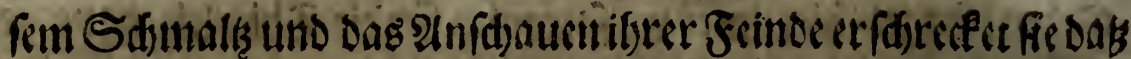
fre Davon lauffen. Man fan aud) Sd) ciffen legen / uno Fallen frellen/uno sine Compofition, von flein zerfroffenem Blafe mit Ging uno Râfe vermenget/tin und wiecer freuten. Gifft unto

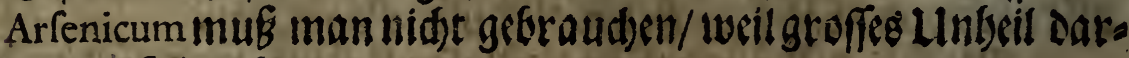
auscittfeben fan.

sie Maul=

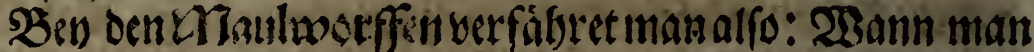
worffen.

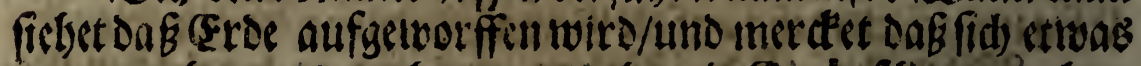
Darunter betweget / Haber inat/ olyne cin (Seriuf(die zuntad)en/

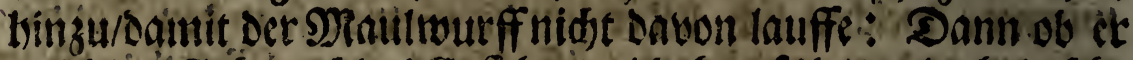

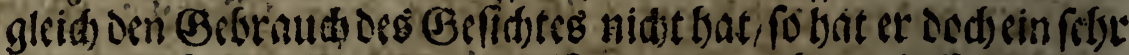

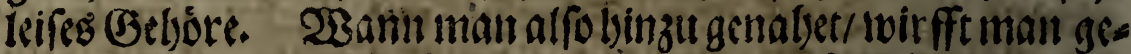

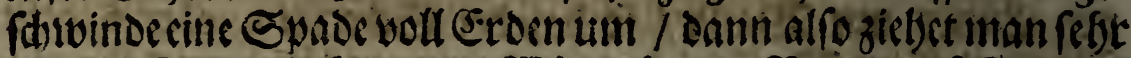

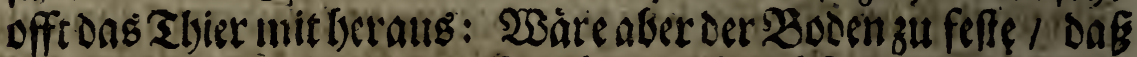
man die (5rde nidtetumberffen fonte / fo milfe man in diefer

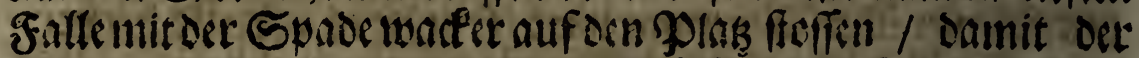

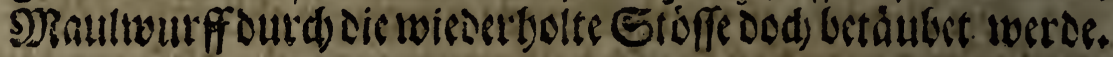

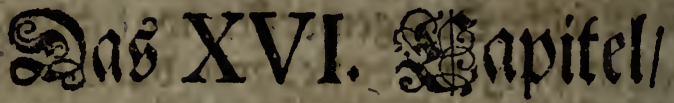

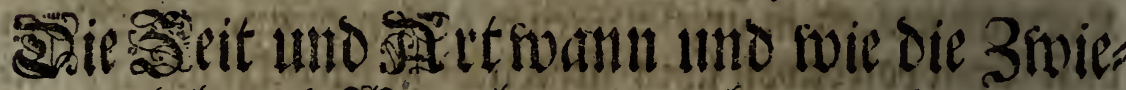

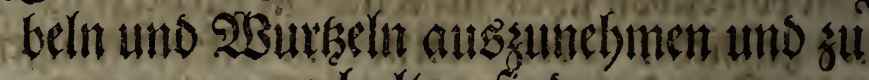
(17xtche celfalten find.

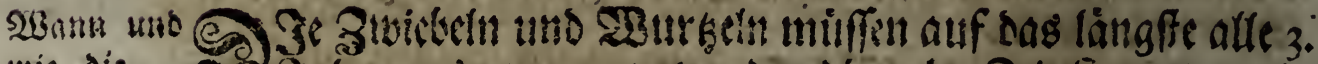
mie dic 3nwicbelin ind $2 \mathfrak{S}_{\mathrm{u}}=$

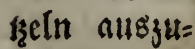
nef̧imen.

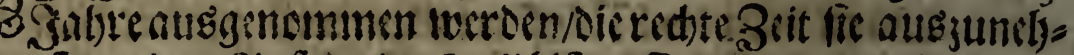

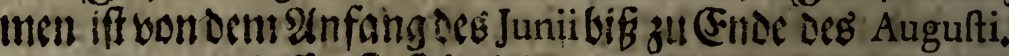

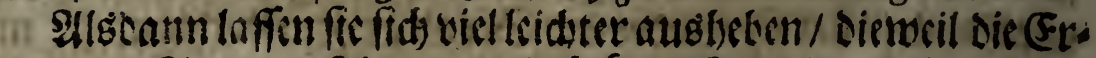

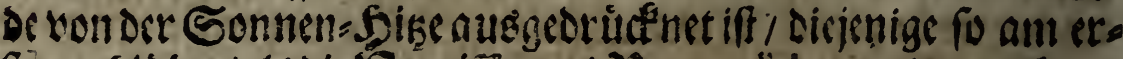

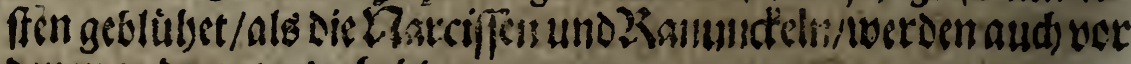
oenen andern ausgebett.

Snoem man sie Erde aufráumet fie betaus zu nebmen/, mus folgende Siegel beotadtet swertecn: 


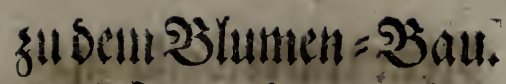

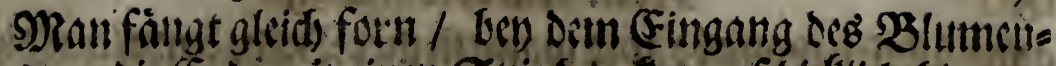

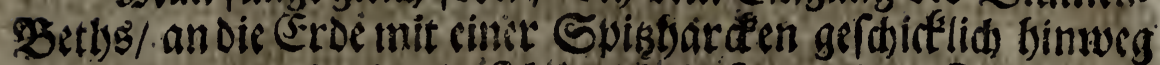

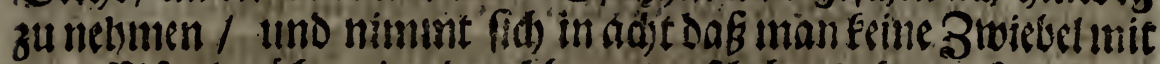

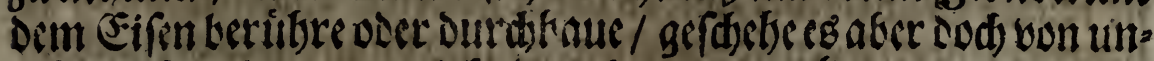

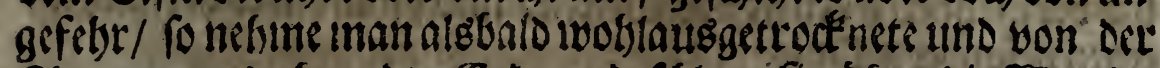

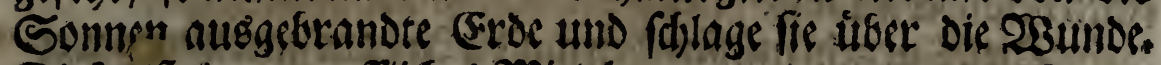
Diefes iff sinvortreffilides Mittel.

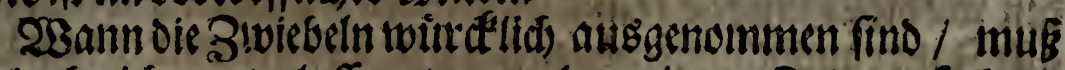

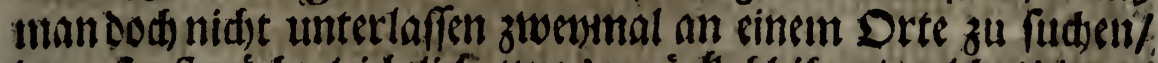

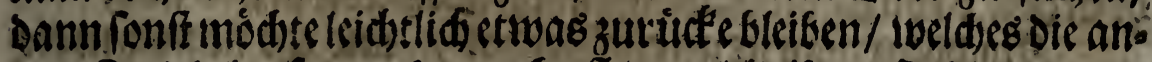

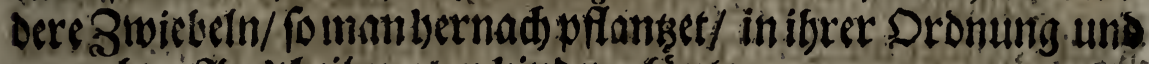
gemad)ter 2 (uätt)eilung verbindern fónte.

Diefe Regel if ben allen SBlumen= Feetern zu oblerviren.

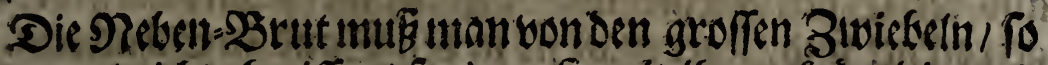
fregegeuget/ nidteabreiffen/ fondern fe init ibren sauttein uno

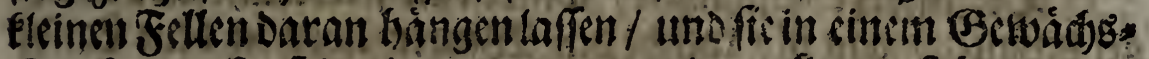
Shaufe ooer fonft in siner warmen und fruftenen Shitten bera

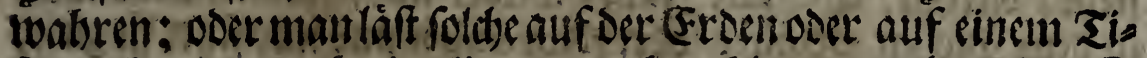

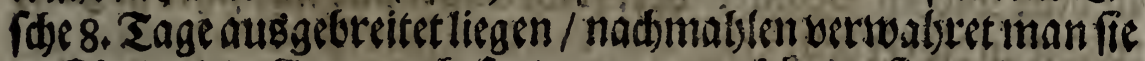
in Rórbe/ icde Oattung befonders / und bänget fie in eincr ans

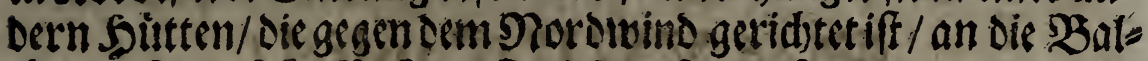

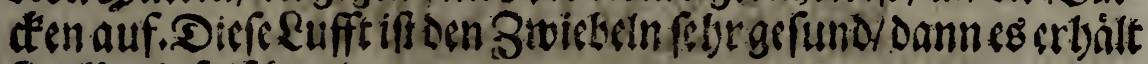
fieallezezit frifd) uno gut.

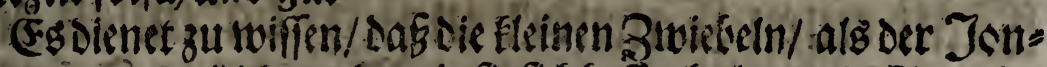

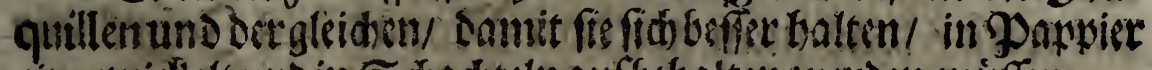

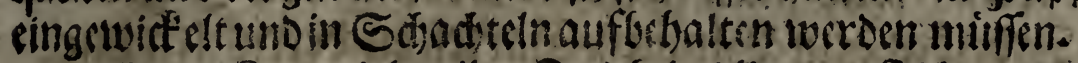

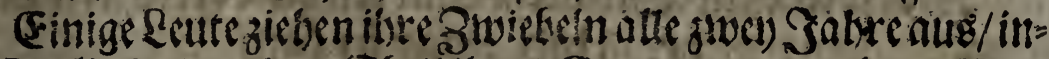

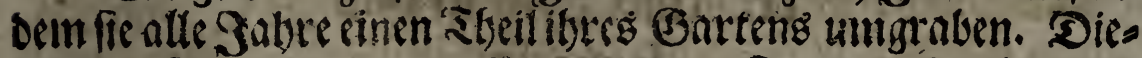

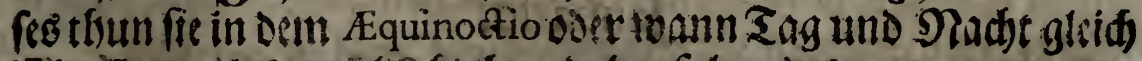

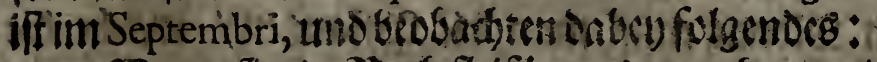

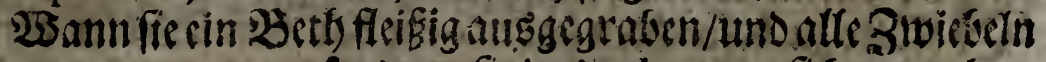
beraus genomumen / fonoern fie sageenige was fid vermethet 
18

\title{
Neue Lluterweifung
}

gank furtil babon ab; und wann fie ibre 3 ettse bann/auf fic and

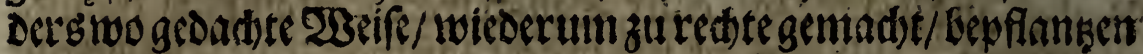

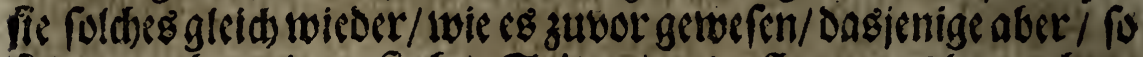
fïb verinebret / leygen fie Gery Seiten / und pflankęen es bernad) an einen Gerondern Drte.

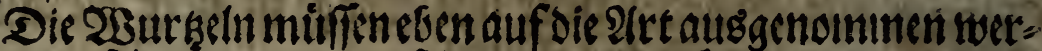

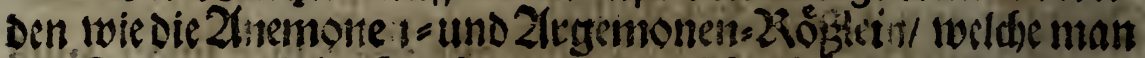

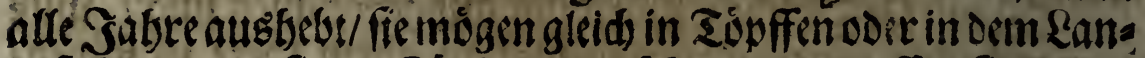
De freben/ bann fic Der Fáulung gar felly untertworffien find.

Thadoen man fie getritudnet bat / und elle fie nod) in bie

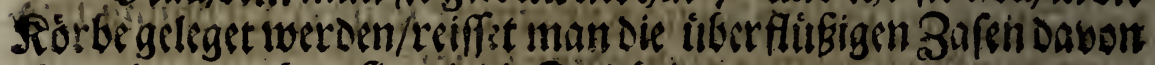
ab/uno verwallyet fie twie tic abiebeln.

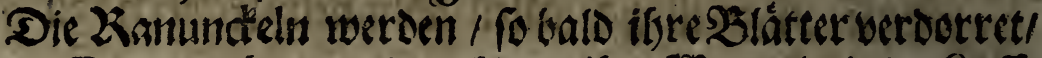

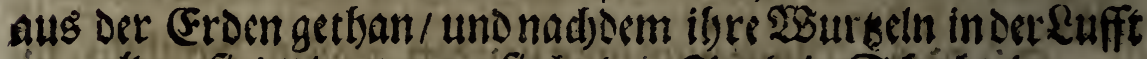

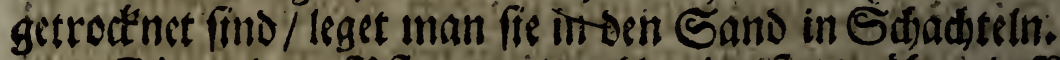

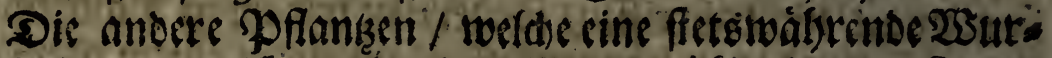
set betgatten/ Das iff / weildse ben 23 inter itberi in bem \&ante

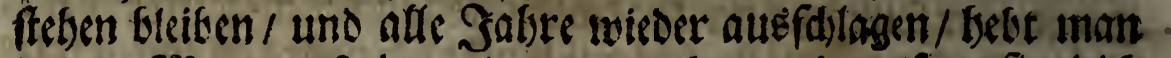

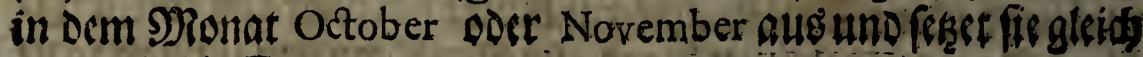
wieder indie Erden.

\section{2ณร์ XVII.Cnpifel/}

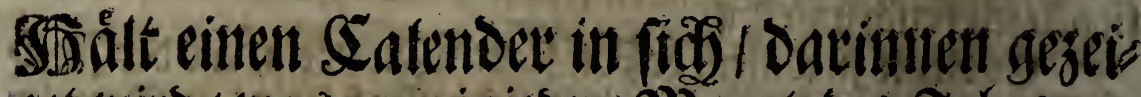
get wirb/ was man iniebem 9)?onat Des Jabrs vor

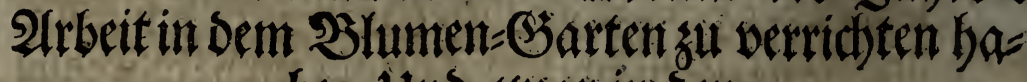
be. Und swar in Dem

\author{
Januario,
}

Jaลuarius.

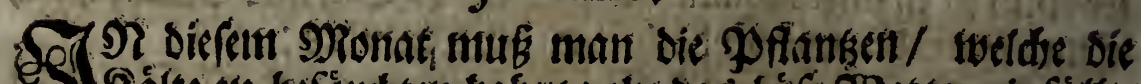

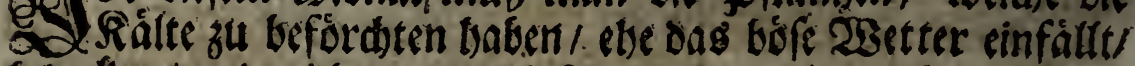

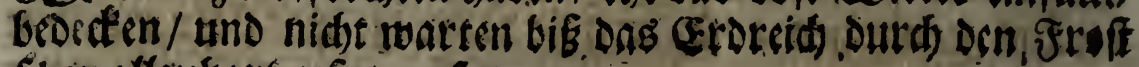
fagonalfoulgarf grfioren fry. 


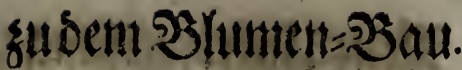

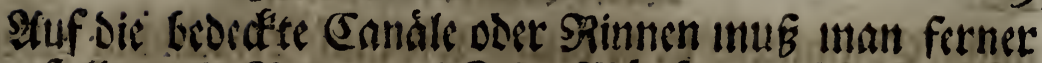

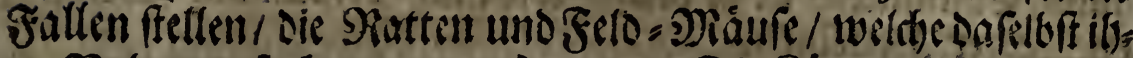

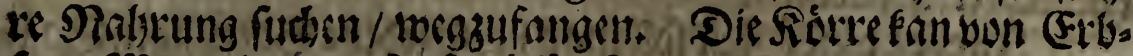

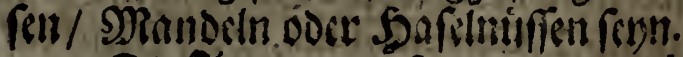

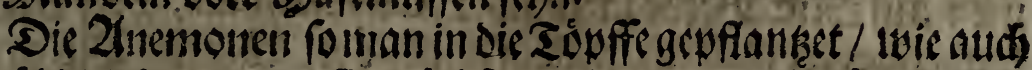

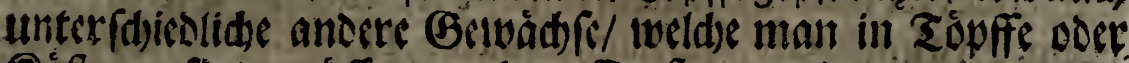
Räfen gefaet / milfifen vor dem Stoff verwabret weroen.

Februario.

Die in vorkergenden Monat beriblerte 3. Irtictel bat mtañ Febraaxiss. bier ebenfalls wieder zu beobaditen. Sonft mus man ferner

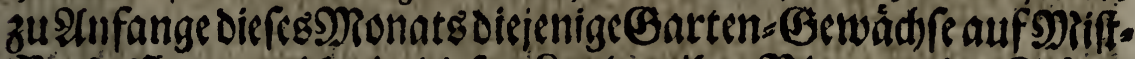
Betbe fäen / welde in dicfen Randen ibre Blumen oder Fridds.

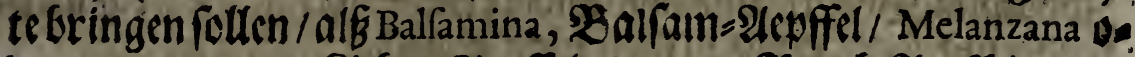
Der Poma Amoris, Riebeg=2lepffel / Datura, SRaud)=2(epffl/ Can-

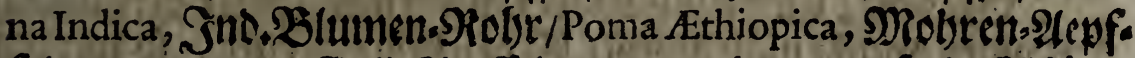
fol/ Poma aurea, Gold=2lepffel/ Amaranthus, taufend=-Sabon'

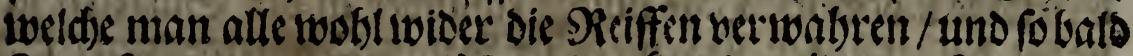
fie aufgegangen / mit glâfern Glocten bececten inus. 2Bäre es notbig/ fo múffe nods iber diefes Strob barauf geffreuet nocts Den/ wie man bey Confervirung Der Anelonen zuttunp pleget.

Martio.

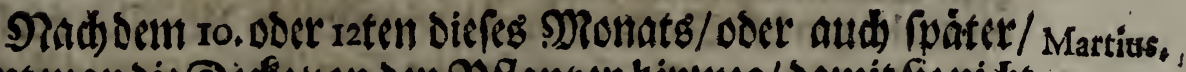
nimtnt man die Deffe von den Pflongen binweg/Damit fie nidt binden nad yon den Sieifen nod hilberfallen werden.

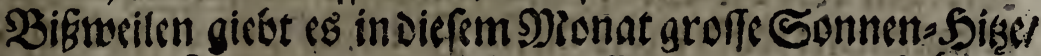

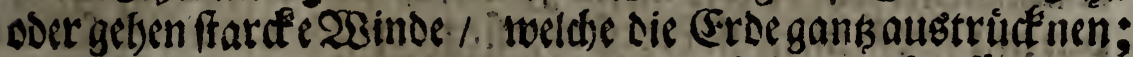
barum foll man weder bei) jener nod beis diefen fáen oder verfersen.

Mitten in bem Martio formen die fibrofen oser 3 afichte Gewo sichfe 1wieder gepflanket wer Den/als: Viola Martix, Merk = 2iolen/Hepaticus flos, Zeler-2Btimulein/Bellides, MRablieben/ Primulx Veris, Sdluffet=:Blumen/Helleborus, Nieftwurk/Chamo-

$$
\$ 2 \text { millix, }
$$




\section{0}

\section{Seue Unteriveifung}

millx, Elamiflen/ u. a. Acrgl. wie aud) Hyacinthus tuberofus, Encllid)ter Suacintb.

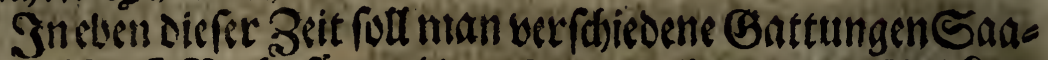
men nuf Mif:-Bethe fáctulals : Caryophyllum, oder Neldeen/ Hefperides vel Violashyemales, 2AGend = oder $23 i n t e r=2$ Biolen $/$ Bafilicum, $\mathfrak{B t r f f i l i e n / C a r y o p h y l l u m ~ I n d i c u m , ~ T h u n i s - g B l u m e / P h a f e o - ~}$ Jum Indicum incarnatum, oder \&eiffarte. Snoianifate Soolnen/

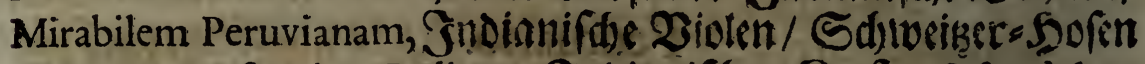
genannt; Nafturtium Indium, Inoianifcher $\operatorname{Rr}$ ह / Calendulam multiplicem, feu flore pleno, gefültte SRingel = Bitumen/Convolvulum 2 sincen von orcnsn Gattungen/ Piper Indicum, Spanie

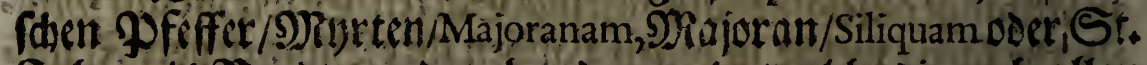

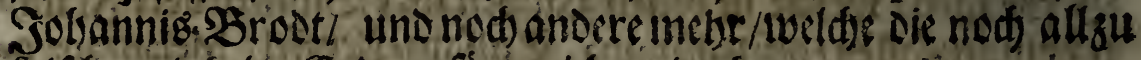
frifde uno falte Eroe zufaren nidts crlaubet.

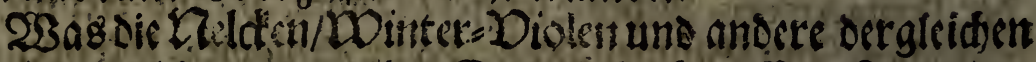

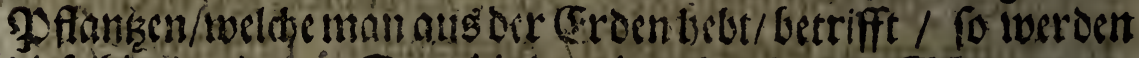
decfellige 8. Dder ro. Zage binder cinander in den Sdatten ges

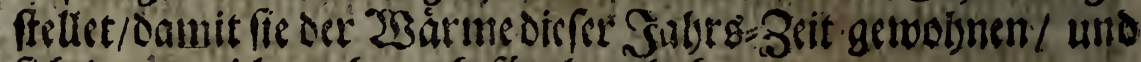
(id) Davor nidst megr zubefitrdetentabent.

Die Basumtein/weldede Rálte nidet beteragen fonnen/ ñcmlid Jafminum Hifanicum, Spanifate Sefinin/ Poomeran. Ben-Báumlcin/ Meyrten/Rofa-Laurus, Oleander/ Cyclamen Au-

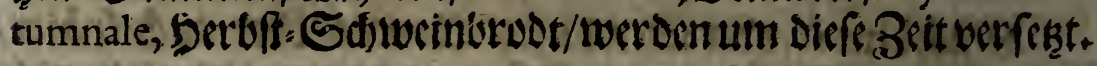

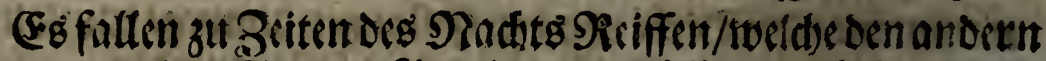

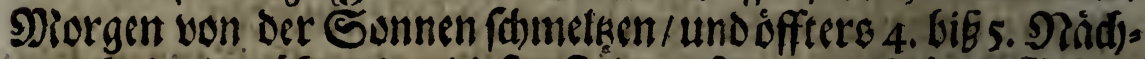

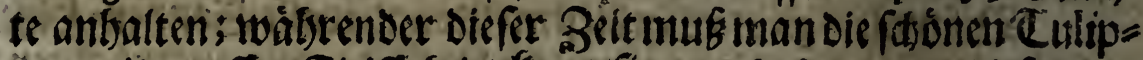

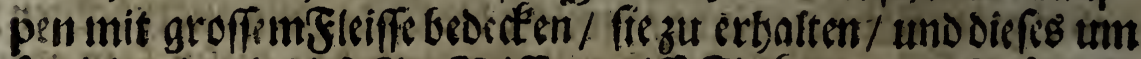

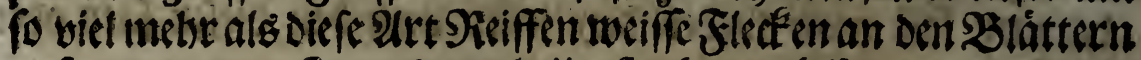
anfsesen/ Davon fie mebrentbeils fterben múffer.

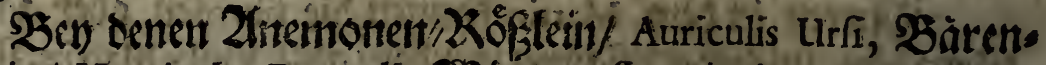
offrtein/ Hyacintho Brumali, 23inters. Syyacintb/ uno Cyclami-

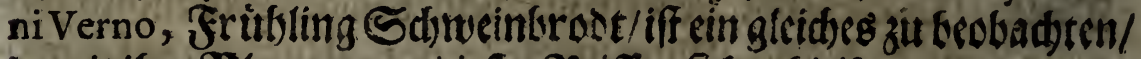
Damit itger 3 lumen vor biefen SRiffen ft ther bleiben. 


\section{zu och Blumen=\$ă.}

Aprili.

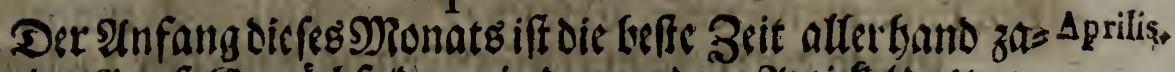

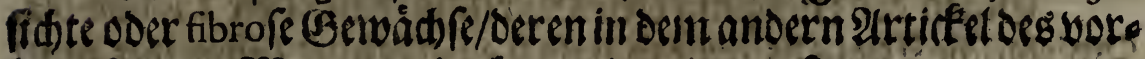
bergebenden פRonats geondtrworden/zuber fesen.

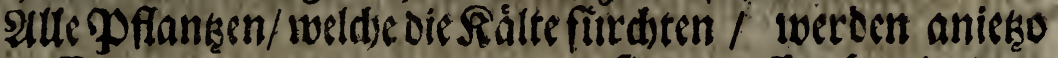
aus ber Eroengenommen/ wanuman fie vergeffen bat in eem Martio beraus zu nelomen.

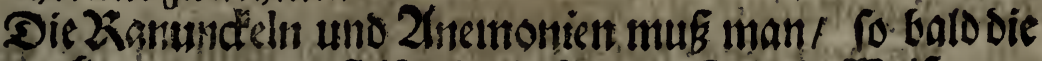

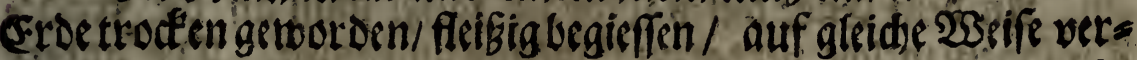
fábretman mit allen benen ilbrigen P flankęn/ welde man in Sdjerben und Siálien bat.

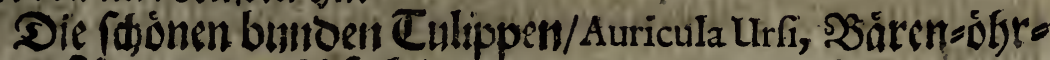

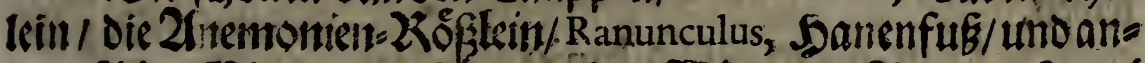
Dere fióne BBlumen wollen vor ben Winden / Siegen / Sagel

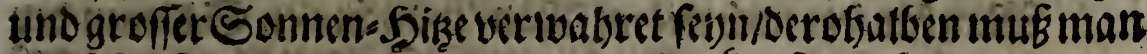
gleid) 2unfangs indiefem Mronat die Deffen fertig balten.

$$
\text { Majo. }
$$

Wannt inan sem Cyclamini Autumnali, Sortbff= Edwein-Majus.

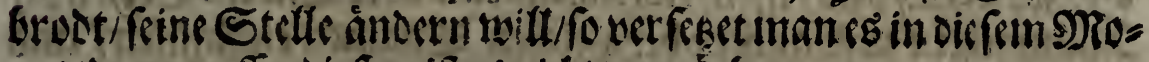
nat/ onnnauffer diefem ifte nicht bonnotben.

Sn Dirfem Monat wirs der 21nemonicu, Snamenteiff! oarumner aud) foltgefamuntet / in cinen trocéenen Drt gebrad)t/

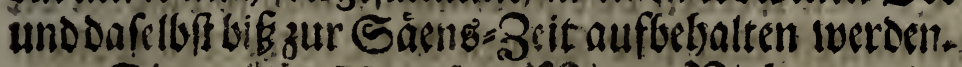

Die gepuilte Musquiste DOinter:Diole / bon Denen Frant= Gofen Julianes genannt / zertbeilct oder reiffet man bon simander fie zu virmetiren.

Mlä faet aud unter (dbiedidje Saaunen oer perennirenoen

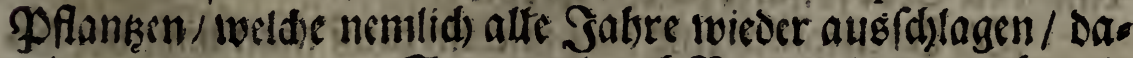
mit man sen gunąen Sommer ourds Slumen davon babe / als ta fito Calendula flore pleno, gefulfte Singelblume/Thlaspi Creticum, eretifder Bautenfenff/Mufcipula. Bafm \&eimftaut Scabiofa hirfuta, gemeine baarige Scabiofe oper apoffemeraut/ 
Cyanus, Rorndtume bon affen Gotten/ und saun Tricolor fen

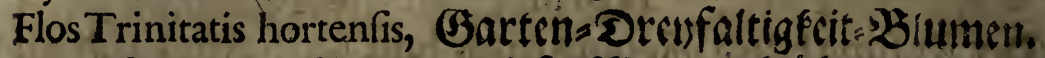

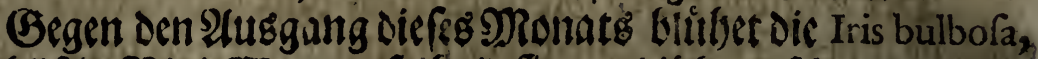

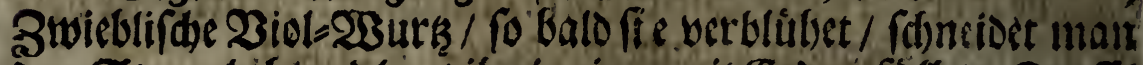

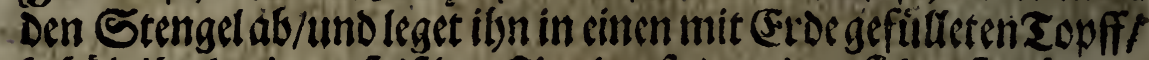
bebalt ibn in sinem frifthen Saal auf / Damtt or fid Deffo lânger

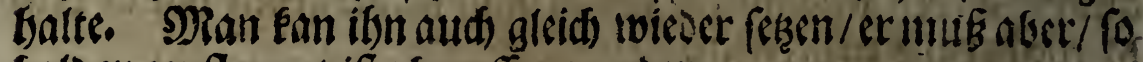
Galder gevflanket iff / begoffen werten.

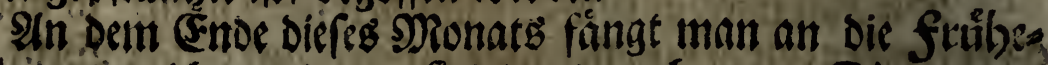
Cullippen/1welde berdorret find/autsumelsmen. Die andere

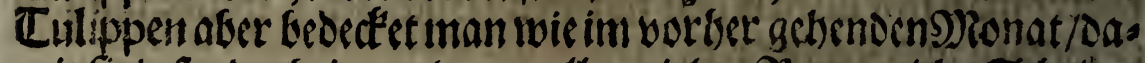
mit fie infonderbeit vondenen allzu vidtin Sigen nidist Sd)aden leioen.

Junius.'

$$
\text { Junio. }
$$

Man fan iest nod twie im May / mandierley Saamen der

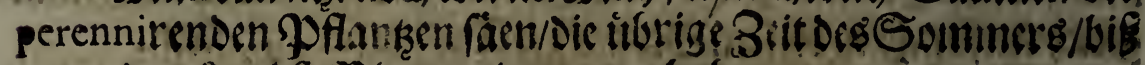
gegenden Seruft/Bblemen Dawer zu haben.

2iudi foll mand oie zeitige Eaamen/nls ben Orientalichen

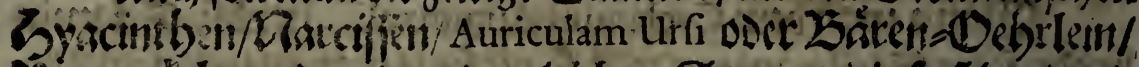
25xnund tell uno andere berglciden Saamen cinfanten / smo fic antrinem truckénen Ortwerwabren/ Daunit man cinen ieden zli friner Beit wicoser fäen fónne.

Die Eu lipen nerden ausgenommen / und fo balo fie bie

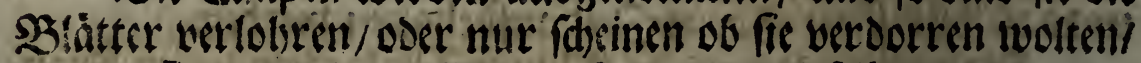

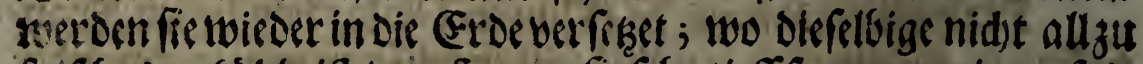

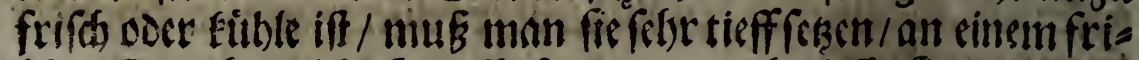
fósen Ort aler nidet fo tieff/ fondermman begieffet fienur oben/.

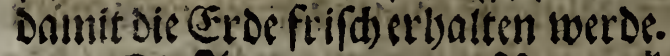

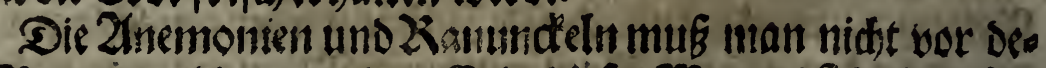

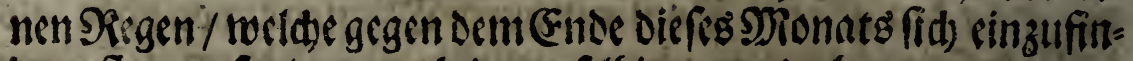

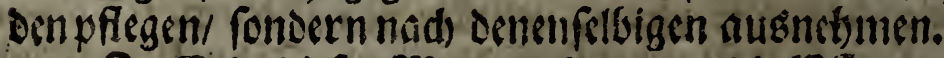

3u Ende Diefes SMonats fan man de Pflangert/ waldse

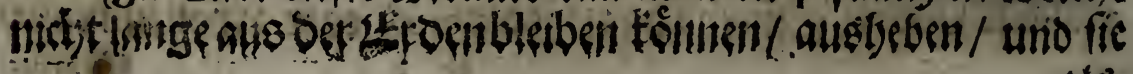




\section{รแ ธem 2 humentรă.}

alobats ivieter Rsen/zum Exempel Cyclarien Vernum, fruth lings Sd)tweinkrod/Hyacinthum orientálem, Morgenlàndiften Swacinth / und andere bulbofe Syacintben / Iridem, 23ide 2Buth / Fritillariam, Fritilliarien/Lemerocalles, gelke Goldilien/

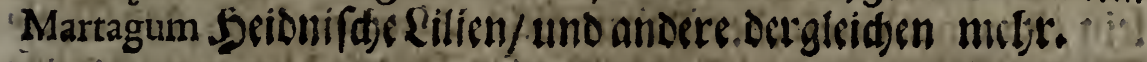

$$
\text { Julio. }
$$

(Fo ift nod) Bcit Cyclamen Vernum, oab frublings Juliws;

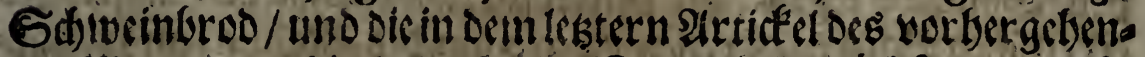

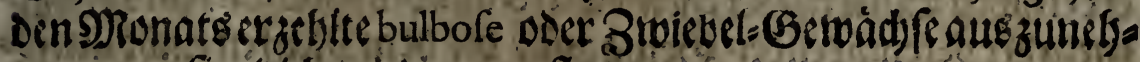
inen / um fiegleid) wieder zu pflankęen.

Der Eaamen yon frublings Sthtvernbros iff in dic:

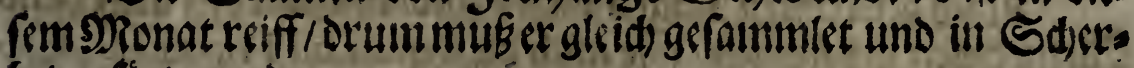
bel gefáet iverien.

Die Mintten-Báumlein / Sefmin= Baumtein / Ponts ranken=Báumlein/ Rofen=Sträudse / unD andere Dergleidan

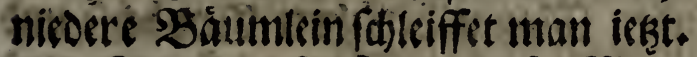

Zon den 2lnfange disfes Monats bíz in Den September

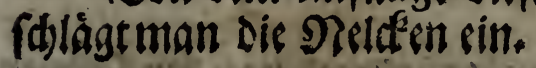

\section{Augufto.}

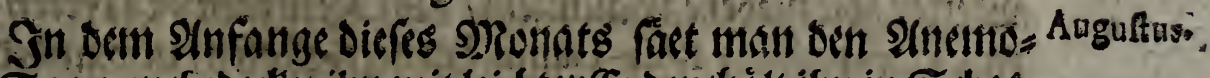

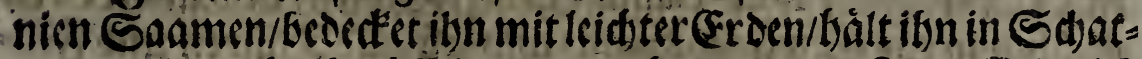
ten uno begieffet ífn offters/ zu berbindern / AnE Das Erorcid nidbt allzutructés werbe.

2(ud) pflanket man bie gemeine ober cinfadte 2nemonient

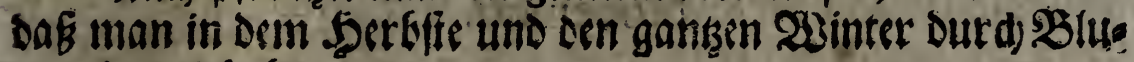
men davon bates.

Sebt if audidr Bcit ben Naarciffen Saamenumd den San: men der Drientalifden Sgyacintben zu fáen.

25 is

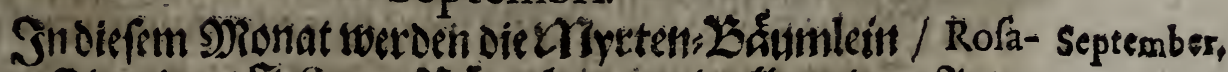

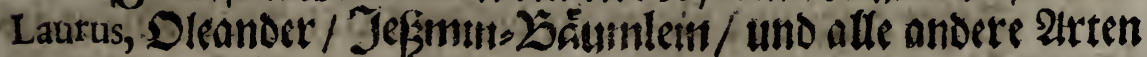
Der fleillen Báume/ welde dem Sisiffen untertworffen find/ oser lafles 


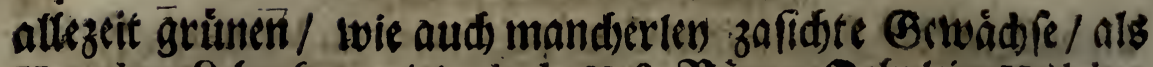

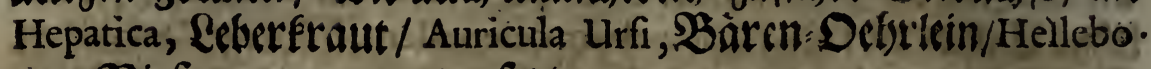
rus, Niéswurk U. a. m.verfskgt.

Ran fáet Dic Saamender Auricularum oder Báren=Deftrlein / Ranunculorum, DerSRanundfeln / Alaterni, Iridis, oer 2 iolo

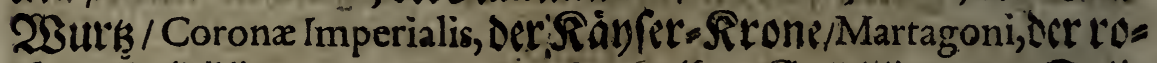
then Golditien/Hemerocallis, oer gellen Bolditien/ Der Tulis pen/confolidx regalis, Der Pittterfporn / Thlaspi de Candia, oss

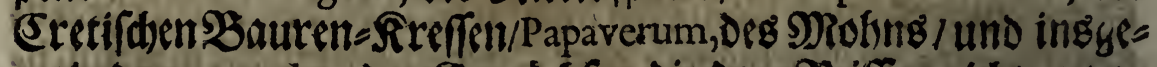
meineerperennirenden Eetwadife / Die dem SReifen nidts unters morffen fino.

Rad) Dentrifen Tagen biefes Monats twerben allerband Zinemonien gepflanket $/$ wie aud) Die. Ranunculi Tripolitani, eripolinichet bantenfing.

Odtober.

\section{Ootobri.}

Die in vorkergehenden Menat beritbrte Berwaidfe und Saamen Eanman alle nods in diefem Slonat pfanken und fáen.

Gegendem Enoe diefes Nontats bringet man bey fadónen

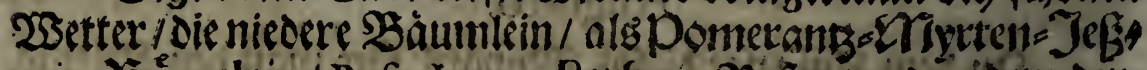

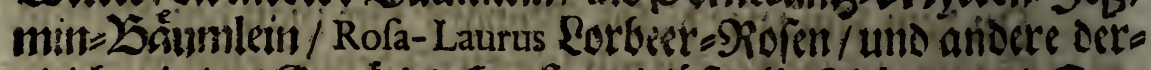

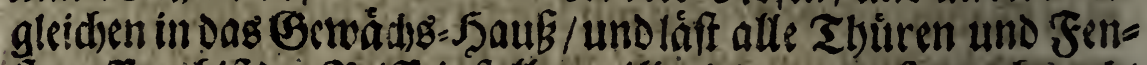

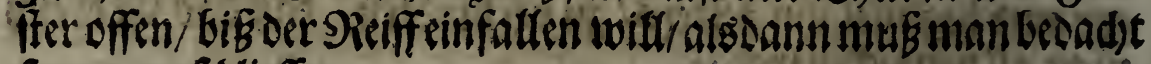
fevn zuzufdslieffen.

\section{Novembri.}

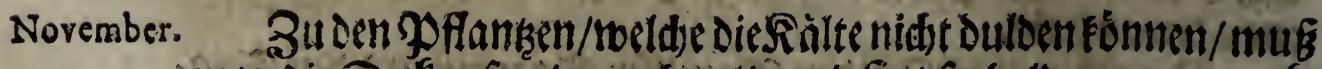
imandie Decfen fertiginadien/ Damit fie/ fo balo man gedendet

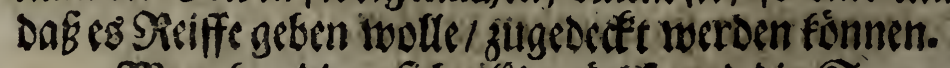

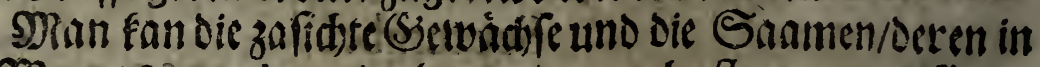
Dein Mionat Sêptember gidantht worden/nod) pflanken uno fäcn.

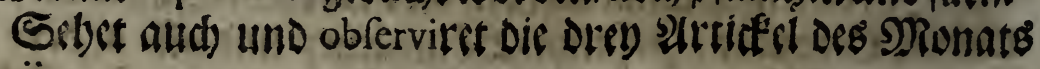
Januarii.

Diefer 


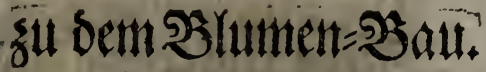

Diefer Monat if bie beffe Zeit die fdosnen buntoen zullipen

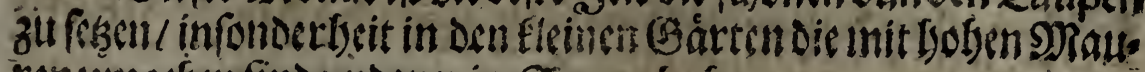
renumgeben fino uno toenig Gome baben.

\section{Decembri.}

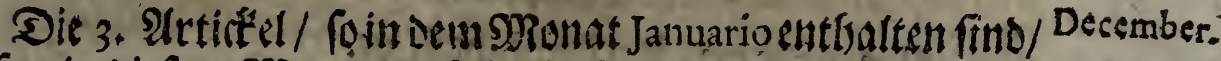

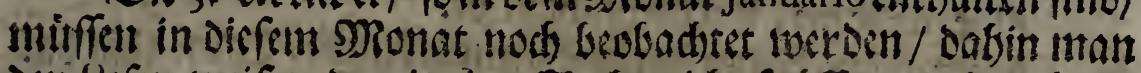

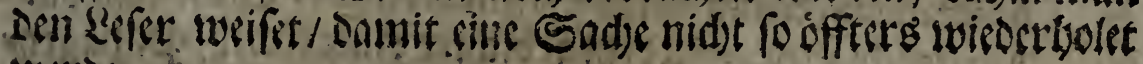
werds.

\section{2aร XIIX. Enpitel|}

Diegifec outer Pflantsen / weldbe Dutd oen Sieiffen verberben / und sivat erfftid) wont benen zarteffert / welke bie Rálte im erften (Bra= De sulbefurtsten babent.

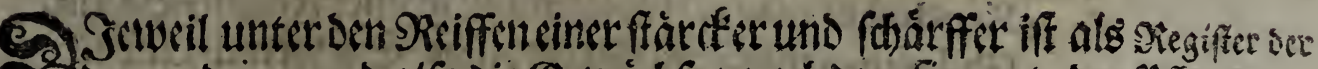

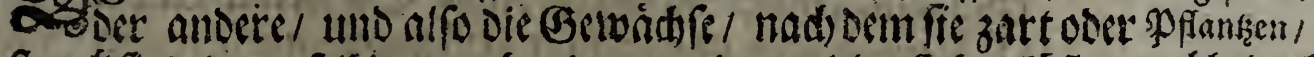

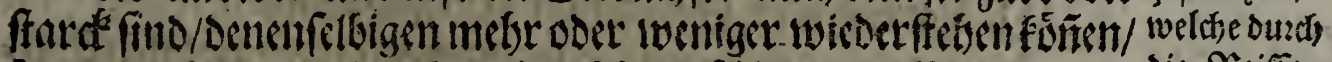

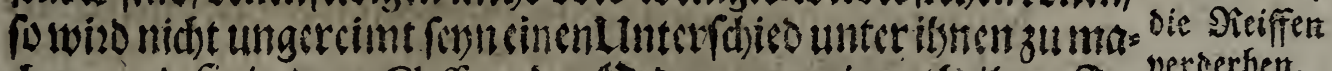

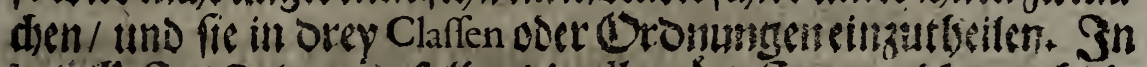

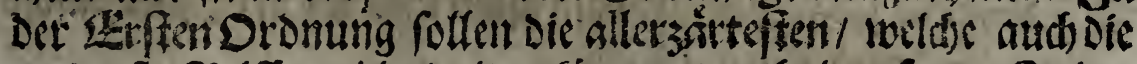

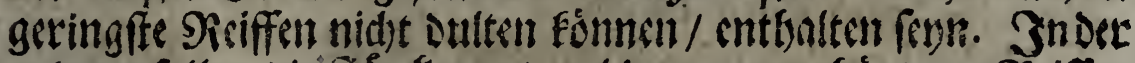

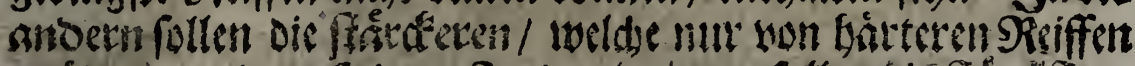

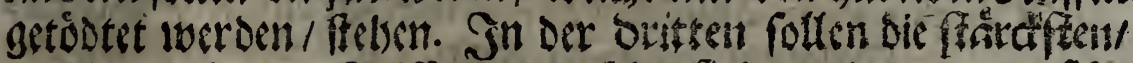

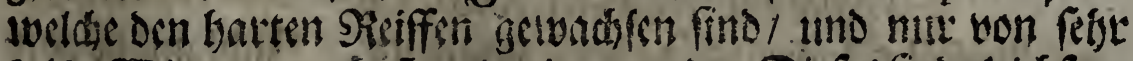

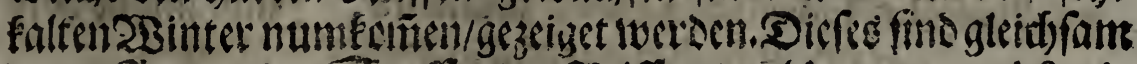

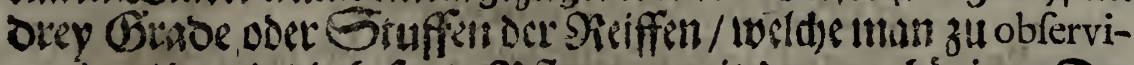
ren bat / Damit bie Gefagte goflangen mit Denen gebogrigen D:

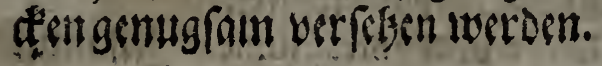

$$
\text { D I. Piegi }
$$


$26 \quad$ Teue Unterweifung

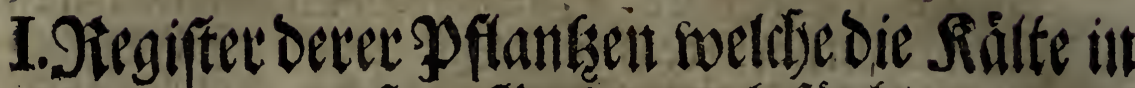
Dem erfiten Grabe su befiurdeten

baben.

Sm $\mathrm{crften}$

Errnor.

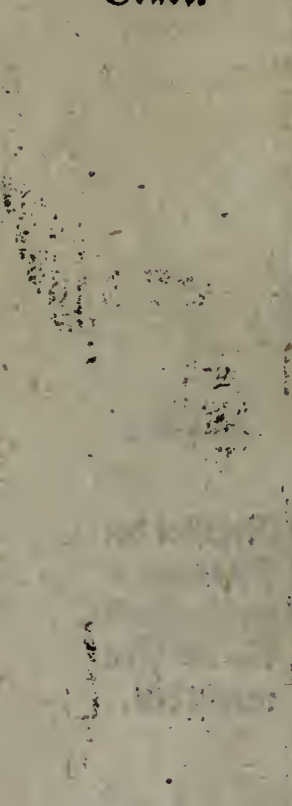

Aloe Africana, $\mathscr{A}$ fricanifde $\mathfrak{A l o}$. Amaranthus, Amarantl/5anumetblume/ Taufendfdont. Amaranthus tricolor, orebfarbidter \&matantly/ \apageve siraut.

Balfamina mas, Balfams Xuffel= Mánnlcin: Bafilicum, $\mathfrak{B a f i l i e n .}$

Canna Indica, Sndianifdacs S: tunten= Siolst.

Caryophyllus Indicus, Snoianifde Nieglein oder Neleen/ รbแni8:-2Blum?.

Elichryfum $\Gamma_{t}$ Flosimmortalis, Sonnen=(Solo-Blume. Ficus Indica Americana valde fpinofa, ffaddid)ter 2 mericas nifdiet Freigen= Bntum.

Ficus Indica major, Sndianifdet groffer feigen=Baum. Gladiolus Æthiopicus, Artbiopifite Sdiwertel=silien. Sndianifdooder Epanifder Pofeffer:Batm. Melanzana, malainfana f. Poma amoris, Rlebed-2lepffl/Toll'

Henffel.

Narciffus Japonenfis, Sapomefifde/ und, andere Snsianifde Parciffen inclyr.

Nafturtium Indicum, Sndianifder Rref.

Ornithogalum Arabicum, Arabifd) (Eronútfe / 20 gel:s Mild ooer felo-Btviebeln.

Phafeolus Indicus fl. rofeo f. incarnato, Snoianifde odet

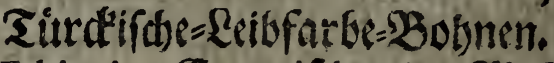

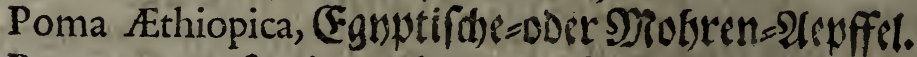
Poma aurea, (fpecies Melanzenæ) GolD = (efffel. Poma fpinofa, fonffen Datura odet Stramonica gènatnty Saud $)$ oder Sted $=2$ (epffel.

Rhabar- 


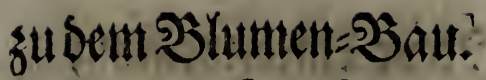

Rhabarbarum erectum, aufgerid)tete ooer getroe Rbsbar: bat.

Satureja ativa, Sormmer Saturey.

II. of flantren weldie die Reilte in oem andent Grabe subefurdsenbaben.

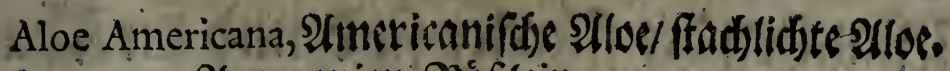
Anemon $x, \mathfrak{A}$ (nemonicn $=$ Sid É Elein.

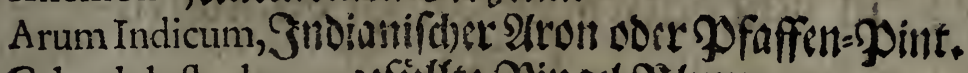

Calendula fl, pleno, gefílfte Singst=SZlume.

Caryophylli, Garten= Neldten.

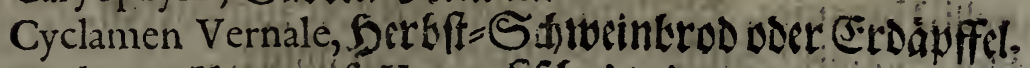

Cyclamen Veronenfe, Veronefffches / oder von Verona foit.

mencc. Sdurin=\$ros.

Digitalis Hifpanica colore ferrugineo, (sifen-oser $\Re$ inudf far:

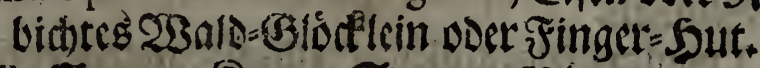

Flos folis, Sontent=sirone/ Sonnen=situmte.

Hyacinthus Peruvianus, \$eruanif her Syacintls:

Jafminum Hifpanicum, Spanifdser Sismin.

Jafminum Indicum fl. luteo, Sncianifoser Se B̈min mit gelo

ben Blumen.

Iris Suffiana, Stiffaniffie Sd)wertel=silie/ Conftantinopolitanifore Diol-2Burs.

Malus aurantia, Pomeranken=ßaum.

Myrtus, Mrsten.

Narciffus flore comofo Orientalis, Orientalif $d e$ Pu(d)=0der

Feder =Narciffen.

Phalangium Creticum, Sretifore ober aus Candia Eomment

oe (Sirab́=Eilien oocr Ero=-Spinnen= Sraut.

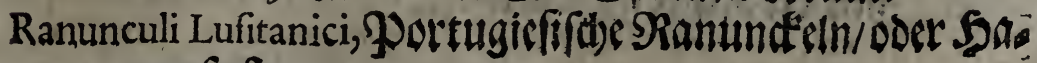
nenfub. 


\section{$28 \quad$ Neue Unterweifung}

Ranunculi Tripolitani f. Cimplici \& pleno, cinfader uno ge: fitlter Tripoliniføer SanenfuB. Rofa - Laurus,Laurus Rofea, Oleander ober Eorbeer=-Rofert. Viola fl, pleno, gefüllte 3 idelen yon alferley ifarben.

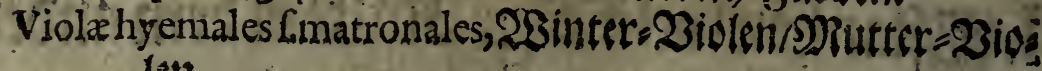
lent.

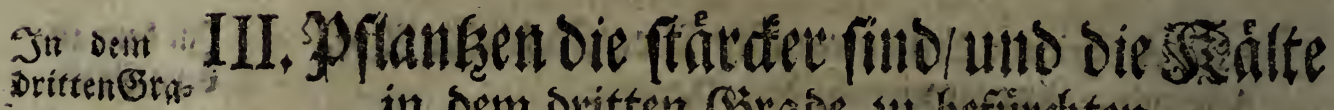

a.. in Dem oritten Brobe su, befirdsten baben.

Bellis Hispanica, Spanifhe Zeitlofen oder MRaflieben. Flos ?asfionis, Dofions:Blume / Granndillt.

Fritillaria montana, Berg. Fritifletit.

Genifta Hispanica flo albo, Spanifuser Ginft mit tociffen Bilunter.

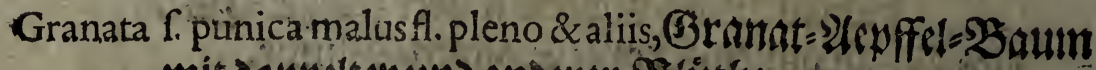
mit boppelter und ancerer \$Bítbs.

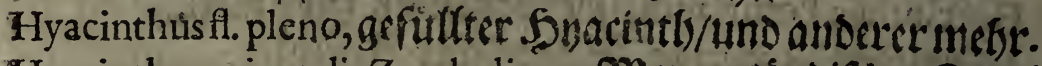
Hyacinthus orientalis Zumbulinus, Morgenlándifder Zumbus: lin= Sonacintt).

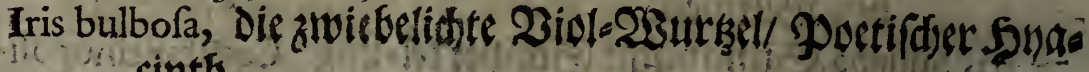
cinth.

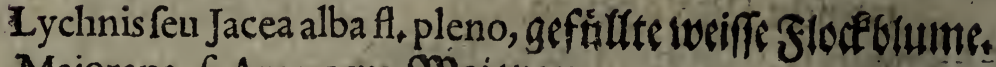

Majorana $f_{*}$ Amaracus, Majoran.

Matricariaft. pleno, gefiltt Muttre = Itraut.

Papaver fpinofum, ftadliditer Mohn ocer MRag=Saament?

Veronica fl pleno, gefitlfer Ebren=idreis.

Viole finplices, ein fade $\mathfrak{B}$ id!en ; Dann die gefuften wiberfer

ben der Ralte nidt forwobl.

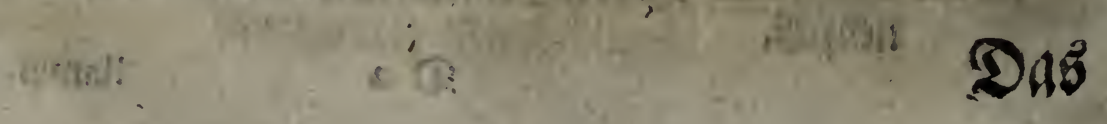




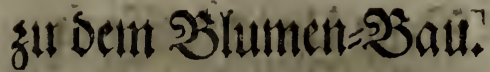 \\ 29 2nื XIX. Capitel/}

SntweldermAfpect oder(Segend der Sonnent man bie 2 Jumenpflankenfolle.

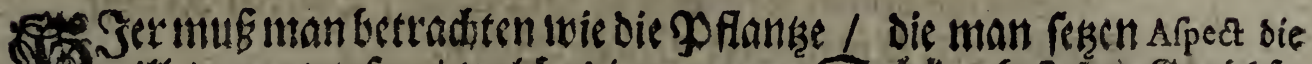

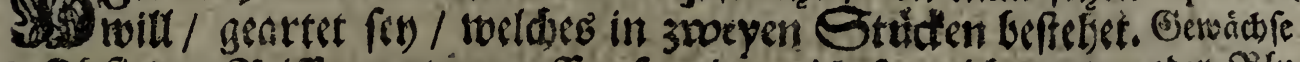

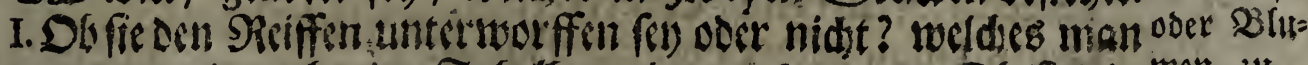

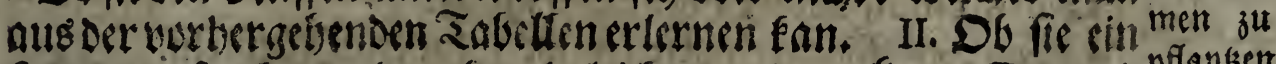

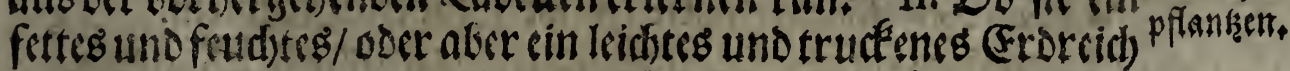

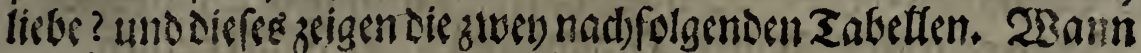

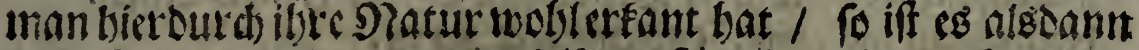

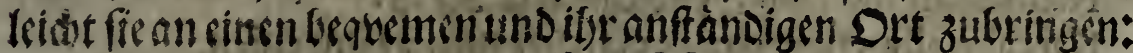

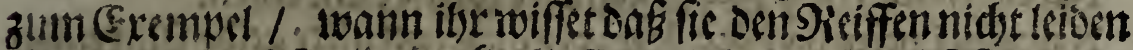

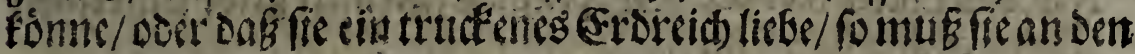
woirtmfern Drt DeE Garteng gewfiangert werben; fan fic im (B); gent beil Die Sälte nobbl vertragen/ und lisbet cinfertess und feud)=

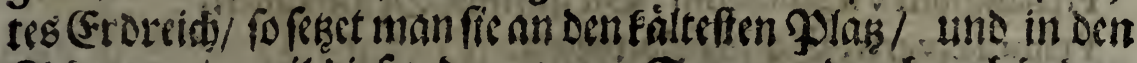
Edatten / weil Diefer Den ganken Sommer Dur wo audd in bem

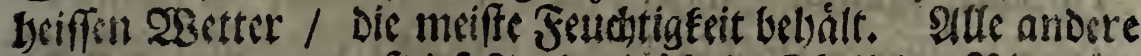

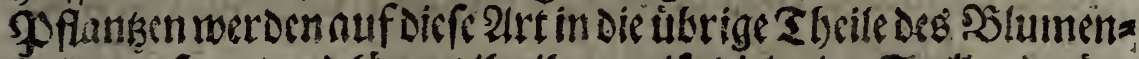

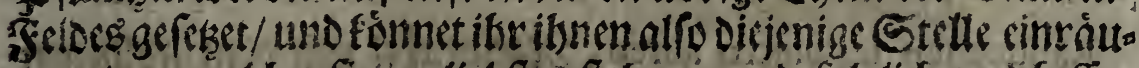

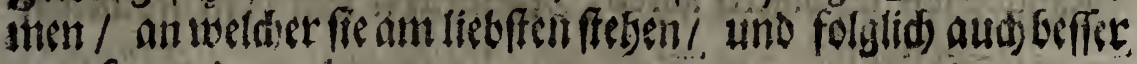
wadf) fen uno zuncebmen.

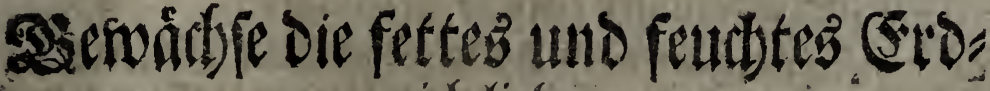 retid) lieben.}

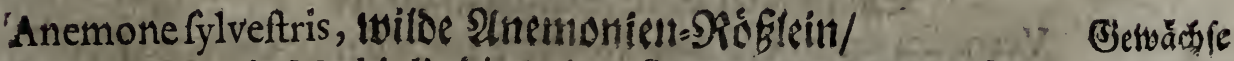
Anemone tertia Mathioli, Die oritte Smemenie Drs Mathioli, Die fett uno

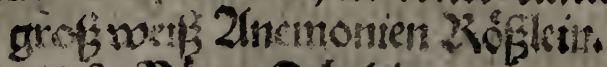
Auricula LIfri, Bậren Debclein. feuthe Er: de lieberti.

D. 3 Belli: 
Bellides fore pleno, gefitulte SPablicten ocer Beitlo fen.

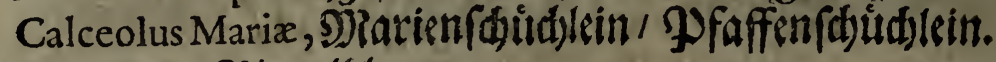

Calendula, Siingelblume.

Cyclanina autumnalia, $2 B i n t e r$ Sfiweinfrod.

Fritillaria communis, gemeine Fritillerie.

Fumaria bulbofa, Snollifiter (Ervtaud/ / Tauben=Sropff.

Hellebori, Chriff=0dir Niib: 23 ure.

Laureola, Retferbat(B/ Rorbecreraut.

Laurus Tinus, wilder Rortbet:= Baum.

Lilium convallium fylveftre, twitoe Manent: Blúntein.

Limonium vulgare, $23 a 10=91 a n g 0 l d /$ genteiner Mangolo.

Martagum, Solowurk / Senonifde Rilien/ Seucr=Rilien.

Nafturtium Indicum, Snoianiffor Fire.

Narciffus albus flore pleno, gefutlte weiffe $\mathfrak{T a r c i f f e n}$.

Narcifus Luteus fl.pl \& calcare præditus, gefufflte gelbe $\mathfrak{N a r c i f f e n}$ mit Spơrlcin.

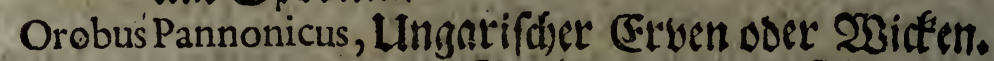

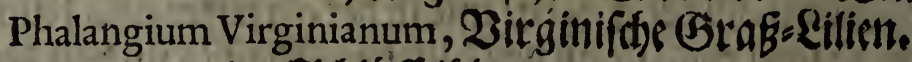

Primule veris, Sd)litfelblumen.

Pulfatilla, Rudfen: $\subseteq d \mathfrak{c}$.

Ranunculusàlbus Anglicanus fl. pl. gefitteter Englifdjer Iyciffer Sanenfub.

Ranunculus involucro aureo, Fumundtel mit oen gurtoenen Sinopffe.

Ranunculus fl. pleno, gefütte Fanundel oder Santenfuf. Satyrium, Stendelivurs/ SimnGen=siraut.

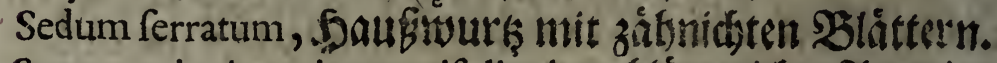
Serpentaria Americana trifolia, orenklátterid)te Amet icauifobe

Soj)langen=oder Draden=W3urb.

Veronica major \& minor, groffer und Eleiner effren-opreifs.

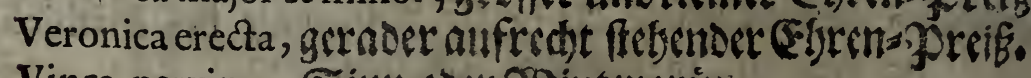

Vinca-pervinca, Sinn-biser 28 intergritt.

Violx, Diolen / braume Deilgen. 


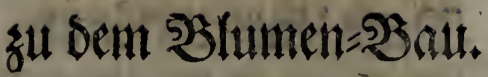

Viola Trinitatis feu Tricolor lutea \& vulgaris, gelbe uns gemtinte Drenfaltigesit Btiunlein oder Jrenfameraut.

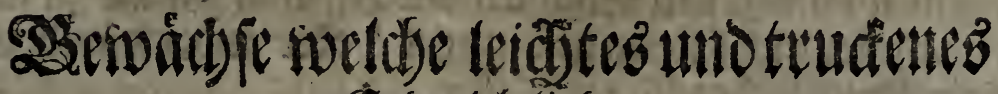 (Erortich) lieben.}

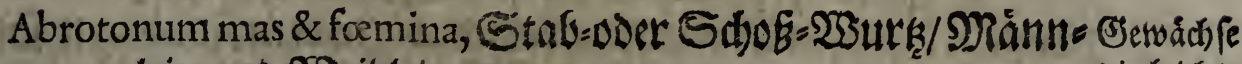
lein uno $\mathfrak{W S \text { cillein. }}$ bie leiciste

Genifta Hifpanica, Spaniforer (Sinft ooer Färber=Slumen. Majorana, Majornn.

Rosmarinus, Slostmarin. uno trucfe $=$ ne Erde lie= ben.

\section{2n XX. Capifell}

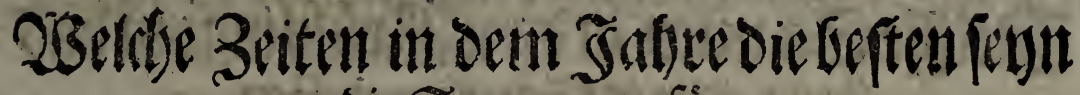
Die Saamen sufáen.

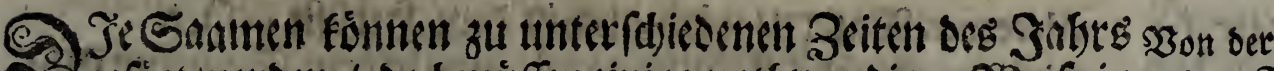

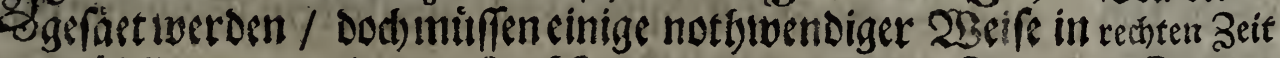

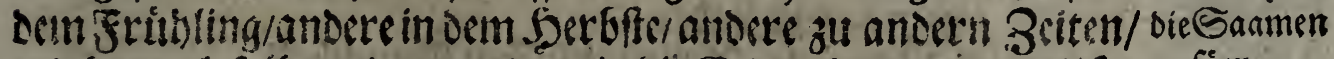

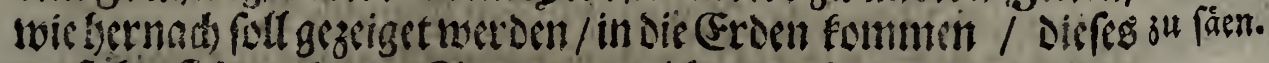

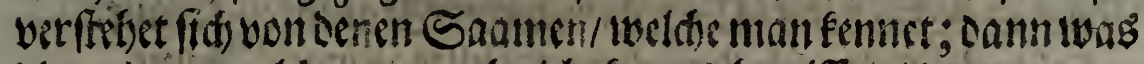

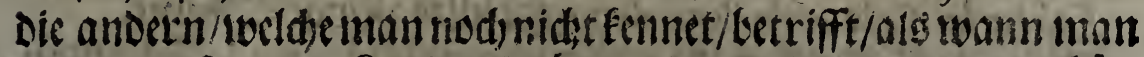

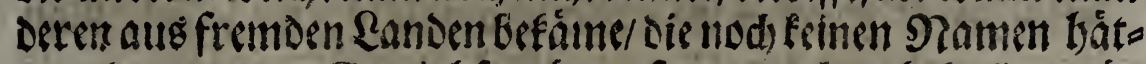

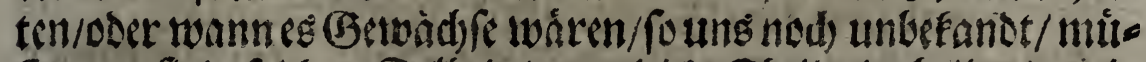

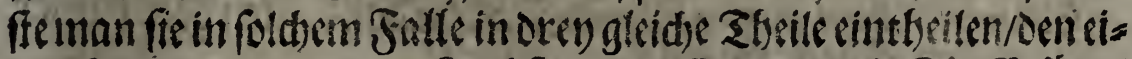

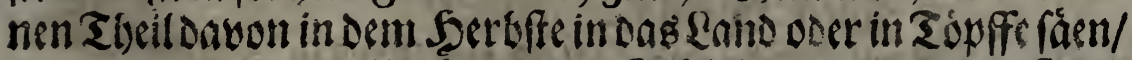

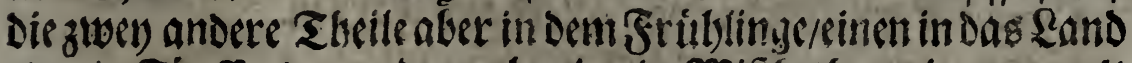
Doer in ₹iuffe; Den andern aber in ein פiffbettbe/ wie man mit Denen Pflansen/ Dicoem Sietifen untertworffen find / zu tbut wfleger. Diefes ill oas enige Mittel fer ficter aufzustringen:

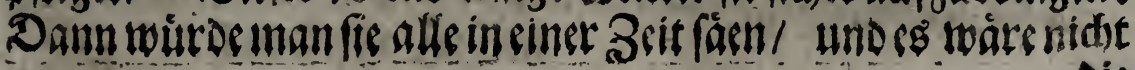
Dir 


\section{2 \\ Tatte Unteriveifiuts}

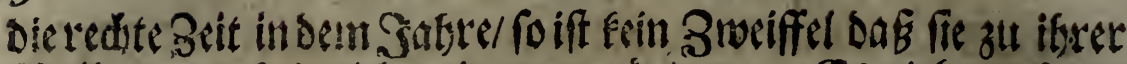

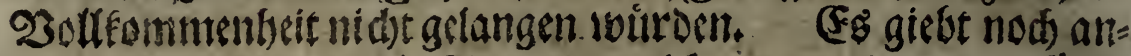
Derc grimeine Siegeth die Sasmen weldse man fennet zu fien/

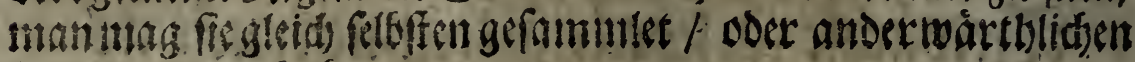
ber be fottitsen baben.

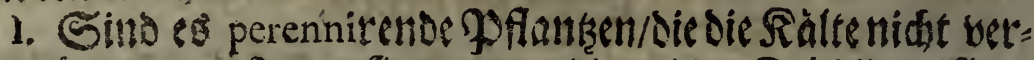

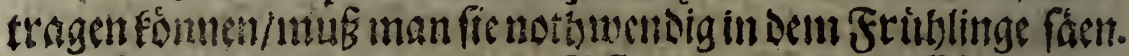

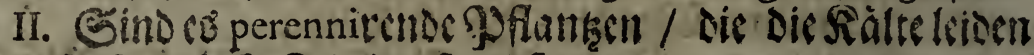

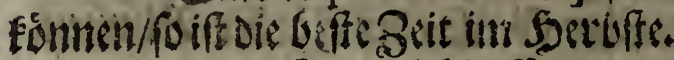

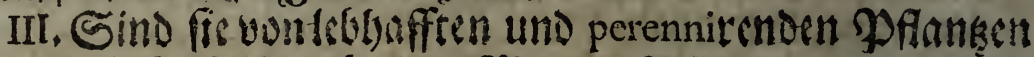

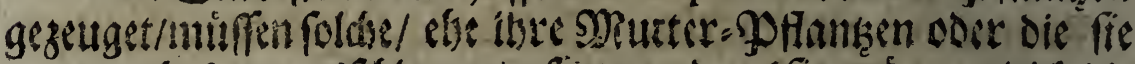

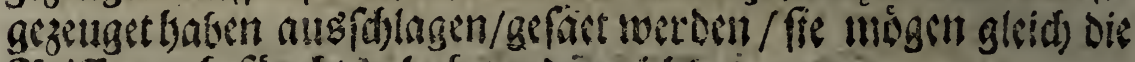

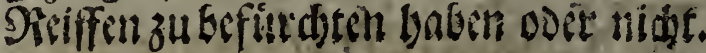

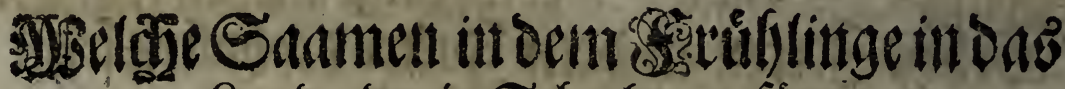 Lanb oder in Sájerben zu fáen.}

Saanten Alaternus, allatern/ wiro audb in Dan Serbffe gefäet:

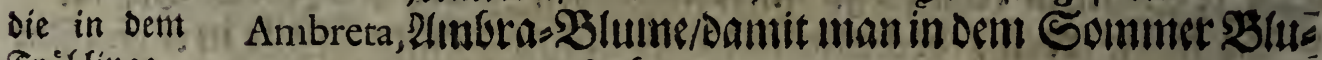
Jrififlinge jul fât? mendavon loake.

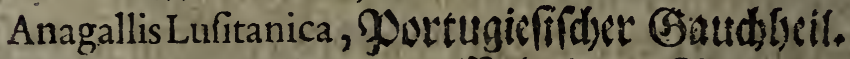
Belvedere feu Belle-videre, \$belvetern/Stubenten= Rrtaut.

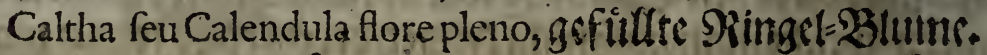

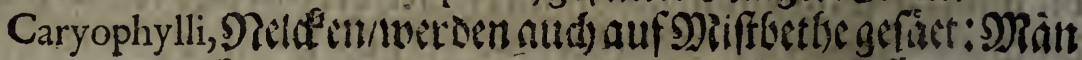
Fan fie in Drm Sommer uno Serbffe nod) fácll.

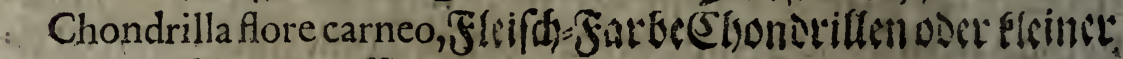
Eonnen= 23 irbel.

Cyanus, Rorns 3 tume/won allerbano Farbin.

Laurus Thinnus, wilder Rorbert=ßaum.

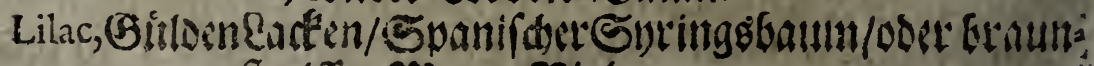
Majorana, Digujoran. geffrciffe PRaul= 3 idelen. 
Mufcipula, zaftmcs \&sim= Rraut.

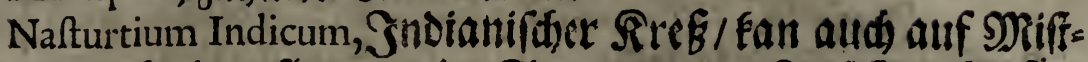
betbe gefact/uno in Goinmer uno Soetbft nadbgefaet lverden.

Papaver erraticum fl,pleno, gefilltet twilder MPofn/ fíappet: odr Rorn= Solen.

Rofa-Laurus, Narium Dlcander $/$ \&erbeet $=$ Rofen.

Scabiofa, 2lpoftem= Rtnut / WBind SR raut.

Thlafpi Canadenfe, (Saltbifd)e Brfin=Sraut/ Baurenfenff/ odet Bautenosirés.

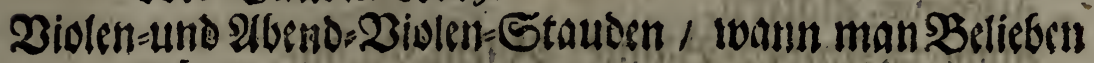
trágt.

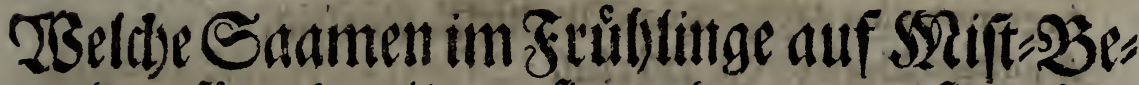
the zufáen/Damitmanfic wondart/ wannfie aufs: gegangen/ in Dag eano verfeke.

Amaranthus, Sammet $\mathfrak{B l i m}$.

Balfamina mas, $\mathfrak{B a l}$ fam= 1 leffel Mälntein.

Bafilicum, Bafflien.

CannaIndica, Sndianifdses Blumen=Sobr/ Pfeil Sobr.

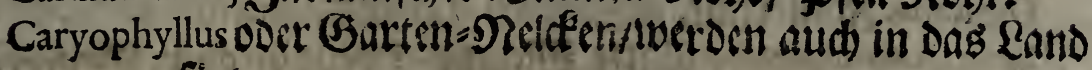

Saamen Dic imfrúf̨= linge in Mift: $\mathfrak{Z}_{\ell}=$ the ju fáen.

\section{gefíct.}

Caryophyllus Indicus, Sndianifde Nelefen/: Gunis=:Blumen/ Eammet = SRobleit.

Flosfolis, Sonnen=:Blume.

Geranium trifte, cine \&rt von Stord=Sdunbel.

Hedifarum Clypeatum, Piltfich / Deren Blitter wic sin

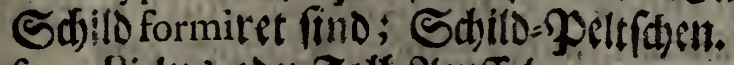

Mala infana, Liebeg-ooer Tolt=2epfel.

Nafturtium Indicum, Sndianiffacr R $\mathrm{r} E \mathrm{~B}$.

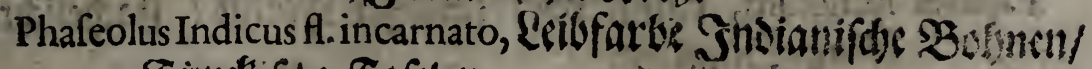

Surctifase Fafelen.

Poma 


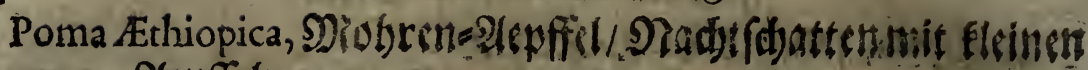
Anufilin.

Poma aurea, Gold-2lipficl.

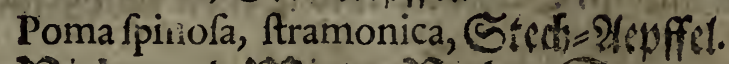

Diolentuno Diner Diglen- Granoen/ wann mantwia.

\section{Weldien Saamen it bem Soctofte 3u. fáen.:}

Earamer Dicin bem Sherbfe bu fáen.

\section{Alaternus, aflaterti.}

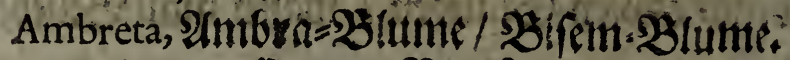

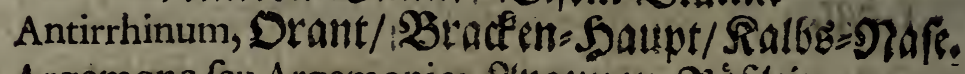

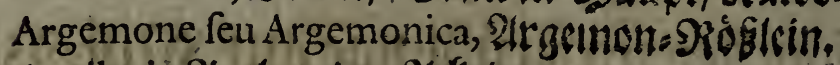

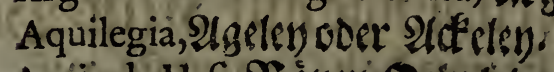
Auricula urfi, $\mathfrak{B a r e n}=$ Dekrtioin. Chamx-lris; fleine $210 !=23$ turset. Confolida Regalis, Siitter=S Sporn.

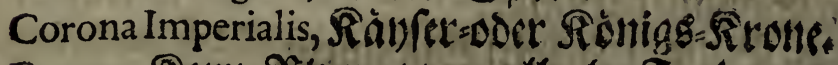
Cyanus, Rorn=SBitume/ bon allerler) Fniben. Cyclamen, Schtwein B Btod.

Digitalis, Singerthut.

Eryngium planum, glatte Nanns: Srelie, doer stacten: Differ.

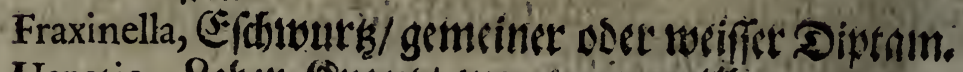
Hepatica, \&ckers:Siraut/ wann man wió. Mufcipula, zabmeg \&eim=-siraut.

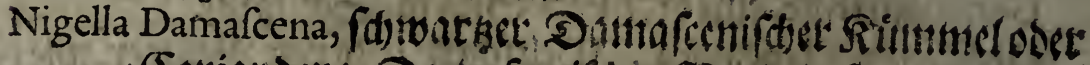
Eoriander: Damafreniface Varosi= Sanmen. Papaver erraticum, wilder Nobtin/ Silayyercofon.

Papaver hortenfe, Sartirn-MRoth?

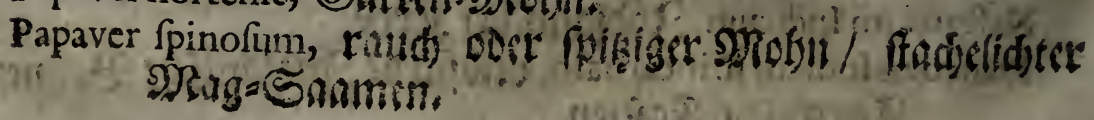




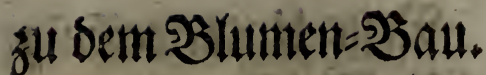

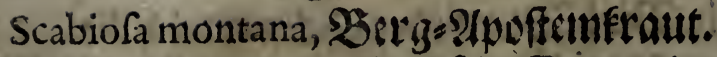

Thlaspi canadenfe, Etetifdie Frven ooer WBifett.

Tulipx, Tulipanton/ Sulipen/obit groffi Plarciffen-Rilien.

\section{2ดื̉ XXI. Capitell}

Tiegiftet deree gafluzeitenlan weläben eint iebes

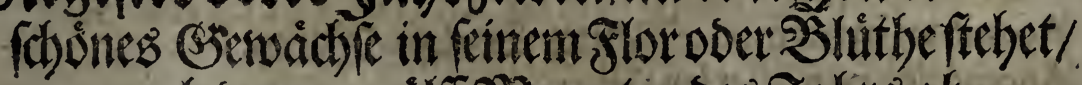
nad) Denen stwólf Monaten Des Jabits ab:

\section{getheilet. Indem \\ Januario."}

Aconitum hybernum, $\mathfrak{W}$ int

Januarius.

Anemonxfimplices, cinfodor Anemonien-Sioficin/bott aller=

bantofarben.

Anemone violacea pilis phœniceis feu rubris, 2Biol:6latte 21nemes

nienmir rorben Saaren. Die Regatren/ ( fo cine art

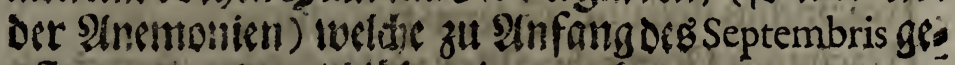

pflanger worsen/.bluken iest aud)

Cyclamina hyemalia, 23 inter Sdite eit $=3100 \mathrm{t}$.

Hyácinthi brumales, 23 inter 5 nacintben.

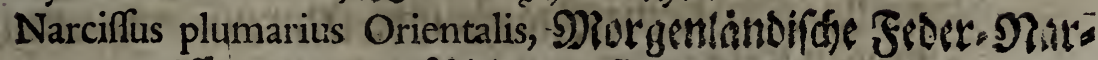

cifie/ voin unterfobicdenen Battungert.

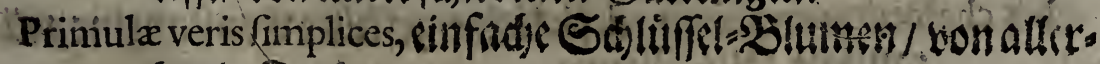

bano farten.

Februario.

Aconitum hybernum, 2 inter 20 olf

Februarius.

Anemonæ fimplices, einfadie Anemonen= Rö Blein:

Anemonx pracoces pilofx, frube Anemonentinit Daaren.

Crocus vernalis, Ftülting=Sifran.

Hepatica fimplex, cinfadieg Eebereraut/ oder das nut cinfadide Sluinen bat.:

$$
\text { (5) Iris }
$$




\section{$3^{6}$

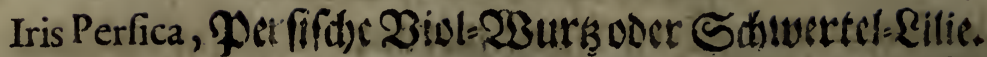

Leucoium triphyllum, Drenblatterichte Leucoiłn oter $23 e$ (d)e Deilgen / fo dic Frankofen Perce neige neunem.

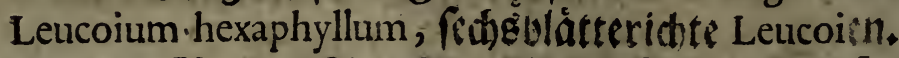

Die gelke2Biolen. Staubenmit groffen23lumen fins zutsilen in diefrn Monatim Slor.

\section{Martio.}

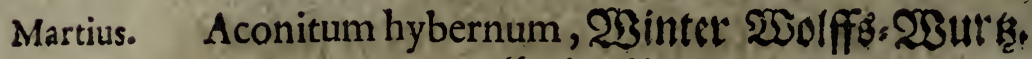
Anemonen won allerley 2 trten. Auricula Urfi pracox, fritbe $\mathfrak{B a r e n}$ Defbrlein. Chamx-Iris, oder fleine 2 iol=2Wure. Cyclamen Vernum, Früblings Sdiveinfrodt. Crocus Vernus, Jriulling:=Saffian. Fritillaria, Sritillerie.

Hepatica florefimplici \& pleno, sinfadtes uno gefitfles \&etects fraut.

Hyacinthus brumalis, 23intet= S5nacinth oder Merkenblumen. Hyacinthus ftellatus, Stern=-Sovacintt).

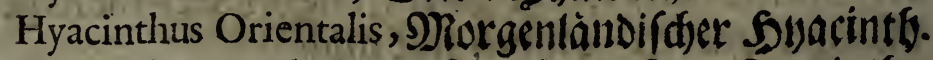
Hyacinthus Zumbulinus, Zumbulinifder Syyacinth. Jonquilla $f_{\text {f }}$ Narciffus Juncifolius fimplex, calice magno, Sort: quille / ooer ficine Staliánifbe Parciffe mit cimem grofín Retds.

Iris chalcedonica minor, fl. pl. fleine gefillte Eonffantinupotis tanifhe $\mathfrak{B i o t = 2 3 u r k . ~}$

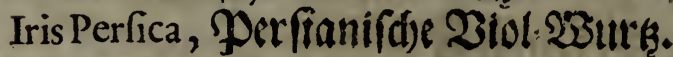

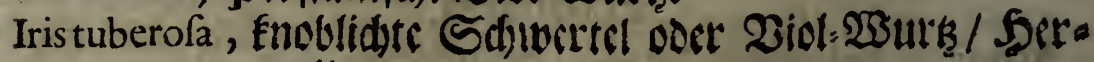
modactru.

Leucoium hexaphyllum, fedggelatteridte Leucoien / ob gre groffe (4ist Ziriln.

Leucoium triphyllum, oren)(vâttetidite Leucoitn.

Narciffus Juncifolius Hispanicus Tromboni, Spanifdes Songuil. lendes Tromboni. Narcis(5) 


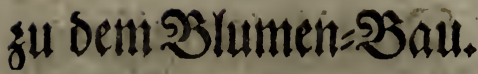

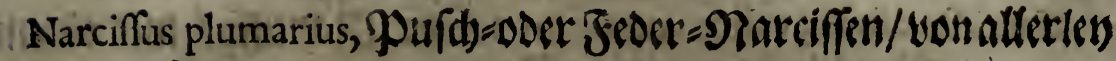
2urten.

Narciffus luteuscommunisfl,pleno,geffillte getlbe פarciffin ooce 5ornunges=2lumen won oen gemeinen.

Narciffus luteus Anglicus, fl. pl.gelbe gefillte Englifde $\mathfrak{R a r c i f}$ fin.

Narciffus luteus fimplex, cinfüde gellbe $\mathfrak{N a r c i f f e n . ~}$ Narcifus luteus aureus, gelbe Rrone/ Gold . Rron?. Primule veris, oder Sdlluffel Blumen/ non alterlen Farfen. Vivla lutea Germanica, gelloe teut fde 2 iolen=Etide poer Staingsn=23iolin.

$$
\text { Aprili. - }
$$

Anemonin won alferband Sorten. Aprilis.

Auriculx urfi, $\mathfrak{B a ́ r e n = D e l l y r l e i n . ~}$

Bellides, Daǵlietsen/ Margretben :Sióblein.

Caprifolium feu Matrifylva, $\mathfrak{B}$ ald $=\mathfrak{W}$ inde / Záunling.

Chame-Iris, fleine 2 idl=23ur/ven ver fojicoenen Farfen.

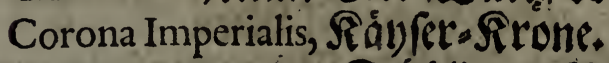

Cyclamen Vernum, Frublings Sd)twin=\$3root.

Flos Trinitatis, Frevfant-Siraut

Fritillaria, Fritiluerien bon allen Sattungen.

Hepatica flore pleno, Eeberfraut mit gefültten BItumen.

Hyacinthus Anglicus, (Englifder Syacinth.

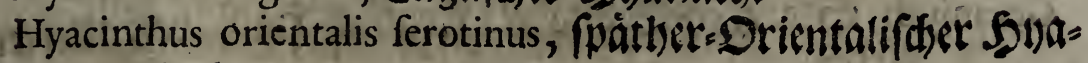
cintio.

Hyacinthus racemofus, Trauben Syacintt).

Hyacinthus ftellatus Germanicus, geffirnter Teutfder Soyas cintl).

Jonquilla H. pl. Brfitlte Sonquillert.

Jonquilla reflexa, frumme ooer zuritef get ogene Sonquiffe. Iris Florentina, Zof cunifche oder Florentiner 2 Bio 6 . 23 urkel. Mufcari, Narcifus Mufcari, moblriech):nde Narciffe. 
Narcifus albus, calice aurantio, weiffe ?arciffe/ mit eineu Ponteranken farben 2 ccher.

Narciffus albusfl, pl. gefütute wiiffe Marciffe.

Narciffus Anglicus Tromböni fl. pl. gefútlte Englifate Varciffe Des Tromboni.

Narciffus aureus vulgaris, gemeine Grlbe-Srone.

Narciffus plumarius variarum fpecierum, affertband Jeder: Parciffen.

Primula veris, Sdjliffilflumen.

Pulfatilla, Rudenfdaellé.

Ranunculus Tripolitanus, aนs Tripoli fommender foanenfußs. Tulipen.

- Violx Martix, Mer $=$ Blolen.

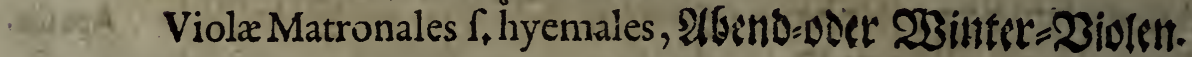

$$
\text { Majo. }
$$

Majus. Anemone tertia Mathioli, Die dritte Ancmone DCE Mathioli. Aquilegia, $\mathfrak{A}\left(\mathfrak{f}^{\mathbf{C}}(\mathrm{lty})\right.$.

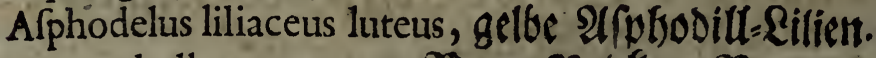

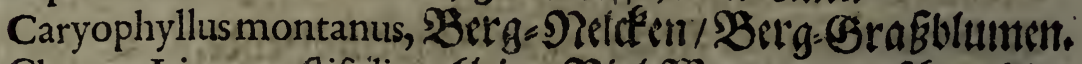
Chamx-Iris anguttifolia, flemin 2 iol-233ure mit fajmablen Blítrern.

Cyanus, forndhume vonalferlen Sarben.

Fraxinella, (5.towutrs.

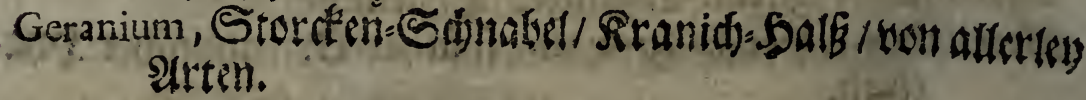

Gladioli, Shlwittel=Rilien.

Hemerocallis lutea, gelte (3ord-Rilien.

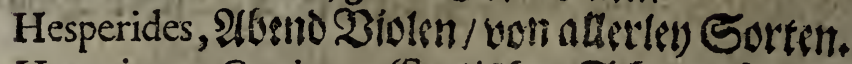

Horminum Creticum, (Sretirfter Sdjatiad).

Hyacinthus variegatus, bunder Syacintl).

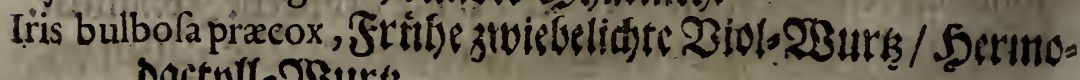
Dactyllo23urs. 


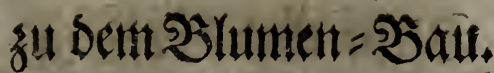

Lilium pracox colore aurantio, Frutle-Spommeranken:gelbe

\section{Eilien.}

Liliunt convalliumfylvefre, witle Mámengltimlcin.

Lychnis, (Jacea fl, pleno dicta) alba \& rubra, tweiffe uns rothe Flod

Maglieken/ Margrethen=\$liumlein.

Phalangium Alpinum, SrâB \&ilien fo auf oen આlpen Gebirgen wad)fon / 2 (tp = Spimenfraut.

Poeonix, Peonien= Rufen / Gid)t $=$ Rofen / von affen Sorten: Poeten-Dideter.

Ranunculi diverf, fpec, alferley Sanenfuf,

Rofen.

Sedum ferratum, Souß̧w rine Sege.

Syringa, Sprincten/ Syringg:=\$Baum.

Tulipx Serotinx, fpátbe Tulipen.

Veronica major \& minor, grob́ uno fleiner (strempteis.

Violx Mofchate fl. fimpl. \& pleno, cinfadis und gefitllic 2 iolen/.

Die wic BBifanriedsen/:Bifam=2Biden.

Junio.

Antirhinon, Orant oser Sunos. Rivff/ won atten Farben. Junius. Argemonia, Argemonen= :

Aurantia malus, OSotneranken=2Baum.

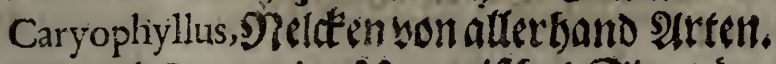

Clematis Pannonica, Lngarifdes Singrun ober $23 a l d r e 6 e n$.

Confolida regalis precox, fritbe Sitterfporn.

Cyanus, Rainbumen/ von alferlen. Jarben.

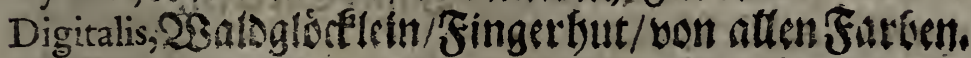

Filipendula, Filimemoel=20urb/rotber Steintorod.

Flos Trinitatis, Drestaltigkerit=2Blunte.

Geranium, Stords= Stunabel / yon aftettano Gattumgen?

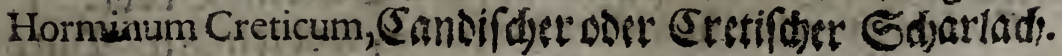


Hyacinthustuberofus Indicus, Snoinnifher Enoflidfert Syva cintt).

Iris bulbofa, 2 idl=23urk oder Sd)wertel mit siner Zwiebelid; . ten 23urkel/Poeten Syacintl.

Irislutea variegata Anglicana, gelbe gefprendete Englifte 2 iols 2Burk.

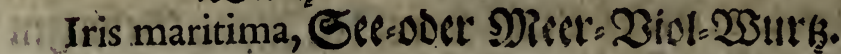

Lychnis alba \& rubra flore pleno, gefitute woiffe und rotbe פRa rien=oder Frauen=SRófilein.

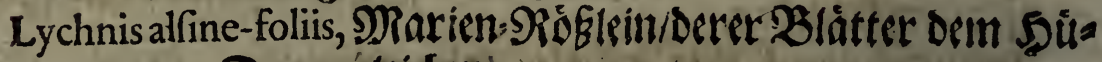
ner=Darm gleidjen:

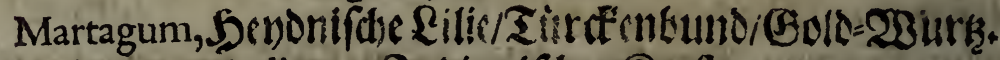

Nafturtium Indicum, Inoinuifher $\operatorname{Rer}(\beta$.

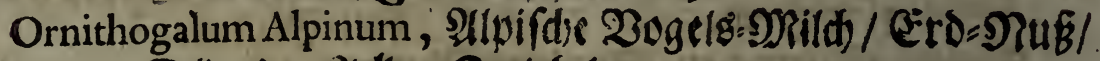

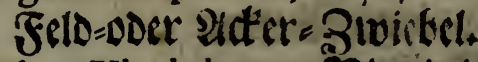

Phalangium Virginianum, $\mathfrak{B i r g i n i f d s e ~ G r a f = - R i l i e n / o b c r ~}$ Fre fpinnen= Rraut.

Salvia fl. albo, Salbey mit wotifien $\mathfrak{B}$ lumen.

Thlaspi Creticum, Candifthes Befent= Rraut.

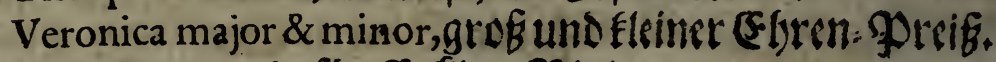
Viola Pentagonia, finfficffigte $2 i o l s$.

Julius.

$$
\text { Julio. }
$$

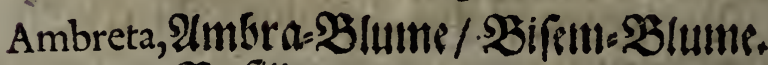

Bafilicum, $\mathfrak{B}$ nfilien.

Bellis,9Raflietern.

Calendula fl. pleno, gefitlte Ringel=Blument.

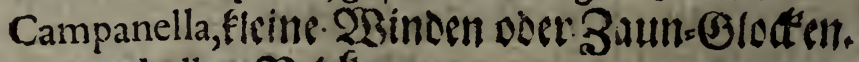

Caryophyllus, $\mathfrak{N e l d f}$ in.

Confolida regalisfl. pleno, gefuftte SRitterfporn/wont allewisno Farben.

Cyclamen Veronenfe, 23erontefifdics Sdiveints Brodt.

Cyclamen odoratum flore purpurco, woblriedent Pourpurs

farbes Sdiveins:Brodt.

Digi- 


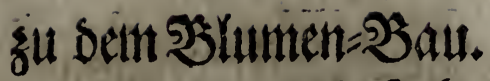

Digitalis ferruginea Hifpanica, EFifenfarber Spattiffare Sint gerfut.

Eryngium planum, glatte Ranms:TKeu.

Geranium Creticum, Candifwer Sturcen Sdmubte?

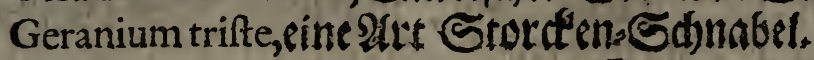

Granata malus fl. fimplici \& pleno, (Siranat=2pffet-5 aum mis.

rinfodier uno gefúuter sititle.

Hefperis var. fpec. 2lbend=23idlen von allerbano (Eattungers.

Hyacinthustuberofus Indicus, Snoianifder fnollidter Sobng cintl).

Laurus Rofea, Oleanber/SRofen-Rorbertn.

Limonium, 2 Bald $=$ mangolt.

Lunaria Cretica, (Sandifds: Monfraut oder MRontauten.

Lychnis, jacea alba dicta, weiffe Floffen-SBlume.

Nafturtium Indicun, Sndianipd)er Rreke.

Phafeolus Indicus rubro-aureus, ?acarat=Sarbe i Subianifoje Bobnen.

Rof Mofchata, SMifrat =SRofe.

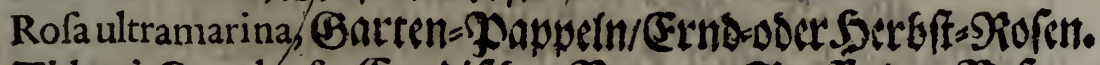
Thlaspi Canadenfe, Sandifwer Bauren=Senff ooer Befen: Siraut.

Veronica major \& minor, groffer und fleiner Efbren=preig.

Volubilis folio malva, 2Binden mit Pappet-Sלlattern.

\section{Auguifo.}

Amaranthus, 2Umarantb. Ambreta, Ambra $=$ Blume.

After atticus f.oculus Chrift, Sd)arten. Sraut / Steth Sitrutt. Aurea f. aurantia malus, pomeranken $\mathfrak{B a u m}$.

Calendula fi. pleno, geffittre SRingel= $=$ Bitutten.

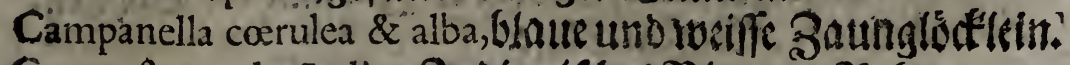

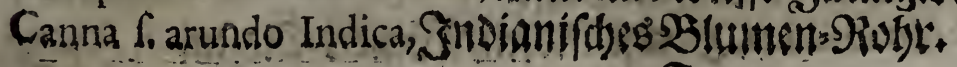


42

\section{Peue Unterweifung}

Clematis, Sinngrum/bonallen Sattungent.

Confolida regalis, bon allerbano Sitterfworn.

Cyclamen Veronenle, Sdiwocinbtoot bon Verona;

Cyclamen purpuraceum odoratum, 100blriedsendes purpurs farbes Sdowsinbrodt.

Cyclamen autumnale Byzantinum, Sonfantinopditanifacs Serbft $=$ Sallocinorodt.

Elichryfum rflos immortalis, Eonnens (S) Stunte:

Flos Pasfionis, Pafiong.\$Blume / Granadille.

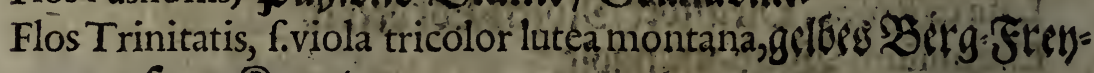

fain= Sraut.

Geranium trifte, Stocfen= Sdinabel.

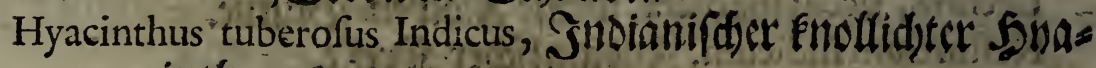
cintlb.

Jafminum Hifpanicum, Spanifacr Sébilin.

Jafminum Indicum luteum odoratum, Smbianifdat woblrie =

denoer gélber Sefimin.

Laurus Rofea, Rorn Rorbertn.

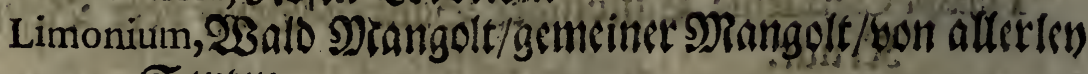

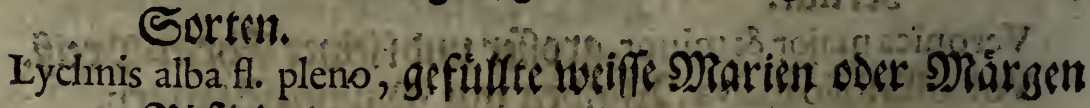
Sióflein.

Mirabilis Peruviana, Sđtwcik̨er Sofen / Prtuanifde Wunt Det: $=$ Siole.

Myrtus, Morten / won allet fand Srttet.

Nafturtium Indicum, Sndianifter Sref.

- Ocelli S. Caryophylli Indici, aflerley Snolanlfabe Netlefen / voer Sammet Róblein.

Phafeolus Rofeus Indicus, Reibfatbe Sndanifal Polynen.,

Rofa Morchata, M) Mufint:Siofs.

Rofa ultramarina, Sertoft:SRoferi/23interisofen. 


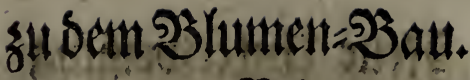

Scoparia, herba Studioforum, Relococrn/ Studenten-Rmut.

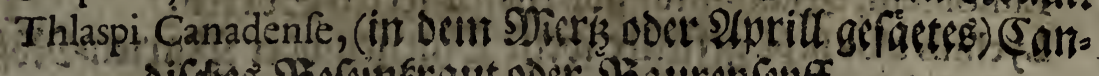

difdes Befrnetrut do der Bauren fenff.

Veronica; Sbrenpreif.

Volubilis, Winsenson alferband Enttungen.

Septembri.

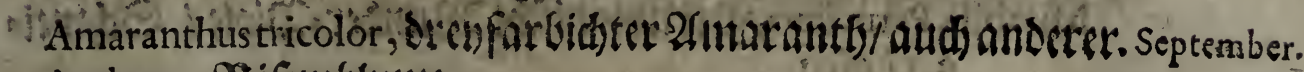
Ambreta, $B i f$ cmtlume.

Anagallis Lufitanica, Porttigheffober Eaudbbeil.

2) Antirrhinum, Drant / Stard Eraut / bon aflerlin Farbent. After atticus, f. oculus Chrift, Stert= Doer Edfarten=Sraut. Aurantia, malus, Sontersinenen $=2$ aum.

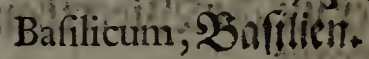

Bellis Hifpanica major, greffe Swanifde Mafelieben.

Caleridula fl pl. gefíltre simgeisluntert.

Campanella fl.albo, Iosifie 23 insen vor Baunglodelcin.

Canna Indica, Inotanif dis:-s3lument=Siobr.

Caryophyllus Indicus, SnDianifde Milferr/sbunigblumen.

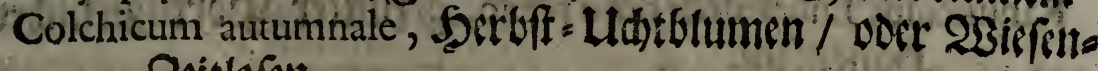
Beitloren.

C clamen autumnale, Serfift=Sdiverintrodt oder Eroápffl. Digitalis corulea \& alba, blauer uno tweiffer Fit!gerlyut.

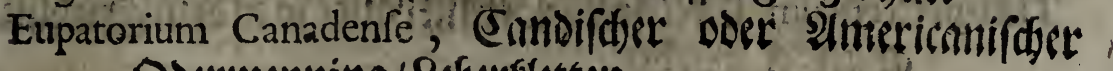

Dorrmenning/ Reberfletten.

FlosSolis, Sonnentume.

Geranium Creticum, Eandifdier Storden=Sthnafe!.

Geranium trifte, cinc Art Storden=Sdnatel.

Granadilla, Pafíntis=:Blume.

Hyacinthus tuberofus Indicus, Sndianifder Snollen= S1ya: cintis.

Jafminum feu Gefminum Hifpanicum, Spaniffar Sefmin. Laurus Rofea, Rofen=Rortocin.

$$
\mathfrak{F}_{2}, \quad \text { Limo- }
$$


Limonium, $23 a l o-$ Mlangolt/won allerley Sortên.

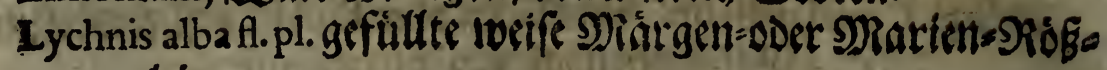
lein.

Lylio-Narcifus, Narcifus LiliaceusIndicus, Inbianifote Bilgene oder Eilien=: Ratciffe.

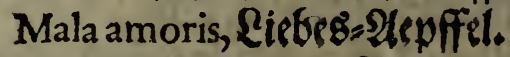

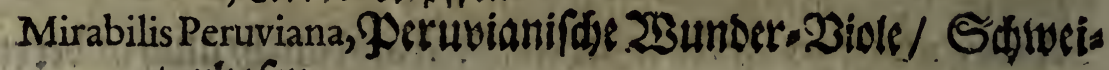
kerbofen.

Myrtus var. (pec. allerlen DRurten:

Narciffus Lufitanicus autumnalis, Portugiefifde Serbfte?lat: ciffe.

Nafturtium Indicum, Indianifater Sireg.

Phalangium Virginianum, $23 i r g i n i a n i f(t e r$ weiffer $23 i b e r t b o n !$. Brab-Eilien/ oder Erofpinnenftaut.

Phafeolus Indicus incarnato colore, Eeibfarbe Sndianif the Fa: felnober Bubinen.

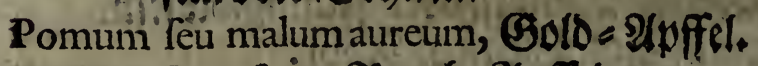

Pomum (pinofum, SRaud)- $\mathfrak{l}$ pffel:

Ranunculus Lufitanicus flore pleno, gefillter \$ortugiefifdet Sanenfuf.

Rofa Mofchata, Mufcat-9ofe.

RofaMenftrua, Mionat. Siofs.

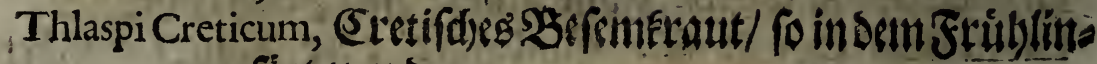
ge gefiet worden.

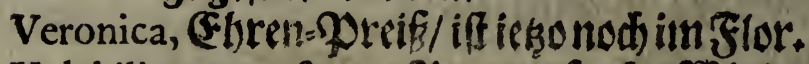
Volubilispurpurafcens, Putpurfarbe $23 i n d e n$.

\section{Ostobri.}

OAtober:

Amaranthus, Taufendfhion. Amaranthus tricolor, Brenfarbidhter Taufenofdogni. Antirninon, Ornnt/ Qó wen= Miáulet: After atticus, Strrn= Riraut. 


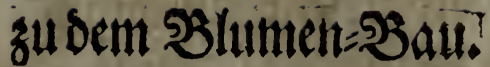

45

Calendula fi. pl. gefittlte SingetosBlumen:

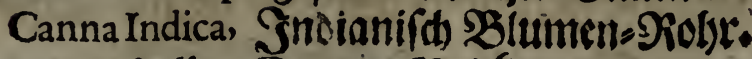

Caryophyllus, Gartens:Nelcéen.

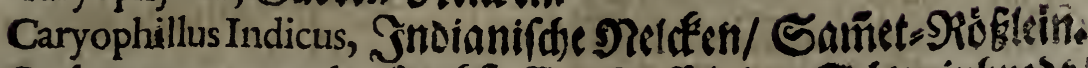
Cyclamen autumnale, \$erEffr-(Fro-2upfel oder Sdiveinbrodt: Flos feu Viola Trinitatis, Drevf faltigfeit $\mathfrak{B} /$ lume/ fo in Dem $\mathfrak{A}$ guffo gefaet morden.

Granadilla, Pa afíungs:Blume.

Nafturtium Indicum, Sndianifder Rref.

Phalangium Virginianum, Birginianifhes crofpinnemfrạut. Pomerantęn-3Bátume.

Poma aurea, Sisldo=2lepffel.

PomaAtlaiopica, Mobren-2epffel/ Nadtffatten init fleinen Acpffin.

Poma Indica, 3ndianifase 2 epeffel.

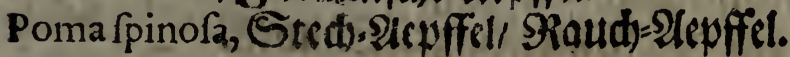

RanunculusLufitanicus flore fimplici \& pleno, einfadie uno gefiffl:

te Portugieffifde Sanundel eln ober SanenfuB.

Rofa Mofchata, Mufrat=SRofe.

- Rofa ultramarina, (in DemIstitlinge gefäete) Garten=Pappeln!

Ernd oder Wsinter Rofen.

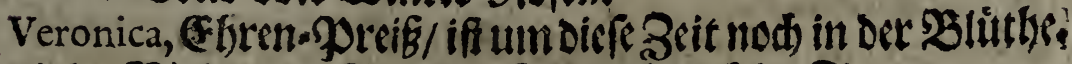

Violx, Ziolen oder Zeilgen/ fino audh nod im Flor.

Novembri.

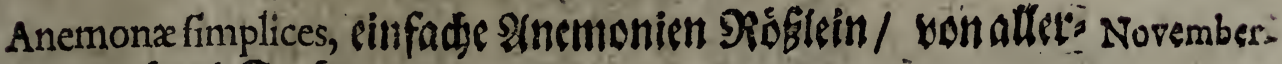
band Farten.

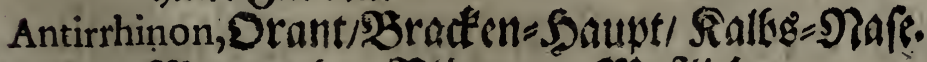

Bellides, Mararethen=SBiumgen / Maflieben.

Caryophylli, $\mathfrak{M e} ! f^{\prime} \mathfrak{m}$.

Cyclamen Perficum hyemale, Perfianif 2 Binter: Ed)weing

Brodt.

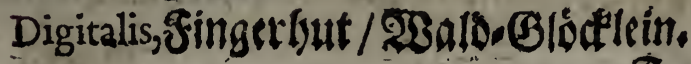




\section{- 46 Raue Unterneifung.}

Helleborus niger pracox, frube fojwarke Niefieoder Ebuiff:

\section{Burk.}

Jafminum Hifpanicum, Spanifder Sefmin.

Rofa Mofchata, S) Rufatesiof p?

- Veronica, Efyren=spreib.

Violx fl.pleno, gefinlte 2 iolen.

Violx hyemales, $\mathscr{Z}$ inter $=\mathfrak{B i v l e n t}$.

- Viola Tricolor f, Trinitatis, Jreufant-Sraut/ Drenfaltigfeit.

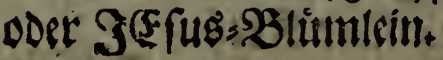

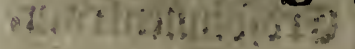 \\ Decembri.}

December.

Anemon $x$ fimplices diverfor,colorum \& pracoces pilofe, $\operatorname{cinf} \mathfrak{a}=$

d) Anemonen boin unter fdicoliden Sarben/wie aud

baarid)e Trrits=2(nemonen.

Antirrhinon, Orant/Sunt B= Sopff.

Calendula flore pleno, gefüllte SRingel=SBlument.

Caryophylli; शeldéen.

Cyclamen hybernum commune, gemein $\$$

Brodt.

Cyclamen Perficum hyemale, Perfianifdes:23inter: Sd)tweit:-

SBrodt.

Primulæ Veris fimplices, einfadie Stiliffel=\$lumen.

Viole matronales, 2 Sinter $=$ Biolen/ Mitter $=$ Biolen.

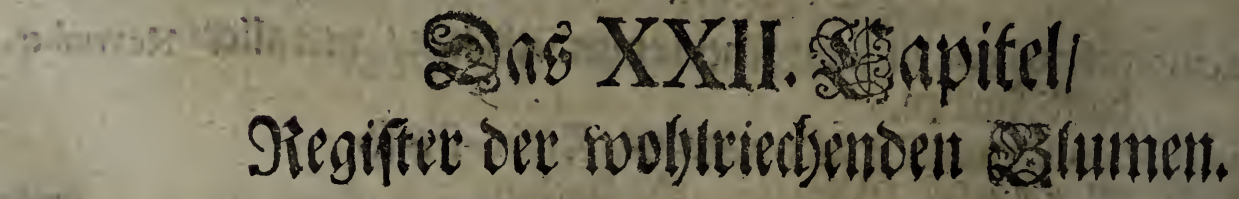

2Eof̧ifrie

d)ende Dilu.

Afphodelus, 2anfroditl : 25urth.

nen.

Caryophyllus, $\mathfrak{T}$ ietéen.

Cyclamen Byzantinum, Eonfantinopolitanifdes Sdubein= brodt. 


\section{รุน bem}

Cyclamen Perficum, Perfinmifdeg Sdiweinbrodt.

Cyclamen Veronenfe Vernum, Zeronefifd)rba Srubling:

Stivcinebrodt. -

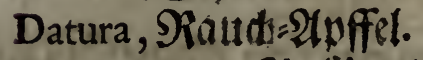

Flos Paffionis, Pontion: $=$ Blume.

Flos Trinitatis hortenfis, Garten Drmpeltigfeit:

Geranium trifte, sine elrt Storcfern=Sdnnabel.

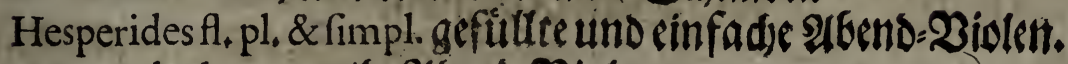

Hesperides lutex, gslbe abend= $3 i d l e n$.

Hyacinthus Indicus tuberofus, fmorridgter Sndianifajer Syaj cint5.

Hyacinthus Orientalis, Margenlánbifder Sowacinth.

Jafminum Hifpanicum, Spaniffjer SeB́inin.

Jafminum Indicum luteum, gelber Snoianifdier Sesmin.

Iris, 23iol-203urk/ inciffen theils.

Johquillae, Sonquillen meiffen theils.

Leucoium bulboím hexaphyllum, fed)eblätteridtes Leucoitun

oner groffe Ziole unit ciner 3twicbel-23urket.

Lilium album, woite Silien.

Lilium convallium fylveftre; twilde $\mathfrak{S R a y e n b l u m m l e i n . ~}$

Malus f. pomusaurantia, Yomerapkert=ミ3aum.

Matrifylva, caprifolium, $23 a$ aldwinde / Zaunlilie / OBeibglat.

Narciffus, ?arciffen/Der groffe Theil.

Nardus montana, $\mathfrak{B} r \mathrm{rg}=$ Plarde.

Nafturtium Indicum, Sndinnifher Sire B.

Poma Paradiff. Paradifiaca, Paradieß $=2$ le $\mathrm{pffl}$.

Ranunculi lutei Lufitanici \& autumnales, gelber Portugieffifaer:

uno Serbit: -

Satyrium odoratum, 1wothiried)enoes Rnafenfraut.

Syringa, Suringen / Sgringsbaum.

Thymelaa, Zeilans / RellertbalB.

Tilia vulgaris, gemeine \&inoen.

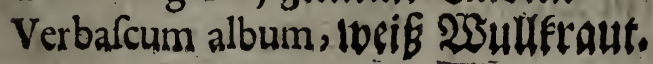


48

Violx Martia, Mer

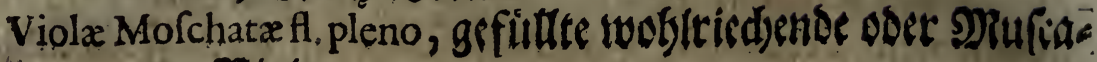
ten $=$ Jiolen.

\section{अแล ter/ Derenfich die Frantsofen bey bemißlumen: כaubedienen.}

Ajufter, peigner \& refendre I Oeillet, Dir Nellfe zu redfte Gringen/fámmen uno wicder auffpalten. 23ann fid bic VRel=

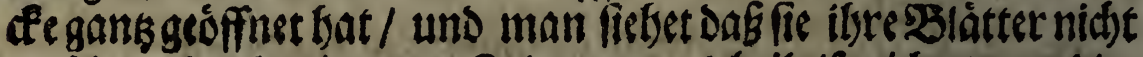
wobl ivende/ober in guter oronung austbeile/fo ridtet mandies felsige wieder derge fralt mit 1wobl gctwafdenen faubern und von allem Sdneifí abgetructéneten Sänden/ Daf́ cin iedes feinen Plaks uno Dronung befomme. Damit Die Preldete aud zugleids

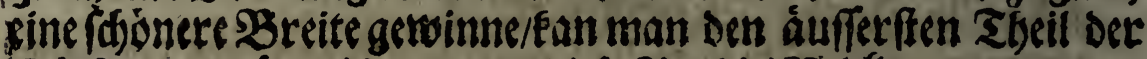

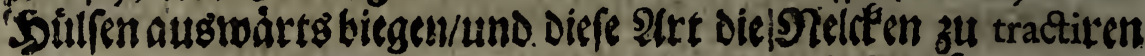
nennet man Ajufter,peigner, refendre l' oeillet, Die VReldfen zu redja te bringen etc.

Amander, miffern/Dingen/beffern; WSits in Anfegung Des

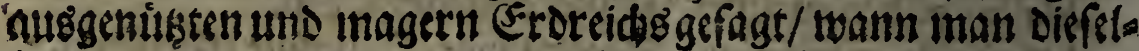
bige init guter Dungung vermifhet: alfo fagt inan von Detn

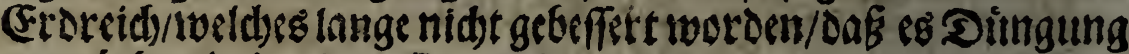
vonnetten babe; Das Gegentbsil aber twird von gang firrslich. gedingtem Eroreide gefagt. Stervon fan La Quintinie, in

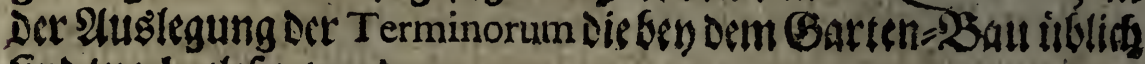
find/ nadigelefen werden.

Bequiller, hsiffet dir (Frde in ben seitfedm/ saften ober Sdjer ben utit einen Shaumer obar cinen felor fleinen Sarceen untigras

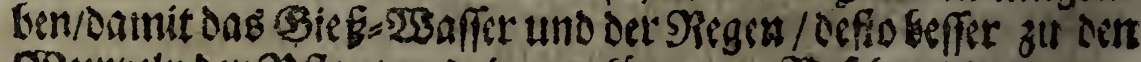

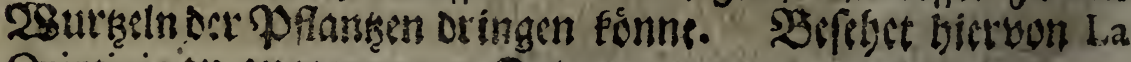
Quintinic an angizogrnem Dits. 


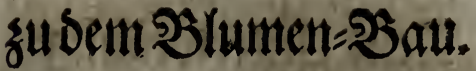

Blane, iff eingelber/audd zu Zeiten wociffer SRoff / Iveldere

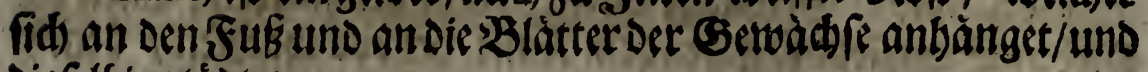
Diefellige tódter.

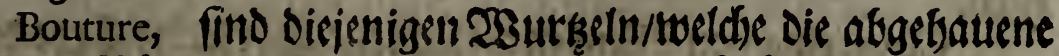

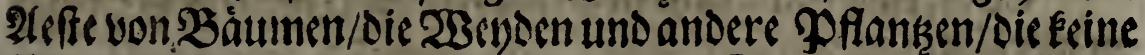

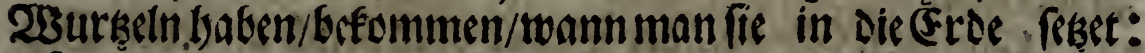

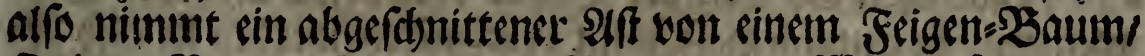
Qvitten-3aum / Stadelbeer-Stauden 2 . WBicber feine Bonture ober 23 urtel/ / hiewen fan la Quintinie in angefitltertem Drte/, und Furetiere in fintem Dictionario nadige(d)lagen iver bent.

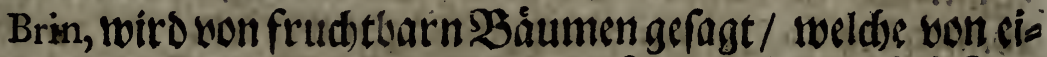
ner gutendet/geradc/unovon redteter Dife nadjibrer groffe find; alforpricht man: Choifir des arbres d'un bean brin, einen guten/ge-

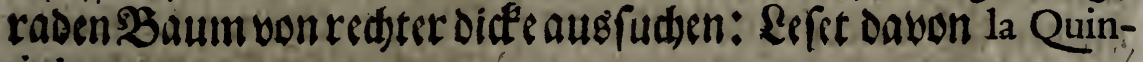
tinie.

Brouille, biefes Termini bedienen fid die \$lumen=Gärtner/

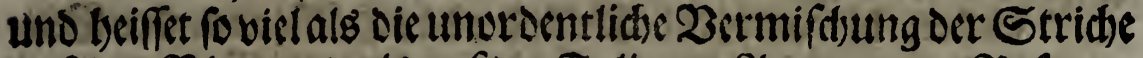

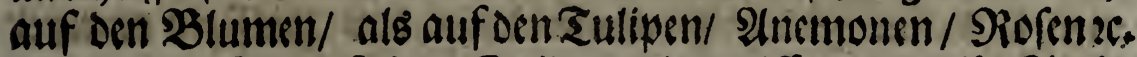
ellso wann fid auf ciner Tulipen die weiffe oder geller Strie

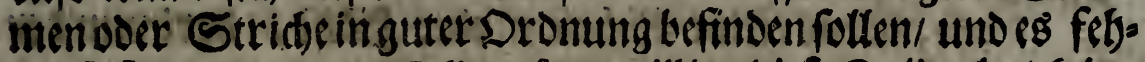
let/fof fagt man: cette Tulipe eft Brouillee, Diefe Tullipe bat feine orbentlidte Strienten. La Quintinie an melly befagtem Drte.

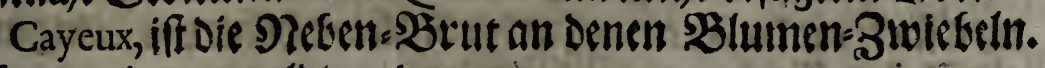
SSeferbect Den iegest genneldoten Autorem.

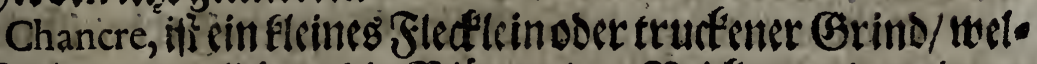

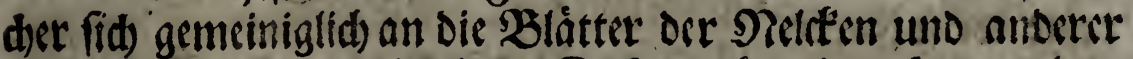

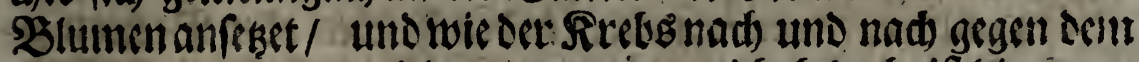

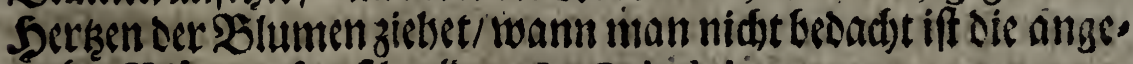

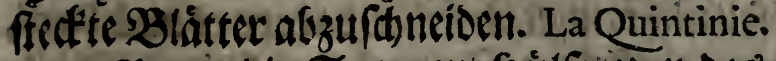

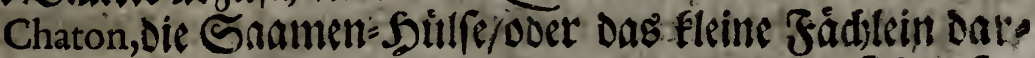
innen Der Tullipensober anderer SBlumen= Saamen fid) bofints Det. 


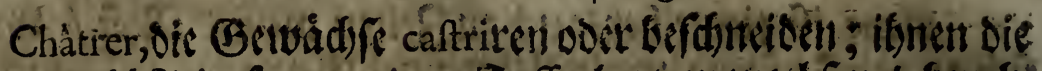

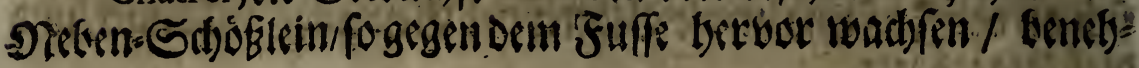
men. artwerffon.

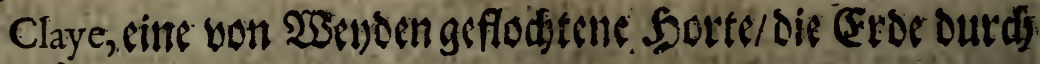

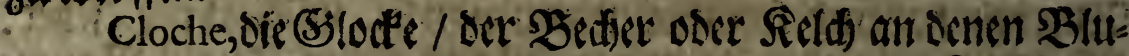
men/weil feenemlid) Diefe Figur prefentiten/wetsen fie alfo geo nannt: Yon dem Syacintly und yon den Bärch= Detrlein fast iman: La cloche de ce Jacinthe eft belle, Die Gloffe an Dieferm

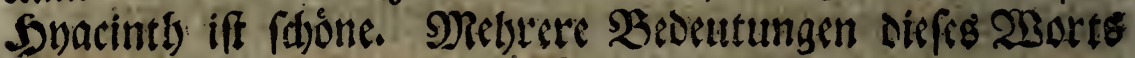
tomnen ben La Quintinie nadigefollagent werien.

Se Confiner, wiro vout Denen Misldent gefagt wonnifid)

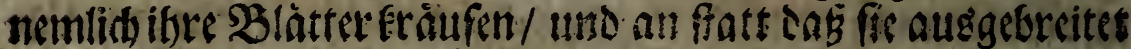
Eleiben/fids wieder cinwide In uno zufammm/rgen. Les feuilles de mes Oeilletsfe reconfinent, incine Plelfét lauffen twicder zus fammen. La Quintinie.

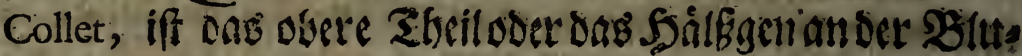
nten/endommager le collet d'une Plante, Lag SólBgen an einer Pfiante verberbent.

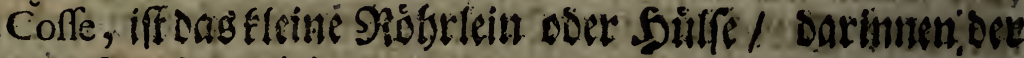
Saamen formitt wird.

Couche, ein Miff betlse/in toelders man am 2 Sinter Saas

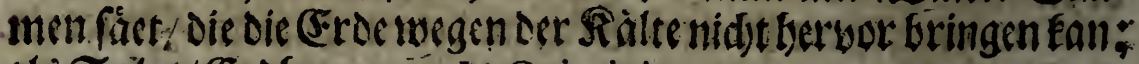

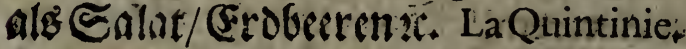

Couleur de Soupe de lait, MRild)=Suppen= Sartb/ iff cincun: reime tweife Sarbe.

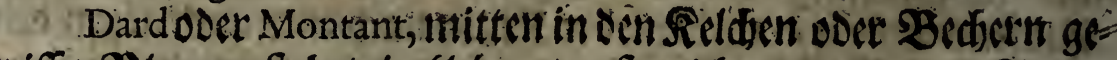
wiffer SB/tumen ftebet ein fleince/ aufgerid)tetes/ rundes Splits

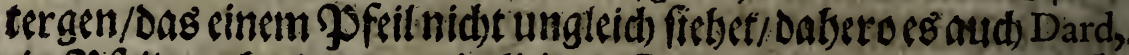
ein Pofeil/aud)Montant, ein fleiner Stengel oder fleines Pfoffts gen won Denen Frankzufen genennet wirb. Sebet biewon Richelet and Furetiere in ibsen Dictionariis.

Dardille, Der Stialandar Nalfen. 


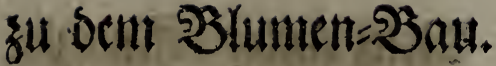

Dardiller, biefen Terminum getraudt Imatt bet) einigen Blumen/ und bsiffet fo vid/ a!s Das obgebadte Elcille Pfeilgen treiben oder ffoffen. L' oeillet dardille, die Plalef treibet oder ffofe,

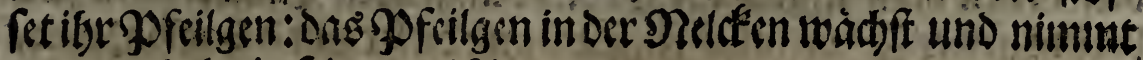
34. Richelet in feinem Diction.

Dentelé, ée, geferbet/ oder das Zábne bat toiecine Såge:

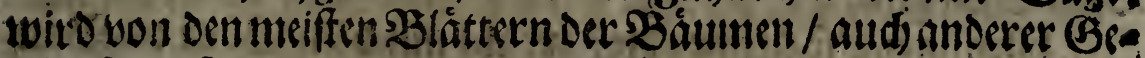
wàd)fengefaget / tocldse um Den SRano berun ausgefdnitten find/und Denen Spiken gleid) fetsen. La Quintinie uno Richelet.

Deplanter, cincn 3 aum/ odet eine andere $\$$ flanke/ alts det. Croen beraus netmen. Snfonderbcit wir o es von einem Baum oder Pflanke verftanden/welde mit einetn getwiffer Snftument (Deplantoir) berausgeboben/uno gan(3 gludelid) an einen ambern Solake/ obne Dab fie Sdaben genommen batten/ver fegt wordern/,

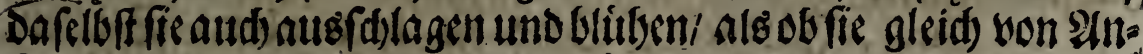
fange babin gepflanker wor den twären. La Quintinie.

Deplantoir, ein Seber / wie cin Sdjaffer=Stab geffaltriffeit Stucte (Sifen 4. Daumen breit / 6. bif 7+ Daumen lang/ sinex

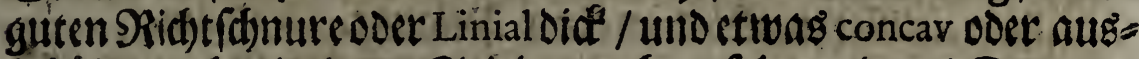
gebólt / aud) mit einten Stid boll olongefebr 5. oder 6. Daumen lang verfsten ; es dientet die Eleine Getwadsfe/ weldse nidst allzu

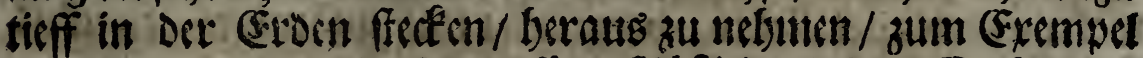
Die Tulipanen / Die Natiffen-Sióblein / das Erofectens Rraut oder Staudtcin / de Anemonen= Roblein $x$. Die

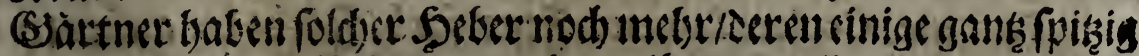

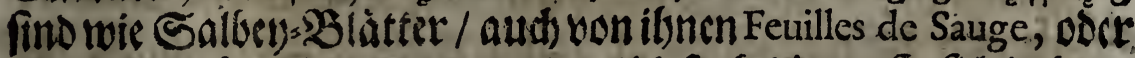
Salbev=:B!atter genennet werden/ biefer fedienen fie fid) in bat ter uno freinideter Sroen ; andere fins gants viereffidt / und lauffen untenber nut cin E!eincs menig in bie SRunce aub / uno fold)egebraudit man bey luckerer und leideter (Erden. Diefsumb

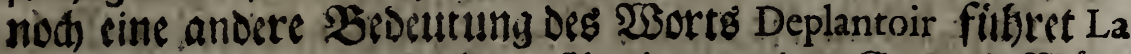
Quintinie in mebr gemeloter. A4slegung oet Garten= 23or. tet an.

(3)

Ecus- 
Ecuffon Jaune, gelfer Sdillo. Die Irides bulbofre, oder Zntwies

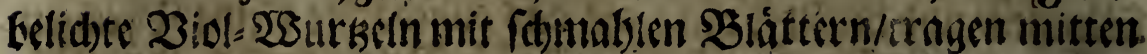
auf oenen orey gigen Der Eroen laangenden Blattern ein faft

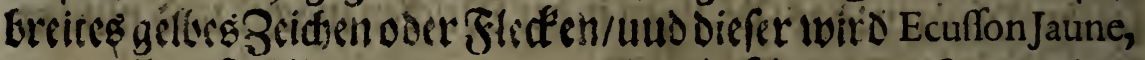
oder gilbir Sd)illo genannt. Morinus in feinem Tractat ven Den Biol= 2liurkelin.

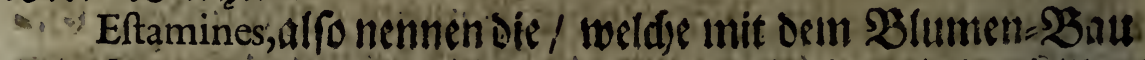

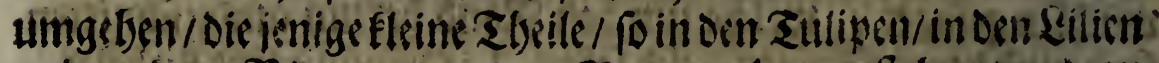
uns andern Blumen um den Saamen berumfteben/ uno an fleinen Faferden oder Saden bangen. Die Sulipin werden ant lodiffen aefháket / toilde cinen blauen Boden uno befagte

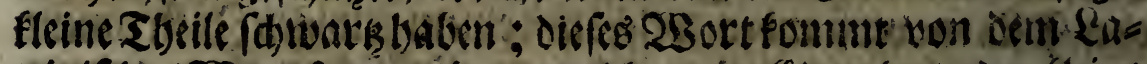

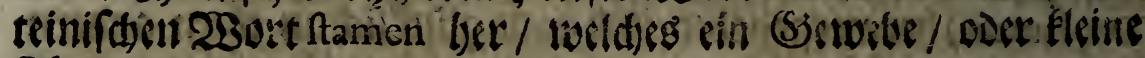
Sádentedecuter.

Etendards, Săbmlein: Sind Die orcin bbern Blátter

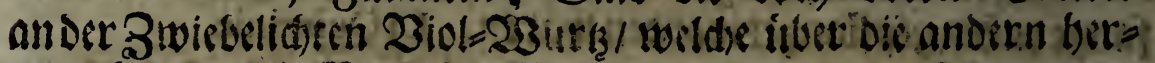
vorgethenund oic Blume volleoimmen formiten. Sie twerden aud) Voiles, Segeln oder Sdblener genannt. Morinus.

Fane, bciffer cin Blat an ciner Pflanke. La Quint. (1) Faner, fe faner, tbito von oen Bláttern oir \&aumin uno

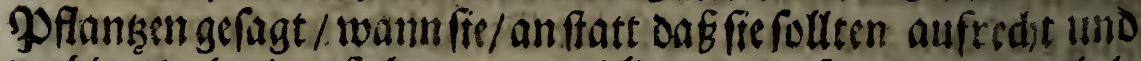

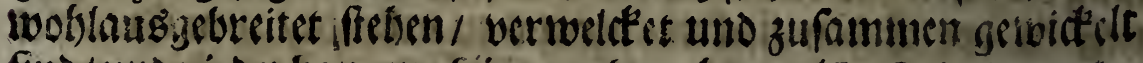
find/ uno niederbaingen. Sirrvon fan aberma! La Quintinie geles fen werden.

Fiamette, Couleur fiamette, feucrfarb/Farbe dic auf rotb) zieffer. Richelet.

Gagner un oeillet, eine Neldée gerwinten: Die curib fe giebs

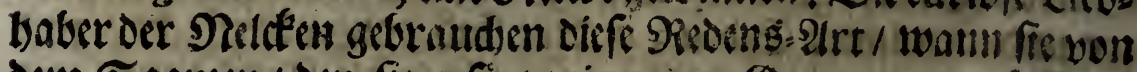
Dem Saamen/ Den fie grfaet/ eine me Battung von fodinen Velden befom!nen. Richelet uno Quintinie.

Galle, bebcutet fo vill als Chancre, bavon ofen fogen Mela oung gefdetecti:

$$
-(s)
$$

Glaife, 


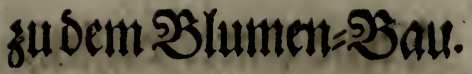

53

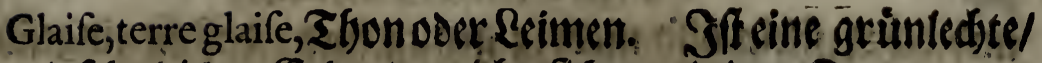

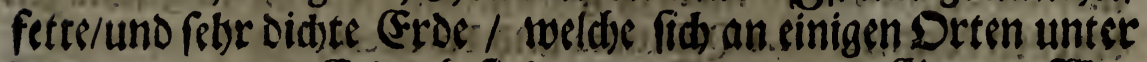
Der andern guten Eroen be findet/4mD dem ganken (S) atten-2Se= fen felbr fdáablid iff. La Quintinie.

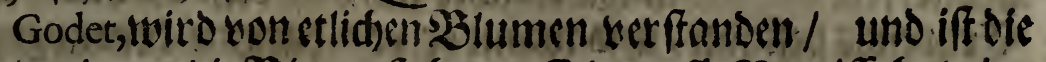
Suilfe darinnen die SBlume fistbet. Die groffe Narciffe bat eine

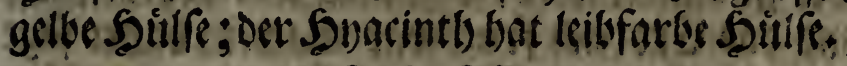

Hatif, hative, frutbe/fruilyeitig: Oarunter if alles begrif=

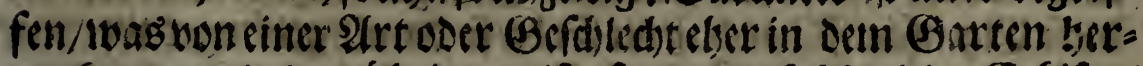
nor foumt als das ifforige; alfo frgt man fruthzeitige (Erbifen/

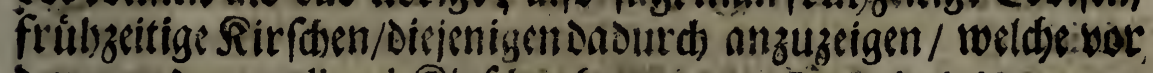
Denen andern ordinari-尺irfdten foinmien. La Quintinie.

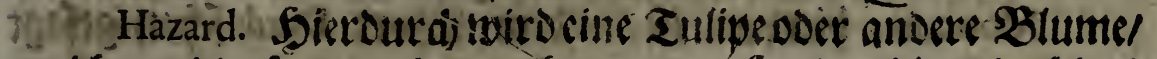

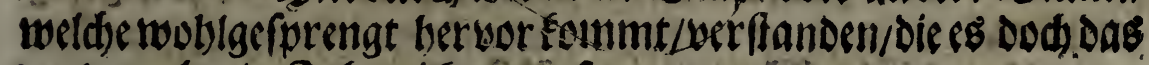
vorbergetbende Rabir nidfr getweren.

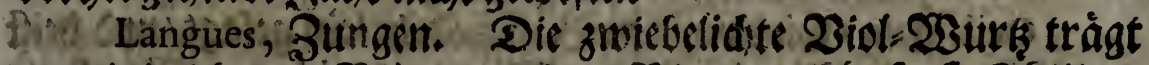

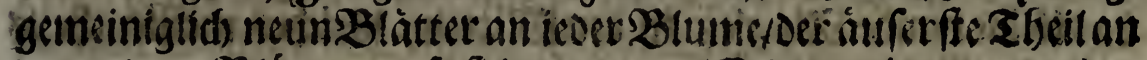

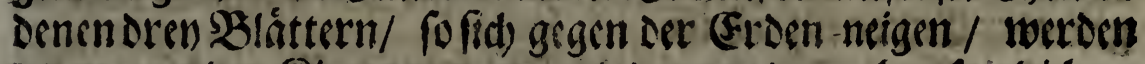

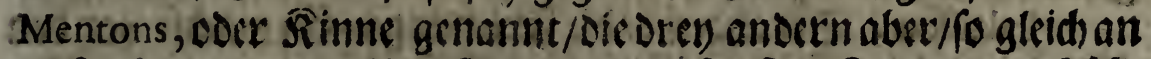

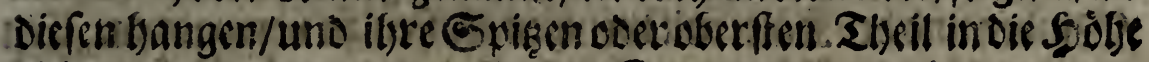

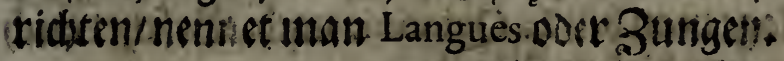

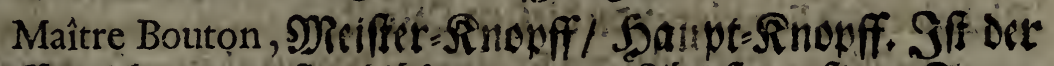

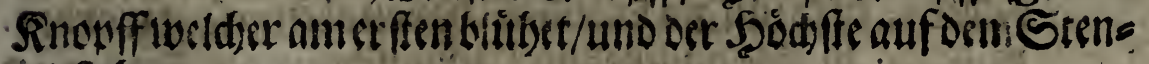
git frellect.

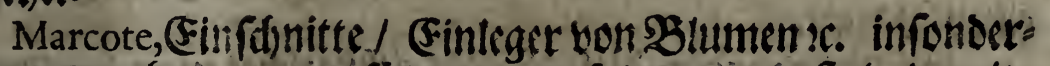
Beituon Neldeen/und berfaberet man folgender geffalt samit: Manmadt unter cinem Rnoten einen Ereinen SiiB ober Sdjnitt in sen Etod"and fittlet ibn wieder mit foiner (Griens au\& / umb

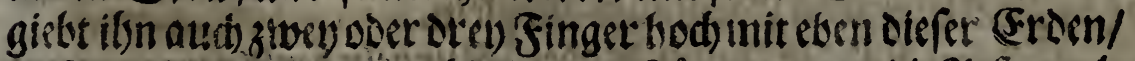

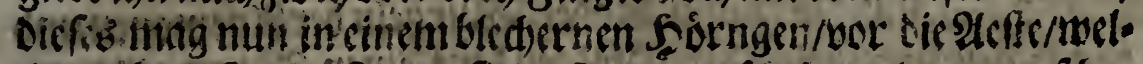

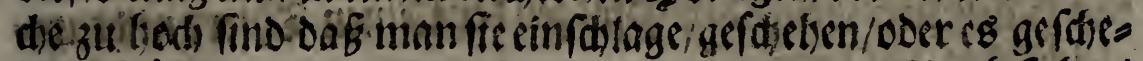

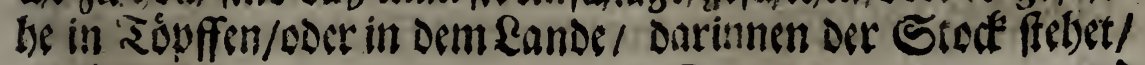

(S) 3 uns 
54 Teue Lnteriveifung

uns bie-seffecin alfo sicorig genug fino $/$ das fer singefalagen werden fónneh. La Quintinie und Furetiere.

- Marne, Margel/ Ding=Eroe. Sft cine Art won weiden Rald'/fett uno graulid)t/ weldher fid all sem Grunde etlides Eroreids befindet / uno hoann ef non Dannen lgetaltogezogen/ und auf oie Selder gefdinttet toiro / fo gitt nls eine vortrefflidse Dingung ift/ und Das (Eroreith fruditkat madjct; anber fagt

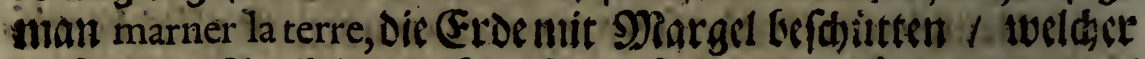
Diefe CFigenfdafft bat/Da B Die Frde/ fo damit gedinget wordeny dasandere und oritte Sabe beffer wiroals das etffe. La Quintinie.

Mentons, Gefétet $\$ a \mathfrak{B} 2 \mathfrak{3 0 r}$ Langues.

Montans, biervon iff in Dem $230 r t$ Dard fdon igefagt worden.

Navet, if Die 23 urnel cinct Pflanke:

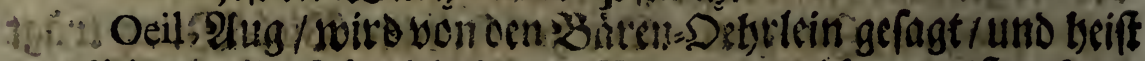
Dag fleine rumbe Siinglein in ber Ditten / weeldes meifentbeits gello oder Eitronenfarts iff.

Palaifon, Stroboedte / sie Fritblings: Ssemádfe vor den

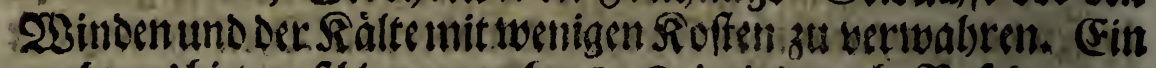

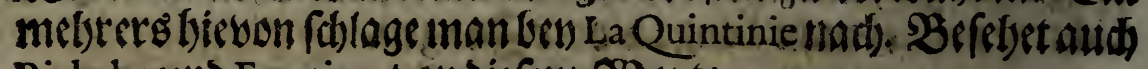
Richelet und Furetiere von biefcm $230 \mathrm{otc}$.

Paillettes, iff fo vicl als Etamines, Davon oben gefagt wor ben:

Panache, iff cine angenctbme Dirmifdung ber Farben an siner 3 lume.

Se Parangonner, Diefes 250 ort geforauthet man bey Sulipen

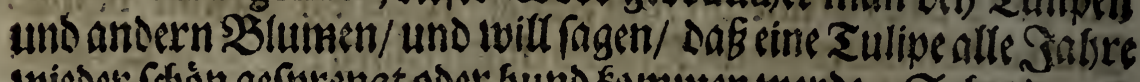

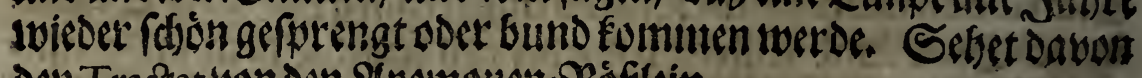
Den Tractat bonden 2encmonen=SRóblein.

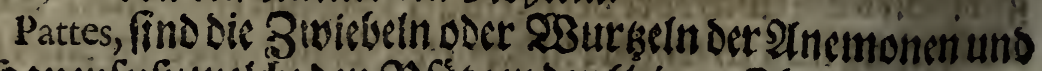

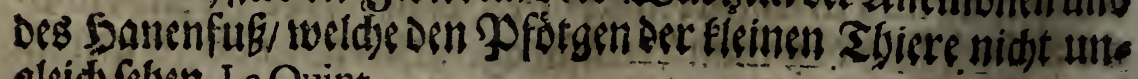
gleidg felgen. La Quint. 


\section{subetit Slumen=-Sall.}

55

Planches, defes fino dic. Strile coer Betbecines (3arter

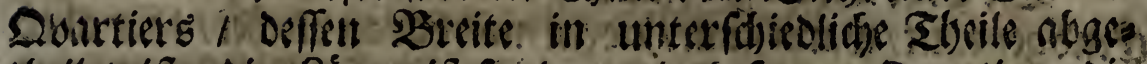

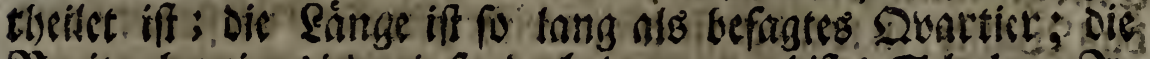

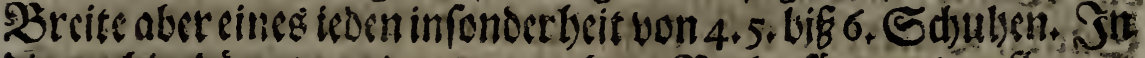
oie wotblgctingte uno tuthgegratene Betbe faet uno pflanket mon die Sallen=Friddteimo Enttens Srâter.

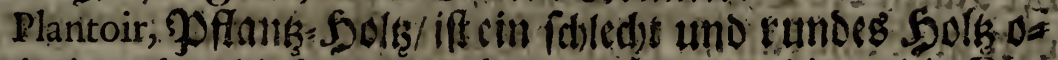

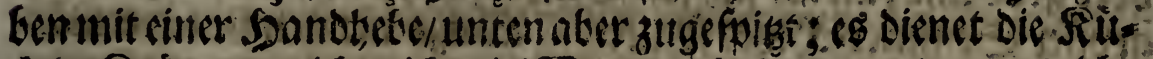

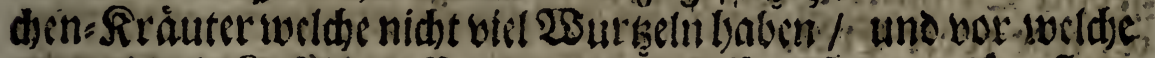

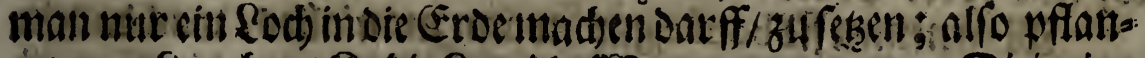

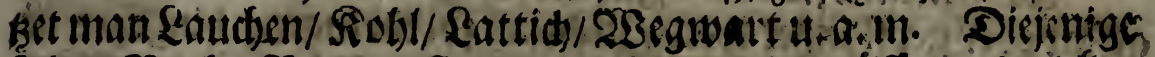
fo Den \$3

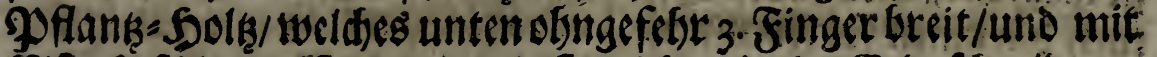

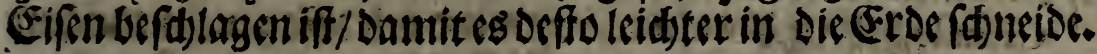

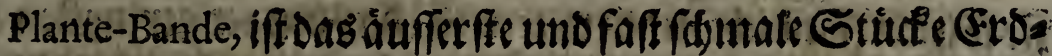
reid) / po um Das ganke SEltrmen Selo berum gebet/uno gethrinig:

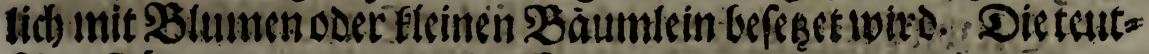
fđen Sártuer nenten ç cine Sante. Richel. und La Quint.

Puceron, cin Cro = Flod)/Deffens sfforcibung ift ben La Quintinie zu finden.

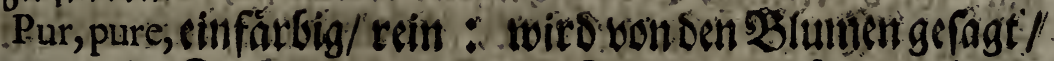
welde nur eine Jarbebaben/ oder on fre buno getwefen/ wieder sinfarbig werden/und diefe Stumen werden den sund farbigen entgegengeferst. La Quint.

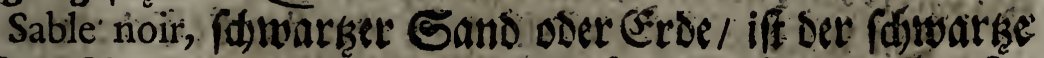

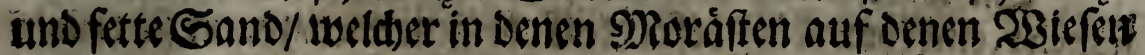
uno an benen Drten/ die nabean den Flúfen und Sáden liegeny gefundent twird.

Terre, Groe/Eroreidy/ wiro ben Den Gärtnern bor Den Bruno oder Boden genornmen/ in velde men sadume uno

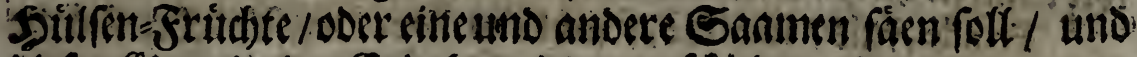

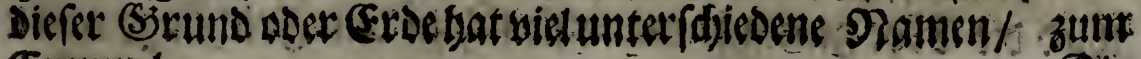
Exempil: 
Die Erbe woird aigre, fatter/amere, Gitter/uns puante, ffint ceno genennt / wo ann inan / indeen man baran ricdet / oder ater Das 23 affer / in weldser fie eingendeidft gerwefen / berfudjet / eine Gáure/BBitterfeit/ oder Beftance Daran finde t.

Sie wirs argilleufe, (eimid)t oder thonidst genennt/wann fie

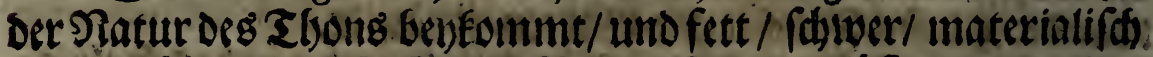

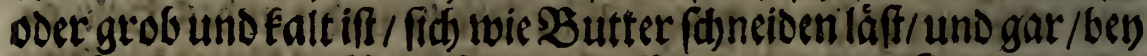
groffer Sommer- Silser fwaltet. Einige nenuen fie terre morte, eine todte Eroe.

Mannennet fie bonne, gut / wann mar'attes / was sarein. gefaet oder gepflunket wiro / leidttlidy fortbringet; thingegen if

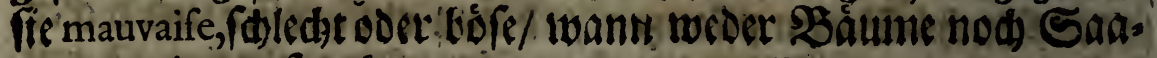
men darinnen fortfommen.

Chaude, Gei i uno brûlante, becmeno wirb fie genennt/nowin

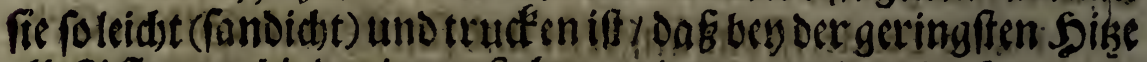

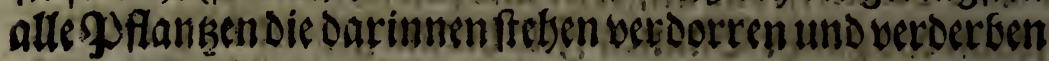

Sie wirb terre grovette, einefigidte (Erde benaftmet/wann vide fleine Steine Darunter gemifotet find

at. Terre coriace, zád / uno von sinigen acariâtre, twiber fwetts ftig / wiro diejenige (Groe getseiffen / welde fid) faft elen mitcect

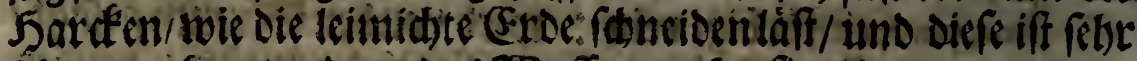

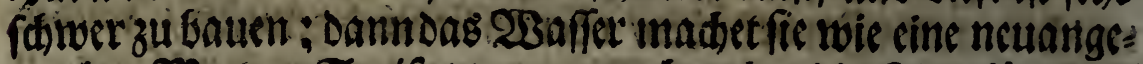

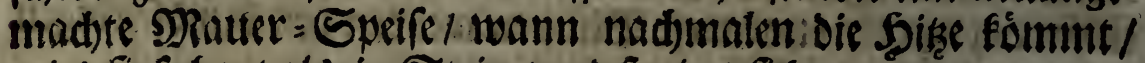
wiro fie fobart algein Stein / und fwaltet fid.

Sie wirb terre forte, cine feffe boer ftarfíe (Erde / uno terre

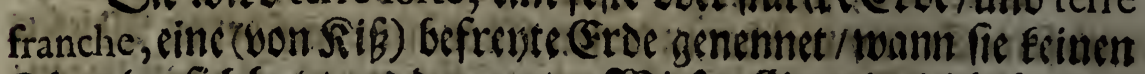

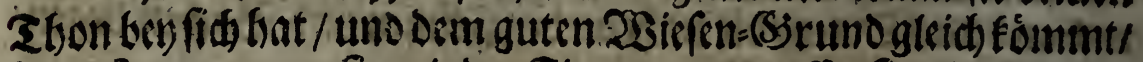
fo/ Dabi Lann man fie mit ben Singern angreifft/fie gleids einem

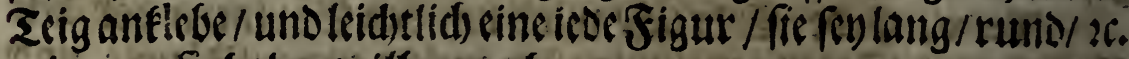
wic man fre haben will annelsute.

Froide, falt $/$ humide, fcudit/ tardive, langfam vocr fipatbe wirb Die (Eroe genennt/ . wann fie fid) in Dem Srriblinge faum 


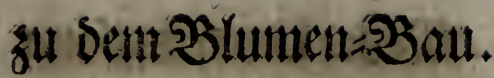

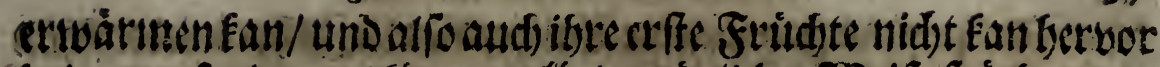

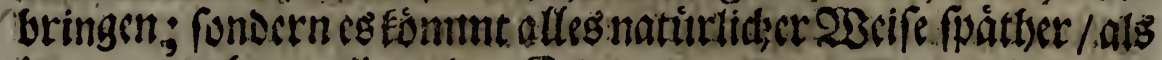
in Dernatse berumiliegenden Eroen.

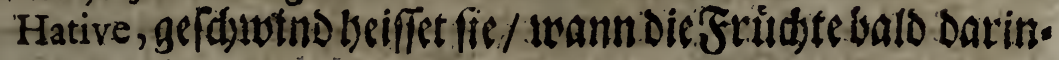
nen zeitig werden.

Nan nennet fie terre meuble, cine beiveglidje / uno legere,

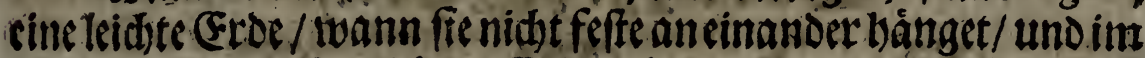

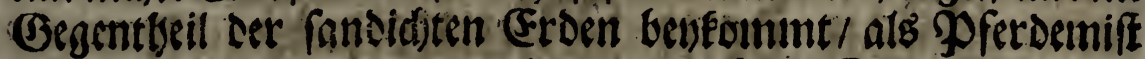

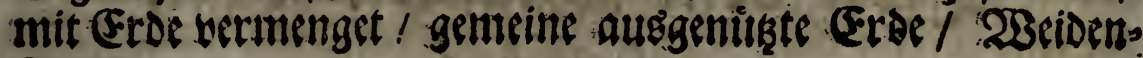
(Grunbic.

Terre neuve, netue Erse wiro fiegenennt/wann fieniemabsta

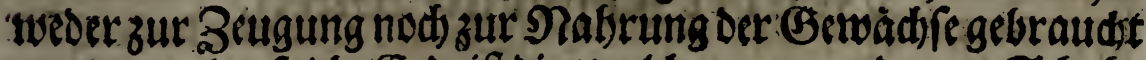
worden; ; eine foldse Groe iff bie/ weelde man 3. Doer 4. Sdulbe

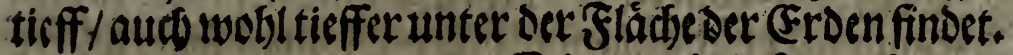

Terre porté, getragene Erde/1weldes infonderbsit won: cinem Dolase auffer Dem Garten getholet / und won Dar in cen Garten gettagen tworden.

Die Erde / weldes e in / ztwen / und metbr Safrecungebautet gelegen / miro terre repofee, sine auegerubete Eroc genemnet.

Terre travaillée, eime ausggentbeitete / und ulce, eine ausggsnilste Eroe nennet man die/ weldele lange Beit nadseinander Sriuder getragen / uns in Diefer Beitecine Diingung befommen bat.

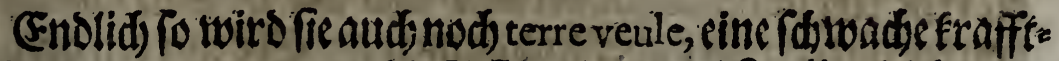

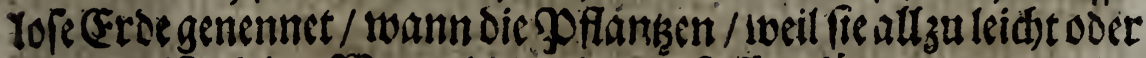

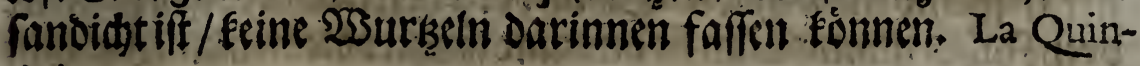
tinie.

Terrotober Terreau, iffein alter/werfaulter/uns mit Froen vermengter Niff oder. Dingung / da $\mathrm{B}$ or eljer cine fotwarke

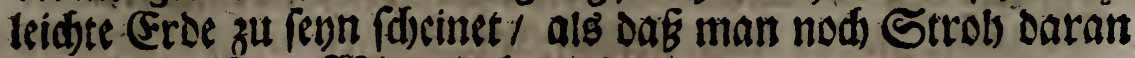

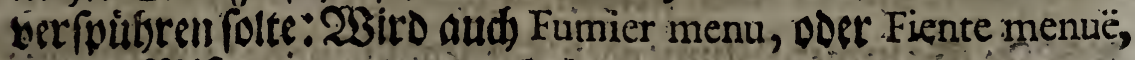
furser SRip/genannt, La Quint. 
58 Teue Unterweifung

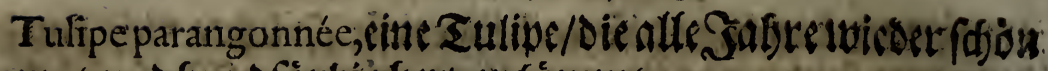
gefprengt und Gund färbig Gerbor fómut.

Voiles. Seftet Etendards.

S3ont on: 2Affodill: 29Br:

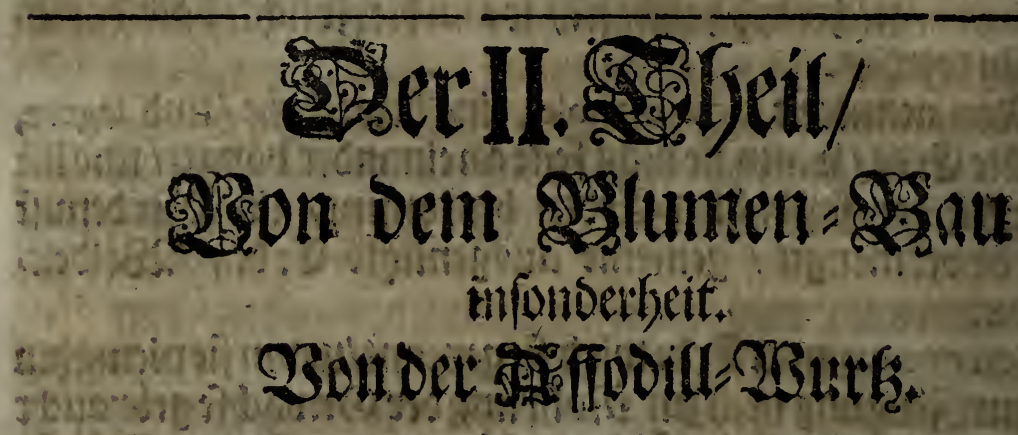

infonderbect.

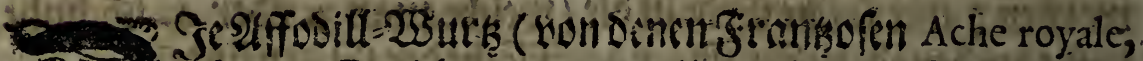

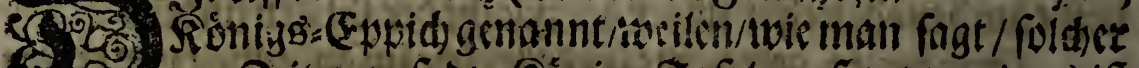
soor 3riten auf ser Rónige Safern gefeset roorden) ift zweberleb/sic cine gele/und die andere nciË: 2ule bes" De formiren oben auf ten Stingel cinen groffen goufd won SBlus

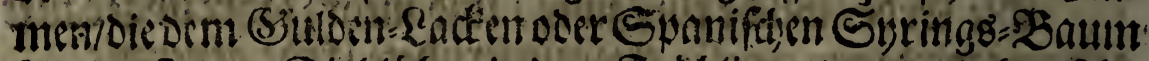

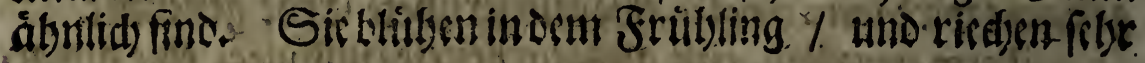
gut:

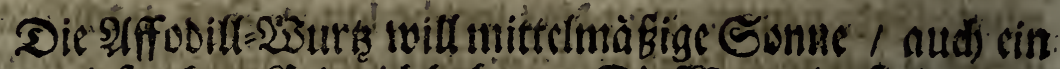

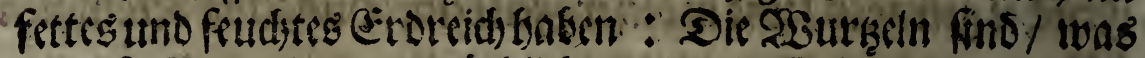
Die crffe Sert mublangt/ rotblidet/ und wis Eideln formirt; die vonder andern ärt ater fino gank wei s: Sie werden orei) Fin.

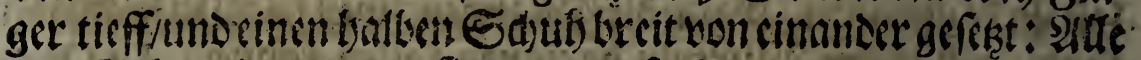

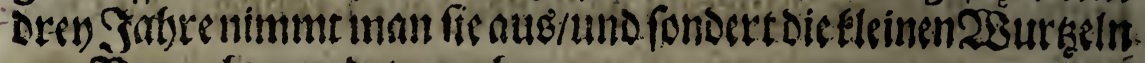
zur Zermelorung.Lavon ab.

\section{- Son det Sammet:S2lume ober alw I. Tondofhont.}

Fon ser: Banmet: 2)โนne.

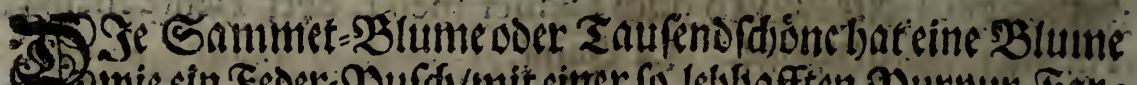

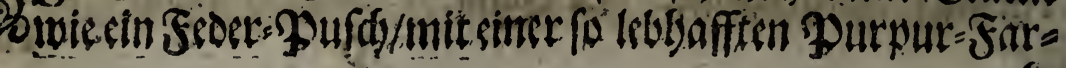
ac: 


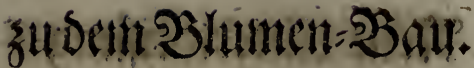

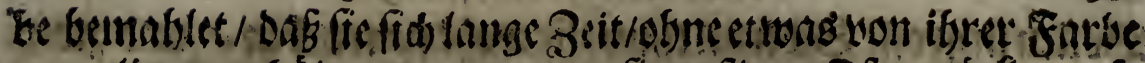

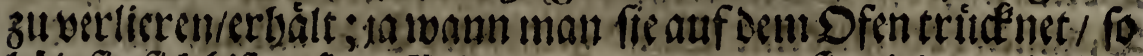

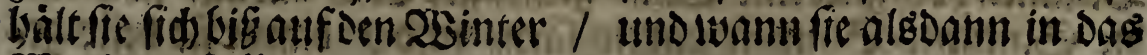
2Baffer geffeflet wird/fo bringt fie elendeneslank und die Sarbe woicder berbor/weld)e fic im Eoumer batte. Sie blithet bon beri

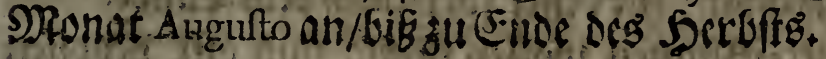

Die Iluaranthenoder GammetsBlumen/ infonderbeit Dietaren / lvolten bey guter $23 a$ arme unter Gläfern oder bon

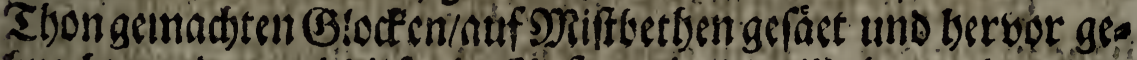
bindst werden/und betess in 2infange Des Aprilis, ben $5.00 \mathrm{er}$ 6ten

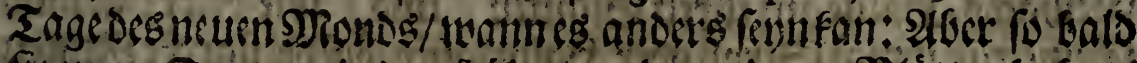

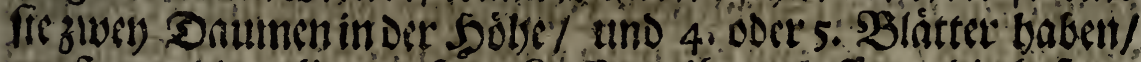

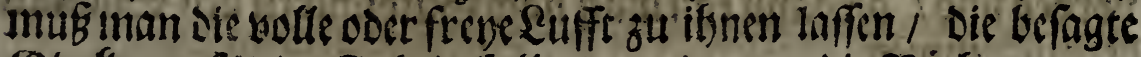

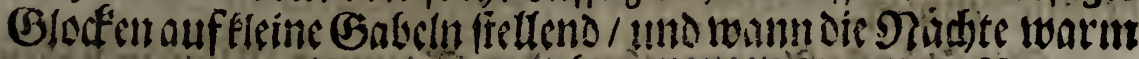

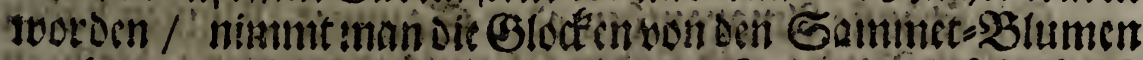

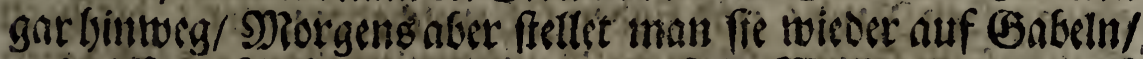

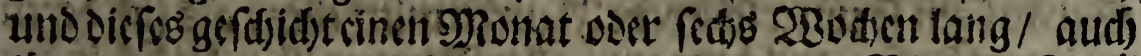

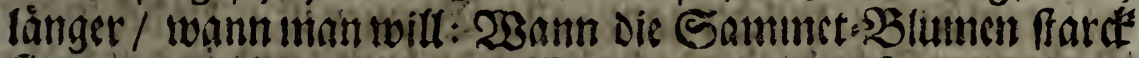

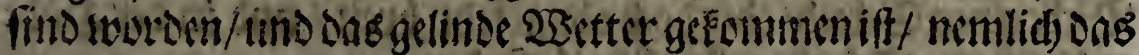

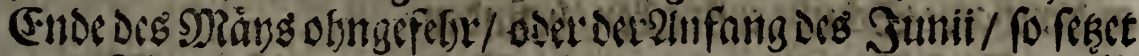
anan fer/gufant ser borantiángendent Grocn/ wo inan bin will/

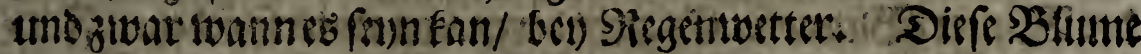
if febs zort in faltem Rándern fortgcbradt zu werden.

Diefesiff Die Sart mit Den faidnen Saumet=Blumen ums

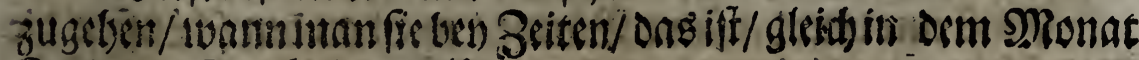
Suliv/im Flor Lasemvilí:

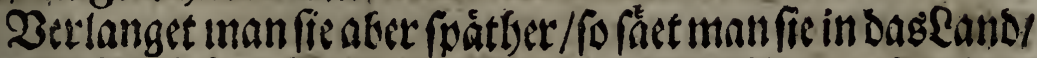
Iveldjeg woblygedinget/mit eineın oritten Theil Sano zubereitet/

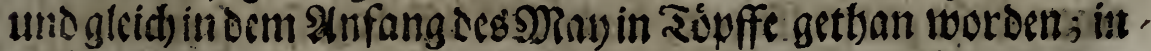
Diefen Fall oringenfie ibreslumenerftid) in Dem Monat 2 th guffo.

An Itatt der lautern Eroen Ean Inan gans warine Sofs: $\$ 2$ Sollen 
60

\section{Neue Unteriveifung}

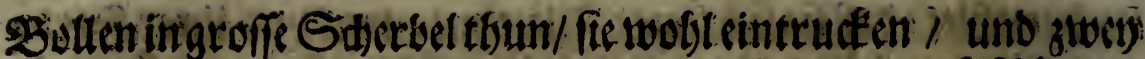

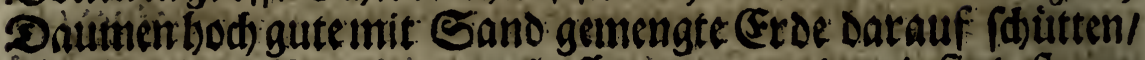

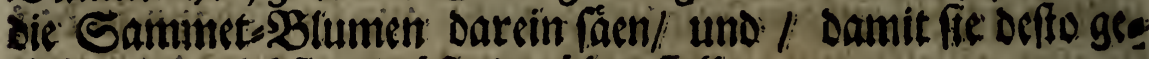

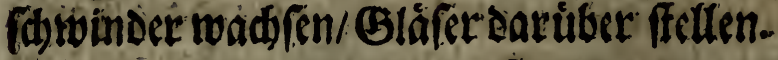

Sin Sderbel formmen fie beffere fort alsin bent Eande.

(sin).

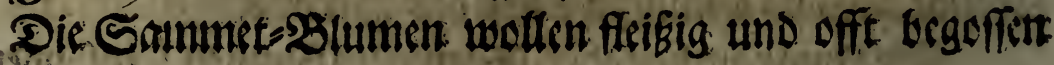

Es iff gut wwann man fie fitibe bat/Danit ter Saamen Beit

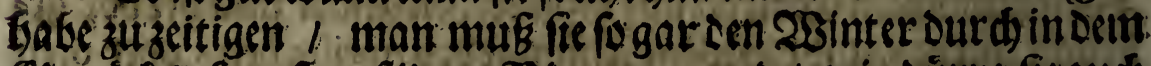

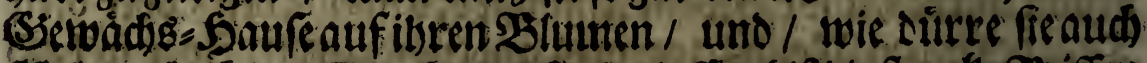

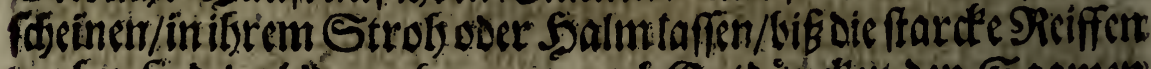

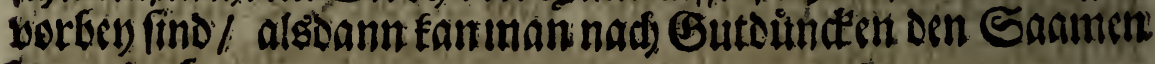
Geraus̆ nefimert.

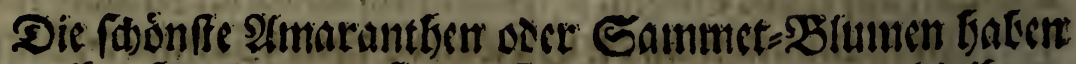

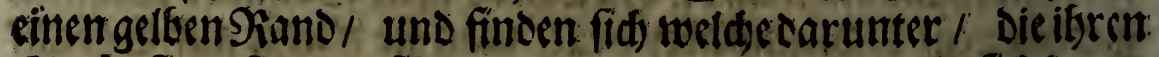

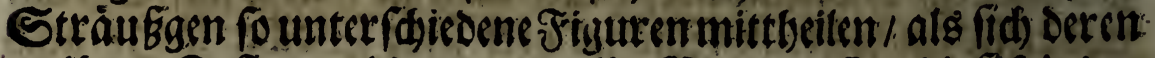

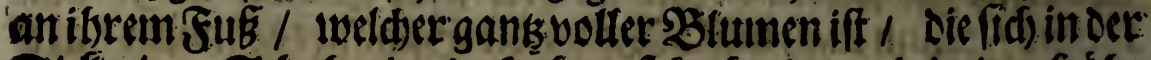

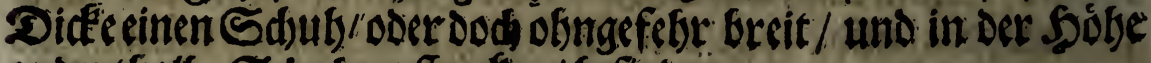
anderetfallbe Sadube erffrecteen/ Sefinoers-

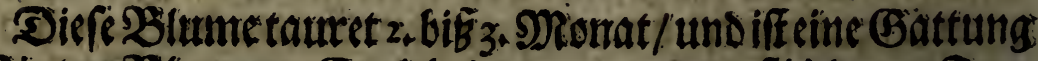

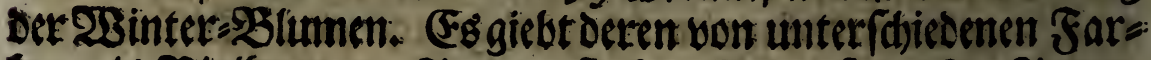
ben/als. 2iollbraune/ \$ourpurfarbel Earmefinrotbe/ Doome: rankęenfarbe/ rottse/ geltbe u. a. m.

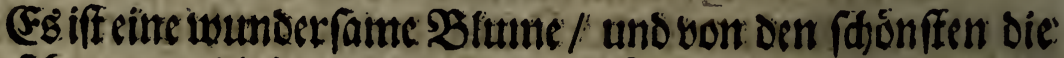

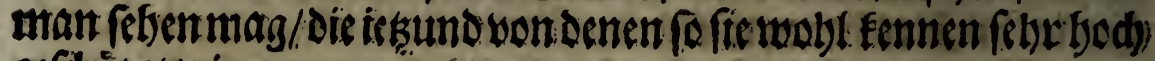
gefdaübetwir.

Sic iff getre wo nidfte alfzu biel Sonne binfosmme / in

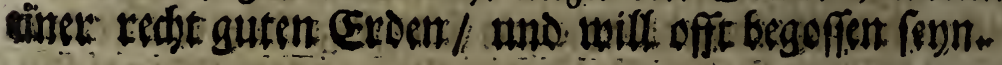

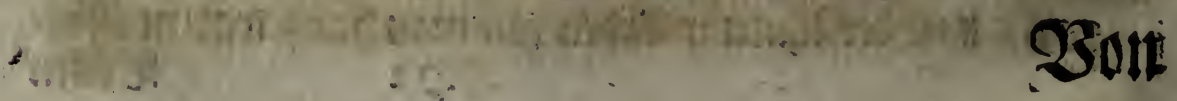




\section{รuben}

\section{Sas I. CapifeV

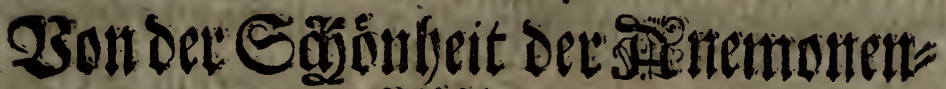 Fióflein.}

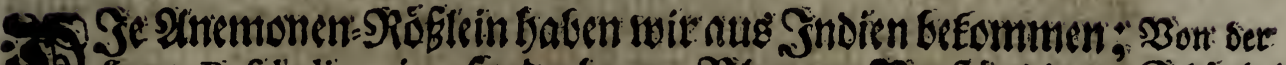

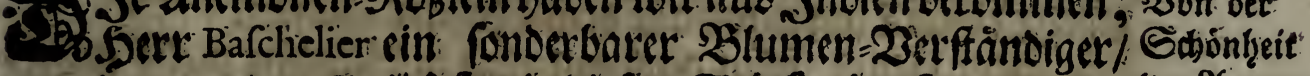

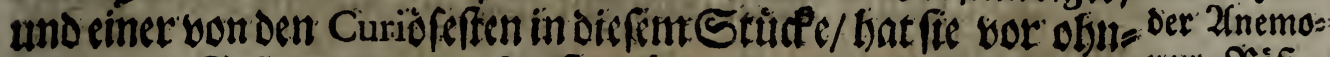

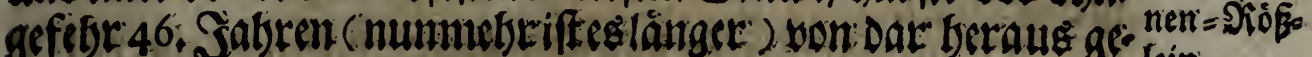
bradjt.

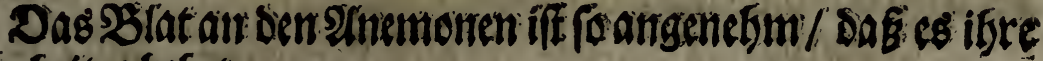
Sdisubsiterthefert.

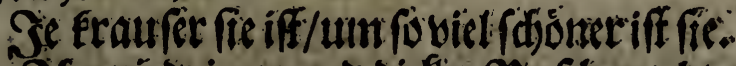

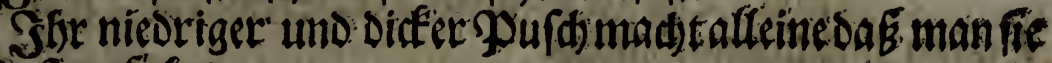
miteufte anfietret.

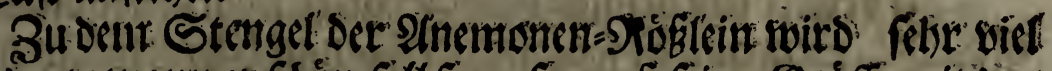

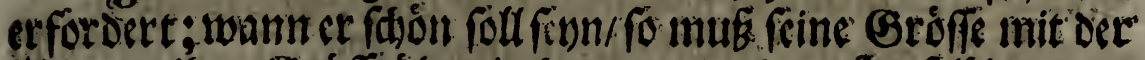

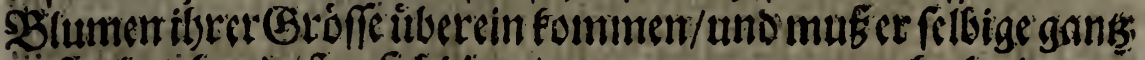

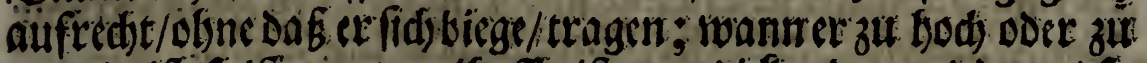

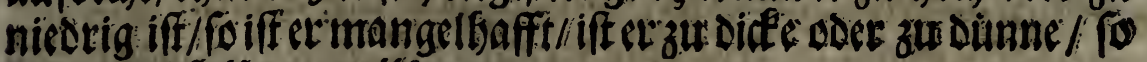

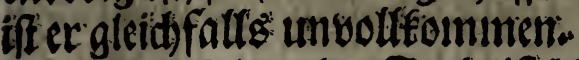

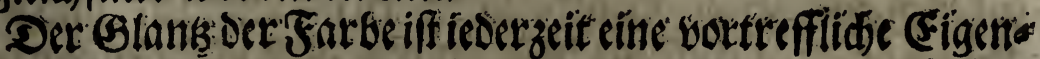

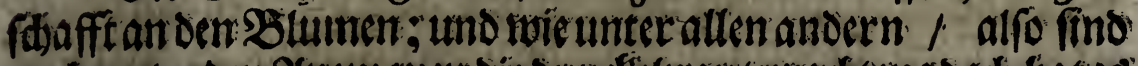

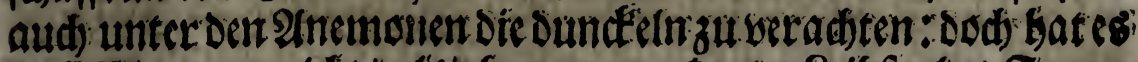

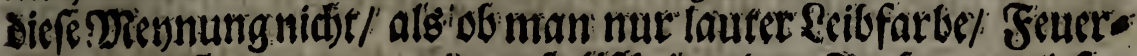

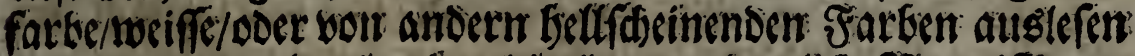

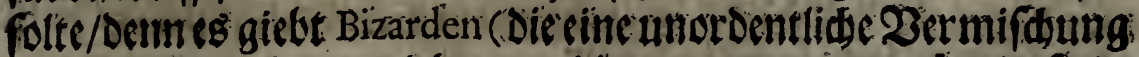
Der Farben baben) uns braane die vertwundecns würdig find:

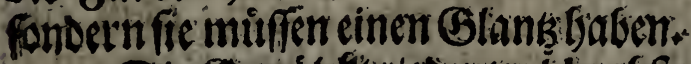

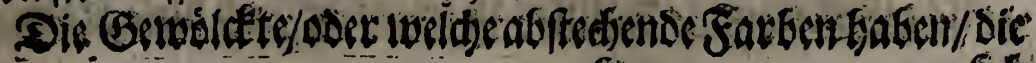
S) 3 
62

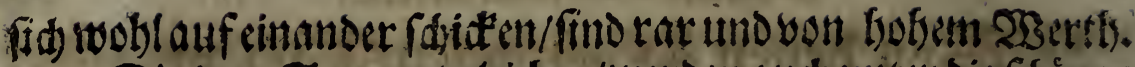

Die den Sammet gleiden/werden aud) unter bie fajonen gezeblet.

Die Butnofárbige fins oenen einfärbigen vorzuziefen/

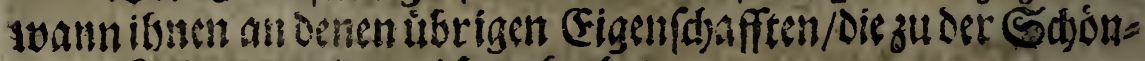

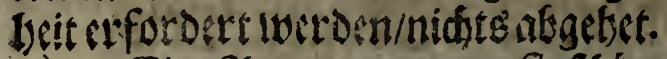

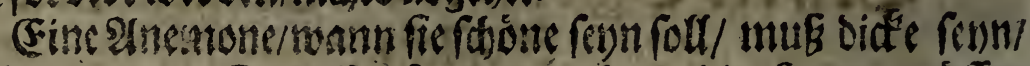

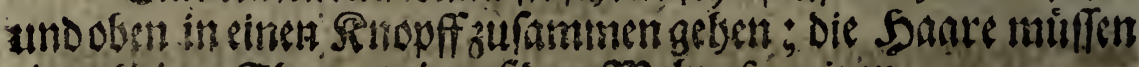

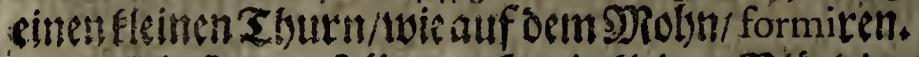

Die Sare follen aươ mit fleinen Blátlein wobl unter: inenget rom.

4. Diegrofen Blatter folfen Die Saare/bod nid)t unt viel/ in Der Diffe utsertueffen.

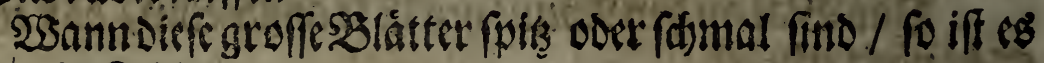
singroffer Fibler.

Die Eleinen Bláttermitfen an ber Spizeruno feun ; Die Ppisigen find unamnefsmlid).

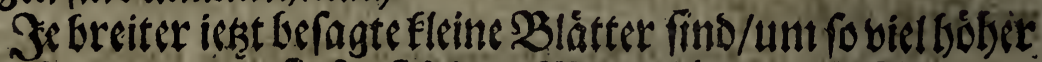
if sie :Blume/mann fie fonft frinen Mangel bat / zu fdáken.

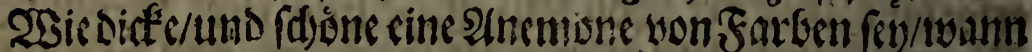

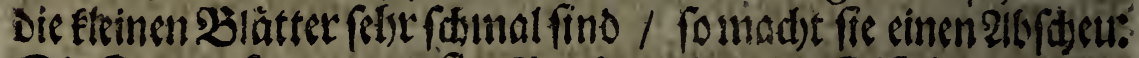
Die Frantsolennennen fic Chardon, ober citte Diffel.

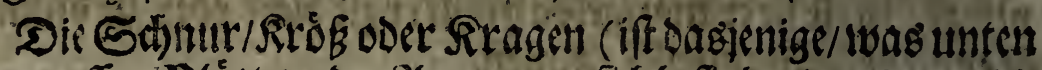

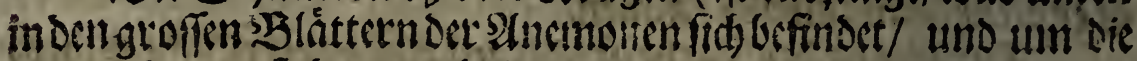

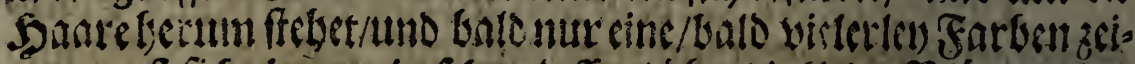

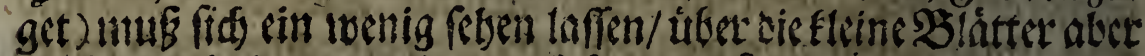

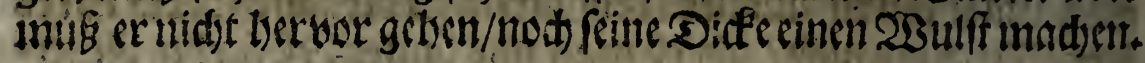

TBann dief Sdmur aus vielerlen / uno von ifern groffen

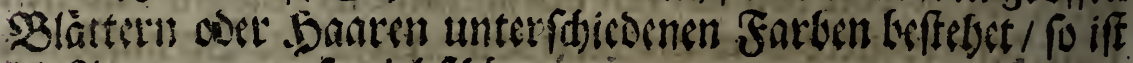
dir Sincmone tum fo vicl foboner.

Die Sdmur foll gant Esine Sornlein Jaben; cs if cinc

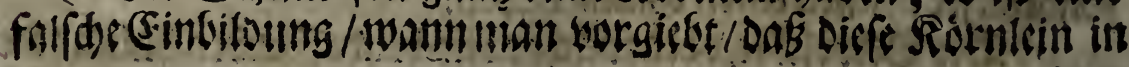




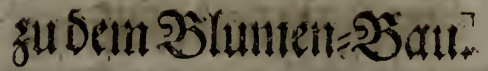

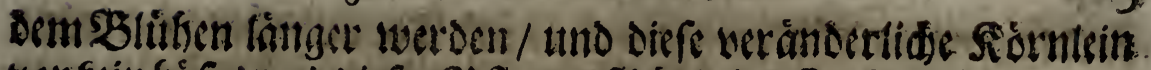

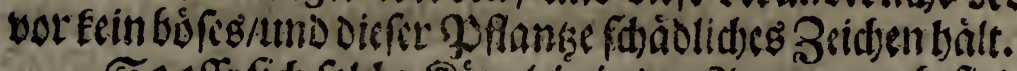

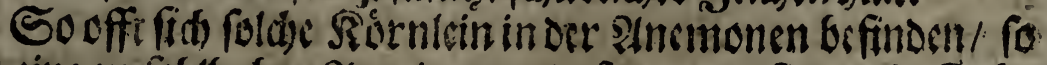

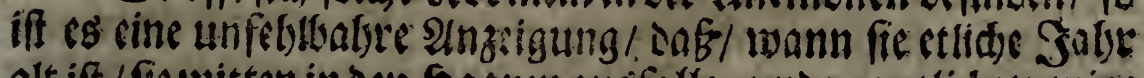
alt iff / fie mitten in den -Daaren ausfalle/ und nur ettidge wenige fleime Slätter Geblalte.

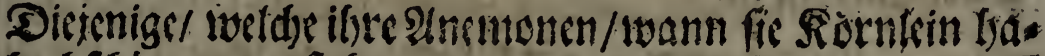

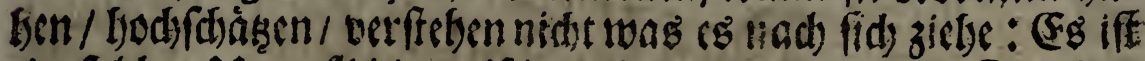

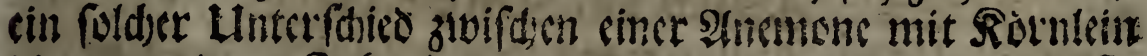

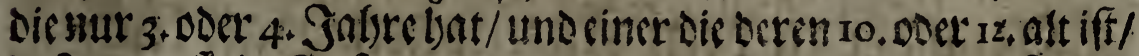

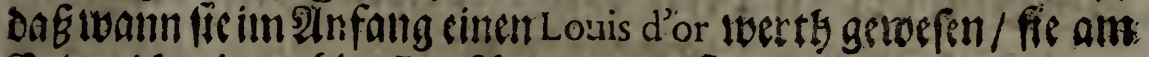
Entenidst cinmaft 2. Grofdsstwertes iff.

Die 2memonen/wedde eine flare bier. reine Sdnure uno

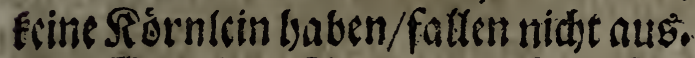

Zonciner Incentonen ibrer Edsenfscit mus mantin bem

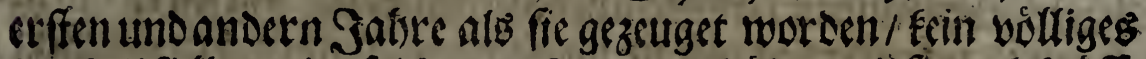

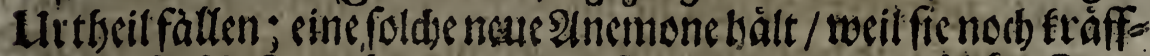

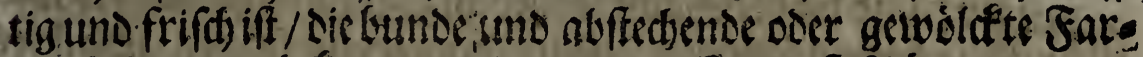

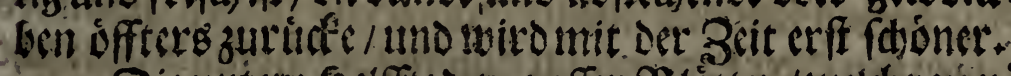

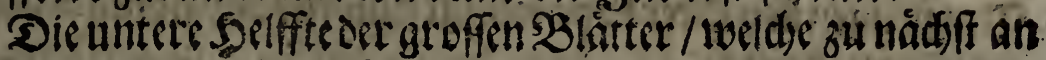

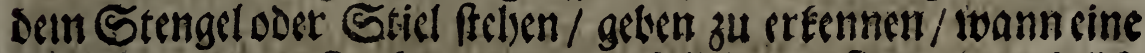

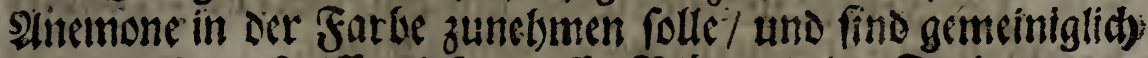

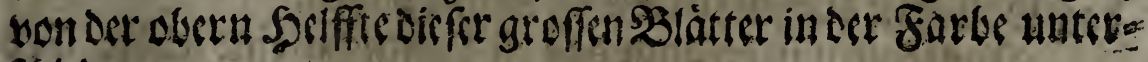
fojicoent.

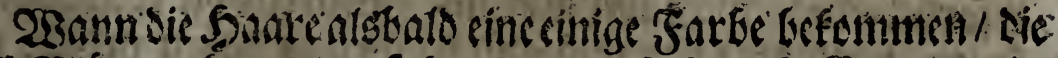

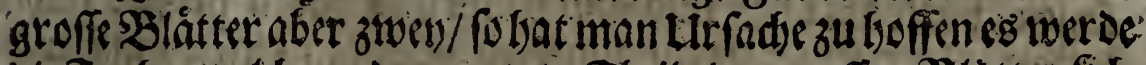

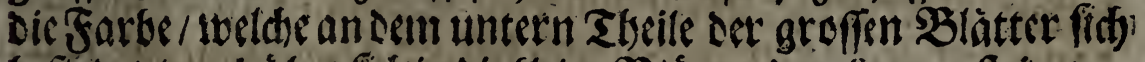

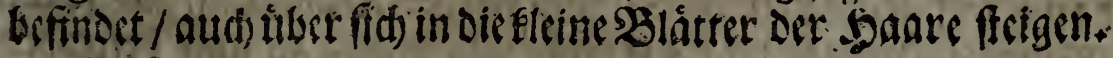

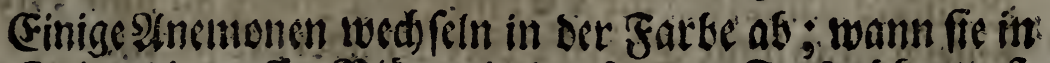
eintem Sabre die groffen 2 lâtter in Der bunden Farbe übertrof. fen / uno Greit gefprengt find / und itbre Eleine Sláttlein cinen

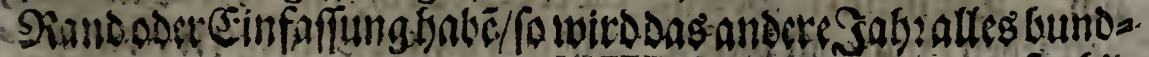
fartig 


\section{4 \\ Tene Unternoeifung}

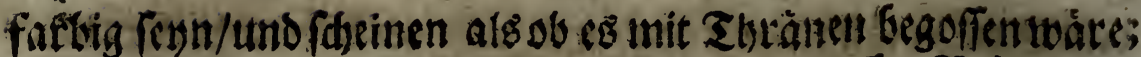

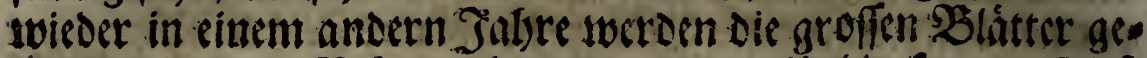

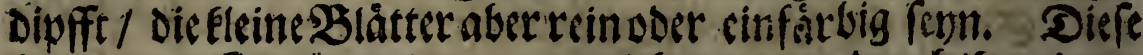
Sanemonen find ben anoern vor zuzieten ; Dann surds ifsec cigente

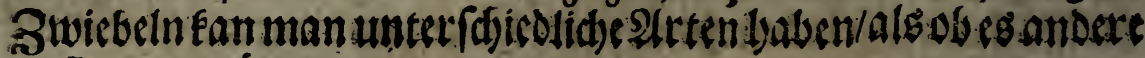
Poflankęn wáren.

\section{2ażII.Capitel|

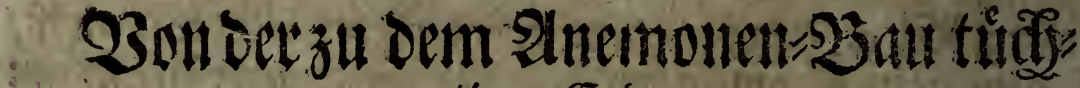 tigen Erben.}

Szon ber túchtigen Erdenza oein 2(ne= monen. Dalt.

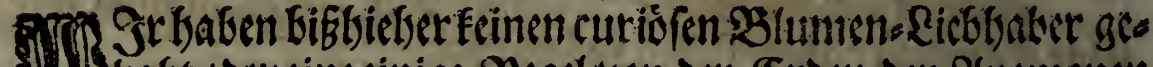

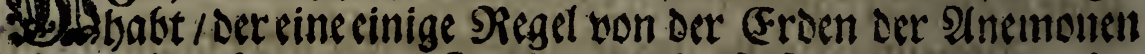

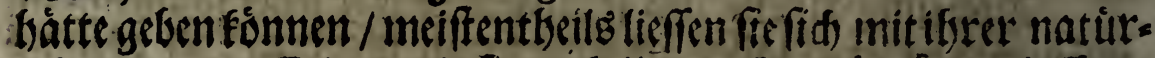

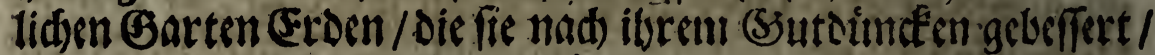
Gegnigen; und Die Die Sade flitger anzugreiffen gedaditen/ uno neter, Eroe berben bringen lieffern/ baben cin foldes fdiledtes

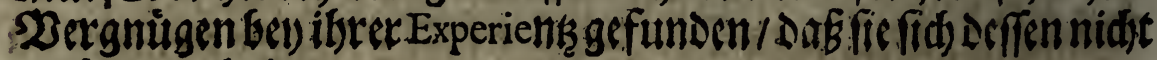
geritbmet baben.

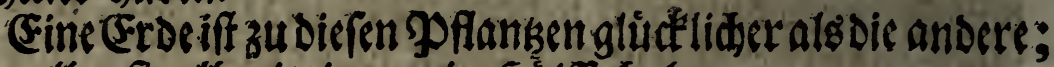
podyodtenfic altezeit ein wentig Sülffe Laben.

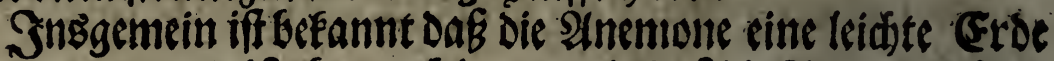

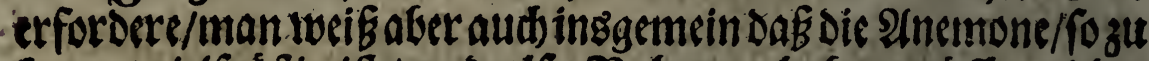
fagen / vielfrísigig if / und alfo Nabrung baben muiffe; niddts Deffoweniger fferbet fie gern in dern Sande; biefen muB man Dann mit gefdideter Croen und furker Dingungi in folder Mengé/als man burdb oic Erfabrung genug zu fern befunden/

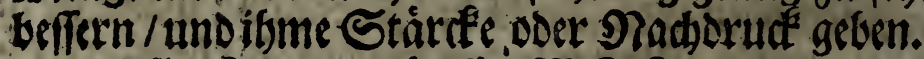

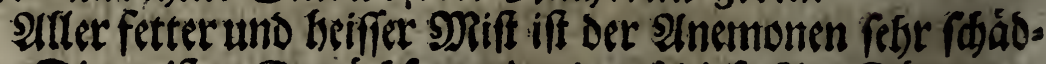

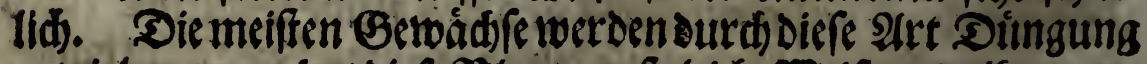

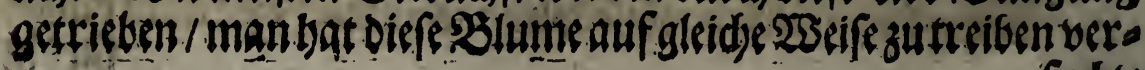




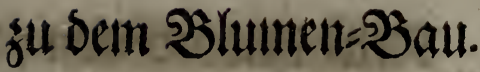

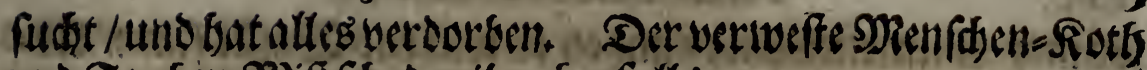

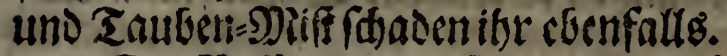

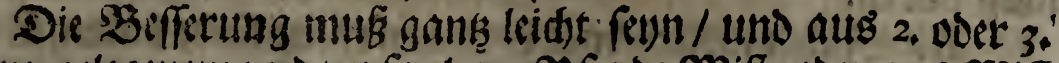

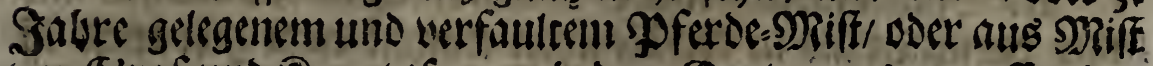

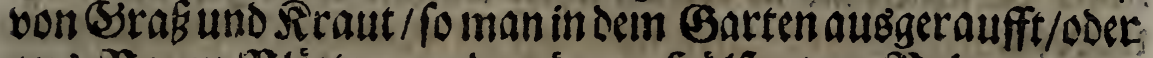

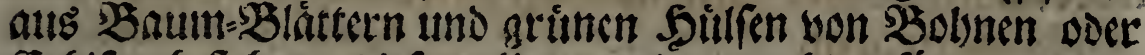

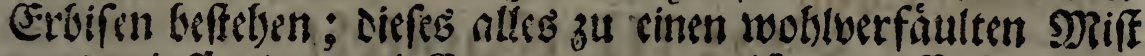

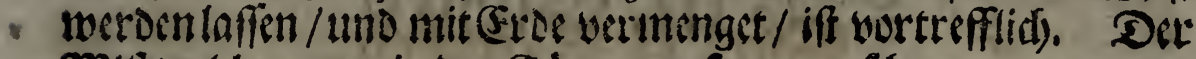

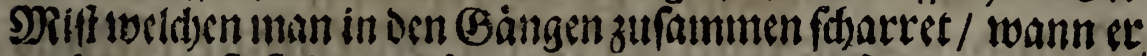
woblwertweft iff fan gar begnem Darunter genif fdet werdern.

Die beffe Erde wire auts 5. Butten Sande / 3. Butten frifder Erbern unt 4. bi 5 . Butten furker Dilltgung gettadto.

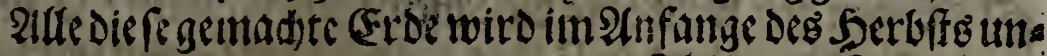

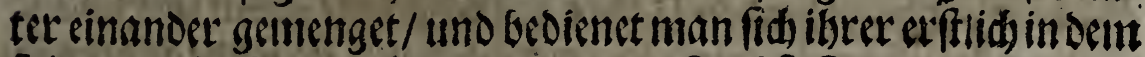

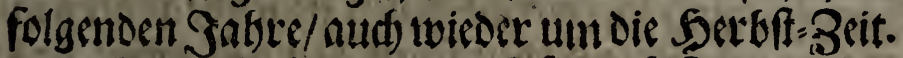

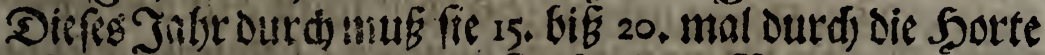
getworffern werbert / wann man fie aber indie Betbe tbun willy/

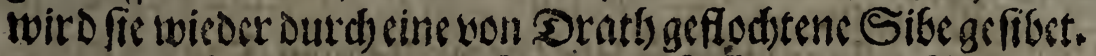

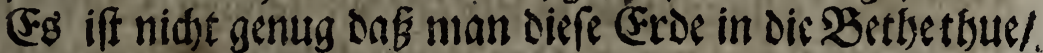
wwann Der Gruno odir Socen Des Gartene nidet fandidtt vDer

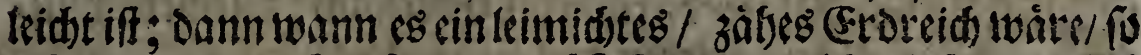

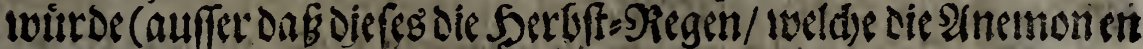

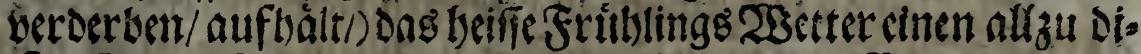

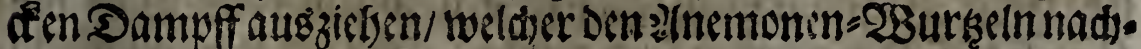
theilig fern twirde: Derobalken wann Det Booen yon cinem

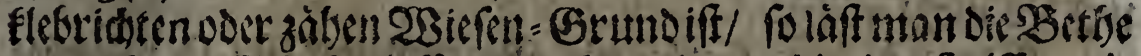

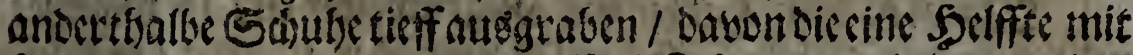

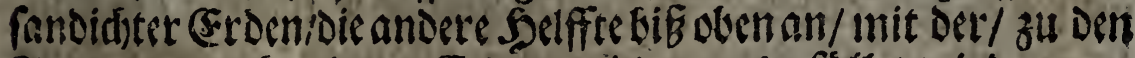
Atmemonen zuberciteten Erosm/ wiecter ausgeffittet wird.

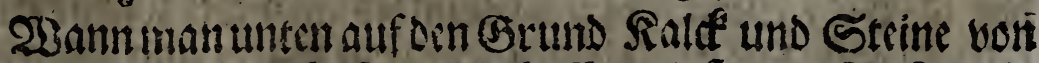

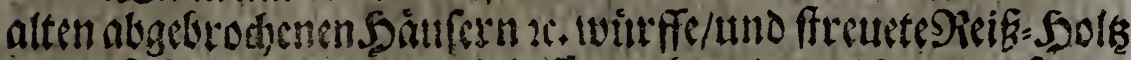

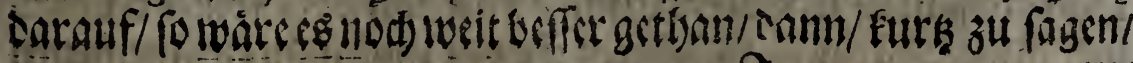




\section{6}

Neue Untertweifung

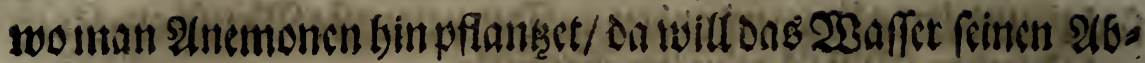
lauff baben.

ellfe Sablec woduen diefe Ganwádsencue Groe haben/fie find

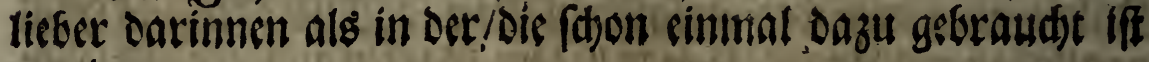
worden.

\section{III. Snpitel।

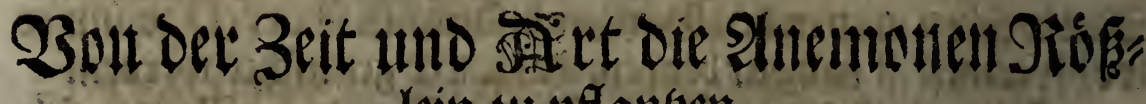 Tein zu pflanken. \\ W.

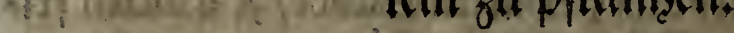

3eit uns

2irt oie $\mathfrak{Z}=$ nemonen bu pflankelt.

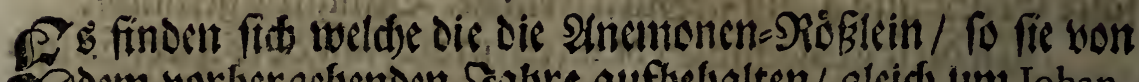
Sodem vorbergethenden Jabre aufbelialten/gleids um Johannis Baptifta pflangen / uno hiersurd// wann fie forthe anders in meue und ein swenig getecferte (Froen fesen / und fo lange das

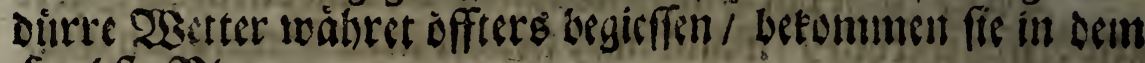
Shiveffe Blument.

Indoerc p flanķęn fie foăter / gegen Remigii Tag im Octobri, oamit fie fribe treiben oder bernor foninen/ alsoann Getgalten

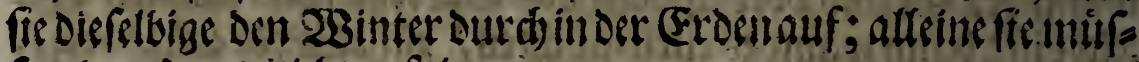
fen Durdhaus itidst gefrieren.

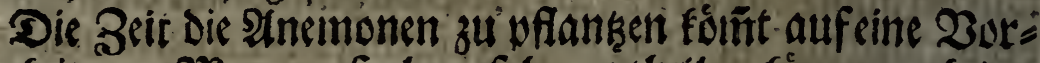
fidtigfeit an. NRan inuB obngcfebr urtbeilen foinnen/ ob Der

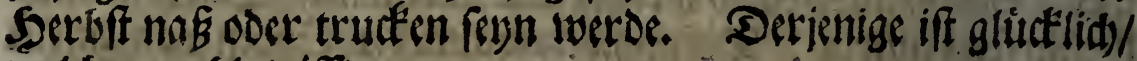
ivelder wobl trifft.

2Bann in Dem SSerbfrt viel Siegentwetter iff / to pflankect mitten in Dem Octobri; if bas $23 \mathrm{set}$ ter aber tructen / fo mulf fer itbr um bie Soelffte des Septembris pflankęn; Dá̧ Die Erde cuers Garten=Grundes entweeder warm wie Der

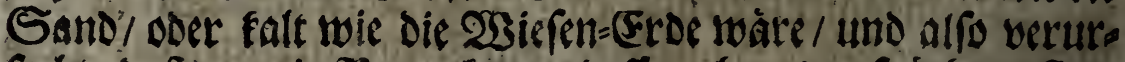

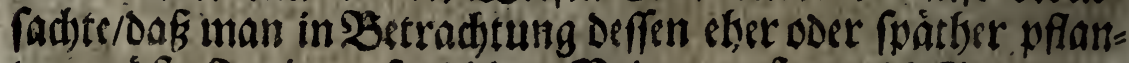

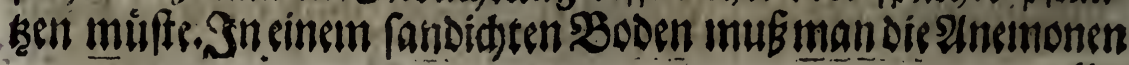




\section{zu bem Эlunten=⿰冫aนt.}

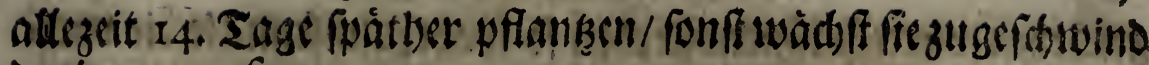
Darinnen nuf.

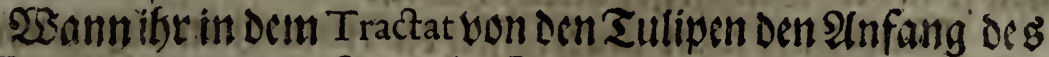
IV. Eapitels/bon ser Art Die Tulipen zU fflanken / lefen werdet / fo werdet ibs eben sicicnige Sert / wie ibr mit denen

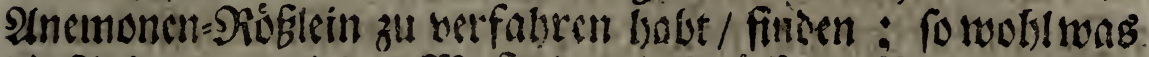

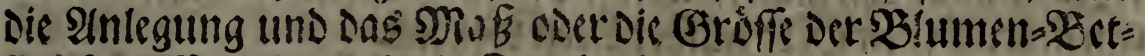
ben betrifft / als aud) die Swicbeln / in welder Dronung fie netulids in die (5rod zu resen feven.

Die Amemonen follen nid)t uteer 3. gute Finger tieffin dit

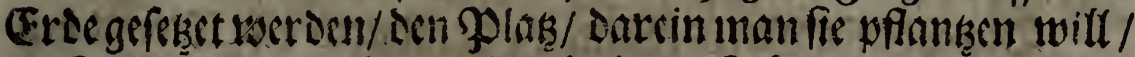
mub man Init oer Sand als init cinem Sefer zu redite madsen!

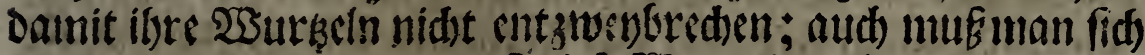

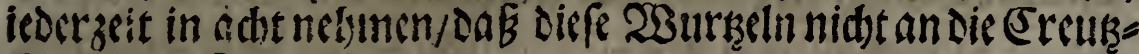
Stride zuffels Eommen.

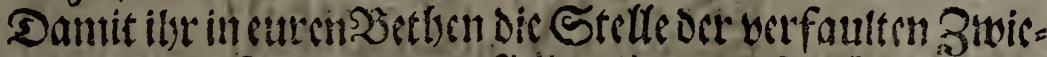
betn wicserum erfsch uno susfitlen fonnet / fo pflanger un.

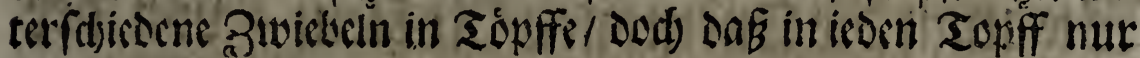
sine geferset wetres.

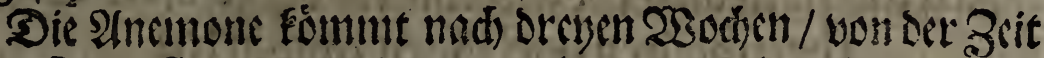
an als fie gepfanket worden zu rednen/ aus Dec Croen wis =

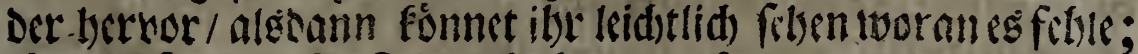

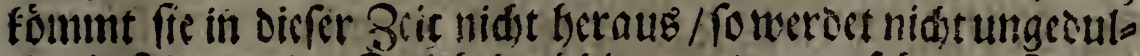

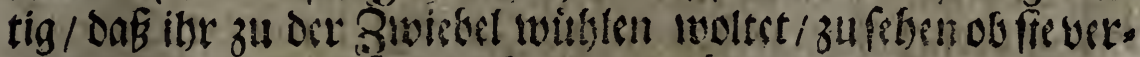
faulet fery / ooer ob fir langfaun und träge imbondfentoorden/ twartet lieber sinen guten s) Romat; sam wain man alfo wilfs.

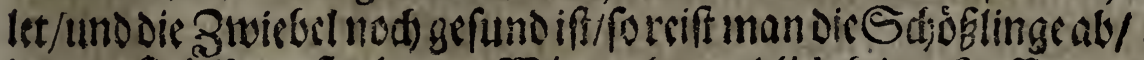
Davon fic offerg ffertent. Wäre aler endid feine Soffnung

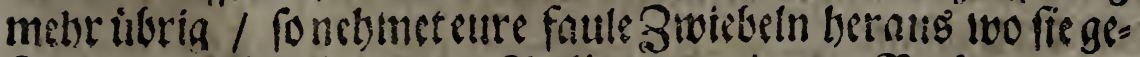
frandern/und frset an ceren Stelle andere in eare 3 Betbe / welde

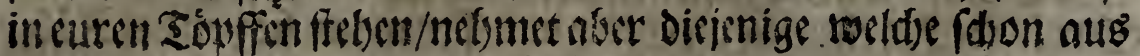
Det Erden herbor geturoden baten / Dann wann diefes nids

$$
\mathfrak{I}_{2}
$$




\section{Netue Lnterweifung}

gefdeben wade/ fo fónten fie eben fo woblf faul feun als bie vorio gen/fo in den Betben geftanden baben.

Man mus nidet unterlaffen die :enemtonen abzuzeidjen/ woie nu feinem Orte von den Tulipengefagt werben folle.

Dis Zlviebel=233urkitn Der Inemonen Galten fid' 2. oder

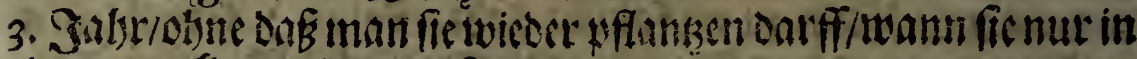
cincon truffenen Drte nuf sebalten werdern.

TSannibr im Martio Alurmonen-Sioblein in Sdjerbel y fanket/fo befoummt ilfr gegen folgenden Johannis Baptifta Rag 3/umen bavon/wann fie ander' redt getwarter werden.

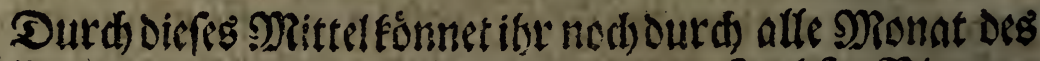
Fritblings/Solnuers / uns einen Thsil Des Serbfts Bltunen basen; ibr dirffrteren turt aile Mionat in Dem Fritblinge fes B̧Cn.

\section{2ณย์ IV. Cnpitell}

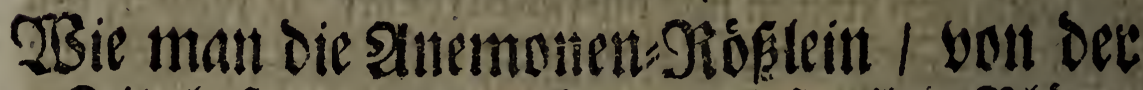

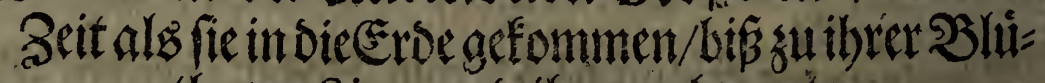
the/tractirem umb ibuen abrwarten

muife.

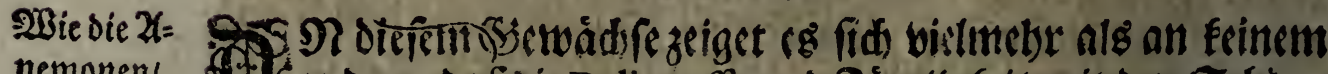
nemonen/ yon ber Zeit Der Berfe= sung bi

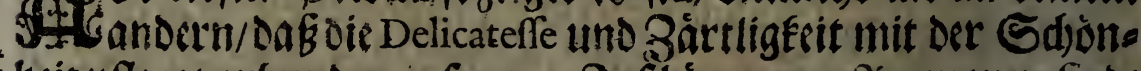
beit pflege verbunoen zu fenn. Se fidoner eure anemonen find ie metrere 23artung baben fe vonnotben: Sut Soerbffe wollen jur Blüthe/ fie begoffen feyn/wanndas 2Better trufeen ift; regnet ç aber

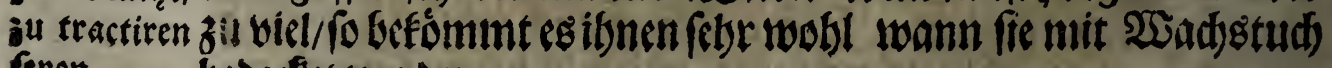
fryen. bededfet werden.

Ben Den erffen Sieiffen muk man nid)t aflzu ferge mit Den Strol)=Deden eilen/fie werben nur beffer wann fie won der Siàls te cimsenig bart und dauerbaff gemadje woroen; aber wann 
Die fardten Froffe cinfatten/fo Dectet fie nidst nur init ben Des

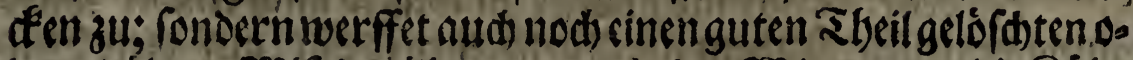
Der getósten Miff Dariber/ uno swic Der 23 inter oder Die Rälte

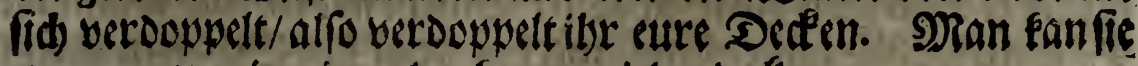
ztwar z̆ wenig/niemain aber zu viel zusećfen.

23ann der Freff worbew iff/und Da 23etter wieder. gelint-

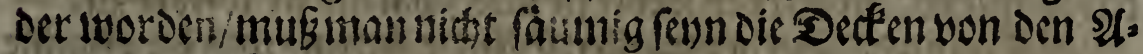
nemonen auf zulseten/und iknen frilfde \&ufft zu geten : Damit fie aber nid)t won einem Sieiffin iuberfallen werben / Dectetet man fie alle agend wieder zu.

Soltc die Sälte wivder anfangen'/ fo thut mit euren Des

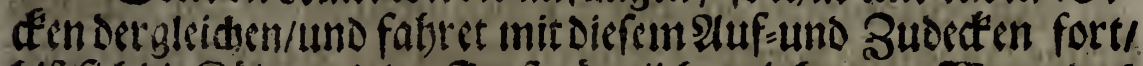

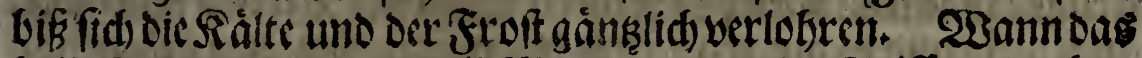

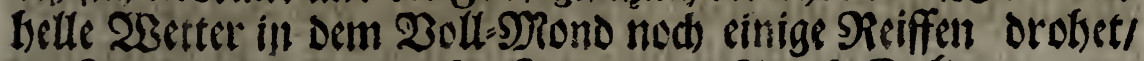

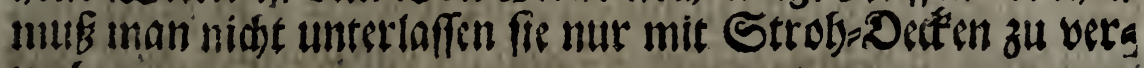
wabiscit.

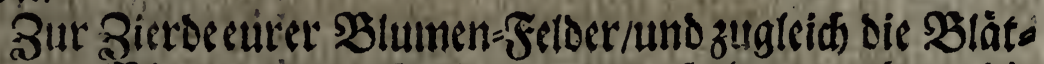
ter an Din iblumen curer 2anemonen zu erbalten / nelgmet Dic

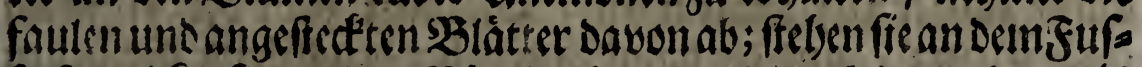

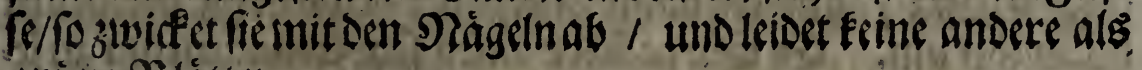
grime SBläster.

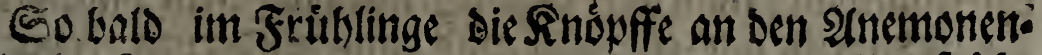
Sióbleinanfangen berwor zu fummen / (Dann Die allzu frutbe Sinopffe fallen gemeiniglid ab) fo begieffet fie mitten oder am Endec Deg Februarii, und Decteter fie affe 2lbend mieder zu/ itter 3 .

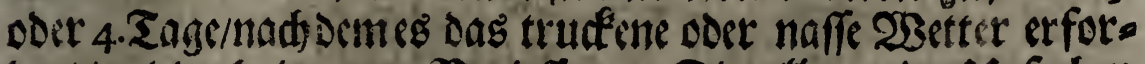
Dert/ miedertholet euer Begieffen. Die allgemeime Uurfad)en

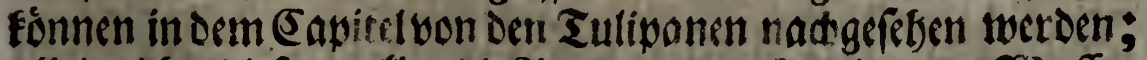

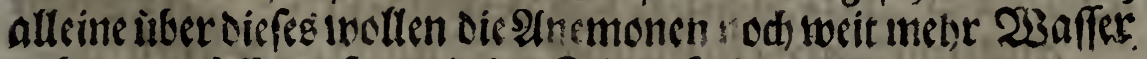
babsen/ uns ifferes fo gar in ser Bcit Ba fic ber ver fommer.

3u Dem begieffen nimmt man 28 affer uvie es aus dem

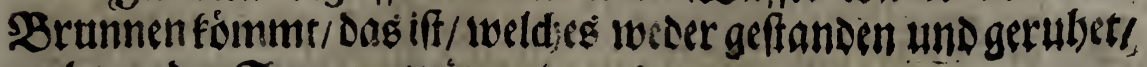
nod) yon Der Sonne getwarmet worden. 


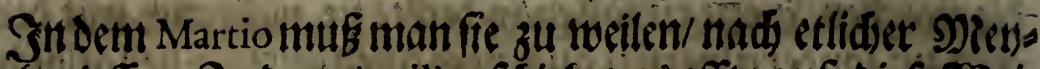

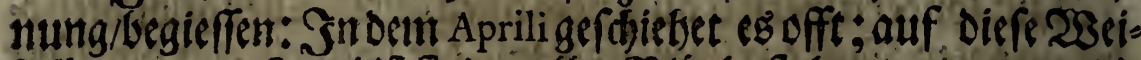

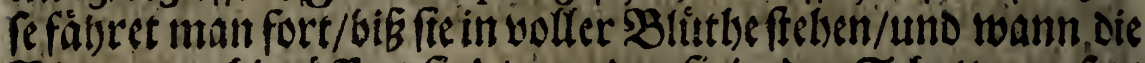
Bilumentwobl gedoffnet find/ werden fie in den Sdjatten gefest

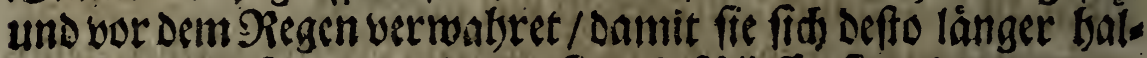

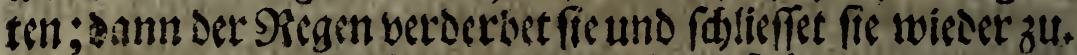

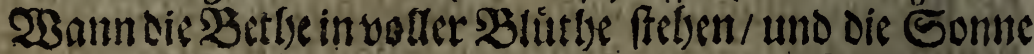

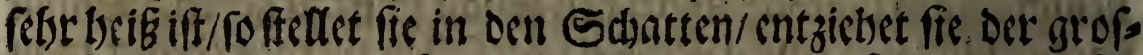

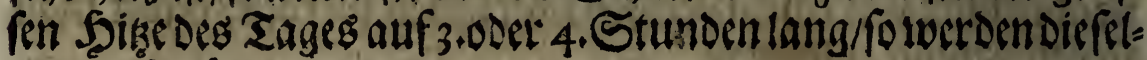
bige defto lánger tauren.

In Dem Eapitcl won den Sultipen iff zu fegen/ wie man bie-

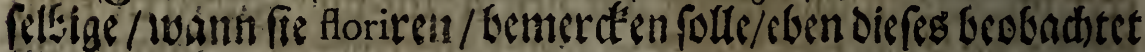
aud) bier/ und swann tman cudy 2Anctmonen SPóblein geben bat/

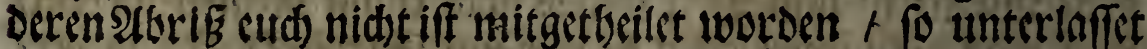

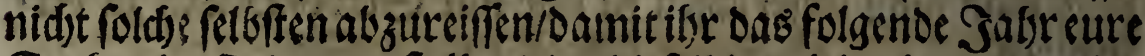
Farben in Oronung fretlen/Docr Diefelbige victluelbr unter cin=

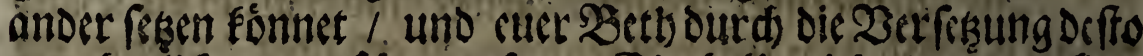

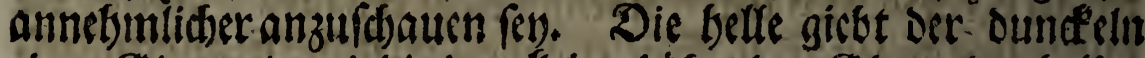

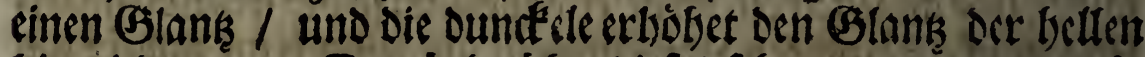

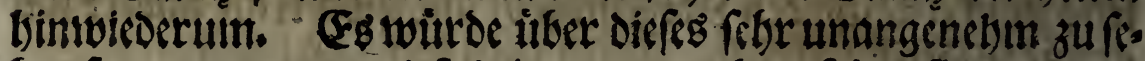
ben fenn/wann iman diffe Bglumen nur obngefelor w flantigen/und

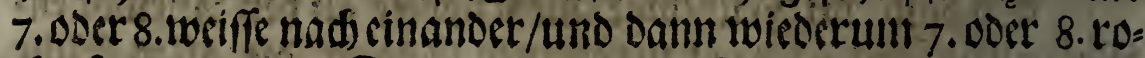

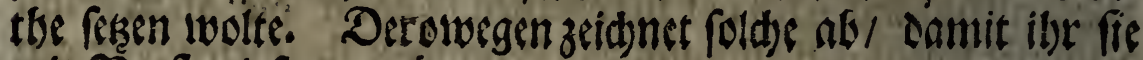
init 2 erftand fersen móget.

\section{2n5 V. Enpitel/}

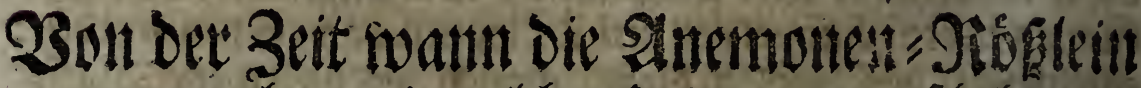
aussunebmen/intweld)er Oromunges gerchelen folle/uno wiefiezuerbaltenfenen.

SBont ber Beit ote?nes

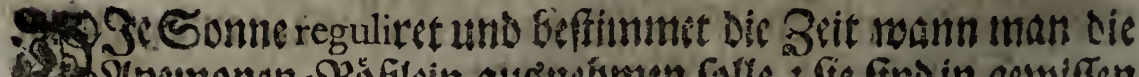

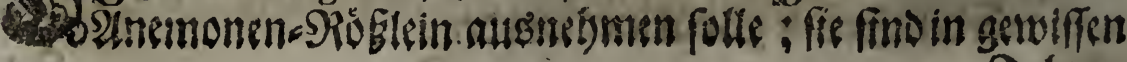
12, Babren 


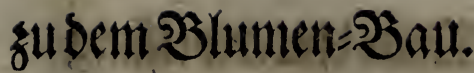

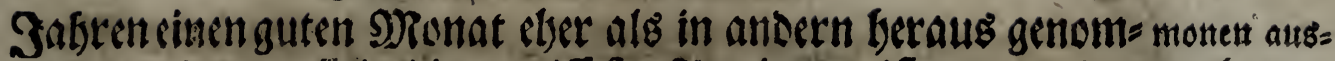

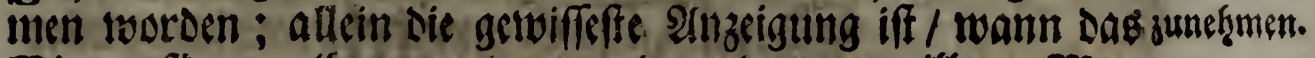
Blat anfängt gello zu merten / und verborren mill. Makt

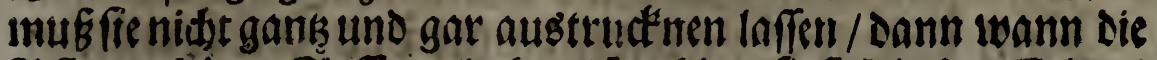

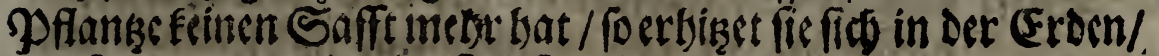
und faullet wont oer getringffen Feuthtsigfiti.

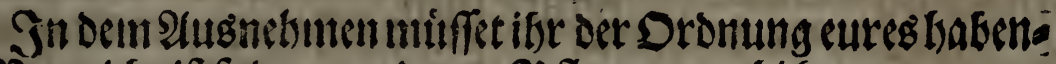

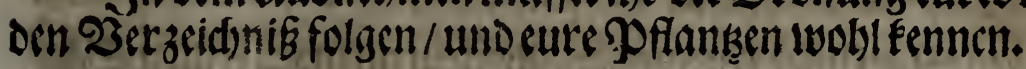

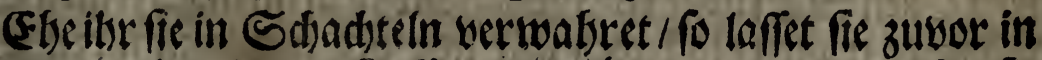
cincin (Germade / in Der \&ufft austrodenen: Dods iniffen fie DiBbuegchan fesinen allzuwbarmen ort geleget swerden / Dann es. ibnen beffer iff / waun fie nads und nad austruténen.

Nadjbifen faubert fietwobls/ und nefsmet alles faule / und was nid) e einte lebendige Bwicbel ift/Dabon ab / Dann offers fint

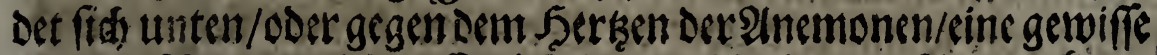

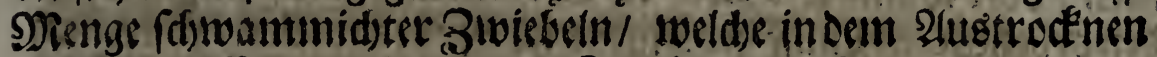

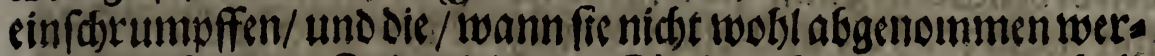
Desn / Das folgende Sabre viel zu oer Făulung bentragen; Derohalo ben traget fein Be edentén / wann itgr fie reiniget/ biß̈ auf Das Sorkęe bincin zu fonciden.

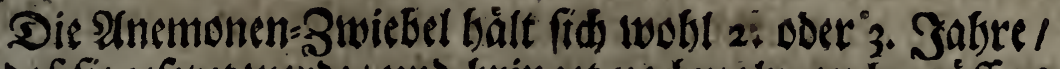
obme Daß fie gefezect tuerde/ und bringet nadimaln auth gróffere 2blumen. 23seil es Sabbe giebt/in welden biefe Blumen gerne faulem/unb ber grofle Froff / wieder alle angetwandete Sorge/

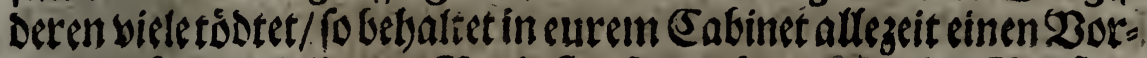

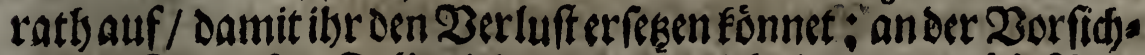

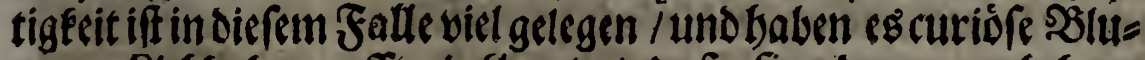
men = Eicbbaber ufft beflaget / Dá fie Deren entbegren miffen. 


\section{2 Reue Unterweifung

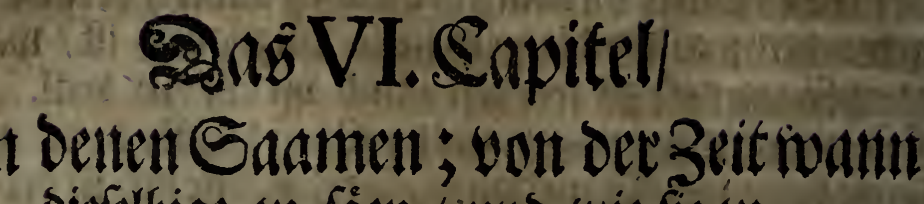 \\ Bañ VI. Copitell
Son benten Saamen; von der Zeitwann biefelbige su fäen / und woie fie su bauenfints. \\ A) is}

Welches die בaeit bié Saamen zil fáen/ und wie fie bu bauten.

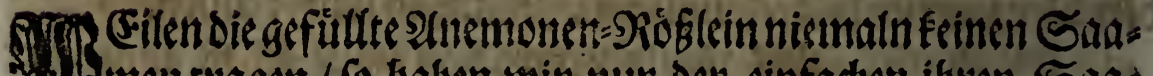

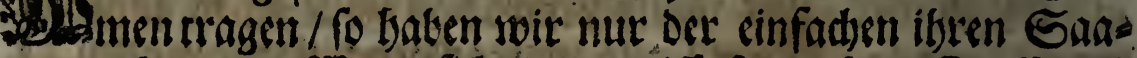

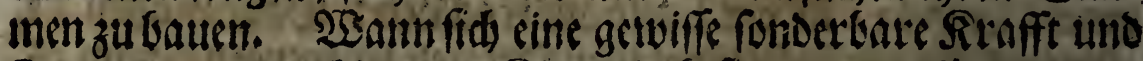
Tugend ineinent Saamen Rörnlein befinder / und Eormmt eine

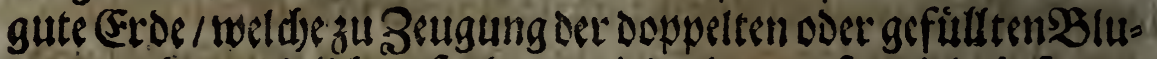
imen notbirendiglid erforbert witb / bazแ / fo wirb befagtes

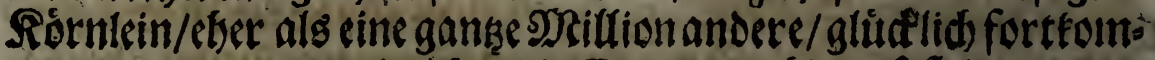
men; ober woann twir thber Die Ereaftuten binauf ffeigen / und Den ordentliảen Rauff Der Natur ilbergeben wodlen / po fónnent

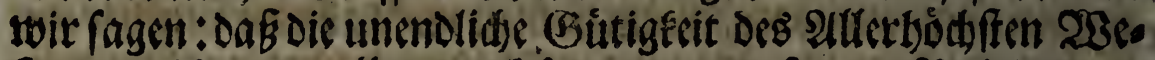
fens / weldes vor alfes / aud) fo gat vor unfere unfauldige und

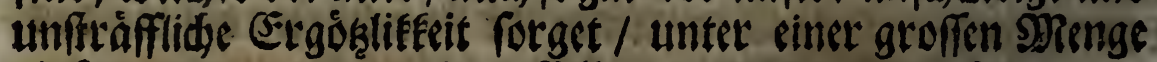
cinfader Anemonen sinige gefultte berworfommen laffe.

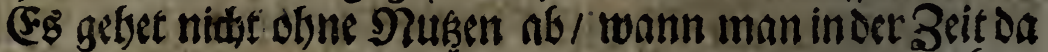
Dic cinfadbe Anemonen blitben/ Diejenige Blunnei bemerefet/

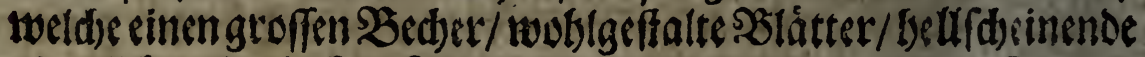
oder lid)te / ingleiden felsain unter cinander gemengte Farben

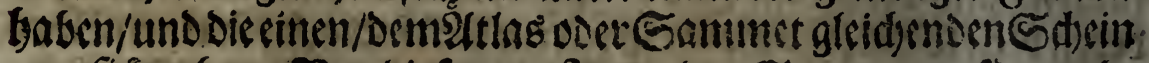

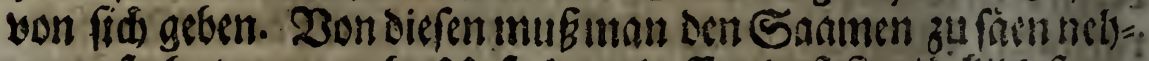

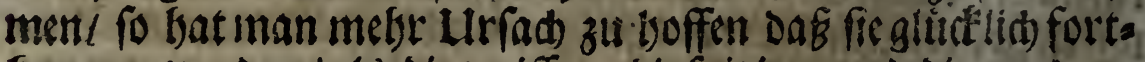
Eommen werden / als die rweiffen / diefpisigen und die von oun= delen ifarben find.

Diefer Saamen foll eter nid)t gefamtet luctben/als twamn er das otere Theil ober Den! Ropff des Stengelguerlaffen / uno

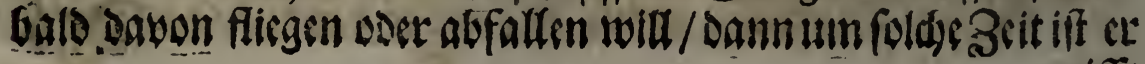




\section{รubem}

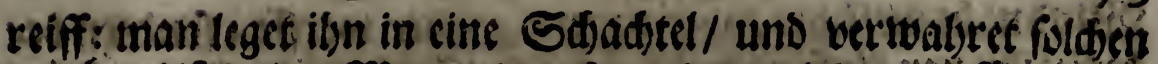

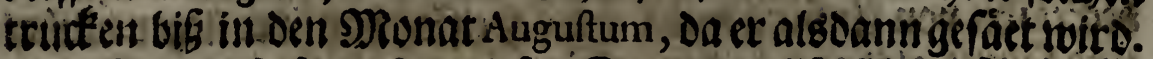

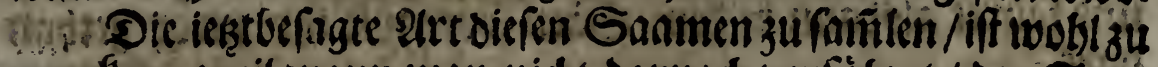

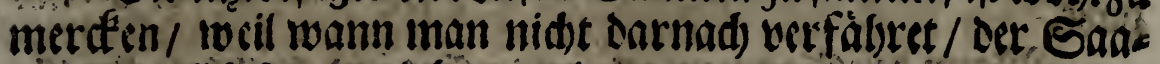

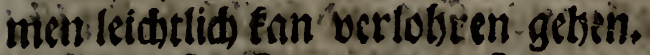

- ne Diefer Saanen - mus in feine anderc/als eine zuberceitefte

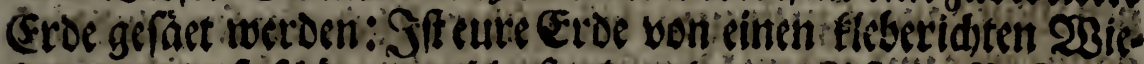

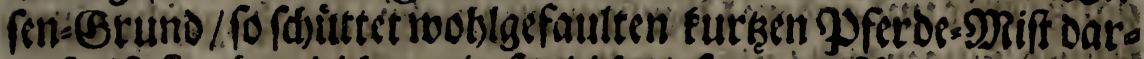
auf; iff fie aber leidet und fandidst / fo bermifdete curen fur-

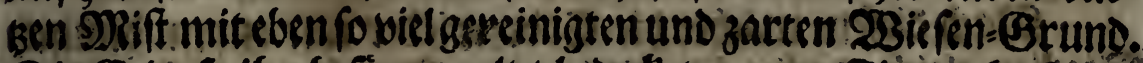

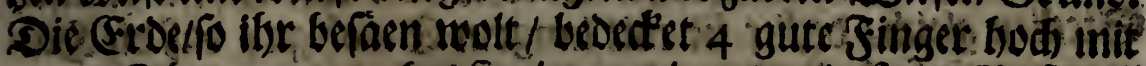

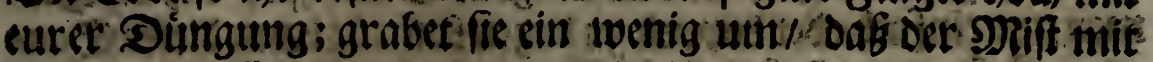

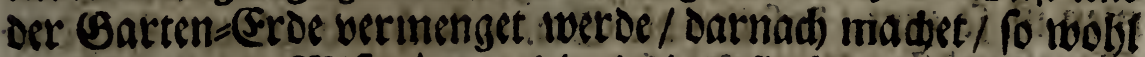

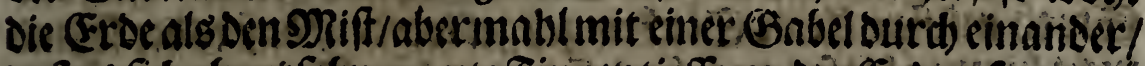

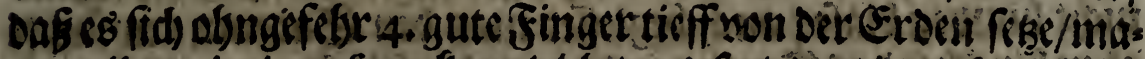

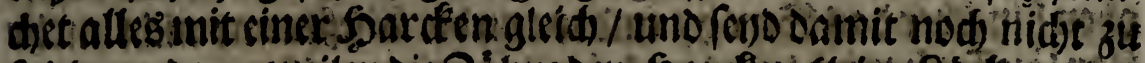

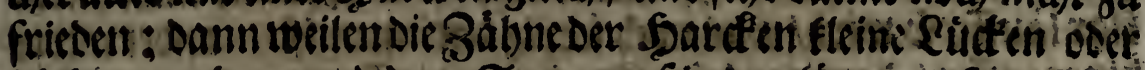

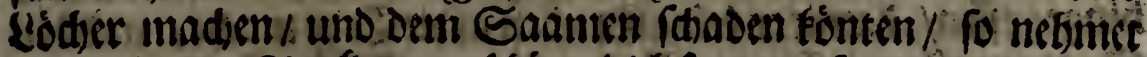

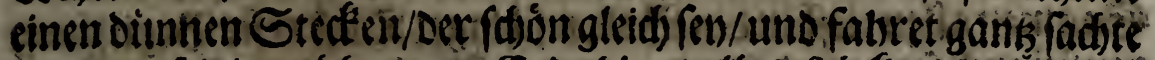

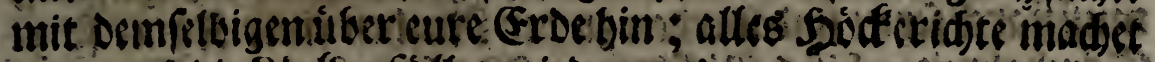

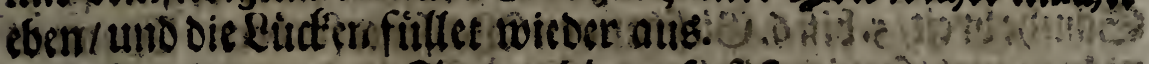

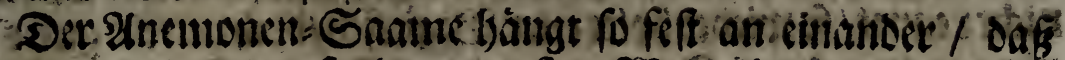

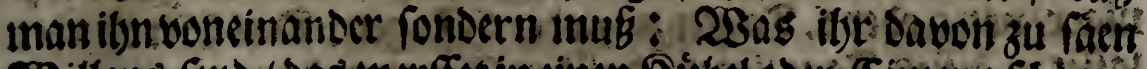

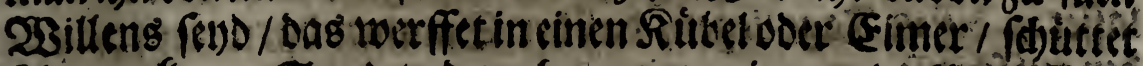

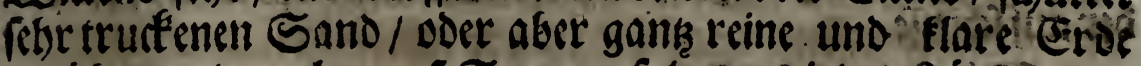

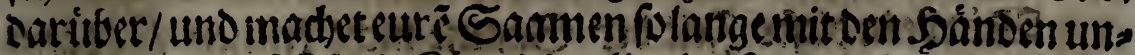

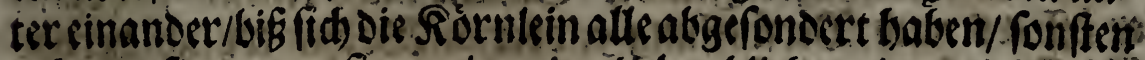

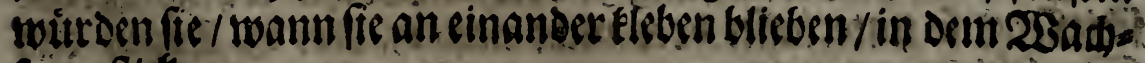
fen erftideten.

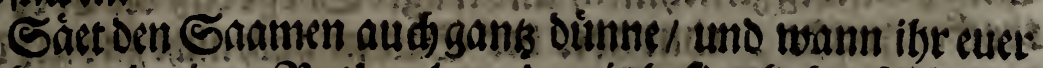

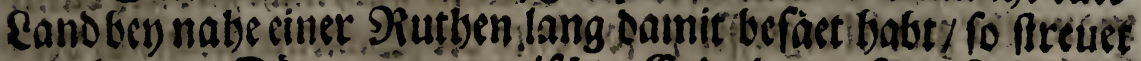

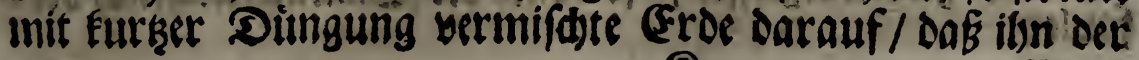
5.32 


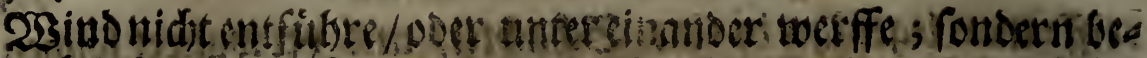

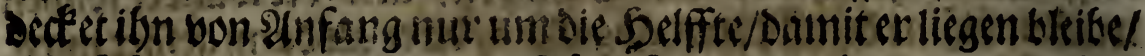
und fabret alsoban in dem Sáen fort/ Iwie ibr zubor Betban babst.

23ann oer Saamen alle ausgerfact und ball bedecéet iff!

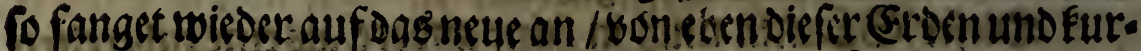

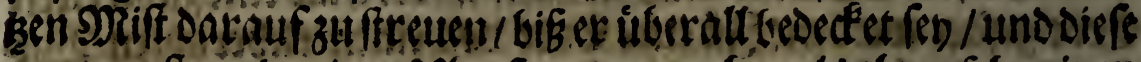

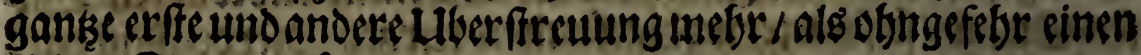
Elecinen Singer Difa'/ nid)t austrage.

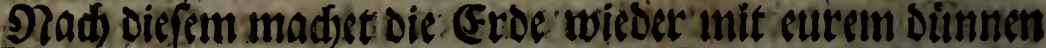

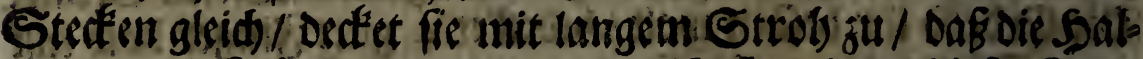
men nur cinfä oder bappelt zu liegen foment dann ofefer Saas

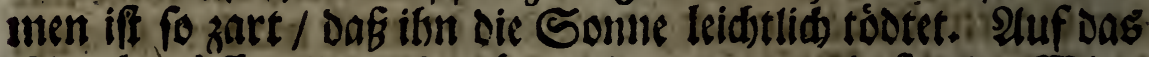
Stroh inuiffer Eleine Stecten gelegetwerden/ Daf es ber 23 ind

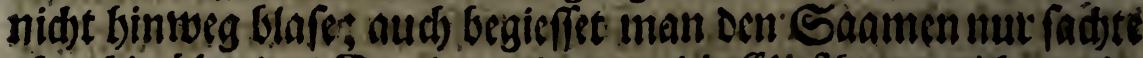

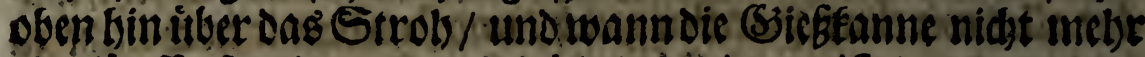

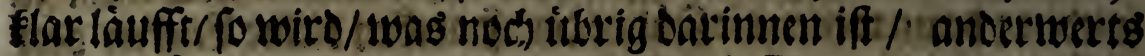
bingegoffen/ Damite é feine (B) ruben in die Erde mader und Den

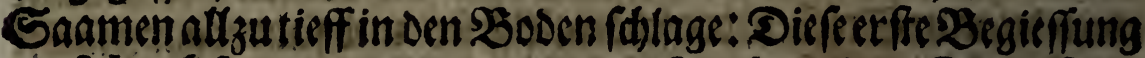

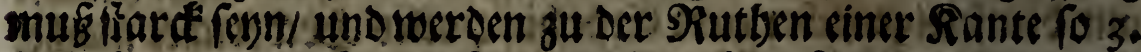

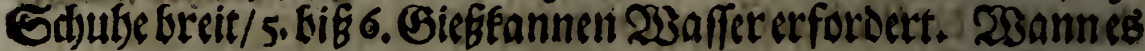
nidht regnet/ fo wwiedertlotetet euer \$2egieffen/Dod) um ein gutcs moso niger/yon 5. oder 6. Zagen zu 5.00er 6. Zagen: Das Stroly aber lafiet 15. bi: 18. Zage liegen/ DaG Der Saanen Darunter feime D. ber auffoieffe.

23 uirbe intiefer Beit ber Saame nidte Feimen / (bann er ifferes nad 2erfiliefrung 5. oder 6. 230den erflid bervor (fdieffet/) fo unterlaffet Dods nidte nadh is. Doer is. Tagen bag Strof binmeg a unetsmen/ uno traget Sorge daf die (Erde nidbe troffen werbe: : thut aber ber: Saderi auda nidit zu viel; Dann wann ibr zu biel begieffert 7 fo fonte ber Saamen leid)tlid wer= faulen. 


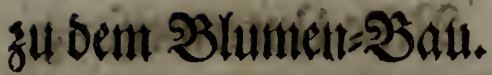

Die Saat foll indecm Augufte gefdectien $/$ und iwann alfes

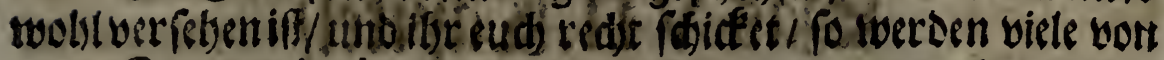

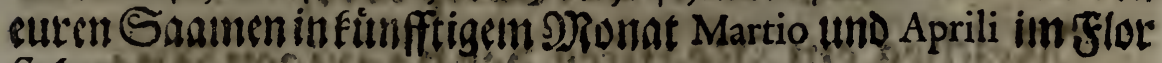
fitberti.

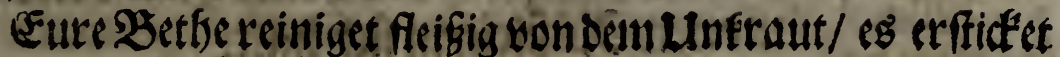
bie Saamen fonften elie fie faum lyervor fommen/ und ziebet fiet

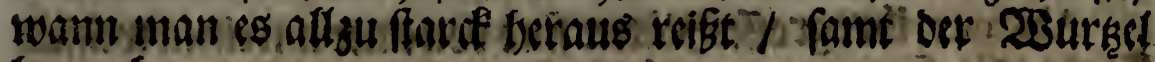
thernid.

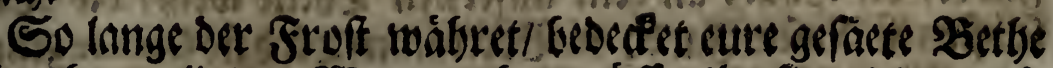
wobl; ber gelinden 23 etter aber miffet ilse fie wieder aufo Defér.

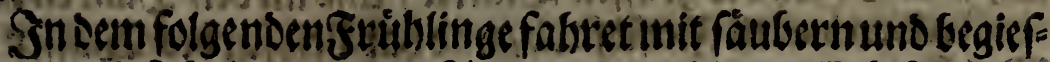
fen fort/ und fo balo an euren Saanem/ weldec zu (Erbifen ooer

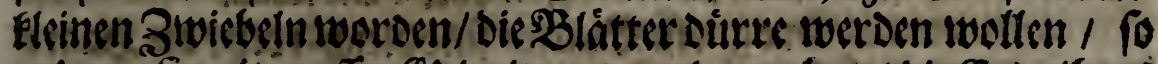
nebmet fie mit greffer (sisbult aus : ober nebmet Die Croe ibres

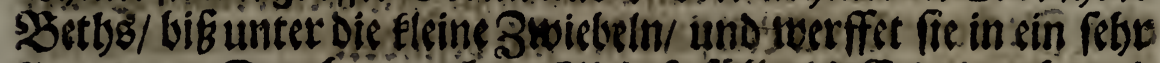

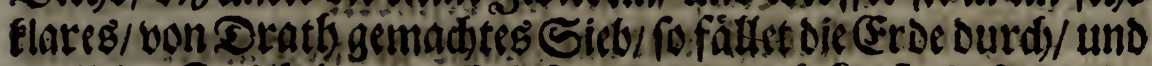

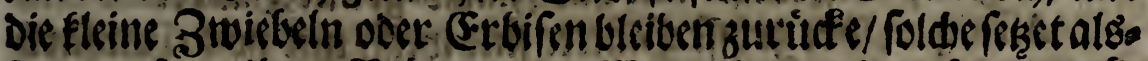

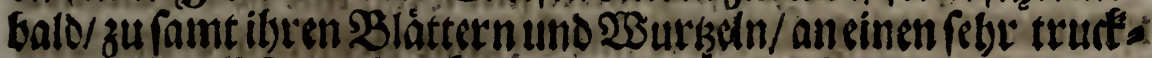

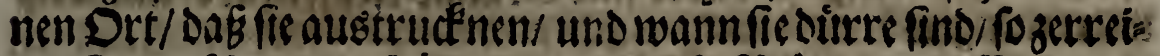

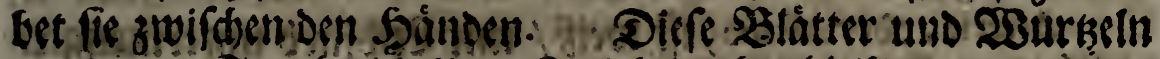
seerden zu Staube/ Die fleine ziviebeln aber bleiken.

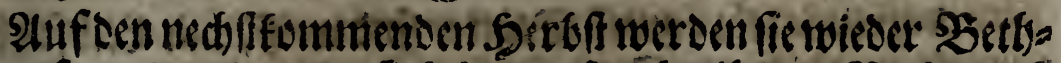

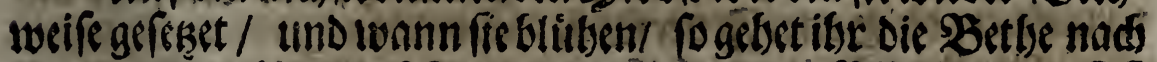

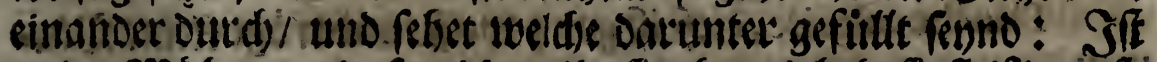

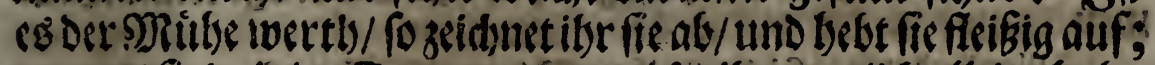

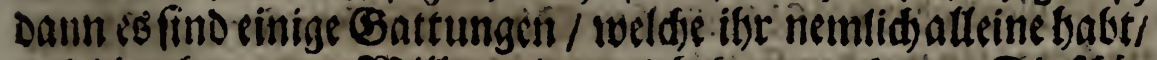

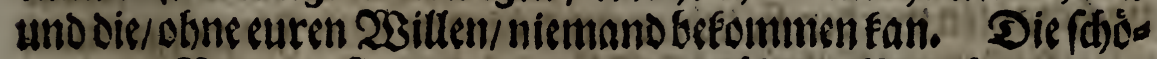

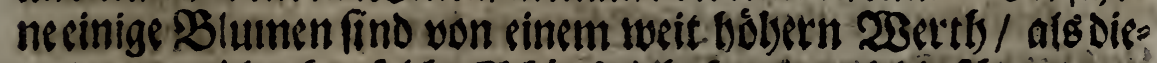

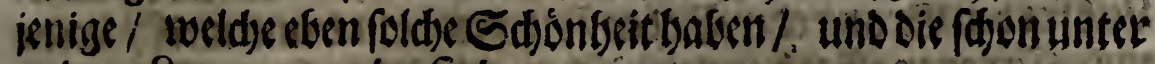
andernireuten gemeine find.

$$
\sqrt{2}
$$




\section{6 \\ Reuc Unterweifung.}

\section{2ab VII. Enpitel|}

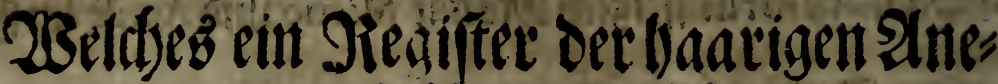

monen=?tóslein infich băft.

Abicante, ibregroffeßláttet find vonciner unreinen toeiffen

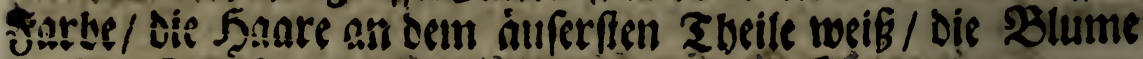
felbfen ift Siofen: Fare; in Stet tanien wirc fir Carnée genennt.

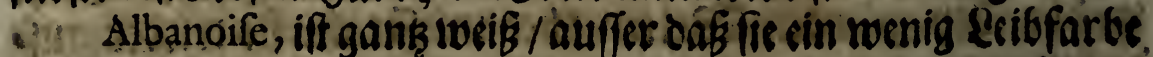
auf bem Boden der groffen $\mathfrak{B}$ látter / und an oen Saaren bat. 7 : Albertine, iff Sleiftifarb / und bat Reibfarbes 28 affer ooer 2280lden/einige nennen fie Parangon ober Paf́e fcalla.

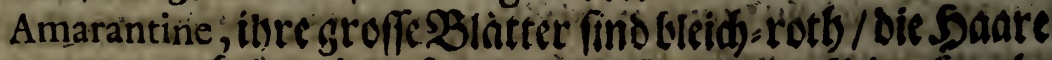

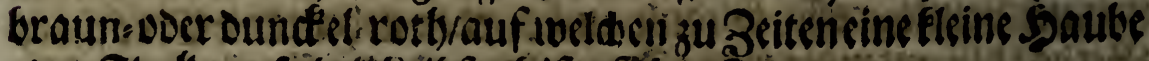

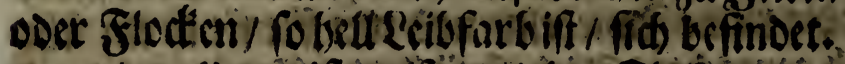

birn Angelique, if tweib / und bat Sladis graut Ssaare.

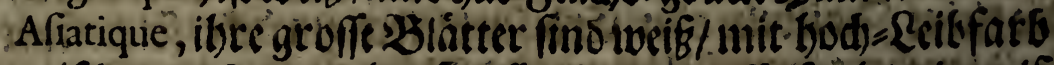

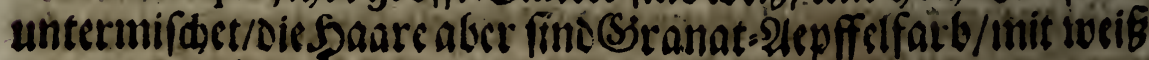
untermenget:

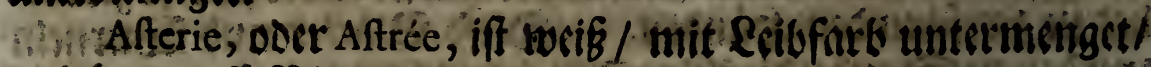
und hat groffesblumen.

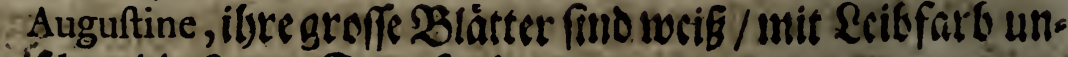
tetmifhet / die Saare Seurerfarts.

Blanche vulgaire, Diefe iff gank tocí / und trägt flcine $B$ lumen.

Bleuë ober quafi bleuë, ifsre Slumen zaithen forn auf blau/ nadmablen werden fie lidter / und binden nad) Flades gra:r.

Boulonnoife, ilbregroffe Blátcr fino weifí / uno baben cinen

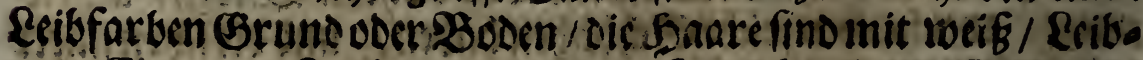

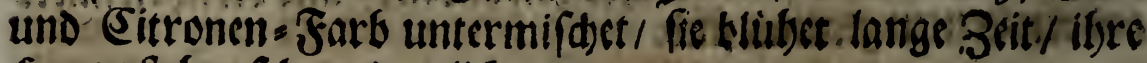
Saate freben febr eroentlid.

Briote, 


\section{zudem Slumen=:Bau.}

Briote, hat groffe tweiffe sblatter / mit bether Ecibfarbe un. termenger / Die Sutare find gank von Diefer Reibfartle.

La Bury, hat sine unreine iveiffe Sarbe/ mit Ecibfartce un.

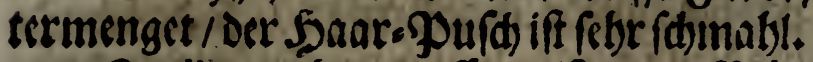

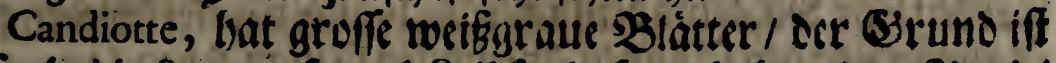
Eeibfarb/ Die Saare / ro aud Ecibfarbe fine / baben einen Piand/

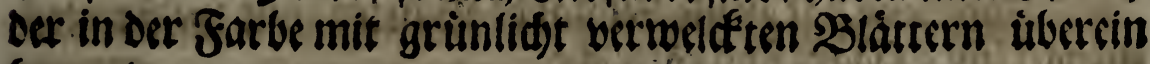
tommt.

Carnea groffa, iff gank Sleifdfarb / auf Ecibfarb zichenol

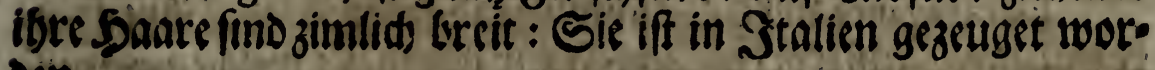
Den.

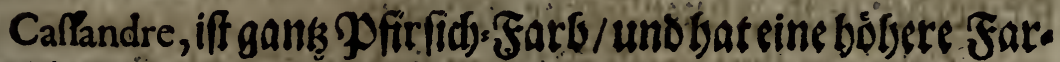
beale Die Perfiquine vuigaire.

Cazette doer Cazettane, bat grofferotbe 28 lätter/mit einewi Sdineffirgetben SRano/Die Saare find hodersetuer-rott.

Celeftine, bat grefferweiffe Blättcr / Die Saare fino 'weiB! mit Eitronenfurb untermenger / oie bod zulest gank weils werien.

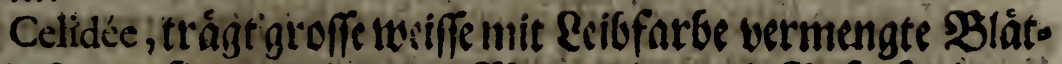

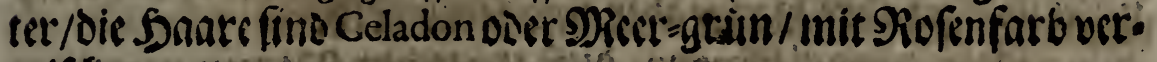
mifdist.

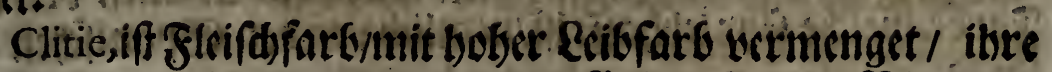

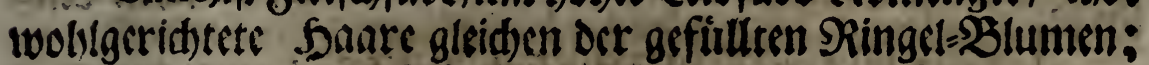

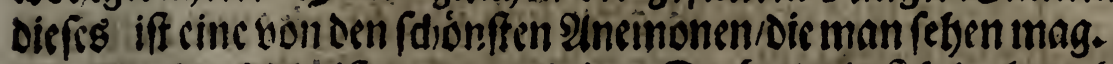

Colombine, if gants bon einer Farbe / Die fid Bed) mebr

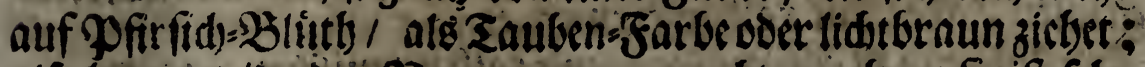

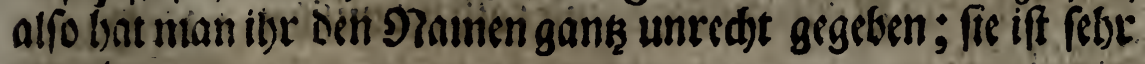
gentin.

Cord, Violetet,obsr Cinq-Couleurs, hat groffere rothe Blatter

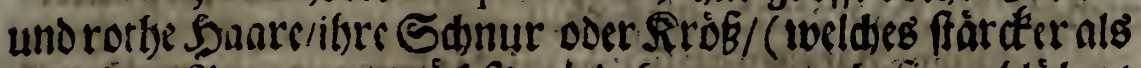

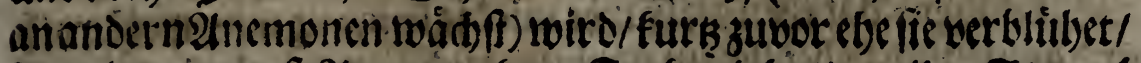
Ziol-srain auf 2amarantben= Sarbe ziebend; ibr Stenget 


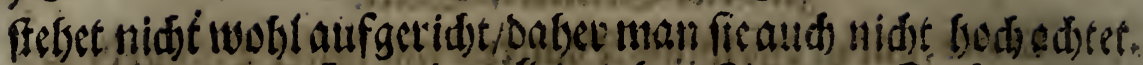

Cramoifie, if von Dumáel rotber Sammer-Sarbe $/$ ibit: Suareffebin in feltr gutet oronung.

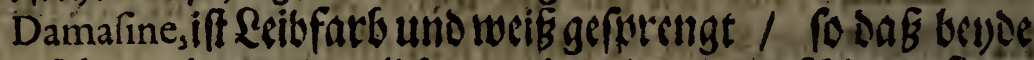

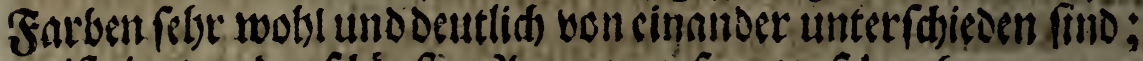

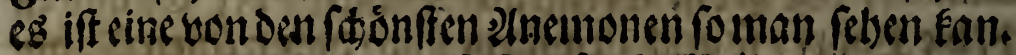

Dorimene, hat groffe Ecibfarbe SBlätter/mit weif unter menget/ ilire saare fino rótblid)t.

Exiftee, eincncue und febr (d)öne Perfiquine.

Extravagante, wird aub́d)weiffeno genennt/ weil itge Sand

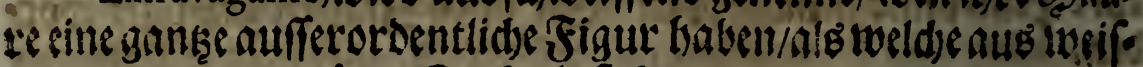
fer/rotber/und grimer Sarbe bifteben.

Gabrielle, ibte grofle Slátter fino tweib / die Saaregrim/. woik und leibfarto.

Galipoli de Touloufe, iff Feurt farb/mit Iwcí vermifaset.

Gayetane, ibre erffe Blumen fino tweib mit Purpur-botben

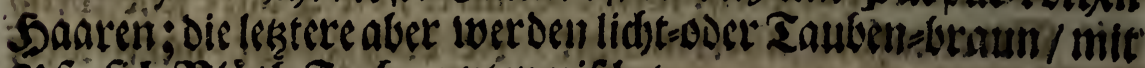

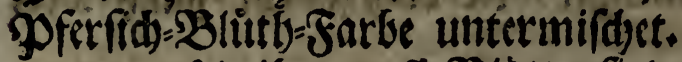

Herifsé, ibre groffe Blatter fino roth/ und zu weilen weiß untermenget/ibre Saare aber fino feuererotb.

Incarnadine d' Efpagne, Diefe trágt Den Namen bon ifect

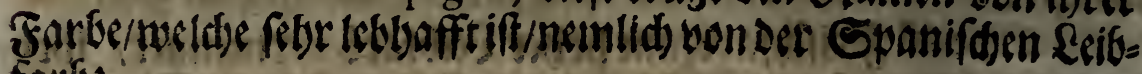
farbi.

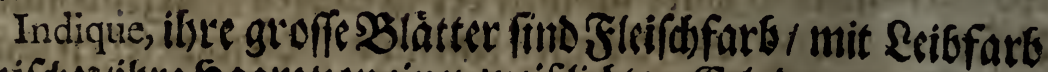

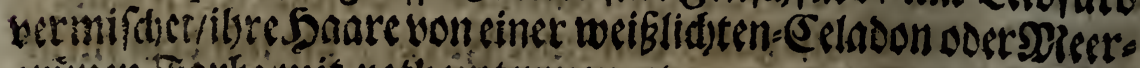
grintic Forbeinit roth unternienget.

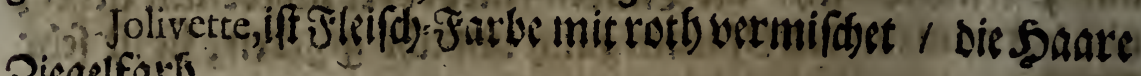
Birgelfatrs.

Juliane, iftre groffe Olätter fino weiß/ mit \&eibfarb unter menget/ Die Saarefino Ecibfark.

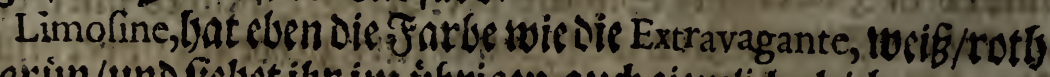
uno grin/uno ficket ibe in úbrigen aud zienslidg gleidb.

Lion- 


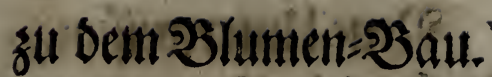

Lionnoife, bat tweif grimlidste greffe Blätter / atud eine.

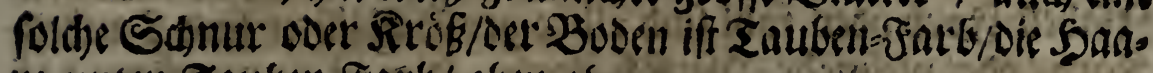
ic unten Tauben= Farb/ oben aber giau.

Mantuane, if sitronen F Farb/ und bat einen leibfarbes nen Poden.

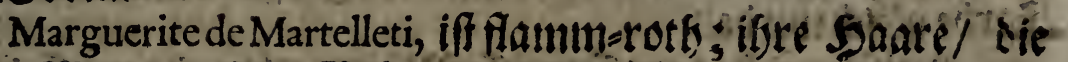

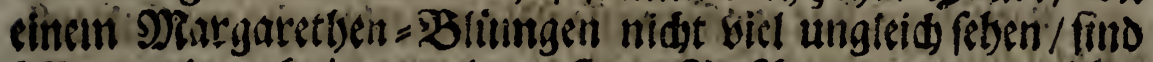

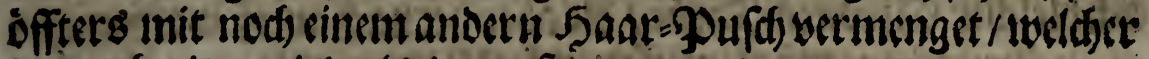
lestere freiter wird als Det erffe.

Melidore, ift gank fettet farb / braun und tweib. wis?

Merveille de Bretagne, iff ballo tweif / uno balb Earmefin: cotb.

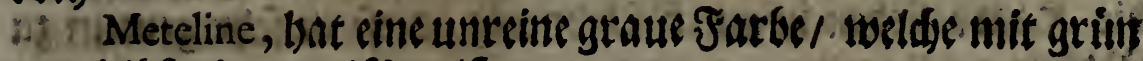
und lribfarb vermifdet iff.

- Milanbife, ift eine Perfiquine, weldfe fob groffe solumen Eningt.

Moresque, iff bon ciner melirten ober betmifdeten Reibfar

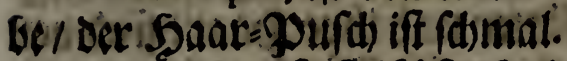

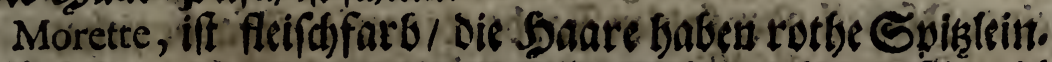

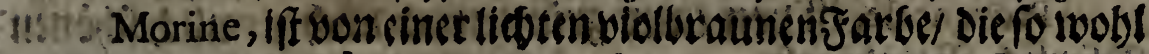
in Den groffen Bláttern / als aud inden Saaren oem ofyrpur uiabeformmt.

Nantoife, iff gank leibfarb/ Dlefe gelanget zuetner fáonen Solbe.

Natolie, iff weif mit fober Relbfarbe wetmenget / fo wobt an ben Blattern als aúd) an ben Saaren

Noiron, iffe groffe Slatter fino rotb / bie saare rotbuns

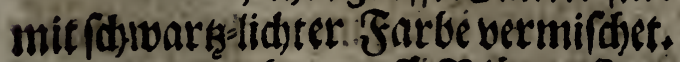

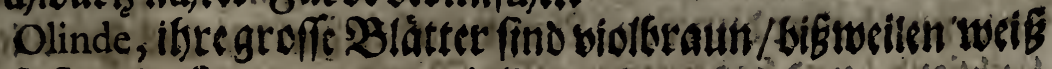
cingefaft / Die Saare gans, biolbraun.

Orientale, iff Ravenoel=grau / und Jiebet / fo woblin Den Sauten / als aud in ben grofen Slattern auf Sdifferfein Sarbe, Sietragtgroffe Slumen.

Panne 
Panñe Ifabelle, fie roiro alfo genennst / waiten iber Gaure

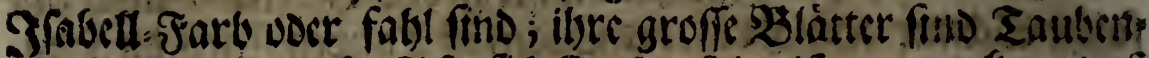

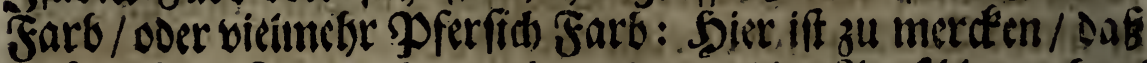
Diefe in ibren Saaren degeneriren oter auళ Der Ulet falagen fan/

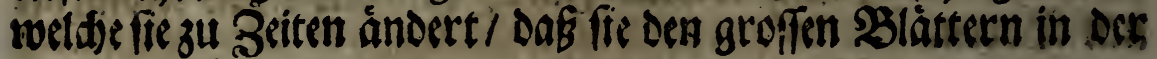
Farbe gletd) werden.

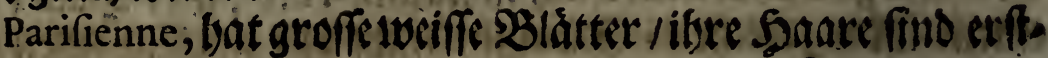
liableidser Sitronen-Farbe / Die aber bernad) weif werden:

Parmefane, trágt groffe weiffe Slätter / mit sinem rotben SBoden I die Gaare find zwifden Rofen=und, Reibfarb / und bleid)gilo.

Perciquine, oder Perfiquine, iff ganis Pferfich Bliuth=Sanly Die Saare Ifehen in guter Dronung; diefe ift felbrigenein zu Pario.

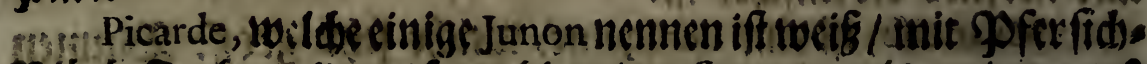

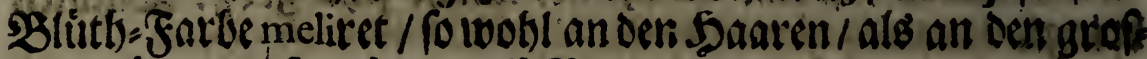
ferrblatteun fieträgt groffe $B$ lumen.

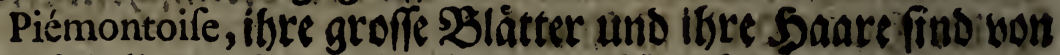
ciner \$fabedl=oder fablen Farbe/ Dieauf \&eibfarbe ziefet.

Provençale, iff bon einer grimen uno rods ziemlidj fajonen

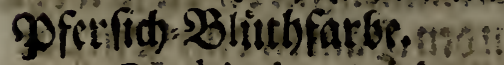

Quadricolor, twit ou Paris Amaranthe régale genennet; Sext Morinus battederen bier (Battungen.

Die srifte bat Die groffen Blátter rotb mit tweiß untere inengt/ sies Jare find beneiner sunde'endimacantbengarbe/auf oeren Sitte cin fleiner rotber Slede cober Saublein/ forotbs iff/ fitbet.

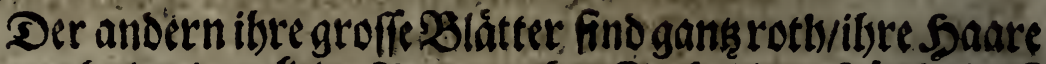
uraunroth poer oundeleter Amarantben Sarbe/ Das Sáublein if Ecibfarb / und bat cincnibeiffen Rand.

Die oritte/Belle-Francoife genannt/ bat ibregroffe Blátter

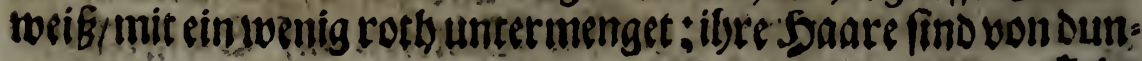




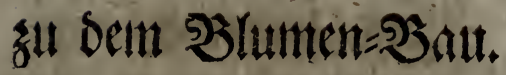

$8 \mathrm{x}$

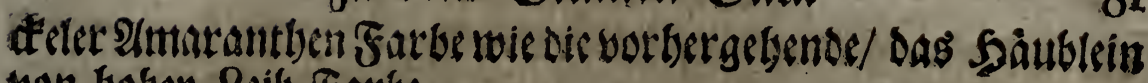
won bober Reib:Farbe.

Dievierote bat rotber mit tweiB,vertmifdete groffe Blätter/ sic Saare find Dunetésler semarantben=₹artbe / ausgenommen

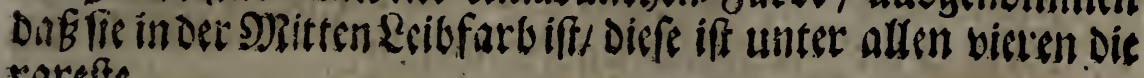
rareffe.

Régale, if rotily unit tweib untermenget/ infondocrbeit an den groffen sblattertr.

Renonculee, oie Farbe won biefer iff allein in Den Greiten

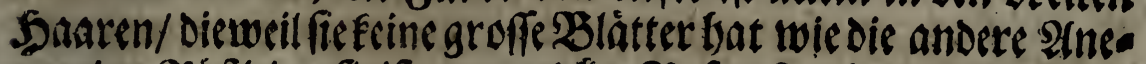

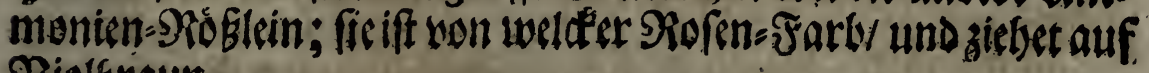
Biolbraun.

Rouge vulgaire, bieferiff ganth roth/ unt pertbr gemein.

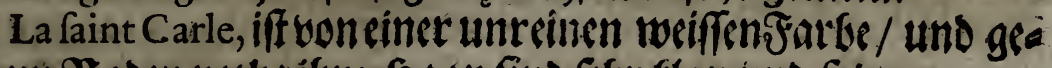

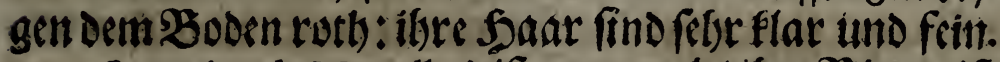

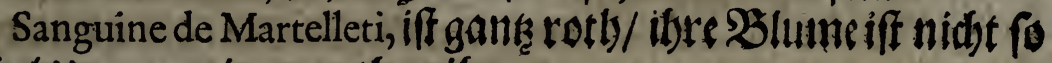
grofalsoer gemeinen rotben ibre.

Scalla, bat groffe unreine weciffe Bglátter / itters Saare fing Jetuerfarb.

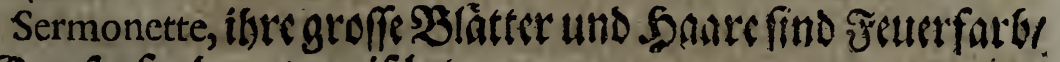
mit Gemfenfarb untermifdest.

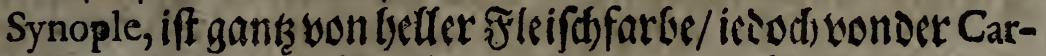

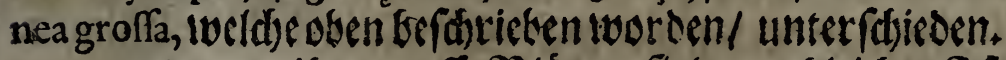

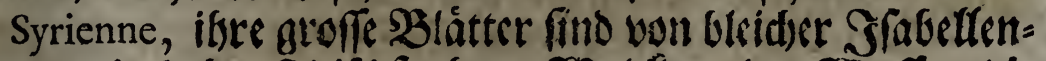

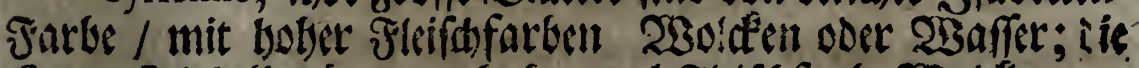

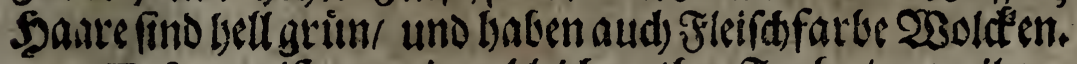

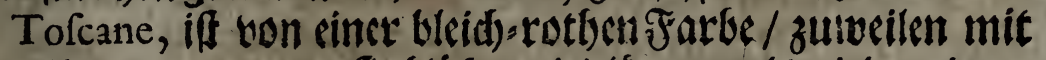
bleidggell unterinenget; fir blitber viel linger als viele andere.

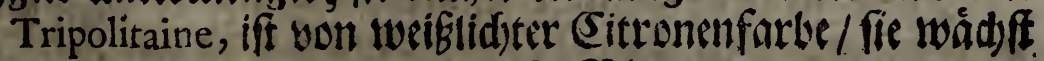
bod yon ber Eroem / und bat groffe $B$ blumen.

Turquoife, iff weiß / uno bat cinen \&eiffarsen $\mathfrak{B} 0$ oden / ro

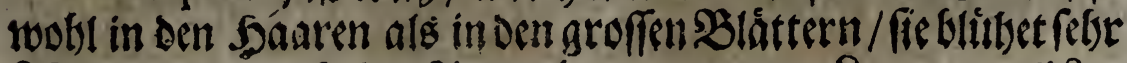
fpartbe/ uno bat loobe Srembst. 


\section{Teue Unterweifuns}

Victorieufe, ilste groffe $B$ lätter fino Fleifdfarb/mit Reibs farte untermenget; die 5aare fino bleidh=gel6 und Seitfarts.

Violette vulgaire, biefe iff in ibrer Blintbe gank 2 biolbraun/ nad)malen aber mirs fie bleids uno graulicht: Die Staliáner nen= nen fie Pavonaffo; die Sriederlánder aber / Cude Tahon, ober

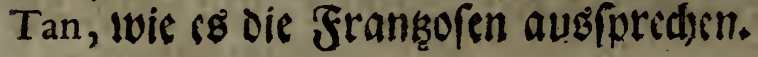

\section{3on dem Verbafco Conftantinopolitano oder Sonftantinopolitanifhen $2 B$ ulfferaut.}

Eonftanti= (Fo erbebet feinen Etengel olngefebr 2. Sabule bod/

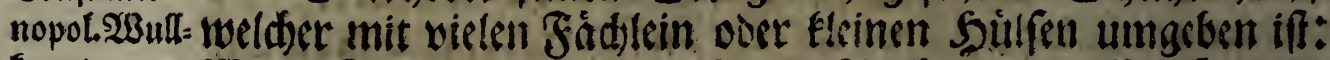
fraut. Wann fid diefe zeigen und berboridgoffen / iwerffen fie eine groffe Mienge fleiter Sinopife / sie/ twann fie aufgegangen/ sinen Blumen=\$Ball formiren / und dicfe Slumen / welde vole

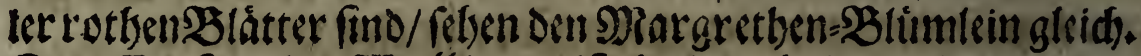
Das Conftantin. 2Bufleraut ift lod) zu balten / Dann cser. bâlt feine Blittbe/lang und wábrenden ganken Sommer durch.

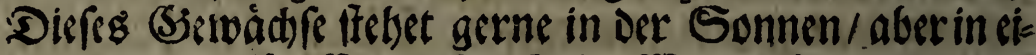

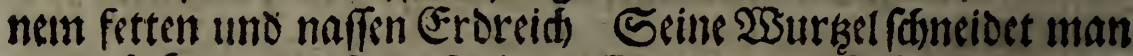

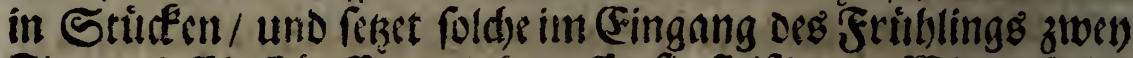
Finger tieff in $\mathcal{T}$ ppffe / und begeffet fie fleibig; im winter brin. get man fie an einen warmen Drt $/$ ' uns im Sommer/ wann fie blitbet / wiro fie in Sd)atten geffetht / Damit ibre SBlumen. Defto lánger tauren/ und fijoner werden.

\section{ASon Det Bellide Hifpanica, Spanifiden Margrethgen oder Maflieben.}

Gpani(the Die Spanirde Mrablieben baben einen erbabenen Sten.

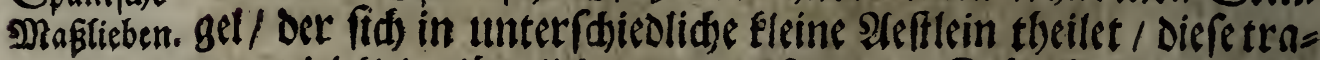
gen biel fleine lánglidste und gefiprengte finopfflein/ welde) waun fie fid geoffinet / fo vicl fleine Rugeln zu fenn fdeinen/ 


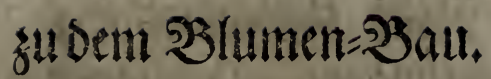

Die ferte angenelum z"l felsen find. Sie verlangen anders nid)ts als ftarte Sonne/ cin gutes Eroteid)/ und viel :asaffer.

\section{Zon den Campanulis luteis noet gelfent} Glocten $=$ Blumen.

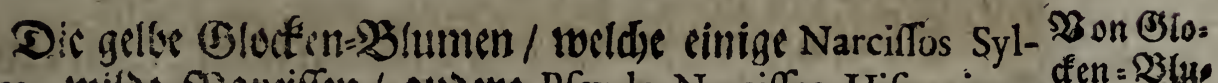
veftres, wiloe giarciffen / antiere Pfeudo-Narciffos Hifpanicos, $\mathfrak{d e n}_{\mathrm{men}}$.

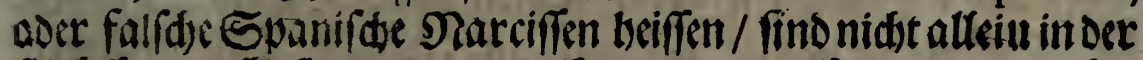
(siroffe und Sseftalt; Dannss gibet Deren groffe / Fleine / einfa= de / und gefuffte; fontern aud in Der Farbe von einander un. terfdieden: etlide find bellgelb / andere von einer angenebmen gewóleften oder getwafferter gelben Sarbe / einige aber fino weiblidt).

Die cinfade bat fed): Blâtter $/$ aus deren Mitte cin Reld berworfeciget / fo fafteines balben f̧ingers lang / uno gegen Dem Boden enge und rund ifit / gegen derm Spunde oder Eingang wird er nads uno nad) weiter / und ffellet sine Trompete odar Blodten vor.

Die fleine if won ber groffen nidft unterfajicoen/ als dab fie gar zแ flein/ im ùbrigen aber fónnunt fie gank uns gar mit iffr itbersin.

Die gelle gewàfferte / uno die weiflidte baten won Det vorbergelyenden/auffer der Farbe / nidts Wefonderg. Der griops = pilten ooer gefullten gelben Blodét = Blumen fino viererley (Gnttungen / nemlid ored) groffe / uno eine fleine/ bie greffen waiden alfo unterfajieden:

Die erfe fommt in Der Blume mit sim Narcifo rofeo-

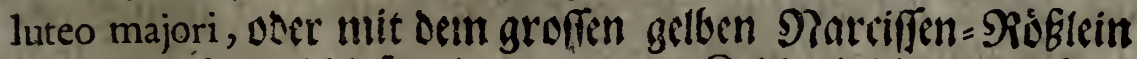
itberein / obwobbl diefes einen runtoern Reld als die andere bat.

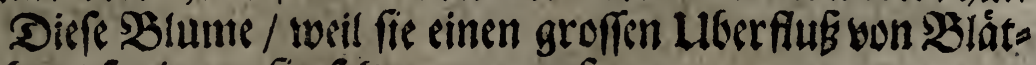
tern bat/ foringer fie fifis gerne auf.

$$
\mathbb{R} 2
$$




\section{$\$ 4$ Pecue Unterweifuitg

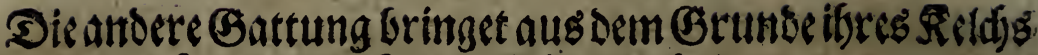 sin ziemnlid) Diféen Strauk von Blättern listuor. \\ Die oritte bat ztwengeder / einen in bem anderriffectens/ weeldese fie febre augenelyme madjt.

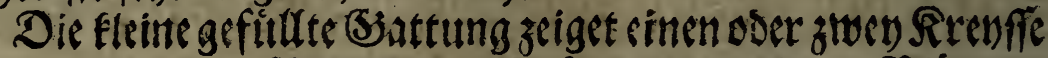 Bláater / in Deren Mitter cin SBedese / mit andern Slättern

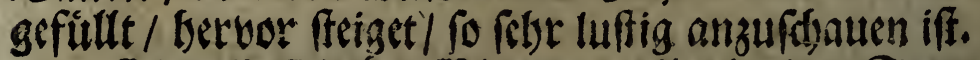 \\ Die gelbeGloctensblumen wo wen in einen Sormen reidisa

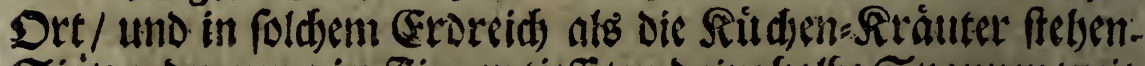 Eie werben nut vier Finger tieff / und cine Galbs Spamen weit

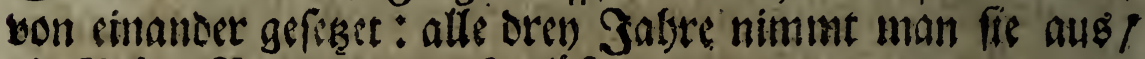 Die Neben=3 rut Davon agzulósen.

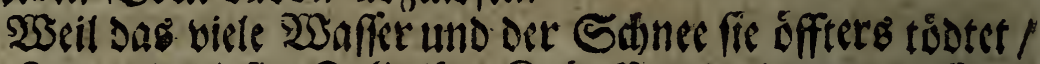

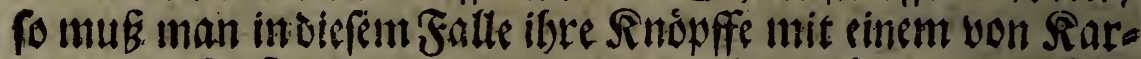

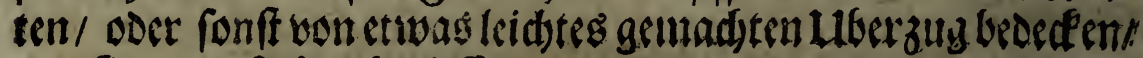 uno fie gang fach)te begieffien. \\ Bon dem Sameetstank / oder Det weiffet Rron=Narcifien.}

Sontel Şalp.

- Dir Rameel- Salf bat diefen Pamen/ Dietweil crindem er btiblet / Den Ropff gegen oer Srocn banget/ uno din Sale frum gebogen wie ein Sinmed tragt. Sonft toird or aud Narciffus capite feu calice oblongo, die ?larciffe poer Sornungse Blume mit Dein langen Relde/ ooer aud) Narciffus Coronarius,

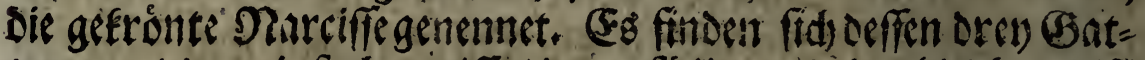
tungen / Der einfadbe toeiffe / Der gefillite und Der bleich = lacif fi.

Dir einfade weiffe twirfft fedb Blättex/ aub deren \$Ritte ein Bed)er berborgeket/ Ioelder oben berum mit sinem ros then Saun cingefabt iff.

Der bleids=tweiffe bat eine fleincre blunte / arcin er trägt

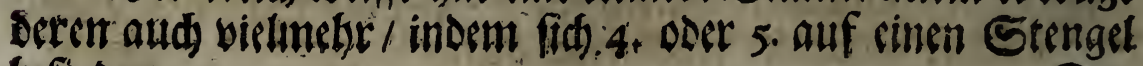
befindert.

Der 


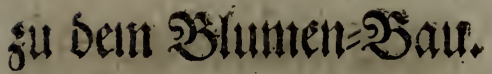

85

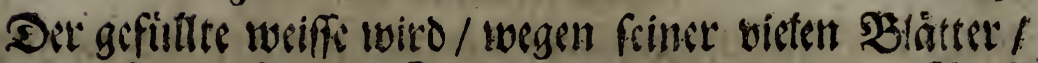

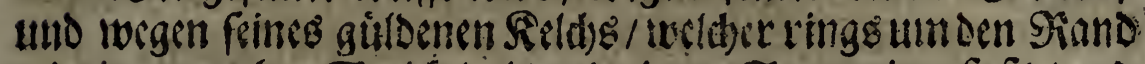

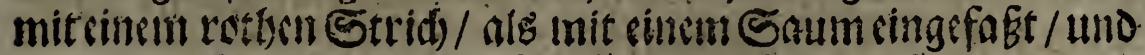

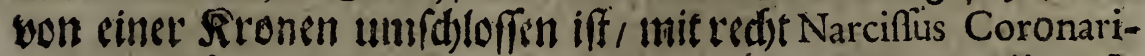

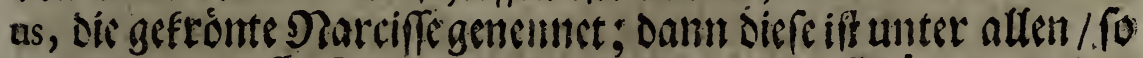

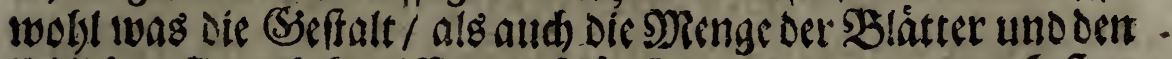
liebliidsen Gerud Getriffe / Die fajonfe / und die am wertbeffen geffalten wird.

Bicke Srankgofen nemnen fic Rofédenôtre Dame, ober unt Rer Eiefsen Graten Siofe.

Diefe Bitume will nawi alten secten Gattungen nidft viel Sonne baben/ pondern fretert getne in einem fetten und

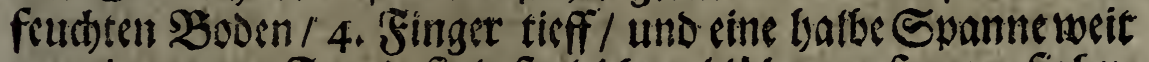
wen cinanocr. Daunit fie deffo lecideter blitbe / mus man fie bery Dem S:

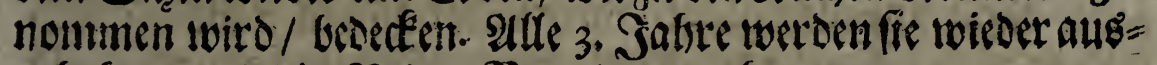
getboben / und oic פeven=3Brut Davon abgenoumen.

\section{Bon bem Rapuntio Americano oder Det Sardinals=:Blume.}

Diefe Pflanke wird fonff Trachelium Americanum, won Carbitrals

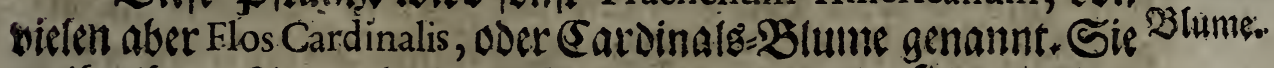

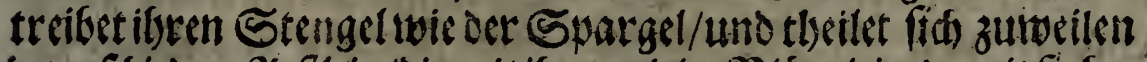

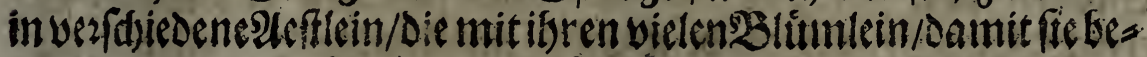

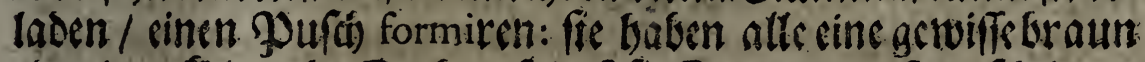

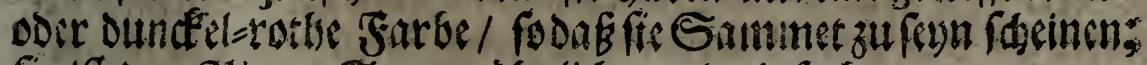

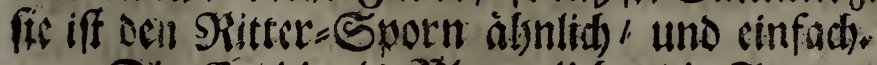

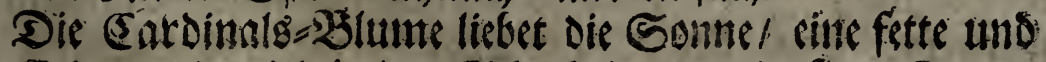

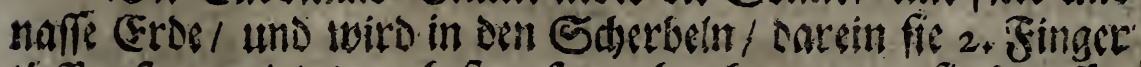
ticff gefereet wird / aul beffen fortgebradst: wann fie begufien

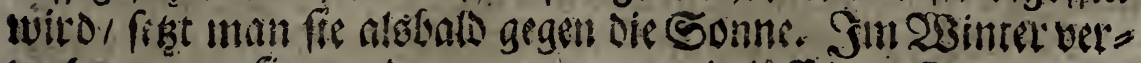
wablert inan fie an cinem wartent uno liuffigen Drte. Selue

$$
\varepsilon_{3}
$$




\section{.86 \\ Reue Unterweifung}

Salsce lwiro fie in Februario auggenommen / und die Nelvelle Srut daben abgefondert / welde man in andere Topffe feBset Daınit man fie fortwflanisen fonne.

\section{Bon oet Ráty jev Rrone.}

Sianner:

Srone.

Dieff Blume wirb aud Lys-Royal, oder Die Rónigg=-Rilie genennet. Döen auf ibrem Stengel trägt fe cinen flecinen 90 ufd

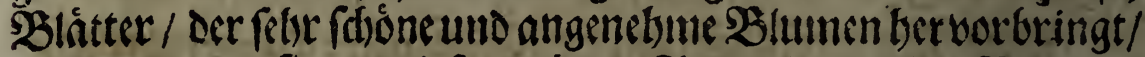
weldes / waun fie und diefen grünen Stengel unter den \$blättern berborfabieffen / unt nieder bängen/ cine sirone abbiloen/ Die die fál)ferlide genennet wire.

Diefe slumen / fo ben silien gleidf feten/ baben feinen zurutele getogenen SRand/ und firthenan ber Deffinung nid)t al=

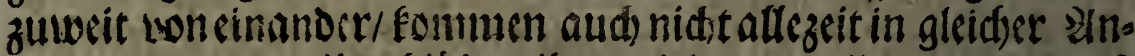
zal) / / Bann zuweilen blitisen ifber viele/ zumeilen wenig: auds find fre nid)t allezeit von gleider Farte; fondern bald gelb/balo

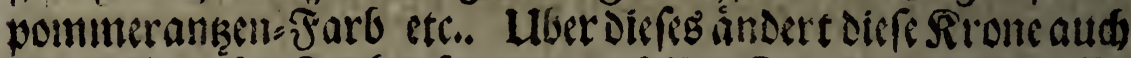
nidt alkein iber Jarbe; fondern aud) itbre Dronung uno Stille! in weldser fie um Denl Stchgel berumbänget; Dann min fits

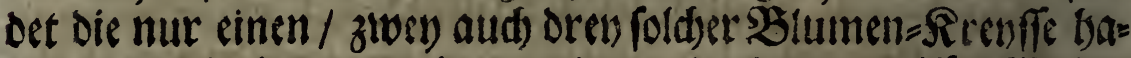
ben / und cin ieder you dem andern / in cincr getwiffen 23 sitel abfelbet. Mitten aus der Blumen fommen freben fleine yelbe Splitter ooer Bápfflein berfite / unter welden daz Mittelffe etwas lánger / and an Dent Enoe ein twenig differ iff als Die anbere. Suf Dem Grunde cincs leden Biats diefer Blume be= finder fid sine getwiffe wafferidte Fettdotigesit / Die wie sine its beraus weiffe Sperle formiret ift / unb bernad) allgemad cin

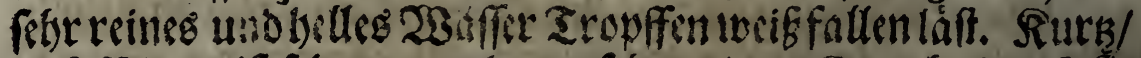

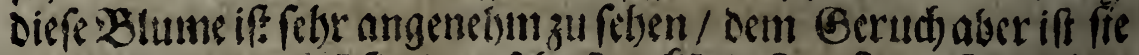

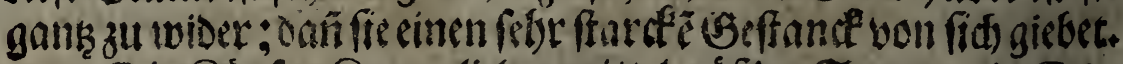

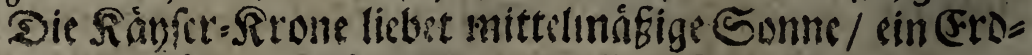

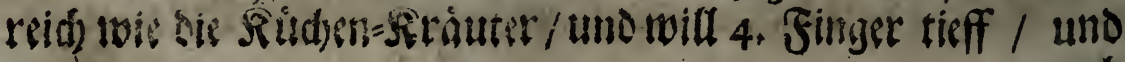




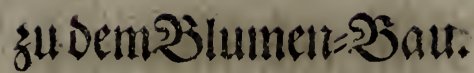

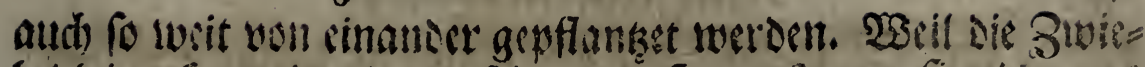

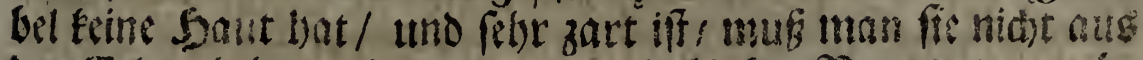

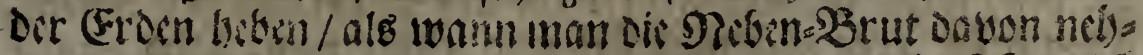

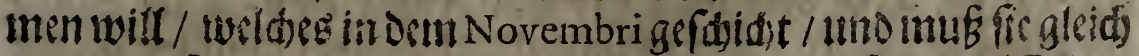

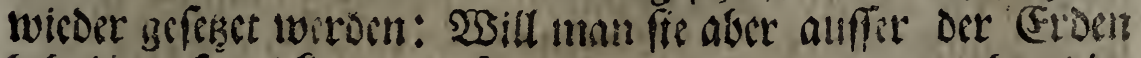

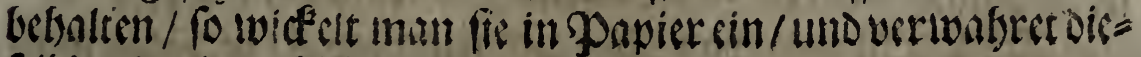
Retligige in ciner Edjudtel.

\section{3on orm Cyclamini, SaineintSbrobt ooer

$$
\text { END }=2 \text { Ip ffel. }
$$

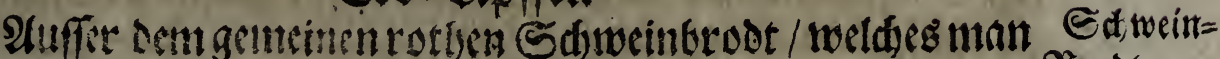
von fici) Peltefin in greffer Dienge auf Dem Felde wadfen fie $=$ Brodt.

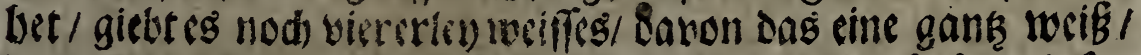
DaÉ andere oben therum roth if / bende sattungen baben cinfae de B Blu:nen: Das britte iff geffullt / uno bat felbr viel'Blátter:

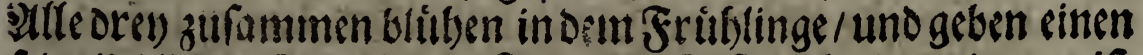
fets licbliden (Gerud) won fid). Sonft iff nod) sin ander wecife fess Sd)weinbrodt/Das in Dein Fritblinge blithet/und ob ces gleid)

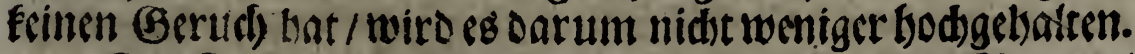

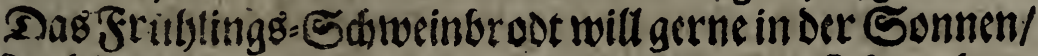

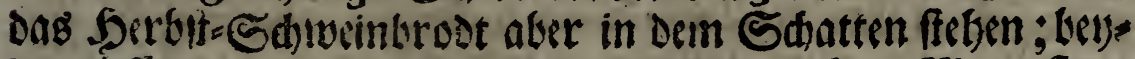

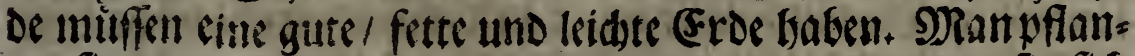

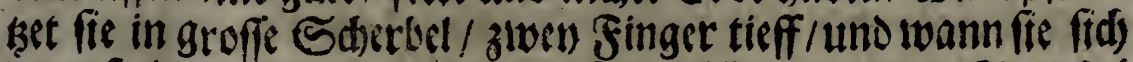

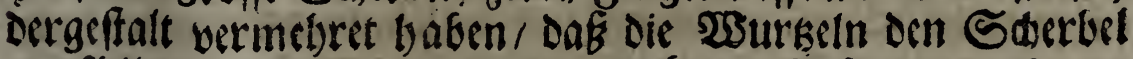

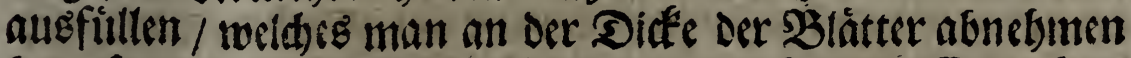

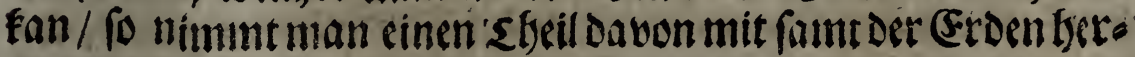
auk / undo verreseet es in andere Sdaerbel.

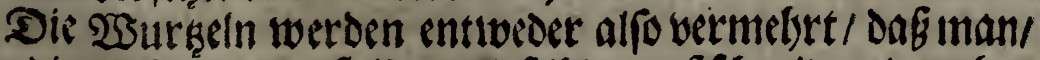

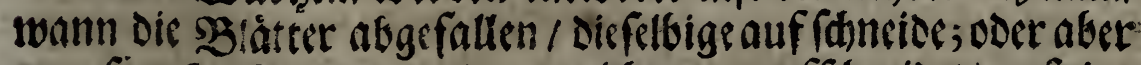

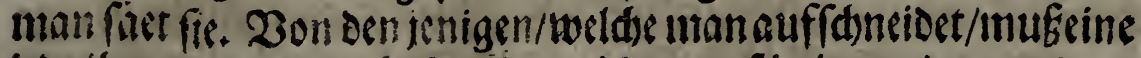

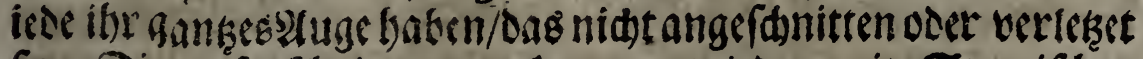

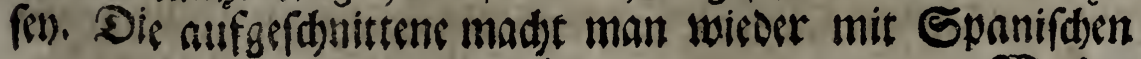
2sadje? 
88

\section{Neue Unteriveifung}

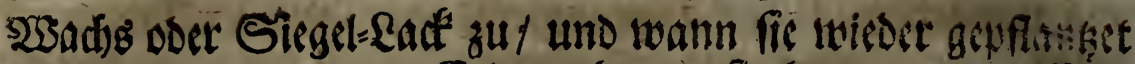
swerden / wito magere Erde nabe unn fie bertum serworfferi: alle itbrige Eroe aber mus fott und leídite fonn. Utmo samit

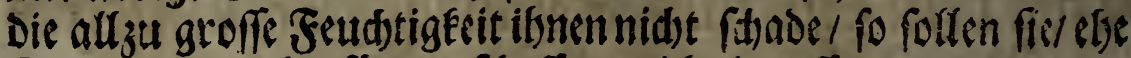

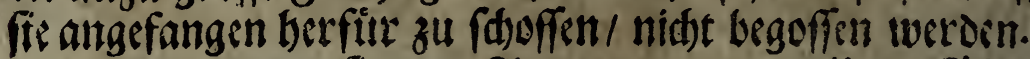

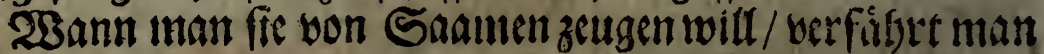

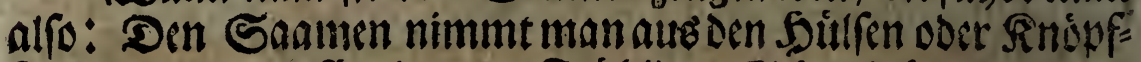
fen beraus / une fáet den ven Fritblings Sd)weinbrod in Deint Friilsinge / uno oen von berbff . Sdjycingrodt in Dem

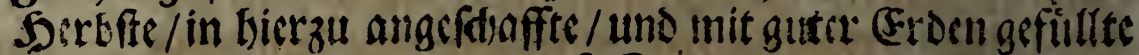
Tópfe; nadsmalen wertoen diefe Siamen an die : Sonneiges ffelft / und nor srenen Sabren nidjt aug̈getnommen.

\section{Bon Dem Dictamno noer sిtiptan.}

Diptan.

Diofcorides und Theophraftus getente en Deever befondern

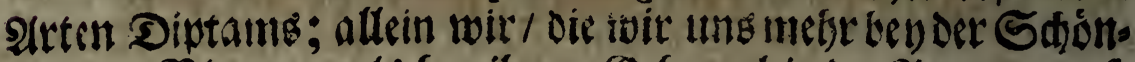

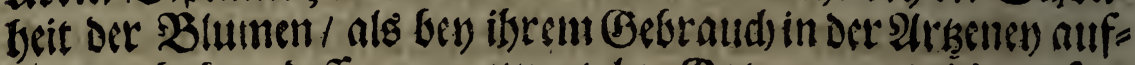
balten/ baben deffen mur zuenerley Batungen / Die unfere Gärten zieren / Memlich) Deri Dictamnum Creticum, oder (Stes tídsen Diptant / uno Dictamnum noftratem, oder unferen Sno

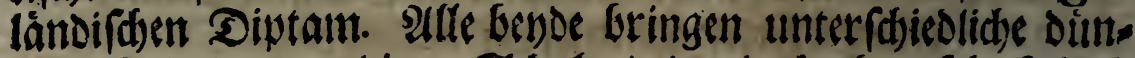
ne Aleftein lervor/ die 2. Sduble / ober dob obngefebr fo bods in sie Sob fe feigetl / aud ringo um mit $\mathfrak{B}$ lattern tumgeben fino/ Deren ie ztoed une ztwey in febr guter Dranung bey cinander ffe ben. Die alleroberfe 2leftein tragen auf ibrem (Bipffel Blus

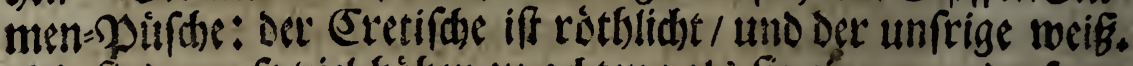
Eie fino um fo viel bober zu adten/ als fie cine mumberfame

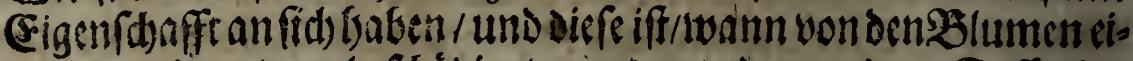

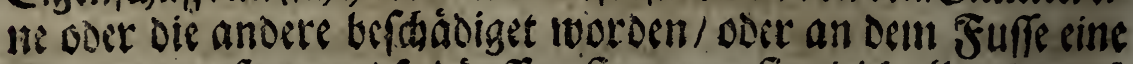
203mbe emplangen / fo dirffen fie wann fie gleidnallen Gertud

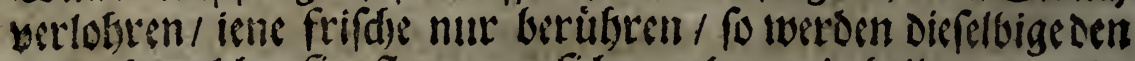

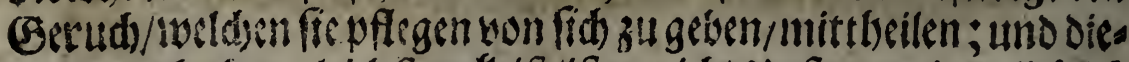

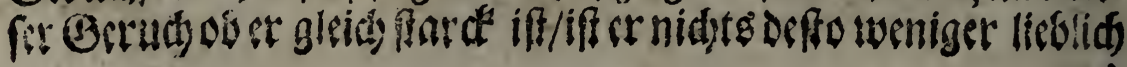




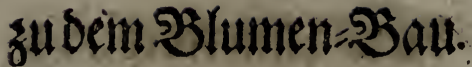

uns angenefume. Der Diptam will nur gemeine 23 artung haben.

\section{Bon bein Hormio, Sảarladi/ odergitter: Sreus.}

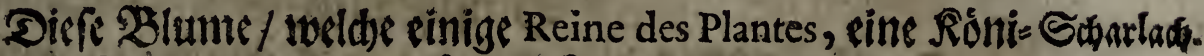
gin oer sp flatieset nennen/trägt auf dem Gipffel feines Sten=

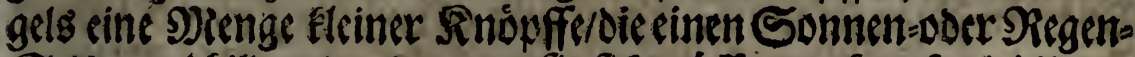
Sdirm abbilden / uno wann fie fid geoffnet / eben fo viel fleine

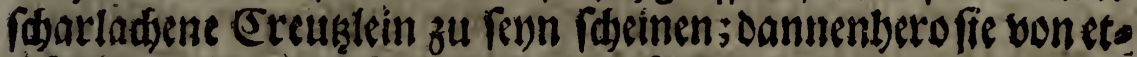
liden Den Namen SRitter-ereuke befommen.

Der Sdbarladi liebet cinen Sonnenreidten Drts cine (5t: be rwie die Rutden-Ricauter; man begieffet ibn fo offt als er es von notben bat.

\section{Bon oer Fritillaria, ober Fritilletie.}

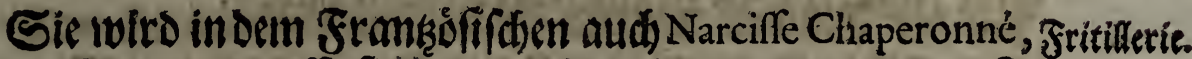
von dem Naunen derg Erfinders benabmet. Andere nennen fie Lys marbré, DRarmor-Rilie / andere aber Meleagride, welders fo viel beift / als eine Snoianifde ober Ealscutifd)e. Senne; Dann fie eben wie disfes feder=2leth gezeidnet iff.

Bon Der Spibe ibres Stengels bängen zlwei) wie (Blos dén geffalte $\mathfrak{B l u m e n}$ berunter / cie bieredeidite Slecten oder

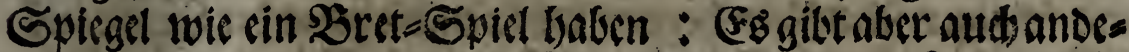
re / die nut won ciner Farte frino / biefe baben toeiflidte SRiba ben/ auf welden fids eine getwiffe grime Sinie ober fdmales Striflein bis in Die Mitte Des SBlats ziebet / inwendig in Der Solumen foumuten fleine Fáferd)en/ Jwifden ped) Eleinen gets ben pitslein berbor/ die nidte anders fetsen I als of fie mit Staub beftreutet wàren.

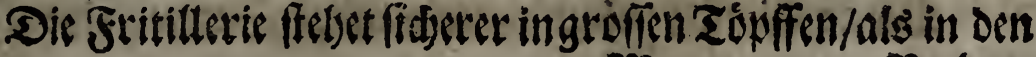
$\mathfrak{R}$ Betben; 
90

Teue Unteribaifung.

Bethert; fe begethrt nid)t vidl Sonne / aber cin gutes fettes unto befeudteteg (Erbreid) / wirdoren Singer tieff gefegt / und in dem Nonat Septembri ausgenounumin.

\section{Son oem Digitali, Sesingetfut noer Sondofhuti).}

Singerf̧ut.

Der Sandofjud ocer Fingerfut iff eine stlume bie von Samen gezeuget wiro; oeren gibt es von orencrley farken. Dann man'fielet weiffe / rotbe und Eeibfarbe. Dic sblatter: Diefer Blume fino Dem Burretfab voer Ddfenzungen gleids/ auffer dab fie griffer uno nidt to raud find. Der Stengelt

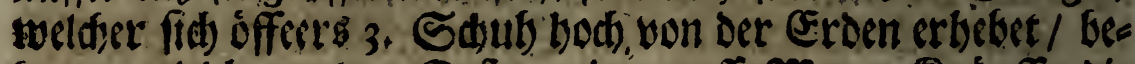

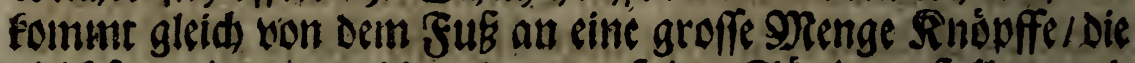
gleiḑfam eine Pyramide, ober zugerpiste Sáule vorffellen / uno wann bic Bltumen fid aufthun / fo fobeinet es/ ob waten cs lauter Fingerbitte oser Sanofdud: baber fie / in enfebung tbrer Figur/biefen Naimen befommen baben.

\section{Son der GeniftaAlba, oder fweiffen \\ Ginfter.}

SWeiffer Ginfter.

Diefer Genft oder Binfer waddff fo fdjon uno lsod) / Daß Inan ifon unter dic Báume zeblen módte : Fr befountent viele Rutlen oder Aeffe/ aus welden sine Menge fubtiler / fleiner

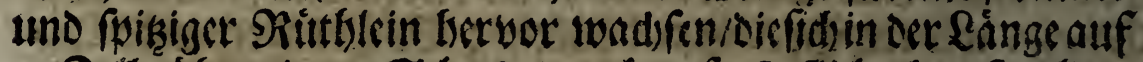
2. Bolle ilver einen Sdjud / audh auf $1_{2}^{\frac{1}{2}}$ Sdoud crftreden: und diefe Siuttblein tragen fleine SBlatter wic die SRaute / uno felse vicle SBlumen / welde auf oem Boden rotb / in interigen

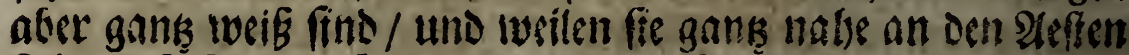

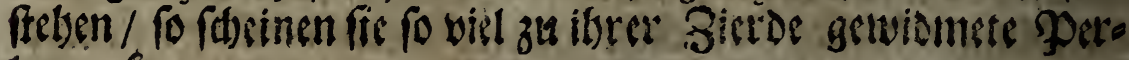
leir zu ferun.

Diefer (Sinfter lieter mittefmàbige Sonne/ eine Erse wic 


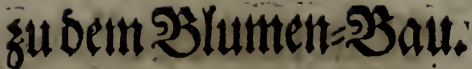

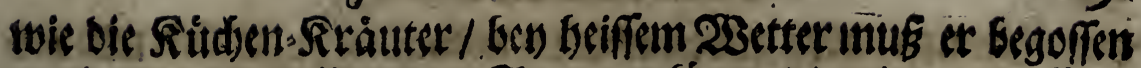
werben / uno weil er won Saamen fómmt / wiro or gefaet: Das Saduttein itber bem Saamen if bart / foldces aber weich unib zart zu maden verfábret man nadj benen Risgetn/weeldee

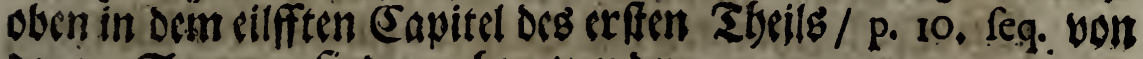
Denen Stamen find gegesen worden.

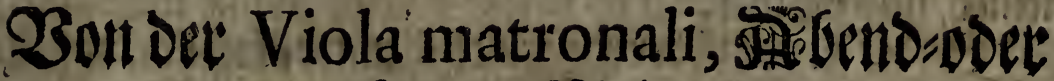 Putter= Biole.}

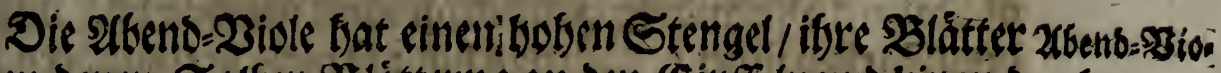
gleiden denen Salben-sBlâttern; an ben Ginffelm und bin und is.

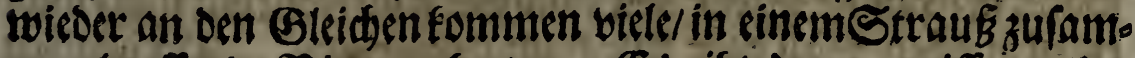
men lauffende sBlumen berbor. Es gibt deren weiffer rother toic atud von anderen Farben.

\section{Bon $\$$ ivacintbert.}

Die Sivacintben fins/twegen ibrer mandberlet) Battunt Syacintfe: gin / glesidfaun fo viel Protei in Denen Gárten / Die mit Denen

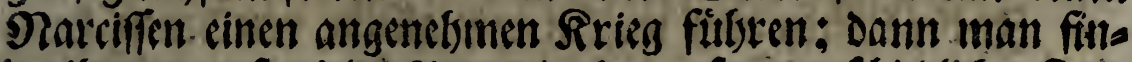

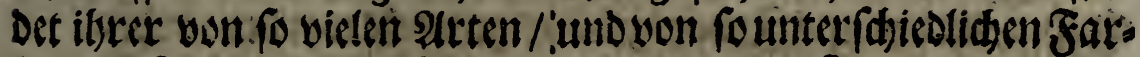
ben/ sąs man fids Daribber verwundern mus.

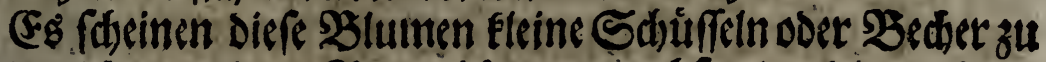

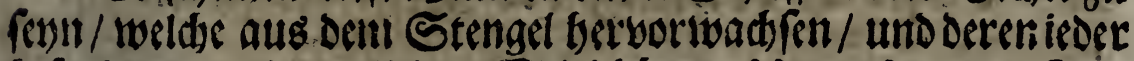

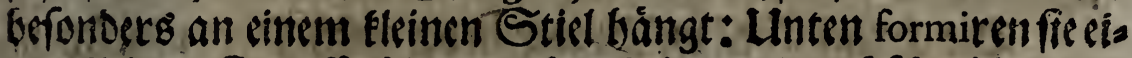

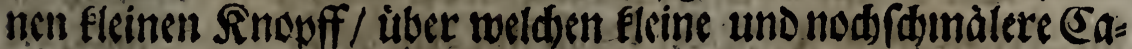

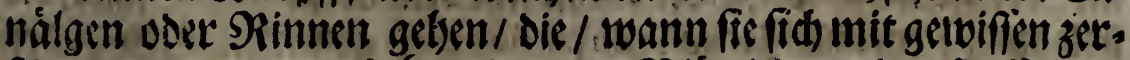
f(t)nittenen uno zuriutée gebogeneri Blâttlein an oer Deffinumg ausbresiten oder von sinander thun/ Die Figur fo viel fleiner \& $i_{=}$ lien darffetten. Sie blittsen meiffenttbeils rings um den Stens get berum / Dod sffnet fid sin Zbeil mebrals oer andere.

Ein Syacintb trägt wenig/ cin anderes sinen ulberfus R 2. 
92 Reue Unterweifung

yon sfiumen/ serobalfen er aud Polianthos, ober ber mit viclen Blumen genennet wirs. Finer bat einen geneinen/ein ant= Derer aber einen grofferen Bedjer / unto diefer wirt Hyacinthus Orientalis, ober Morgenlándifder Syacintt) genennet.

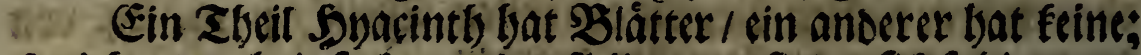

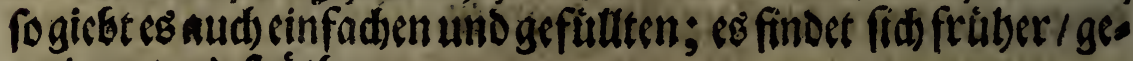
meiner / und pátber.

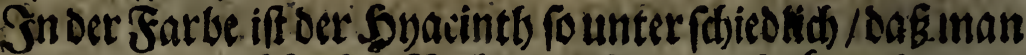
meiffenmit einemleibfarben Beder/rotten/gewobléten/staucn/ afdfarben/SRofmarin-Sarben/grumen uno von nod) metbr ans

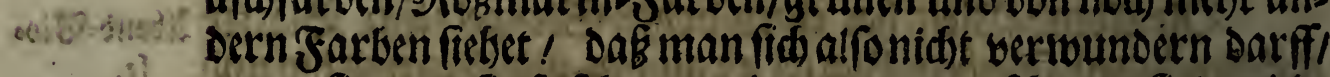

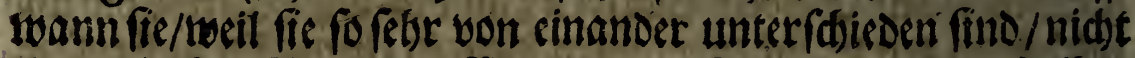
cinen gleidien Sau oder 23 artung erfordern. Derohalten wollen wir fie/ bie Sadbedeffoleidter zu maden/ in brev Dro= nungen abtbeilen.

Snder erffen Oronumg roften diejenige/ weldte eine allge meine 23 artung erfordern/feten.

ben wollen.

Snderandern/ die/ weldecine Gefontere $23 a r t u n g$ bas Snder oritten aber wollen wir alfeine von denen Syge cintben/welde aus Sndien zu uns gebrad)t worden / reden.

\section{Srfte Dronung oer \$oyacintlen.}

Erfte Drb=

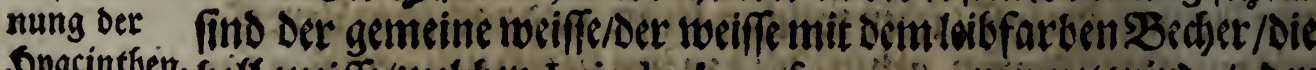

Die Snacinttse / welde wir in bererfen Dronung fegent befl-sweiffe/melder Jacinthe du parfumeur, genennet wito / oer blaut/fo auf Slobimarin Farbe ziebet/Der oundeleblaut/ /welder

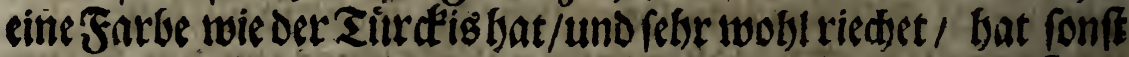
Den Vamen Jacinthe de Bizance oder de Conftantinople, Eonffane tinopolitanifaer syacint5.

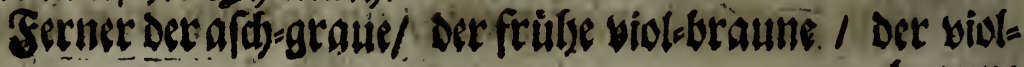




\section{รุ ธem}

93

Graume mit fraufen $B$ lattern / le richecramoifi, ser reide Cars mefin-Farbegenannt / Der martletiette biob-braune/und der gesfüldte Bleumourant boer Gleideblaute / mit vielen fleinen Blatt= tern.

Atteb bier obenbenannte Syacintben twothen in Ber Sonne

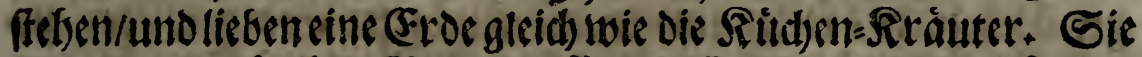
werden einen falben Sö)ud tieffi in die (Erden / und eben fo weit

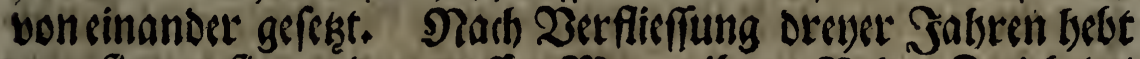
manfienus/fiec vonder groffen Nenge ibrer Neben 3wibbeln/. weldes fiid) big Dabinuertmebret//ubefreven.

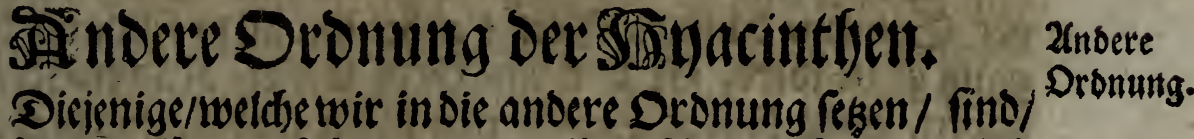

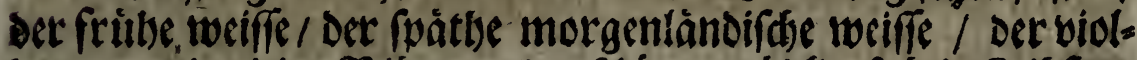

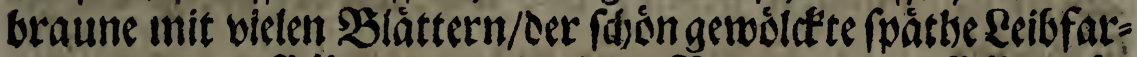

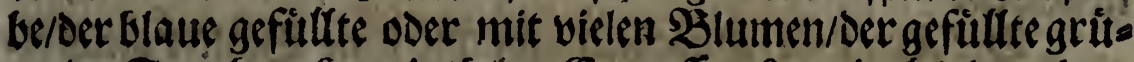

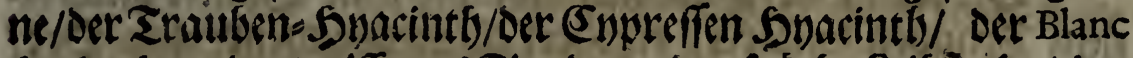

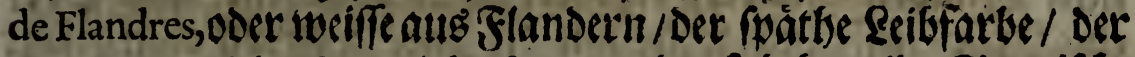
Turquois, und der Tanné d' Epagne, oder fpàtbe gellbe Spanifdec Syacintly.

Der fritbe weiffe Syyacinth frebet gerne in Der Sonmen/ und in ciner Eroe twie Die Siuden - Srauter baten : wird vier Singer tieff und einer Spannen weit in den Bocen gefest : Luno

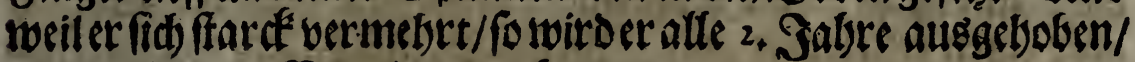
und Die Deben=2Brut savon abgenommen.

Der (pätbe Orientalif(f) mill autd einen Sonnenreiden ort/und eine (Erde gleid) Dem borigen baben; er wird einen Gal: - ben Sdutud tieff und ecken fo weit von einander gefergt. Diefer

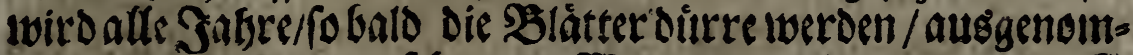

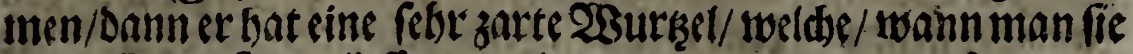

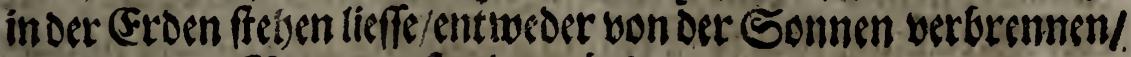
ader bon dem Piegenverfaulen muirde. 


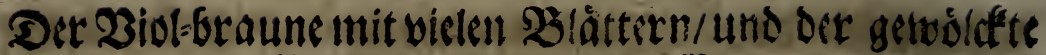
fpatthe Eeibfartue wollen die vortergetsinde 23artung baten.

Dir blaue gefitlte liebet die Sonne / sine neue magere Eroe / will einen balben Satuch tieff / uno chen fo weit bon cinander gepfanket frun. Die Stwiebeln werden mit zwey Fin. ger hod guter / fetter uno woblesfeuditeter (Erden woicder zue geoct't / Dainit Die magere / weldse unten liegt / Diefrnulung ver= bindere / uno bie gute feete/ twelde oben if / ibnen sine gemáffigte Nabrung mittbeile. Nan inus fie nur alte ores) Sabre ausbeben / die Vieben=Zwicbeln davon abzunefimen.

Der gefiutle grime, ffebet lieber in Dem Sthatten als in oer Sonnen/ Dann bie Sonne zieber isn allzu febr aub/ Daber gantz grau wirb. Er will cince (Froe wie die Rúdena Rráuter baben / einen balken Sdudd) tieff in oer Eroen/ und in efen ber 23eite yon sinander ffeten / und wiro wie der vorige ausze: nominen.

Der Trauben = Soyacintb / Iveld)er feine Blätter gleid) eis nein Trauben formiret / erfodert sinen Sonnenteiden Drt/ eine Eres / tisffe und tweite twie bie andere/Davon oben gefage morden.

Der Enpreffen Syacinth / welder deen Baume diefes Namtens gleid) fretet / ivito aud) Iacinthe de Sienne genannt /

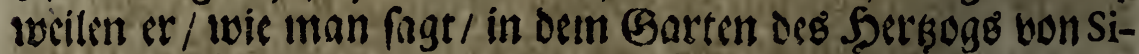
enne zu etft gezeuget warden. Diefer will nidst biel Sonnel nber cinen feffen oder guten23icfen=-Grund baben/ wiro 4. Fintger tieff/ uno cine Spanne woit won cinaneer geferset. Man

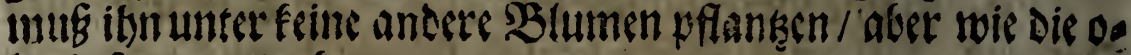
binberagte ausnetgmen.

Der Blane de Flandres, oer Turquois uno Reibfarbe lieben niast viel Sonne / wollen 3. Finger tieff tune 4. Finger weit non

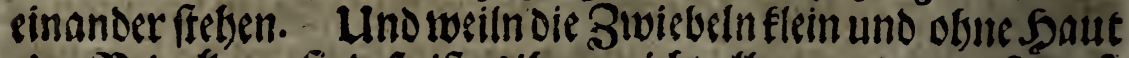
oder sBedectung find/fo iff esilgnen nidst allzugut/watn fie aufo 


\section{zu bem $B l u m e n=$ Bau.}

fer ber Ercen fommen/sarum unuË man fie nidft beraus beben; fondern nur Dic Viebens:28rut davon abnetbmen.

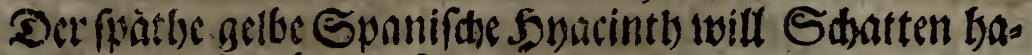

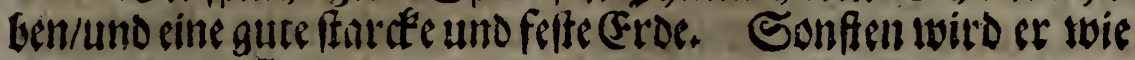
Die andere gepflankşt uno ausgenommen.

\section{Bon Denen Sndianiajen Syacintjen.}

Es giebt z weterley Syacintb/weldier aus Sndien in diefes Jndiani

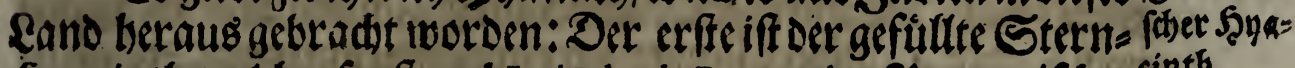

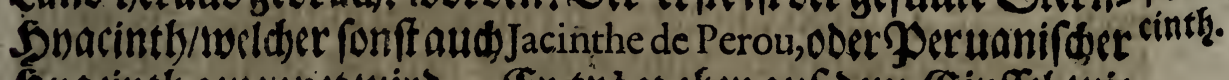
Suacinth genentict wirt. Ev tragt oben auf dem Bipffel wie

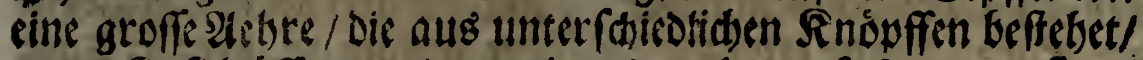
waunfie fid offinen uno von cinander thun / fo formiren fie eis nen Straliz , fo aus manderley/als leibfarben/mesiffen uns blauen Sternen beffelet: Es iff zwar wabr/Daf fie nidst alte. zuglcids blitsen/fonoern fie fangen bon unten an / uno waun

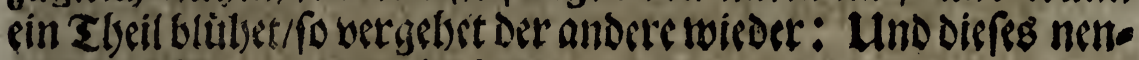
net inan Poeten 5 yacintben.

Diefe Blume liebet cinen Sdjattenteiden Ort/ eine (Er:

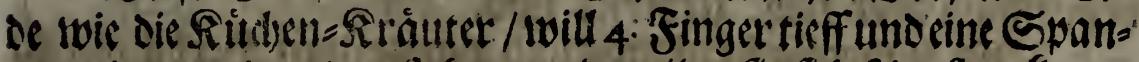
ne weit wan sinanoer fteben: uno weilen fie fid febr ffatcé vir.

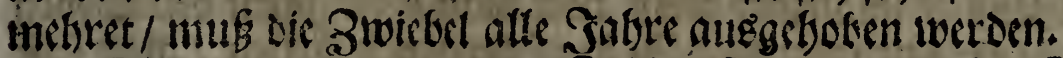

Die anderc Gattung Des Sndianifden Syyacintbo iff bie Tuberofe/ Daboin unten unter Dem Titul der bonder Tubero= fe fan gefobin wiren.

\section{Gon Denen Sefminen.}

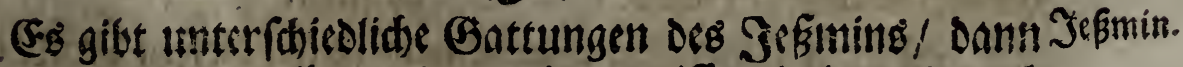

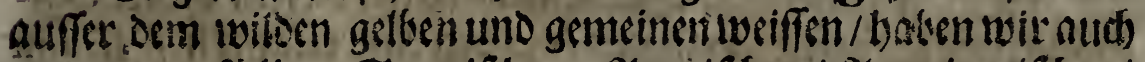
noth Den gefullten Spanifden/ Arausifden/ Itmericunifden/ und den groffen Gubianifdern/Der eine gan/s rothe SBiume bat! Hind Damn den Eatalonifuren. Dirfer 


\section{6}

Reue Unterweifung

Diefer Catalonifde Seçimin trágt an donen àufruffen

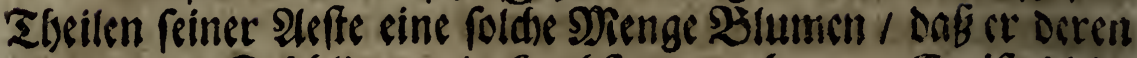
Den gangen Fritlling und berbff genug bat. (Fr if bleid)

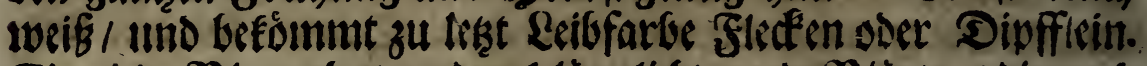

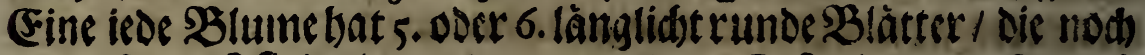
eines fo grof find als an dem gemeinen Sebinin: Der Gerud) iff felor lieblid.

Der gefüute Spanifdes SeEmin bat chen diefe Farbe/ und

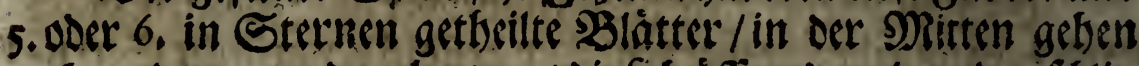
now 3. Doer 4, andere leerwor / Die fid iffiters an einander fajlice fen / und einen fleinen Zaal formiren. Er bat cinen febr anges

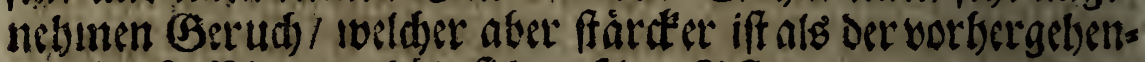

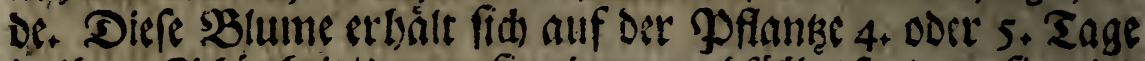

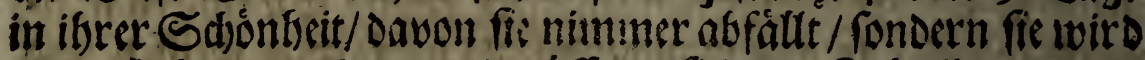

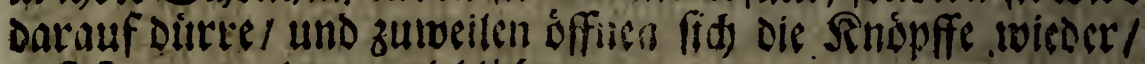
DáB fie zum andernmal blitser.

Der Arnabifdee SeEmin wiro won:oenen Arabern Zam-

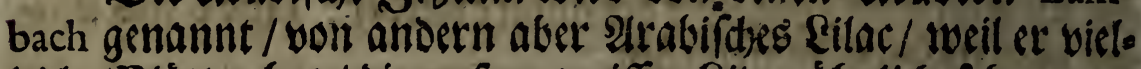

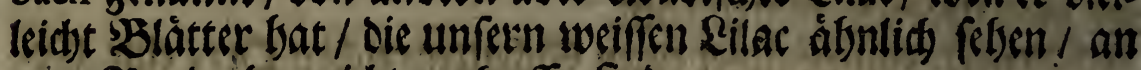
Dein Siand aker nidts zerferfft fimd.

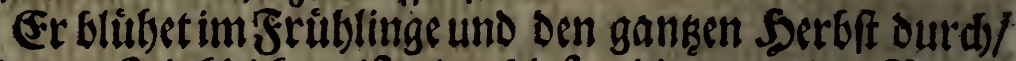

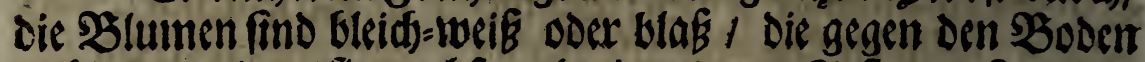

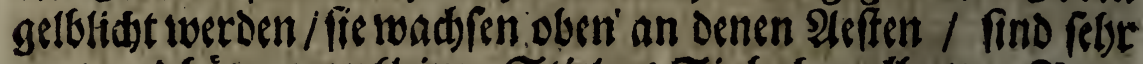
zart/uno bängen an fleinen Stielen: Sie faben alle zwen siang

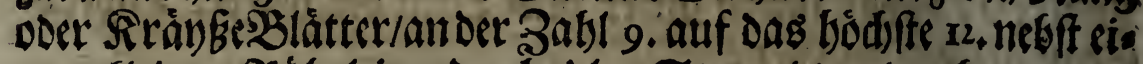
nem Eleinen SRobtrtein Doer boblten Stengel/ und geben cinen wounder genelsmen Geruds von fids/ welderer Dem Gerud) ber Dooumeranesen=slatthe felor nabe fómmt.

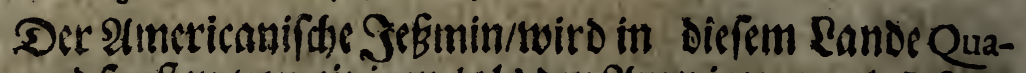
moclit, into fonffen yon cinigen / als den 2(mericanern / Jafmin

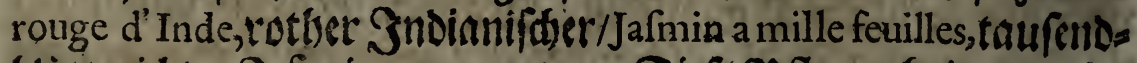

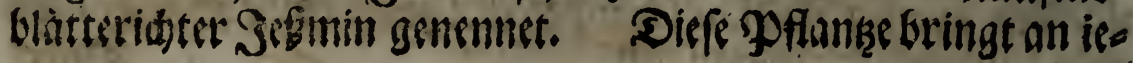




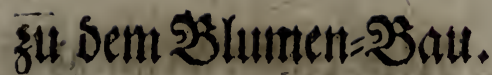

Dem affe einte ooer ziven Blumen bon verweldeter sRofenfarbe

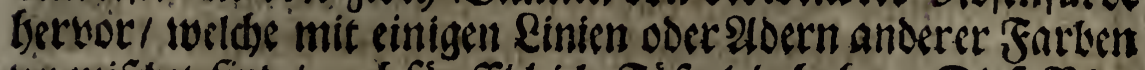

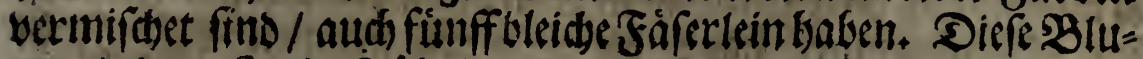

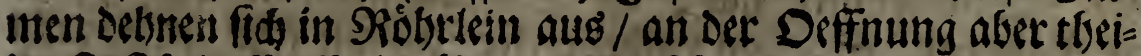

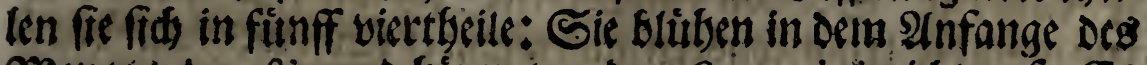
Mronats Augutti, und bören vor Dein Septembri nidft auf. (Fes

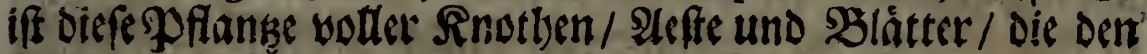

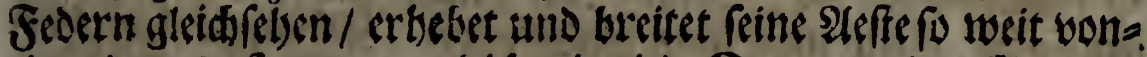

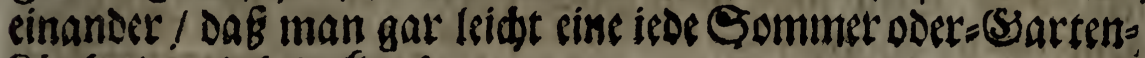

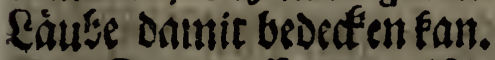

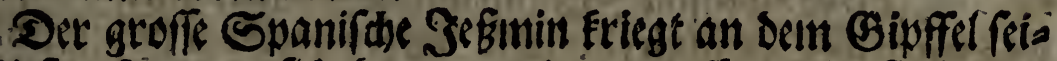

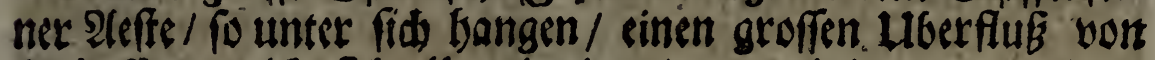

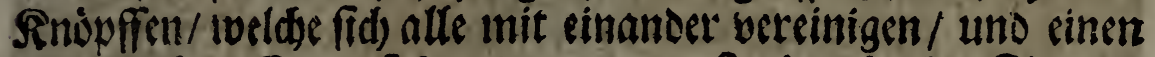
gank rotben Straub formiren; wann fie eines balben Fingers

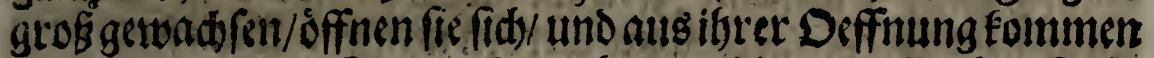
wie Siobse/ sines Jingers lang/ Hetwor/ Dievon getElidter Fat.

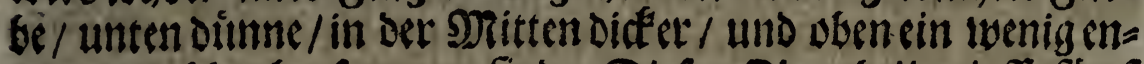
ger ooer náber beyfaumunen fint : Diefer Dbertbeil twirfft finf

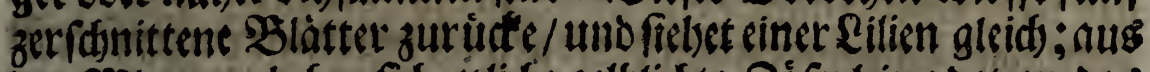

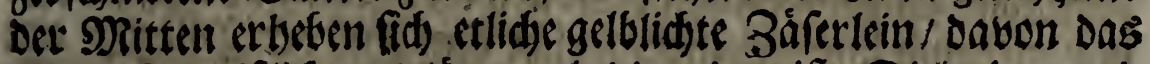

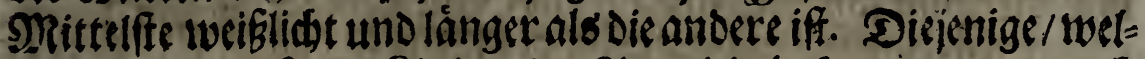
des fleine Gorlofarbe Rinien oder Sedectlein baben / werden nad

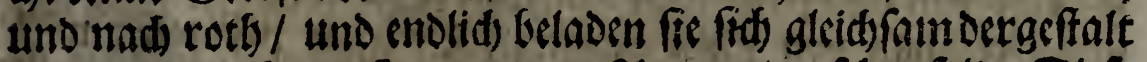

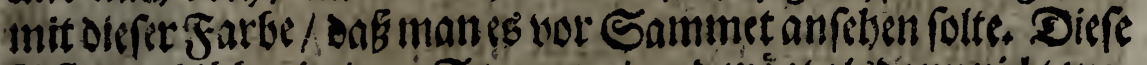

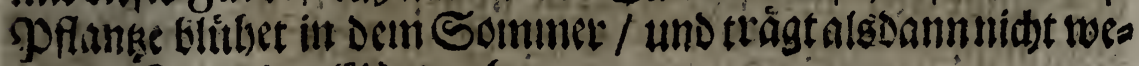
nig aur Bierdeder \$sarten bey.'

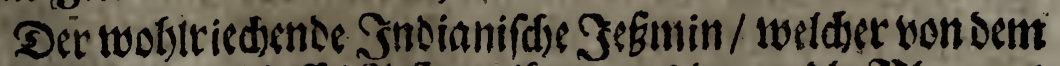

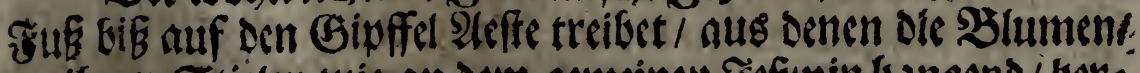
on ibren Stielen wie an oem gemeinen Jefinin bangend/ bero

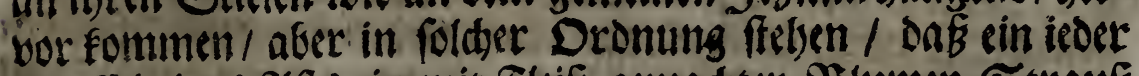

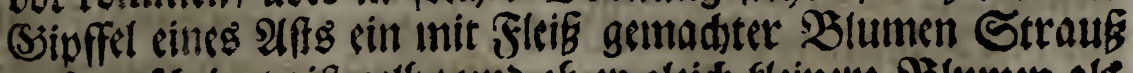

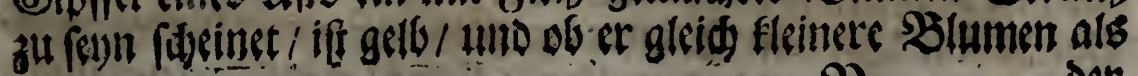

? 
98

\section{Neue Unterweinumg}

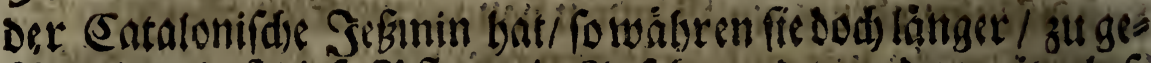

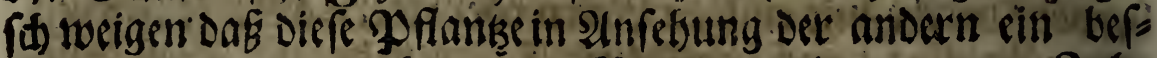
fers 2Badjsthum bat; Die SBlumen nethmen von Sallse

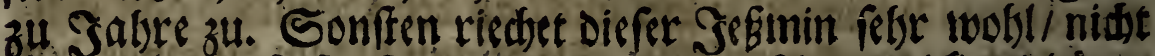

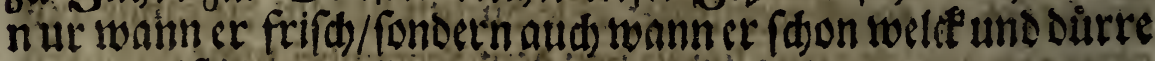
worden iff.

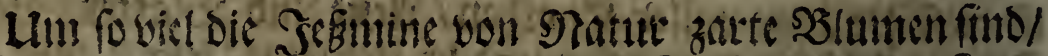

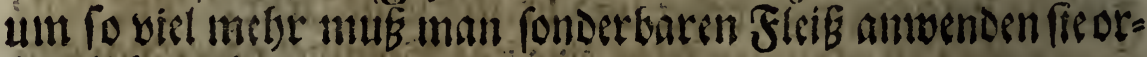
Dentlid zu bituen.

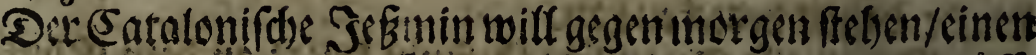

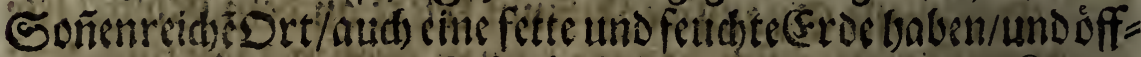

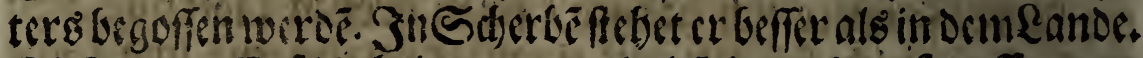

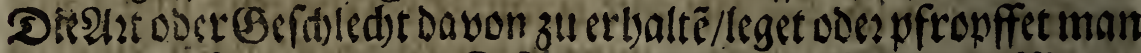

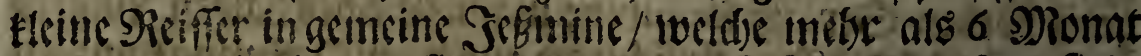

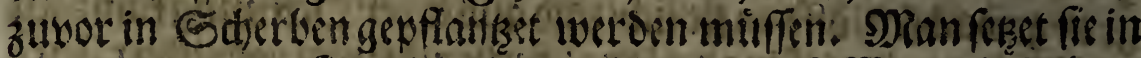

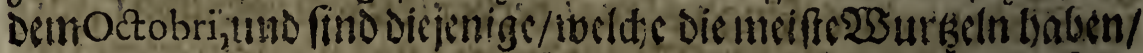

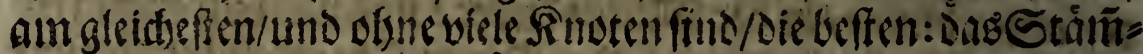

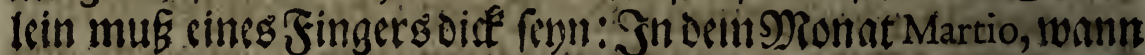

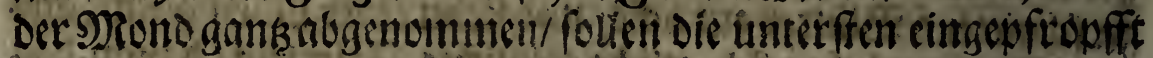

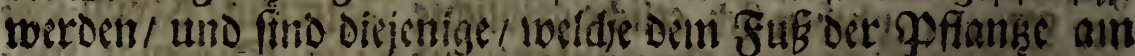

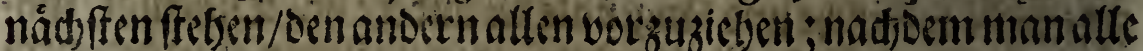

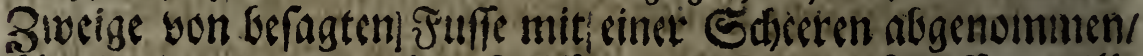
fdureidet man von affen gieifern / sie man bfrovffen willty

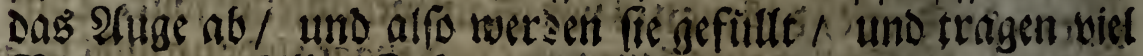

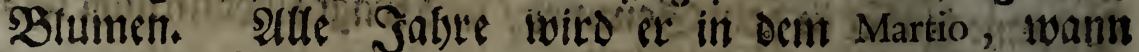

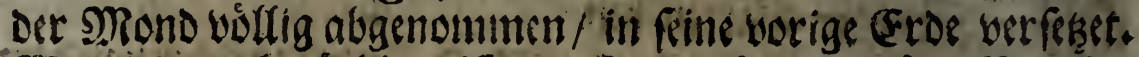

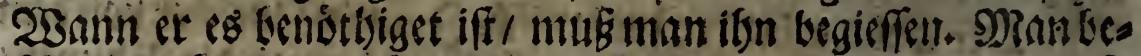

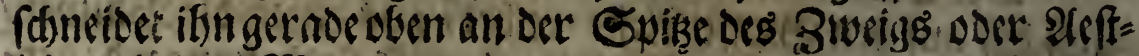
'Teins: in Derm Monat Junid uns Julio, fan man ibra aud, oculiren oder äuglen / in derit than cinen fleinen runden Edjnitt it

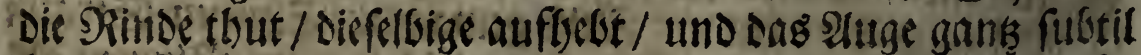

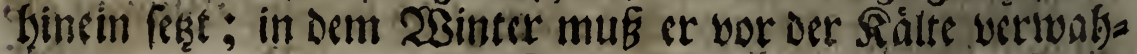

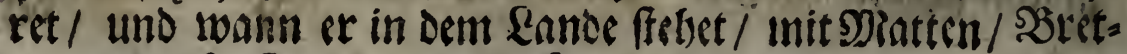
tern/ ooer fonft bequemen Deffen werferben wereen. Der. 


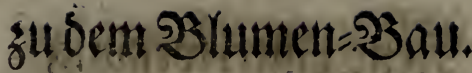

Der Spanifore Sefmin/ locil er bon eben diefer alt iff

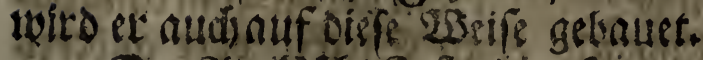

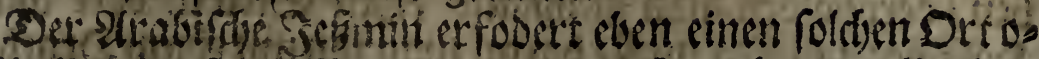

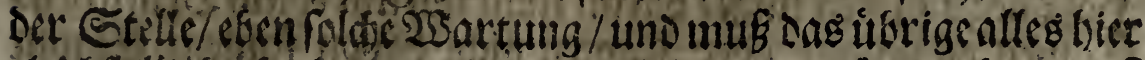
glcichfallis bcosadtat toersen. Dod bat er defes melyt i DaE

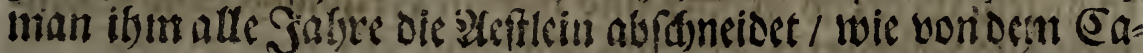

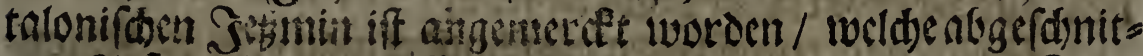

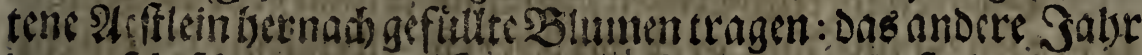

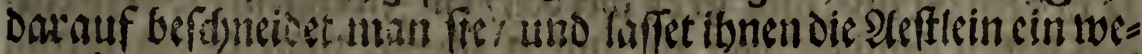
nig lánger: in sem oricten uno bieroten Sabre fábret man mit befinneioen fort/ fo/Daf biedefteim allezcit ctmas länger gelaffet

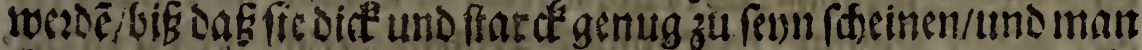

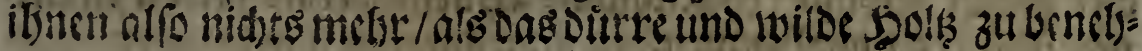
men bat.

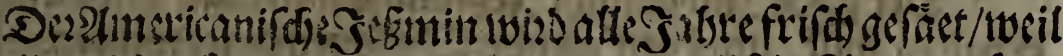

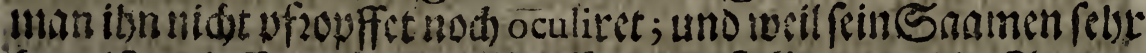

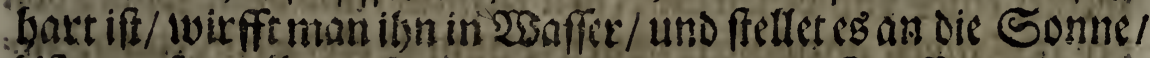
biser gefatvetle/ agldam twerden in ieden Topff 2 . oder. 3. Sornlein/ glbit) Finger tief/ / und in gute (srde gefret: Diefes gerdidt in Sonat Majo uno Junio, imanfong des פreuen \&idt:s. DRan mufítbn um SRittage obne Linterlag begiefen / Damit or

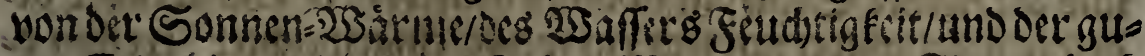

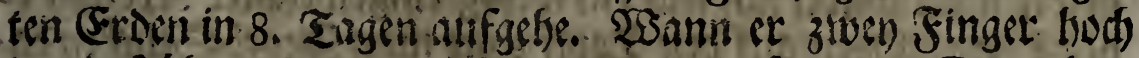

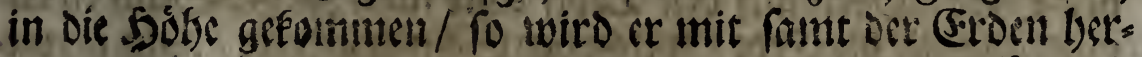
aub genoinmen / uno tur cime \$P fanke carinnen gelaffen / die zlocy anderen aber feset man/ eme iebe bifondocrs / in andere

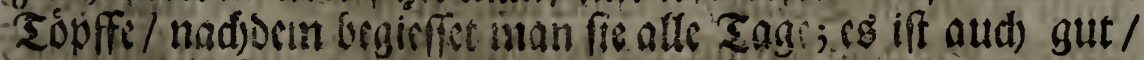
Ionnn man ffe in ertien Simat oder Gitcl/ Darsin inan zuoot 2Jaffer getban / ferle / und die (stoe nud bon unten befeudte.

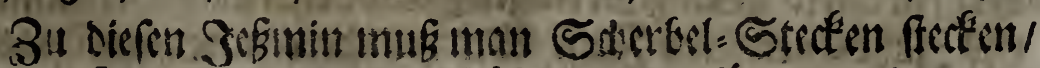

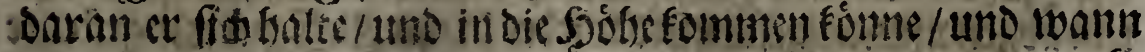

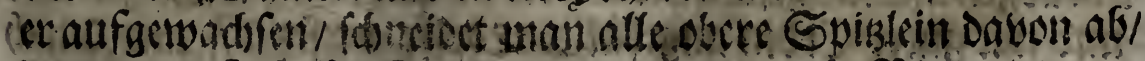
Damit et Defto foffer Rraffe bofomme/uno inelgr Blumentrage. 
Dor groffe Sndianifare Sefmin will vorige Wsartung ba Gen/Berobnalben man gleidfalles cinen Steffen oder anberes Sols Dazu ffecten mus / Daran man ibminit einemoratb beffe te / tweil Die (Sileide oder Inoten nidit onvon faulen: Erwill in gutem Erorcid ffeben / uno in ocen Friblinge uno Som: iner alfe steno reidlid) begoffen fenn.

i Solden fortzupflamsen / fo fdneidet man / ebe die Sinopf:

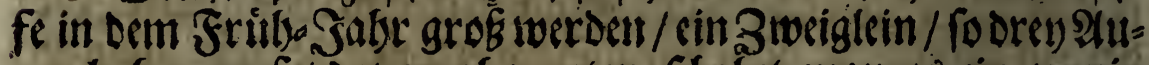
gen baben muB / Davon ab/ unten fohabet man es ein wenig init cinem Meffer / alsbann wird cs Gis an Das andere Auge in Die Gerde gefeget / Daf das dritte alleine nod bauffen bleibe / fol= der geffalt getwinnet ro gefdrwino 23 urseln / uno treibet in Eur. Ben SBlätter uno SBlumen.

Der gelfe Sndianifac Sefmin/wann ınan fein (Befhled)t stbalten twill / ImuB auf gleide 23 eife getwartet werben. Man weblet cines von denen unterffen Reffein / uno obne foldis von

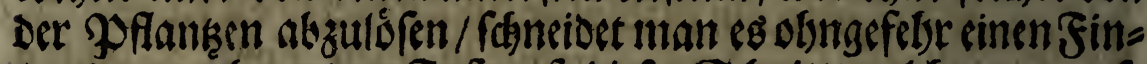
ger lang nabern Dem Sü auf; diefer Sdonitt/ weldger von aufs

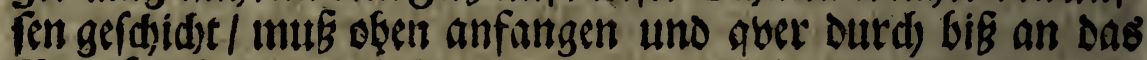
Marfe geten / Darnad) wird er ein wenig von sinander gemad)t

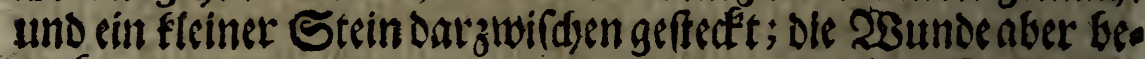
Decfer man roicoerum unit cin twenig cingetweid)ter firciden o= Der Tloon. Oben auf den Topff leget man Biegel. Stuttén Daa ruln / Damit die Erde / weldeden Sdunitt bedect' / nidte beruns ter falle: Vadbeem Das Aefftein wobl begoffen worden / ffellet manes an bic Sonne / uno vertwakret foldes vor dem V?ord:

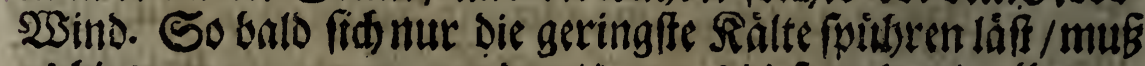

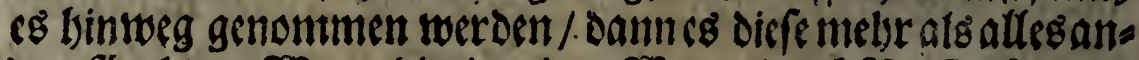

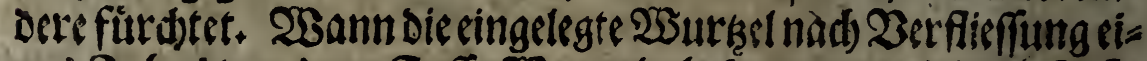

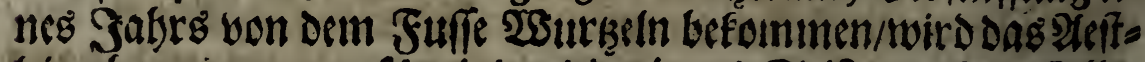
tein abgenoinmen/gefatwind wieder in mit Sleiß zurced) geffellte uns mit guter Erden angefülts sopffe verfeger/. und Dutd) 
+ biefen Fleis erfezect man wieder / wag sic Pratur diefer Pflan: Ben / Iveld)e Eeinen Saauen trägt / berfaget.

\section{Bon Denen Jonquillen oder Staliånirken Narcifien= Pióficim.}

Or es wobl cine groffe Senzabl (5attungen Der Sonquile Sonquifer. len gibt / Fan uman fie Dod) unter z wolffe / weldje Die ronderbar: ffe und bodigendteffe find / bringen/ Deren Namen find:

Jonquille de Lorraine, oder Die \&otbaringifde Sonquilte! dic fraufe Sonquille / Die Jonquilfe mit Den groffen 3 eder / Die Spanifate groffe / Eleine / cinfade / und gefullte Jonquillen/. weld)e alle cine Sididgelles Farbe baben.

ulber biefe finden fid aud nod i bie groffe und fleine weiffe Sonquilfe / die meiffe mitoen Eitronen farben Bedser: und die iveiffe und grime Serbfts Sonquilfe.

Jonquille de Lorraine unie, Die \&otbaringiffde vereinigte

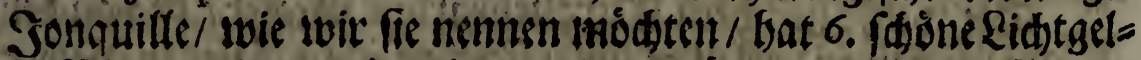

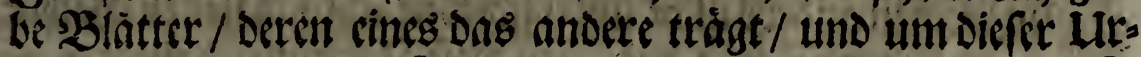
fadse willen bat man fie Unie boer die vereinigte genenut; fie

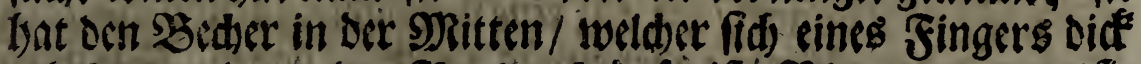

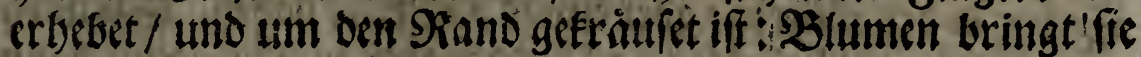
stwar nidte viel / biefen SRangel aber weib fie wieder fegr woblt

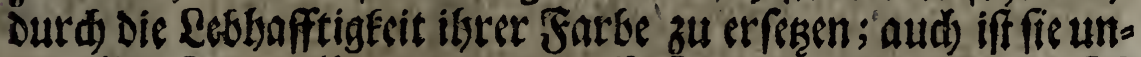
ter aflen Jonquillen die tauterbaffefte uno von Deren imanfí aun meifen zu verfichern bat / bas fie fort fommen werde.

Die Eraufe Sonquille bat dicfen Namen / weil fid itre

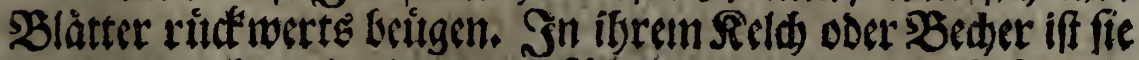

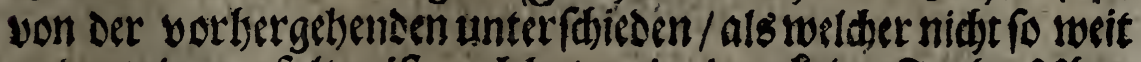
unowenizer gefalten iff/aud bater eine oundelere Yarbe: Lobe Diefes iff auth Die Slume felloften yon Farbe Duncteler.

Die. Sonquille mit Dem groffen seder wirb affo genannt/

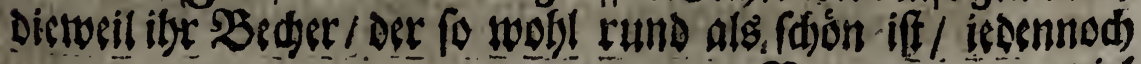


102

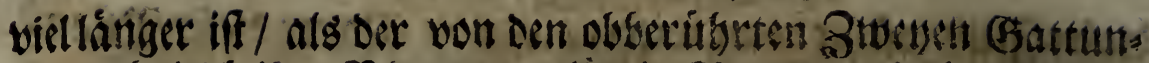

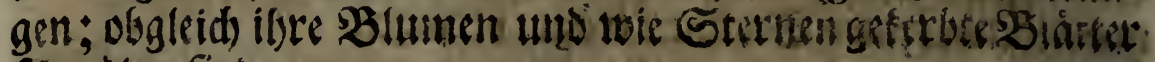
finimaler fino.

11. Die Spanifue Sonquiftenfind/ weilen ntan freatı Swa. nien zu ung gebratte/a!fo genenntt trotsen. Sie baben fet)

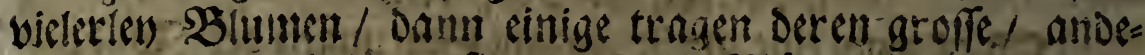
re Eleine: cinige bringen fie mit wanig Bblattern/ andere defto

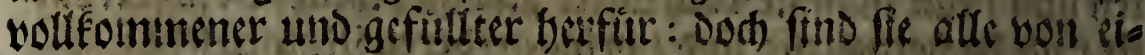

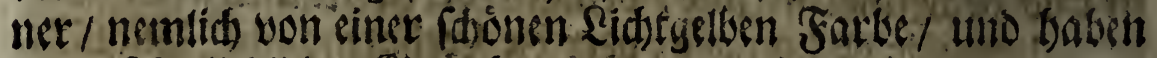
cinen fefre liebliden (sicrud.

Die groffe weiffe Sonquille if von dor groffen Spaniffien

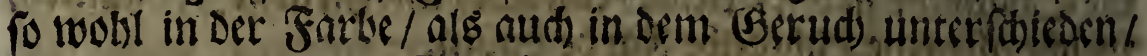
Dann Dinfe bat Eeincn Geruh.

Die Eleite weiffe bat aud von der Spanifhen einen Lin=

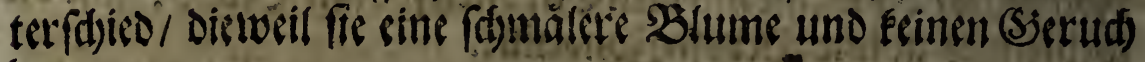
bat.

- Dis De weiffentit den Citroncufarben Becter / if bon der

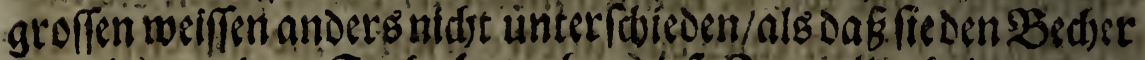
yon ciner andern Farbe bat; eben diefe Jonquitie bringt 4 . of Dar 5. toeiffe SBlumen/ Die auf eine tweiglichte Farbe zieken/Den Beder in Der \$itten/ aber etwas duncéeler baben. Sie twird

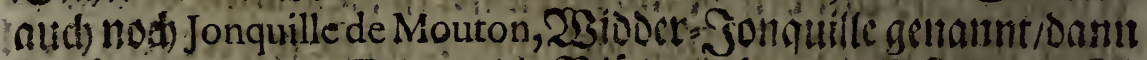

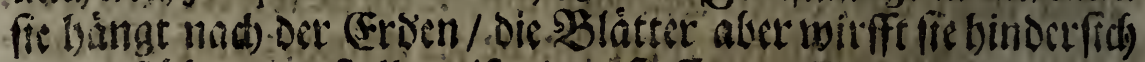

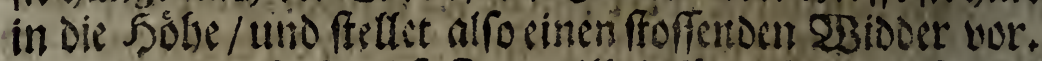

Dic weiffe Sarboft Sonquilfe breomint 3. Weiffe Blunten/

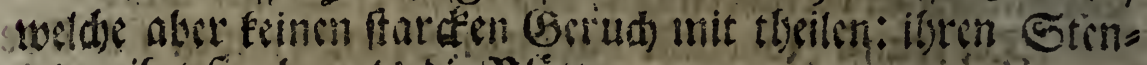
get treibet fie cher als die Blatter.

Die grime geftirnte Sentuffe / weldse aud in ben fort

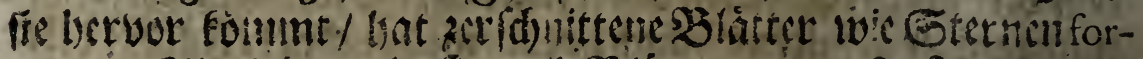

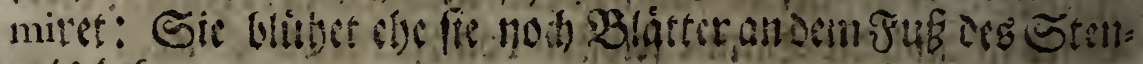
geis tofomut.

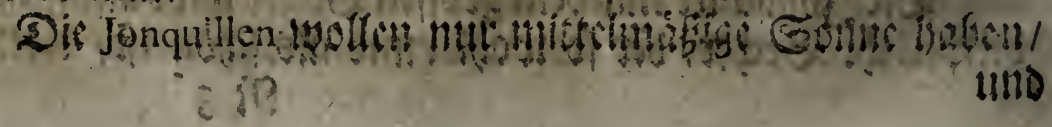




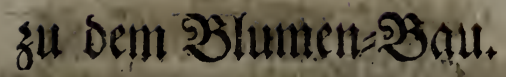

103

underfoedern sine (sroede nidt feffel abet aud) nidgt leidste fev; Iman foket fie 3. Tinger tieff / utlo sben fo wo sit won simane oer; alle 3. Sabre werden fie ausgenommen/ uno die Viebene. Srut argeronoert.

He Diensiffe und gelbe gefultte feben beffer in Ederthen

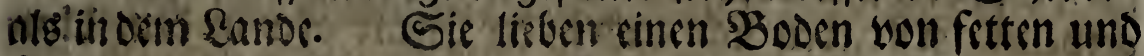
feudtem (erorsid); allsin bas Betle uber Diefem Boben / Dar. cin than fie pflansen loild/mub bon einer magern uno leidsten

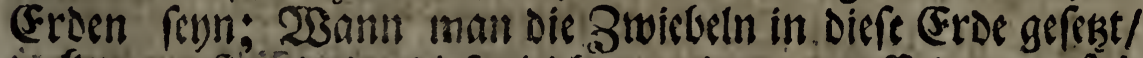

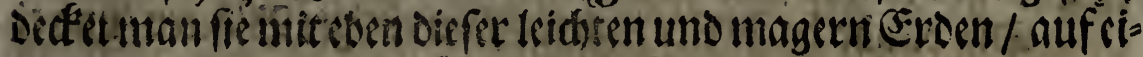
nen Sdudu bod guten fetten (Froreidjs / neieder zu.

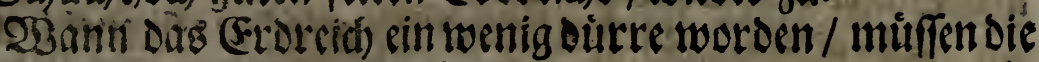
Jonquillen gank fad)te begoffen twerden; Dann biersurd) net): men fie zth/Das man fid datiber bertwundern mus.

Ban nimme-fie nidit aus / als nut die Fäferden von des ten Bubenabzurtueiden/ und oiefeg foll in Dem Septembri ge fdetsm. Gie muiffen gleid wieder in die Gree fommen/ Dann diefefleite Blviebeln find auffer der Srden $/$ w we die faugende

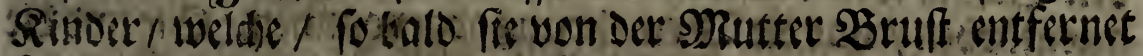

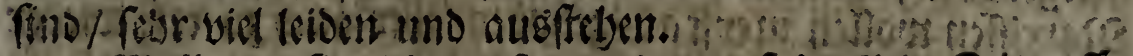

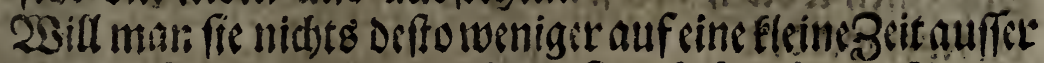
ser croen laffen / fan uman es thun; fie mutfen aber in papier. singelvidelt/ uno in Sdadgteln vertwabest werden:

\section{2ison benti Taffeten.}

(Fo gibt Tafeten bon bislerlev) Battungen uno Sarbin/als Ibciffe gelbe / bleid) / sinfad) / gefuldte / groffe/gemeine / frus be uno pátbe.

Die groffe find ztweberley / sin Sbeil bat bereinigte Das andere bon einander gefonderte oder zertbeilte Blátter / Die bers

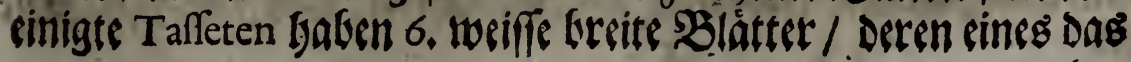


104

andere auf fid liegen fat und tràgt/ ber Reld if in Der SRite teii / uns bat Bleide Sarbs.

Die zertbeilte oser won einander gefonderte baben gleids:

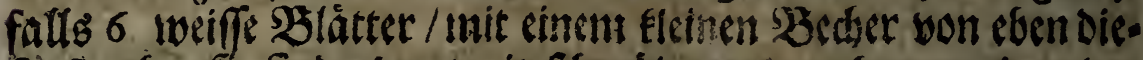
fer Jarbe; fer fino aber tweit fónáler uno mebr bon cinander

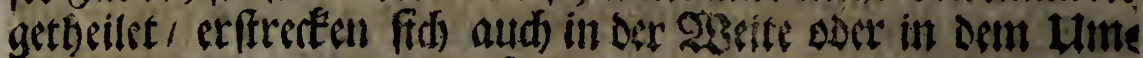
freiß nid)t forweit alg Die crffe.

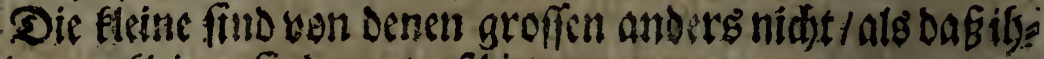
re Blumen fleiner find / watter fdicsen.

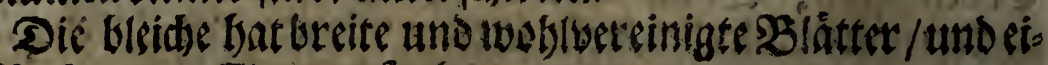
nen Bedser. von Eitronenfarte.

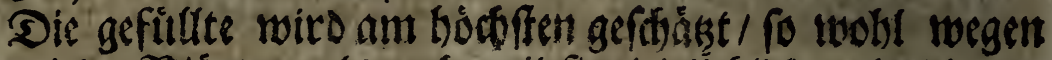

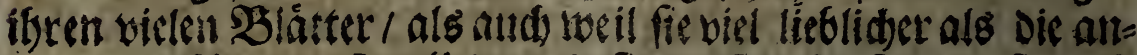

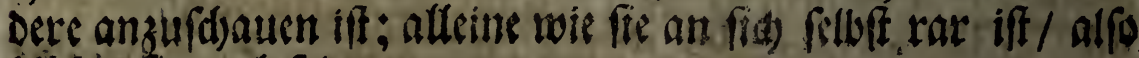
blitibet fie aud faten.

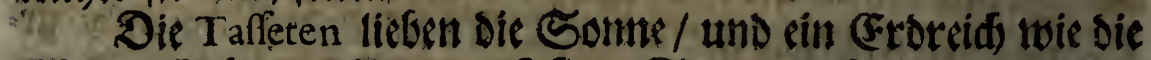

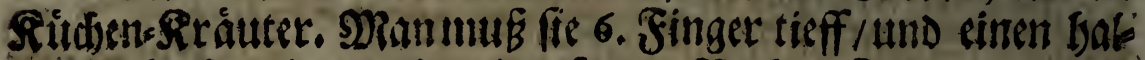
ben Sdud) weit yon cinander fiken. Nad) 3 . Jahten wiro fie ausgethofen / und dic 2ermelsrung nbgenommen. Sie uno dic garciffen wotten ztherf auggeboben/aber aud) zu erff wieder. werfeset weroein.

\section{8un bet Iride, oder Biol:2ButE.}

Biolivurks.

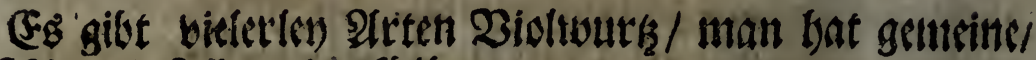
Perfifde / cinfadse uno gefillte.

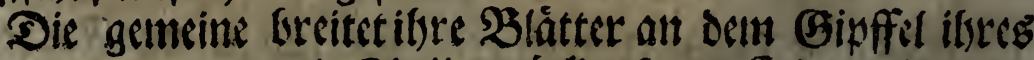
Stengels aus / Deren cin Theil zurutet gebogen fino / unt untes:

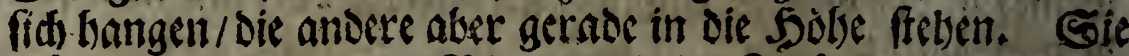

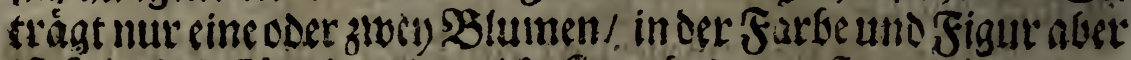

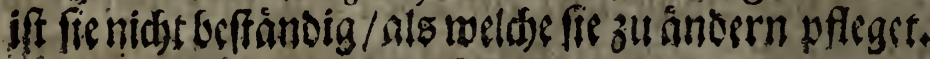




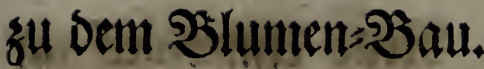

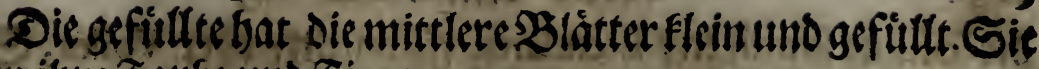
änoert ibre Jarbe und figur.

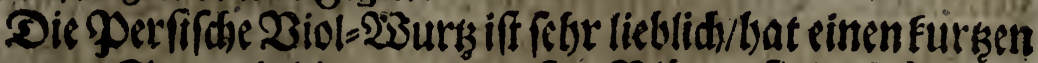
und zarten Stengel ; Die oren unterffen 2 bätter find rìd"weerts

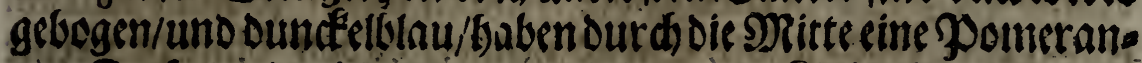

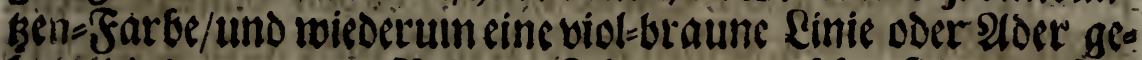
ben / Die oren andere Slatter ffeben gerade itber fids/ und find betlblau. Sie blíbit in Dein 28 inter / und tràgt viber 7 . odert 8. Dolumen nidte / Deren einevergebet indem die andere blübet.

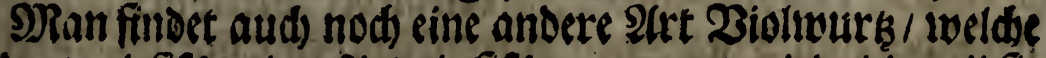
Die portugieffiftec ober sendaluffifte genennet twird/ Dietweil fie

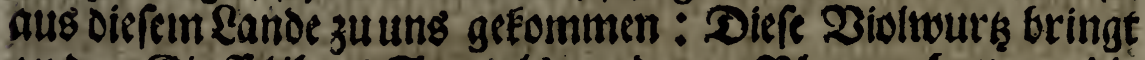
an oem Gipffit ibres Stengels 12, DDer 15. 2Blumen berbor $/$ Die felbr furrs/an fleinen Stielen bon ziwenerley Farben bangen; Dann zu tocilen find diefe Stiele Duncéellotau/ cint andermal

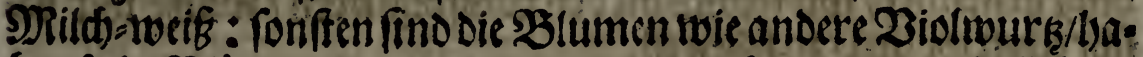

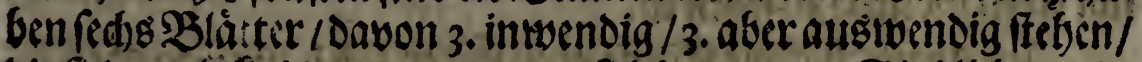
Die fid zu ritée biegen/und unterfids bangen. Sieblithen mite ten indecin 28 inter.

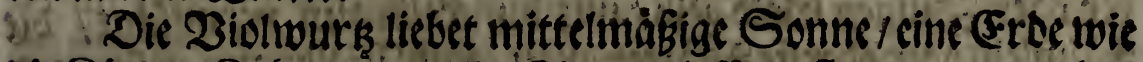

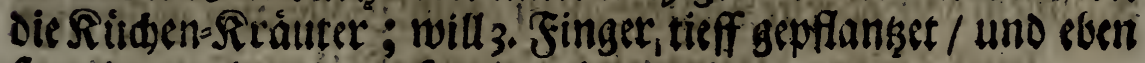
fotweit won sinander geffeset toerdent.

\section{Tiegifter Der Iridumbulbofarum, oder

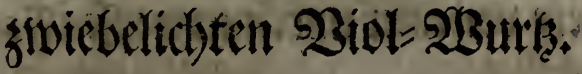

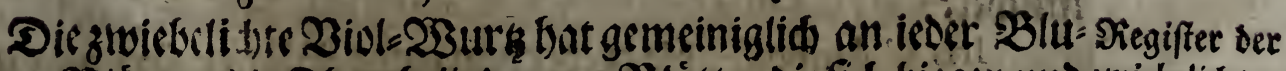

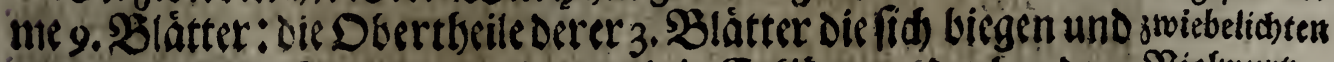

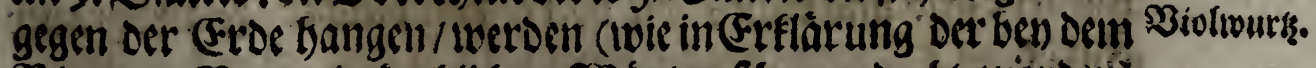

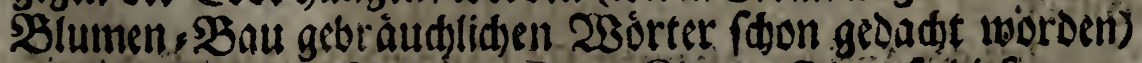
worn Denent Frankzofent Mentons bDer Simne; Die 3 fo Dieferm am

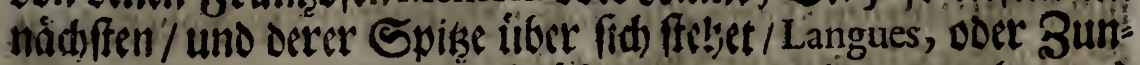

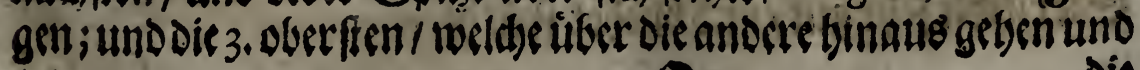


Die SBlume formiten / Etendarts, Sábnlein / oder Voiles, Seglen

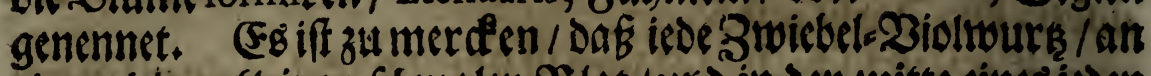
einem iedem fleinen fajmalen SBlat / urid in Der mitte cines ieden Rinnsein zimlid) breites gelbes Beiden babe $;$. fo man Ecuffon jaune, ober cinen gelben Sdjilo nemmet / Davon binfitbro feime weitere Mieloung gefdecten wird / weil er einer ieden 2 iolwutrs gemein iff i und man eine Sadie zuroiderbolen zu vermeiden fï. dist.

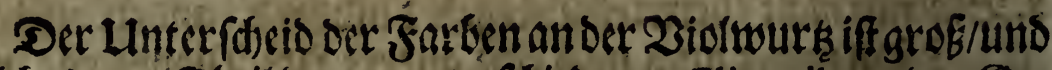

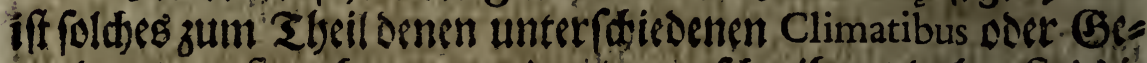
genden / wo fie gebauet worden / zu zufdoreiben / daber find die Gielerlev) (Sattungen uno ? a amen gefoummen ; oder man hat fie yon benen / welde fie zu erft nus dem Saamen gezertget baben; Doer aber nad) Dem Eande / von Dannen fie z uns gebrad)t wore Den / genennet / wie foldes ain sen nadifolgenden/ rvelde twir bee fobreiben wollen / zu fiben iff.

Iris Agaté, bat Die Riume oder unter fíd bàttgende Blátter gelb mit blau untermenget / bie mittlere uber fíd ftebende SBlàte ter oder 3ungen Golo gel6 / mit Dundellbraun vermifoet / Die Fablinlein oder oberffe $\mathfrak{B}$ latter grau / und 2 Bol braun gefwrengt:

Irisd' Afrique, Die unter fid bàngende'S látter fino gello mit blau bermifdet / Dic inittlere bellblau/ sie dbere \$iolbraun.

Iris d'Alep, bie unter fid kangende Blätter fino gelb/ bie mittlere und obere voneiner unreinen weiffen Farbe/gel unter. mifdet.

Iris d'Amboire, bie niederbángente 3 lättet fino gel6/ Die mittlere gelf und blau / bie obere von bleider Fladsgrauer Farue.

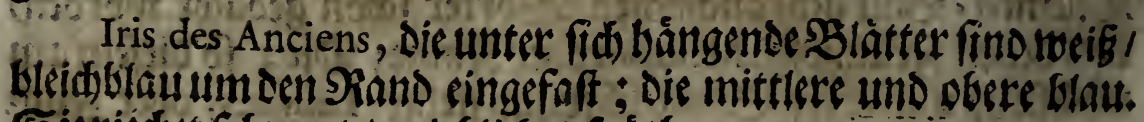
Sieriedert /shegut/uno blubet fuatbe 


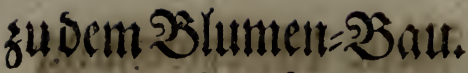

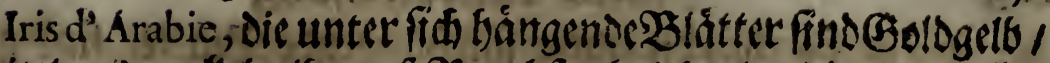

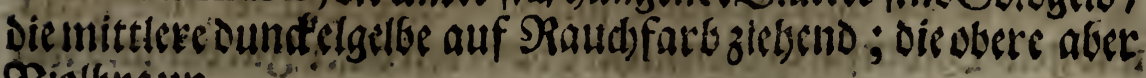
ziólbraun.

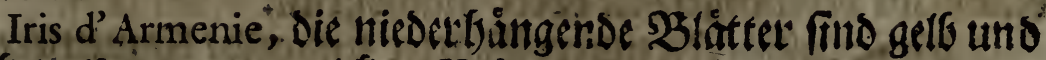

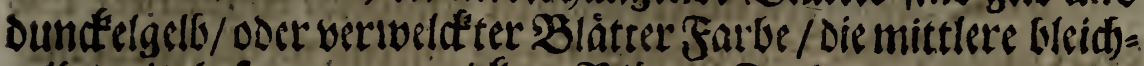
gellb / mit befagter ver weeléter Slatter Farbe vermenget ; bie obere 2iolblau.

Iris d' Auvergne, Dic untere 3 tátter find geff mit Glaut unt

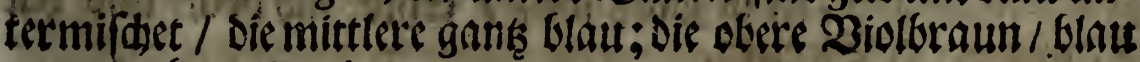
und Dundétigelb gefiprengt.

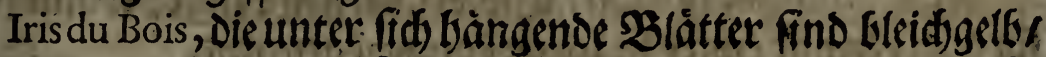

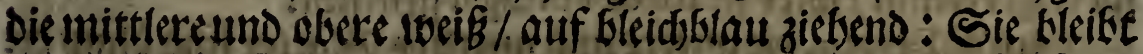

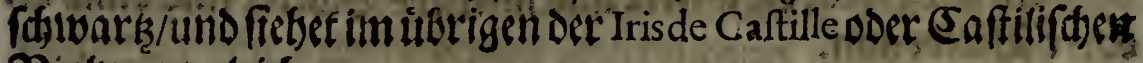
Bioltuursgleid.

Iris Blaifois, Die untere Blâtter find gello und gurorf fare/.

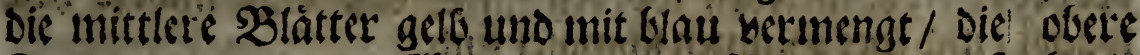

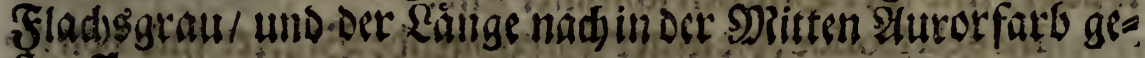
Intent:

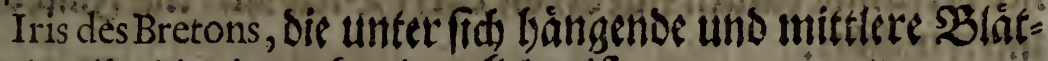

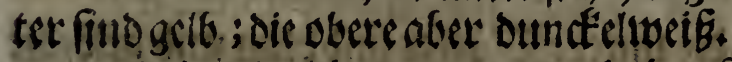

Iris de Brie, oie untere und mittlere sblätter find wisig uno

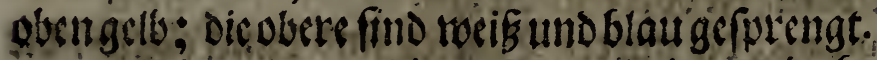

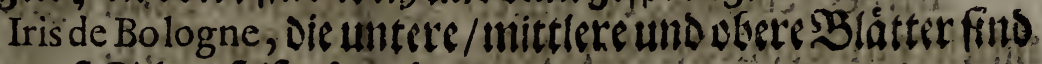
weib/auf Sdibeferf farb zicterno.

Irisde Calabre, bat gankz gelbe $\mathfrak{B}$ lumen.

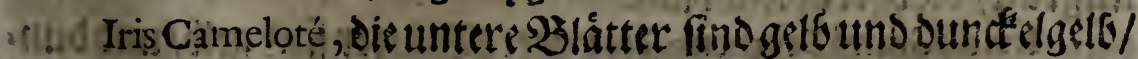

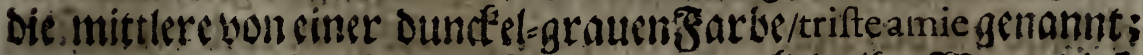

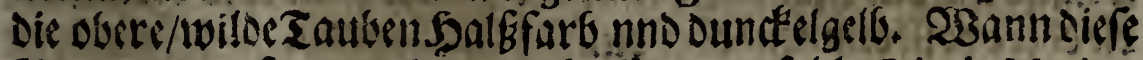
Zioltuure gefprengt fomme / beifiet man foldet Iris de Morins,

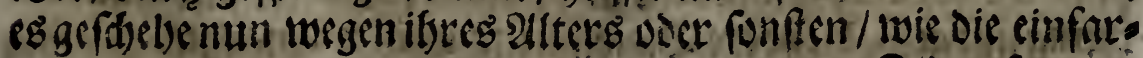

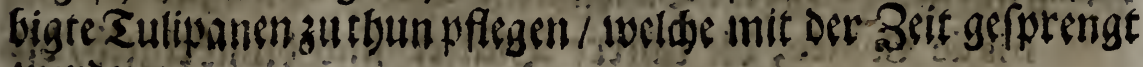
wastoen:

$$
\mathrm{O}_{2} \text { Iris }
$$


Iris de Candie, bie unter fid bảngende Sláttet fino grün

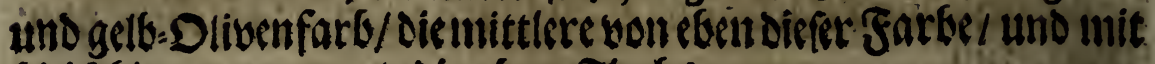
bleidblau vermenget / Die obere Fladgegrau.

Iris de Caftille, Dis untere Bláttel find gelo/ / bie mittlere unb obere fino DRild=Suppenfarb/ fo eine unreine weiffe Jarbe iff.

Iris dela Chine, if blau gefprengt / bleibt fdsuarts / uns

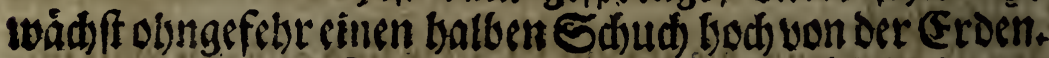

Irisde Crete, fte iff gan!s loeí / erbebt fid bods / und bat zicmlid) Gerite Blument.

Iris Damaffé, iff Glau / Violbraun geforengt: wann fie ges forengt foununt / wiro fie Iris de Portugal genennt.

Tris d' Egypte, oie untete und inittlere 2 latter fino blau/ bic obere 2ioloraum.

Iris de Florence, iff gank-tweif/ / vie die Iris de Crete, Ioeld)e borber fajon befdrieben tworden / nur dab diefe nidst fo bod wähff / uno ibre Blumen fämáler finc.

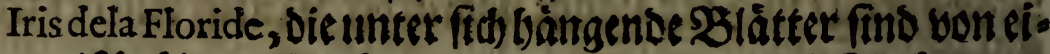

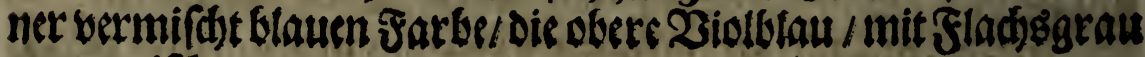
untermifaet.

Iris dela Frontiere, die untere 2 lâtter find blau und gel6/bie mittlere sunctelblau/ bie obere Diolotau.

Iris des Feuillans, Dic untere slatter find oundelgelo , die mittlere trifteamie, oie obcte twilde sauben= Salkfarb.

Iris de Gafcogne, die untere und inittlere sBlatter find spere lengrau/dois okerebleidblat.

Iris duGrand Seigneurs, Die unteres Blatter finb getb/und oute felgelbumben Sand / Sie mittlere Fladiggrau uno vermifht! die obere volfeommen/ oser Dunde (Flad)ograu.

Iris de Grece, die untere tino mittlete s) blátter find blau/ cint wenig mit geto/ oie obere 2Biolblaumit weif birmenget.

Iris de Guinée, Die tnitere Bláttet fino sundfel gel6/ Die mittlereblau melirt/ Die obere aber Diolbraun. 


\section{รu bem}

109

Iris des Indes, oic untere uno mittlere $\$$ Blátter fino geto $/$ Die - bere Fladjegraumit Biolblau bermifthet.

Iris des Indes, Die untere $3 B$ lätfer fins gello/blau untermen:

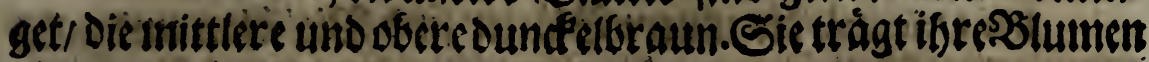
niedriger als oie andere 2 iollwurken.

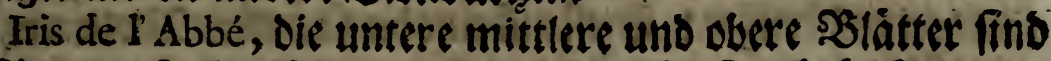
bod) Purpurfarb/ blitifet langfam/uno wad df nidt bod ; mann fie aus der Eroen berfir Esomunt if die Sülle/ barinnen fid Die Sbläter befinden / grumuno Durpurrotb geflect / eben wie bie Pflanke fo man grof Sdjlangen=Rraut ooer Dradsen-23urs nennet.

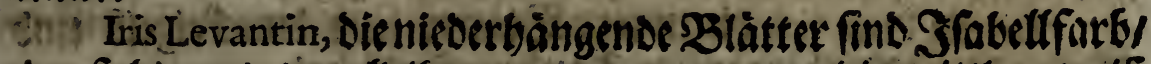
Doer fabl/ mit Dundelbraun untermenget / bie inittlere weis und betlblau/Die obere mit Biolfiraun vermifhet.

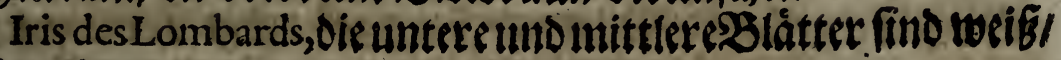
Die obereblau.

Iris de Lorraine, Die unteres lätter finoweib / Die mittlere und obere weiB/auf bleidblat zichens.

Iris de Libye, ole untere SBlätter fino gelo / Die mittlere uno obere aber baben sine unterinengte gellbe Farbe.

Iris de Macedoine, oie untere Pladtter/ twie audd bie mittlere find Aurorfarbund gelb/ de obere wilde Tauben Đalsfarb.

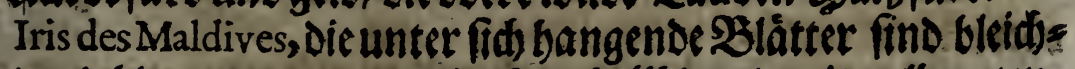
gelb/ mit blau birntenget/ bie beere betrblau / mit gello untere imif

Irisde Melinde, iff gank Ziolloraun/ auf Sourpur zitbeno/ nur der Sdjito auggenommen/welder Gologello/ und fleiner als an feiner anderin 2 iotrourksif.

Irisde Mexique, Dieuntere Blátter find gelo / Die mittlere getb / mit blau bermirdet / Dic obere flact)ggrau uno 2Biole braun.

Iris de Milan, bicuntete unomitterc? Blatter fino beUblaul. dic elere Fladjgegrau. 


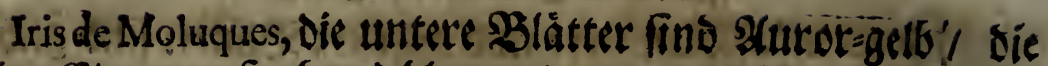
inittlere(Sitronen=farb und Glau untermenget/Die dbere blau nit cinem 2 iol buraunen BoDsen.

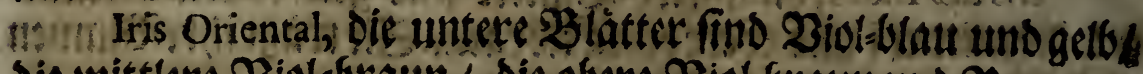

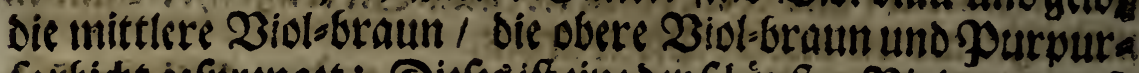

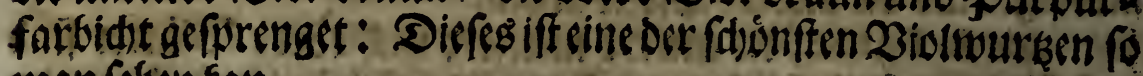
aman fetsen fan.:

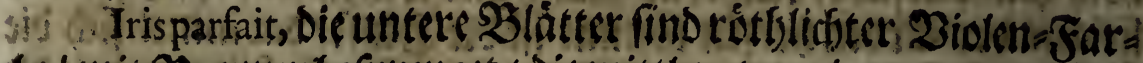
be/ mit Purpur befprenget / bie mittlere von einer berinifoten Dic.obere von einer fegr lebbaffen 23 iol-braunen farbe; fic woirs imit unter die fóöne 2 Bioltwurken Diefer Beit gezeblet.

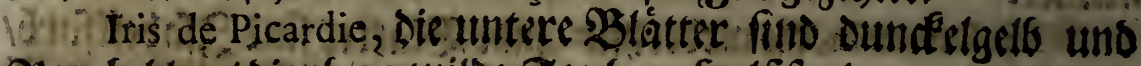

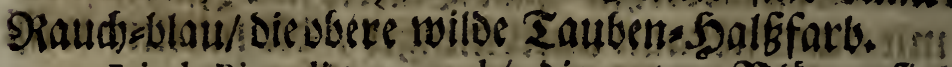

Iris de Picardie pannache, oie untere $\mathfrak{B}$ látter fino an diefer init bundelegelb uno Pourpur = Farb gejprengt / Die inittlere

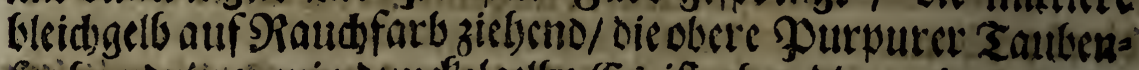
forbiunoctin wenig cumfelgelb: Es ift eben bie vorbergetsente

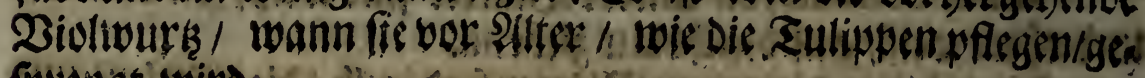
fplengt twirs:

Iris des Poëtes, Die untete B lâtter find Oliven-griun / mit.

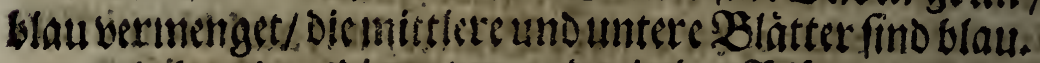

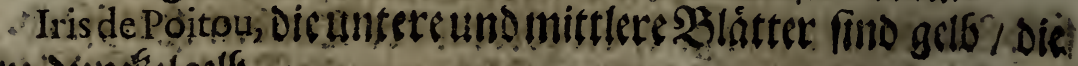
Abrive dinctelgello.

37. Iris de Portugal, Oavon vorker fojon gefagt tworden / iff feges gemein / ifre 2 liume iff ganks 2 lob b braun / und cine bon denem fribeffen/oeer die an enften berfur fomulen.

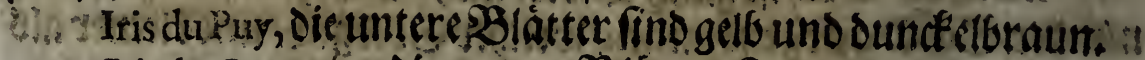

Iris des Pyrenees, die untete $\mathfrak{B l a ́ t t e r ~ f i n o ~ g e l f o ~ / ~ d i e ~ m i t t l e r ~}$ Glatuntermif derl Dic obere befublaut.

46. TrisRochetain, but gelfo untere uno mittlere Blätter / Dic obercaluer fino $\mathfrak{F}$ lad)

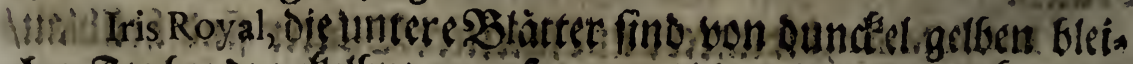

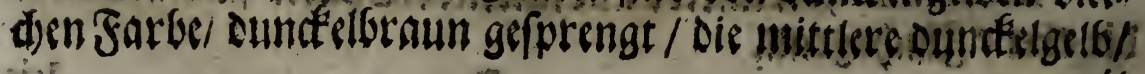
קili

mit: 


\section{zu Dem Blunen=-Bă:}

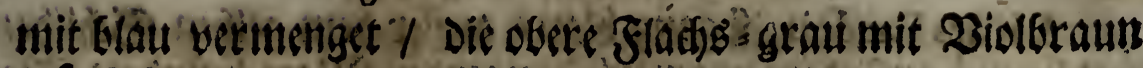
gefprengt.

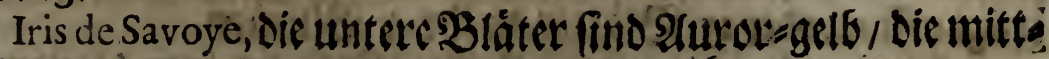

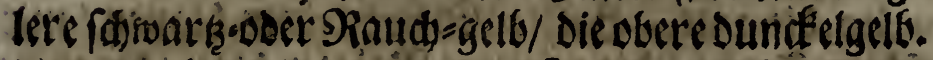

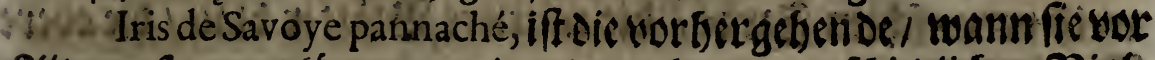
alter gifprengt fommt/ toic eg Denn ten unterfdiedidaen 2 iof surken und Sulipanen zu gerdeben pfleget.

Iris Senois, iff gank gilb twie dic Iris de Calabre pder salabri:

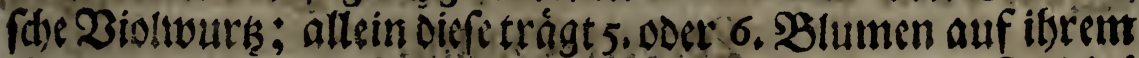
Stengel/aledenn infonderbeit/ wonnthere Bulbe oder $3^{\text {twietel }}$ grof genurg if / fonft bringt fietiber 2 oder 3 , nidt 1 eben woic dic mtiffen 2 iolwutken tlsun.

Iris de Sicile, iff aud) gank gelg/ nur Daf iffre Blumte nidt fo breit oder veit if als oer (salabrifden.

Iris de Surfe, Die untere 2 latter find gels/ Die mittlete und obere fino bon einer gelben intit blau bermengten Farbe.

Iris Syrien, Dic untere Blatter find oundelbraum/ die mittle: re uno abere bellolau.

Iris de Tartarie, Die unter fidb bangende Slátter fino von cis. ner bermengten bleidjgellen/ diectere aber bon einer unteinen blatten Farbe:

Iris de Touraine, de untere uno ntittleriglatter fino blaus: gelb/ Die obere blaut.

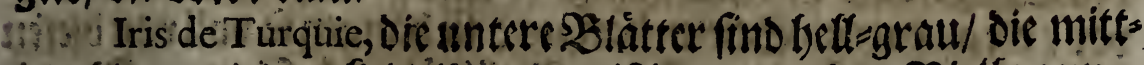
fere llaw/ mit oundelgello untermifdet/ Die obere 2 iolbraun.

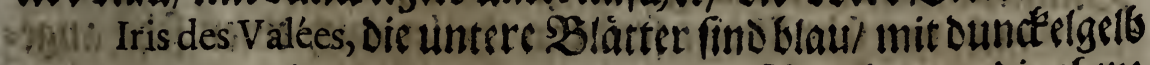
untermenget/ Die mittlere von einer verinifd)tenblauen/sic ofere bon ciner $\mathfrak{B}$ iolbraunen Farbe.

H) Iris de Valois, Die untere Slatter fino gel6/ Die inittlete bon einer gelb vertmengten/ bie obere bon ciner unreinen Fladggrau. en Farbe/ ber Ràngenad) in ber Mitten gelb geffrcifft. Sie iff

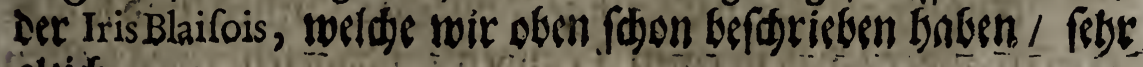
gleid. 


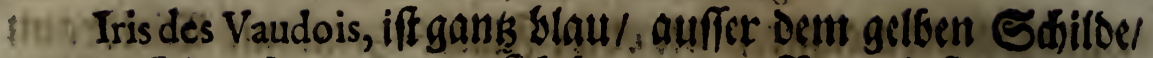
weldher fid auf iederm unter fid bangenden 3 late befineet: Sie trágt offt 12, 0Der 15. Blätter an ibrer Bltumen.

Iris Venitien, Die untere Blátter find voneiner blauen/mit weif vermifdten Sarbe / Dic mittlere Blatter blau/Die ofere Biol-brauth.

Tnoiani= fher \&or= beerbaum.

\section{Dison Dem Lauro Indica, oder S̈ndianifden Sorbeer=SBaum. \\ is}

Der Snoianifde Rorbeet-sGaum/ welder fonft oudd) Laurus Americana, oder Der 2umericanifde Eorkeers=Bauln genennet wwird/ bat 'Blâtter wbie Der Eitronen=\$aum/ und trágt tweiffe SBlumen.

Er liebet mittelmábige Sonne/ cinc gute fette umb feudite

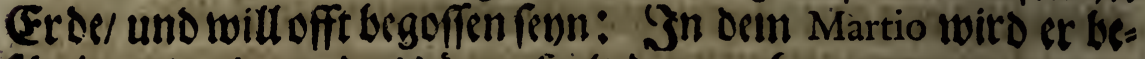
fajnitten/ uns nur Das durres Solks davon abgenommen.

\section{Bon dem weiffen Lilac odet Spanif́den Siyrings=:Baum.}

weipsilac.

- (Fr exbefet feine 2effe / uno breitet fie aus / und oben an ifs ren Spiken oder Bipffeln bringt ar fleine weiffe stitmlein bere. vor / die an furken Stielen bangen; ffe bangen fo boll bon diefen

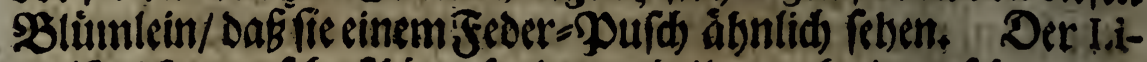
laciff nidft nur febr fdoon/ fondern theilet suds einen febr anges nelsmen (Berud) mit.

\section{Bondemblauen Lilac, oder Spanif(c)ent Syrings:-20um.}

blausilac

Cr bringt wie cin (sreus gerd)nittene Slumen/uno fodids: teincinander / dab́feceinen Srauben / obngefebreines balben 


\section{su bem Slumen=-\$au.}

113

Gøuda lang / formiren; fie fino aud febr faronte unb twoble riedient:

\section{Bonl benten Sillen.}

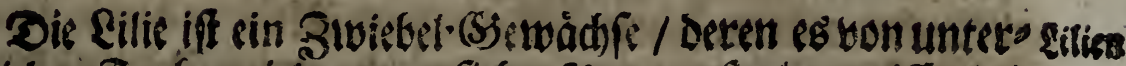

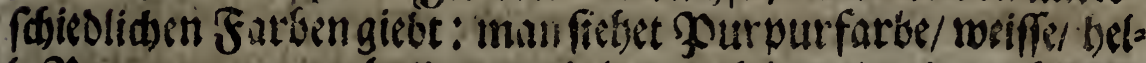
le Poolntrankenscotbe/ daron cinige gar Ecinen/ andere aber einen ubelen Berud baben; man fiebet rotbe die loobl fogattirt fino oder fdoune $2 B o l f e n$ baben / fonft fdoone Binober rotber

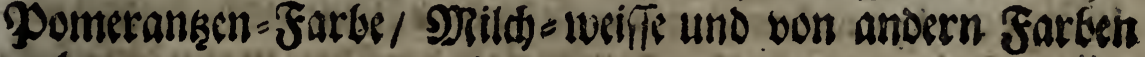
mebr.

Diespurputfatte Silie/toelde man Martagum montanum, DiessevonifdisBirg= Riliencnit / trágt oben an orm (sipffel ibres

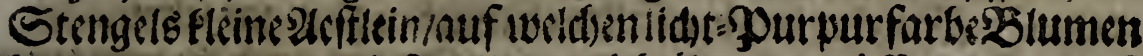

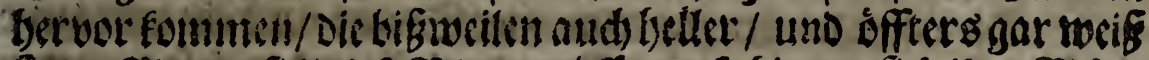
fino: 2Bann fidjoiefe Slumen offten/ fo biegen fid ilyre Slàto

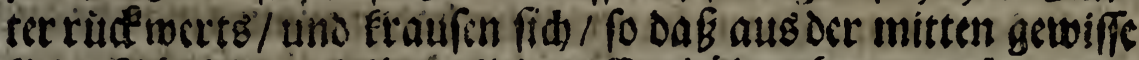

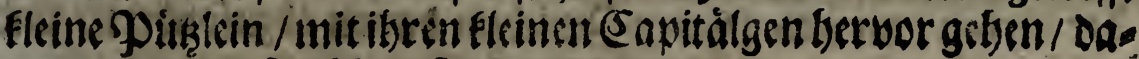
vondas mittelfe bobar iff als de andere.

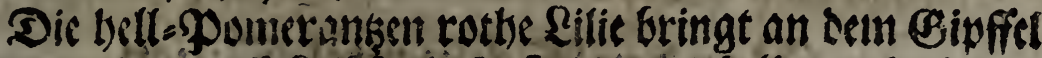

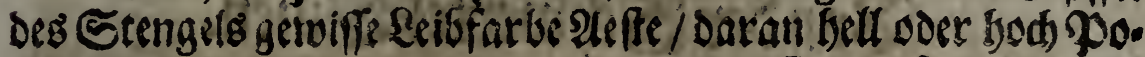
meransinfaró 2 blumen bengen/ uno tosil fie freufe uno raude Blatter bat / nennen fie rinige Riche-Madame, Nan finder Drren aud geloe.

Die Lis de Pompone ober Rilie bon Pompone if ser vorber

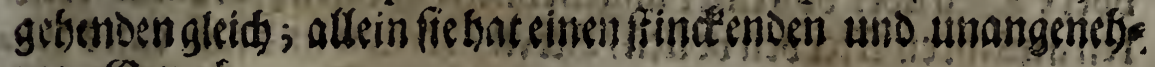
men (Gerudi).

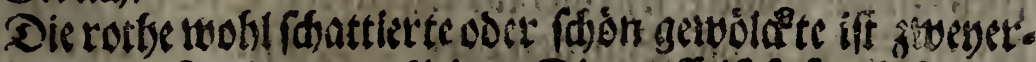

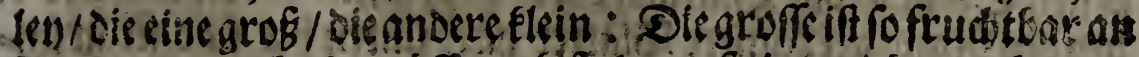

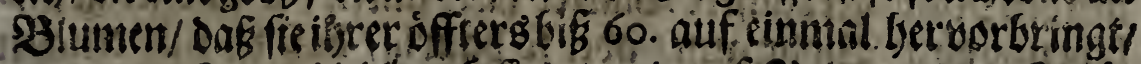
Die an Der Furbe bleidrot fino / uno all Pomeransen Jarbe ziefen. Die fleine blubet zbat nidt in foldem Loerfug / fe iff

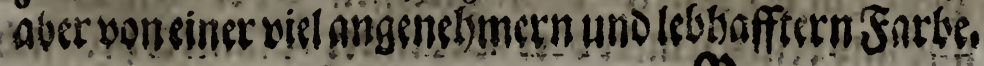

9 
III

Die Binoberrothe tragt mebr 3wiebeln als Silumen.

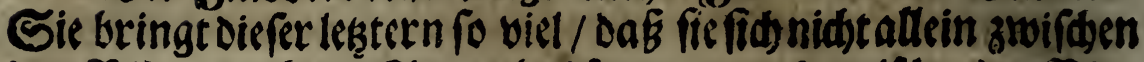

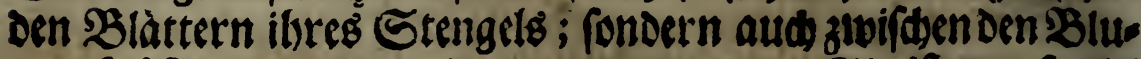
men felbften formiren und bervor tommen. Sie if um fo viel lieblider als ibre Farbe bellglänęend if?.

Die Pomerankenfarbe/ welde cinige poeten= Soyacinth nennen/ gat eine groffe PRenge Poumerankenfarbidter Slumen/ bie mit etlid)en braunen Strident bezcidinet find.

Die tweiffe/ weldbe aud Lys de nôtre Dame, unfer frauen Rilie / oder Lys de faint Antoine de Padouë, \&ilie Des beiligen Antonii bon Padua genennet wirt/ weil fe in ber 3eit / wann diefefeffe einfallen/ blitbet/iff fo wobl in ibrer Farbe/als aud/ negen ibrer Geftalt einem ieden beeant / Derobalben es unnottbigift Dabon zu reden. Dan bar audh gefitute / fieblübenaber gar felten.

Die Rilien noullen mittelmá Bige Sonne / unb ein gutesuns teidtes (Froreid baben / eine Spunne tieff/ uno aud fo weit von cinander fteben. WBann fie verblithet baben/nimmt man fie aus Der (Srden / Die viele Neben=3wickeln Davon abzufondern / uno ber feset fie alsoann gleid wieder.

\section{Zonder of dwertel ssilien.}

Sditwertel: - Eilie.

Die Sdjwertel=Rilie / welde von einigen TuberoIndiano ges nennet wird/treibet unten an Dem Stengel febr viele groffe und oben fpisige SBlátter bervor / oeren untere Theil twei B̈lidt / Der obere Theil aber bon einer angenebmen grunen Sarbeif. DRit. ten ausibren Nerven vodten / Diden / breiten und faft eines 2tr. meslangen Blättern fteiget ein fnotidter Stengel kerfür / an beffen Spike groffe Blumen berwor wadsfen/ Deren eine iede 6 . umben Fano geeràufete sBlàtter bat / unten ber fino fie grü: lidt und ob:n Biolbraun/ aber fo baarig/ Daf fie mit etliden Eleinen meiffen Stecten befprengtem Sammet gleids reben. Diefe SBlárter baben in Der פpitten einen gerviffen erhobenen Qver. Strid/ und aus dem Erunde dDer 25oden der sslume erbebt fíd 


\section{4 bem Slumen=ミ3au.}

efnmitandern fleinen Båfercben oder. Fàden umgebenes Pints? lein/ weldes oben einen Eleinen/ mit oreven EDelgefteinen beftón. ten Straub formiret.

Sic blúbet indeen Martio uno Aprili, Die SBlumen tod́bren

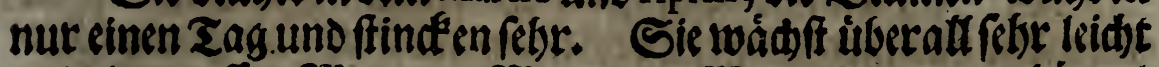
uno in groffer \$Renge. W3ann die 23ursel Dabon gedorcret

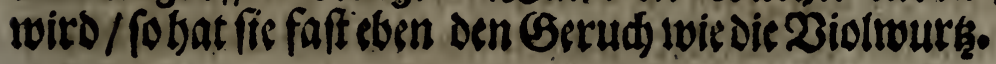

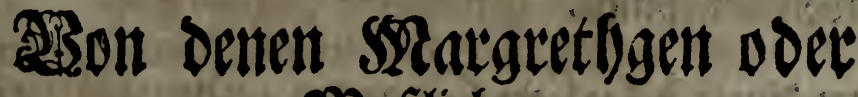 SRaplieber.}

Die \$látter an Denen Margretbgen find Dem Betonien Margretg. gleid. Stan nennet fie befivegen alfo / weil ibre SBlumen / Die gen. zutweilen einfad) / zu tweilen aber gank voller slätter / gans blas oder bleidtweib find / und wie die perlen feben. Sie noo len in einer fetten und feud)ten Erden gebauet werden/ und an rinem Sonnenreidjen Drte freben.

\section{Bon Denen Martagis obet Sendont: foten Rilien.}

Es giebt Derfelbigen von unterfdicdliden Farben: Puts Şenbrifde purfarbe / wo iffe/bodt)=Pomerankenfarbe / 2 . Sier Ean Das je = Eilien. nige / mas in Dem Eapitel von denen Rilien gefagt worden / wies Derbolt werden.

\section{Bondem LentifcoIndica, oder ğndia nif(t)en 2)Raftitz:Saum.}

Diefes ift ber Terpentin = Baum mit fleinen SBlâttern / Janbianis

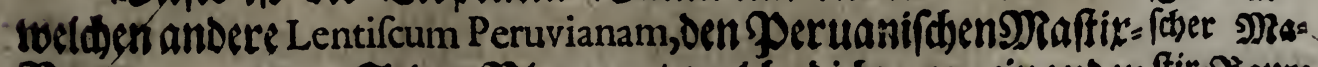
Baum nennen. Seine Blumen / welde didte, an cinander ftir=23aums: $P_{2}$

bane 


\section{ti6 \\ Reue untertweifung}

bangen/ und cinen Trauben/ obngefert ciner Spannen lang formiren/fino von siner weiffen farbic/uno baben inmendig rôth: (id)te Fâferden. Er Glitbet in dern Augufto und Septembri.

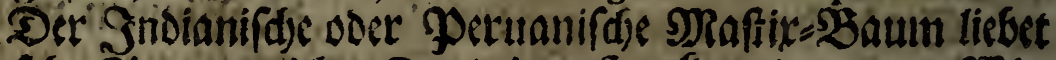
einen febr Somenteicien Drt / cinen ftardfen ober guten $23 i e=$

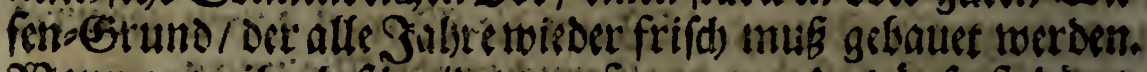

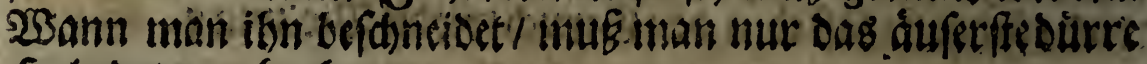
Solkz Davon abnebmen.

\section{Bon dem Mufco Greco, obel Griedis (d)}

Briethi(d) Moop.

Man bat viercelen (Sattungen des (Striedifden NRooft

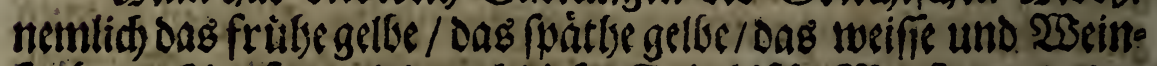

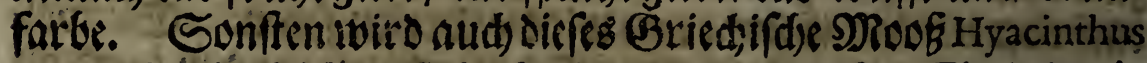
Botryoides, ingleidien Chalcedonicus uno racemofus, Ehalceoonis fajer und Trauben Syacintb genant / Dant von Der פRitten feic nes Stengels bí b ben an if es mit unendid) viel runden und

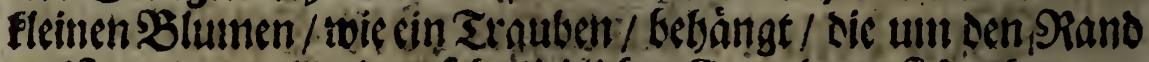

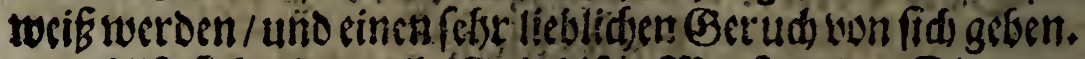

A! fo fieleet Das gelte (Grichifde Meos aus. Die zmen ane Dere Arten aber fino umilsren Stengel gleidfalls mit fo vielen fleinen Blumen umgeteen / weld)e fo viel fleine SDerlen zu fenn

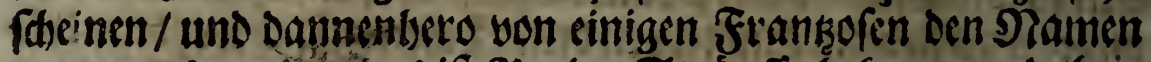
Bouquets de perles, Das iff Derlen Strauffe befommen baben. Sis find von Farbe weis und 2 einfarbidte und baben feinen

i. (s)eruö:

\section{Bondem Lilio Convallio doer elęanen in Bhimlein:}

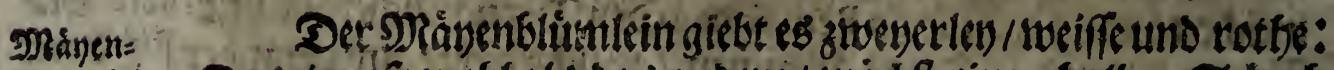

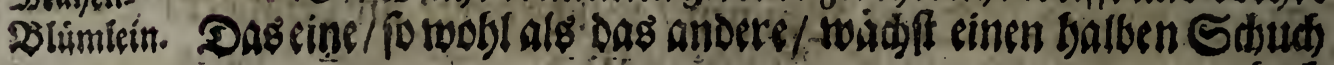
bodi) 


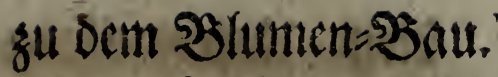

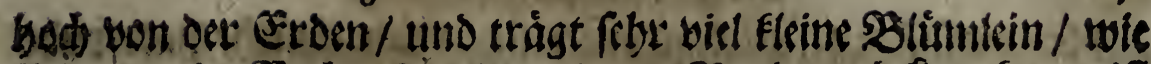
Eleine runde Becher formitet / Deren SRand zurücé gebogen if

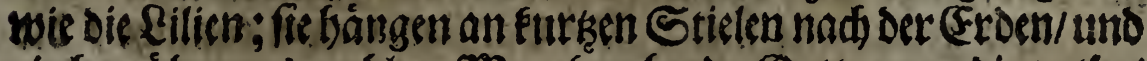
riedten itberaus 10065. Man Ean beyde Eattungen Dic rotbel

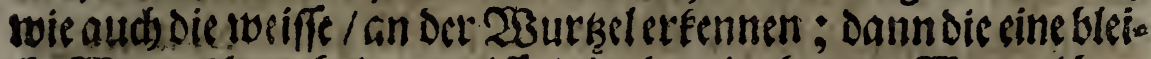

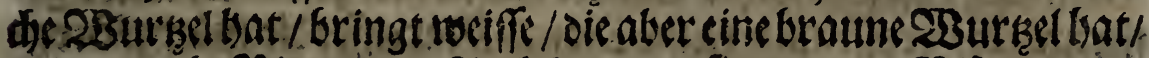

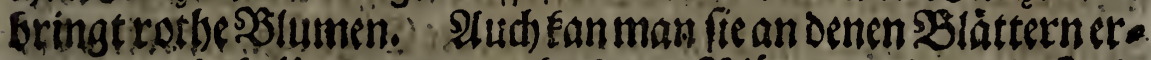

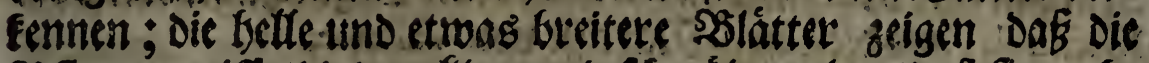

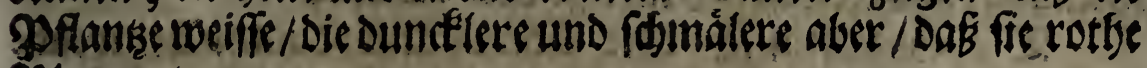
s8lumentrage.

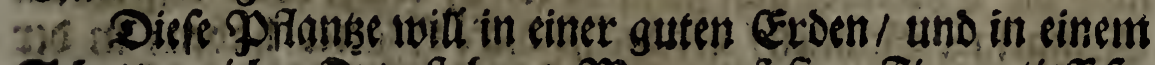

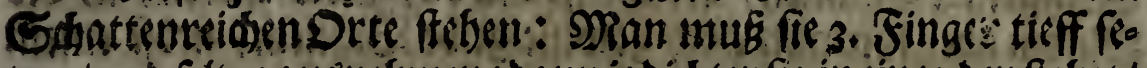

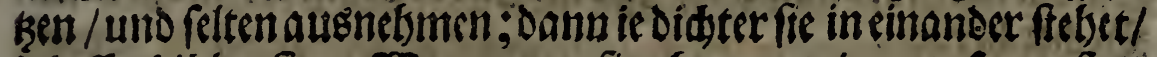

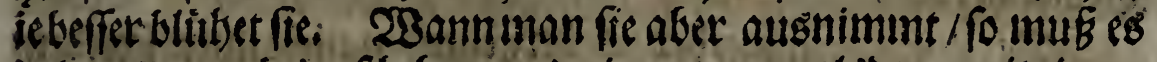
in sem Decombrige fdetlen, und nimunt man alsbann init sinctu

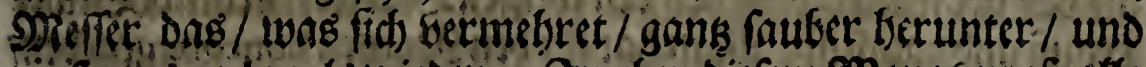

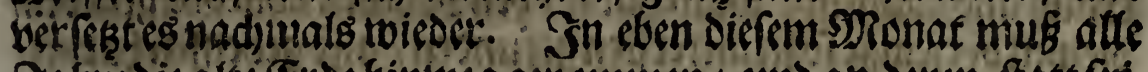

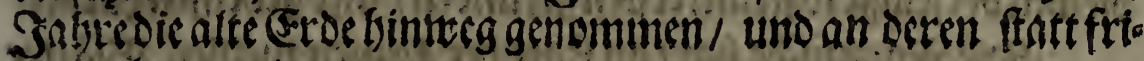
Socgerthan wersein.

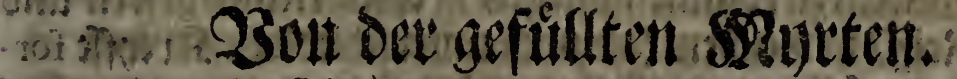

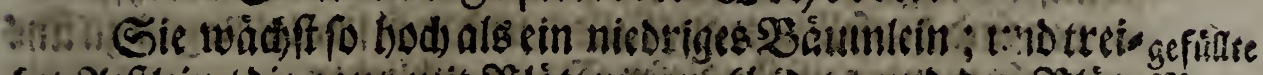

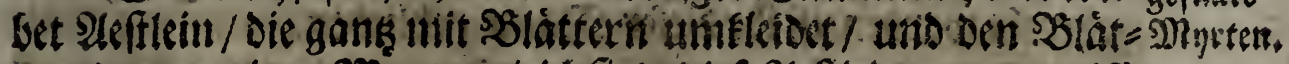

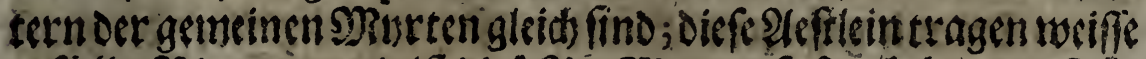

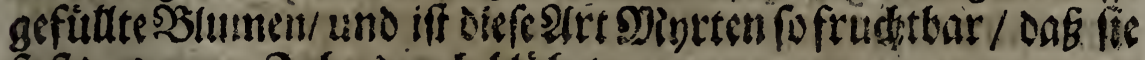

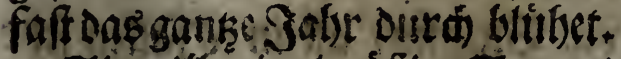

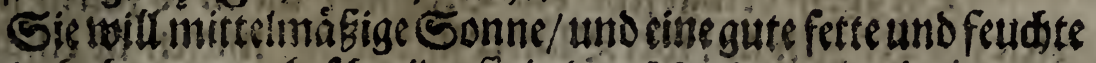
CrDe Gaben; man beffoneidet fic in Dem Martio, und nimint nur Davoriaboas burre.

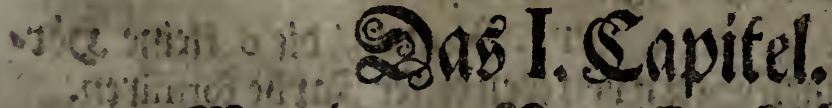

Son Denen Raveifen=gevefteit.

$2 \pi$

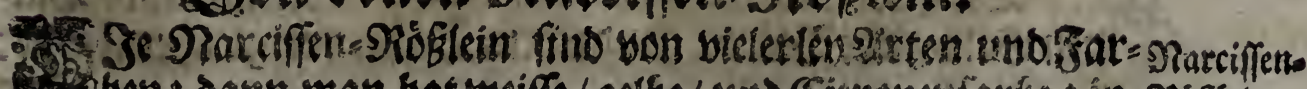

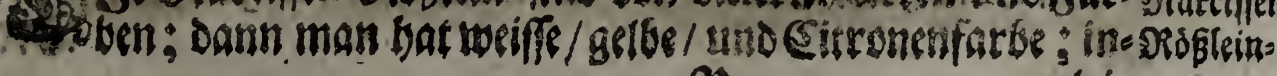

$$
\mathrm{PO}_{3} \text { glela }
$$


I18

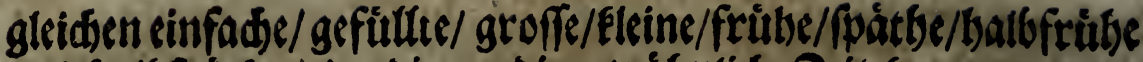

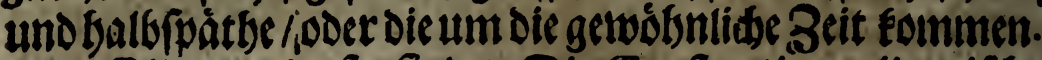

Die gemeineffe fino: Die Eonffantinopolitanifde / Die

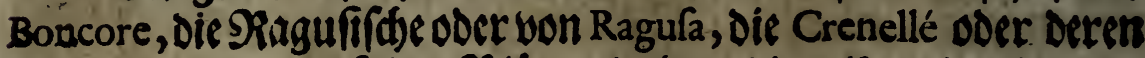

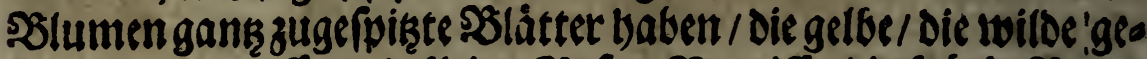

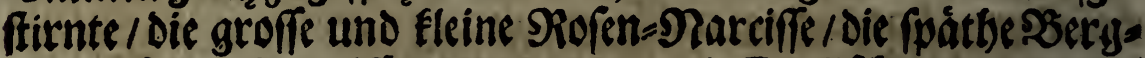
Narciffe / Die Narciffevon Narbonne, Dic Englifwerdie Dritte Des Matthioli, und bie \&ilienc-Narciffe von Valence,

Die Byzantinifose oder Eonftantinewolitanifoser weldse aud bie Egalcebonifde genennt wiro/ trágt oben auf itgrem Stengel 12. Blumen/ Die reeiffe Dide's Slatter baben; in Der MRitten aber Eonumen aud) gerwiffi gelbe SBlätlein / nebf cinem Decder bervor.

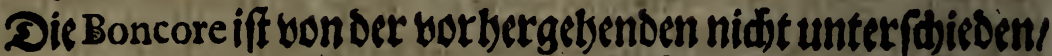

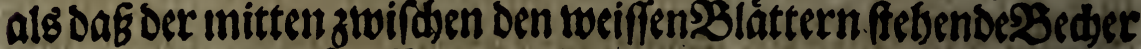
frauß und raudi iff. NRan bat ibr Den Namen Boncore' gegebemI Dieweil berienige fo fie aum erferen gefunden / alfo getbeiffen bat.

Die SRaguffifae bat / an ftatt Der Éleinen sweiffen slátter Die in ber Mitten zu Eomemen pilegen / einen Eleinen gelben uno Eraufen SReiff/ in weldem fid nod) unter fdjectide Srenffe formiren uno denfelligen ausf futten/ und wesil fie aus Ragufa zuuns gebradst worden/ift ibr diefer Name geblieben. undefline.

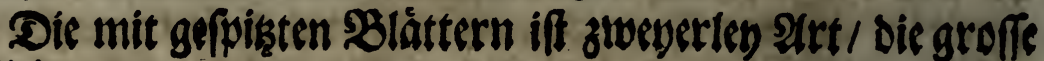

Die groffebringt fertr viel Blumen/ allein es fallen febr

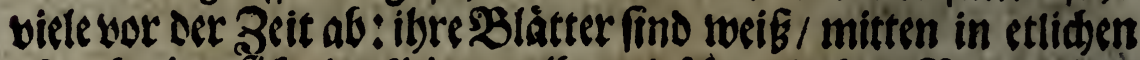

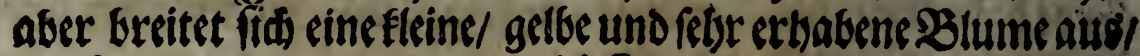
Die oben einem fleinen Sorn gleid) fiebet.

Die fleinetrágt nur 4.00er 5. Blumen/ Die 6. Fleine Sör. ner baben / und einen Stern bont eben Diefer Farbe formiren.

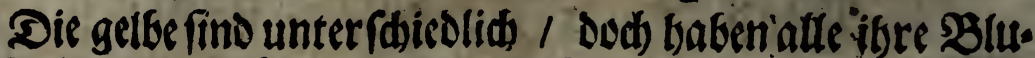
men Gollogellber Blätter / und cinem 2 edser won gleider farbe: 


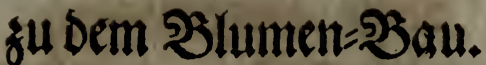

Der Unter facid beffebet nar Darinnen/Dab eine groffer oder Elei: ner/beller oder buncfuler als bie andere iff.

Dienviloe geffirnte bat eine gefuttte SBiume/ beren Blattet Strobfarb oder bleidggelb find/ und wie cin Stern abgetbeilet freben.

Die fleine Siofen= Narciffe if lidtgelo / und gants votter Blátter: Sie wird aud Narciffe frife oder die fraufe Narciffe genannt/ weil fie fraufe uno runslid)te $\mathfrak{B l a ̆ t t e r ~ b a t ~ w i e ~ R u b l ~}$ oder Eartid); fie fálut aber gerne vor cer Bcit ab.

Die groffe SRofen=?Rarciffe/ Ibelde aud Sylveftrisultramontanus beift / trägt nur cine Slume: in Der mitten bringt fie/ an ftatt cines soeders / febr biel geooppelt liegenoe Blátter berfür / Dabon sinige lidbtgel6 I uno grünlidet fino: 20ann fie fids offnen und nad und nad auseinander breiten / fo focinet es eine gelbe Siofe zu fenn: allein ber Sdonee und Die 23affer oder SRegen maden offt dofíf fie plaksen oder auf: fpringen.

Die fpattbe Berg=narcifetràgt Drev oder bier Blumen mit weiffen SBláttern / oie gróffer findals Der gemeinen Narciffel fie find aber gebroden / und feben fo / Dafíf fie Die Figur eines Sterngborfellen. Siehaben einenbreiten Beder Eitronen! uno zumeilen Pomeranken-Sarb.

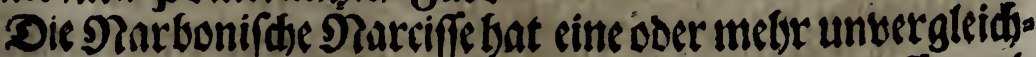
lid) Eleinere $\mathfrak{B}$ lumen als die andere Parciffen/ einen groffen gelo ben seder / Der fid) an Der Deffnung wie cine Glofte auss breitet.

Die Engliffie bat eine etwas groffere SBlume als bie vot: bergebende; Der $\mathfrak{B}$ ed)er iff aud gelb / und iberall von gleider. 2sseite.

Die dritte Narciffe deg Matthioli, tràgt auf tem Gipffel ifg res Stengels / Der melyr breit als rund ift / 10. Dder 12. weiffe Blumen/ Die 6. lange uno fímale SBlátter augbereiten / weldes bonsinander gefondert/und wie Sternenausgetbeilet fetben/ in 


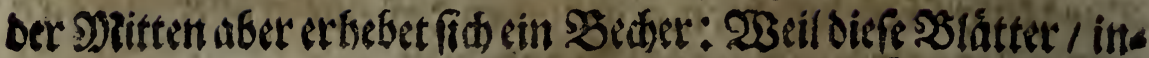

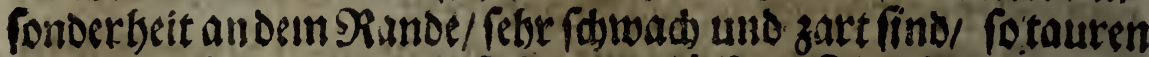
fiesuluds nidet lange. Diere sslumen óffnen fid nad einander)

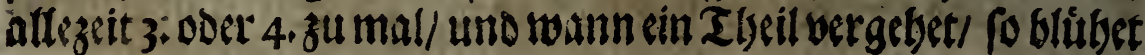
ser andere toiederum.

Dir Rilien=97neciffe von Valence, ober Lilio-Narciffus Valentinus f. folio Hemerocall, trägt auf Dem Gipffel ibres Sten gel' 8. Doer ro. \$3lumen / die denen/ welde roir iest befabrefen

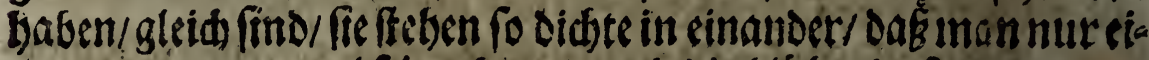
ac oder ziwey zumal fithen fan / und die blitkende fangenan zu

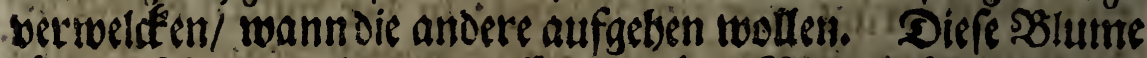

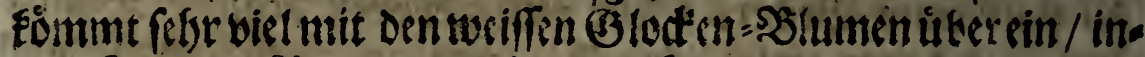
Dem fie lange/ fosmale/ son einander fishende / wie ein Stern for-

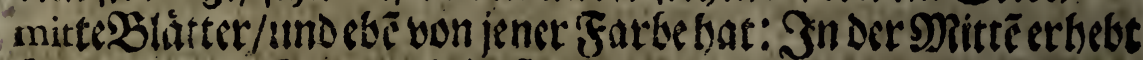

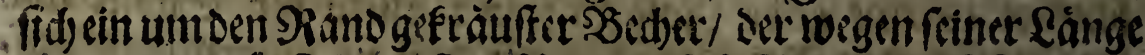

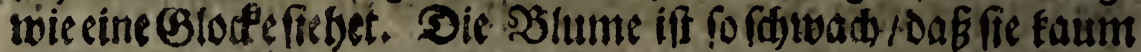

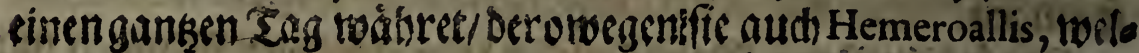
des ebenfo viel als eine sslume ober Edjonbsit / bie nur sinen Sag tauret / getnennerwiro.

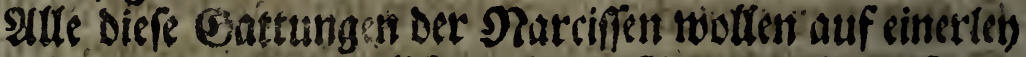
2Beife gebautetwerden/nemlidi) an einem Sonnenteiden Drtel

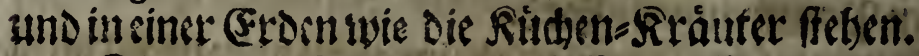

Sis twerdenfed) E Finger tieffin die (Groe/ und cinen halben Sdud) tweit won einnoner gefe(tst.

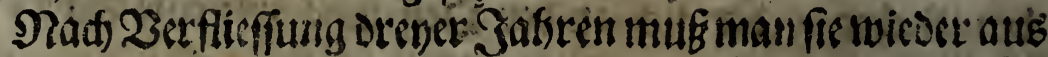
Der (Frben berausnetsmen / und Die Vicben=şrut/ ineide fid) in dicfer Bsit gemebret hat/sabon absonoern.

$$
\text { 2.2n II. Cnpitel| }
$$

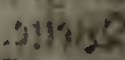

5. Bon Dev gufopen Ravciffe/ Nompareil genannt.

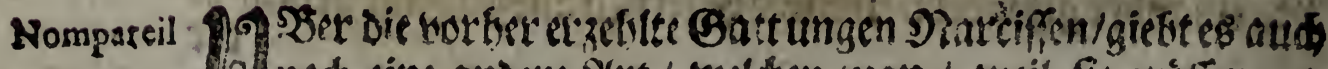

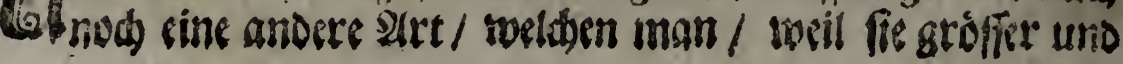




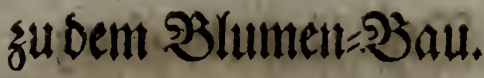

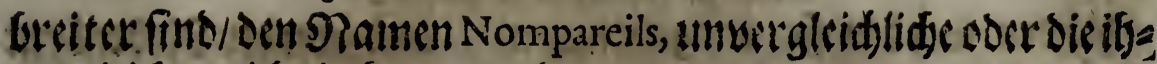
resg gleiden nid)t baten/ gegeten.

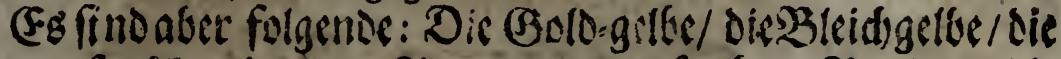
Citrontenfartse nit dem Pomeranken = farben Siande / die groffe weiffe/ cie fleine weiffs und die geffitlute Eitrenenfarbe.

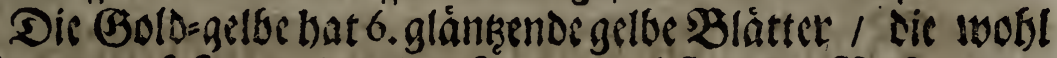

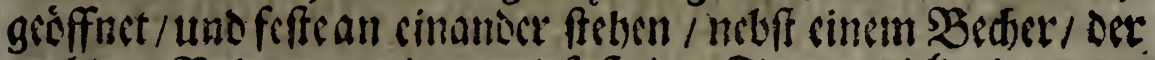

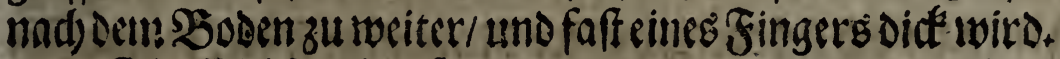

Die Sblididgelbe if bon Der vorbergebenden nidbt unter-

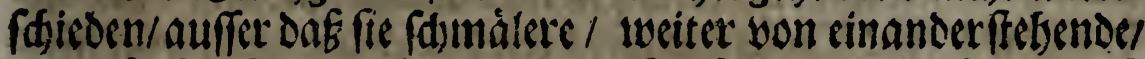

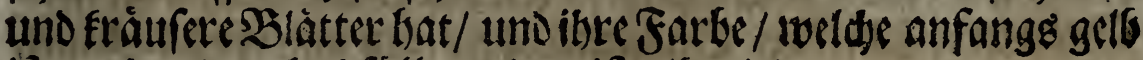

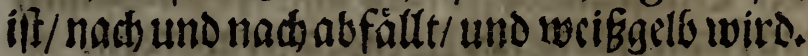

Die Sitronen farbe/ mit decm Spomerangenfarbern SRanber

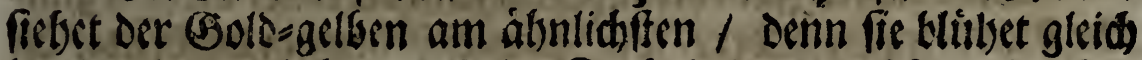

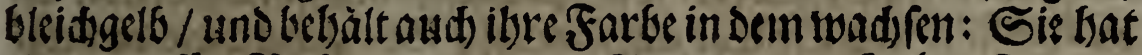
cinengreffien 2Bedert / mit cimem poomerankenfarben Siande; Die B lätter find audh Greiter / und ffel bon Didster in cinander.

Die groffe meiffe tresitct itse SBlätter aus cinander / aber Die Eleine bat fie näber benfaummen uno beffer vereiniget: 2Alfo

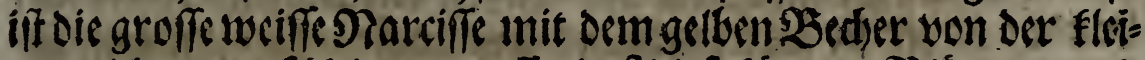

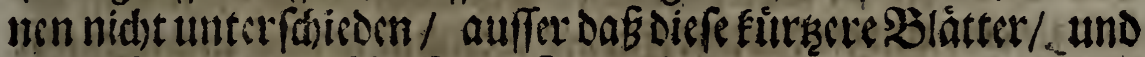
einen 3 Beder von lebbafferer Farbe bat.

Die gefitute Eitronenfarbe bat bī bren SReiben zientid) groffe SBlätter rings berum / und in difen Srenffer voadfifen

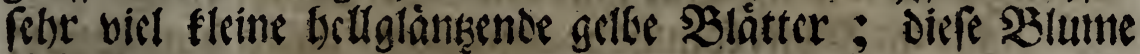

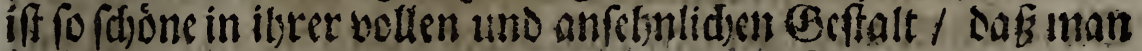

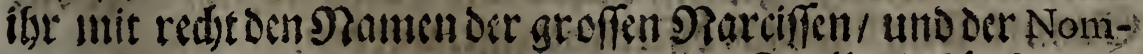
pareil ober obne gleid/geben fan; Denn fie alle Sdjonbeiten/. Die manbern andern 3 ertllyeiler findect/ alleinan fid bat.

Diefe Battung Der Paurciffen twill an einem mittellmàf

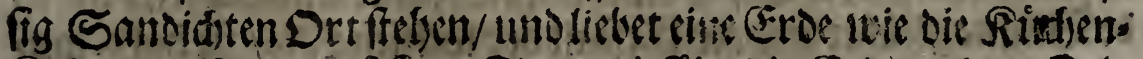

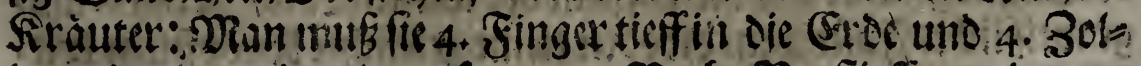

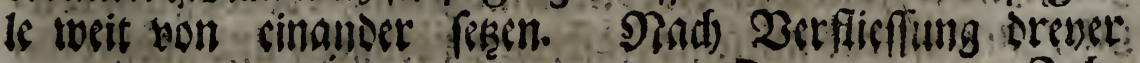


Sabren werben fie auggenommen / uno bon oer Negentrut befrevet.

\section{2ณร III. Snpitell \\ Bon Denen Indianifäen Parcifín.}

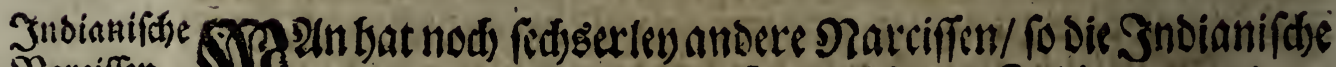
Siarcifen.

$22 \mathrm{~s}$ genennet werden/ weilen fe neulid) aus Sndien zu uns ges bradjt worden: Die Birginifde twirs attd Darunter begriffen. SBienun Diefe in ibren B lumen und Farben unterfdied lid find/ alfo wollen fie aud) auf unter foied lide art gebautet werden.

Sienad) ber Zahl berzufagen/ fo iff Die erffe/ Die Zirginis

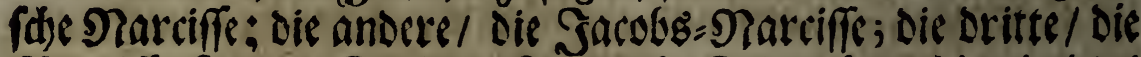
Sarciffe/ ro in ber Farbe nutf Dierotbe Rilie zietet ; Die vierdote/ Dienuf 23 einfarbe ziebet; dic fünffte/ cie Diarciffe foauf Liliun

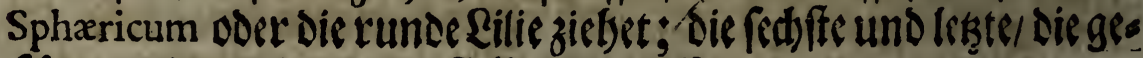
fohuppte doppelte ober gefulfte Sarciffs.

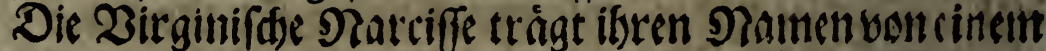
Sande/ Daber fie gefornmen ift: 2 Saln fie anfángt zublitten/ Gat fie cine unteine weiffe Farbe/ Die fid aber nad) uno nadj mit

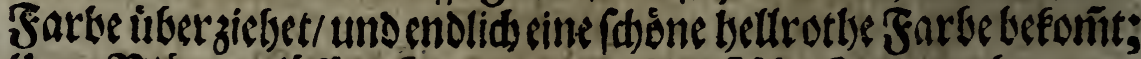
ibre Blátter láffet fie wie sine Perfiffoe Tullippe bantgen' nur oags fie ein wenig greffer find/ uno fich niemaloffnen.

Sndem Topffe fomme fie beffer fort / als in Dem Rande: Sie will uber 2, Finger tieff nidt in ser (erden fteben / nid)t biel Sonne baben/ und nidt of ferers ver fesetwerden.

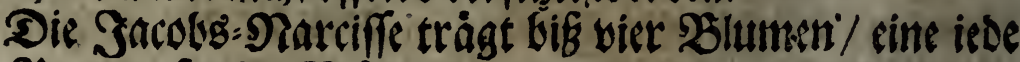
yon 6. Putruturfarben Bl n̂ttern/ Die unten stwag in Der Farbe abfalten/oben aber aufPotmeranken, Sarbe audlauffen; ein ie:

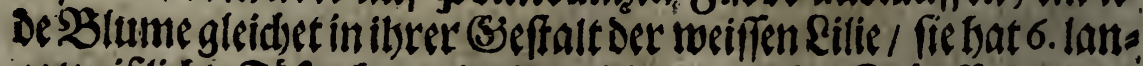
ge weiglid)te Fäferden/Die oben Eleine getblid)te Rnêpfflein frie: gen L uno if das mittelfe Fáferden rótgliogt/ uno groffer als 


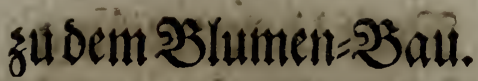

Die ürrige: Diefe

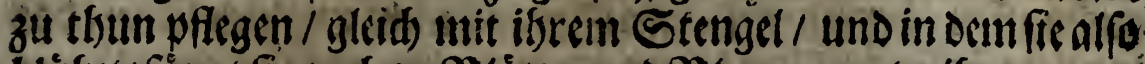

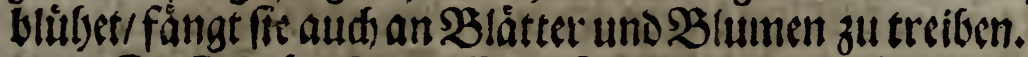

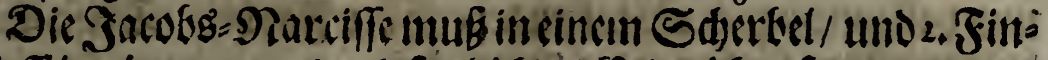

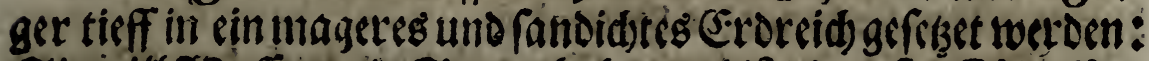

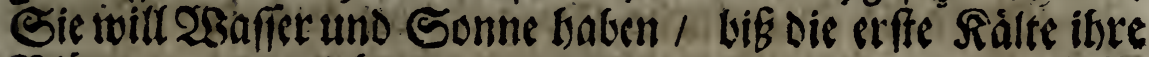
Blâtter ausgetrodénet und betborret bat I alsbenn ffellfe

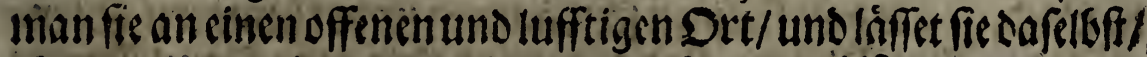

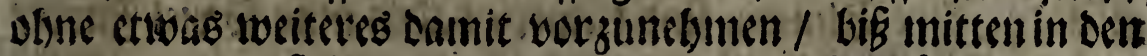

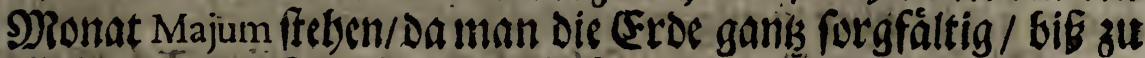

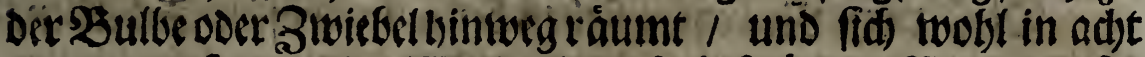

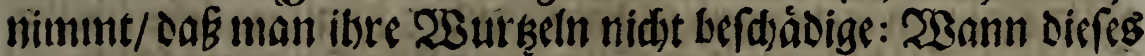

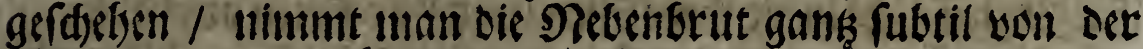

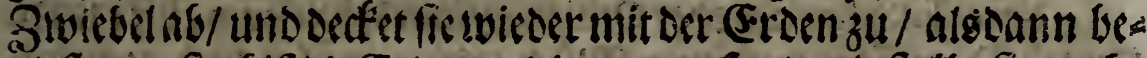

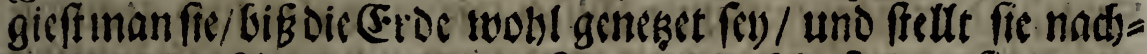

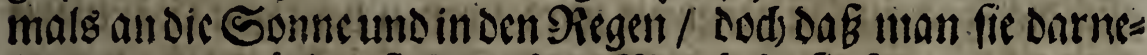

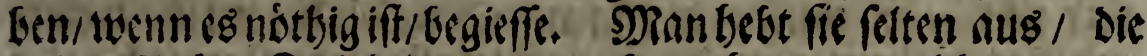

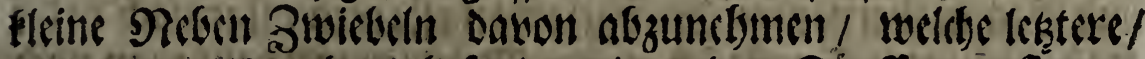

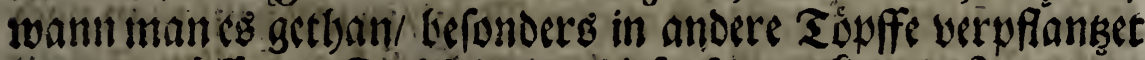

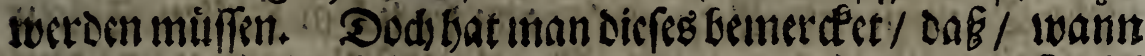

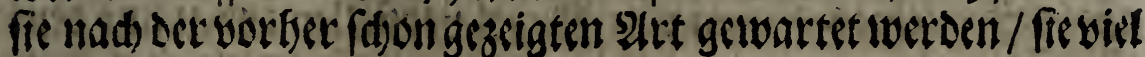
beffer Elitilien.

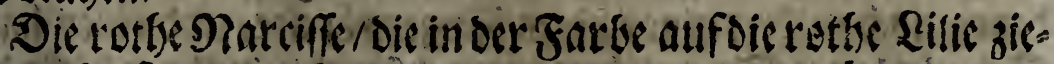
bet / unt fonften Narciffe Madame genemnet witro / trägt 20, und

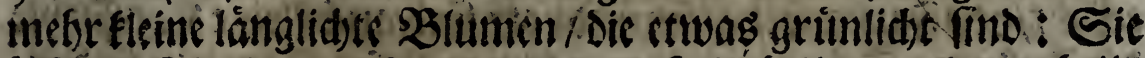
siffien fid eine nad) Der andern/ find theils gerade / theils

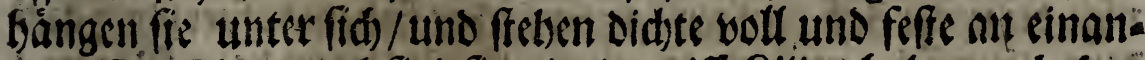

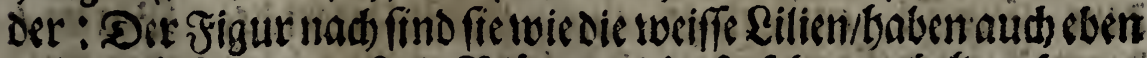

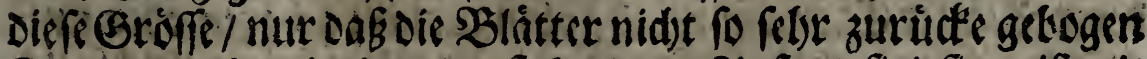

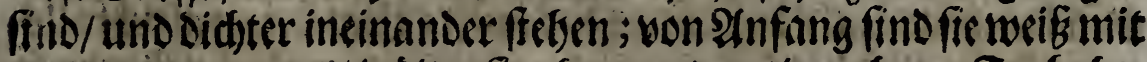
roth untermenget'/ iea alter fie aber werden / ic mebrere Sarbe be

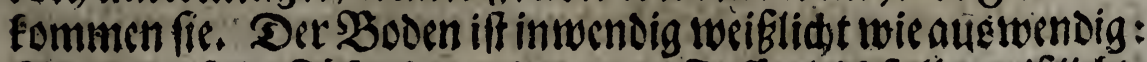

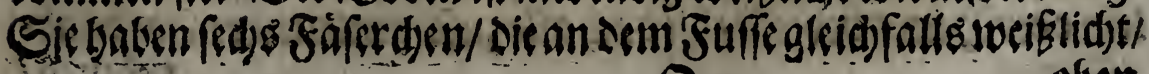


oben afer rottslid) find / und auf sinen flinen runeen (Gipffel

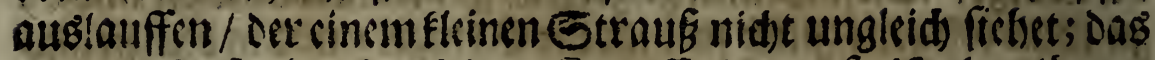
mittlere Fäferden bat frinen Rnopffoben nuf / iff aber länger unowolleommener als bic andere in der Farbe. Diefe $5 B$ lume Whither in Dem 2 Anfanac des Septembris.

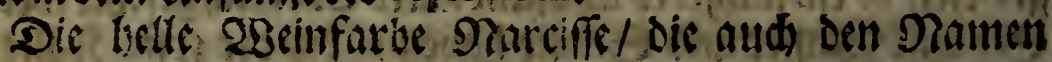

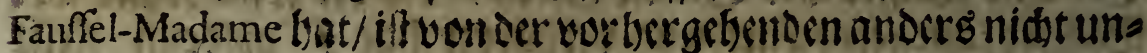

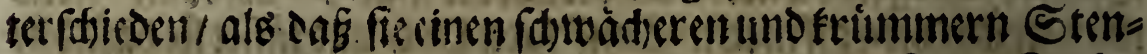
gel bat; Sflore Blumen fino fleiner/ baben nidet fo viel Sarbel. aud) träst fie ibrer weniger.

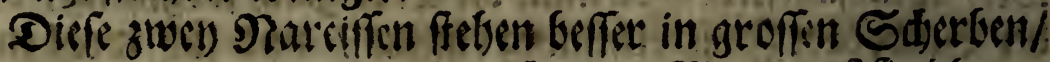

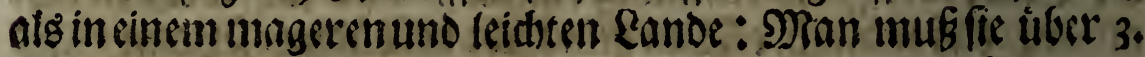
Finger tieff nides in dic (Frde fersen / und febtr folten ausbeben.

Narciflus Spharicus DDer Ornithogalum Sphericum, Die runde

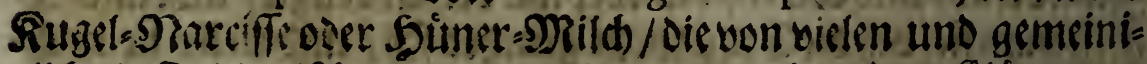

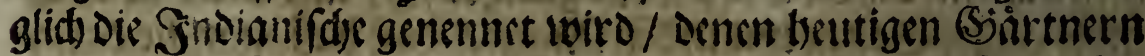

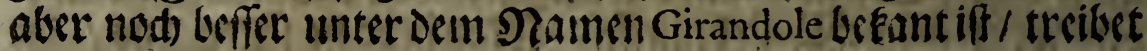

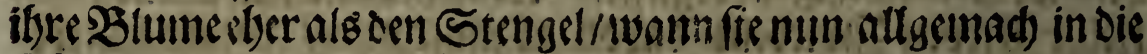

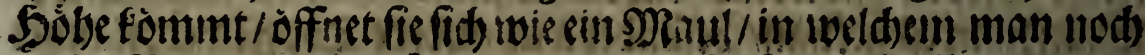

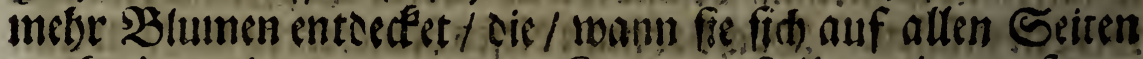
ausbreiten/ cine Spharam ocer Siugch berftetlen; ; oben auf oem

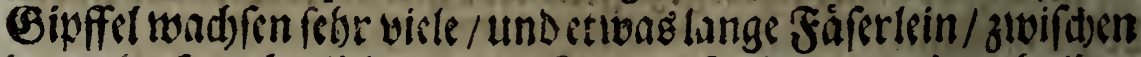
Denen nod mebr flcine / cintes Singers frecite/ und eines balben

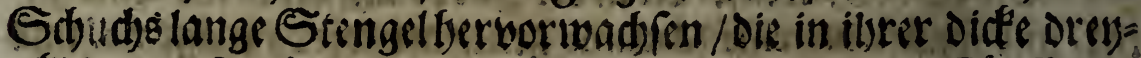

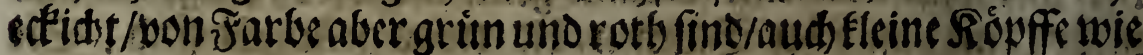

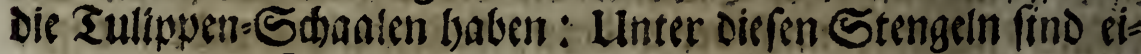
nige Die unter fidh bangen / andere aber frethen aufgeridte ; aus

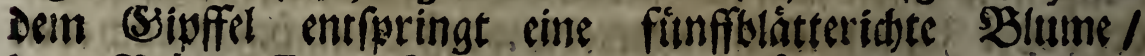

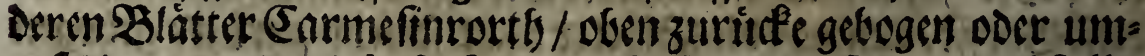

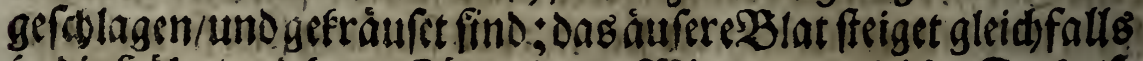

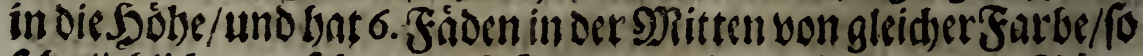

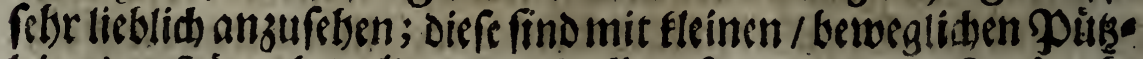

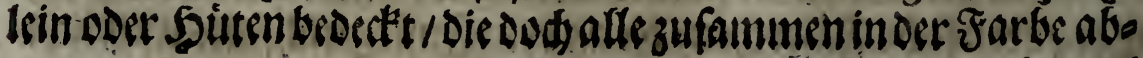
\$nis 


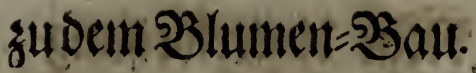

netsmin / und Graungell werdern. Der fiebenbe Faden iff länger

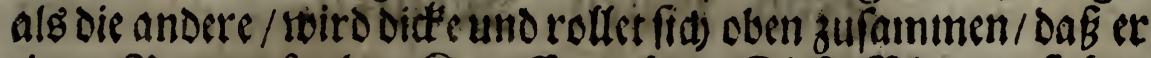

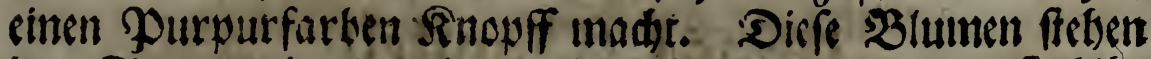
Dren Finger weit / oder sin menig iveiter won einander; fie blit= ben nad) einander/ une, vergether nidft cine einige/Dag nidft an

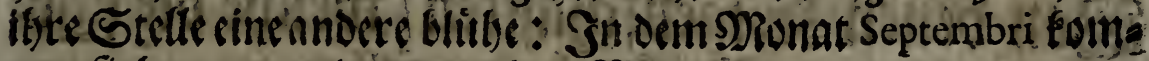
men fietberwor / und tauren cinen Pronat.

Sie witd twie Die yorther gelsende gebauet / nur daE man

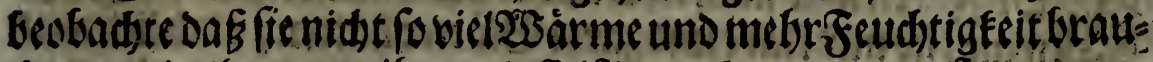

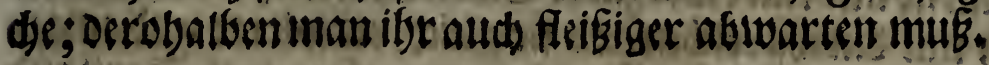

Dic gefdunpte Varcifife/ Fonfen aud Suertro Colchicum; offters aber Indicum genannt/ bringt aus ibrer Sillen cine Blume wie cine (Siranate init 6 . zul weilen aud mebr fdónen Feurcrothen Blattern / und in diefen $B$ lumen fino nod febte vile

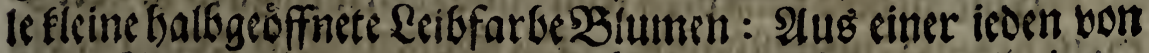

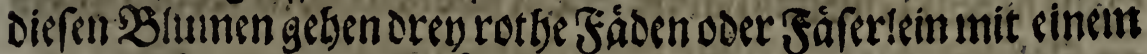

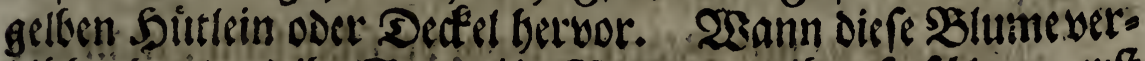

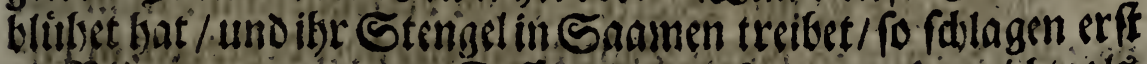

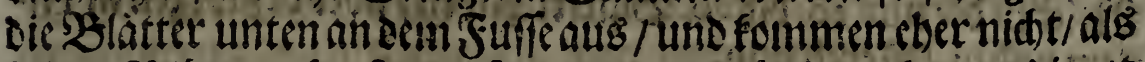

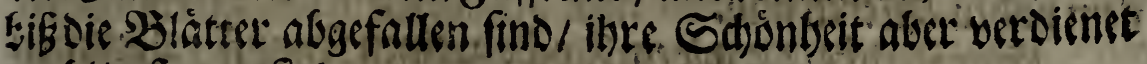
Hoobl da

Diefe orarciffe for man liefer in zipfe/ fo mit magerer und fansideter Eroels angefitllet find / und 3 . Finger tieff / als in

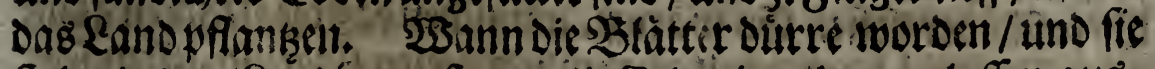

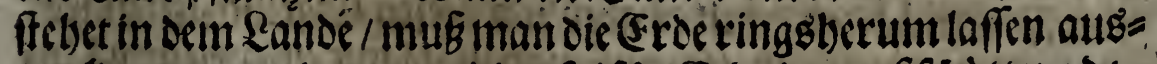

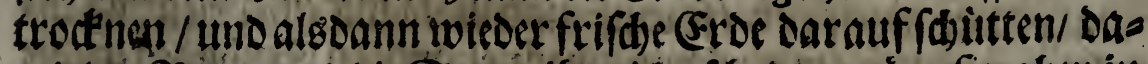

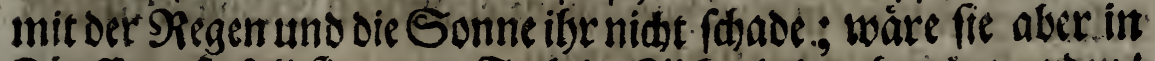

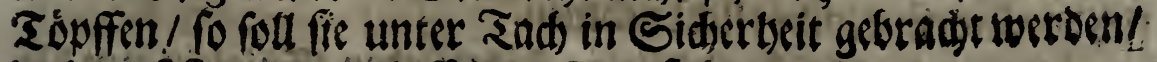
DodimuE fre an sinein lufftigen orte frelen. 


\section{(3) aร̃I. S. apitell}

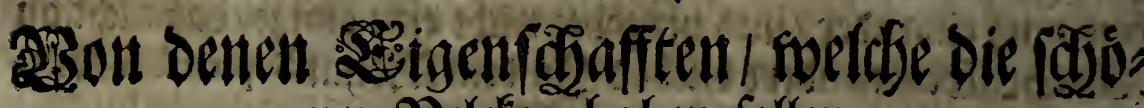
nen reldeten baben follen.

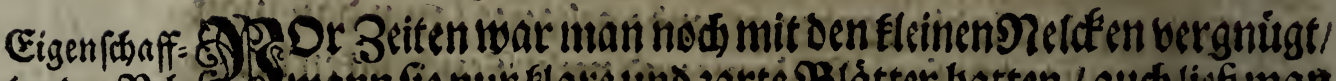

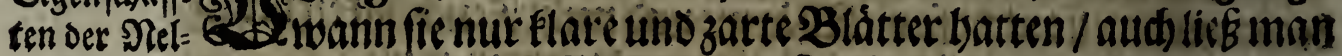
cfen.

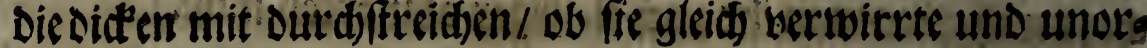
Dentlid bermifate Farben batten ; wer aber. cinen Zerffano Davonbat / verivirfft foldies / Dann an Den SBlumen muk man nadj Der Sdjónbeit feben /. und die NRängel / fo fid) Daran befins den $/$ veradsten.

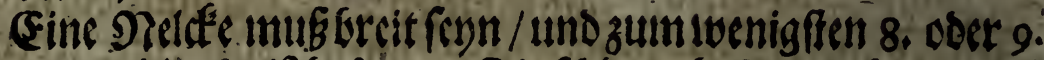

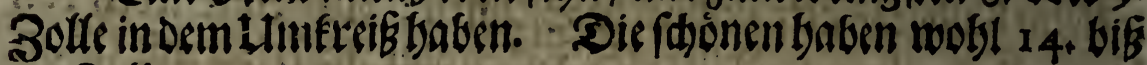
15. Bolle.

2ud) mus fie mit 2 láttern'wobl verfegen fenn ; man bat

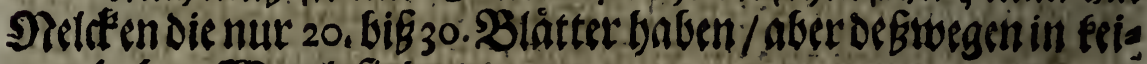
nein boben 2 serth fint.

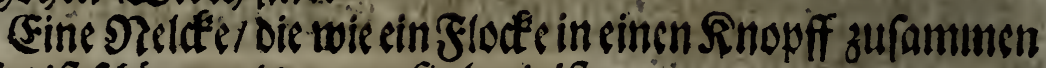
láuff / iff fáoner als twann fie breit iff.

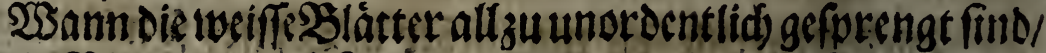
fo iff die Blume verorieslide uno unangenebune. Se reiner fie.

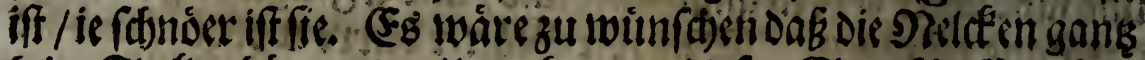

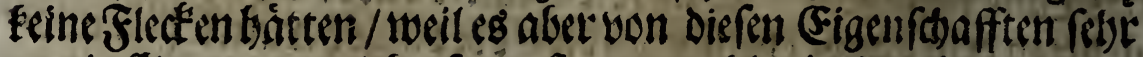
wenig SSattungen giefsi fo inus man to obs init einer flcinen un

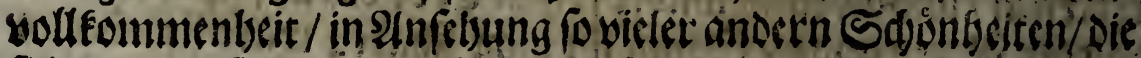
fid Daranbefinden/vorliebt nebmen.

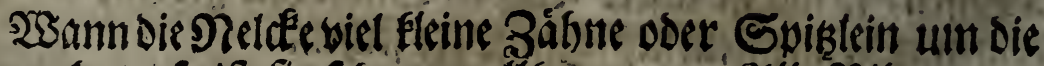
sBlatter bat / fo iff fie fabr unbollfeommen. SUle Sblátter Der

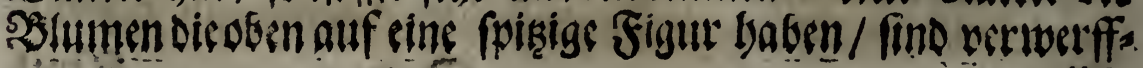




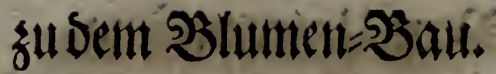

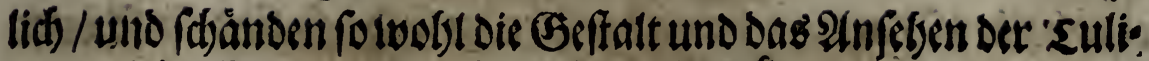
pen und der itnemonen / als audi ber Reldeen.

Es getset folver bet fo dife ?elcfen zu befommen/als matt

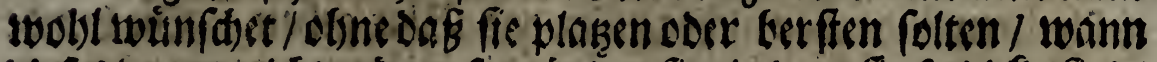

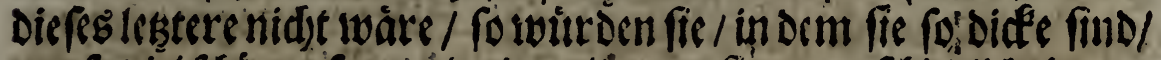

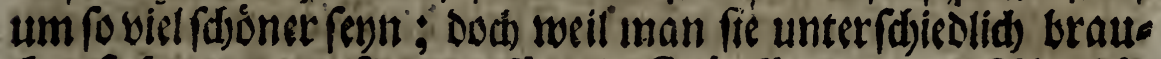
det/ fo fan man auf oen groffen viel sinopffe uno unter f diedidse obere Stengel laffen / wannman fie Dem Srauenzimmer verels. rentwill. Diefererd den nidte fo breit / uno plasen nidbt fo weit von cinander / zu Zeiten aud) gar nid)t / wamn man ifuen nut

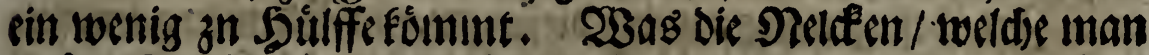
aufoie Stellagen oder Gelänoer fersen will / betriffe / Diefelbige inuB man treiben uno twadfen laffen/ fo weit fie ç bringen fơn= nen/ bann das ftarcée Papier / ober was man fonfent Darum

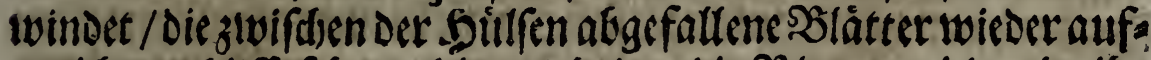

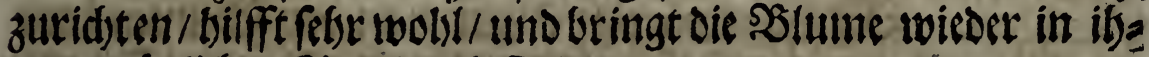
rennatiurliden Stand und Ordnung.

Fine aufgefpaltene und wicder zugeridstete Velde iff viel fdooner als cine andere; $e^{2}$ iff cin alter Febler / Den man aber

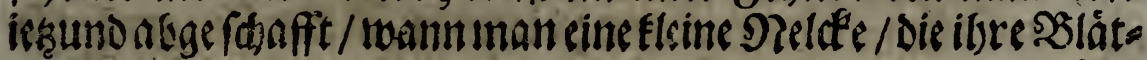
ter felb fist in guter Oronung leget tmo austbeilet / einer febr gtoffen / an die man Sand anlegen imuk / bat vorgezogen / Die

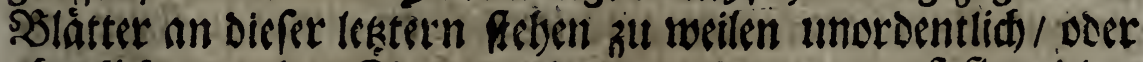
aber fleben von dent Shau an sinander / Darum muk fie wieder geridstet uno in Dronung gefrad)t werden. San muß alles auf Das beffe unaden / als eg feyn fan : Man mus aber der Sade nidbt zu viel thun / nodd diesslätter siner SSlumen / bie man breia

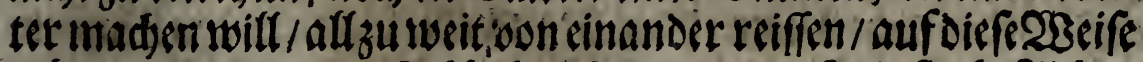

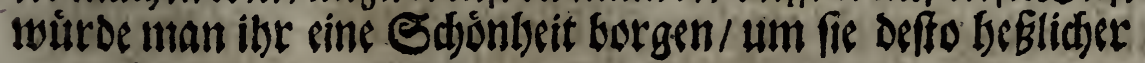
zu mad)en.

Se gleider cine Sslume gefprengt/ oder von Farte iff / ie foimer if biefelbige.

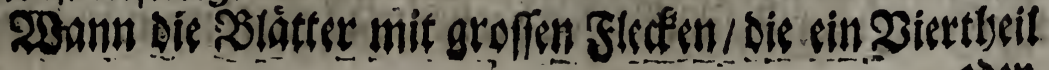
QDe 
Doer balkes s3lat einnebmen / geforengt fino / fo find fie fajonet als die / welde Eleine Fletfen baben.

CEg iff allezeit beffer / wann die Flecten wobl gezogen oder

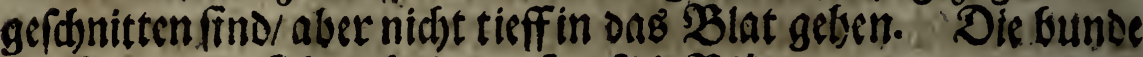

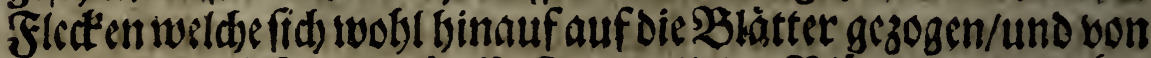

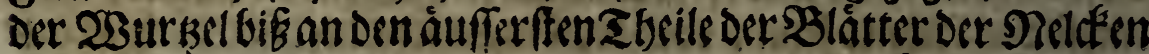
fid)erftrecen/f fmo angenelsuter als Die andere Flecten/Die feinen ursprung baben. Sen ben Tulippen nennendie Francofendies feșlesterè aeux, ober à Isle; die 2ugen oder Infuln baben / uno diefegfintes/ die ammeiffen gefudte twerden.

Sekt befagte Regel if bendiefen ztwensen Blumen gang twis Derwartig/ unto bat nictsts deffo weniger feine Ur fadse / Dienteil nemlid) Die Tultipe ein breites S3lat bat $/$ das von Dem SBlat der

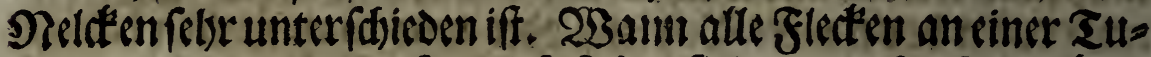
lipe gants bon unten anfangë/ fo fetsen fie in einer abgefdemad" ten (s)leidbeit. Die widerwärtige J̈iguten an Den S5ltumen / mit

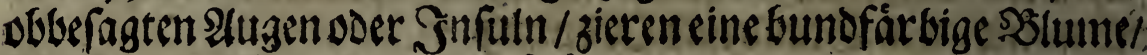
Die cin breites S3lat bat/ weit fdjoner als cine andere. Die Net afe bat biefes nidst von notthen/ibre S3 und farbe fan obne Unter=

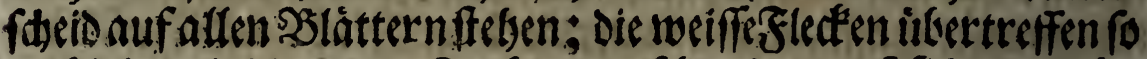

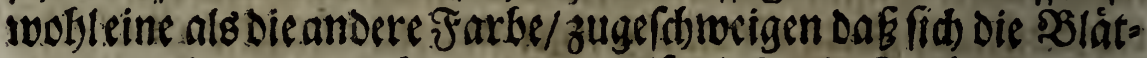
ter unter einander verbergen/ und alfo Die Gunde farben zu un=

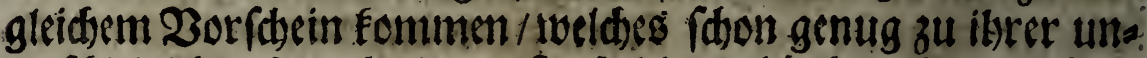

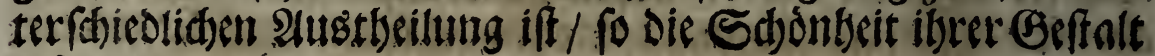
erfordert.

DRan rebet biet nifbe vondenen (Figenfdafiten Derisnigen Pelfer welche le nouveau monde genemet wiro: Diefios if eine:

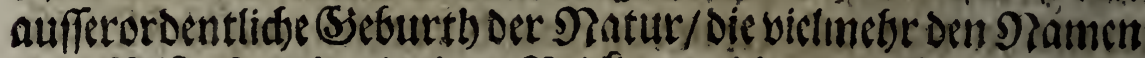

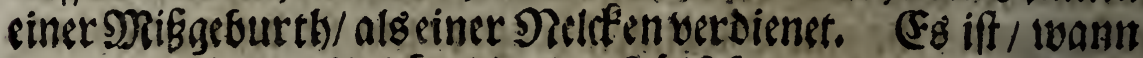

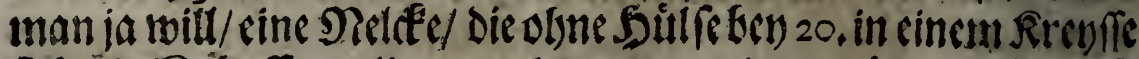

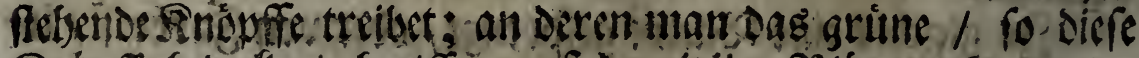

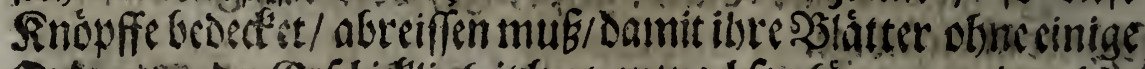

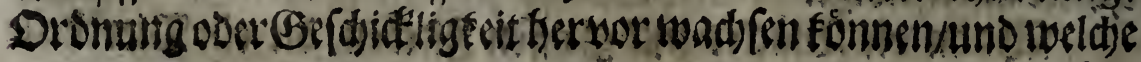




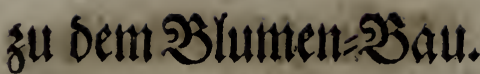

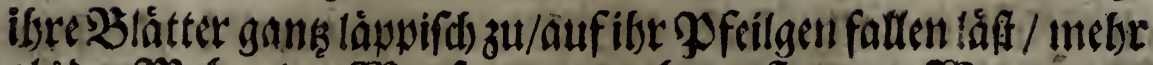
als Der Molsn voer SPRg fanmen zu thun pfleget. WBann man. fie oroentlid) auf ein Papier ausgebreitet bat / fo verwundern

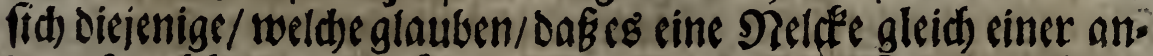
Dern fen/ itber ibre Didfe vber Llmfang; wann fie nber wüfen

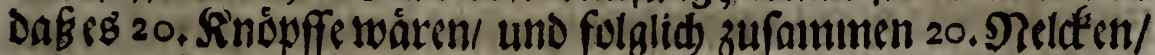
wirben fie fid verivundern Dak fie fo feler Elein iff : Diefe

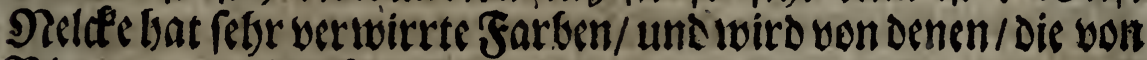
Slumen gute 2Biffenforfft baben/felse wenig geadjt.

\section{2å̉ II. Capitel.}

\section{Bondom ₹opfe oder Sdherbel/Dareinman Die Reldefe pifangen foll.}

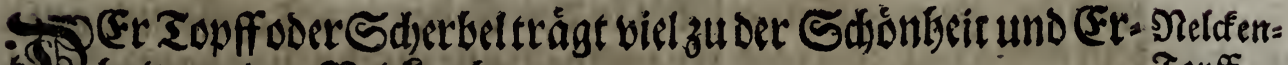
Sobaltung der Neleen ben. Bopff.

Erfflid) zu ilsrer Subonkeit: Dann biele nebmen alfzil groffe/oder allzu fleine Toppfe/ und pwitbren diefen Febler augens fdcinlid. Waann ber Topff zu grof iff / po ziebet die Nelde alfe

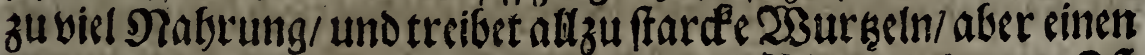
fleinen Rnopff/ ber feine diffe oder groffe Sllume bringt. If

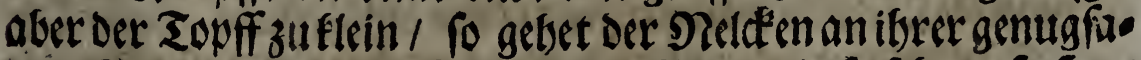

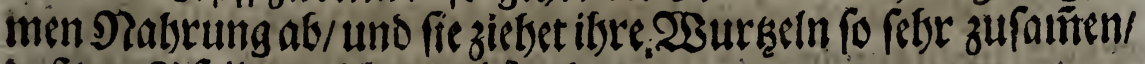
DaÉ Das Pf frilgen nid)t wadhen fan:

Der bequemfte Sopff foll woneiner mittelmábigen Groffe fern/ untenenger als oben/ und darein obngefebr fo vidl (Erde geo be/ als man in einen Sout faffen fan.

Zor Das andere fo dienet er aud) zu (Erbaltung oer Nets den / Dieer vor alf zu bicler Fendtigfeit und Ditrre letwabret/ Davon jene Die Fáule/ Diefe atber Den SRoff verurfadtet. Daber

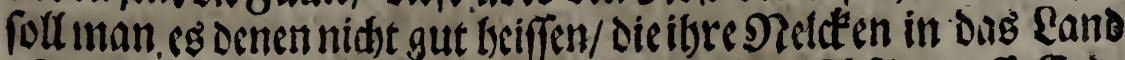

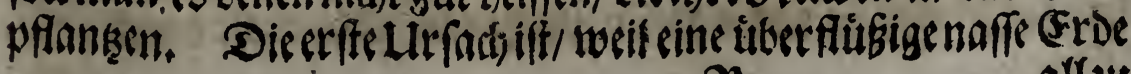
$\Re$ 


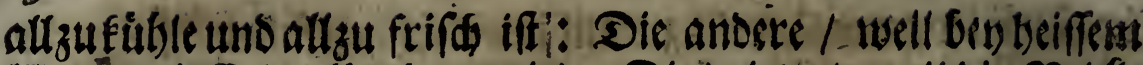

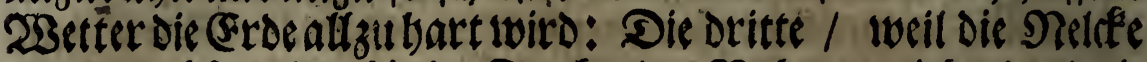
entweder itfer die geborige Srudjt toder Nabrung ziebet/ und ale fo plaket / oder fie zietet zutwenig/ uno bleibt zuElein: Die viero= te / weil twir aus der (Erfabrung baben / DaE . Die Nelde? in Dem Ranoe niemal fo fdjón, bund farbig neird/ nod ibec Stridje oder

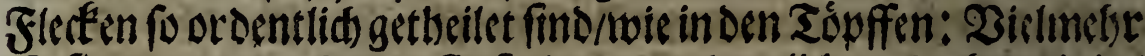
if fie von gans Eeiner (Beffalt / unordentlid) uno olyne cinige Sdjonbeit: Die finffere / weil mangróffere MRitte und Sabits

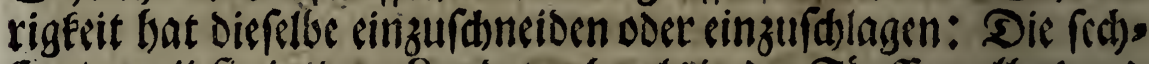

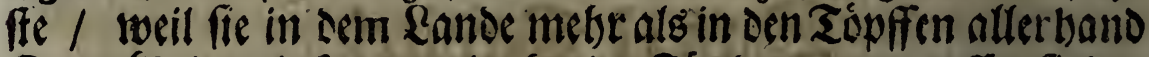
Rrand"beiten/infonterbeit aber Der Fáule/ unterwoerffen fino.

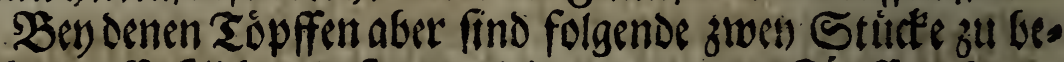
obadten: Erfflid / Dabs man feine gants neue Topffe nelomen

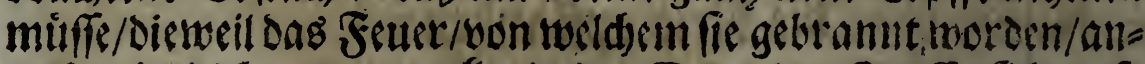
nod) / ob gleid) unvermer(et / in Dek Erden Deg Topff: fid) nutfs

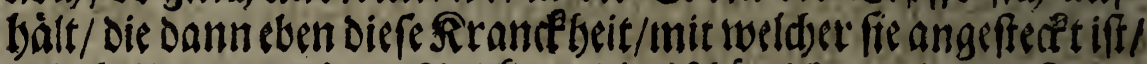

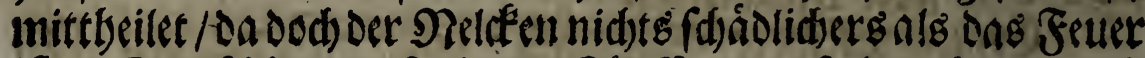
iff. Den Sdanden/ fodientue Topffe berurfadsen fonten/alfo zu verbutten / Imus man fie. entiveder 12. Stunden in einem mit

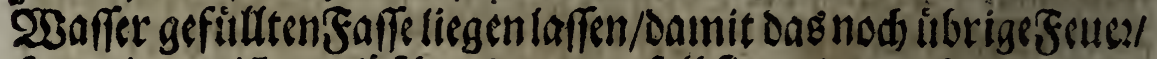

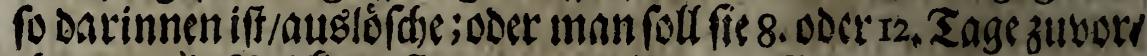
cbe mandic Pelden pflanket / mit Eroe anfitlen.

Dab andere fo man zu beobadben bat/ift dab man die

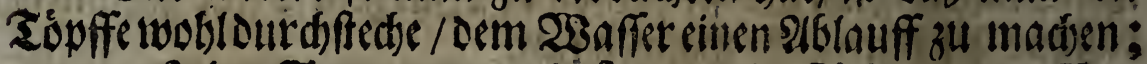

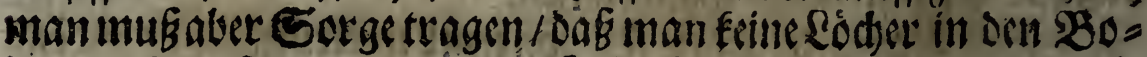
Den madbe : Dann wann man fie fonffere auf Dic Froe fellet / fo

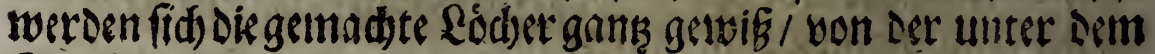

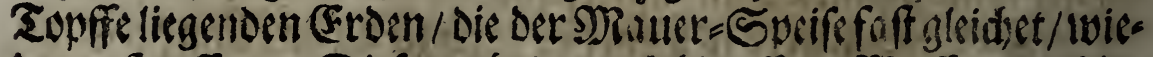

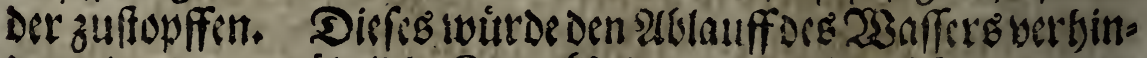

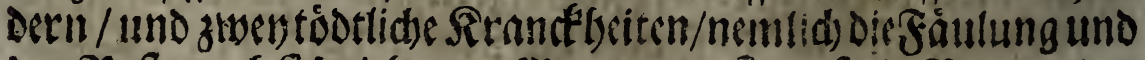
Densioft / nads fids zielsen. Sersect man fie auf oie Bretter Det Oelander / fo fan Das Waffer gleidfalls nidet red)t durd) fom: 


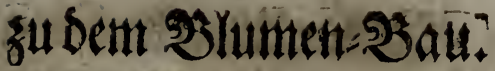

I3i

men: Diefen aglauffoes28affers nun beffobeffer zut beforderen

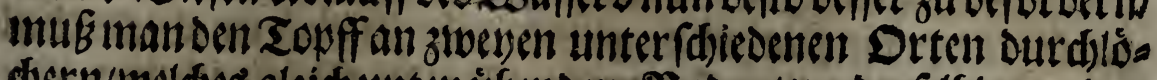

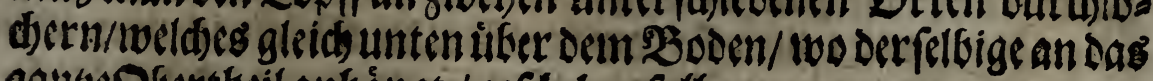

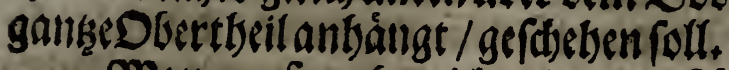

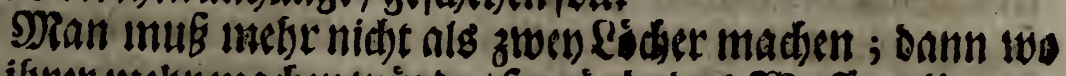

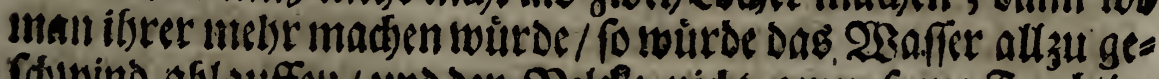

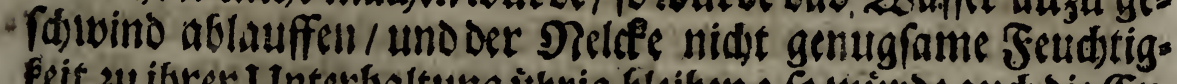

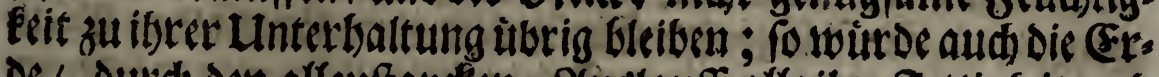

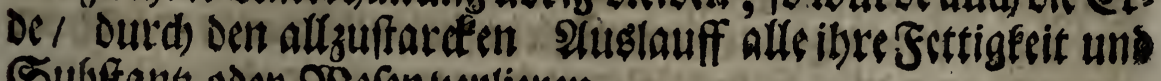
Subfanks oder. 28efen vertieren.

\section{2asill. Sapitel/}

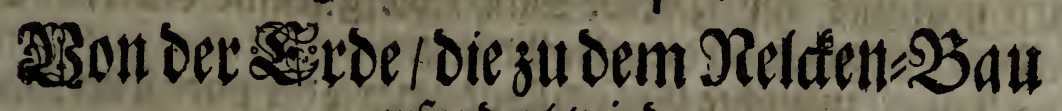
erforbert wirs.

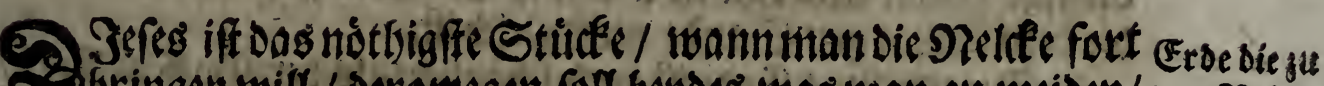

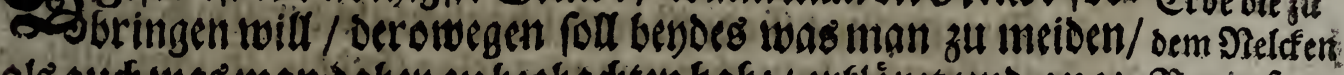

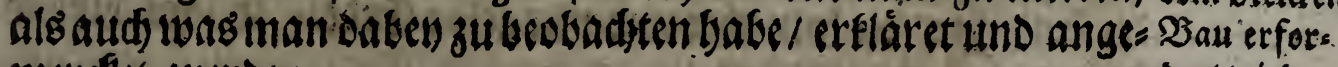
mercéet werden. bert wirto.

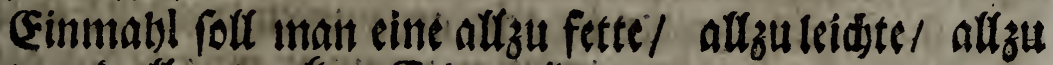
feudite und alfu truterene Eroc meiden.

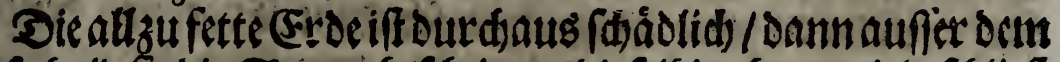

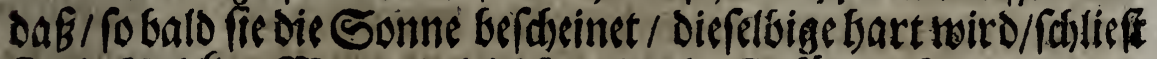

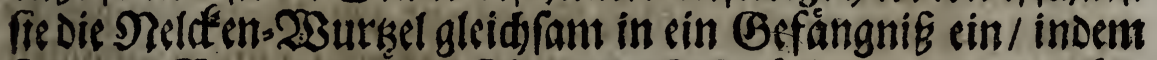

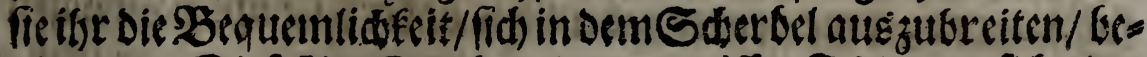
nimmt : Diefsatet Erde bat einen getwiffen Febler an fid / Der

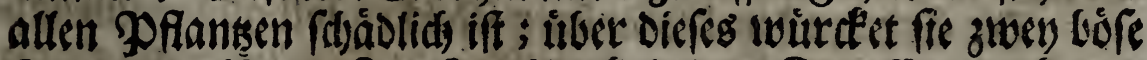

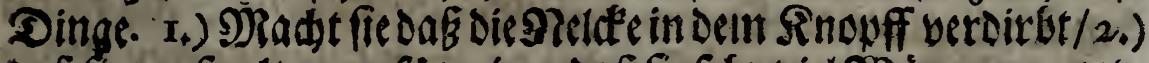

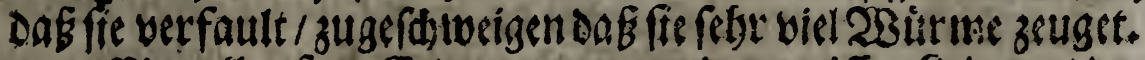

Cine allzu fette Erde nennt man den weiffen Seimen/ oen Sopffer: Tlon; nidst aber den fetten folwarken Sand/ ter in. en 23iefre/an uno um Die Fluffe uno Báde gefunden wirs.

$$
\text { P } 2 \text { Die }
$$


132 Teue Unterweifung

Die alfzuleidte (Er de taugt gar nid)t / Dann twänn bie alfzu

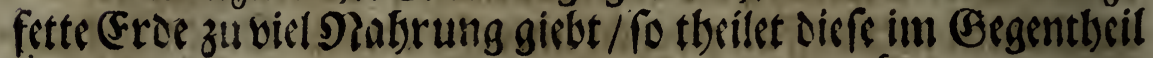

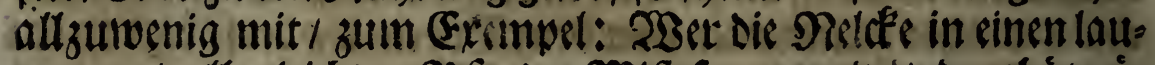

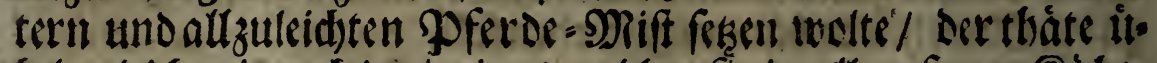
bel / gleid) wie aud) ocrienige / welder fie in allzu ferten Ritbes. Miff pflankter. Daraug folgt/ DaB/ / wann man fidh sinir alls zuleidten Erden bedienet / eer Stengel an Der Nelden fetse

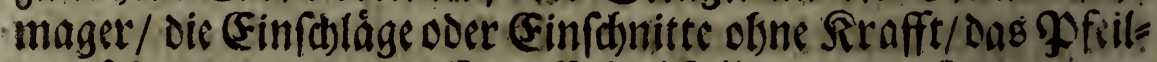

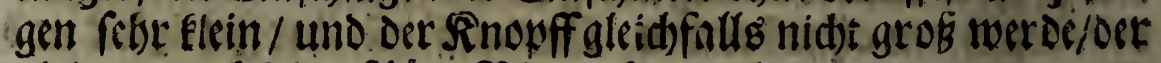
als̈bann aud feine fotone Blume bervor bringen fan.

Die Saupt=Lrfad) Davon ift/ weil diefe (Froe nidftgenugs: fame Frutbt oder vahrung giebt. Eudere uno teid)te (Froe wiro genennet der Pferde=s)dift / die gemeine Barten= (Er = De/ Die Zseiben-Eroe/ Die gelbe Erde ac.

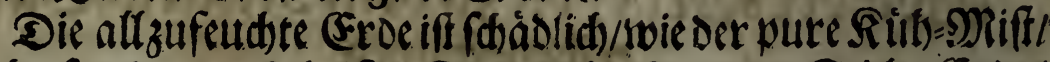

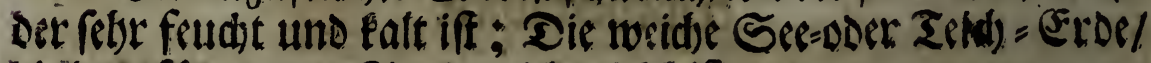
die dem faw warken Sande nid)tgleidifit.

Die tructene (Erbe iff aud), (d)ádlid)/als ber (Baffen= Rutb)

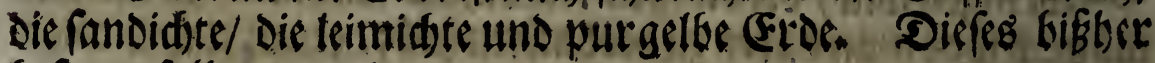
befagte foll manimeioen.

II. Sull folgendes in adit genonmen werden: Efe mir aber Daffelbige Gerubren/muÉ unan zubor niffen/ Daß dic leibs

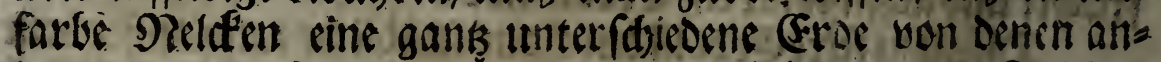
Eeren (Froen erfordern/ und gehoret wittdlid vor die Eeibfars be cine zufereitete aber leid)te Eroe/ uno bor die andere gleidse

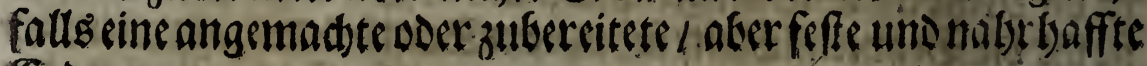
Fros.

Die Erbe zu den leibfaronen Fielfen folf aus cinembats Wen Theil guten woblwerweften Pferde- MRift und ans cinem

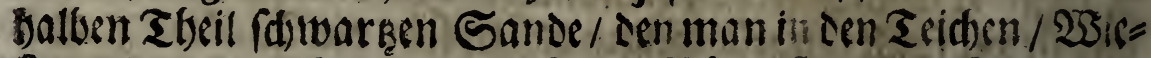
fen und andenLfern der Fluffe oder 3áde fincet / befselen.

Diefe Eroe/ welde man ben fatwarken Sand nennt/ of

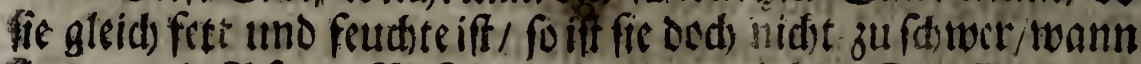

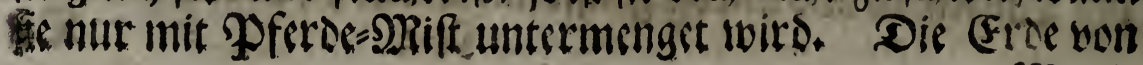
Diauls 


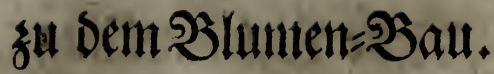

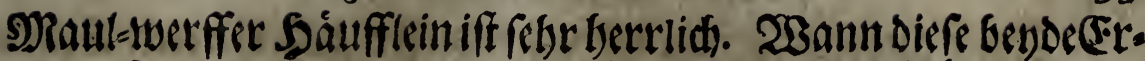
Den zufaummen getban / und twobl zufammen gedritdét und mit cinander redet bermenget merben/ fo find fie bienlid.

Denen 2 Bivlbraunen/Purpurfarben/rotben und andes. ren/'außggenoummen denen \&eibfarben; ; auds denen picotirten os

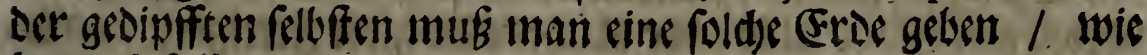
bernad foll gezeiget werden.

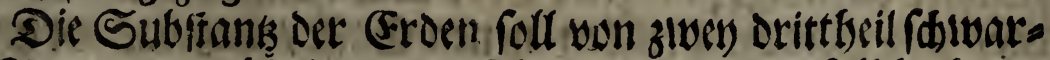
Bem Sande/ Der iblerige oritte Flecil des ganken foll fallb von

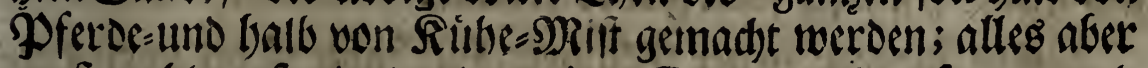

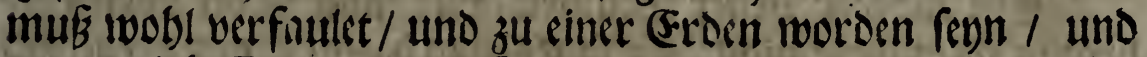
wann diefe Grde wobl gefifeet und vermifdet worden/ woird ein fedffer Theil bon gelber Erden/ oder vondern jenigen wocie

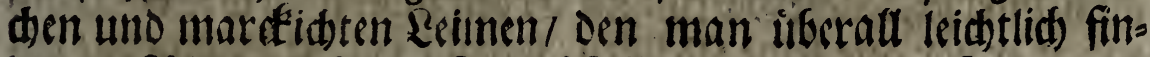

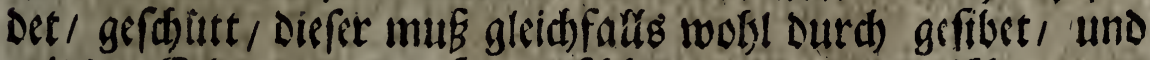

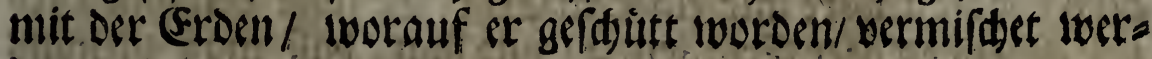
Den.

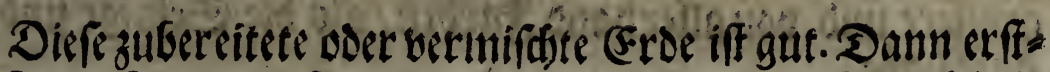
lid ift der fette und fithwarke Sand auffer allem Zlweiffel Die

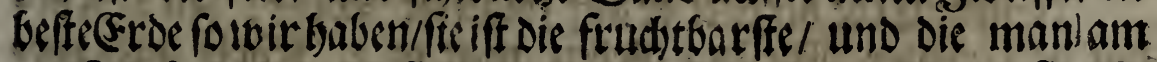

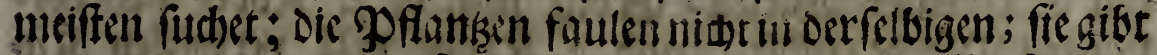

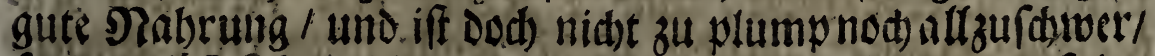
fondern läft fid w woll arbeiten / iff zart und leidtse / und folgs

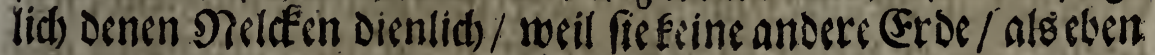
bon Diefer Eigenftaffet / haben wothen.

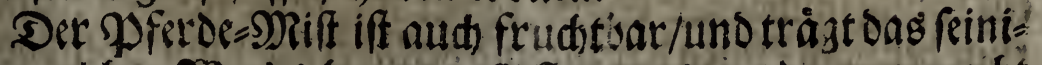

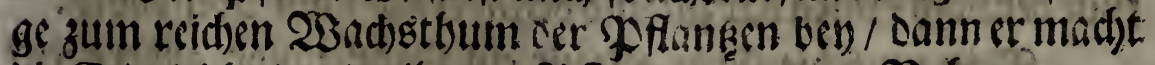
Die Eroe leidft / uno gibe oer Poflange cine gutc Mabrung.

Der Ritte Mifi iff nidf twintiger gut / weril ce fertuno

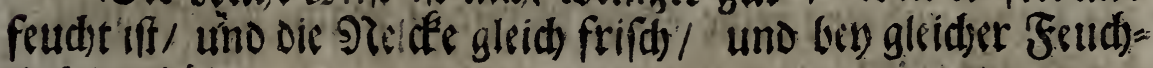
tigéeit erbàlt.

Die gellte (Froe iff gut/1,) 2Beil fie die (Ersen an einanber bàngt / 2.) weeil fre decm (Srimen an ocr Nelffen eine wunser

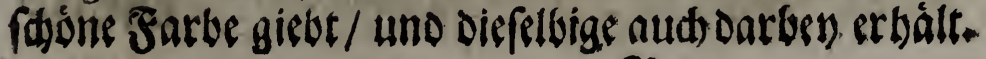


3umi anoern fornmt bie Binte diefer zuberciteten Groen von oerzermifdung after vierererden ber: Dann iver nur lau=

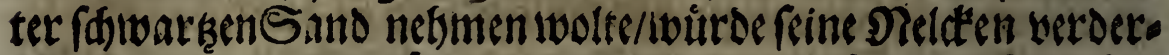

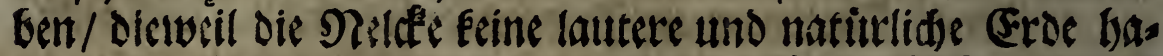
ben will/ fondern eine zubereitete. Derp ferde=-SRiff madit den

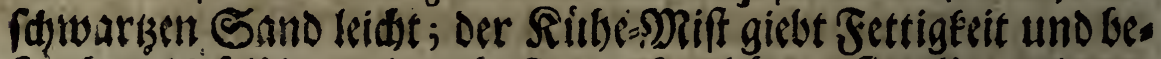

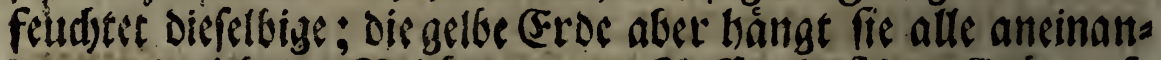
Der/ uno giefot der Nelden neuen Safft / Dáb das Grime / fo fid) an ille befindert/ feime Farbe erbalte.

Ein anderer neuer slumen = Riebsaber iff Der borkerges bettben Mennung nidt. (Fr fagt / man balte fid) nur vergeblid

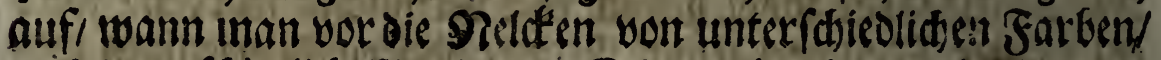

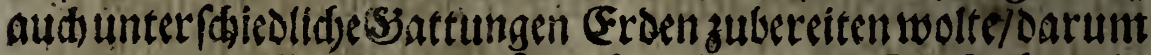
madtet er vor alle feine Neldeen / forwolst wor die Reibfarbe / als aud bor die andere nur einterlen) (Froe: (Fr folgt bietinnen feie ner Experientz ooer (Erfabrung / und fagt / oa B́ man nicmals groffere und von alferhand Jarben/alo dis Seinige find/ges. babt babe.

Seine Erbe bereitet er auf folgende wseife: 3u 3. Siór: ben wolf reiner. 23iefert = Sroen thut er 3. Rorbe volf bers faulten Pferde = Miff / uno 2. Rörbe boll vertweffen Rits

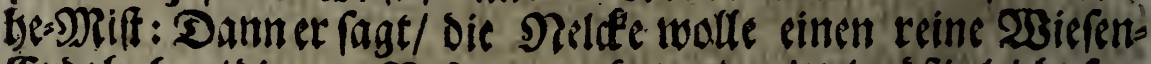
Grdefbaben/ Die gute Vabrung gete/ uns mittelntábigleid)t fey: Seine/ wie er ferner fagt/ ffebet Der Neldét bollfommen an/ ein wenig fdswarker Sand fónne ibs nidbt fdjaden; allein or thut Dennod) Eeinen Darzu/ und befmoet fid nid)t ülec Babey.

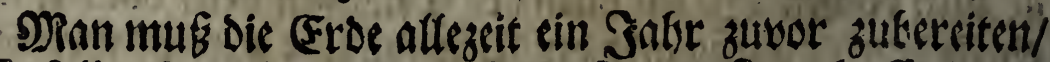
elhe fie foll gebraud)t werben; fo mus man fie audi offt burd bie Sorte und cint reine Sibe lwerffen/ goann manfelwill in dic sopffe thu!n. 


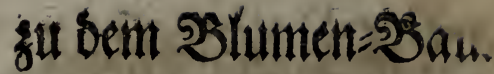 \\ 2aริIV. Sapitell}

335

Sont Det Strt / Die Selelfent einzuld lagen oder cin zuffoneiben.

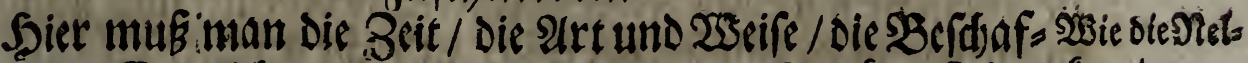

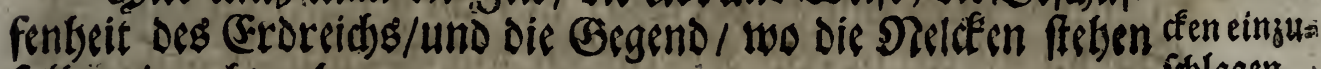
follen / in adjet nebsmen.

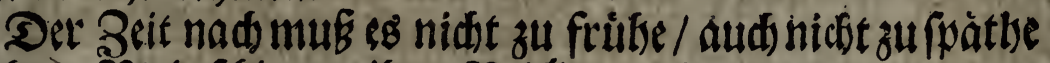
gefdecben. Oiele follagen ibre Deeldeen nod yor S. Johannis Baptiftx Zag sin / tbun aber übel Daran: Erfitid/ w weil fie Den Stengel / Der die Nellefe ttringen fold / unten alteriren und betun=

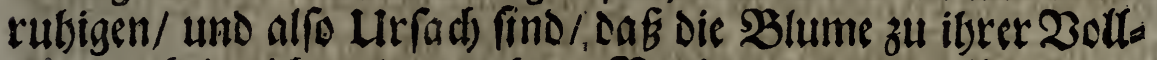

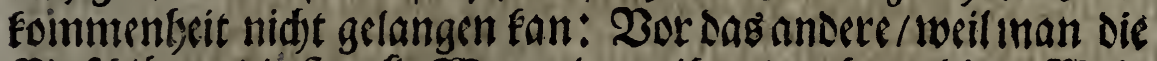

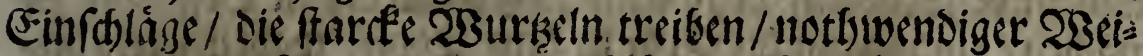

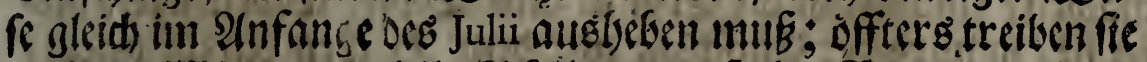

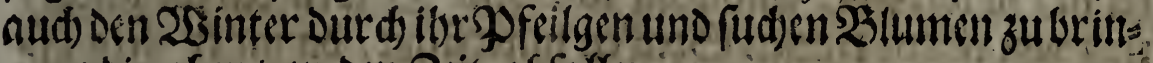
gen/ Die aber vor der Zeit abfallen.

Sendere warten zu lange / und fdlagen fie erfit zu Ende

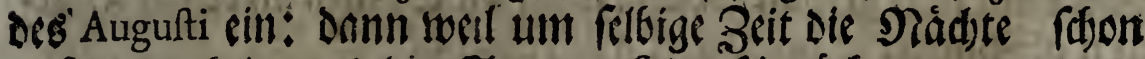

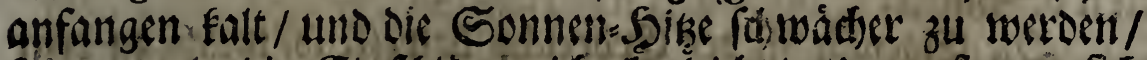

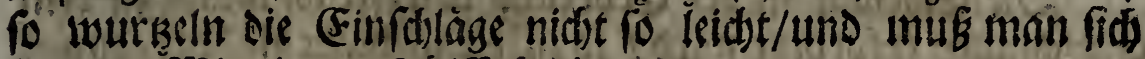
frember Mittel und Suilffe bedienesi.

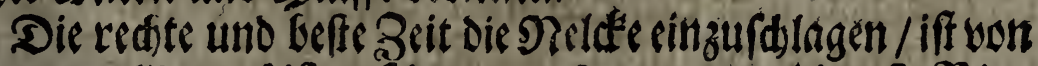

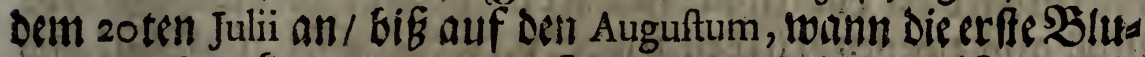

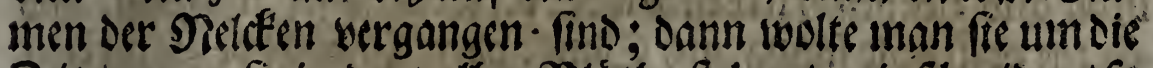

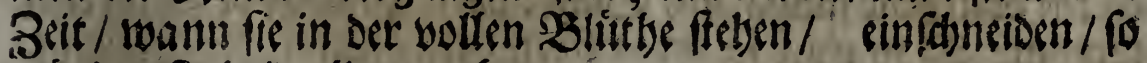
wirden fie bald afle vergetsen.

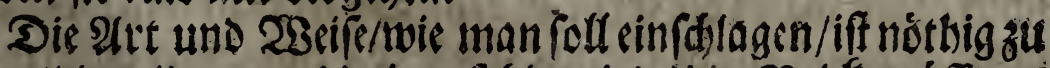

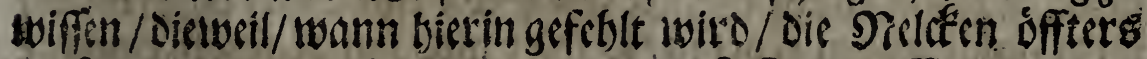

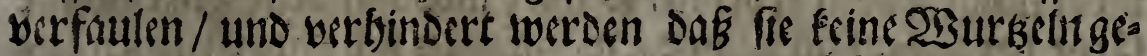

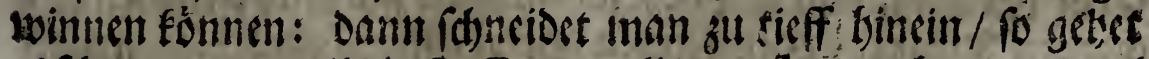

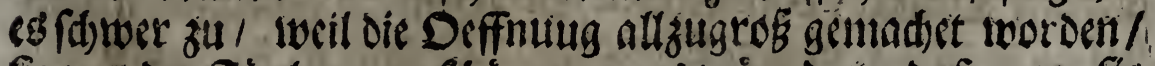

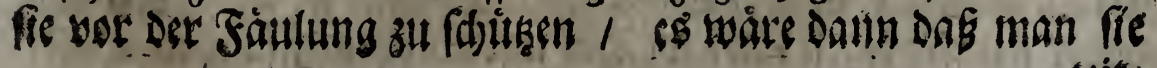
phlagen. 
136 zeitlifif tur ser

gu flein / fo wirsen fie/meil bie Deffnung nidet weit genug iff/ gar fdswertid) 28 urr

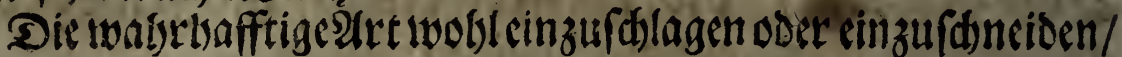

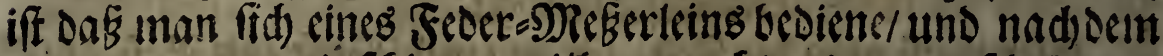

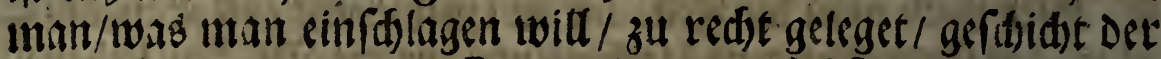

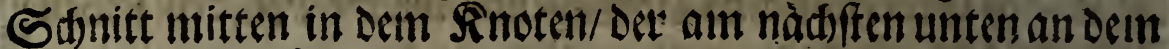

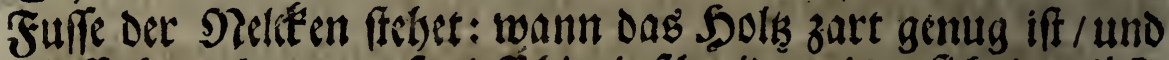
Safft bat / Ean man fo tieff bineinfdmeidern als es fid thun läf:

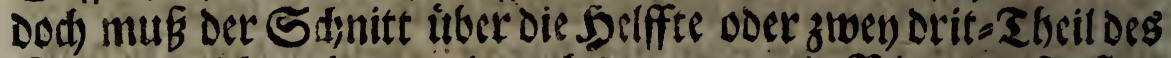
Rnotens nidft gelfen / uno nad dem man ein 2 lat oder fonff et? was bierza dientides in Den Einfdhitt gethan/ Den Sdbaden/

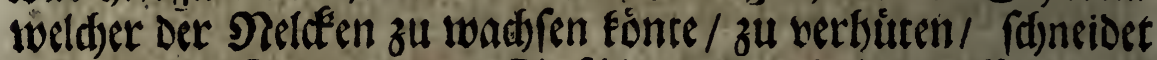
man in Der Rnoten/ Dem (Einfdalag Dadurds cine Deffnumg zu maden / und wann bie Groe in decin Toyffe noblumgearlecis tet iff/ fo witro der Einffalag mit Dem Soufen darcin gelegt/

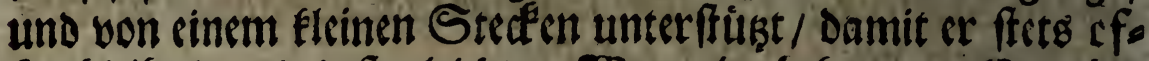
fen bleite / und Beffo leidter 2Burgetn befomme. (EB toàre

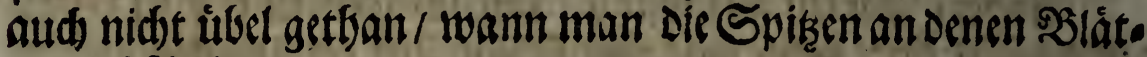
tern abfermitte.

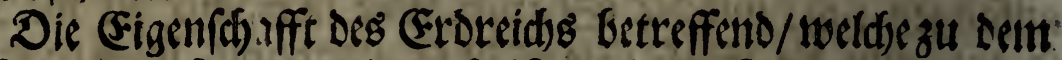
Esinfdalagen erfordert wiro / fo if sie leidereffe dic beffe / Da mic

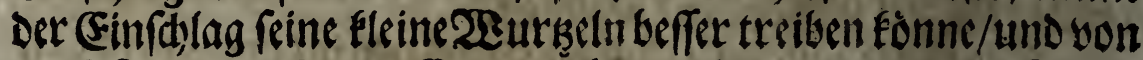
Dee feften o der hartenerden nidft werh indert werdec. Diffe Eroe

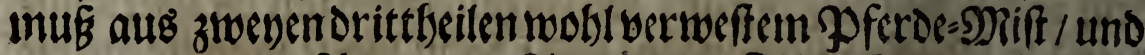

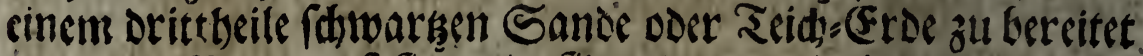

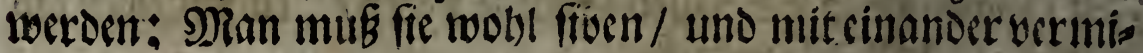
fden / und wann Die Grde in dem Towffe / Darinnen Der Eine fdilag iff / mit einem Studde Solls wie eine Sdippe formires/ wobll umingegraben worden/ fo wiro alsbann diefe angemadtse

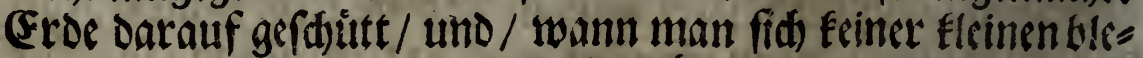

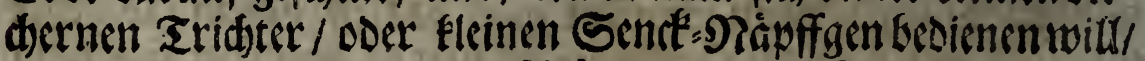
Darein man 1,2, oder 3 . Einfdelàge/nad oem fie nabe ben sin=

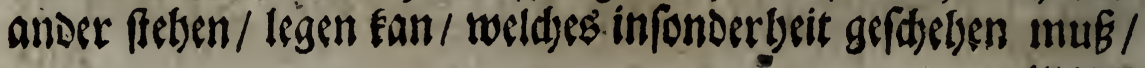




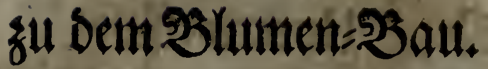

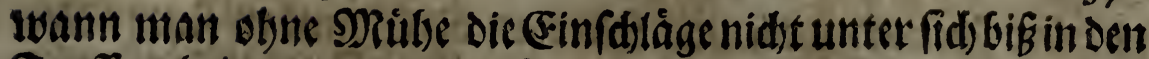

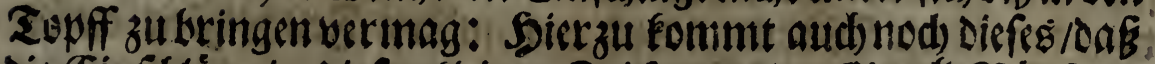

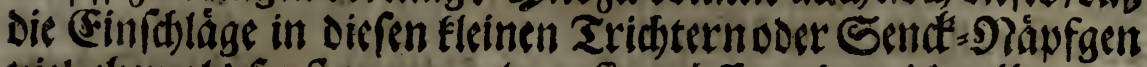

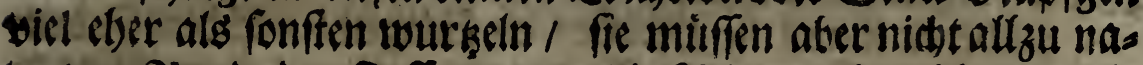
an dert Piando oder Deffinung / andie Seitern/und an Die germact)=

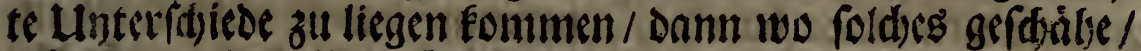

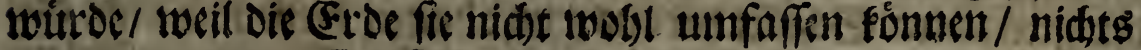
Daraus werben. Esg iff Eein Neben=Stengel / aud Eein Bipffel an benen andern Stengectn/ weldenen man niddt mit Suilffe. Dies

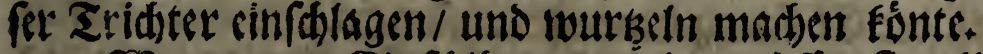

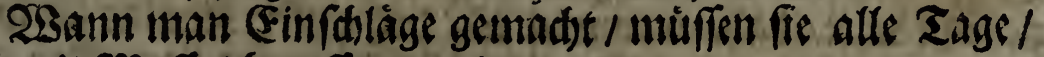
iesood mit Maffe/ begoffen werden.

Der Gegend nadd muli man fie / fo fald fie singerffilas gen fino / 3. oder 4. Tage lang in Den Edjatten fetllen/ nadumalen fegert man fie woieder an bic Sonne / wo fie zuvor/ elbe fie eingerfblagen wourden / geffanden find. Sisegen Den 8. Se-

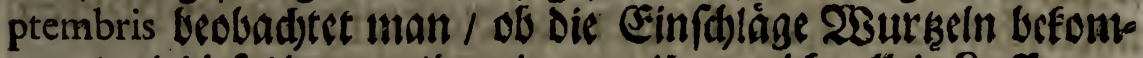
imen/unD Diefes barum/ Damit man ibnen nid)t allein \&ufft tmas

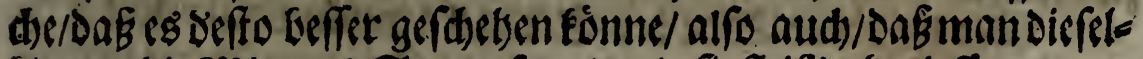
bige an Die Drittagg=Sonne feke/ und fre fleigig begieffe.

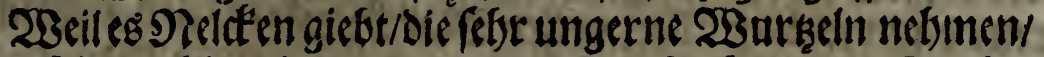

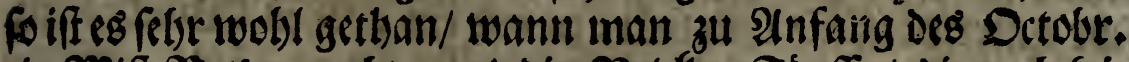

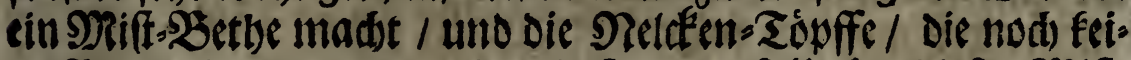

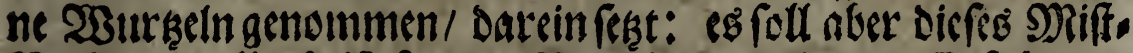

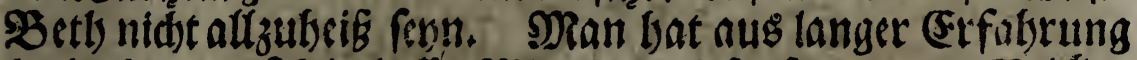

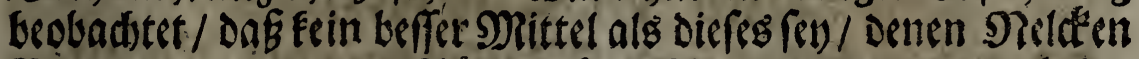

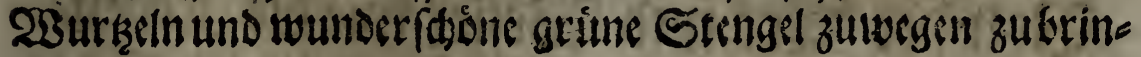
gen.

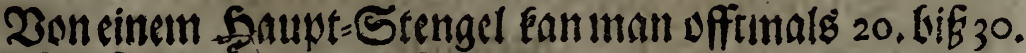

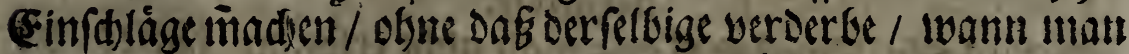

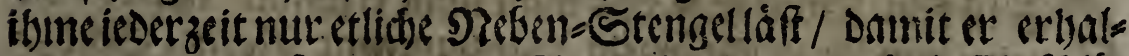

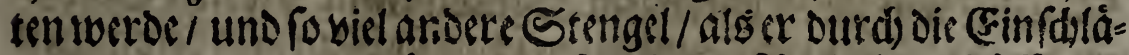

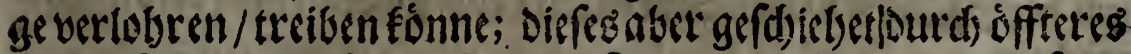

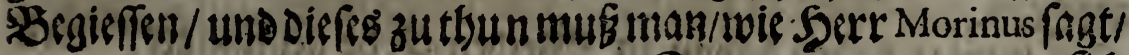




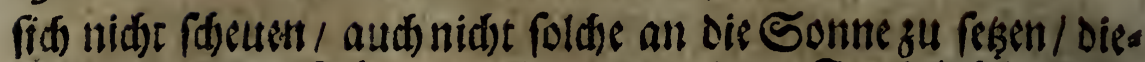

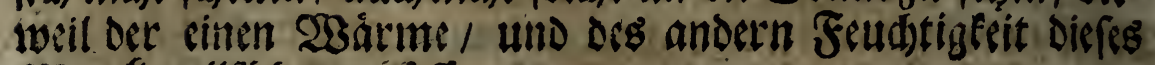

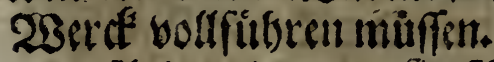

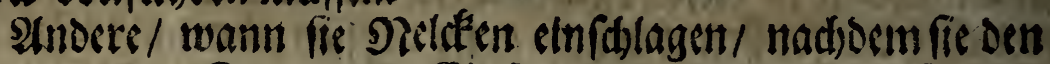
Sdinitt in Den Rinoecen Des (Einfdalags getban / thun fie nod)

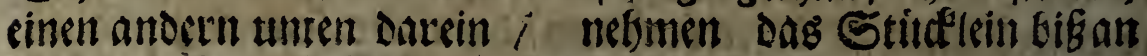

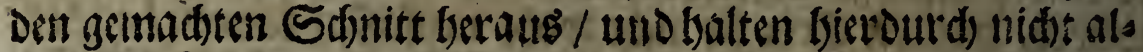
lein cinerreits Dent Saffic auf/ Der in diefen Sinuten geffiegen

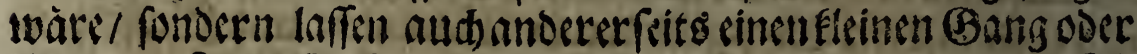

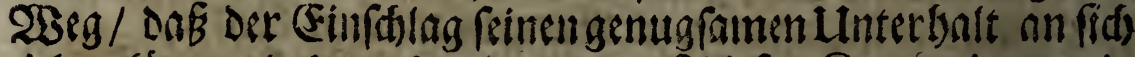

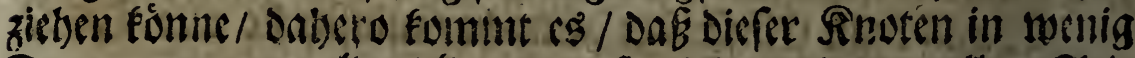
Zagen unbermerctet dict und grog twird / und won allen Seis

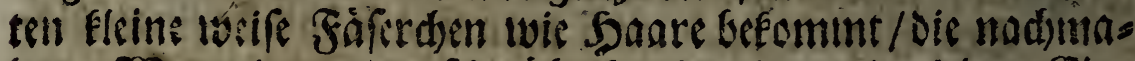

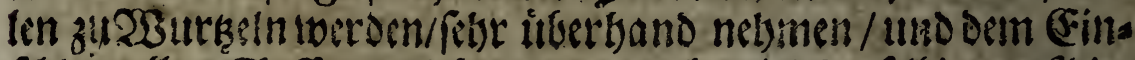

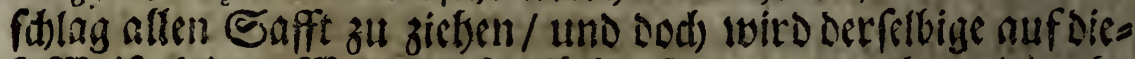

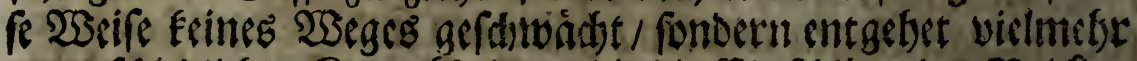

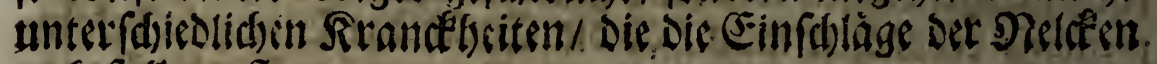
zu befallen pfrgen.

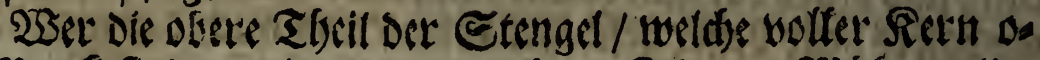

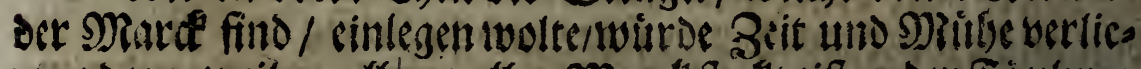

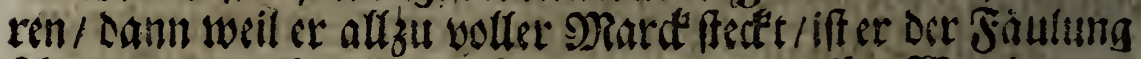

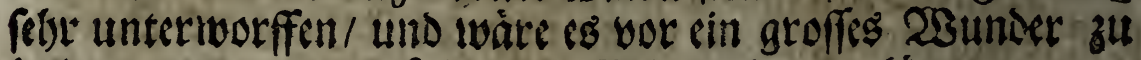
balten / wawn er Den folgenden 23 inter Davon fáme.$$
2 a \mathfrak{s}^{2} \text { V. Enpitel/ }
$$

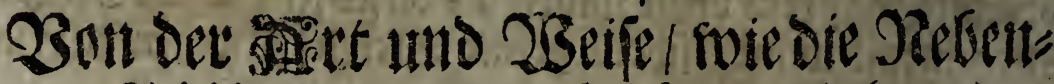 Schoblein won benen Neldeen woblabsu= mebmen.}

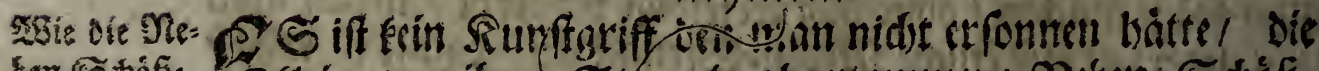

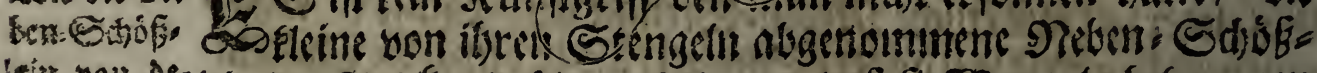

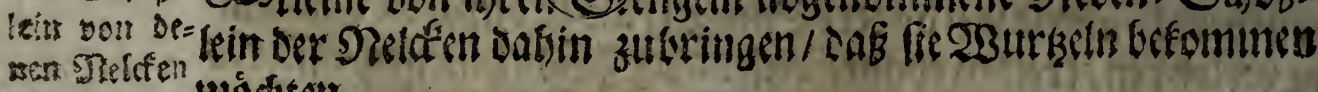

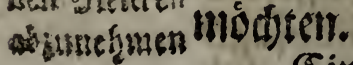

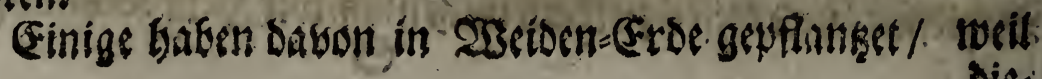




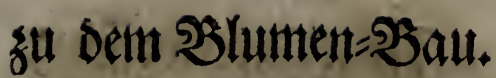

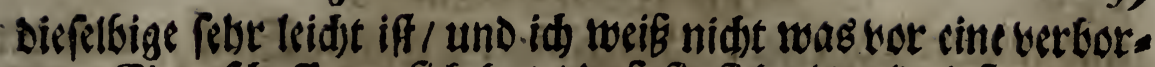

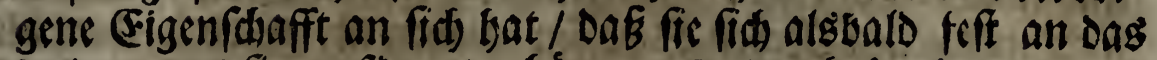

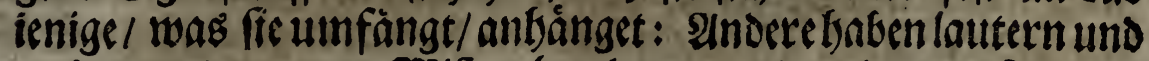
nod) etwas warmen פiif zubersitet / und damit neue Poroben gemadit.

(Es baben fid âud) gefunber / Dic wobst verfaulten Miif

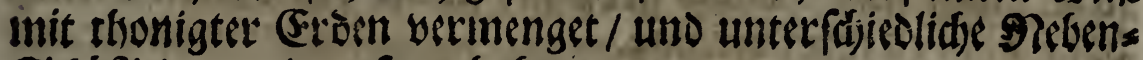
Sdjóblein darcin gefesect bafent.

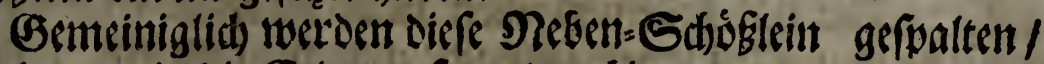
und alsoann in die Erde ver regeet / nadjoem man zusor 2. Doer

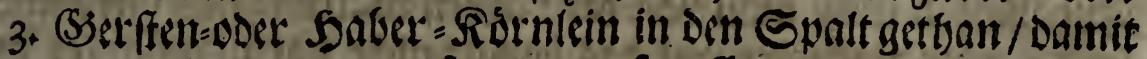

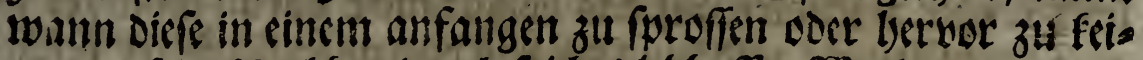

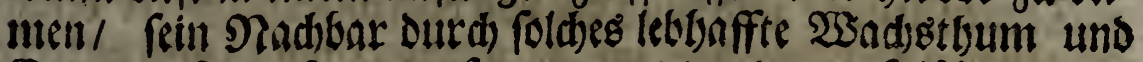
Exempel fo zu fagen aufgenuntert / und angeffif Dergleidjen zu thun.

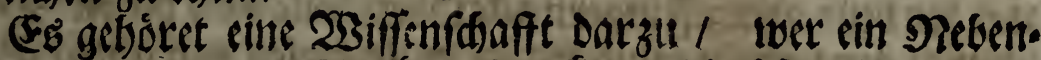

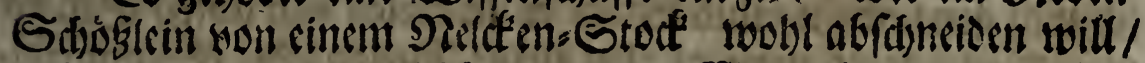

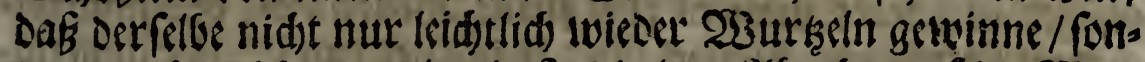

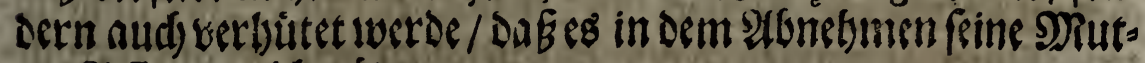
ter=Poflanke nidst tódte.

23olte man foldifs von feinem Stengel abreiffen / und sio

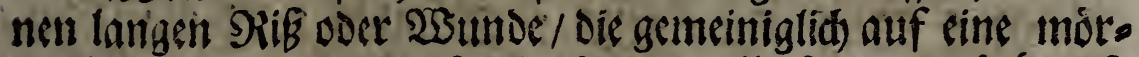

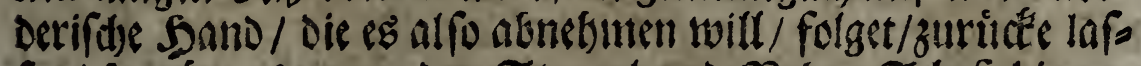

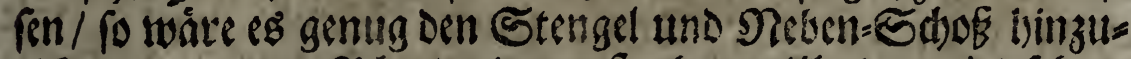

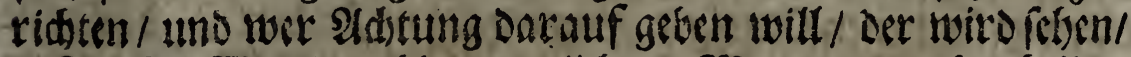

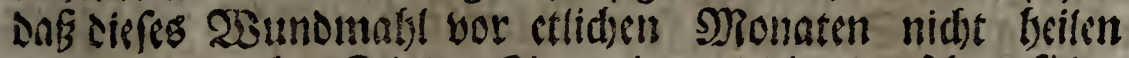

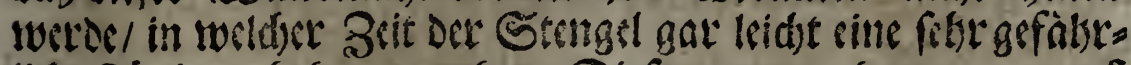

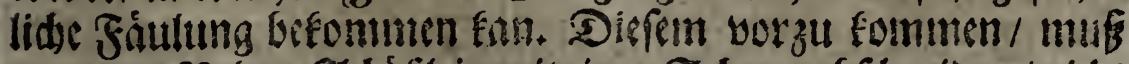

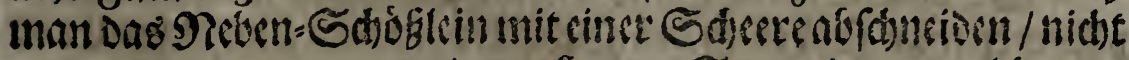

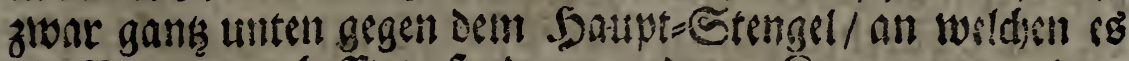

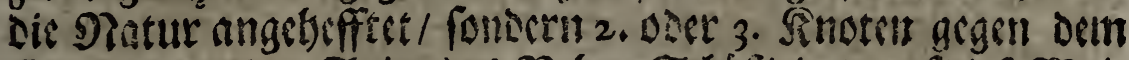

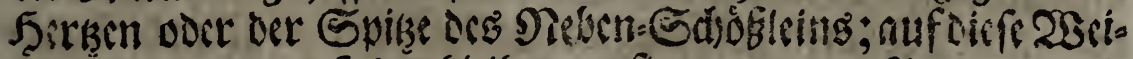

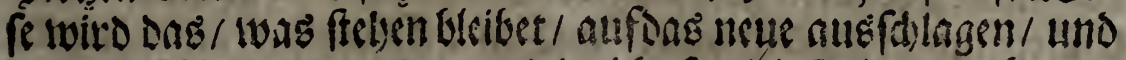

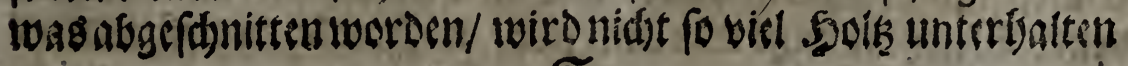


140 Reutuntertweifung

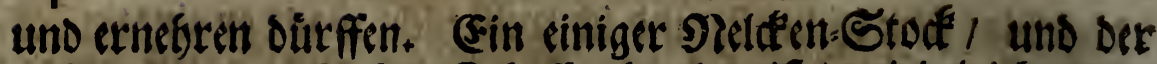

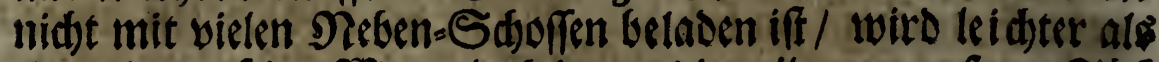

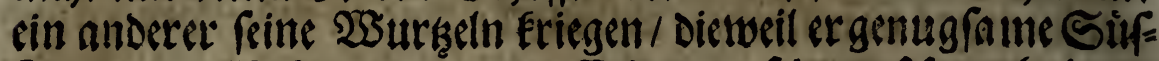

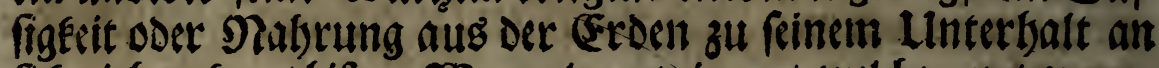

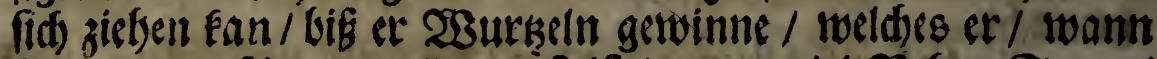

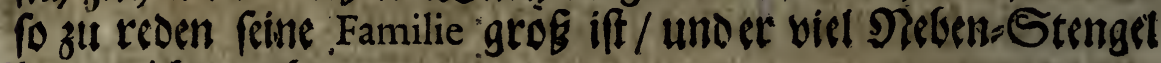
bot / nidst zu thun vermag.

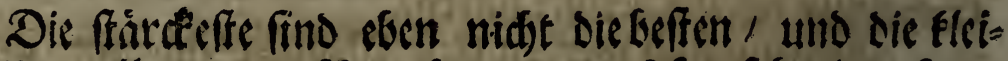

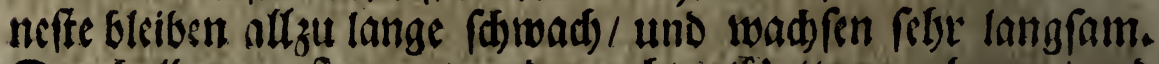

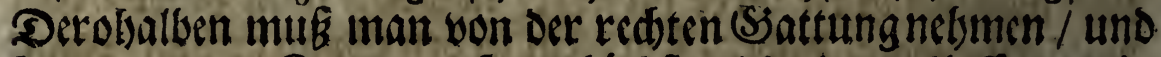
itber 2. oder 3. Rnoten auf das bódffere nidet baran laffer/es in 4. Theile rpalten / und den SRiB yon demt unter ffenleerer Gefage ten Rnoten ober Gleiden anfangen/ Da ç cr fidf an ocm andercen endige / gegen dem Serręen oder Spiąe des Sdjóbleing aber

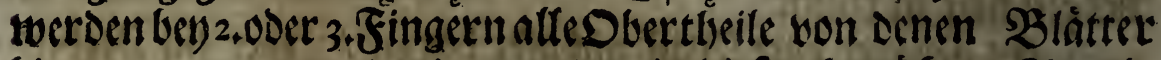
bintueg genoumen / und wann es in Diefen betrubten Sta no geiékert ift / leget mane es cint fleine 23 eite an dir So nne / role

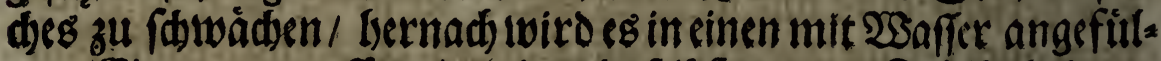

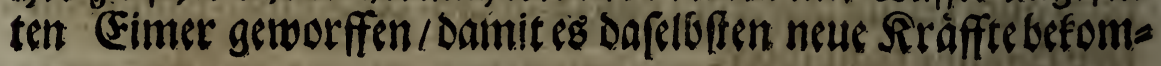
me.

Nad Berfliefitung etlidier Stunden miro man perien/ Dab es grimer ift/ als es icmablen getwefen/ und finden/ twann man die vier IJscile friner 233 moe weit / wic einen gefpaltenen Rettig / wont cinander fonecrt / Dag es it:

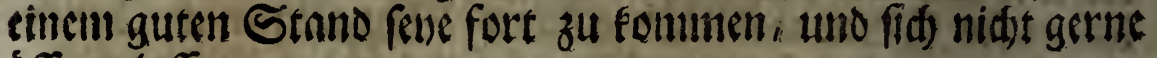
offnen laffi.

So bald es twieder aus dicfen Babe genommen trordent yfianser man foldes in den Sdiatten in cine fetseteidsece (Erber

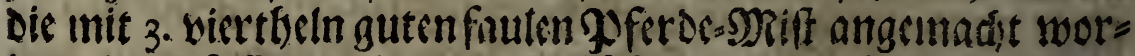

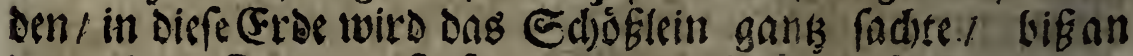

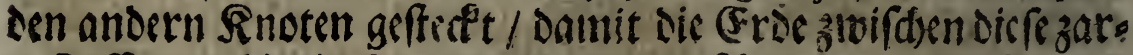
te Deffnung binein formume / uno zu gefdatwinder ?annelsumung

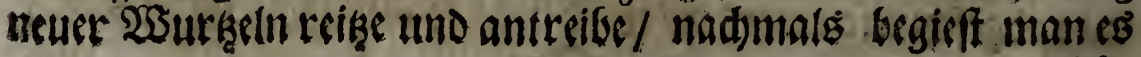




\section{zubem รlumen=:Sau.}

$14 \mathrm{I}$

reid)lid / und fábret auch ins funfftige fleiffigoamit fort / uno laft nid)t zu/Daß es dic Sonne cin einkiges mal befdeine.

Diefe Eleine bungerige Poflanke woird den in oer umbere fiegenden (serden fid befindenden Safft felur fard an fid zis: ben / ztwifden Dem Sols und der Sinde aber toerden fid flei= ne tweiffe Spiklein berbor thun/ de wie Saare roadfen/ uns

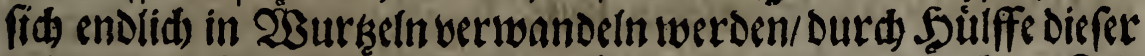
voiro die Pflanke grob und farde werden/ und zu redter Beit eben folde Blumen tragen/ woie Der Stengel/, dawon fie ge= nommen loorden / two diefelbe nid)t gat fdoner uno lebbaffer fino: Das Werd toird fid) aud) bald auffer ber (Erden mit neu= en Pleben=Sdboblein uno Blátern/ Die fid won allen Seiten

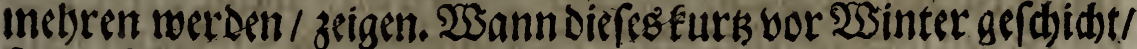

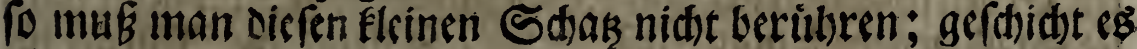

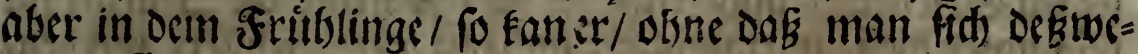
gen zu fordsten babe / mit fant Der Srden ausgenoinmen/uno iil cinen Drt / hos er mebr Saum babe/ berfebet werden.

(Fin beritbmter und curieufer Blumen=Riebbaber will/man

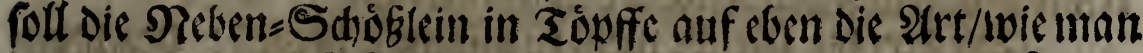
mit Denen jungen Bátumen in den'Baumt=Sdulen zu verfobren

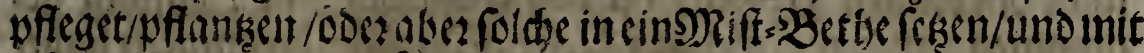

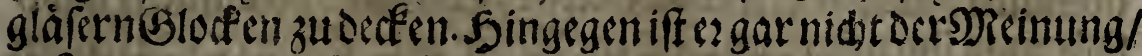

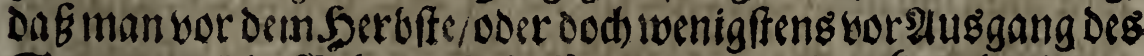
Sonmers/bie Neben = Sdoffe bon Denen Nelefen abnetmen

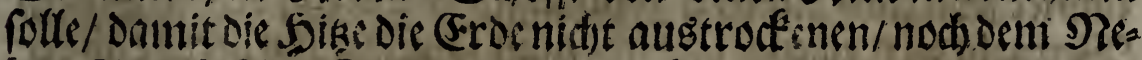
ben=Sibofe feine Sraff benetimen fonne. Diefer legtere twird/ wann cr in einen Sduerbel felset / auf ein Diftesetbe gefeset/ unto mit cinct glafctn (3locfen bedeffet wito / vielleid)ter 23 ur ks:lt getwinnen/ wie fold)es dic (Erfabrung augenfdsinlid) an denen Einfdlägen der Neldern/Die lvenig Wurbeln baben/bot Nugen leget: Dann wo ibnen mit sem MRift=Bertbe uno ocnen Gloceen getsolffen toird 7 fo befoinmen fie zugleid febr farce Wurkeln/ und wann man fie aud) gleid) unten bon Dem Fub

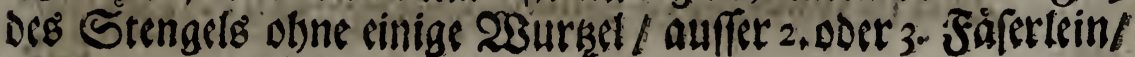
abgenommen bátte. 


\section{2 \\ Feue Unterweifung

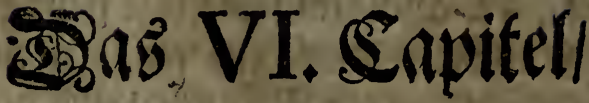

Bon Det Fut und 2Beife/ wie die Relde in

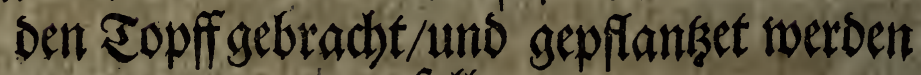

\section{folle.}

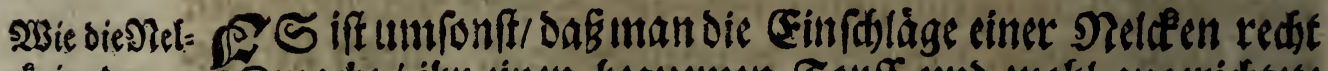
stein ben Zopff gen pfantiket werden folle. Camade/ ibe einen bequemen Topff und twobl zugerid)tete (Fide gebel wann man nidst weif twie man fie red)t pflanksen folt: Dann feget utan fie zu tieff in den Tapff/ fo greiffe ffe unfertloarlid) die Fáule an Dein Serken an / weldese init laus ter Eroen umgeben ift/ oder ibrallzunabe liegt; pflanget man fie iin Gegentkeil nidt tieff genug / fo ftebst Die 2Burşet im Sommer slos und unbedecet/ und Ean leidtlids dirre twerden/ Diefes verbindert Dann ferner Das $23 a d j g$ thum / tructetnet Den

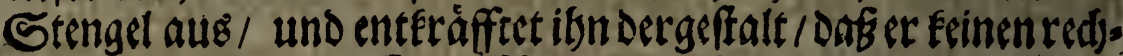
ten und anfebnliden Rnopf Gefommen fan.

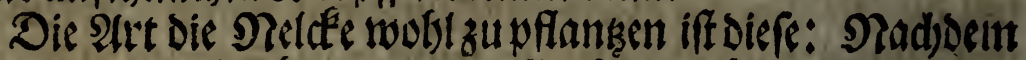
IItan ben fleinen Satéen / Der Den Eimfalag boilt / bintweg ge=

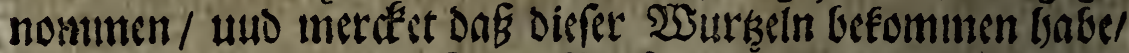
lópet man ibn mit einem Feber=9leffer oder Sd)eete von feinem Fub oder Stofe ab/und diefesfonabe an dem Stengel ale es immer fenn fan/ Damiter geztwungen twerde auf bevden Seiten 23 urkeln zu treiben / Das iff / man fduneiber ith gerade ander gentad)ten Incifion ober an sem Einfdonitte ab/ uno madid das bende Sdsendél gleid) Eommen / und madjocm feine 283urzel/ Fafferlein oder Fibern/ wie man es nennen mag/ wirder erfit: fitet worden/ inderm man fo woblan Der 23 urkel/ als alth an

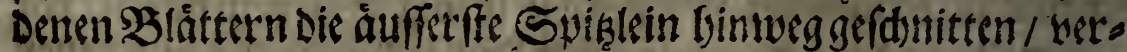
feget man ibn ineinen Sopff / fo inic Eroe angefillet / uno fols gender Beffalt zubercitet ift.

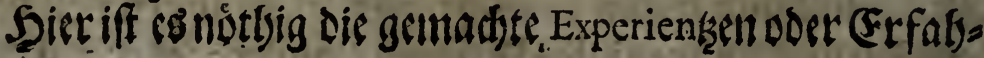




\section{zubem}

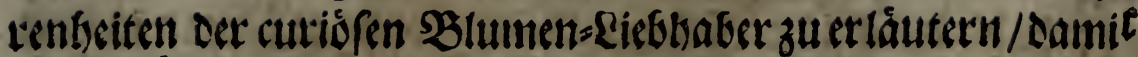
Die Delefen wiber alle 'Bufálle berwabret / und zu ibrer 20 fro fommenbeit'gebrad)t werben; aud) ju zeigen/ twie Der Oruno Deg Topff / Darcin man Den Einfd)lag / wann or yon feinem Juffe abgetofet ift / pflanken will / foule befdsaffen fenn; mit

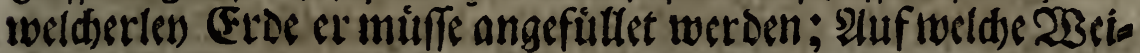
fe man die Eroe in den Topff tbun / und wie man Den (Finfdslug darein fesen folle; weldergeftalt man ibn muiffe begieffen/ uno in nelde Gegeno er/madb oemman ibn gep flanket / folde geffels let werden.

Der Brund des Topffs inuf aus lauterin fursen Pfer.

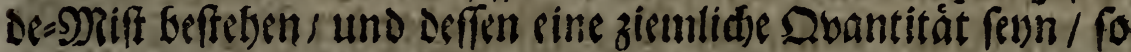

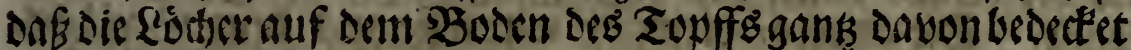

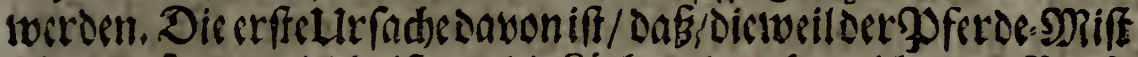

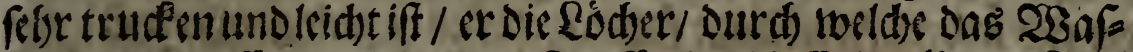

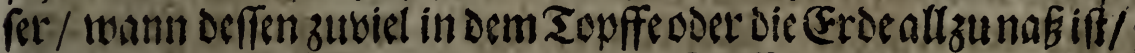
leidttid auzlantfen fan / nicmals verftepfft. Dieandere Lir=

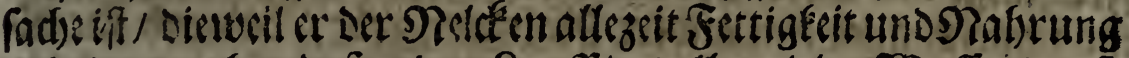

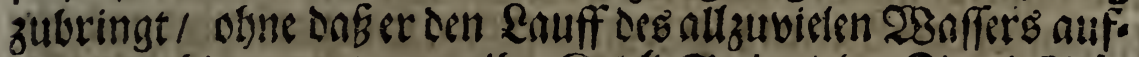
balte / Da bingegen / wann ibr Ralct'=Strine/oder Birgel-Stit dén vout alten rninirten (SebGauden/auf Den Woden Des Topffs leget/ wie eE etlid)e zu tbun pflegen/ nid)t nutr sie gislefe feine Nabrung bavon zislet / fondernes halft das 23affer auds alts

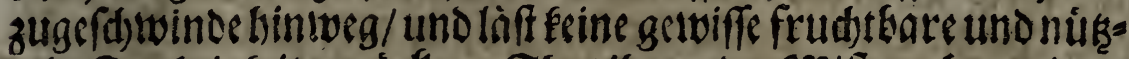

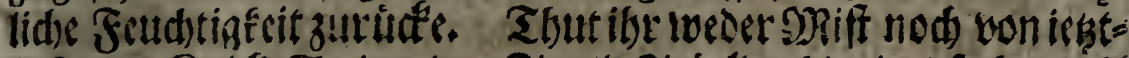
befagten Ra!tt: Stein=oder Bicgel=Stidten hinein/ fo handelt

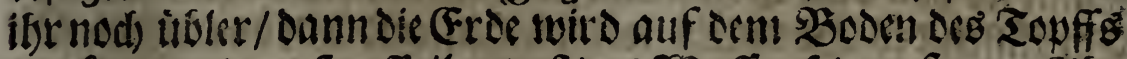
trucéen / uno verftopfft ilsn/Daß dag 23 affer feimen freven sibs

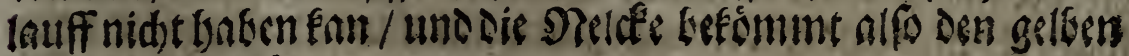
soff und Eir Fantle.

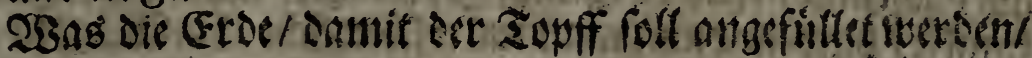
betriffe / fo, weis ntan aus cintr augenfdeinlidben Erfabrung/

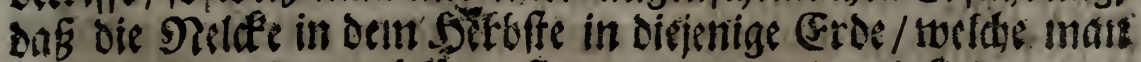

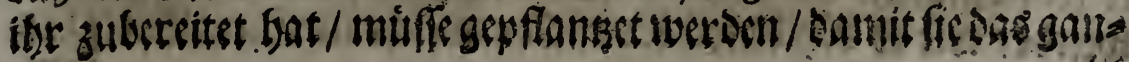




\section{I44 Newe Unterweifung}

Be Safer binourd in der relbigen bleibe/ obne dab wan in sem

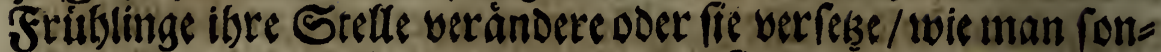
IFen thut / zu bem Ende pflanget man fie auds alleine in cinen 'SOpff.

Diefe Erfabrung iff auf werninnfftige turfadien gegrims

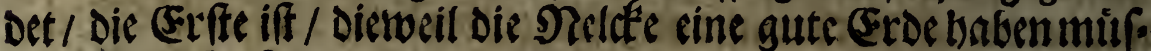

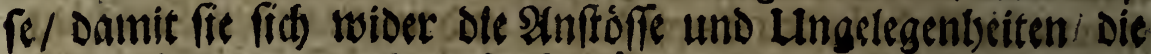

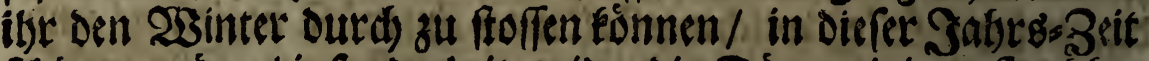

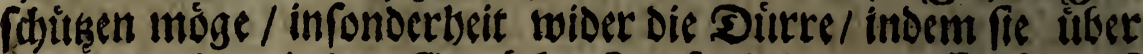

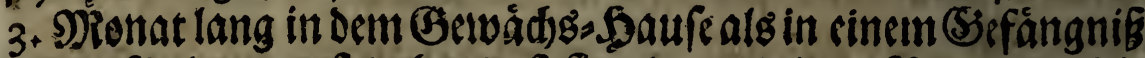

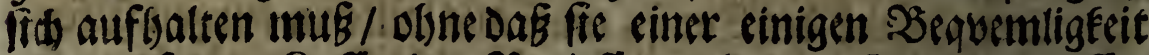

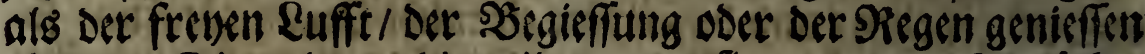

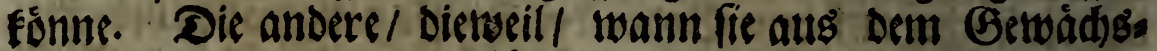
Saufe getban wiro / ben bófen Snfiuenken ober Einfliffen/ Die fid indem frhblinge fwitbren laffen / mit gróffern פradja Druofé wiberfeber. Dic oritte / weil/ wamn man fie in Derin Fritblinge aus ibrer Eros in sinen andern Topff ver ferset/man

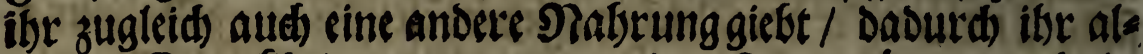

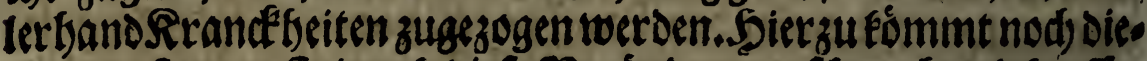

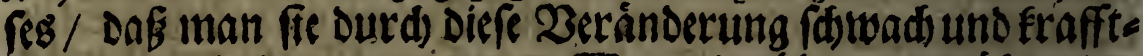

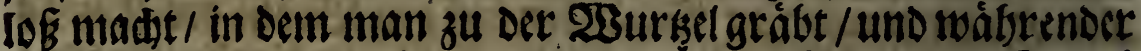
Diefer itherer Sdmwadbeit / netsmlids in Der Beit / als fie nod

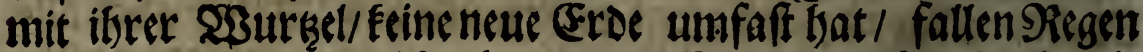

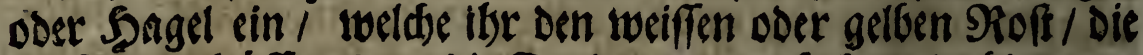

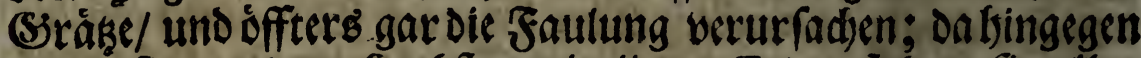
swann fie sorn bem Serbffe an in ibrer. Eroen fielbet/ fie allen Einflinffen des Soimmels widerffelben und austgalten Ean. Die

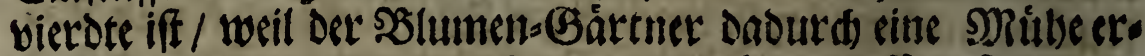

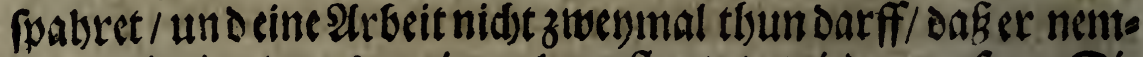

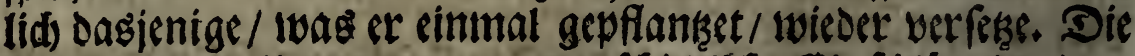

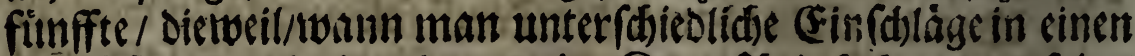
Zopff feget / uno siner Davon eine Rrandefeit befommen folte/ er foldese alsbalo Den anbern auds mittbeilen uno fie anffecten

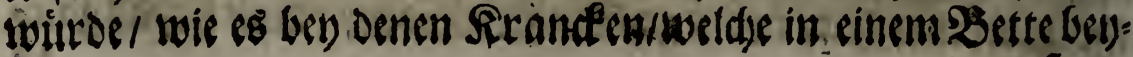




\section{รubent}

fantitten liegen/ uno in grabitenden Seudien bey ornen ange fedefen Đerfonen! zu gefdieben pfleget. Die leste urfadeift

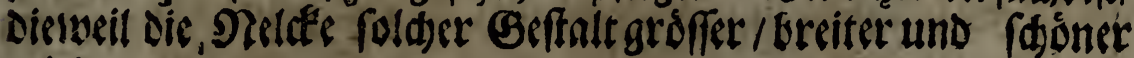
toirt.

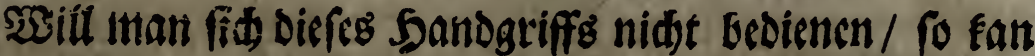
mall wur oet gemeiner art / Dic פelifen auf oen 2Bintet zu pflanken/folgen/ uno foldaer Beftalt gibt man ifnen eine aus

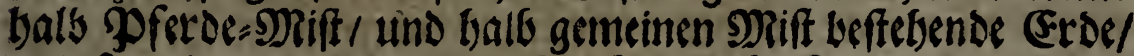
und feket in einen ieden sopff auf Das bod)fe 3. oder 4. Fin. fdslagge / Dalnit diefelbige nidst erfticfen / aud / wann fie bon

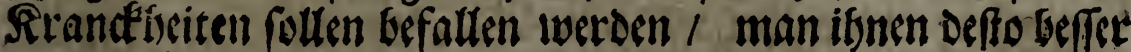
belffen fónile.

Die Frde wirs auf folgende 23 tiffe in Den Topfodet Sdierbel getisan: W3ann Der S5oden mit Mift bileget iff / fo fullet man alsoann Den sopff / mit Der vor die Nelete zubereiteten (Froen / bifí úber ben Rand an/nadimablen oride et man

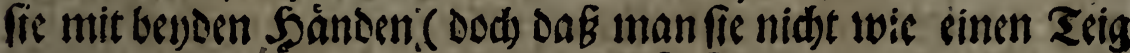
enette) 2. oder 3. Imal nieber / Damit fie fid) obne cinigen 3wang bié auf die Selffe des Rand fende / was lecr bleibet wird detn

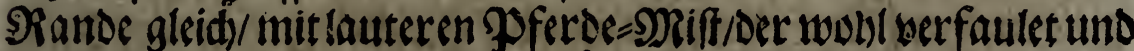
zu Sroen worden/ aud to tructen if atsmanibubaben fan/ ausgefitllet+23ann diefeg gefd)eben / p flanket man den (Finfotag

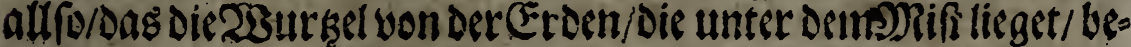
Dectet werde/ Der SRiff abet nod) oben Darauf liegen bleibe:in Demi PPlansen bált man Den Stengel mit ier Sand/ Damit er Defto fefter in ber (Eroen ffebe; ilber diefes nime man zlwen) Elei= neSteden/Die eben won Der Sobthe als Der Stengal fins/ithn zu

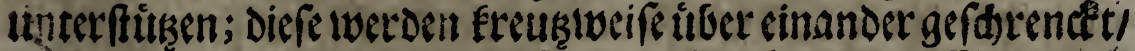
uno unten zugefpist / Damit fis feine Plotb vet Dem23inte leis Den. SnfonoerbeitmuE man fid) wegen bes (sinfd)lags in ad): nelsment Daf iman ifsn nidot allzu tieff fesel, uno ift diefes die Urfade twarum oben gefagt worden/ dafs mun Den (sinfd)lag/fo nabelats es fenn fan/än Den Fuffe abnebmen mitfe / Damit oer

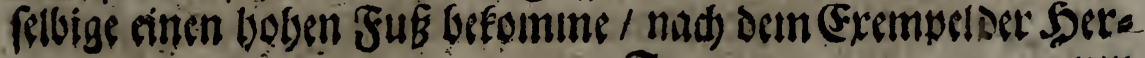




\section{6 \\ Neut Untertweifung}

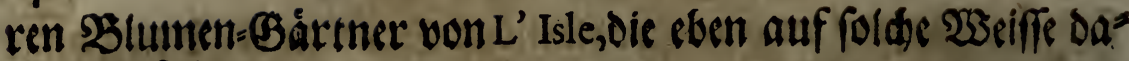
mit berfahteren.

(Fo módten sinige fragen / worzu Der Miff oben auf Dem Tukffe diene / uno twarthiī man ibn darauf lege? Denen twiro

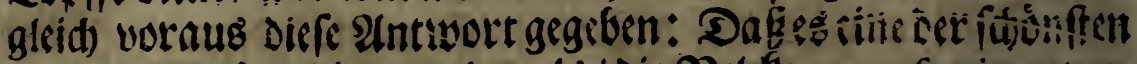

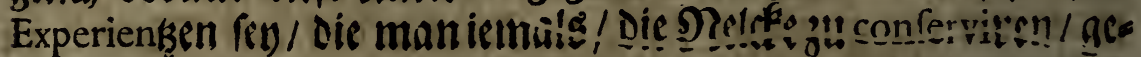

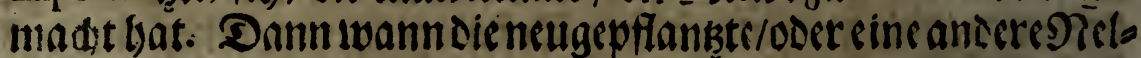
dée begoffen twird/ fo giebt es feine (Bruben in Der Grden/ die Das : Z3affer um fo viet leidter in fids falluctert: Dodo mus man

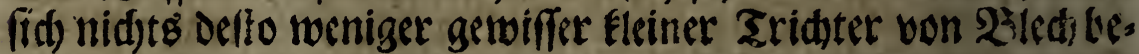
Dienen / (twie Die wabrbofftig: CurieureßBlumen=(Gartner thum/) Die fleine \&ed)lein baben / burds welche das 23 nffer gleid) cinem Rigen rinte.

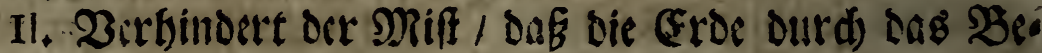
gicffen uno die grofie Piegen nid)t bart worrde.

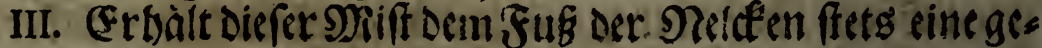
wiffe Fettigfeit/cieibum sienlid) iff/imfonderbeit ben groffer Jsizze.

IV. So madt das Begieffen und der Sirgen / fo durd,

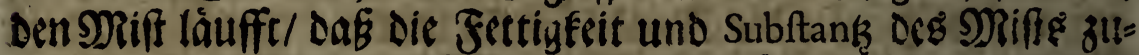
gleid) mit auf oie (Erden falle/und der Nelefen Srudst uno Nabs= rung gebe.

V. Befdithet er Den 2Binter Durd) vor Den SReiffen.

VI. Bertinoert er / DaB bie Jeud)tigfeit oder Der Sdjim=

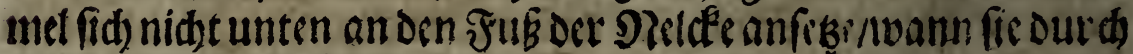
Den 23 inter eingefperrt ftelet.

123as die Zeit anbelangt/ an Deren manden (Fir:fdlag der

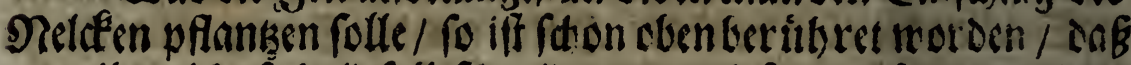

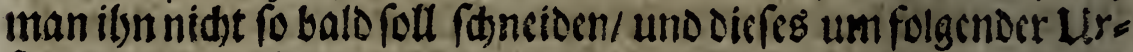
fade wegen: Donnit inan nemliä) nidte verfunten for ifn fo balo zupflansen/ und dadued) zu berhindern/Daber fein Pfeils gen nidst treibe. Dann/ wannman wobst thun milf/ foll man Die (Einfdaláge / ro fpátbe als man immer fan/ pflunken / Dasiff

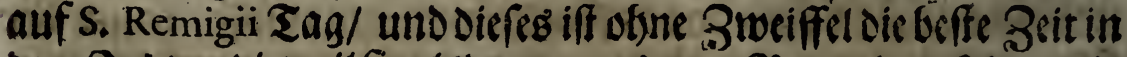
oem Sabte / Dietweillfie alsbann ven denen Regen bes Soimmels 


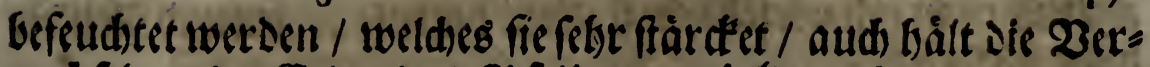

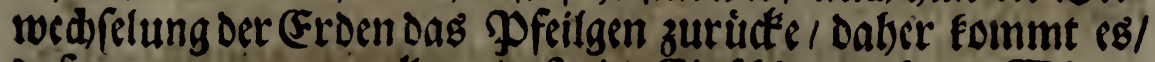

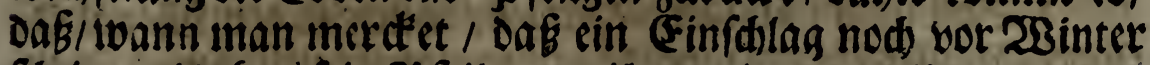

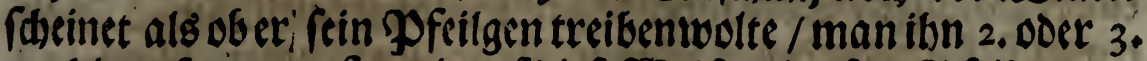

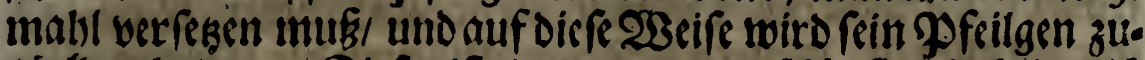

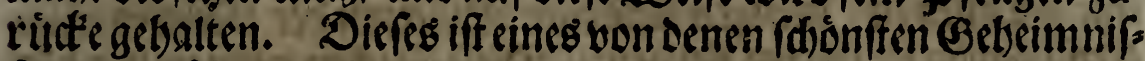

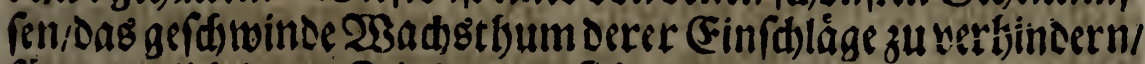

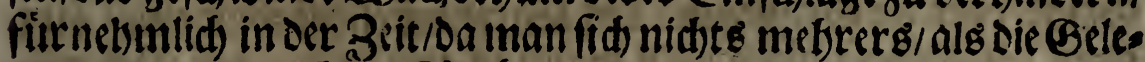

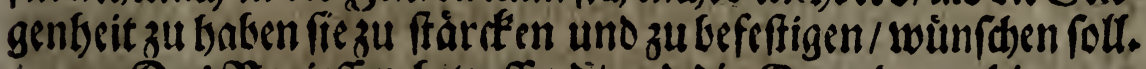

Das Bigieffen Getrefefend/ und die Gigend / wobin man

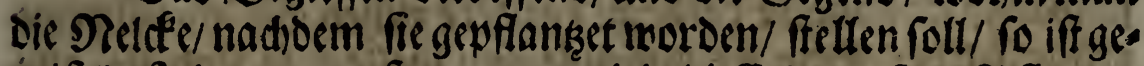

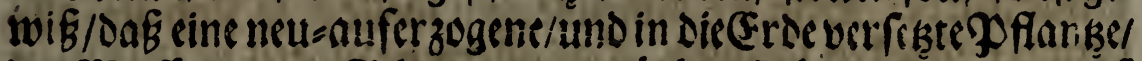
Des $2 B$ affers und Sdattens yonnostben bake. Darum mus

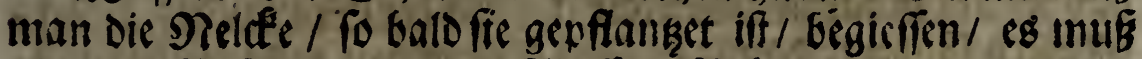
aber mit Bifferibenbeit undSRaffe geffecten / und / mannder

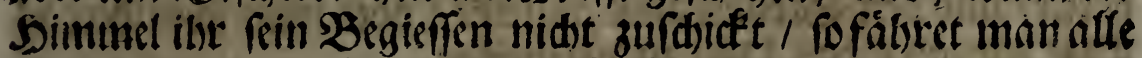

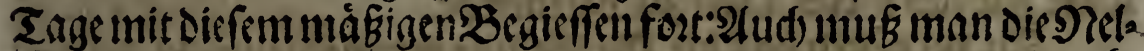
dete 10. 12. Doer wobl gar 15. Tage lang/ ivaum fie feine frardfete

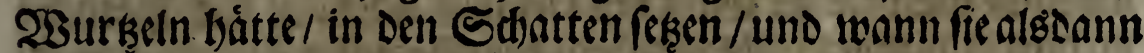

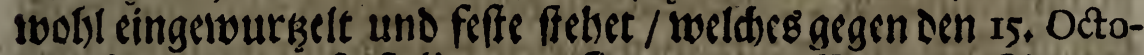
bris fenn woird / fo fettlet man fie gegen Die s)orgen= Sonne/

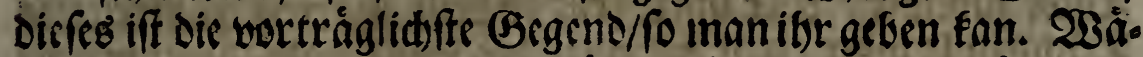

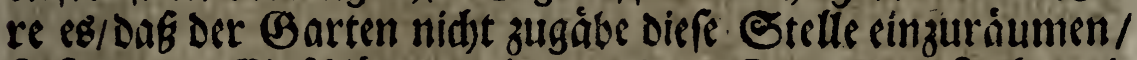

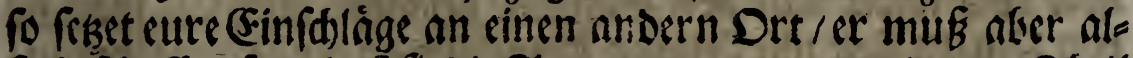

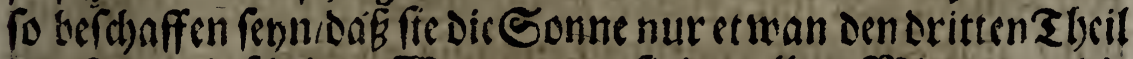

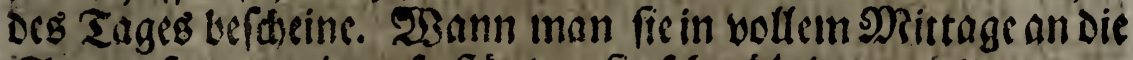

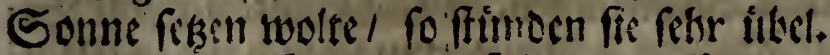

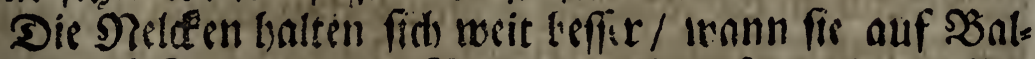

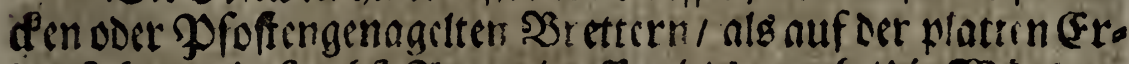

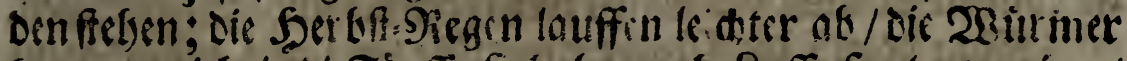

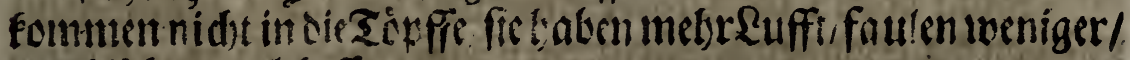
und blithen aitd) befficr.

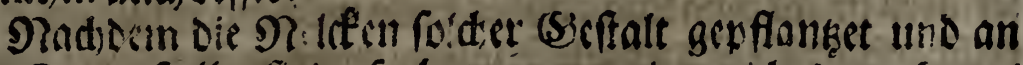
ibren Ort geffetlict find/ fo bat man wositer nidts zut thun I

$$
\mathfrak{S}_{2}
$$




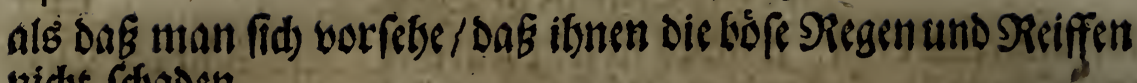
nidjt (d)aden.

1. Soll man fie wiber sie $\Re$ Rgen / welde in DemsNonat Octobri cinfalfen/ verwaberen: Dann tweil oiefe faltfind/und fdjon etwas bófes/ bou denen Siegert / ie in Dem 2Binter founmen/

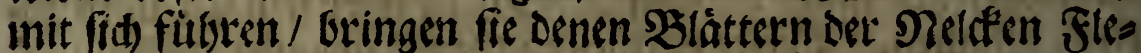
feen / Dabon fte offters fferben. Diefe Flecten nennen wir den

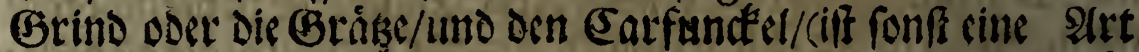

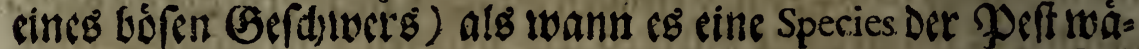
re. Es gielt deren non unterfdsisoliden Farken/ einige find fótwar(3 / uno andere rótbtidst / andere zieberi auf eine unreine graut Fartbe: Doun fers num twie ibm loothe / fo fino fie afte

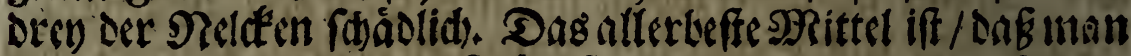

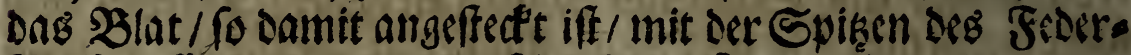
Deffers faubere / Damit co feine Sirundebeit nidet weiterl, auts's breite/ uno den Stengel aud) anffecte; Doer man fóneibetoas Blat gat ab / Das Lbel zu bermeiden.

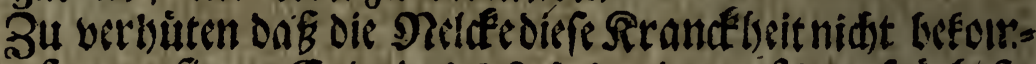
meimus man fie zu Enoe des Octobris, oder auf das fpátlscfe in Dem 2unfange Deg Novembris, Dem?begieffin ses Simmets. Das iff/ Dem Siegen entzieben / inderm man fie mit cinem 23adgs. Sudse zubeffet / Doer unter ein' in Dem Garten zubercitetes

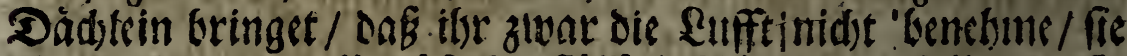

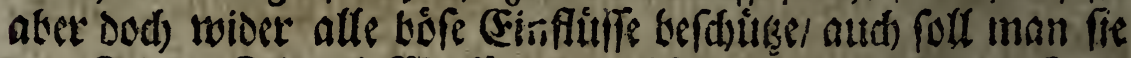

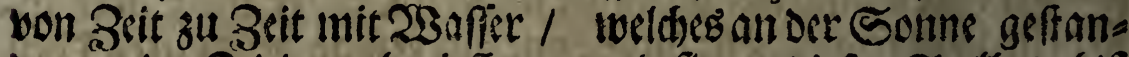
Den / eine Zeritlang begieffen / und fie an Diefer Stedte / bie

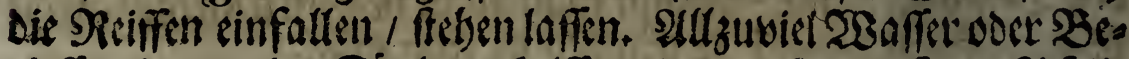

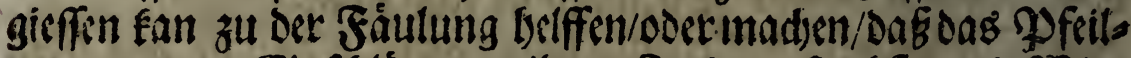

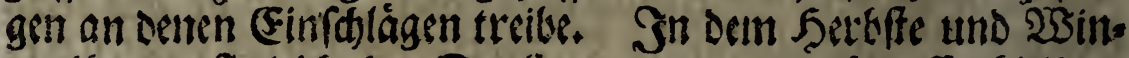
tre fonnen fie leidte oen Dur:tertragen/und unbegoffen b!ciben. Mon begieft bie Nelde niemals/ als init geftandenem

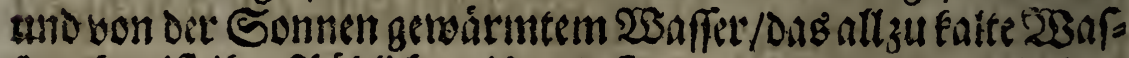

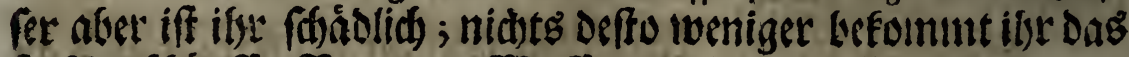

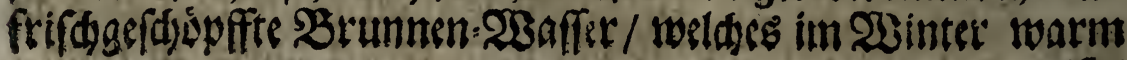




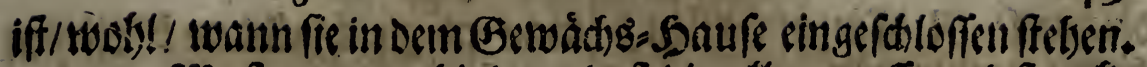

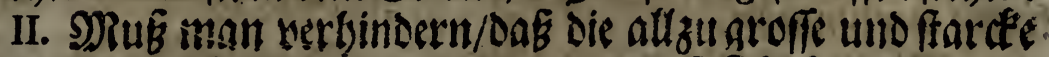

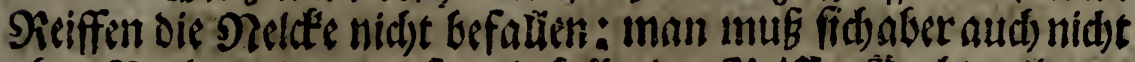

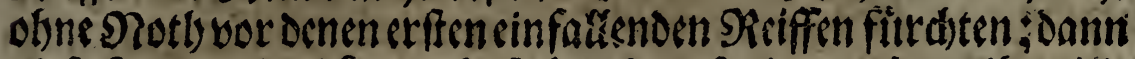

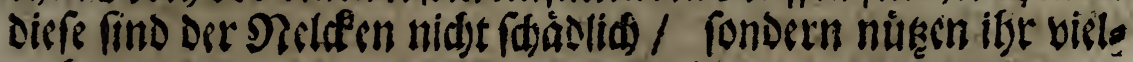
melis.

\section{2nb VII.Cnpitel/}

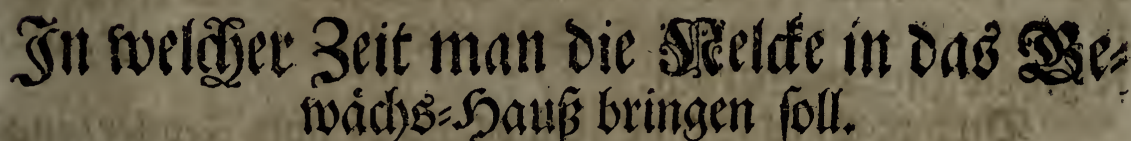

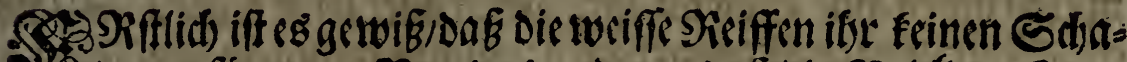

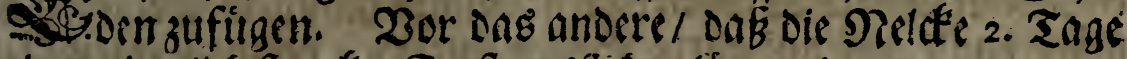

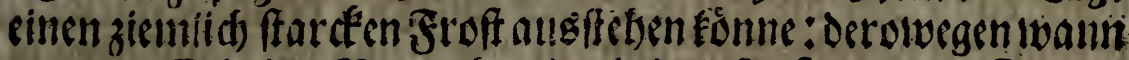

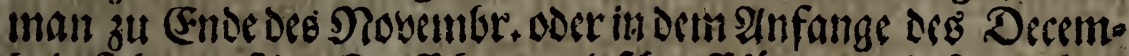

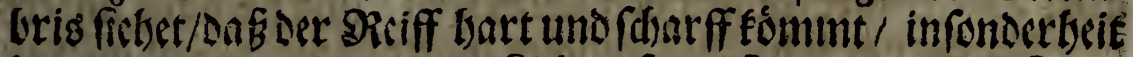

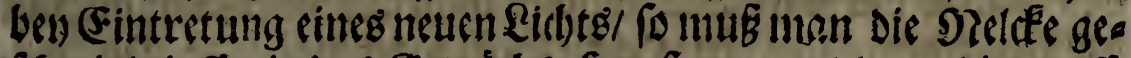

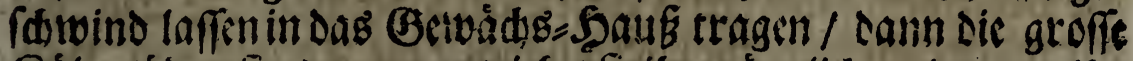

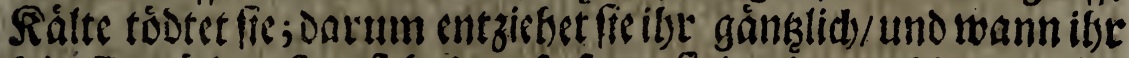

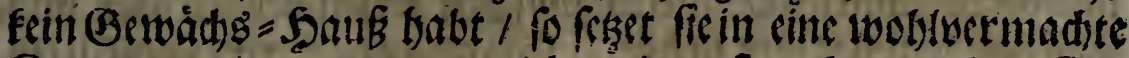

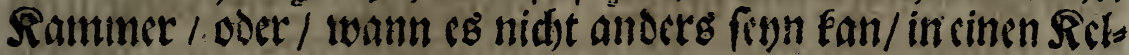
ler Der nidst feudtet fry. Der Zerffano inuB̈ nad) Gelegenbsie Der Drte Nittel an dic Sand getern.

\section{(2)}

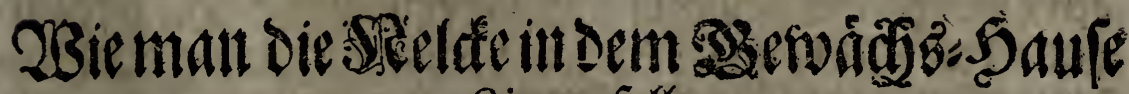
tractiren forl.

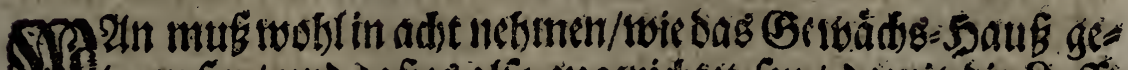

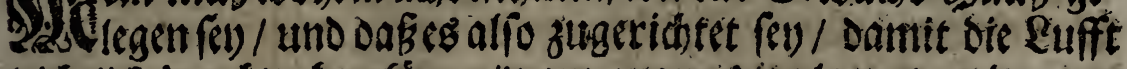

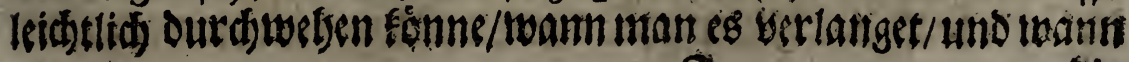

$$
\tau_{3}
$$

sic 


\section{0}

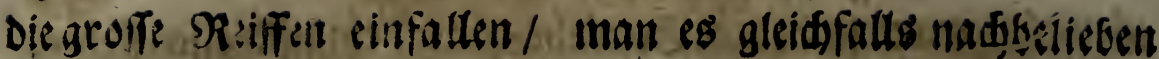
kọnne verbindern.

Die bequimite Situation iff ; wann es gegen NRittage ffe-

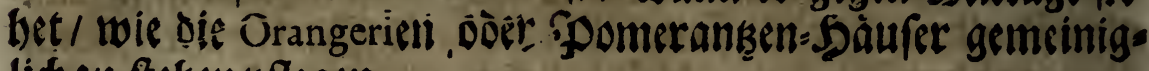
lid zu fteben pflegen.

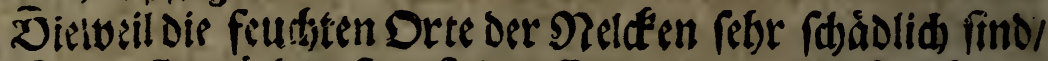

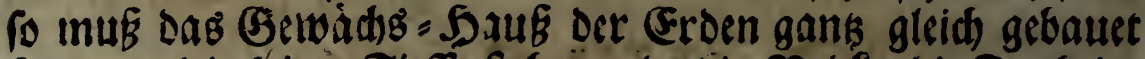
fenn/ und infeiner Sisfe fetben / Da Die Nelefe Die Feud)tig. feit anzielen fónte: Dann wann cinmal oie (Froe feucht iff/ fo bánget fith unfeblbar Der Sdjimmel an Die PPlanke/ uno folget die fálulung Darauf.

Dirolvegen mub cin (B) mitten innen eine Tbutre/auffer diefen aber fonft Eeine Sieffi/als

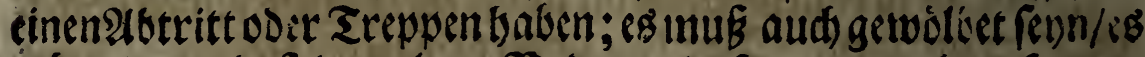
wáre dann bas oer blere Boden mit Seu bertwabret fen / z

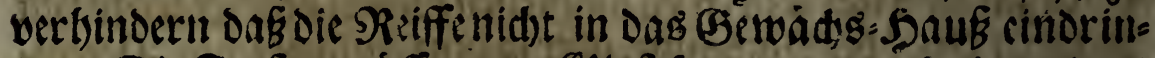
gen: Die Fenfter mirffen, von (šlä́ fenn/ und nods cin anders

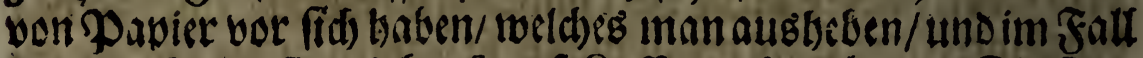

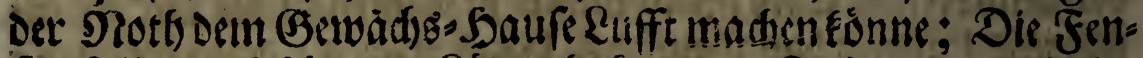
fter follen aud bolkerne \&äen baben / Die Ibüten von Solk/

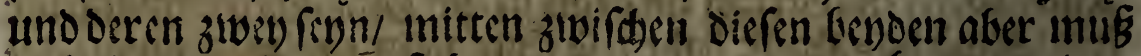
nod) cine von Papier ffechan. Z3ann alzu fardés Sieiffencin= fallen / werden nor bie Sethfer unto shime Matten oder Dis

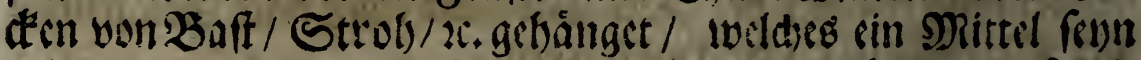

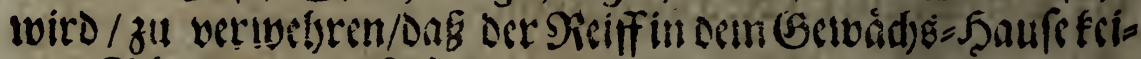
nen Edjaben verurfadie.

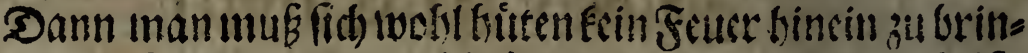
gen / und diefio um viderley Urfaden trillen. Die (Erfeift/

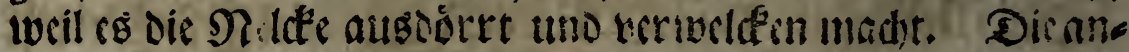
Dere / wann cs Diffelbige nidte gants uno gar augobert / fo twito fie sod) fo weid und fdiwad)/ Daf ibs: Berterben mad:mabls

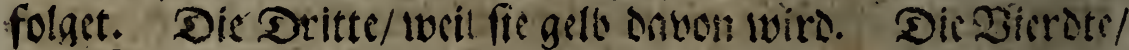

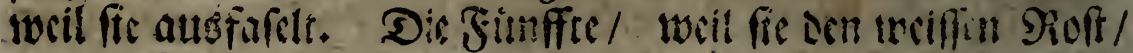

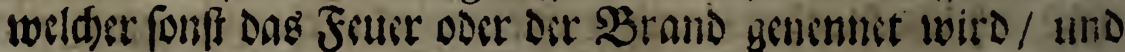




\section{s"l Dem Slumen= Sau.}

cine unbsilbare Srancébeit iff / Davon befomunt; auds um vis:

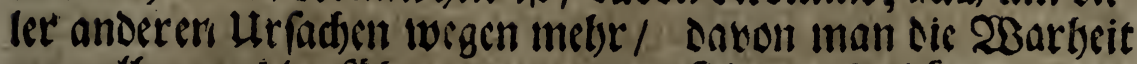

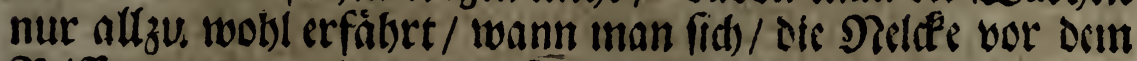

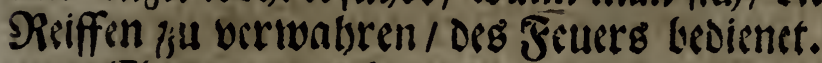

Ebon Darum bat man oben begelbret/ es módten antere

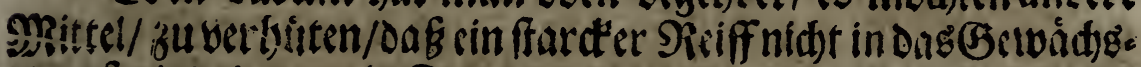
Shaug sinderitige/ als Seuer angeoronet werben: Sd fage / ein

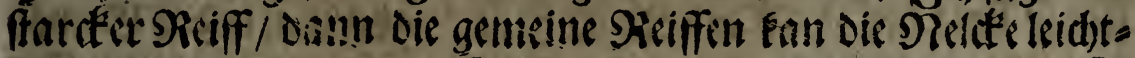

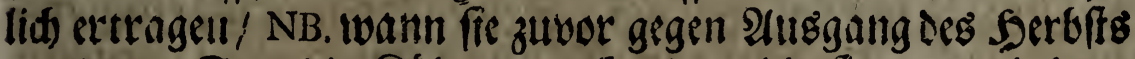

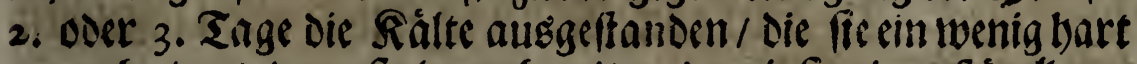
gemadts / uno Dergeffralt vorberritet / Damit fie cinen färacteeten

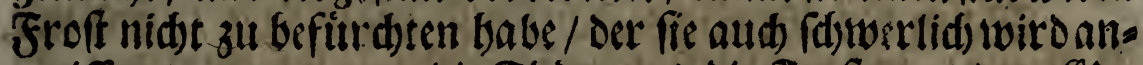
greiffen/ twann man die Shaure und sie Genffer an Dem (Sise

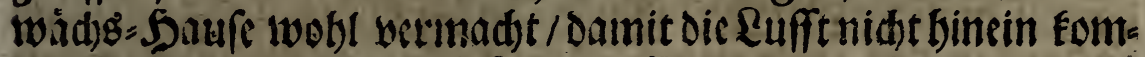

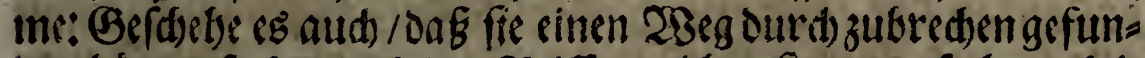

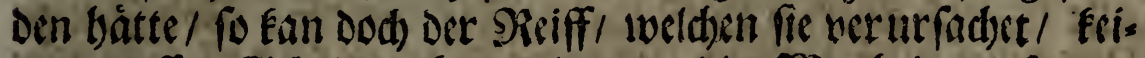
nen groffen Stbaden tbun : Dann/ Die 23artsit zu fagen/

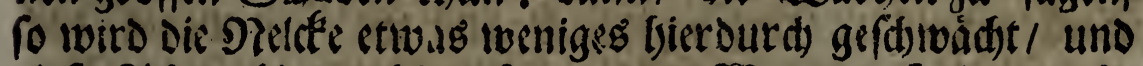

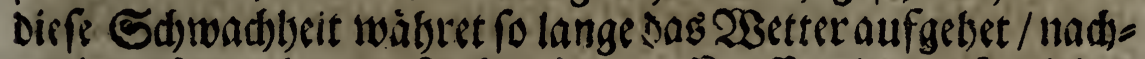
malen aber erlanget fie itsere borige Rrafft twidere / fo vielde.

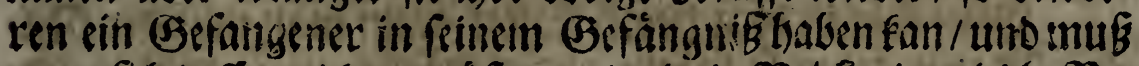

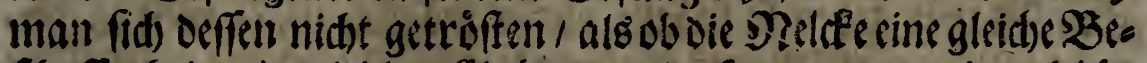

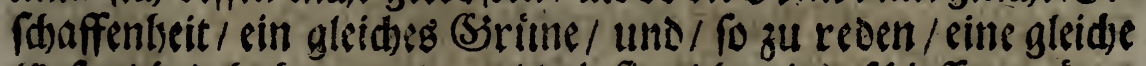
Gefundbeit habin weree / als ob fie nidft citigeffhloffen waike: 3Gre grime Sarbe fiebet man erbseiden / Die Bláterer an Bem

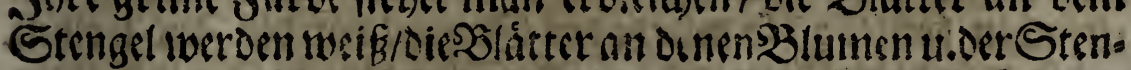

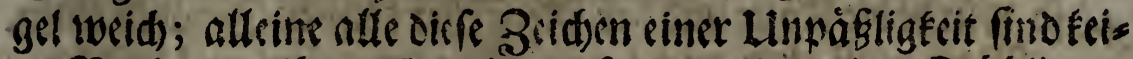

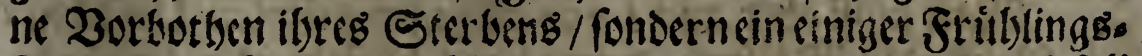

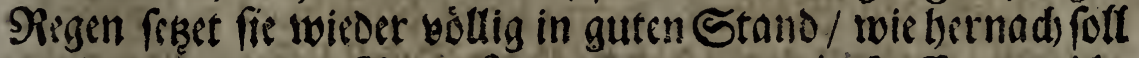
gezciget werden. Sothus man orrowegendie fooffnung nidet gank faden laffen / wann man dic Neldéc von Diefen Edidwadt)

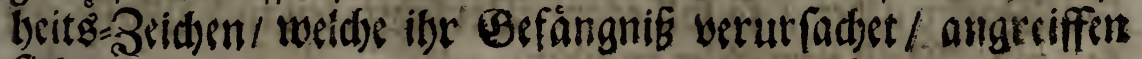
fiebet. 
(Einige Gasen Getwolber in ibren Barten/ die nuffer Der stjilte fonft feine Difnung baben: Iman sadelt fie nidst/ wann fie nut gegen our Sonmen ftelben / feine Tieffe babern/Der Ex=

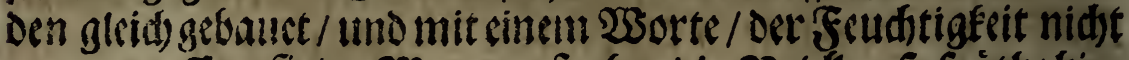

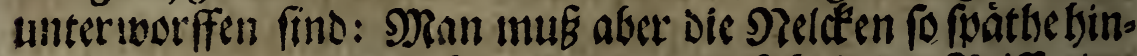

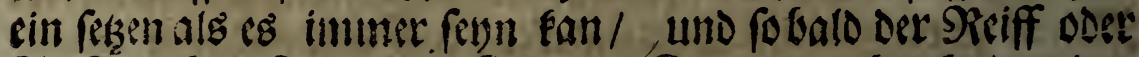
Froff yorbers iff / werden fie in cine Sammer geftendt/won dar

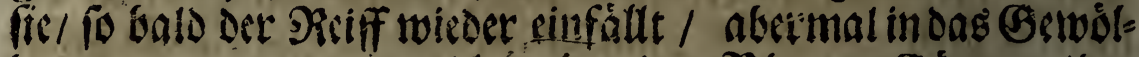
be getragen werden / toeldbes auser cinen Blumen=-Bártner / ber

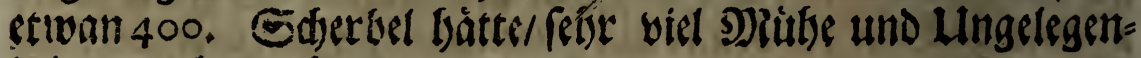
beitenmadyut wirse.

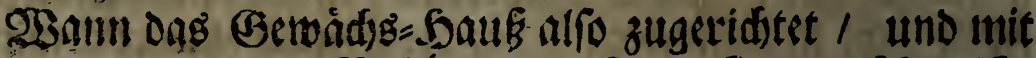

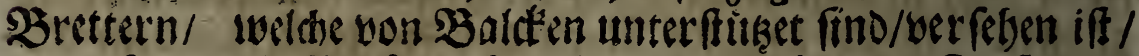
Darauf man die Seclefeit/ fo nalye an die Shure ober Senfer als

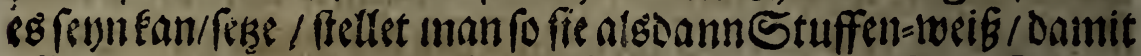

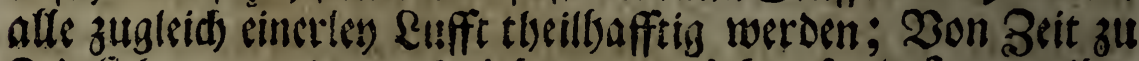
Beit fielset man darned/'ob es von nótben fen Dar man lore Stelle beránterte / uno begieffet fie aud . wobl ein wenig/ ovds unus roldes in sein Votbfalle / uno auf untenbefdriebene 28 ei. re gef́achen.

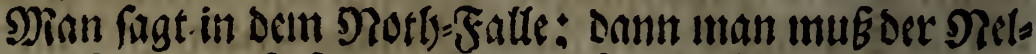
déen $23 a$ ffer geben fo fpattbe als es imóglich iff. I) tweil c8 uns red)t getban sinepQflanke/Die nidst ourftig iff/und De: SBegieffens nid)t broarff / zubegieffit. 2.) Dienveil Die allzugroffe Seudbtig. feit / Die fide in oem Topff/befinden wirtse / Die Fanulung ver

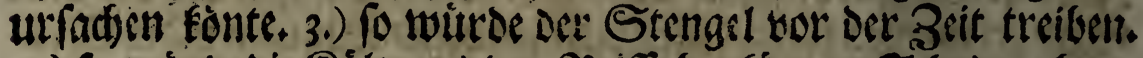

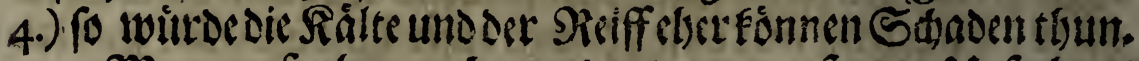

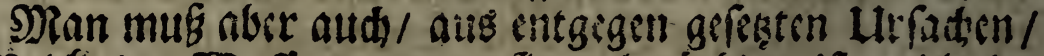

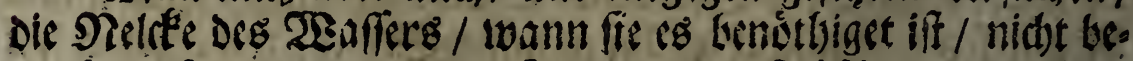
rauben / fondern geben dab fie ibren Durff lofde / zu verbine Detr Das fie nidte ausborte oder wetlvelefs: Alteinc wainn man

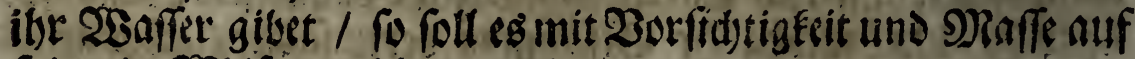
folgende Weife verridstet werden.

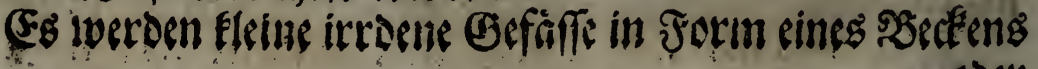
oder 


\section{zusem 3 lument: Ba au.}

153

Doer Sdjuffel angefdinff / in ein iedes twird cin zowff geffetlet/ uns g twar nadjeen es bic 2 loth er fordert/siner nadj Dein andern: Linoiweil man nidt twird untertaffen baben 23 affer an Die Soms

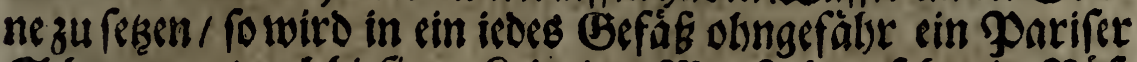

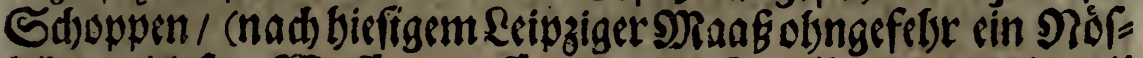
(ei) von Diefem 23 affer gegoffen / Davon fievoll werdeen / Dieweil

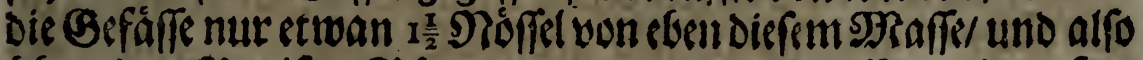

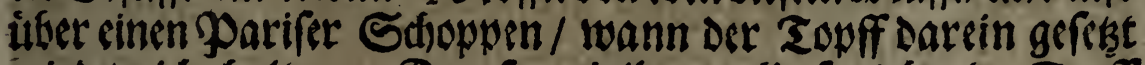

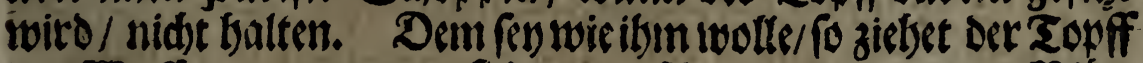

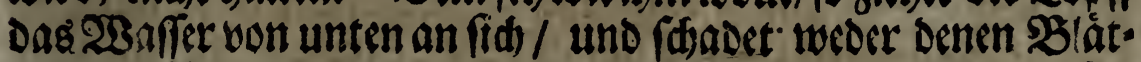

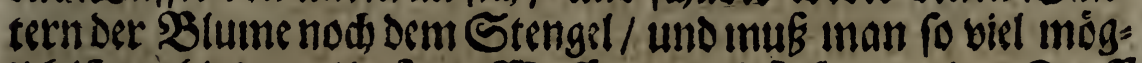

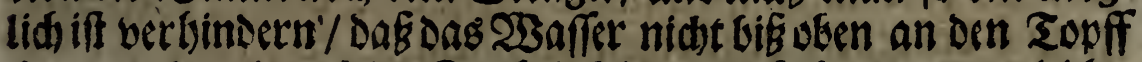

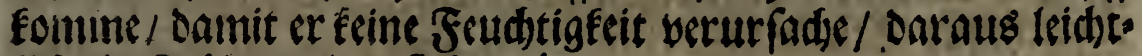
lid cin Edimimel entrfeben fénte.

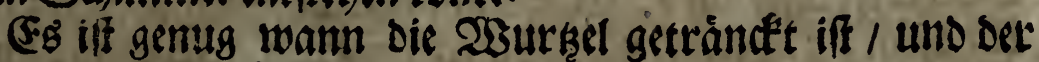

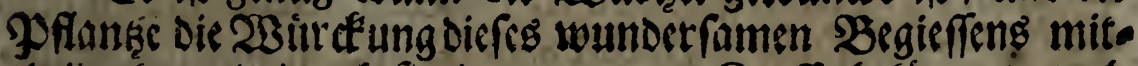
theilen fan/ Badurd fiecine gan/s neue Rrafft befímmat/ wele.

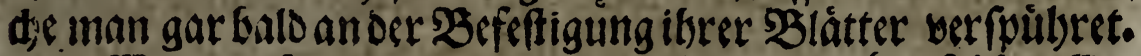

203ann gefagt tworden/man iniffie ber Neldéen foddjer Geo fralt 230 offer geben / fo verffetlet fidh Daß man genna auf Die

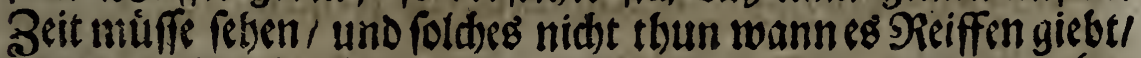

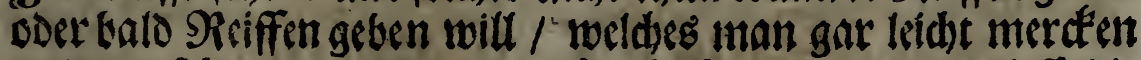
umb yor fefsen fan: Dann es wäre beffer getban man lieffe die

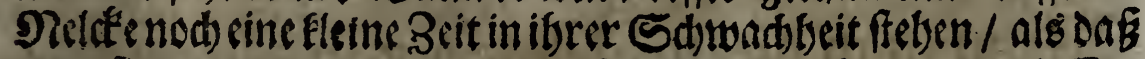

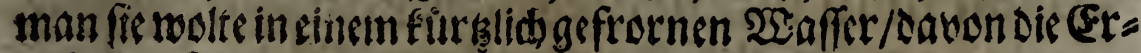
De balo gefrieren fan/erfrieren laffen.

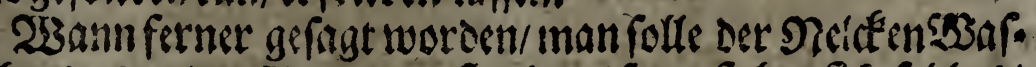

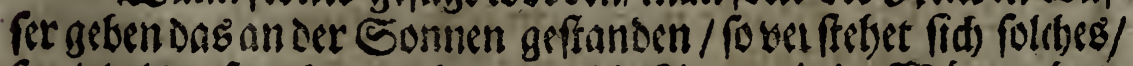
To biel alses fenn fan/ und wann Die Sonnesinige 23árme that;

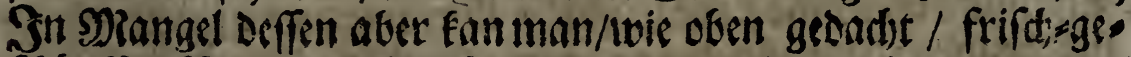

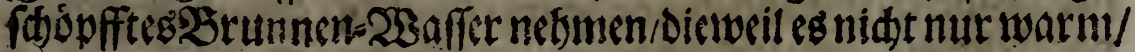

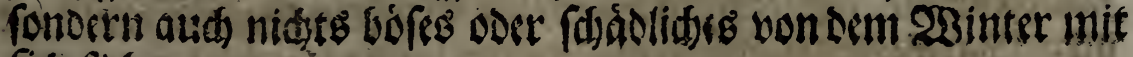
fid fitteret.

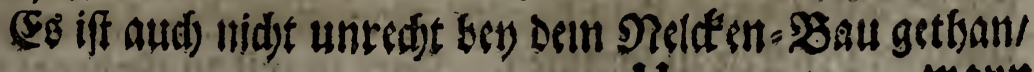
$\mathfrak{u}$ wann 
154

Reue Untertoeifung

rounn in sem (Getwád) = Saufe Die dirtre Blátter Dabon abge: nominen werden; Dann iveilf fie eber als anocre Dic Fecudtige feit anl fid) zirben / fo fónte die Fáulung gar Daraus erfolgen/ soeldes das groffe Letecl ift / fo iman Den 23 inter surd) zube. fordten bat.

Dielveil die Ratten denen Pelefen / fo lange fie interm Gewoids: = Saule frehen / feibr groffen Sdjasch zufigen / fo bat

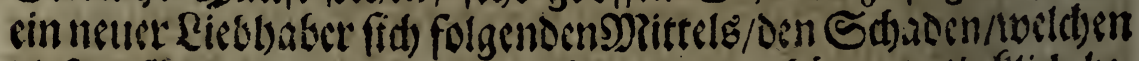

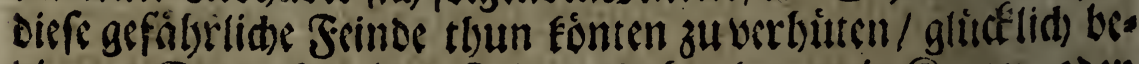
Dienet: Fr madte ciner Rrig/ und tlat davon in Sintten oder

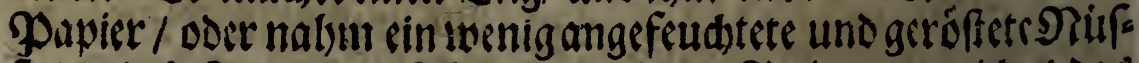
fe/ und beftreuete diefelbige init sinein Pultuer / toeld)is Das vornebinffe Studfe iff/fo or in feinen Teig modset / uno weldses alfo verfertiget wirb: NRann nimint 4. Unkesn voer 8. Qotb als

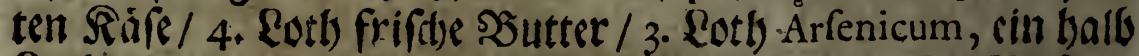

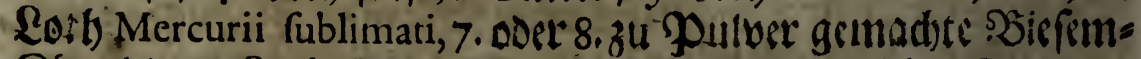

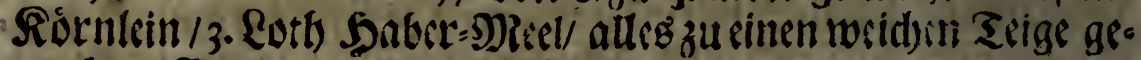
madst. 2Bann mann dic Nhiffe mit pulverifirten Arfenico, Mer. curio fublimato uns Mufco oder Bisfem seffreuet / fo bat man nidbt au beforgen / Dä dic Rakecn Davon freffin.

\section{2nื IX. Capitel|}

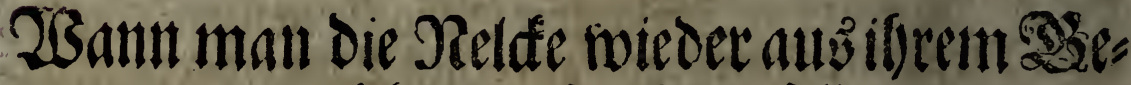 roadbis=Saure nebmen foll.}

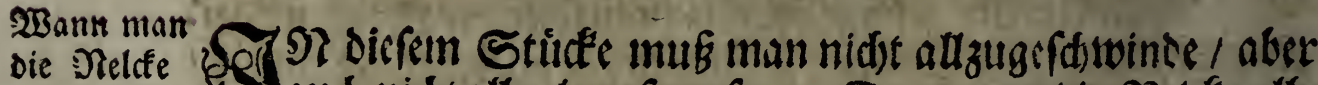

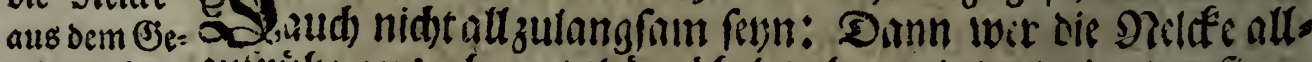

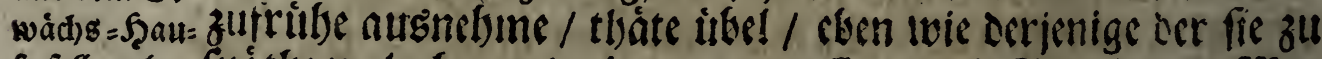

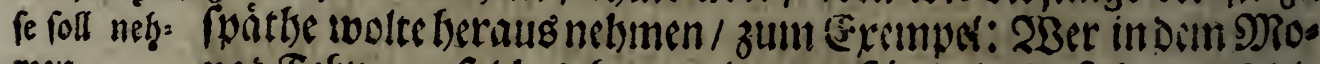
merr.

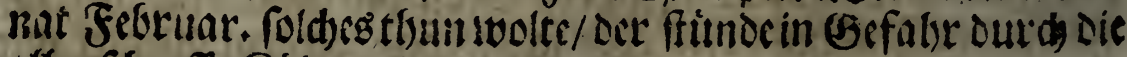

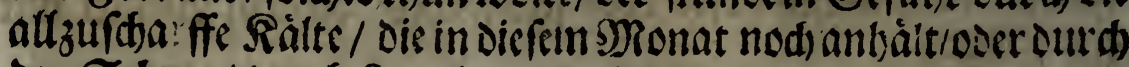
Den Sthnee / ourd) Sagel / ober aber ourd einen falten Siegen

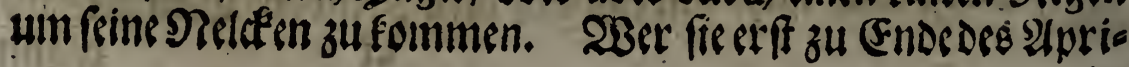




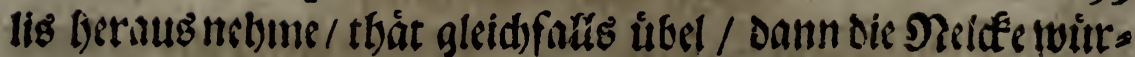

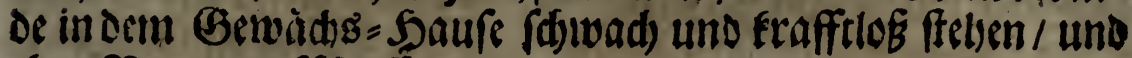
obne शukezin auffítieffin.

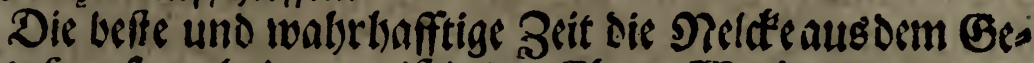

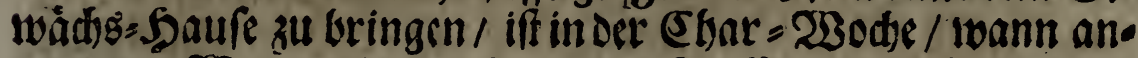

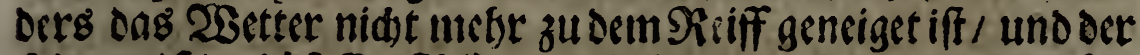

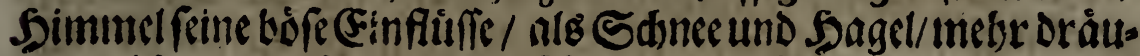
et / wildes in bicfer 230disn fetse fetten gefdieflet. Man fan

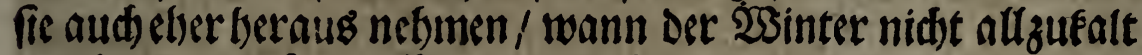
une bart getweren. MNan zeiget bier nur was gemeiniglid/

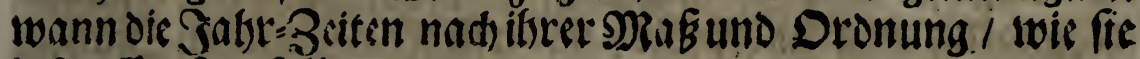
befdsaffen feun roulten / fomment.

Dimfen nun roie fibmntwotte , fo miffien Dicken verfertis

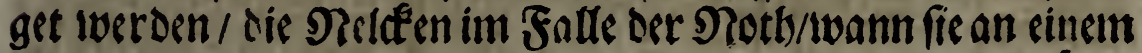
Drte / Da sie Sonne nidet hin foummen fan / Damit zu Gedecéen/

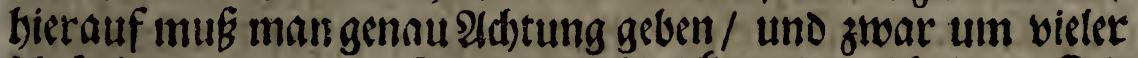

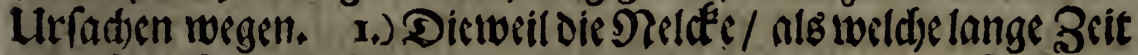

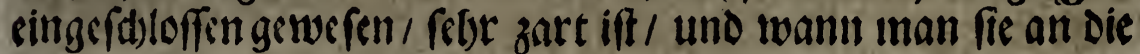

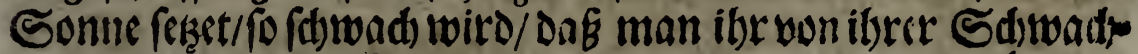

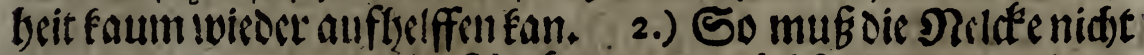

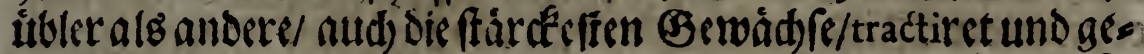
balten werben / Die / fo balo fie nus Denen Drten / wo felbff fic

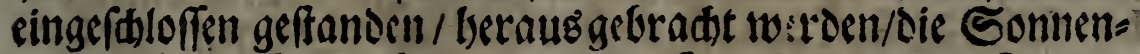

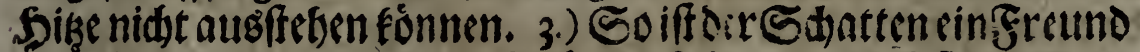

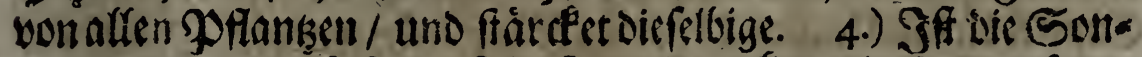

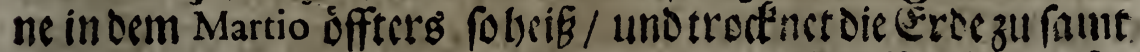
Denendarimuen fretbenden poflanken aus. Die fimffic Lurfat des iff von Der Erffaltrung genominen.

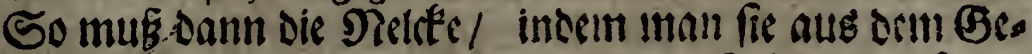
wwád)

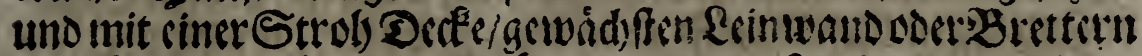

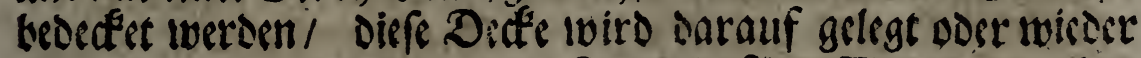

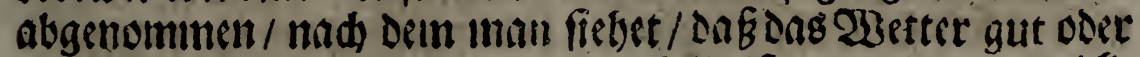

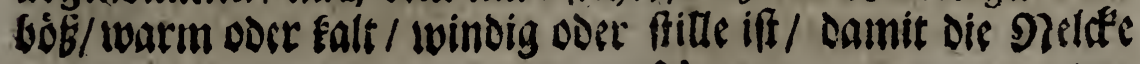


156

Teue Lnterweifung

vor bem Angrifforen ikrer Feinde / Denen falten Siegen / Demi

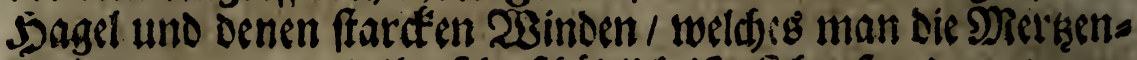

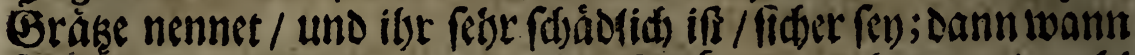
fie mit guten Strob oder andern Decfen umsecten / uno wobl verwabret iff / fo gebet es feber fastwer zu/ Dá̧ ibr diefes alles folte einigen Sdjaden zufúgen/ uno wann its oer Shimmel/ wwie eg fid offers zuträgt / feine angenebme Siegen mittbeilet/ fo mitfien fo wobl unten als obent alfe Derfen hinweg genour men / uno in Dem'fie diefen biummlifosen Tbau empfängt / sine freve \&ufft zu foboffen zu gelaffen twerden. Sierdurd erlangt fie ibe naturlidegrine Farbe/ ibre erffe Rrafft undoen Stano/ in tweldecm fie/ ebe mandiefelbige eingefdilofien/ geftanden/ woieDerum in furber 3eit: Berfaget ibr der Silnmel feinen Siegen/

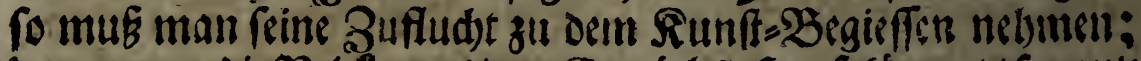

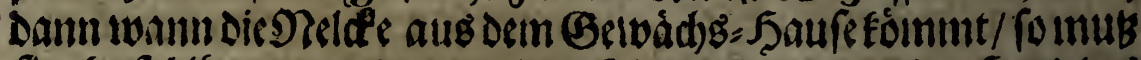
fie ofnfeblbar enttweder von dem. Siminel oder von der Jand bers SBlumen=Gártners befeudtet werdern/ fonft witroe ibe die frepe Rufft febr groffe ungelegentsit verurfaden.

Nadjoem fie alfo 8. Docr 10. Tage in iem Sdattengeftam.

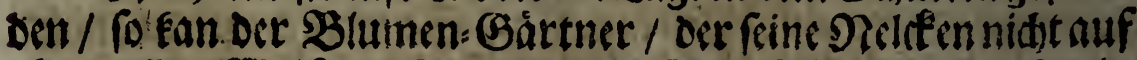
obgemelote Weife gephanket / DaE ift / defelbige in Dem Serbs fte in sine Eroe / Darinnen fie Das ganke Jabr ourd) bàtte ftes ben fouten / gefereet bat/ folde in der Ebar=23odjen in bie (Ee.

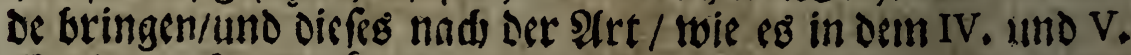

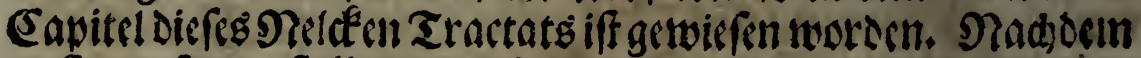
ex fee berfescet / feflet er biefellige 8. Tage lang in den Sdjat

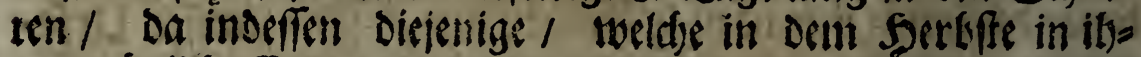
re naturtlide Erde geformmen / Darinnen zu bleiben / en einer ibnen vortrágliden und ifserc Patur gemâfien Sonne ftelsen/

- bis Die / fo crft in Dem Frubling gefręet worden / indem Stan.

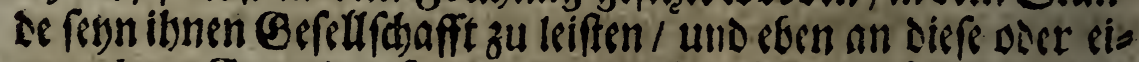
ne antere Gegent gefeseet wetden. Die faule slatter / lwann

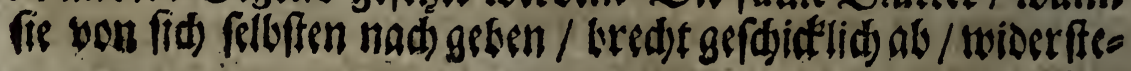


zu DemSBlumen=S Sau.

ben fie aber/fo fonneidet fie ab. Eure PPlanken bultet fete rein und fauber.

\section{2@्b. Capitel/}

2Belden Drt / Segend unt Situation mant ber Nelcfen geben foll.

(5) Sef Frage fomint gank und gar aus Der Erfabruing/ as uno felten ibs viele in diefer Materie/ indem fie der Sas de entiveder zu viel ooer zu ivenig thun. Zuviel thun fie/ ine Deul fee ibre Neleeen gegen Mittage fereen; zu twenis aber/ indern fie ibnen fo wenig Sonne geben/Daf fie ibrep feilgen nidet treiben förnen. Die Dlildée roilt weser zu viel now zu wenig baben / fonocrn man mus ber) ibr in allen Stitefen das MRit -

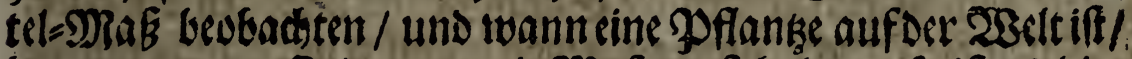

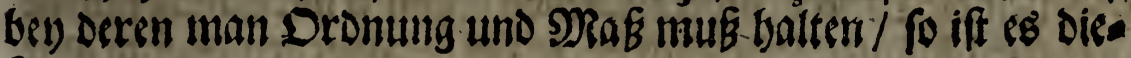
fi.

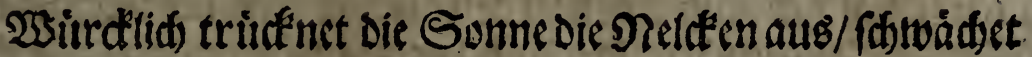

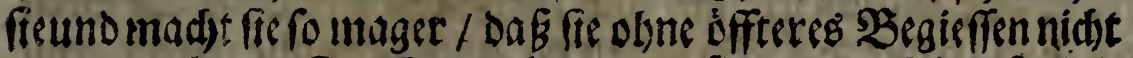
zuntbuten fan: Im Begentheil wiro fie von der alswerenteit aet Sonnen getb / bált ibre SBlumen zuritate/ und madt dab

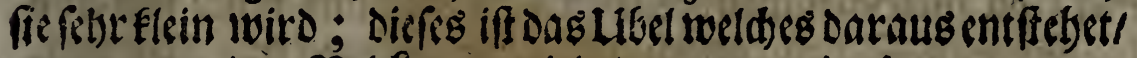
twann man der Nelden zu viel oder zu wenig thut.

Naun folget Det Ditt / Die Gegeno und Situation, weldjeitgr vortságlich fins.

$23 a$ Den Drt setrifft / fo ift ifs erftid die ftarte uns

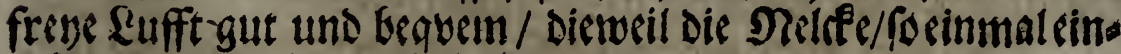

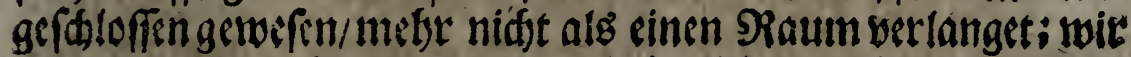
feben Den Luterficeid an Denen Die in fleinen Gàrten gebauet woroen / ocreni Blumen dic Brcite nidtt baben / weic dicjenigel welde Iman in Der frenen \&ufft altfgeforad)t bat; sin gleidjer

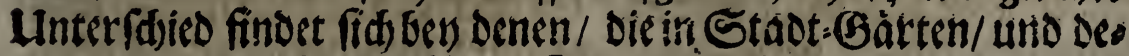

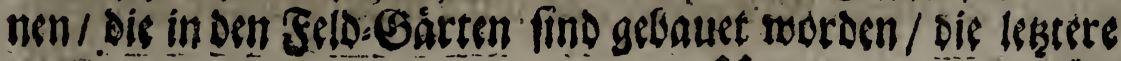


bebalten meiffentbcils in Der Diffe uno Sreite / nidbt aber als lezeit in ber Edionlseit / den 2orzug. Zor das andere tras gen die fumpefige Drte / Die হriefen uno Mioráfte / weldhe na. be liegen two fie gebauet recrden / nidtet wenig zu ibrem gluct"s

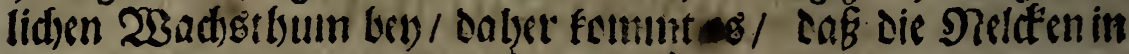
Denenशieder/anden tweit fáoner/ didert uno beeiter ale einem

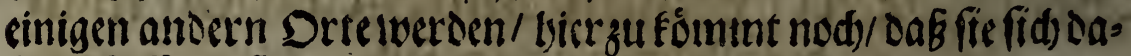
felgft beffer befinden/und felten verloberen getern / da bingegen

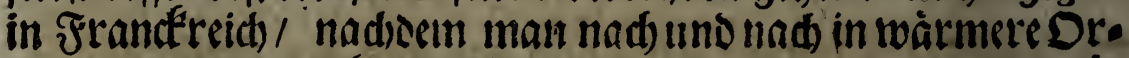

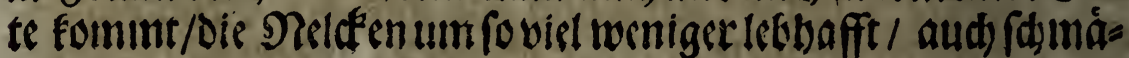
ler find.

Die Gegend bilingeno / fo ffebet Die Nelde Dis Mergens von 6. bif r . Uhbren gegen Der Morgen. Sonne/und cesabents

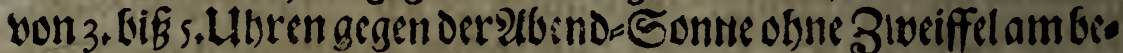
ffen / dann in disen Stumben iff cie Sonnen = Sibe nidt fo grob/ bod iff ron tenden dic Sonne gegen Morgen dic teffe.

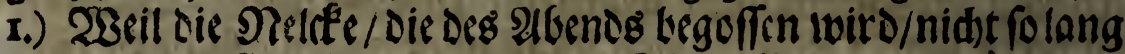
in ibremunflatb bleiben sarff. 2.) Sfr Die Mrorgen=Sunne/twie

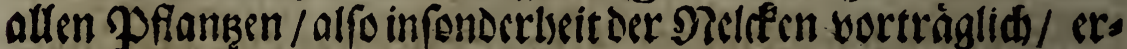
frifdst fie augenfdscinlid / uno madts dag fie alfgemod) ibren

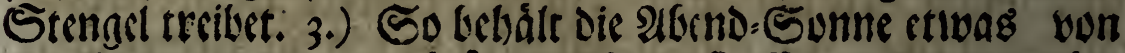
Der NRittages= Sike zurince / welde sie \&ufft und Eroe criwár= met / on im Eegentbeiloes Margents sic \&ufft frifob) ift / urio Die Sonnen= Strablennad) und nad zertheilet und zerftrenet.

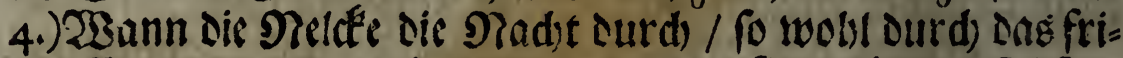

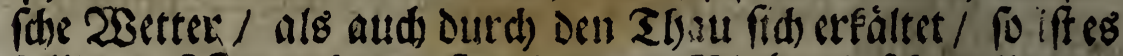

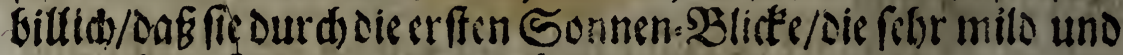
angenclime fins / wieber erwátmet werde.

Ded) fagt Sert Morinus, Dab ar att Eat (Erfaftum wif

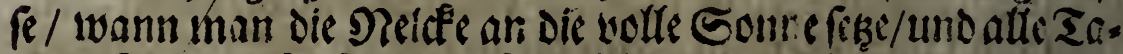
ge fleifig begieffe/ fo twerde fie zufelsends wadfern/und in 8. Ta gen mebr zunebmen/ als fonffen anberwerts in 3. Menaten: 28iro aber Das szegiefen nur ein ooer 2. Tage birgeffen / fo iff gemie die Neläe berlobren / uno wird nimmermebr auffom: mett. 
Die Situation Der Neldefen foll aud in adt genomunen 1 wer Den: Dann umon muE fic wider fecine Mauren frethen / und

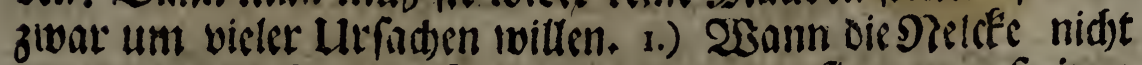
rings tum Den Stengel Rufft bat / fo treibet fie nut nuf ciner

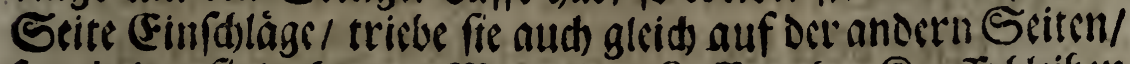
fo louitoen fie Dod) / aus Mangel Der \&ufft / obne Rrafft bleiben

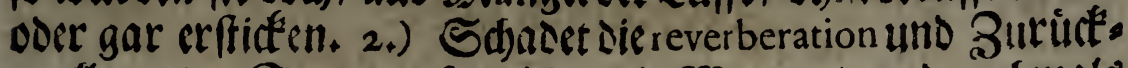
pretlung oer Somen / fo ivicoer die Mauter / und nadsmals

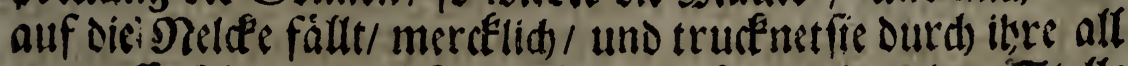

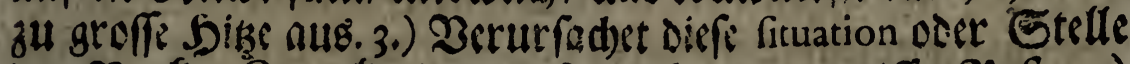

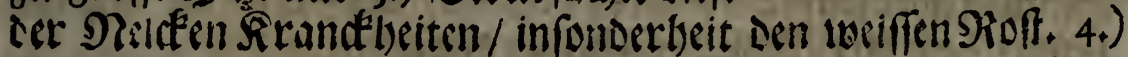
So findet DaE Ungegiefor / Die ibr nadffellen fie zu verdecrkeri/ cinen leidten $23 \mathrm{rg}$ lie anzugrciffen / inderm fic fíd Der Maucr

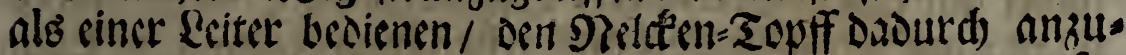

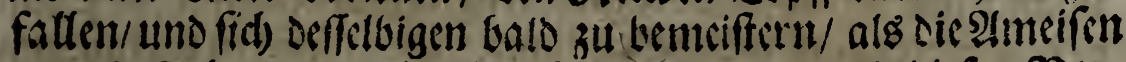

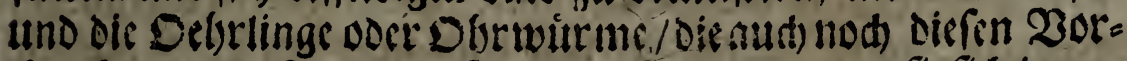

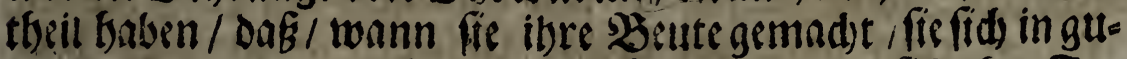

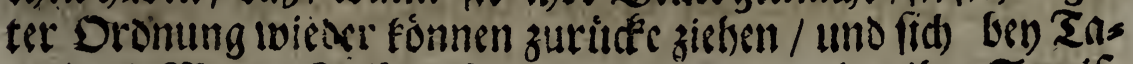

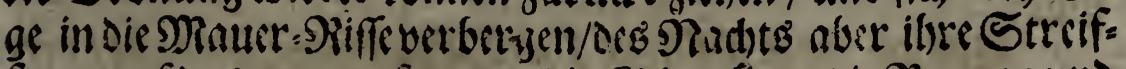

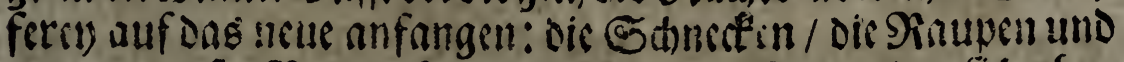

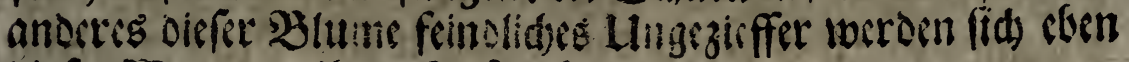

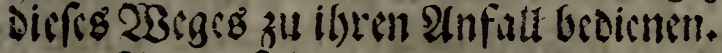

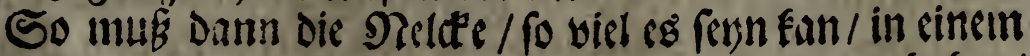
weiten SDlabe ftetben/ oder eod) wenigftens \&ufft genug baben/

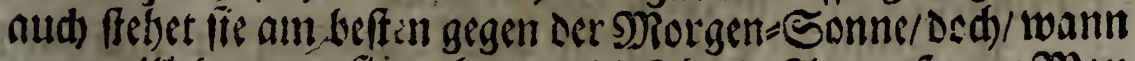

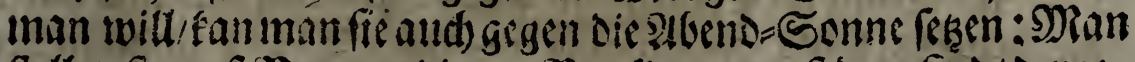

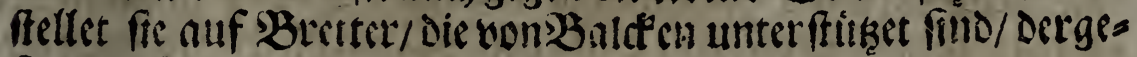
fraltt/ Daf Dir Sufft won allen Sciten zu Dem Stengel formmen/

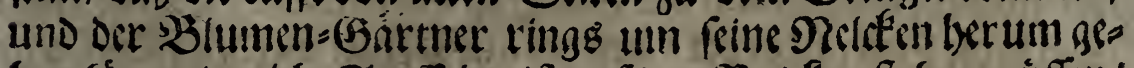

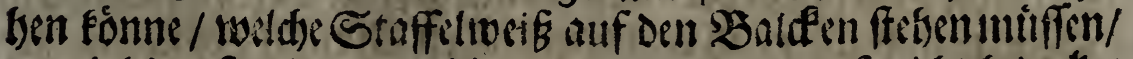

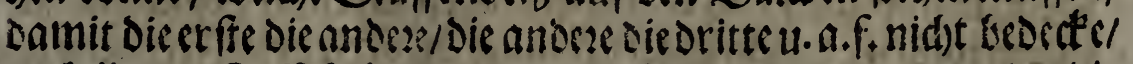

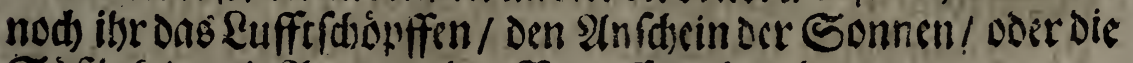

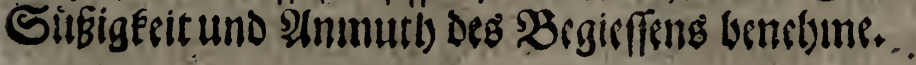




\section{Nene Untertweifung \\ aิ

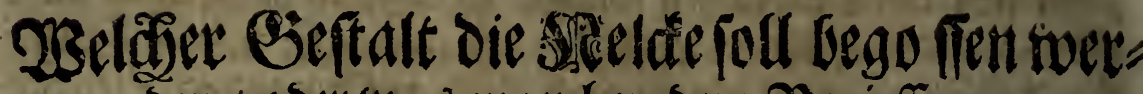 Den/ ober was man ben bem $B$ egiefien zu beobadten babe.}

\$3as ben

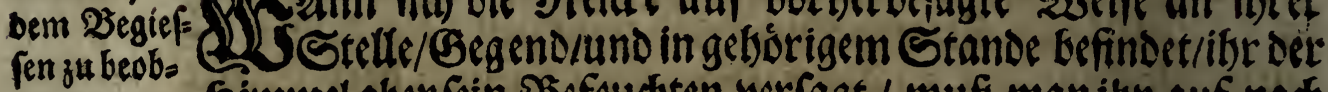
achter. Simmel aber fein Seffudten verfagt / muß manibr auf nad, befariebene Artwafier von der Eroen geben.

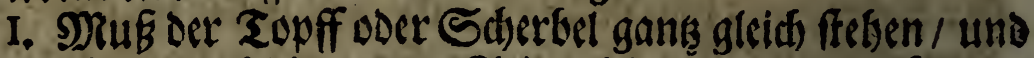
weder auf sine nod die andere Seite abbangen/ damie fid das 23affer auf Dem Edherbel ausbreiten / und der ganken PoflanBe in gleid)er Mias mittkeilen fónne; úber diefes zu verbinoerrn/

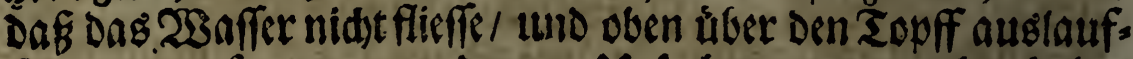
fe / worauf man um Deener Lirfaden swegen adte baten rolu.

Erfflid) iff bie Pflanke ifrer Begieffing beraubt / Deren

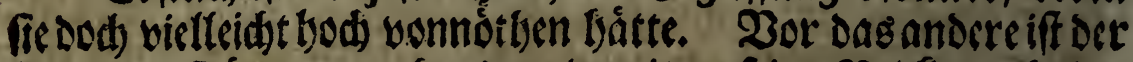
Slumen:Gártmer verbunden/ samit er feine Neldéen erbalte/ feine פeitbe zu verdoppeln / uno diefelksige zum andern mal zu begieffen. Zumoritten/ foláufft die Fettigfeit uno Nabrung Dis SDiffs zu gleid) mit Decm 2Baffer aแB.

II. WSann Die Erde in Dent Topffe austrucf net und Duta)

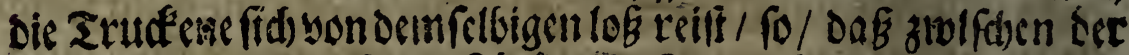

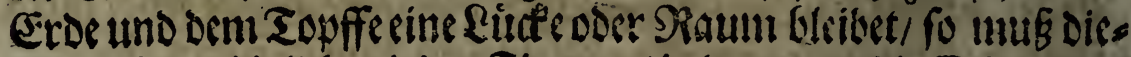
fer nothweendiglid) mit den Singern/ in dern man die (Frof rings

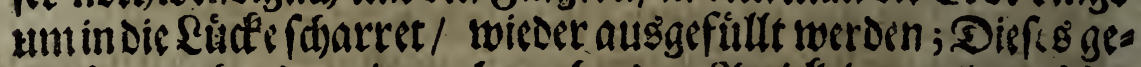

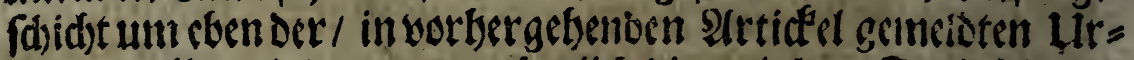
fadsen willen/ indem mannebulid dic verlobsne Fettigfeit uno

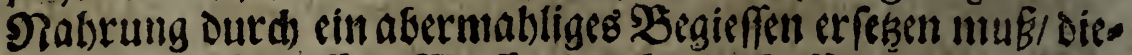
weil das aufgegoffene 23affer durd) oie Deffnungen abfieft/ 


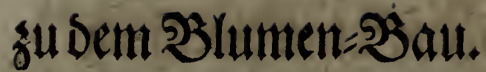

I6I

uno/ obne cinige Jecudtigeeit binter fid in Dem sopfe zแ laffen/ fortgelbet.

III. NuB man gleid) morgengfrutbe 2 affer aus Ient

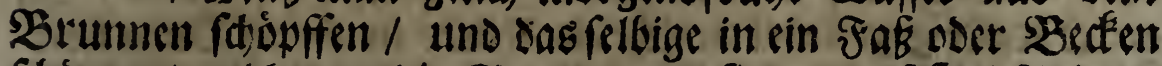
fitieten / weldiss an oie Sonne / wo fie am beifsfen! fdeinet/

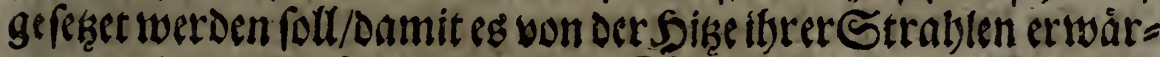
inetwerde / und feine natirlide Siálte/ bie in Dem Sommer viel groffer als in einer andern Salstezcit ift/ verliere.

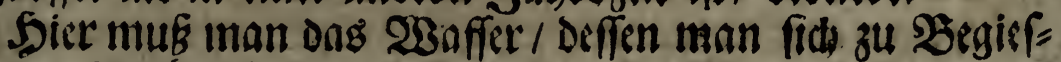
fung oer Nelefen bedienen foll / und die betwegende Lirfad)en os=. rer Die bermifdtes Waffer brauden/ uno in oer Dieinung ff: ben als ob fie Der S?elfe febr, wobl thaten/ examiniren und unterfudien.

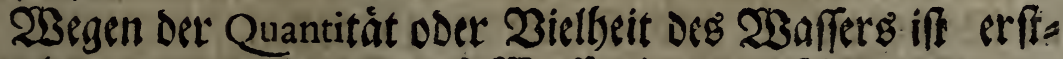

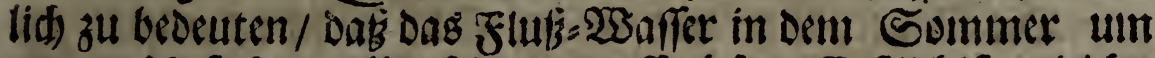
zlweser Lrfaden willen febr bortrefflid) fin. (Erftlid) ift es leidst. Zor Das anoere iff es temperirt uno gemáfigt Duted die aufges fangene Sonnen=SJike; alleine weil der Slumen= Gártner ib=

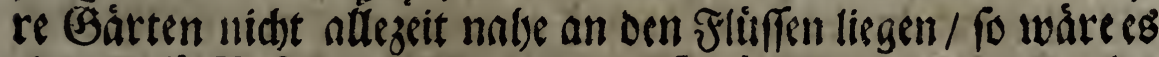

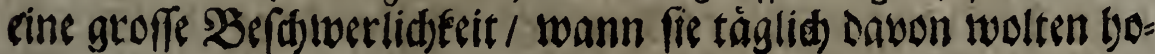
len laffen.

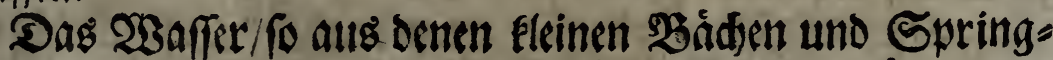

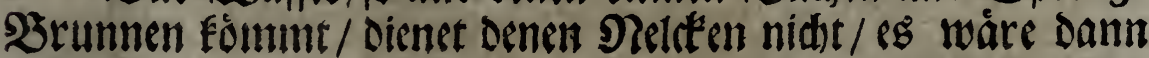
Daf man eg zubor in Faffer getragen und andie Sonne geferet

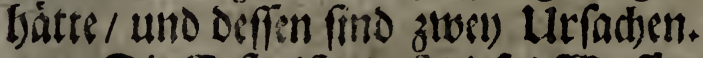

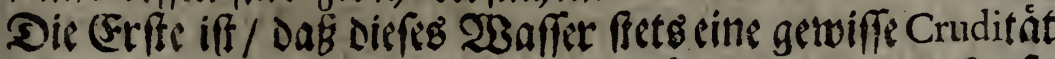

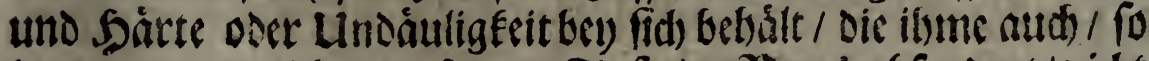

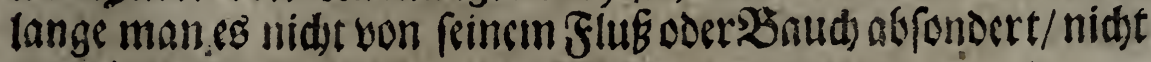
vergethen wird.

Die andere Urfade ift / duf diefer 2 gnffer / wegen det allzunabe liegcnden/ aldi) anderet unter 2 beges fids findenden uno Darzu fieffenden Duillen/ feine Rálte ftets bebalt; Nun

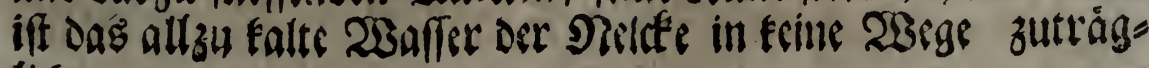
lid, 
162 Neue Unterweifung

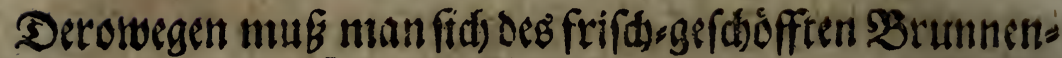
WSaffers / zunn wenigften Den Sommer Dutd/ / nidet bediench;

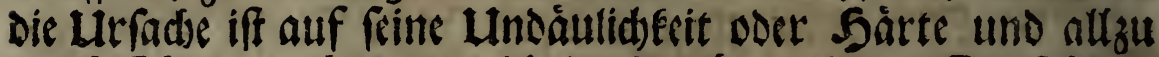

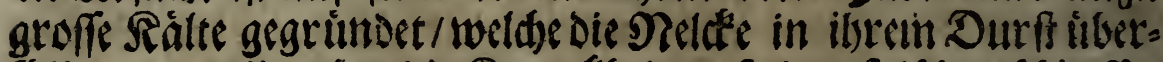

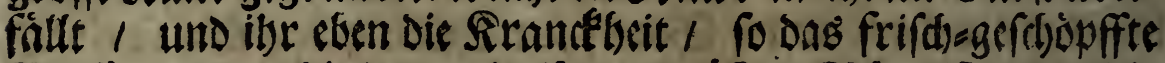
$23 a f f e r /$ benen bie Bavon in ibrem gróffen SdhweiB uno $\$$ jis

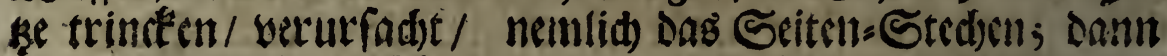

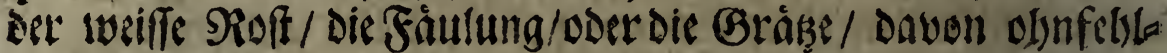

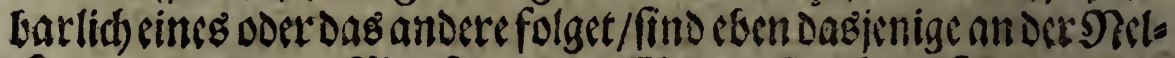

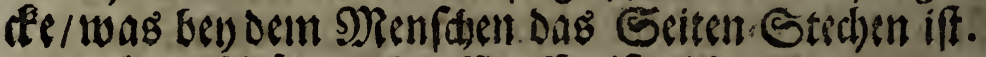

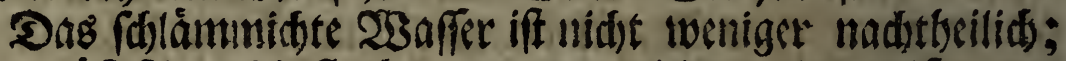

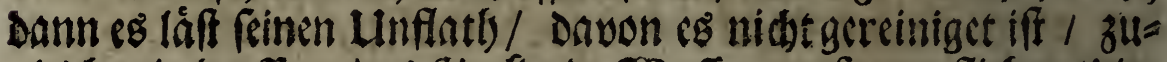

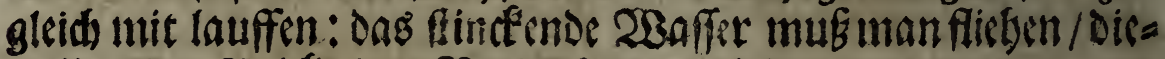

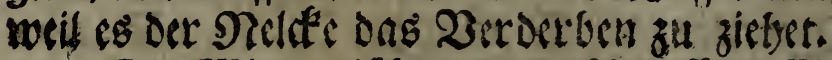

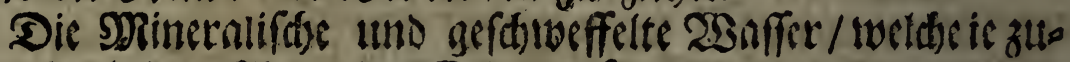
tweilen in einigen 21 errn der Erben gefiunden werden / und oer

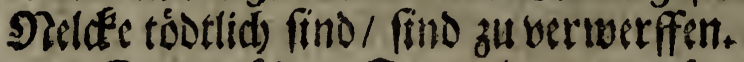

Das auf Dein Feucr laut gemadite 23 offer iff fdlitmmer

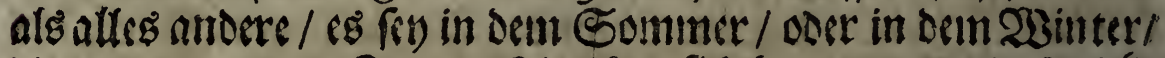

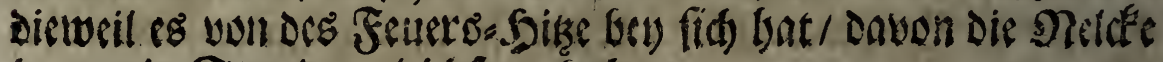
in twenig Stundern glididfain fedst.

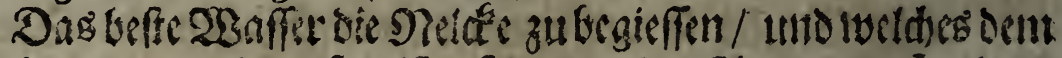

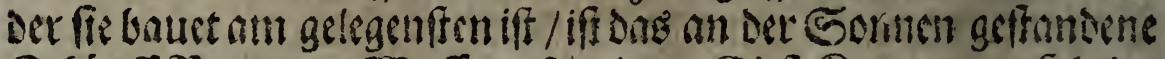

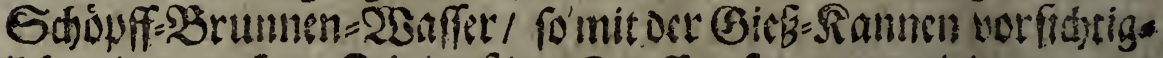

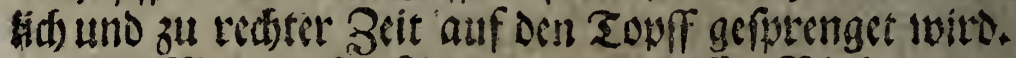

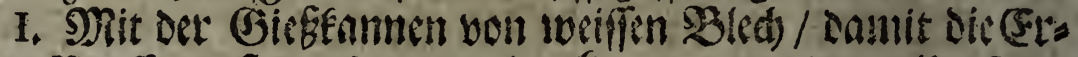

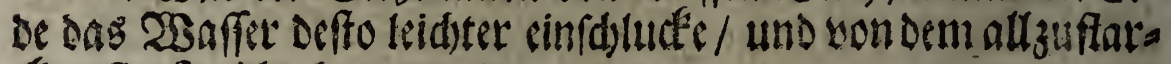
Gén (Bus nidte bart werde.

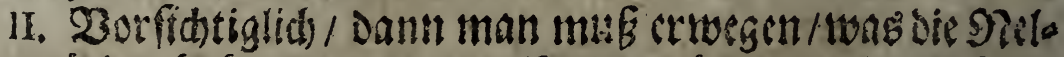

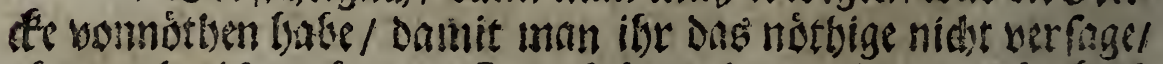

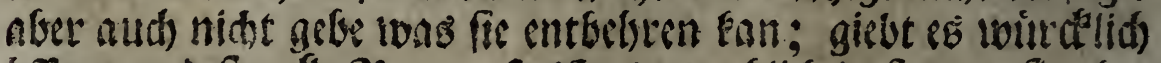

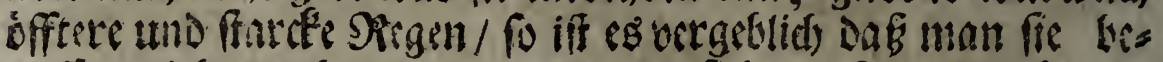

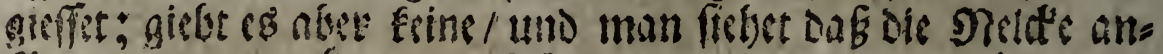

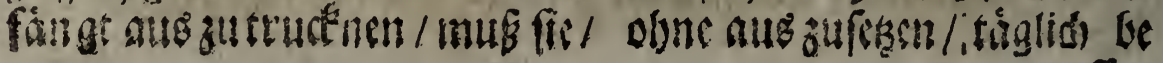
goffin 


\section{zu Dem Slumen=\$2au.}

163

goffen werben / aber nur ein ibenig/Damit fie affezeit in gleider Feudtigerit erbalten werde / Ded) zur benige / Damit fie feis ne Notb leice. Die Zorfidtigfeit wiro birrinmen fach cas פRág gében.

III. Zu rechter Zeit/ Dann man muBscie Deldét tiur ge" gen Abend / ungefebr nad) der. Sonnen Untrgang / begiefien/ wer fie fien wollem Sonnen= Sdsein begieffen wolte $/$ oer wout. De verurfad)en / Daf fein Boegieffen nid)t alueine feimen Nuken

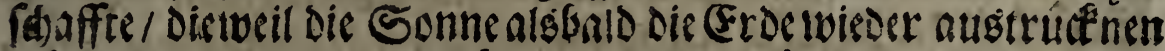

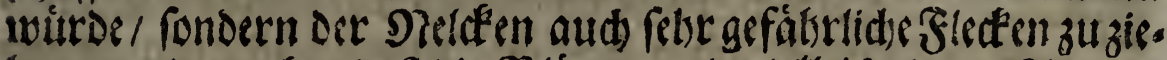
ben/ uno innden oríb die Blátter uno vielleidte ser Stengel

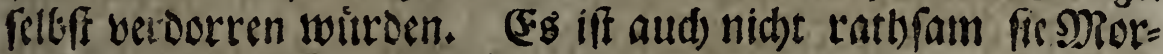
gene yor oer Sonnen-2ufgang zu begieffen / Dann zu gefd wei.

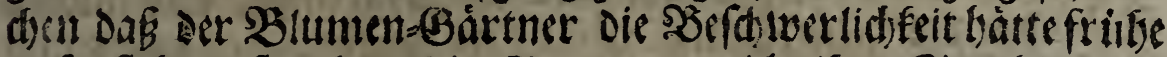
aufauffelgen / fo whroe sie Gonne / weldse itse Strablen auf Die nod) naffe Blátter twirfft / Diefelle gleidf follo austrucénen; uno îter diefes entzoge iman der Veldefe sen Zortbeil / weilden

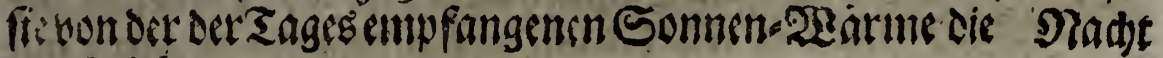
ourds zietert.

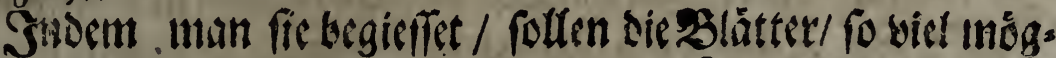

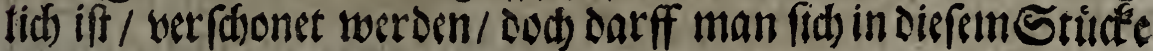
eben fo ferte nidet binden.

23iele Gegieffen itse Vielden/ wie man fonffen in sem Gse: twidds: Soule zu thun pfleget / bedienen fid fleiner irrbenen

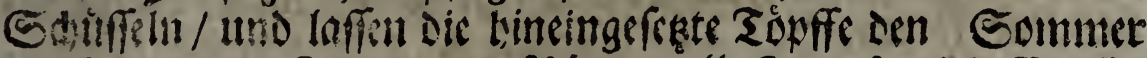

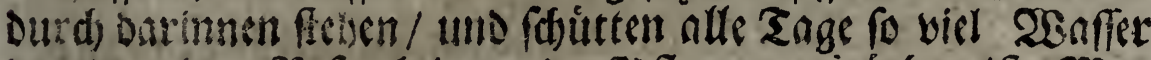

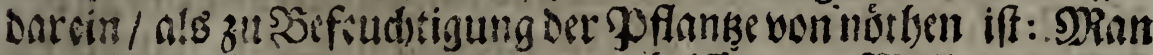

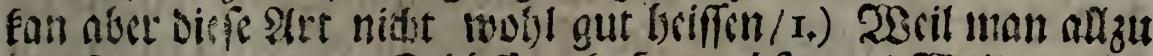

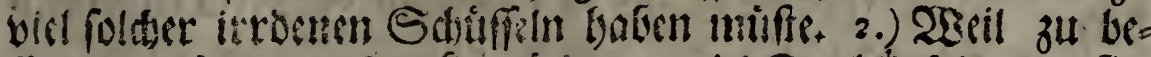

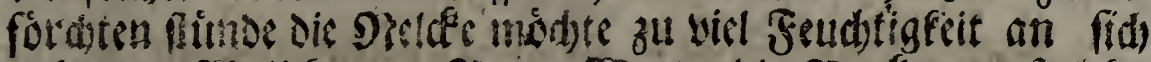

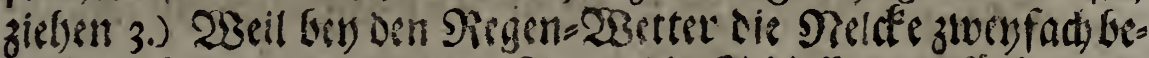

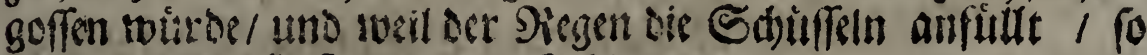

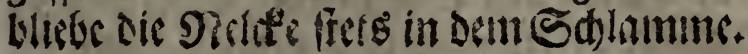

Lum diefer Liffaden wegen fan man dem Zorbaben der: 


\section{4 \\ Neue Unterweifung}

jenigen feinen Benfall geben / Die fid) zu Beforengung ifret

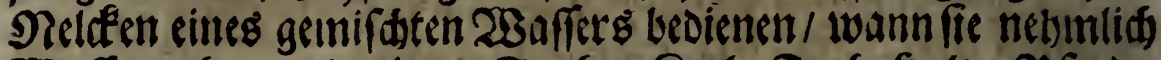

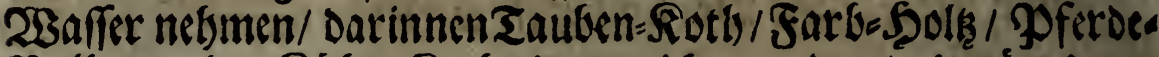

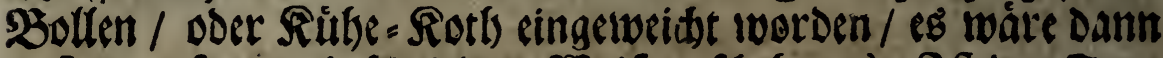
DaÉ es auf untenbefdriebene Wreife gefdetbe. s.) Sff Der Tau.

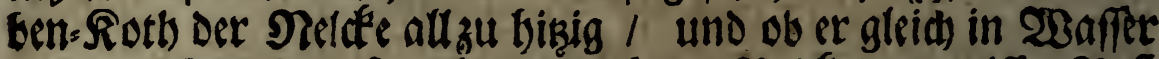

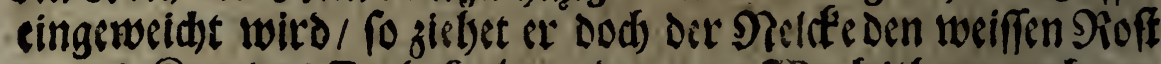

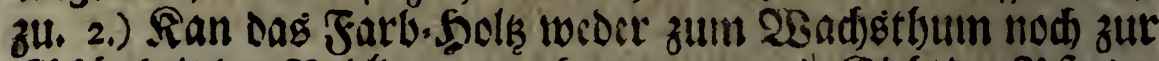
Sdjonbeit Der Neldén etmas bentragen+ 3.) Bicbet der P ferder Sotb Dem $23 a f f e r$ cine febre groffe bike/und dienct nut zu Des nen Pflankęn / Die in Falten uno másigen \&ándern anders nidst als mit groffer Mrube fonnten fortgrbrad)t wersen / alę die Tut. be= Ro ofen / die Eonffantinopolitanifóc Narcifien / uno andere

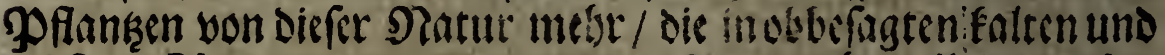

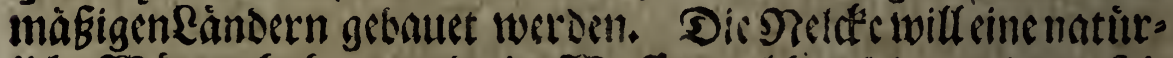

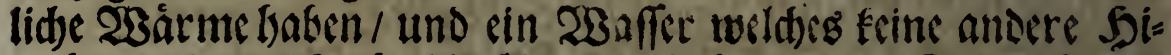
be bat / als weldec ibr bie Sonme mittlseilet. 4.) Dicnet ibt der Ritbe = Siotls nid)t / es twáre daun bne man ifon felten uno mit 2orfidtigecit getoraudte : Selten/ Dann man mus fidj feiner uber 2+ oder 3+ mal nidet bedienen: Init 2orftdtigkeit: Dics weil man nur oen allerftifdeflen Rutbe= Rotb nebmen/ibn in einem Fab voll 23afer wobl umritben/ uno die Ne!dé mit Diefem angemadten 23 affer niemals alb in Dem Sommer /

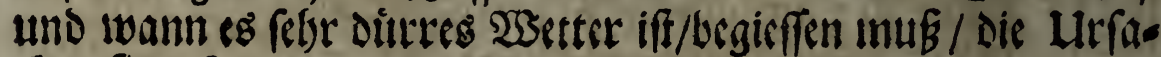
den fino folgende:

1. Sft der Rutles Roth an uno vor fid felbfen zu falt wor Die Neldes / und wer itgn offers gebrauden wolte / witrde/ in =

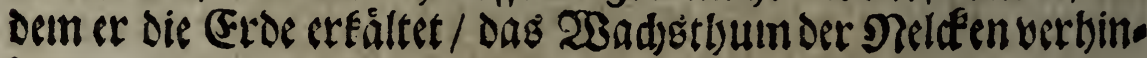
dern.

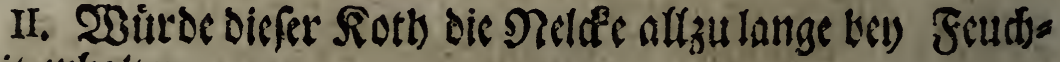
tigfeit erbalten.

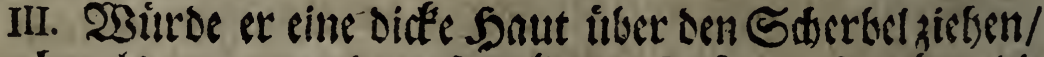
die nadmals unten an Dem Stocte oder Fub Der Veldét oie Fáulung verurfaden Eơnte. 


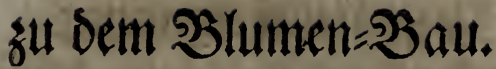

IV. So dienet diefes init Ribles = Ruth vermiffte 23 affer nur ber פieldec cinige Errfrif́chung zu geben / nidft aber biefelbio ge vidtlig abzufithter.

$28 \mathrm{er}$ nun in Der groffen Sommer = Silge cin mit Ritibes

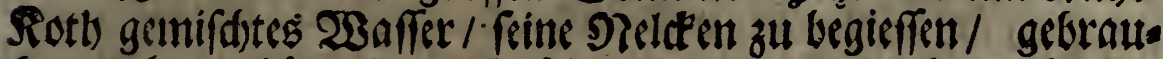
deen wolte / thäte cben niddt íbel / fondern vielmetbr woobs/ es

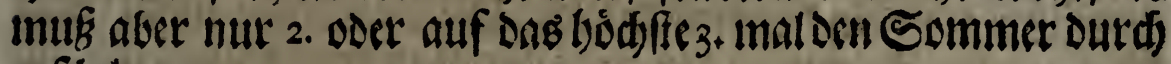
gefdellerm.

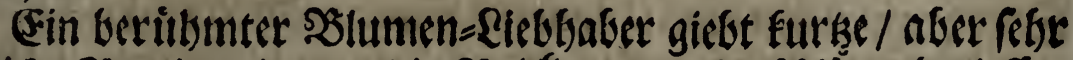

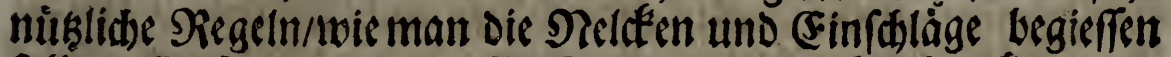

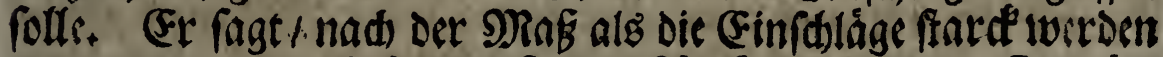

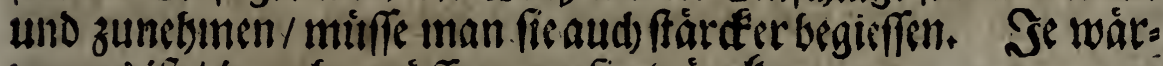

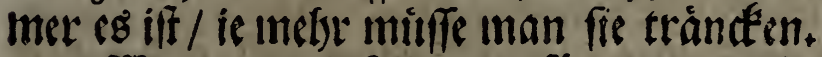

$23 a m n$ Das PF feilgen anfángt zu treiben oocr zu freigen/

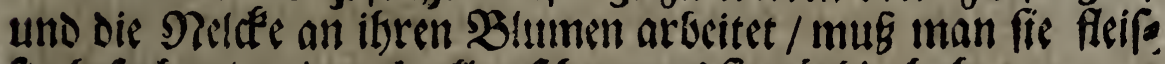
fig befudsen / und nad allen feben iwas fie nottbig babe.

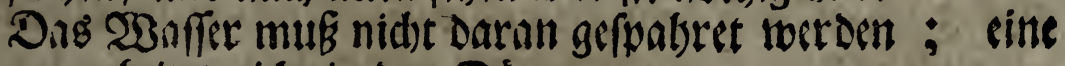
Poflanke arksitet nidet in Der Ditrre.

Sn cinigen beiffen $\mathfrak{z a g e n}$ nelsmet curc Beit in adje / uno

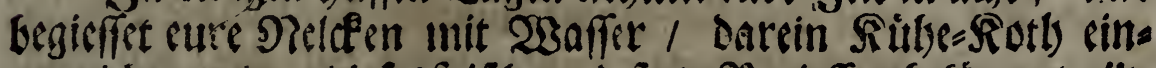

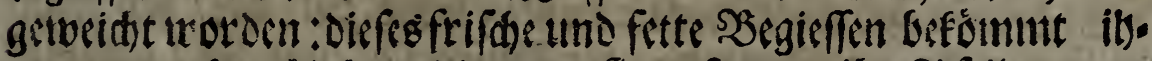

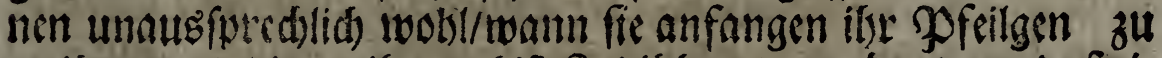

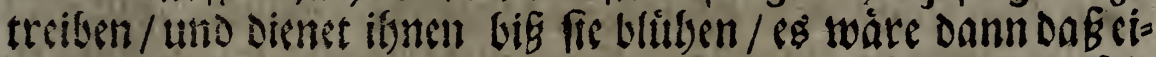

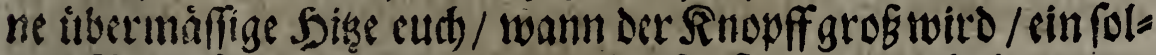
d)es 9Begieffen nidet erlaubte/lweldes fonffen audd nod eine woun oerfame 28sitctung thun wirtir.

\section{2å XII. Capiffll}

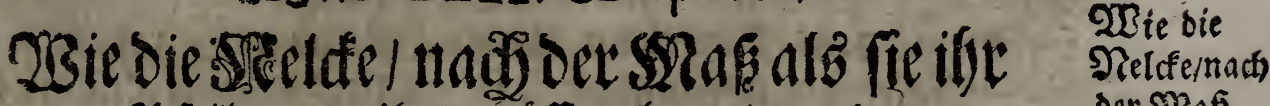
DFeilgen treibet/muiffe gebauet werben. Der SMa als fie ithr

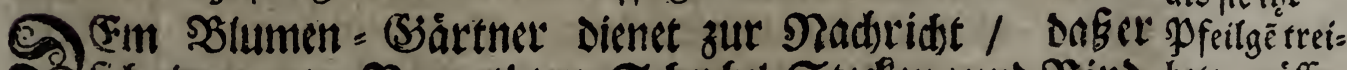

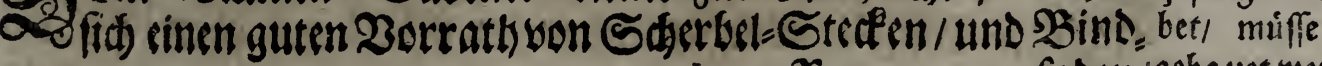

$$
\mathfrak{X}_{3}
$$

fadern' 'geta unet wesa oen. 
166

Soue Unterweifung

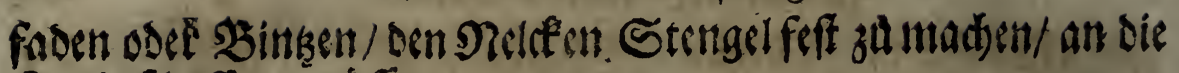
samo fidaffen imilfe.

Das Jols zu diefen Stecten foll / fo ferne co fenn fan/

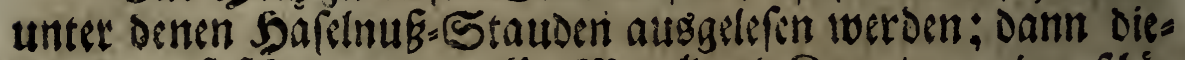

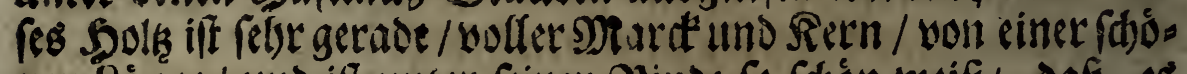

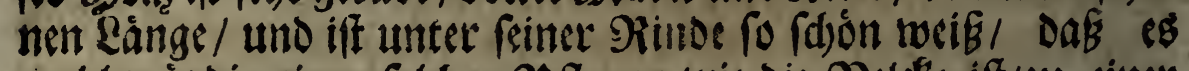

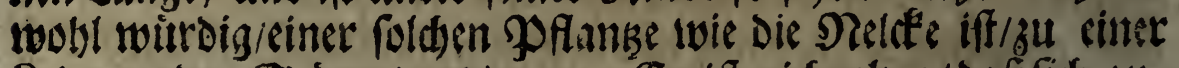

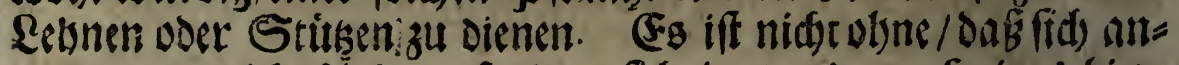

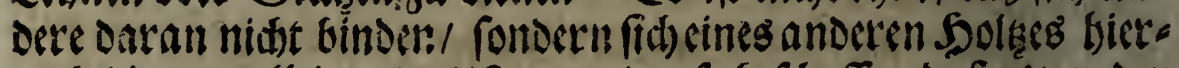
zu bedienen: alleine / esiff entworder fo befdarfen/Dá es vonder Eonnen frumm oder aber allza bitre twiro; tund ong andere

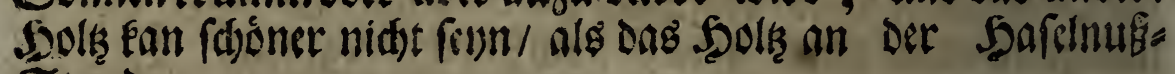
Stallder.

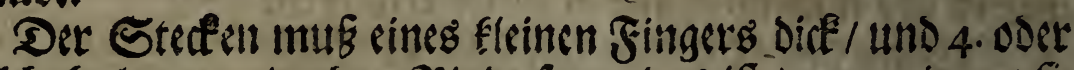
5. Sdutue lang/ uno obste SRinoe foun/ Das iff / man nimmt fie von Dem Solke ab / Die Fendtigkeit/ twelde jwifksen Dem Nels

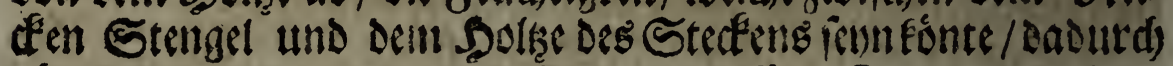

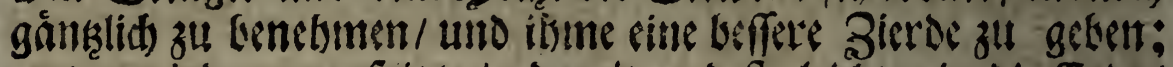
unten wird er zugefisist / Damit er Defto leidter in Die (FrDe /

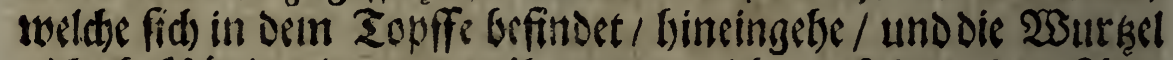
nidet befdadoige: Damm wer ibn unten nidht zurpikte/ der ftün=

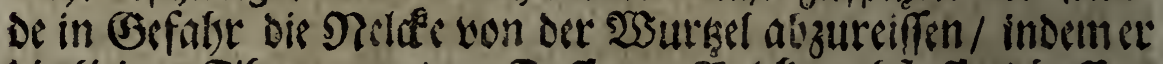

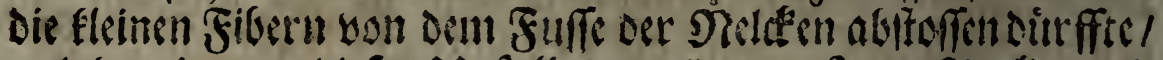
uno damit man diefon Linfald bermeide / muf Der Stectin ci. nen quer Finger weit won bem Vislfern. Etingel geffictet / uno

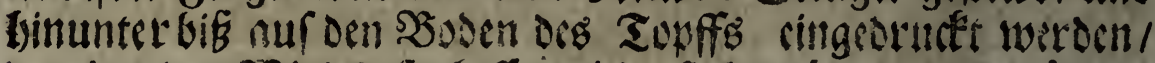

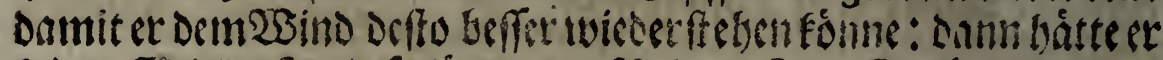

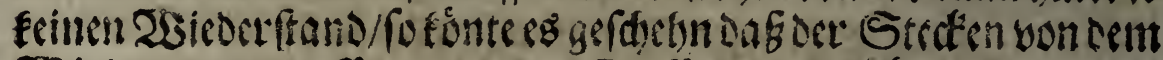

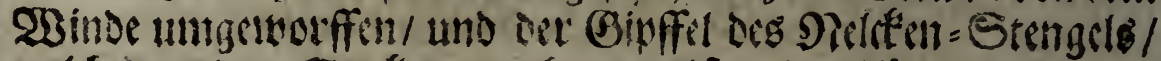

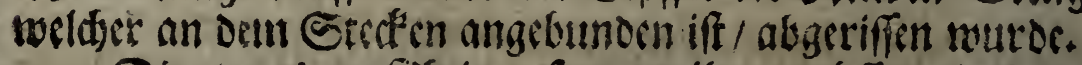

Die etina vorfidstiget feun trollen / mirfen gleids in Dem

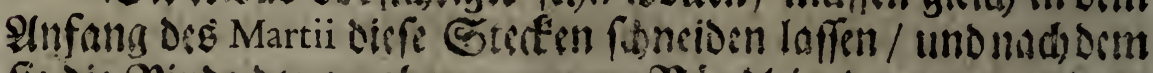
fie sic SRinde Danon abgenommen/ Bitndein Darals insden;

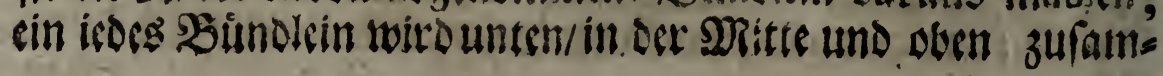




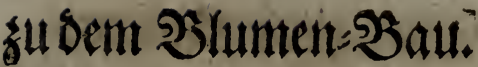

men grounden/ alsbann legt man fie in ben Baté Ofen/ ba

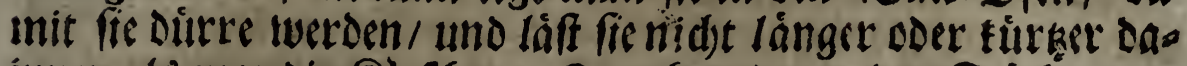
innen als mandie Rirfdsen/ Trauben woer andere Fruiddetedar.

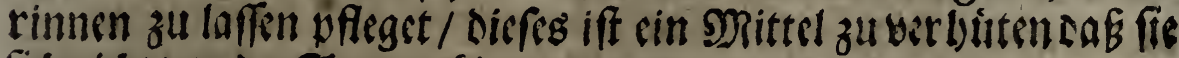
fid nide won der Sonnen Giegenoder frummutwerder.

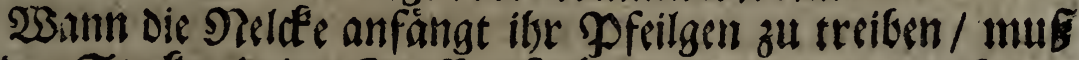
aud ber Stecten in Den Bopff geffecet werben / und nad) Der

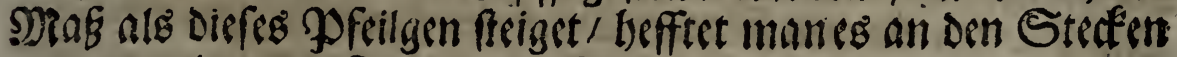

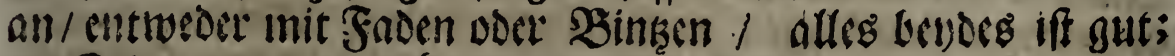

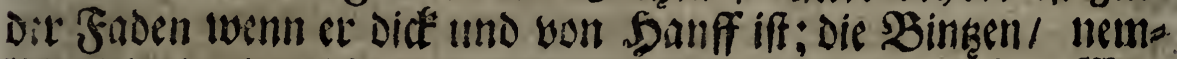

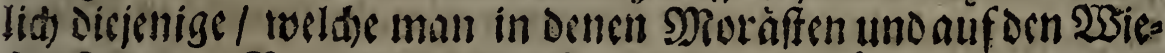

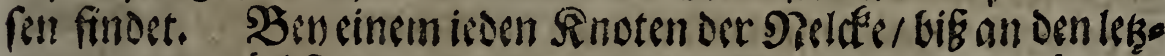

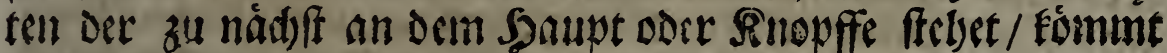

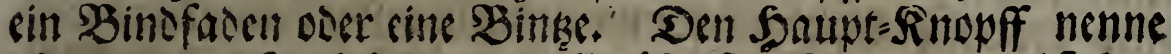

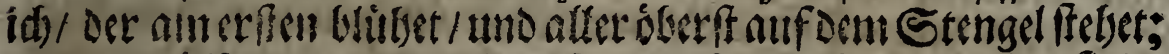

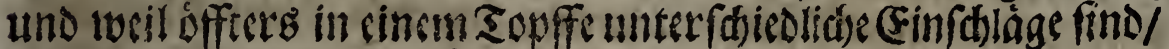
Dic alte won einem Stoffer Herfoummen / und Pofilgen treiben/

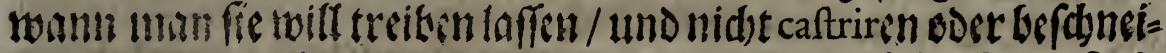

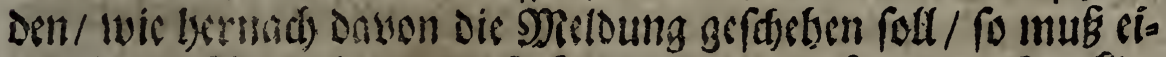

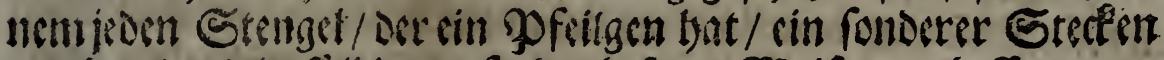

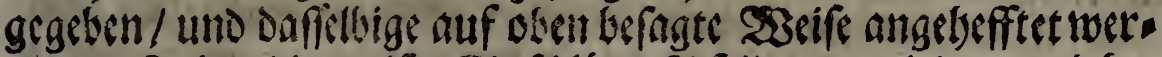

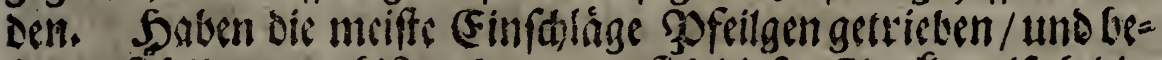

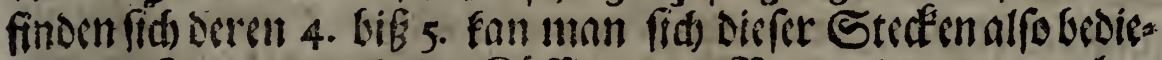

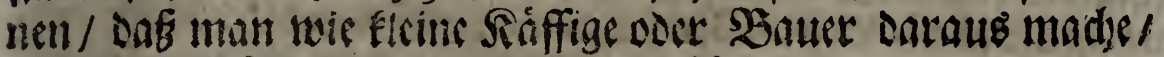
wellde dic \$p fillgen tragen und unterftiukselt.

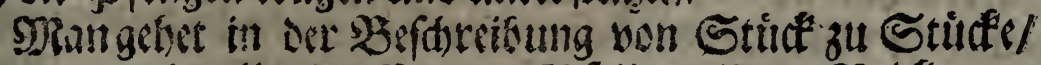

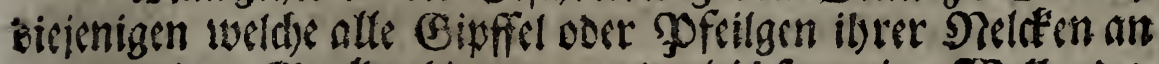
eimen einigen Etetten binoen / und gleitifaut sine 23 stle oser

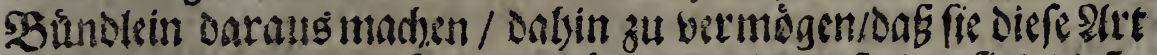

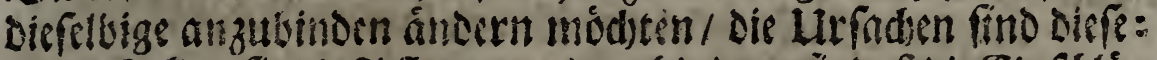

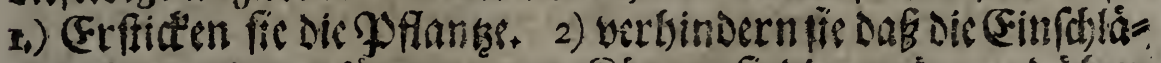

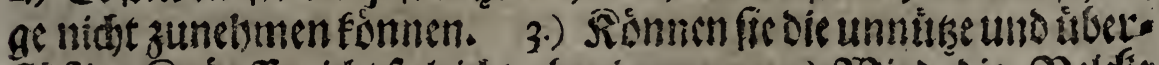

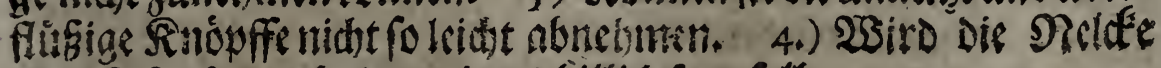
nidst ro fauber gelbalten als cs billide) frum foll. 
168

Taue Unterweifutg

Damit wir tweiter geten. WBann ocr curieufe SBlumen= Riebbater frebet / Daßs die Dielde von allen Seiten P feilgen trei. bet / und feine Vad)folger oder (Finfadláge binterläft/ Dietweil Die/ ivelde auggerdhlagen/ / djon in P feilgen getrieben baben / fo muif fen bie (sinfd)láge fleigig/ uno fo viel man vortràglid zu fern fin= Det/ beid)nitten oder caftritt werdem/ inderm man netgmlids den Ginffel an Dem andern Snoten abnimmt / auf Dą̧ ztwery gute 2Bitrefeungen Daraub folgen: Die erfte / Dainit Die Nilde wie= Derum neuc (sinfabláge berbor bringen fónne; Die anoere/ Daß

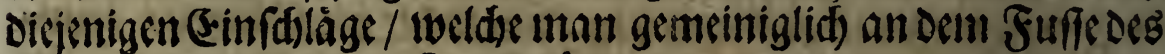
Stengelsausidalagen febet/ fonnen zutelymen / uno oen Plas oerer Die in Pf feilgen getrieben baben wieder erfesen; fo iffes auds Dem Saupt=pofeilgen fehr vortràglid/swann mtan alfo verfábrti/.

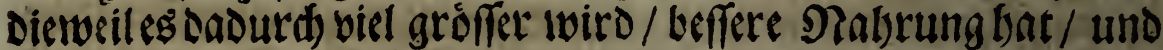
folglid eine viel grófere $\mathfrak{B}$ lume lringt / inoem man ibme cinen Sbeil der andern Pfeilgen / weld)e ilsen von feiner Nalswung

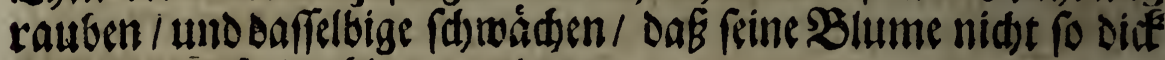
und breit twitrde / bintweg nimmt.

Diefes wird yon Stitú zu Stindecereláret / damit man co defto beffir und beutlidicr verffeben moge.

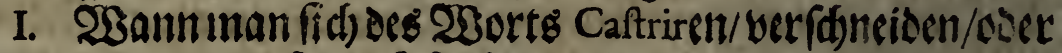
befdneiben bedienct / fo mus fold)es nid)t in uneigentlidecm uno ungebubrlidem 2 erftande genommen twerten: nidst in einem uneigentliden / weil die Neldé caftrirennid)to anders iff / al' vers binbern Daß̧ fie nidte ferner augfdlage: nidte in cinem unges

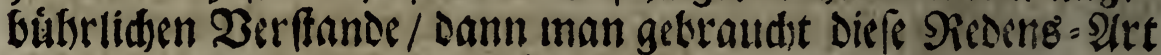
aud) Gen andern POflanken/ ale ber denen Atend oecr Fsinter.

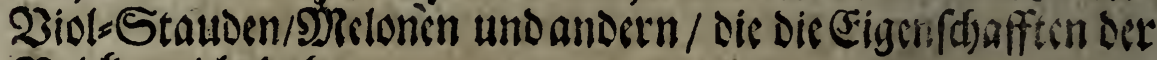
Veldén nidbet baben.

II. Die Nelfé caftriren / iffeben fo viel als Die Einfdela: ge / wann fie ibre Pfeilgen treiben/ oavon abfdineiden/ loclabes

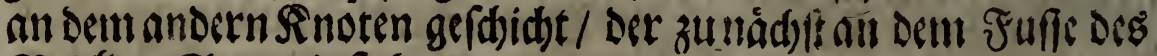
Nelde $\mathrm{in}=$ Stengels fretert.

III. 2Kird gefagt daf man die NAdefe alfo caftriten oder 


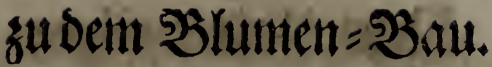

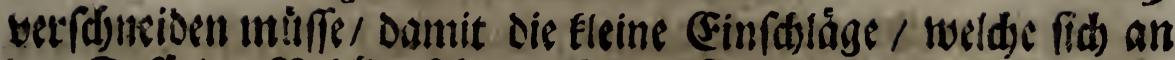
Dem Suffe der Nilde'en festen laffen/ deffo leidster treiben fónnen:

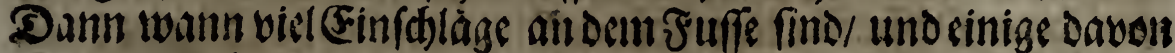

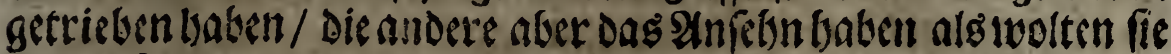

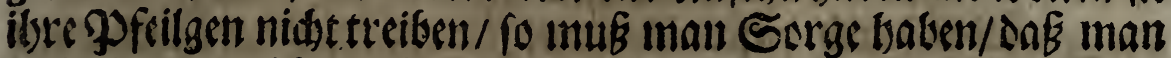

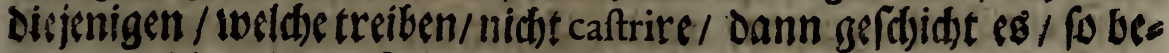
founmen Dieandern//Funidtttriben/Gelegentseit jener ibsen $23 \mathrm{eg}$

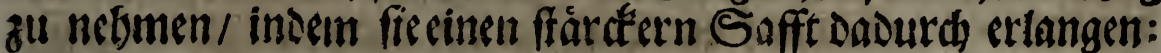

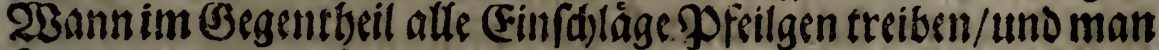

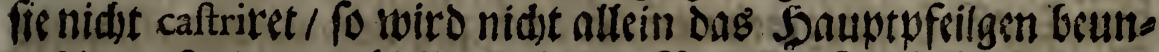

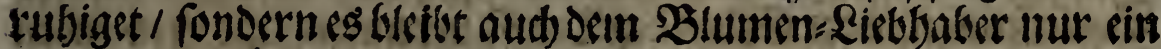

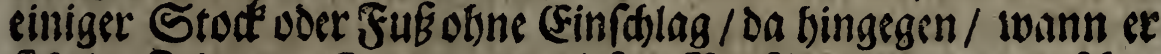
fid in Beit und Dott wegen differ Zerfinneidung vorgefeben

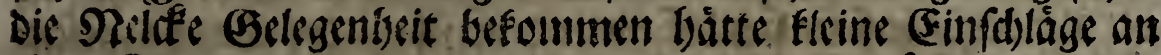

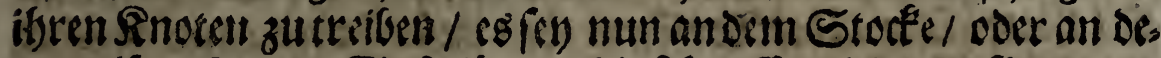

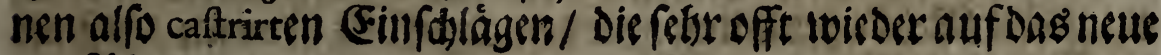
aus[d]lagen.

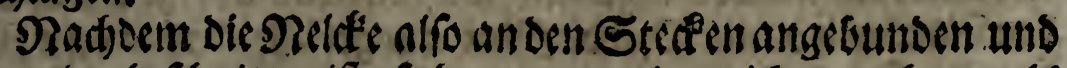

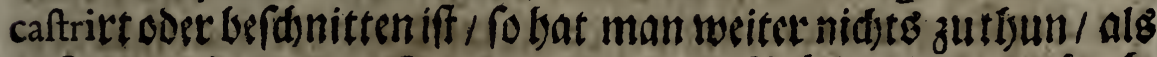

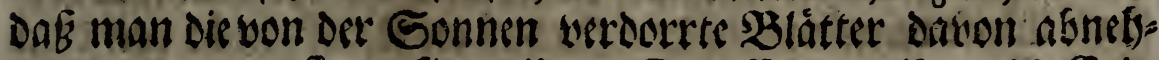
me/ und waann fie anfängt ibren Snovif zu treiben / Dic (Froe

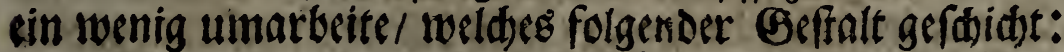

Man nimme cin flein Sthid'tein 5ols cincs Dautmens

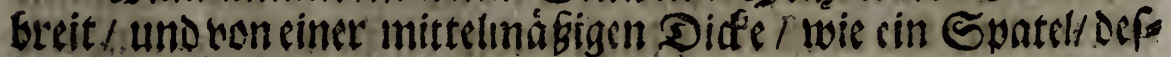

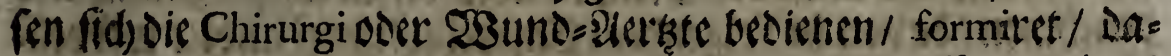
mit fraket oder fdjartr man bie erroe 2. Daumten tieff und rings

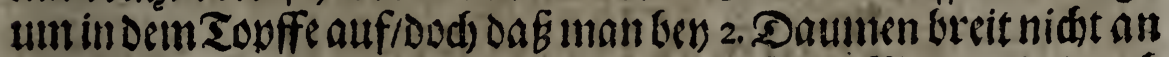

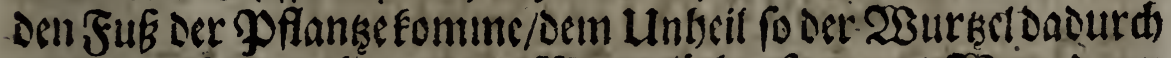

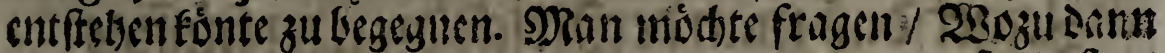

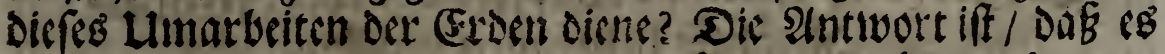

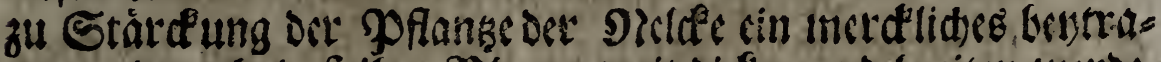

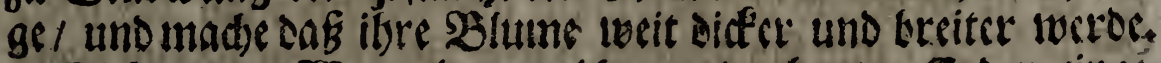

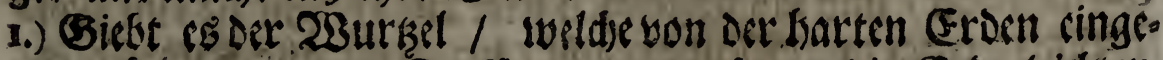

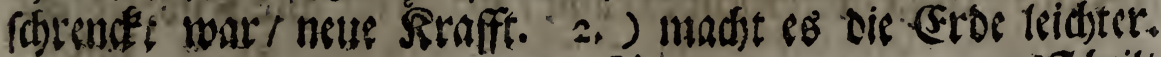




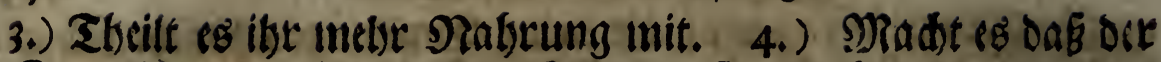

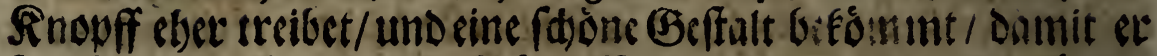
bey feiner Deffnung cine fdone Bluute berbot bringen fonne. 5.) Sffes auf die Erfabrung gegrumbet.

23eil ourd) Diefes Lumarbeiten ber MRiff / welder oben auf sem Sopffe gelegen/ mit Der Fraen bermenget worden / fo

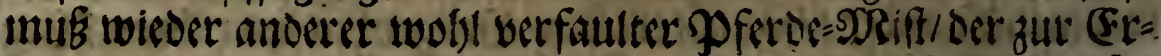
ben worden / oben auf oen Topff gelegt / uno alsbals begeffen werden / Damit ilsn / weil er febr leidst iff / bie 2Binde nidst von Dem Sonffe bintweg trebimen / er aud) zugleid, , bermittelf dicfes Begieffens / mit ber Er den des Tovffo bereiniget uno verbunocn werder.

Sátten die SReren und Das Begieffen dic Sroe dergeffaft

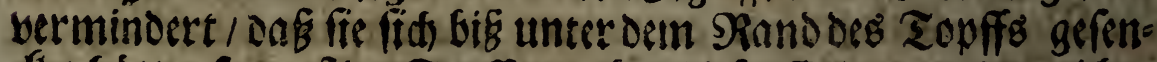

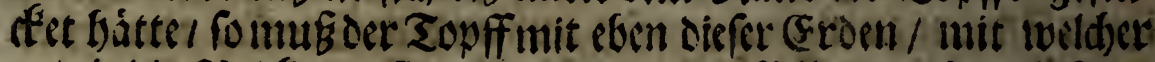

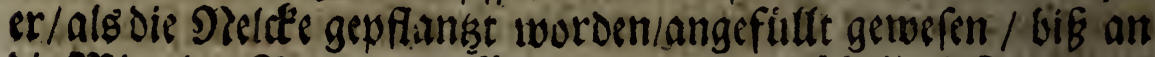
Die Mitte des SRanosangefillt wirden / Das úturige bißz oben an

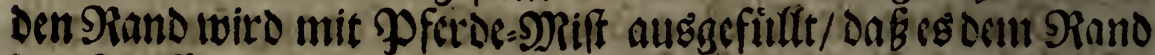

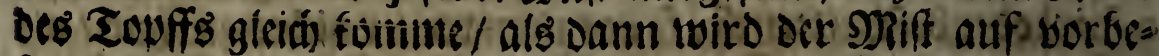

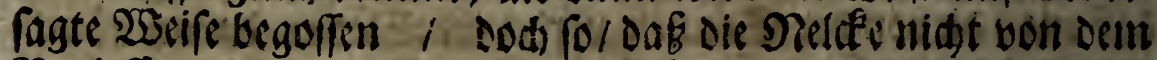
Begieffen untergraben oder auBgebtoót werde.

WBann ibr alles dasjeniys/ was bigber iff gefagt wordent

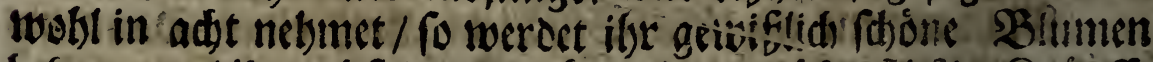

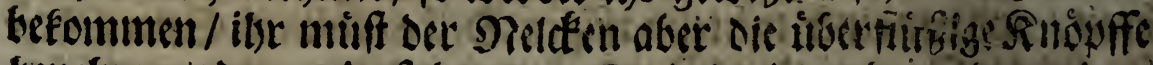
- benelsmen/ davon in folgencem Eapitel wirogebandelt tweroen.

\section{3as XIIL. Snpitel|}

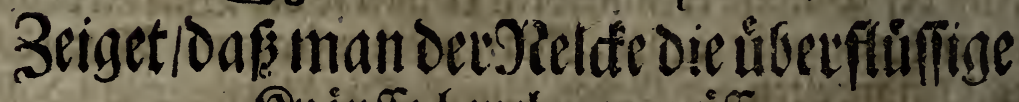
Rnopffe benebmen nuiffe.

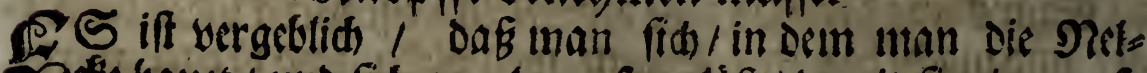

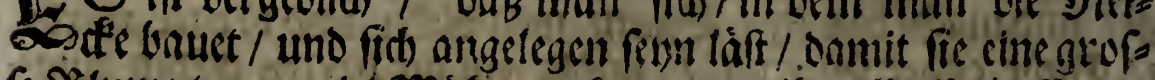

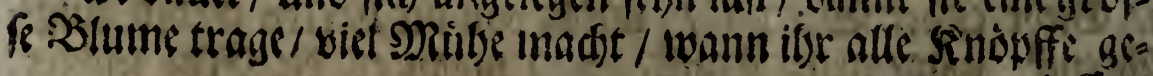




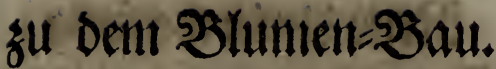

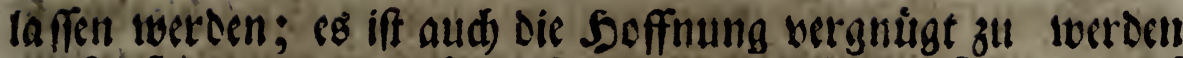

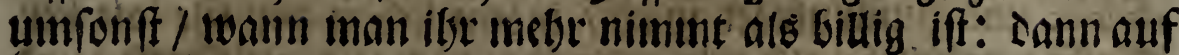
iene 2Scife werden die 2Bitumen zu flein / nuf siefe springen lie

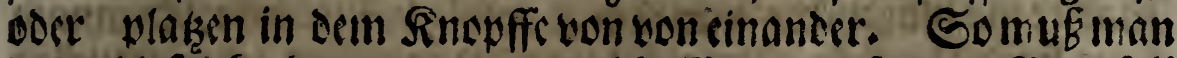
Danu Diefen Genden extremitaren abbelffen / und fagen: Mauf fol Der Neldée weder zu biel ned) zu wernig Siniphfe laffer.

I. DRus man itserer nidts zu biel laffen: Dann thicrourd

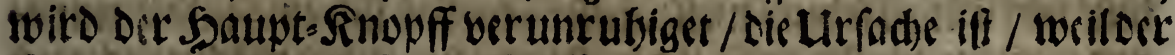
Stengel/ Dabon er feinen Safft jiebset/ Diefen Safft unter ses

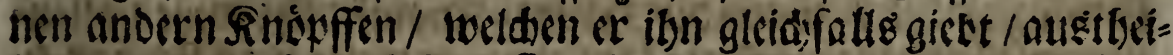
let / und ibme folglid) peine Rraffe bermindert / Dab alfo feine Bitume fo grö̈ nidft twercen fan; wois zum Excrmpct sicienigen

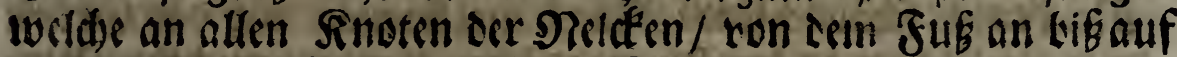

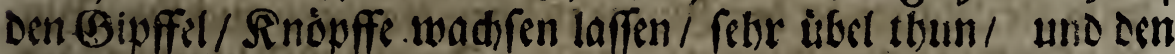

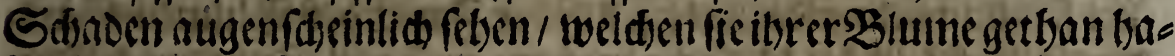

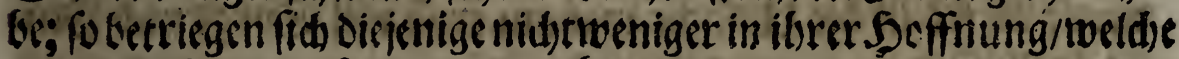

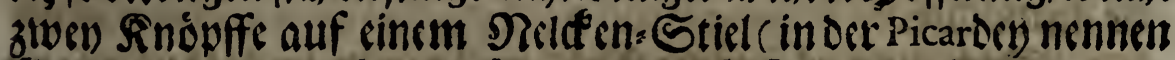

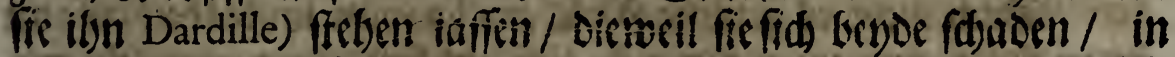

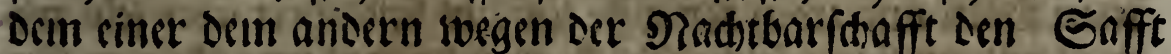
entzitbet / weldder nutr bor cinen genug iff. Die fo an cinem

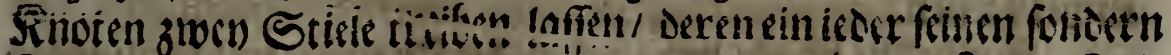

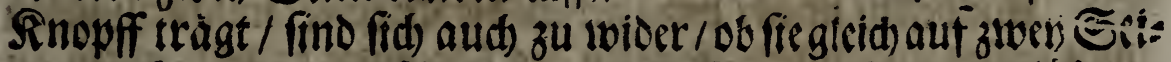

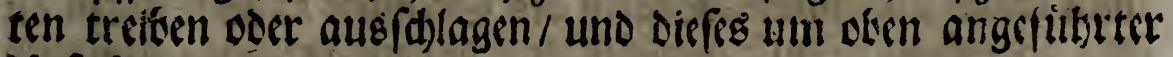
Lurradien wegen.

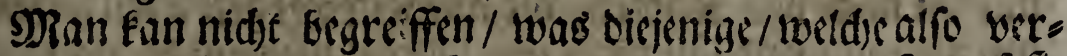

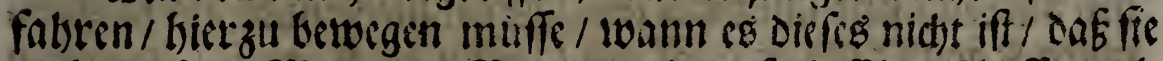

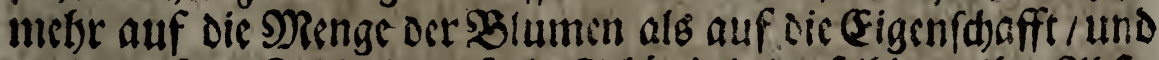

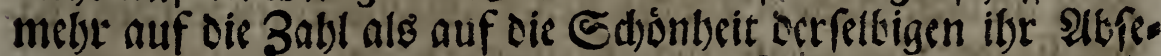

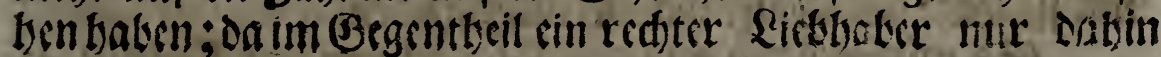

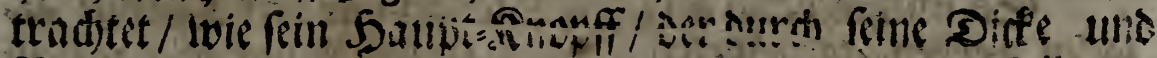

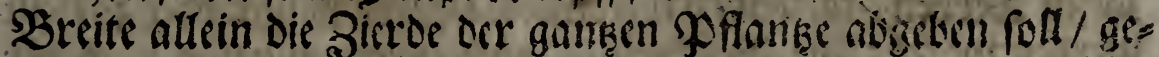

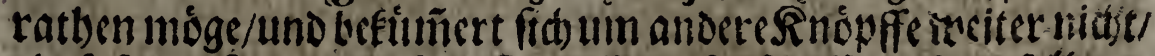

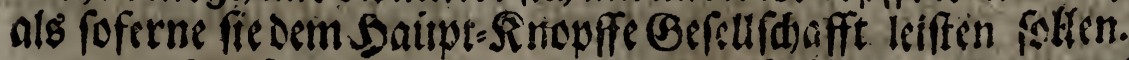

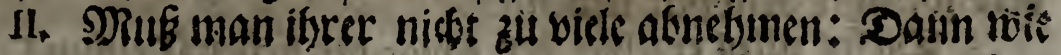




\section{2}

\section{Reat Unternocifung}

ber Saupt = Snowf / wo man ilsm zit bide laff / bierdurd alterire utto beuncubiget wiro / inoem fid) folder (Geffalt oer Safft vertbsilet; allo gete man ibm aud) nllzuviel Safft/ uno madite ibn plasen/two man itsm zu swenig laffen wolte: Demnads ferenfith Die/ welde oben auf dein Stengeleiner irden Veld"en

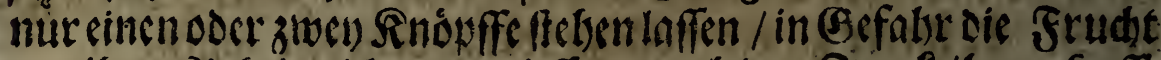

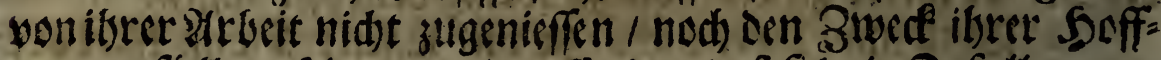
nung erfült zu feben / tweil/auffer dem Das fid ein 3ufall zutras

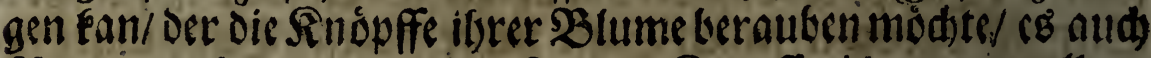

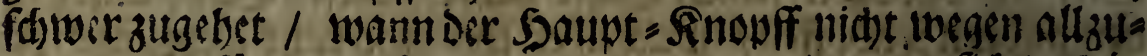
vielem Saff wlaken folte; Lino varum wolte man fids oods its ber diefes mit $23 i$ llen reiner \$Blumen berauben / wann fie bev Nelefenidst fdadolid) find ? Man Gauet fie nid)t nur das (Britne

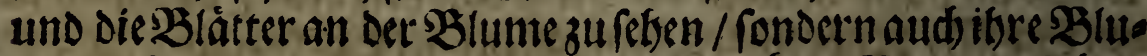

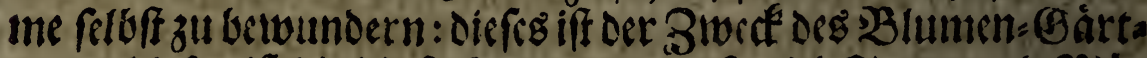
ners: dicfes iff die Uifadje swarum er fo viel Sorge uno Niti= be anivendert.

Dod giebt es getwiffe Relden / Da man mobl tbut / wann man ifnen nur ztwey Snopffe láft / es fino ilfere aber felor twe

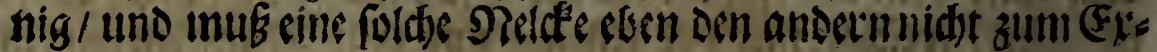
empel dienen.

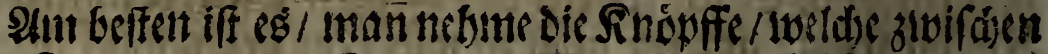
Dem erffen und andern Rnoten Dec Stengels/ wiad) finten on Den Stoct oder Fuffe ausfidelagen / Davon ab/ oben auf nbet milfen nods vier Sinoten / Die alle Sinopffe getriebenbaten/ffe=

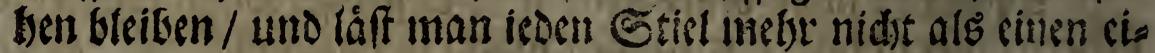
nigen Sinopff; (Es ift aud) gut / wann dic Rnopffe/ dic allzu nabe an oent Saupt= Rnopffe ffeldin/abgenonmen werden / Oas mit fee istme Den Safft nid)t ftreitig maden.

So muifen dann an ireen Ste!ngl mur birr Rnowfe ges

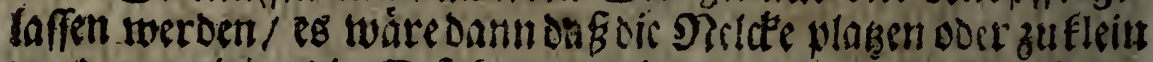

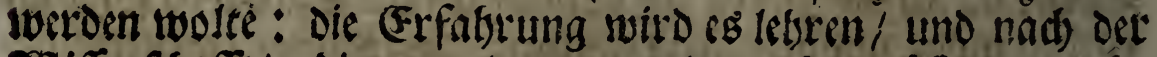
2Biffenfdafft/ dic man Dataug gelernet bat/ láft man metbs Doer iweniger Sinopffe ffelsen.

Diefes affes craelblet Det Autor Des neuen Neléen Tractats 


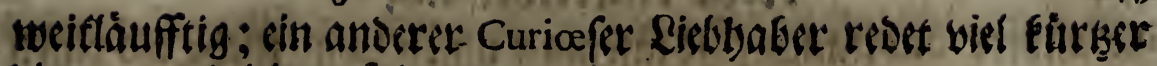
bieven / uno lelbret folgendes:

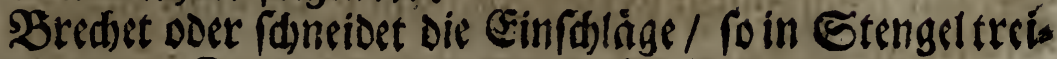
ben/ an sinem Rnoten nabe bern dem Juffe ab.

3n dem zopffe laffet nur einen sinigen Stengel/ banon

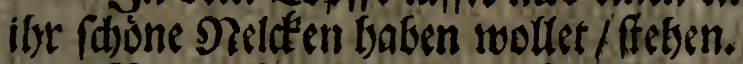

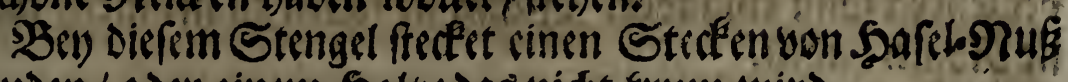
Stauden/ oder einem Solsegeag sidet fratm wird.

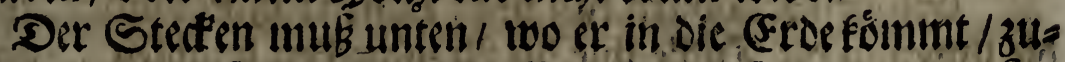

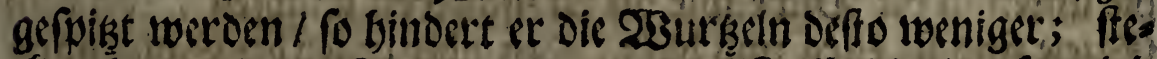

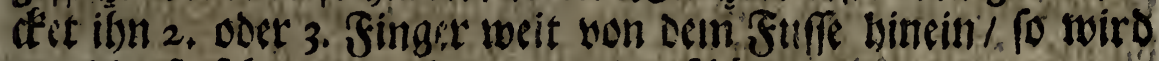
er nid)t fo feffer savon betwegt und erfotittert.

Euren Stengel binter bben bein bem nofeilgen oder (sipffel

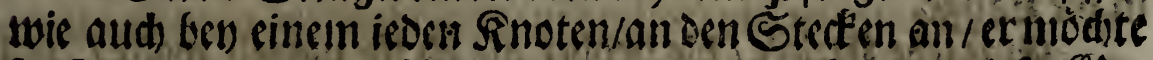
ronft in Dem treiben abbreden; uno Daunit ifer cuch, Dieser 63 se

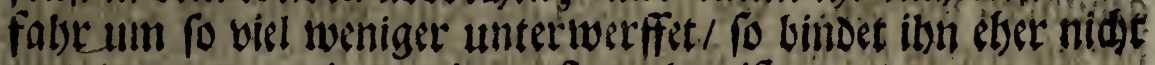
an/als waun er cin Inenig gro É worden ift.

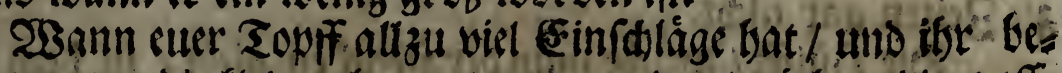

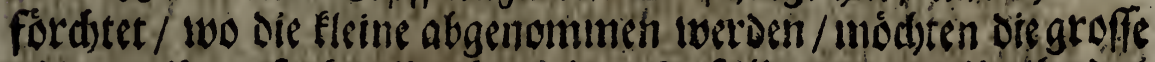

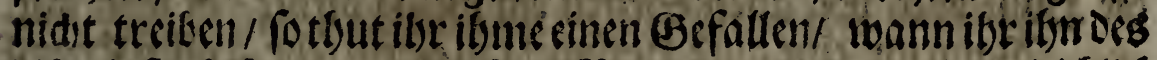

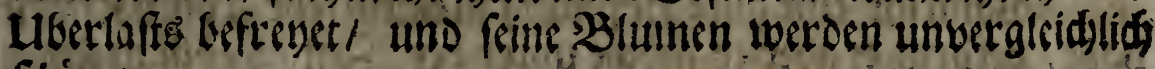
fojoner.

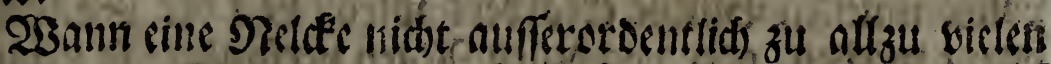

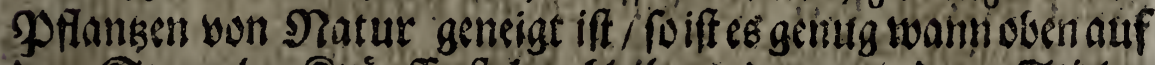

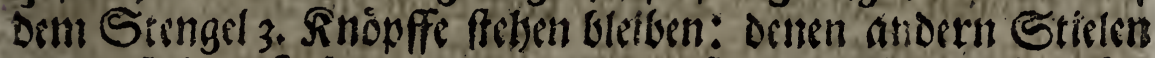

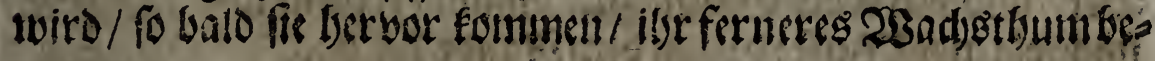
nommen.

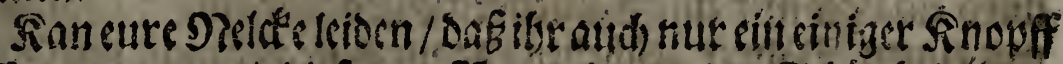

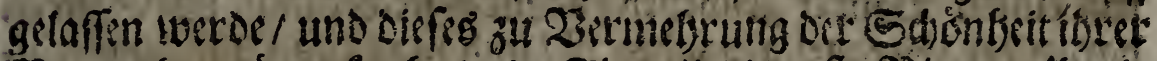

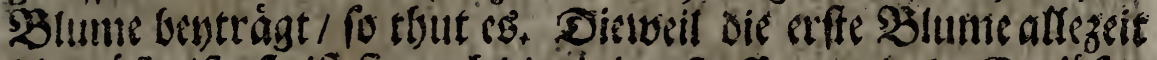

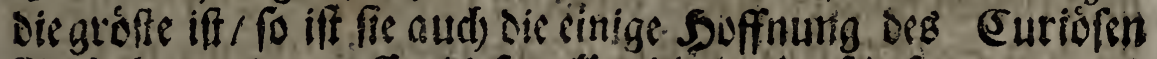

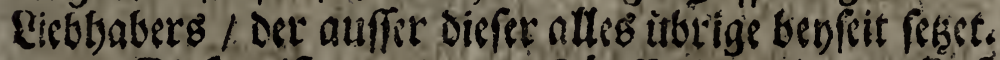

Diefes if von dench zopffen 1 bie zur guff suf sin

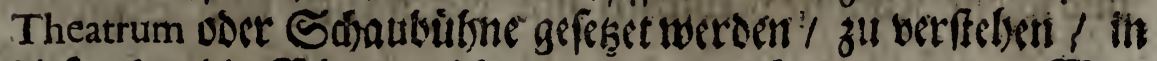

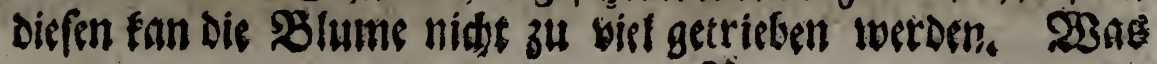


174

Reue Unterweifung

Die andecte anbelange $/$ fo laff man ihneh zwar methe als cinen Stengel / auf cinem iesern afer niemablen imebr als 3.00 er 4. şlunien.

Die Sinofufe twelde un diejenige / bie ibr haben wolt

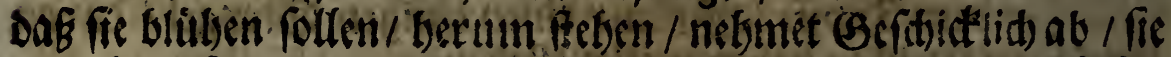
verzegren fonfit sinander. 23 ann fie follen zu netbmen / mitfen fre SRaum baben.

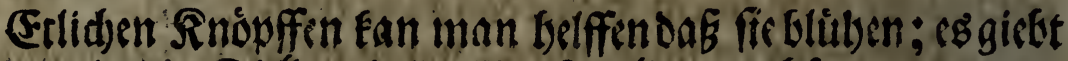

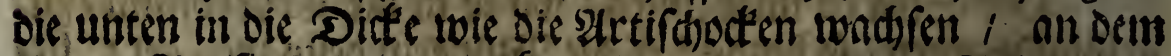

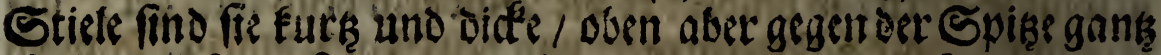
Ditune: Diefe muB inan mit einem Faben binden / fo wiro Das

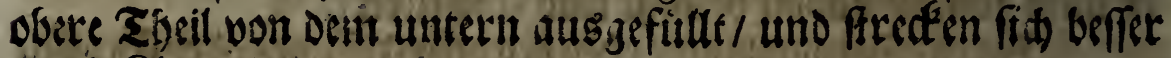
in bie \&ange.

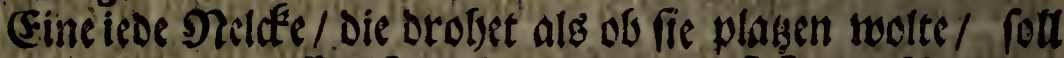

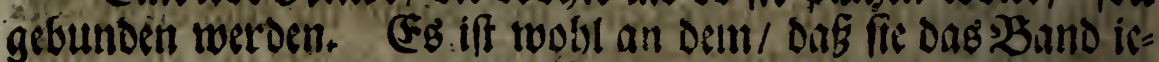

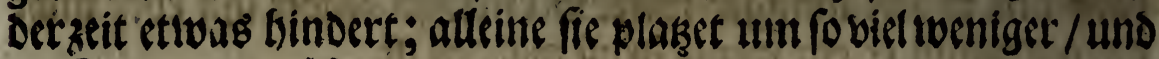
jus Beiten gar nidet.

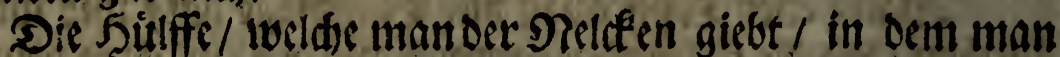
Die Soulfe oben von alden Seiten cin weintg bifnet / iff febr gur.

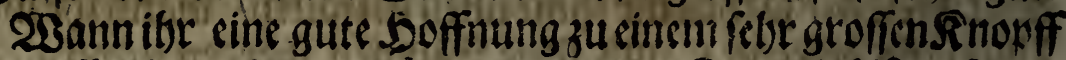

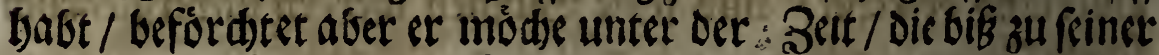
vodffommenen Blittbe erforbert wird / bon der Sonnen vers

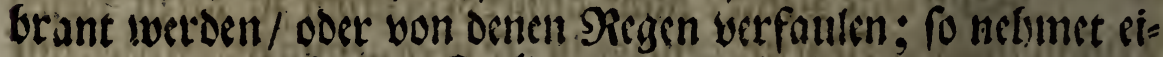
nen runden Sdudtel-Didect/ober aud cin alibercs rumoes

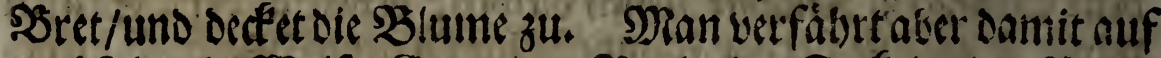

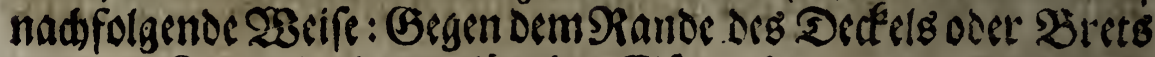

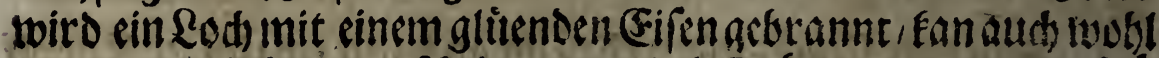
mit sinein Böbrer gefdetben / Dadurds fictét man den Stedein Daran der Stengel gebunden ift/ und inadit Den Dicfell init cis

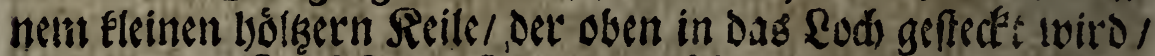

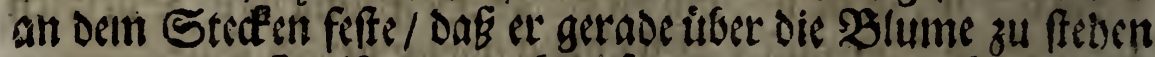
Fomme / und fie affo davon bedeceet werde. Eure fely aroffe

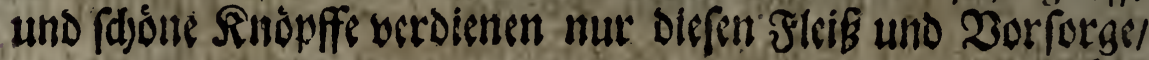




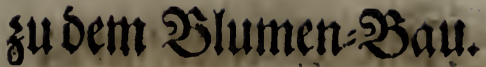

775

of men.

Nad). Der Mafte alo cure Releten fdoone Glibsen / bringet ifre Blume / entweder Durd fàmmen ober wieder aufipalten/ in gute Dronung; windet / wann fees benotbiget if / Das Yoge bier / Darumi / uno ffellet fie algoann auf ein Theatrum oder

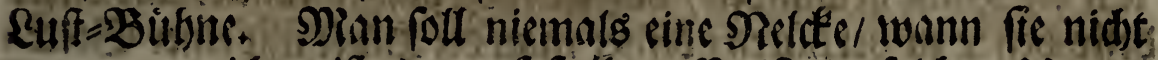
zuvor zugeridetet if / Darauf ffetlin: E:s iff cin folder Unter

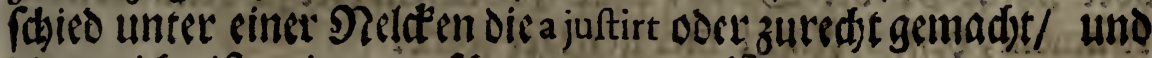
Die co nid)t ift / wie unter fatwark uno weis.

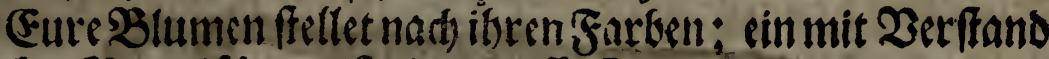

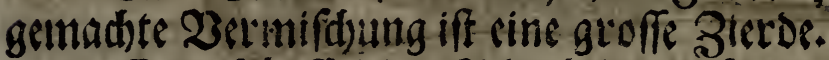

Eure Sopffe ober Sderbel cie auf oem Theatro ober \&uft. Bittone ffeben / werden cin menig offecter begoffen/als ob fie an

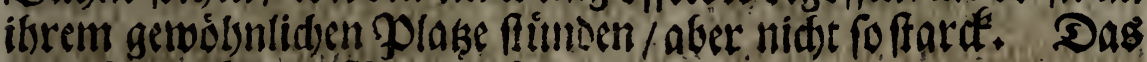
Waffer crtbált die slutue lánger.

\section{2nื่XIV.Capifell}

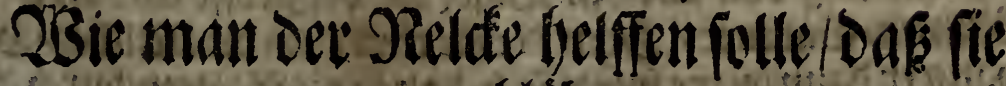
blike.

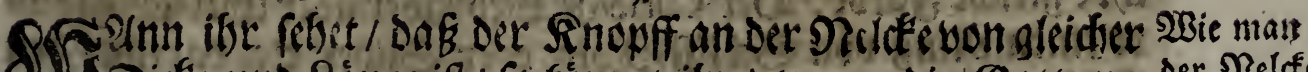
QU Dide' und Rängs iff / so fognnat ibs/ wann die (Gattung

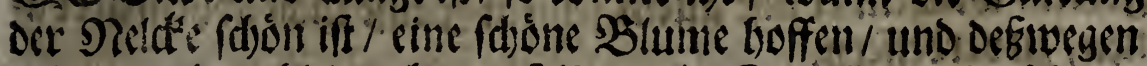
nebunt cud) wools in ad)t / Das ibroisfen Rnopf nidht berubret/ he.

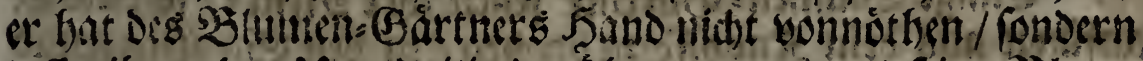

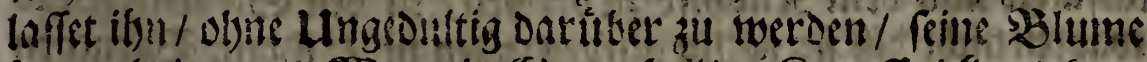
berbolbringen. 23ann in (Sigentheil Det Fnopff oid und furs

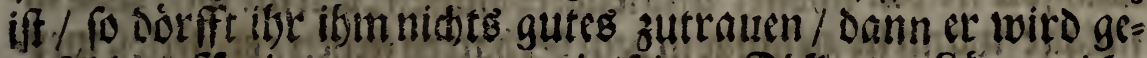

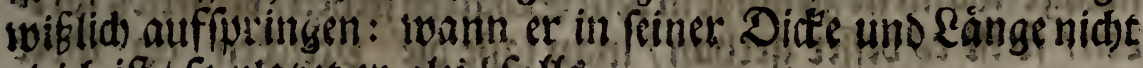
gleid ift / fo plazet er gleidf falle.

Dis Ungliffe num / fo Darous entfethen fonte / abjus

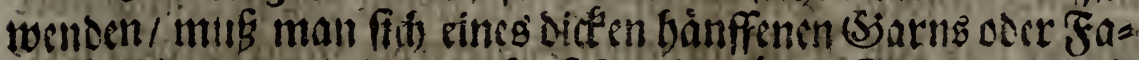

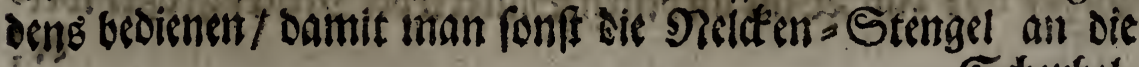


Sderbet=Steteen an bindet / und den Sinopff gegen bem orit= ten Theile feiner Soille unnwinden; ood) muB Der Fadennid)t

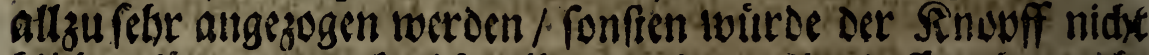
blitben Eonnen / aud) nidf off Dod) auffinringen toitrde: fondern dir Faden wiro dergeffallt

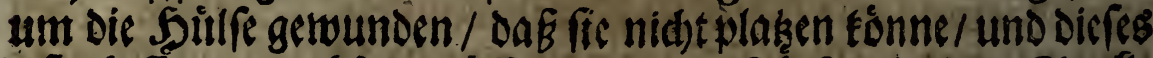
Defto befier zu verbuten / offnet man sie Sullse init einer Stede.

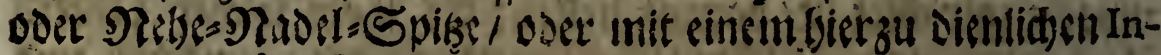
frument, Deffen figut bier gezciget wird.

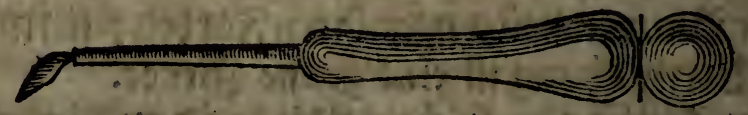

Mit diefem Inftrument leeroen dießlätter an Der Suilfel too fie zufammen geben / ingleidjer 28 cite biz an Den Faden aufgefpalten / Damit bie Slume Euffe biétomme/ uno un fo biel leideer aus dem Rnopffe berfuir bredse.

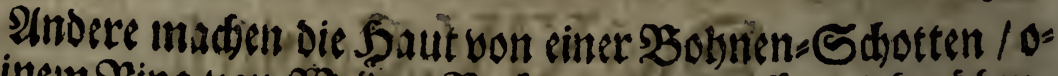

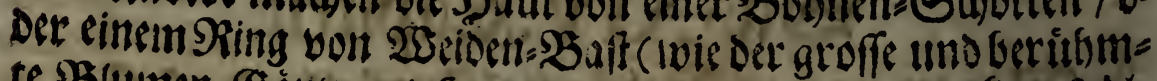

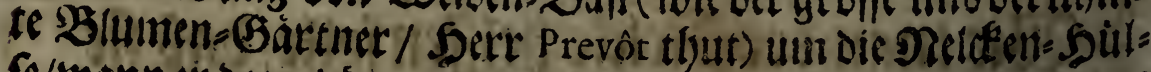

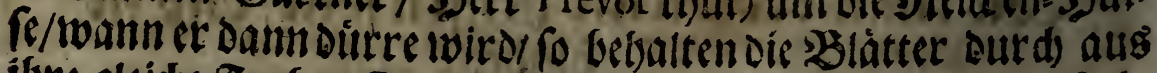
ibre gleidhe Jarbe: Dir Curieu/e Rieblaber aber tbut ganb fad). te cinen SRing you Sdilffesiobr voer Silbar etc. Dartum/ den Febler / weldsein er mit aldem feincm F!eiffe nid)t ablselffen fón: nen/zu verbeffern.

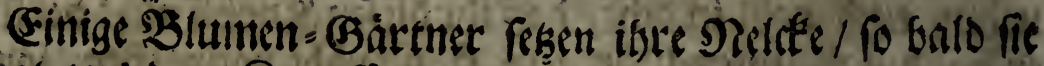
anfaingt aut dem Sitropfie zu bred)en / in Den Sdatten / uno wartennidte biß fie volltig aufgegangen iff / ithrem 20 orgeben nad forf fie biel foboner und leidter blithen; alleine weil oie (sin-

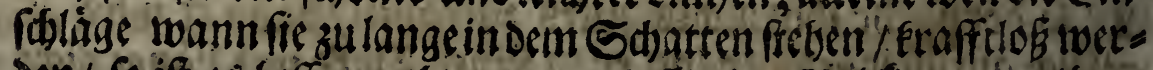
ben / po if es berfer getban/manlaffe Die sielce in an ibres Stefle uno Gegeno / Glitben/ wo fie Sdjon von dem Plonat Martio angeffanden. Der fallende Tlan imad) Dab fie grfáninder

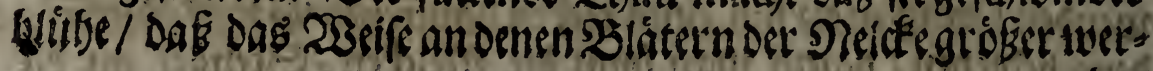




\section{\{ั ธem}

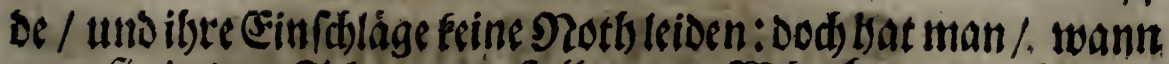

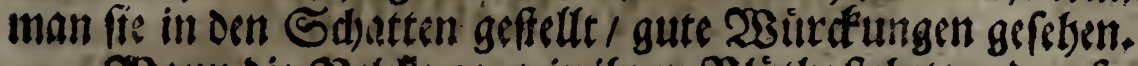

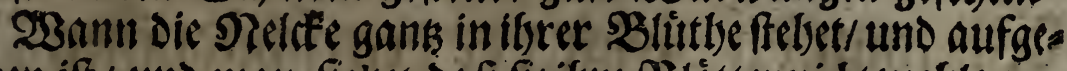

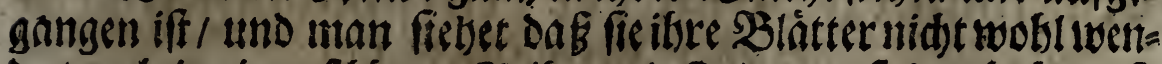
De / now in einer fásuner SReibe uno Dromung fetben babe $/$ fo

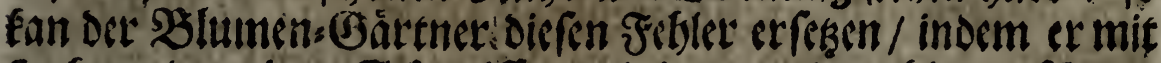

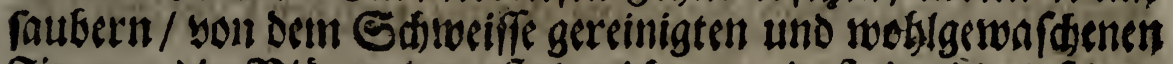

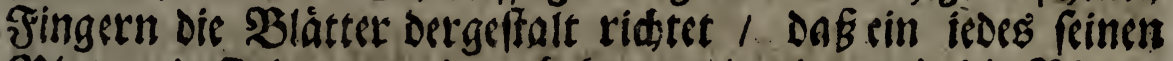
Plakg und Oronung wicoer befoumme / und commit die solume

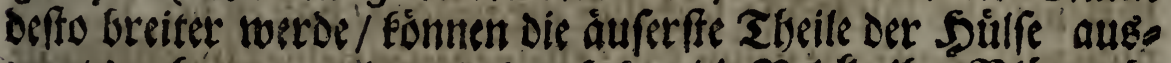

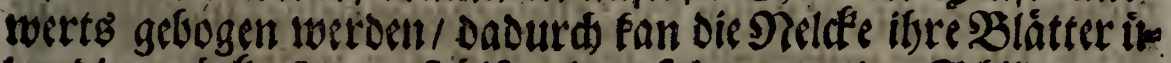

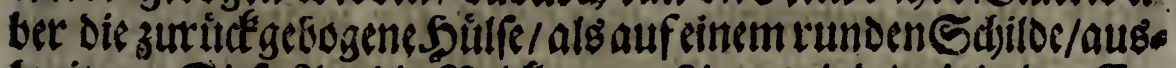

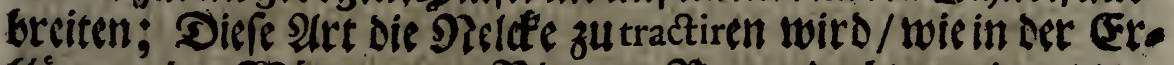

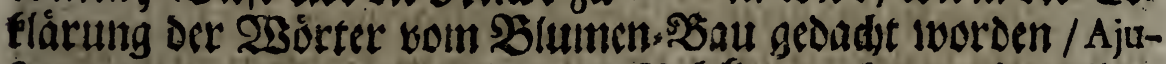

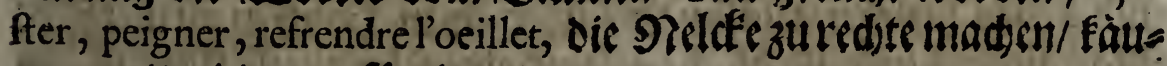
men uns roieder auffpalten / genant.

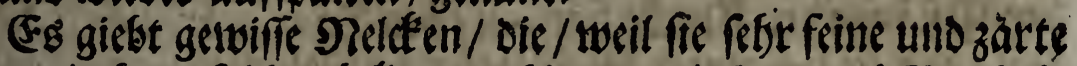
Blátter baben / folder ritutwertrs biegen / als le Grand ChambelIan; le Charmant de nos jours, le Morillon dela Croix , le bear Cramoifi, und andere Dergleidien metbs/ twann man nun die

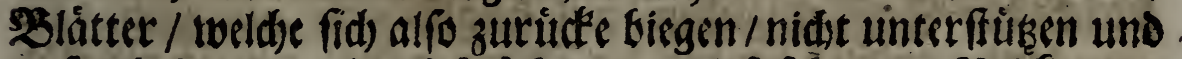

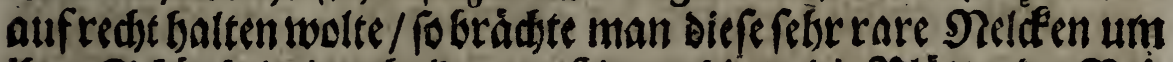

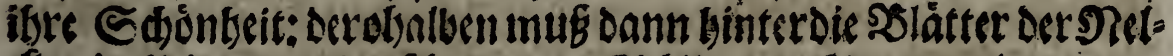

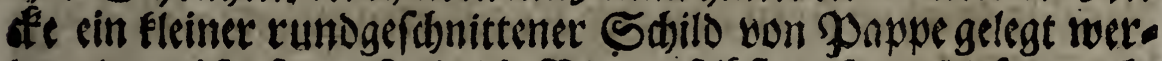

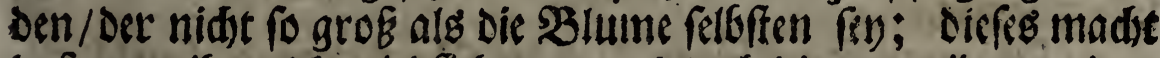

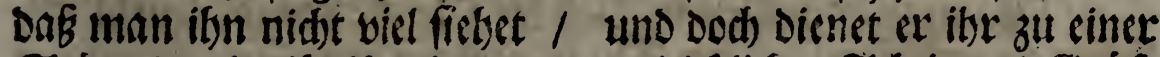

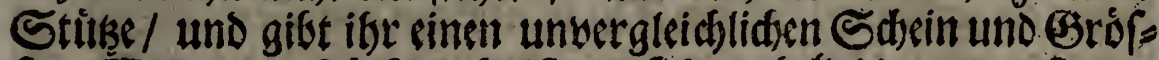

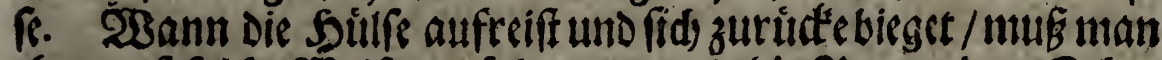
eber auf foldse WSeife verfabren/ saumit Die Pappe sen Edjas

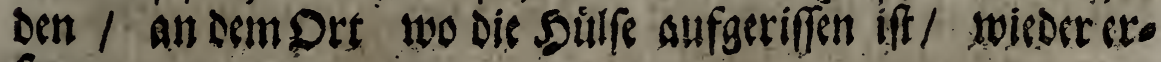
Segere. 


\section{8 \\ Reue Unterweifung \\ 2015 XV. Snpitel/

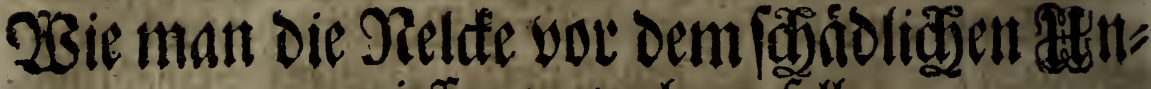 segieffer verwabren foll.}

23ie man Die Nlelde vor bem (i)dolictien Ungejieffer verwafiren foll.
55) Reuerley Ungezieffer greifft die. ORelde an / fie zu berdere Dir Dlorivurin.

Dir Sroflob fan aflein ser Nelde nidst fdaden/Danner if

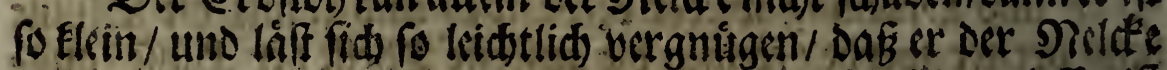

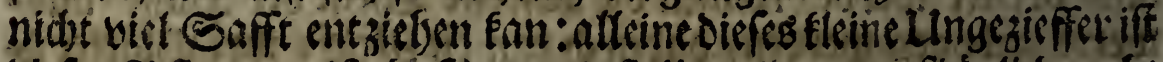
diefer poflanse misginftig / uno frellet ibr unaufborlid) nads

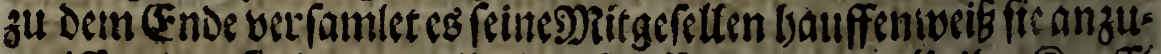
greiffen/und fre/indernes ilst den Saff / Darinnen alle ibres raff

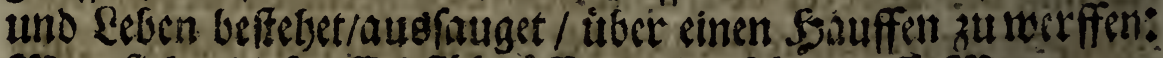

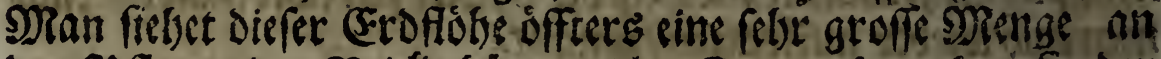

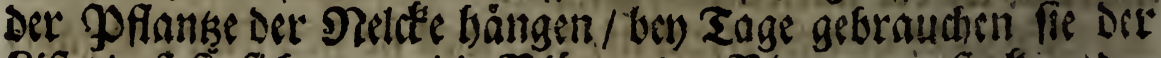
Riff / Daf fie fid unter die SBlatter der Bhumen vetfectén / Da.

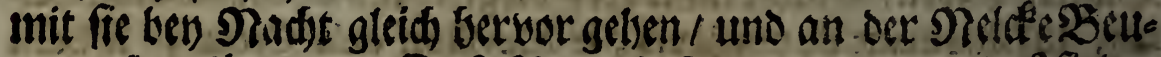
te imadien fonnen. Diefe Sieute beffebet Darinmen/ cab fie ber Me!dfe den Safft entzicten / uno fie alfo nidgt zunchnen fart.

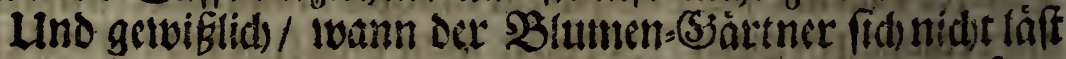
angelegen fenn/Die, \$flantse bon diefon Eleinen shberlein zufau=

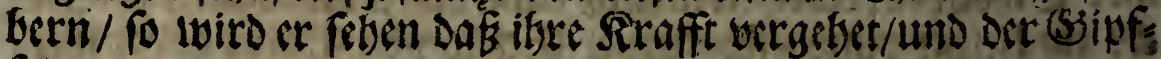
fel veroorter.

2Bann man wiffen will/ob die Neffe bon Diefern Unges Jieffer angegriffen fol / Darff man mur aufgerwiffe weiffe $\bar{F}$ led en \&d)tung geben / die fứ twie Dipflein auf denen Blattetn zsigen/

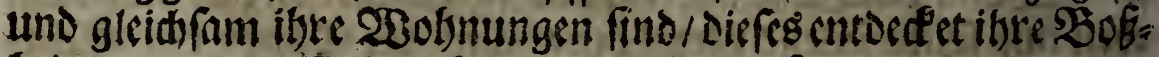
beit / uno giebt Gelegenteit an sie Sano fie auszuroten.

WBer wobl thun will / mus fid) nid)t fordsten/fie init oen Finger zu zerquet foten / Dann fie baben nidts gifftiges oder un= reincs an fid); man nimmt fie aud) mit einer feder hintweg/

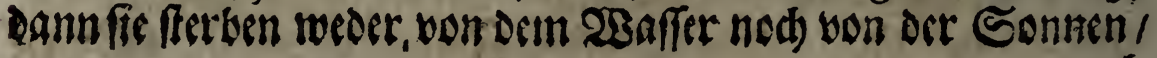
nod) 


\section{ร̆ Dem Slument = Şau}

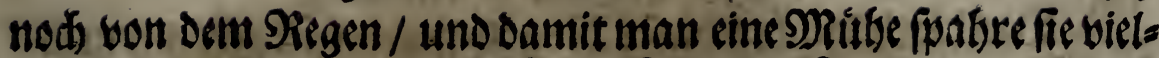
mabl abzunebsmen/ fo iff notbsig fieber 2afgang ber Sonne auf żufuden I Da man fie bann alte benfammen unter benen

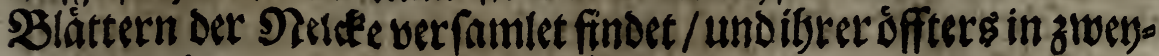
en Streiden mebr als taufend auf einmal umbringen fan. Sie

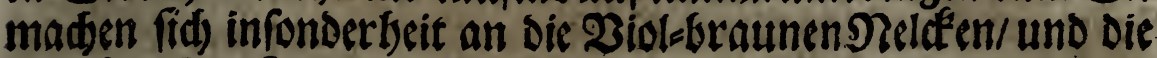
aum zâtreffen fino / Dietweil fie nidft gerne 23iderffand finden.

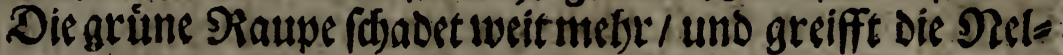
a"e gants anders an; Dann fie fauget ifer niditenur ben Safft aus/ fondern zernaget fie audd) und nimmet das $\$$ fesilgen oder ben Gipffil oben tweg/ und Damitfie/ wann fie Der şlumen= Gárte. ner auffiuden folte / Deffo befier inoddete vertborgen feun / ver ftefeft

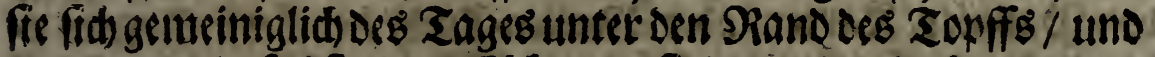

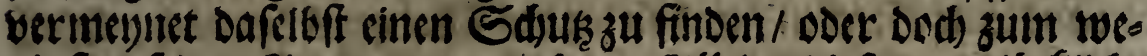

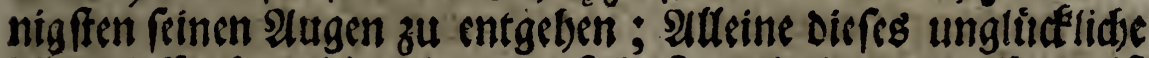

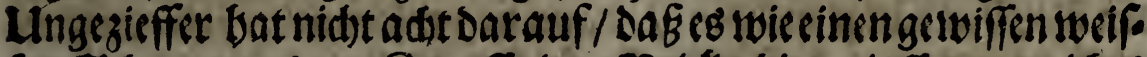

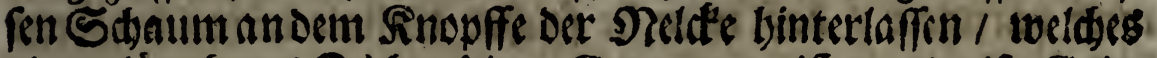
ein unläugbares Beiden feiner Gegentwart iff / und alfo Gelles genbeit giebt es auf zufuden / und entweeder unter dent Raande

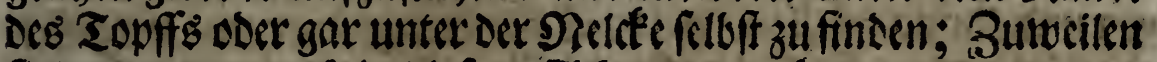
findect man cs aud in biefem Sdaulune vertsorgen / Da iman cs Dann fein fauber mit Denenfingern finwwegnelsmen muB : Dann-

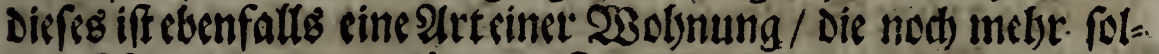

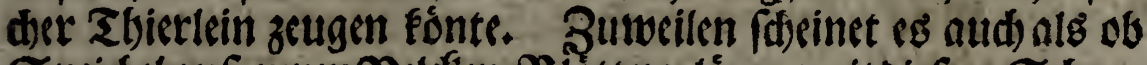

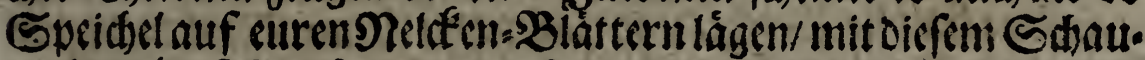

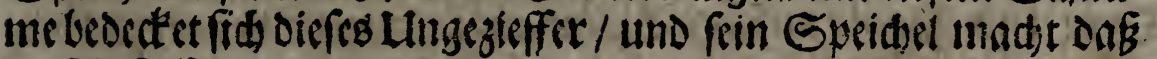

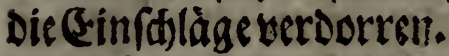

Der Delyrlingoder Dostwurm iff ein abgefragter Shaupt. Fecind Der Neldée / Dann er greifft fie won allen Seiten an/inn Dem

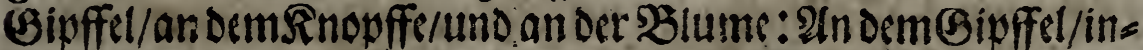

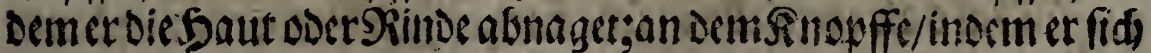

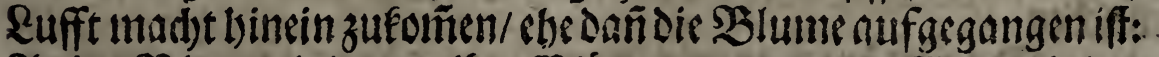

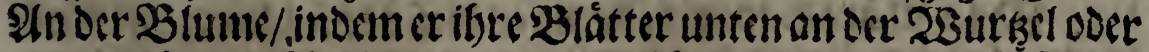

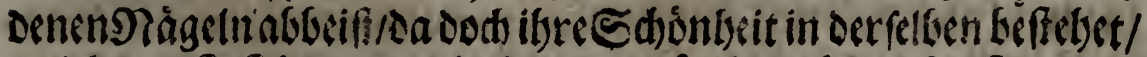

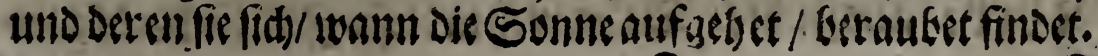




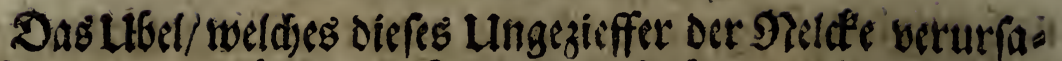

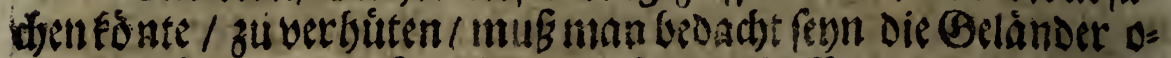
oer Balden/ Darauf die sBretter fo die Topffe tragenliegen/an

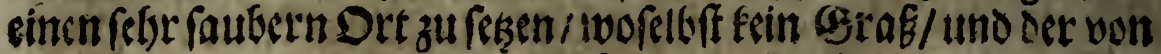

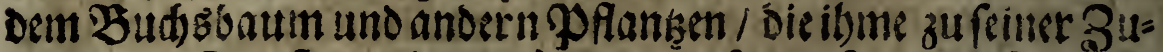

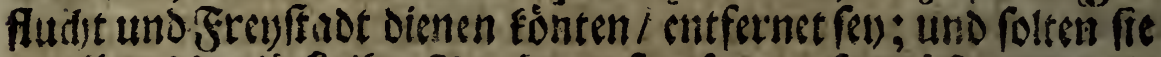
an allem Lnalite eifre SRuberen fortfersen / fo miffe man die

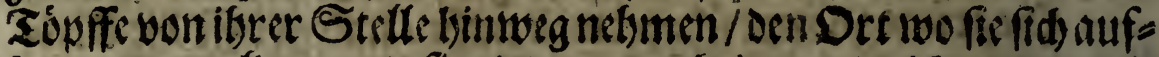
balten eniosdeen / uno fie alsoann untoringen / nidit zroar mit Der Sand / Dann fie baben etwas unreines an fids ; fondern init fiebteiffem $33 a$ fier / cinem Steine / oder aber mit ser platten Sacte: : 3 ann man fie fangen will/ madet man flcine Deuten

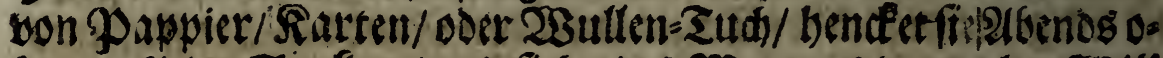
ben an fleine Stecfen / und fiebet Des Norgens Darnads : Wsith man fie aber gar auserotten / fo darff nur ein feudhtes Tud úler Den Topff getjangt werden / Dann fie verfammlen fid bauffen= weis Darunter / DaE man fie folder Geffalt leidutlid tóstent fan.

(Fo finden fid) nod) andere ungezieffer bie die Nelfe befriea gen uno ibr nadffellen / alg saiff eine Sitt grimer uno vergiffi:

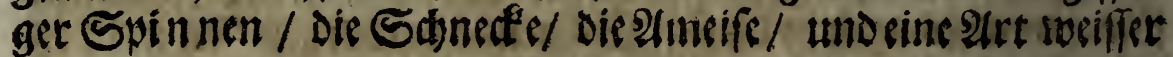
Siaupen.

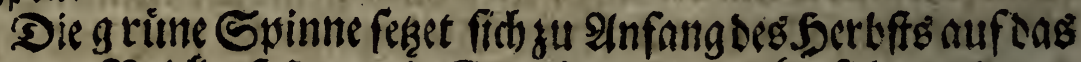

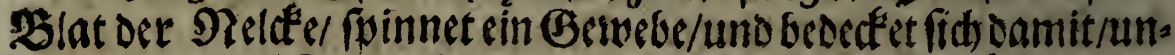

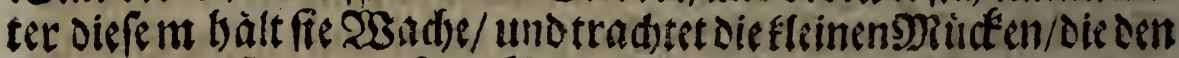

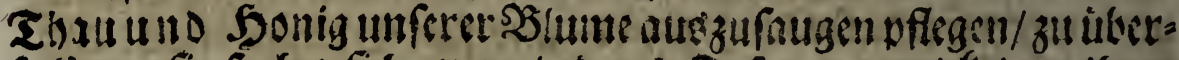

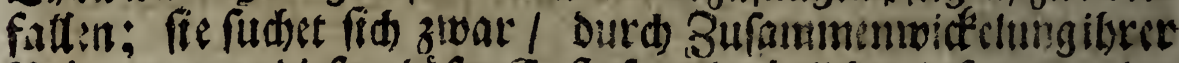
SElatter / bon Diefem bofen Gafte fo viel móglid zubefreven / aber

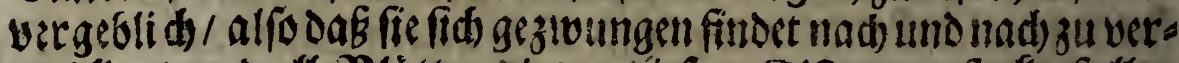

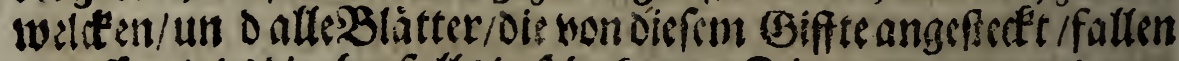

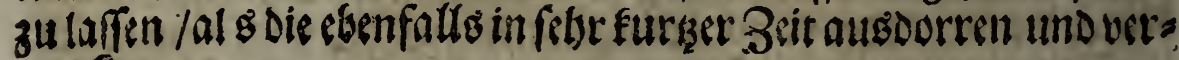
wellén.

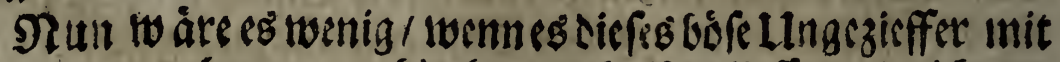

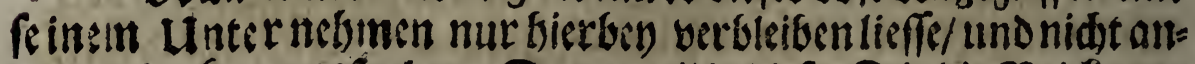

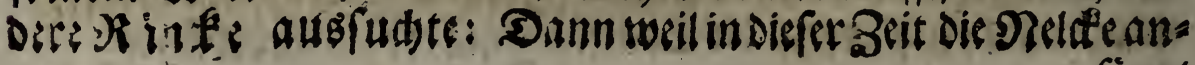




\section{zu bem:Slumen=ミ3au.}

181

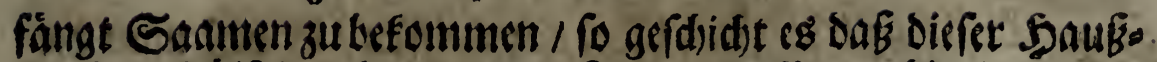

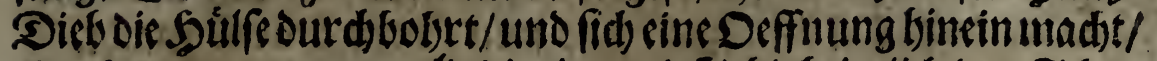

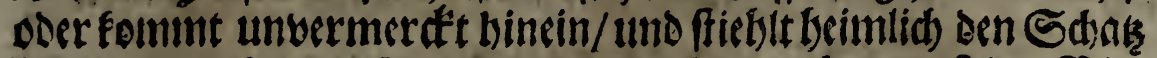

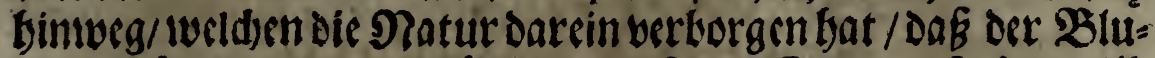

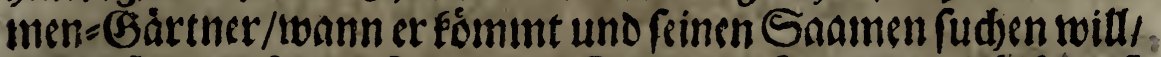

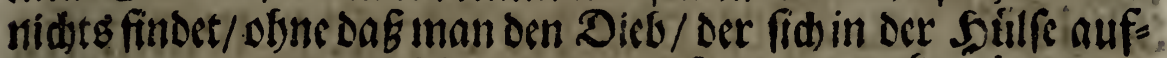

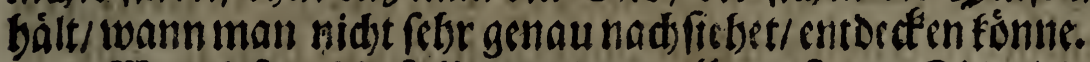

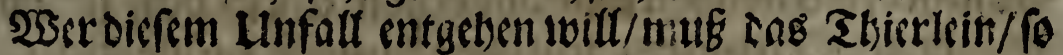

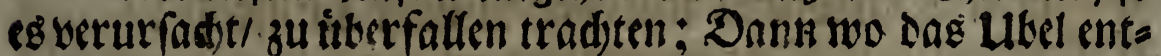

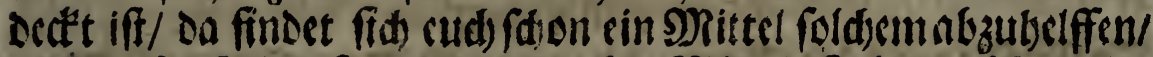
weil Defen Geind finden/ Dae redits Mittel iff ibn zu iberwine Den.

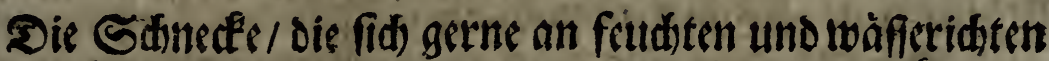

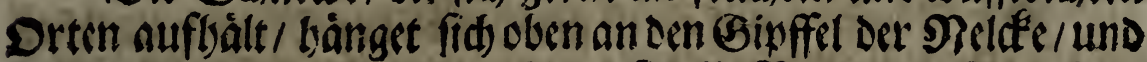

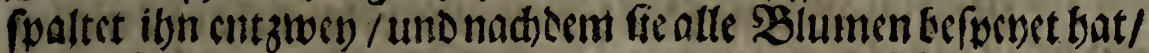

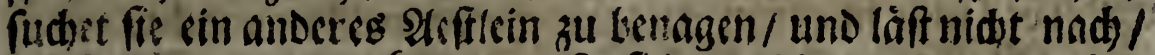

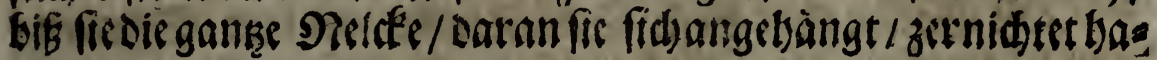
be.

23ann fids Die Auncifen an eure Relléen maden / fotgut Sonig in cinen Bedier / und freller ibn nabe all cure Téffe / fo secroen fie alle Dabinein getgen / und eure Blumen zu fricden laffen.

Die Siaupe iff zwaralteine rood) tf we fie fobr groffen Sdidas Den / Der um fo viel gefábrlider / als sie Ur rade beffen auch des nen vorfidtigffen faft unbefanot iff : cann meil fie fid bers $\mathfrak{T a}$ a

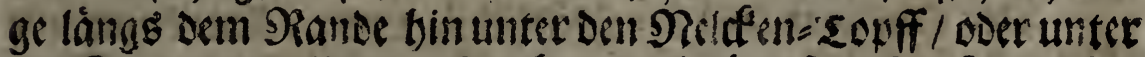
Die Rnoten Der fleinen Steffen verfectet/ fo jicher fie nut Gen

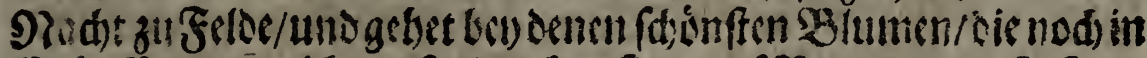
Sinopfin uno nid)t aufyctorod)en find/auf 3 cute nug / frift cin runors \&od indag Siobrelsin oocr den Stengel/und wersirgt fid

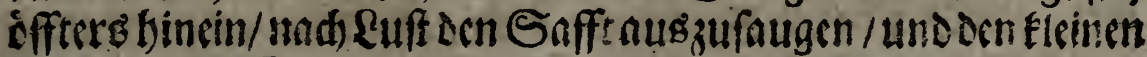
23ortath ecs Saameng/welden bic Natur tarinnen zubereitet/

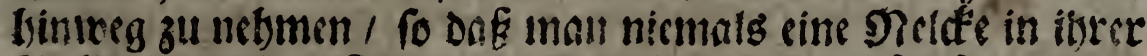
Botteonumenteit fiethet / fonderbatheilg balb verfreffen / theils gar vetrorben findet. 
182

Reuluntertweifunts

Dab MRittel biefen Leel abzubelfen / if bas man bies feg atbier fudft aufsufangen/ und ibm feinen Procels madbt.

\section{2aß XVI Capitel/}

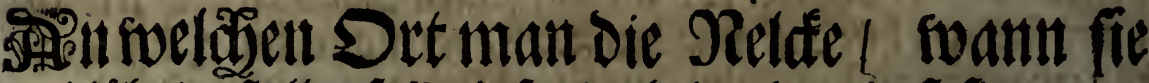
blihbet/ ftellenforf; infonberbeit aber/ baßs fie vor Dem Dhrwurm unto ber Atmeife muife ver: wabret werben.

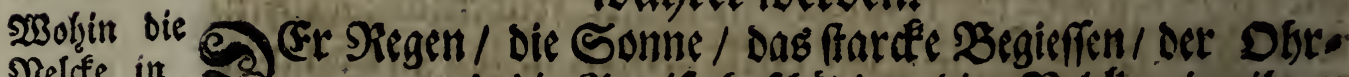
Nellfe in Der Şlitthe ou feellen; Slittbe und verdundeln ibren Blank.

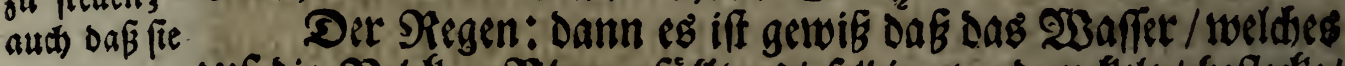

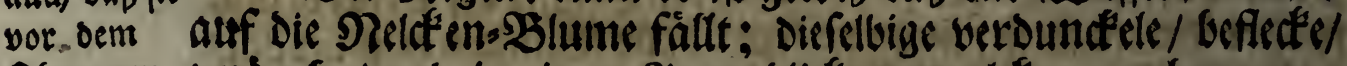

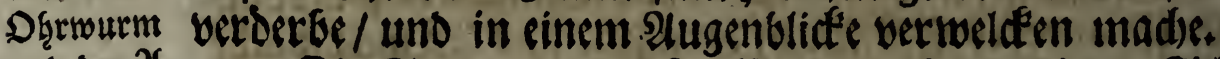

und oer $\mathfrak{A}_{3}$ meife miffe verwafget soerdett.

Die Gonne tbut diefer Blume nid)t weniger Sdjaden/ Dann fie trufénet die Eroe Dergeffalt aus / Daf bie'sBlume gleids: falls bertrodtnen imus.

Das ftardfe Begieffen madbt / Daf fie in cinem sugenblis

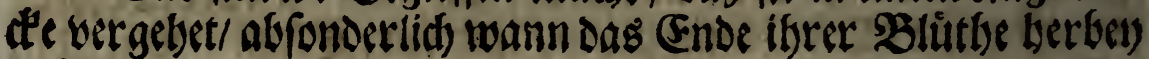
nabet/

Die Ameife zernaget bie Nelate / und bofret burd) Die Blàtter; twie man fie davor befduitsen foule/ift oben fdjon angezeigt worden.

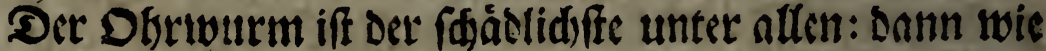
fdjon gedadte worden / fo friff er dießBlume / Deer beif die B!átter zum wenigften an oer 23 urkel ab/ dấ fie wegfallen ete.

Dag Mittel/bie Nelée vor allen dirfen. Bufällen zu vers wahten / ift Daß utan entwetber bon Strob/ober bon BBrettern/

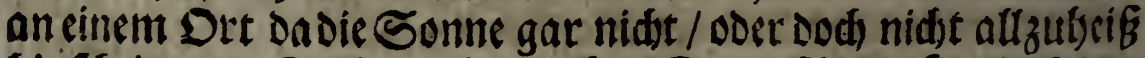
hirifdeine/ ein Dads madeen laffe; Dann fdiene fie gleid) Des Zages cine Stunbe dabin/unt es wäre bie MRorgen-oderabend.

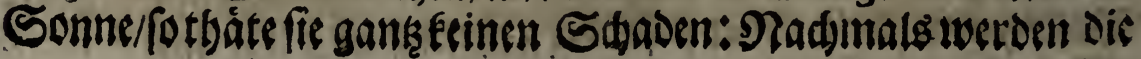




\section{\{ั bem 3 lumen=:Bau.}

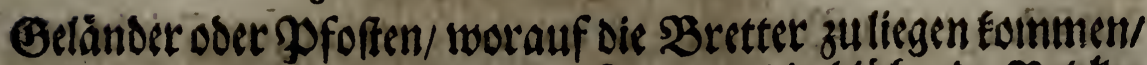

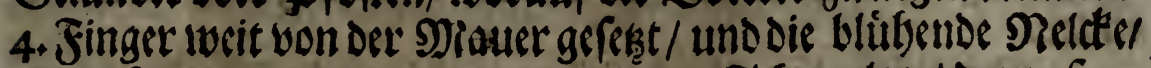
alg auf in Amphitheatrum boer runden S St;auplaks / Darauf ges

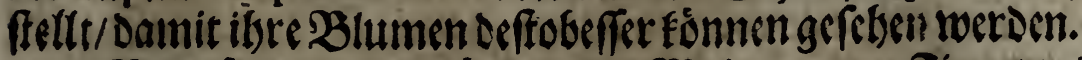

NRan féset Dem Gelánder eime 23eite von 4. Fingern you

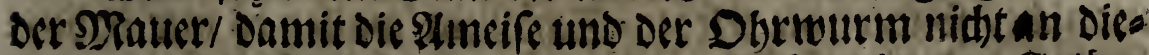

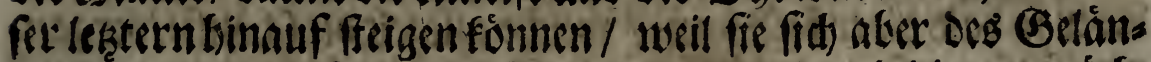

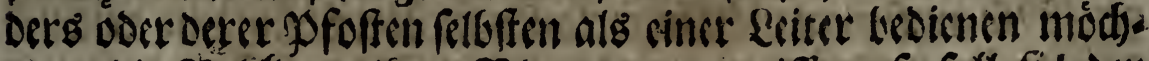

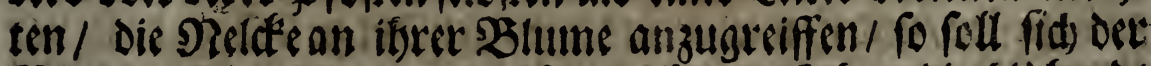

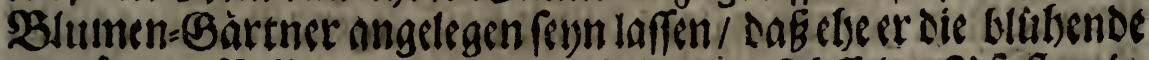

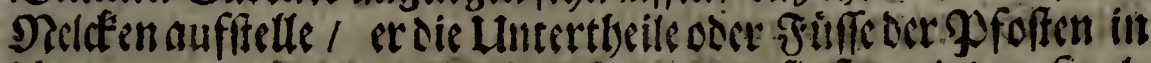

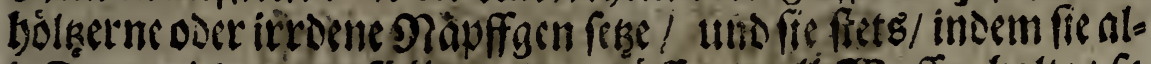

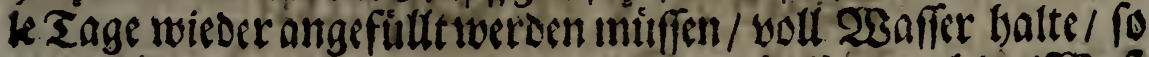

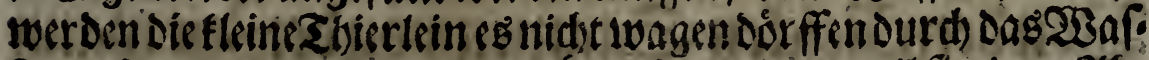

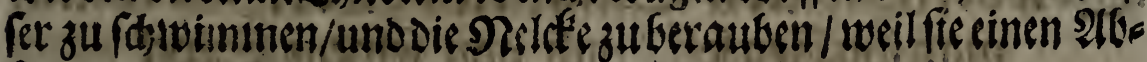
(id) w wor dein $23 a$ fer baben.

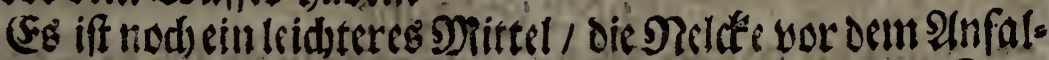

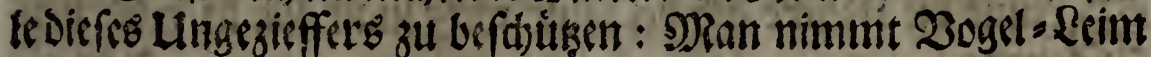

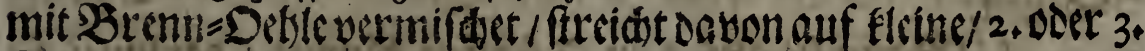

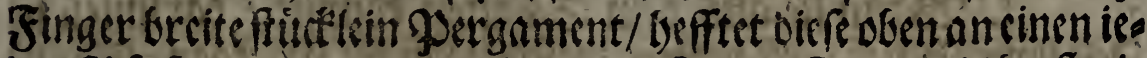

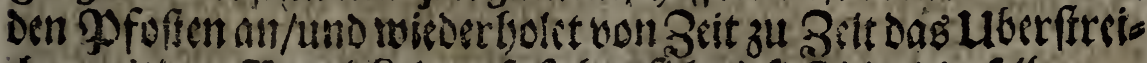

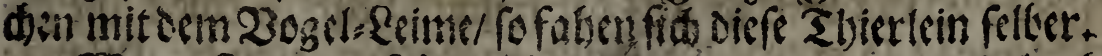

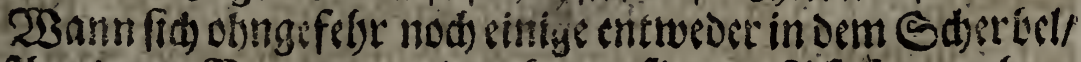

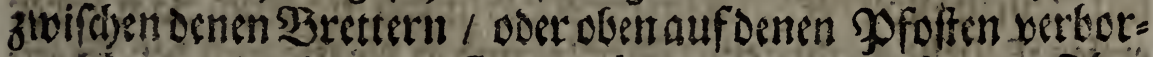
gen fatten/oder Davon geffegen wären/zunn wenigffen ter Dobrs

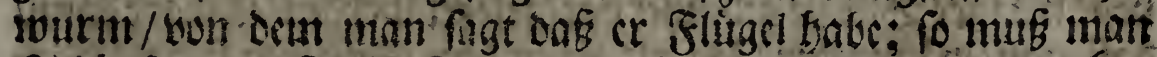

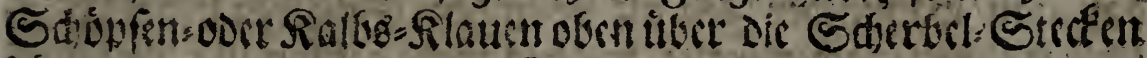

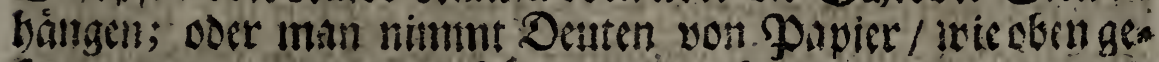

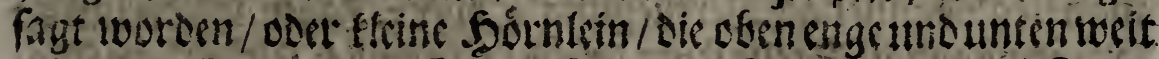

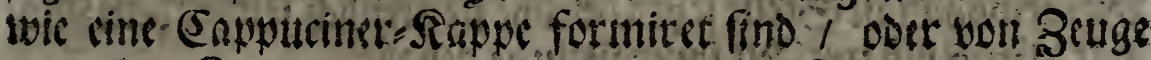
gemnatite Rappin / Dic ieget getritlete Geffalt bofen $/$ und

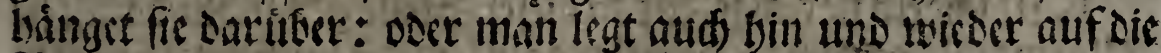

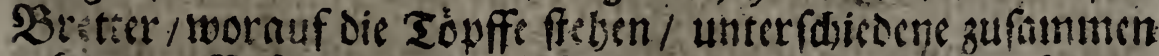

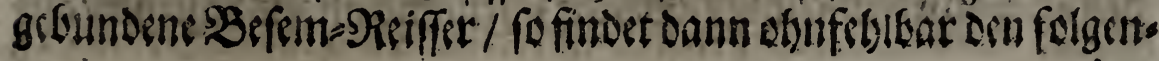


I84. Neute untertiveifung

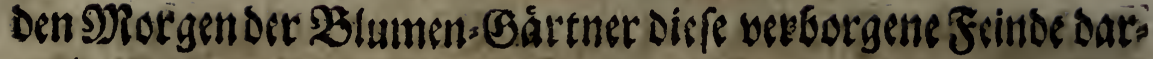
unter.

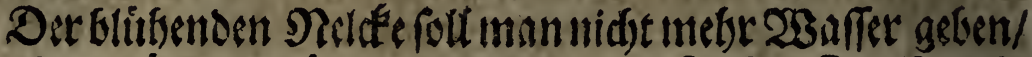

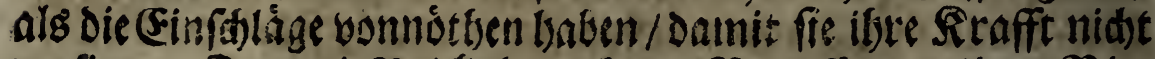

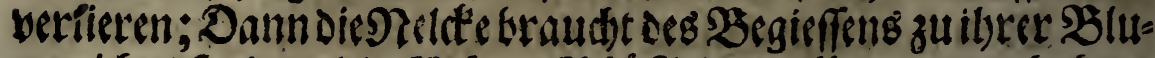
une nidft / Fondern die gle een= Sdjóblein wollen es nut baben: Aber fo Galo bieerffe? Blume / welde allezeit Die fdoonffe/wergate

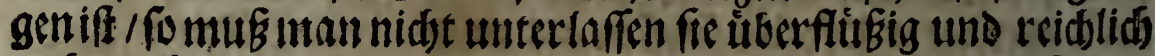
zu Gegieffen / und fie wieder an denienigenort zu fetlen / Da fie vov ibrer SBlutebe geftanden bat / Damit fie Selegenbeit babe dafeloft ibren Saamen zu formiren.

\section{2ä̉XVII.Capitell}

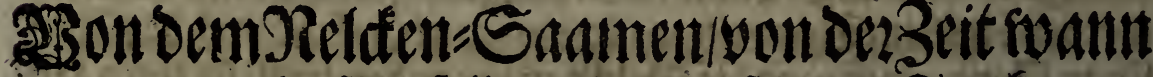
manibnfäenfoll/ uno won feinem Stod

oder Staube.

5230 on bet Beit wann mant ben æelcectu= Saamen fêten foll.

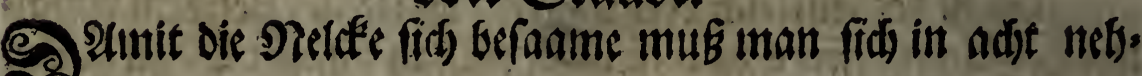
imen.

1. $23 a n n$ fie aus dem Sdiatten fosmme / Darinner fie Beit librer Blittlse geffanden / biefellige in die MittagB = Sonne

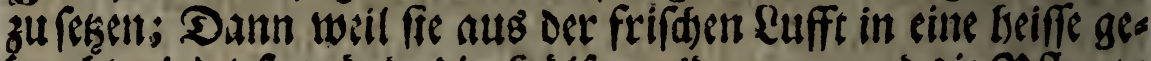

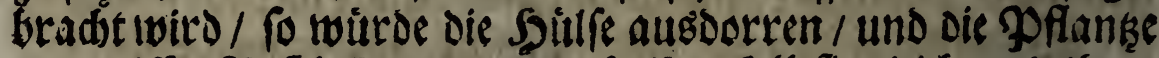
Den weiffen Pioft befommen/ Derobalbin foll fie gleids nad ibrer erfere Blitthe an ilgreerffe Stelte / und in die Gegend Der Soms nen/ wo ibre Blume geblitbet bat/gefeset twerden/ c s máte Dann

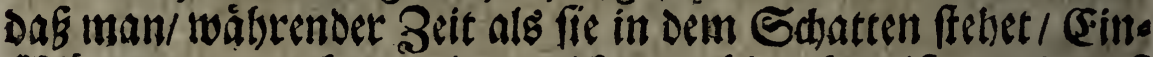

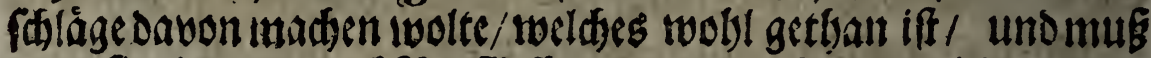

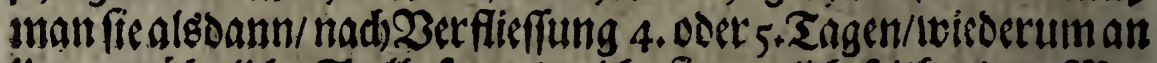

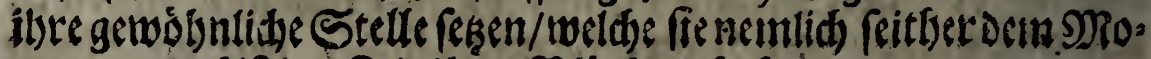
nat Martio,biß zur Zcit ibrer Blitthe gethabt.

II. Oladbem fie cinigezeit an diefer Stefle geffanden/Dantit fie allgemad) dic Sonnens Silse ertragen leme/ fo mus man fie gegen

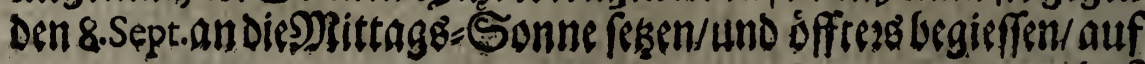




\section{ร4 Dem}

DaE fie gr zutungen twer de Deffo leidter Snamen zu Gringen: Dann Die freus Eufft / Das 23affer und die Sonne tringen ibren Saus

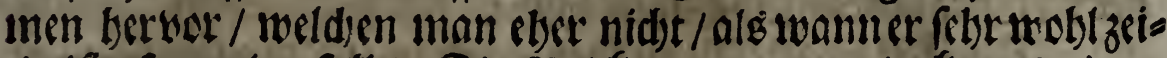

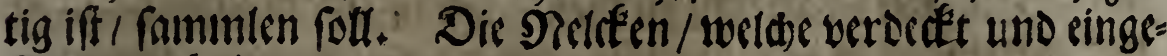
fwerret gebalten iwerden / bringen feinen Eaamen.

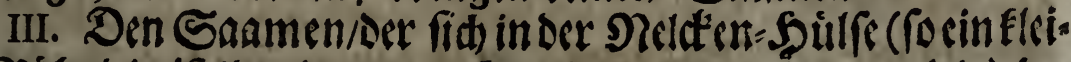

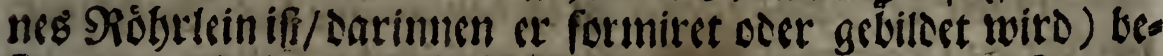

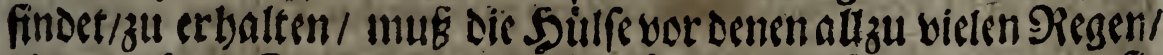
Die vor itsrer Beitigung sinfallen fónten / ver fidert wereen / fie

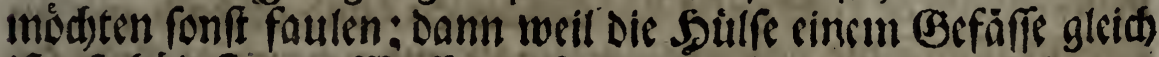

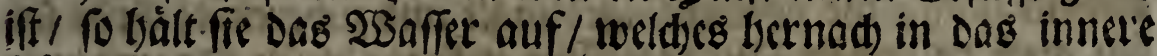
Fádblein / woo der Saamen liegt / binsinoringt und Denferltigen versirkt.

1V. Unter benen פeldeen foll man bicienige austweblen/ weldse an frudtstgatfen fimo / une am lieteffen Snamen tragen/ Daunit man ilmen / in ber Beit nlz ocr Saamen formitret soer. getbiliet wird/deffe fleiffiger abwarte/und den Saamen zu feiner 3esitigung Gringe. Einige tragen leidter Saamen als bie ans Dere/ weldses man twobl an sem Exempel ber Orpheline / Die feitbero oen Damen Abondante ober Mere des oeillets brefemmen

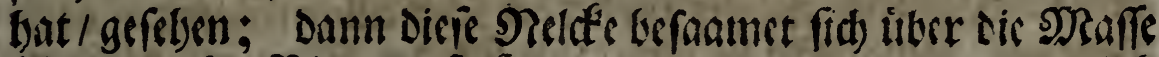

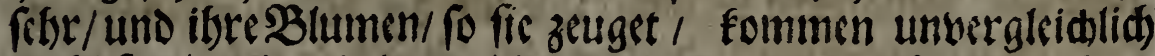
wobl fort / wie wir Dann Die Nompareil, Die Altefe uno Medor, weldteg feltr rare Neldeen find / won ibr baken.

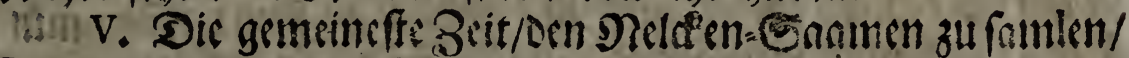

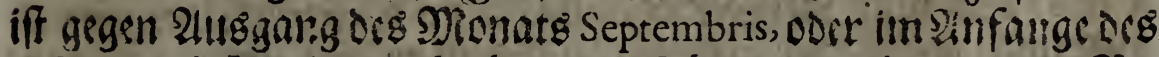

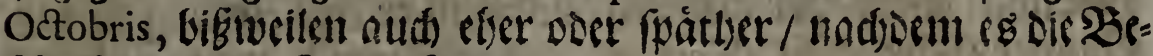
rdaffenleit Der 3it er forocrt.

Wann der Saane eingefamlet iff / muf cicde Gattung bes fanders in cin Papier gettan / umb camit man Den Lutterfdecio

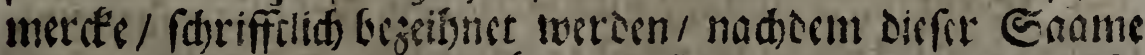

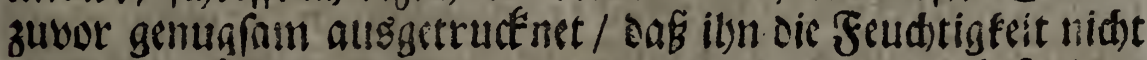
verberben fonm; nadumals wiro attd icde Oattung hefenters in irroene Vapfgen oder Sopffe gefáct/ une cinem iedon Topffe 
186

Trate Unterweifung

cin mit Biffern befdretebenco Zeiden beugetegt i damit mandie Gattungen/tweld)e fortfommen/ertermen/uno von oenen/Die aus Der alrt fdlagen/ unterfdeiden fonne.

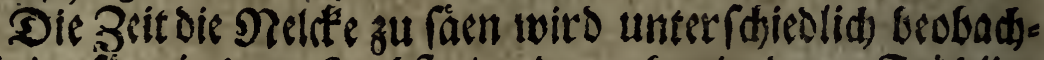
tet; cinige faen in Dem Serbffe / andere aber in Dent Frùblin = ge.

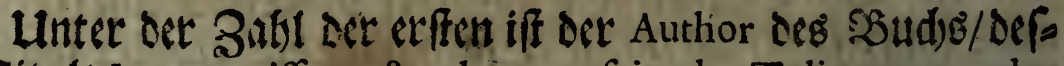
fen Titul: La connoiffance\& culture parfaite des Tulipes rares, des Anemones, des oeillete fins, \&c. Iveldert will man fold oen Saas men/ fo ba!d et redst zeitig ift / cinfamlen / uno alsbalo wieder auf ein Niffbetbe oder woblgedingte und zubeteitete (Erde fas ent aud zu redtet 3eit begieffen; er fagt / diefer Sname treie

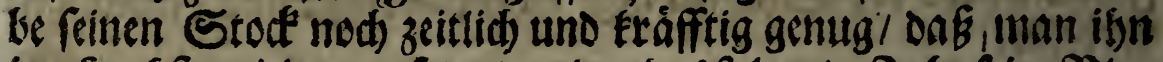
iin Serbfte wiever ver fezen / uno er bas folgende Safte feine?3lus me bervorbringen fónne; Da indeffen die Sauten / die nuffünff. tigen Jrúbling warten/ ibren Saamen zu fần/ ein Jalst dar. ilber verlieren.

2f6er Der Author DeE Nelféen Tractats (du Traité del'oeillet)

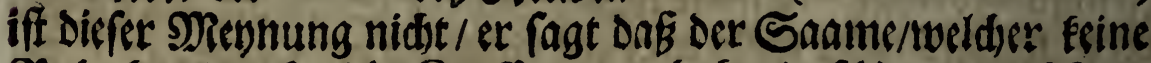

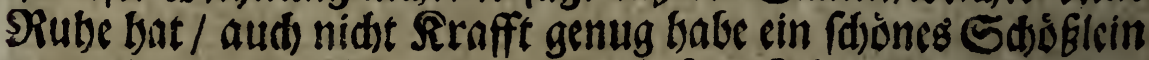
zu trelben/inderm 23 inter verliere cr feine \&ebbafftigfeit / oore trage Dod feine foldse SBlume / wie fid der SBlumen:Bärtner

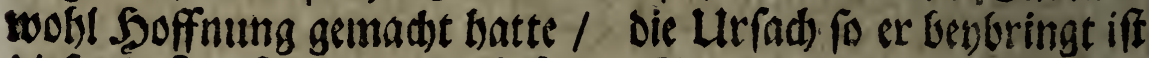
Diefe / Dak cr fagt/ man milfe den Saamen zeitigen laffen / olso He ikn/ fo balo er singefaunlet iff / wisoer zu faen: Man mirs

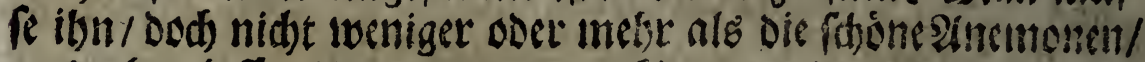
aubrutben laffen/ Der algbann / nadsocm er cine zsitlatig in Des 23lumen.(Báreners Cabinet vertwablt gelegin/ twsit greffere Bilumen treibet / als er fonffen/ wann cr iábslid) wicoer in die Croe loáre gefáct, tworden/getbsun bätte.

Scinc Drennungiff / man foll in dem Frublinge faen/umo nid)t in Deun Februario, wie etlide zu thumn fiegen / esemtiffe aber/

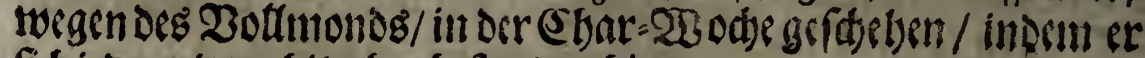
fid iederzeit wobl dabed befunden bätte. 


\section{รu bem Şlumen=:Să.}

187

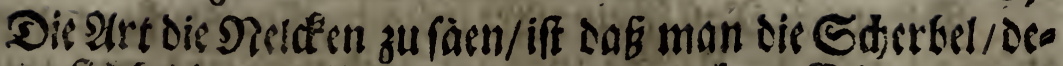
ren man fiübecienan will / tmit siner angemad)ten Erden/ Deren

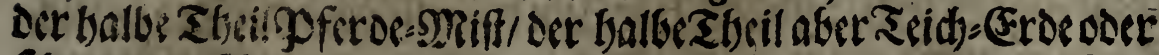

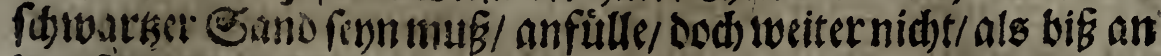

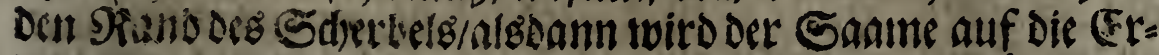

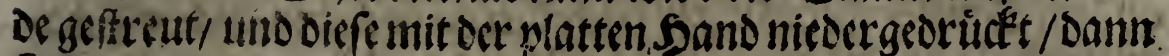

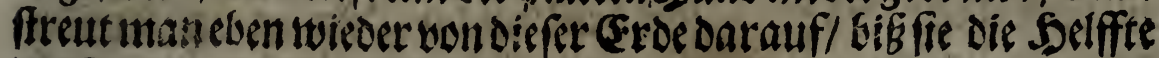

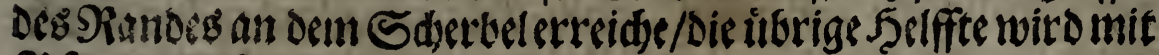

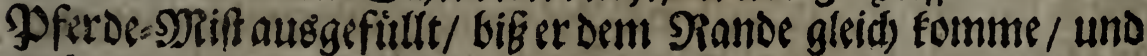

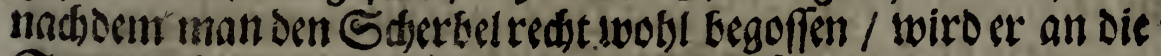
Sonne gerebs/ Damit der Saame auffdieffe.

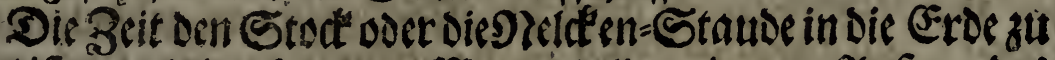

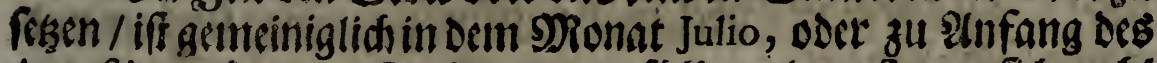

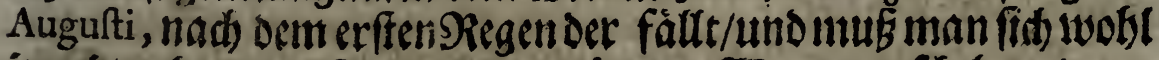

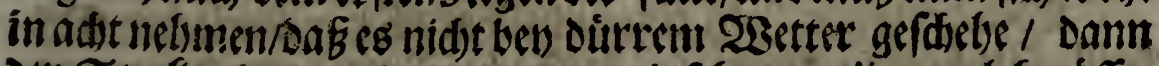

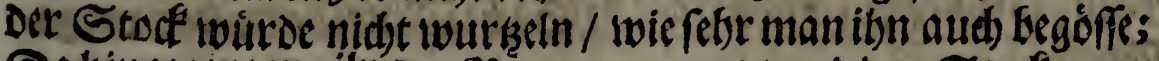
Daljingegen/ wwo ithroen Siegen erwartet/ und Den Stofe 7. oo

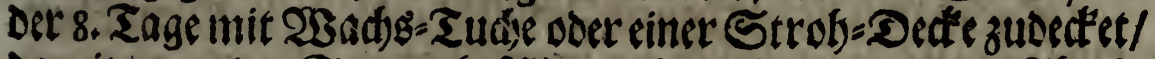

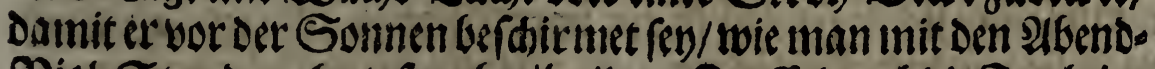

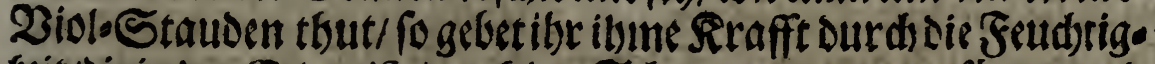

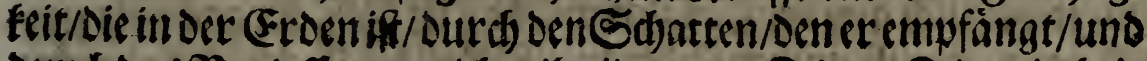

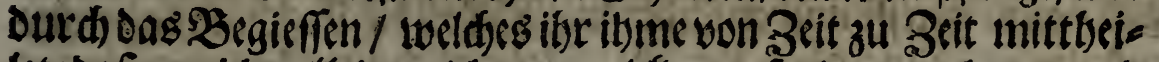

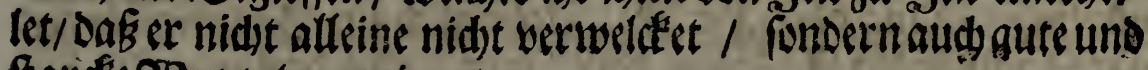
frarffe 28 ursęeln getwinnet.

\section{2n XVIII. Eapitel!}

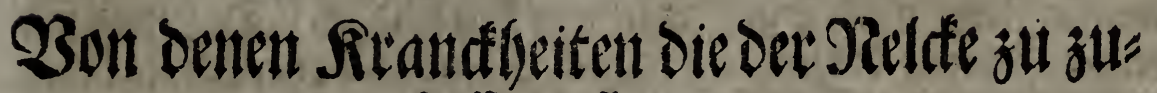
ftofien. pflegen.

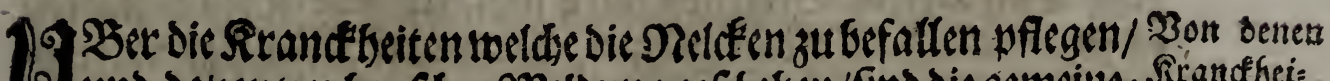

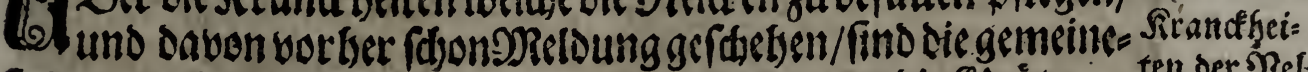

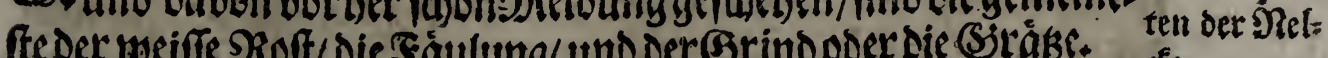

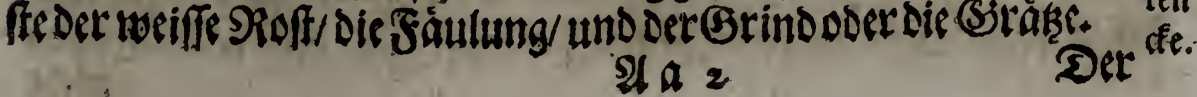


Der weiffe Roof iff eine Art cines tweiffen Flectens/ Der fid) an bie Blátter ber Neldéc anbàngt/ uno nads uno nad roie Die

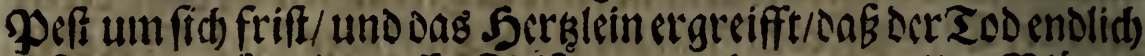
erfolgen musi / wie groffen Sleiş man aud) antwerde ibre Slätter

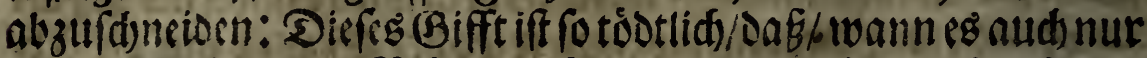

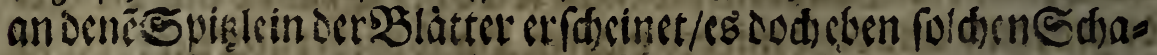

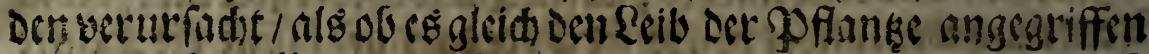
batte / Daber affe curieufe Blumen=(Bärmer glauben / co minfe

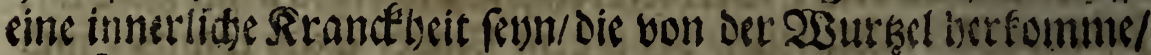

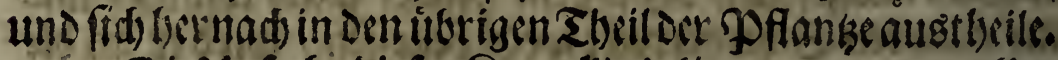

Dic Utrfadse Diefer Frandebeit foum non Der allzugrofs fen Dirrer oder twann man dic Nelde' nid)t an geborlgen Drt

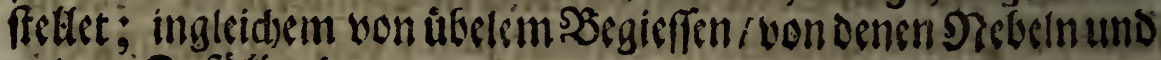
atoern Bufálten ber.

W3il Der weiffe SRoff cine unbeitbare. Rrund"beit Der Nel-

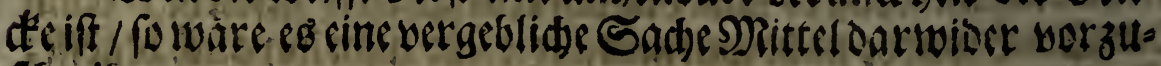
伤reiben.

Duds bamie fie vor Denen Bufálen / die diefe Rrandfleit

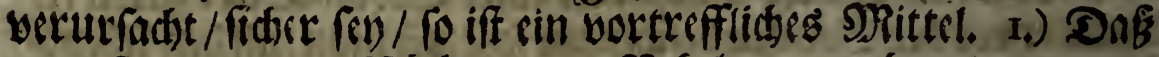
man fie vor falten Naicteten und Nebeln verivabere; donn mant

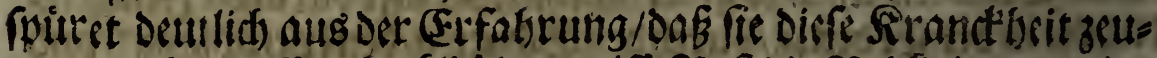

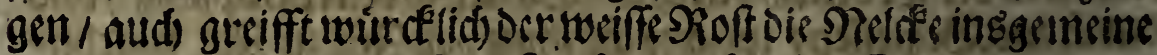
nur imfribling oder Satrbife / fetten nber im Somnter an / es

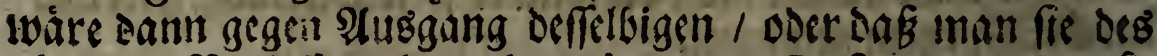

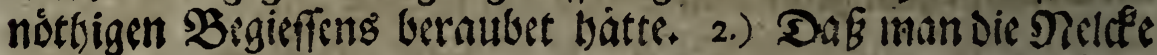
in sie freve \&uffe fobs: Dann man rimmt an oenen Veld"en/

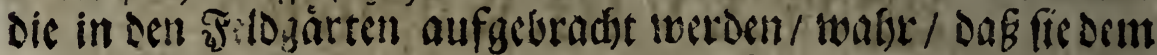
weiffen SRoft nidte fo gar untermorffen find. 3.) DaÉman fids

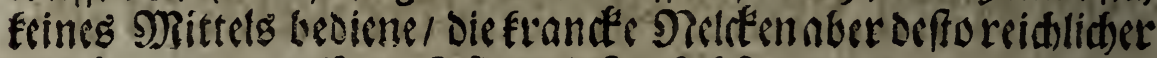

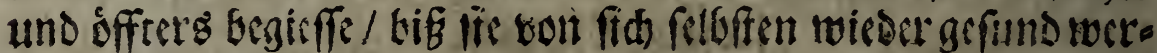
Den: $\mathfrak{B}$ ey diefern Begieffen wiro inan fid) feke wobl lefinsen/

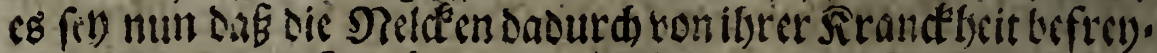

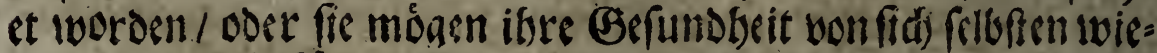
Der erlanget baben. Dem ien nun wie ibm wodte/ man mus nidst 


\section{zudem Slument:Bau.}

189

nidif alfzu biel boffen / abet aud nidst alle Soffnung fatlen lafs fen/ wie diejenige tbun/ die fo bald ibre Preleten nur angegrifs? fen twerden / diefelbige gleid) aus reiffen; man mub (3edult ba= ben/ und feben of Der weiffe Flecten nidst etwan aufroth oder gelb ziele / weil alsoann nod) Soffnung zu der (Benefungutorig

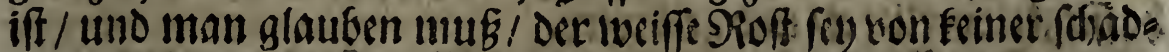
lidben Eigenldafft getwefen: Diefer fan an ber Indicrofe ertwie=

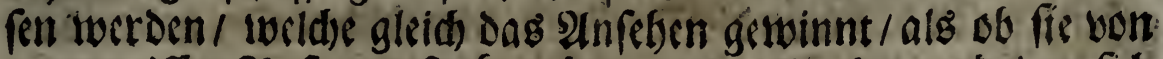
bent weiffen Soff angeffecft iwäre / nadinato afer berindert fid) bie toeife in cine rotblide Farbe / die ibe gant fein Lunbeil zu=

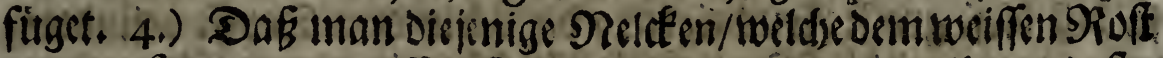
alm imeifen unterworffen fino/ bor ancern fenne/ ibnen cefto

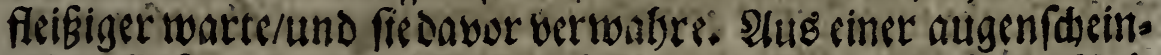
liden Erfahrung bat Iman/Daf oie Incarnat oder Eeibfarbe Olel= cen ebe den meifiten Siof alsandere befommen / und diefes mag cine Liffide fenn / wo arum man ibnen eine leid)tere Erde/als Denen rotben und Biolbratmen gibt.

Die Fanulung iff cine Art Deg falten Brands/ oder faulen

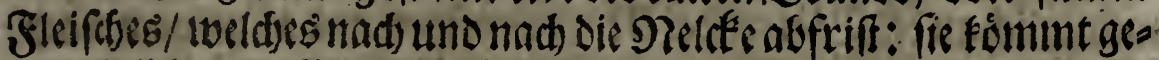
meiniglid) vonallzubieler Feudtigkeit der (Froen / von aldzu bies len Suatten / von ungefunden bofen $23 a f e r n /$ bon feudten Drtell ic.

$23 a n n$ fes Das 5erslein nidt angreifft / fonoern nur unten an Deut Fuffe bleibet / fo fant Die Vielde nod erbalen wersen/ walm mannur mit ber Spikedes FeDer=MReffre alles Faule an. Dem Juffe/bif ansas frifde ooer lebendige/hintueg fdneider/ uns

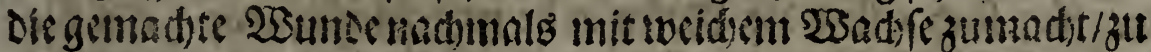

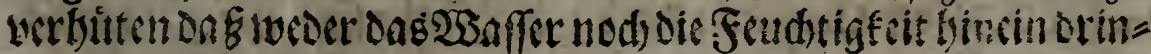

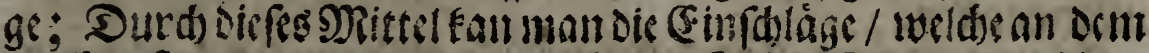
Fuffegeftanden / aud) crbalten/ wann fie ber) Zciten einge/d) la = get werden; Man Darff aber diefie Sabr feine Blume hoffen. Z3aum cinige bon cuten Sinfdalágen oie Faulung batten / miffen

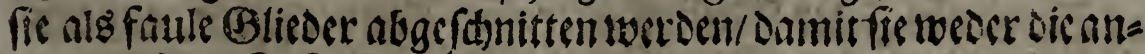
oere/nod) Den SuB anfféten. 


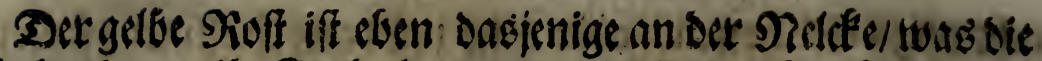

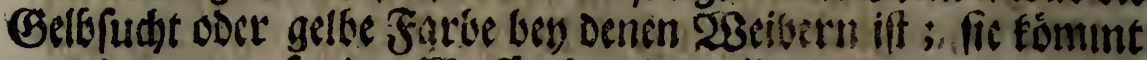
von cinem ungefunten 3 affer ber / DaE all zulange in Dem Topf-

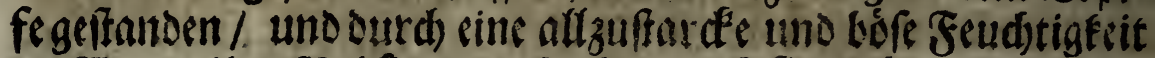
bie 23urkelber-Shelfe verderfer bat / DaE fie Daritber ibte \&egs bafftigkeit verlieret/ und gelb wird.

Das Mittel/ fo viel man einet halb -erfforlenen Pflanke

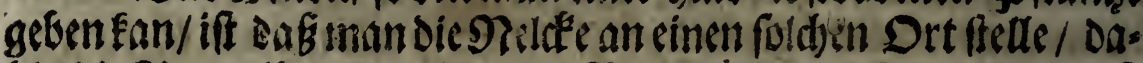
bindie Sonne ithre Etrablen deg Morgeng zwen Stunden werf fen Ean/ obnedä́ man fie begieffe / coer Diefeléige beregnen laf fe/ bis Diefe groffe Seudtigfeit / Die fid) in dem Topfe befinder/ vergangen/ und Die 23urkel/ bie gleidfan in cinem Eloac Doer

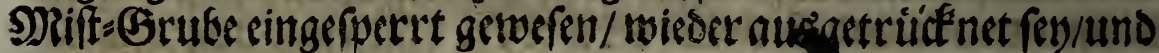
fómmt Diefe Rrancetheit insgemein Baser / mann Die 2tuggånge

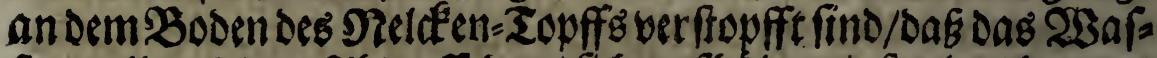
fer/weil es feinen âblauff bat / fids aufbált uno faulet / Daraus

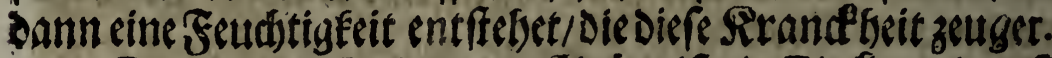

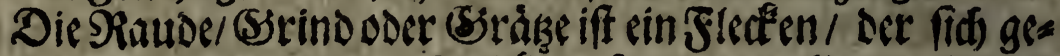

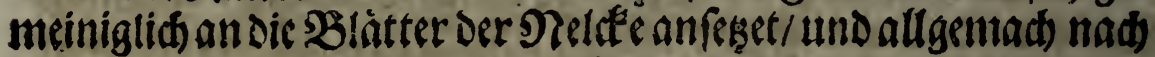
Dem Sersen greifft / wann man ibm nidit weblet/ und bic anger fecfte Blatter abfdjneibet.

Diefe Rrancf beit fommt inggemtein in been Frttbling oder. Serbfte / von Denen garffigen Plebeln/und falten SRegen; zutwei= Ien aud im23inter von Der Jeudtigfeit Der Erden oder DeE23 et= ters.

Dis Nelden/weld)e Dirfer Rrancétseit ammeiffen unter.

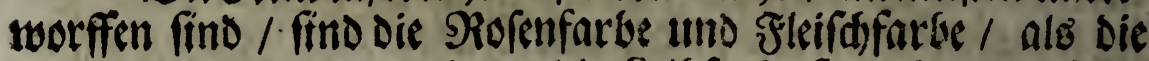
Indicrofe, Die Die Maréchale \&c. Die Reibfarbe fino ibs gleidffalls unterworffen.

Bu verbindern Dafis diefe Srantét beit nid)t um fid) freffe/mus

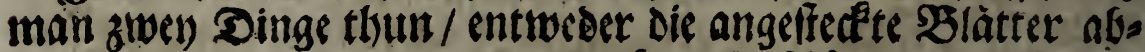

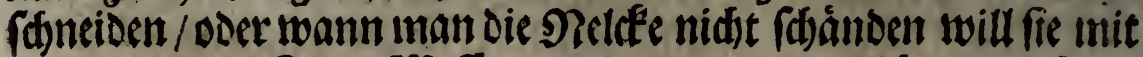
Der Spike Des Feder-MRefferg abfraken / zuberbuten/Dabjeas ubel nidt. aut ien Stengel angreiffe. 


\section{subem $\mathfrak{B l u m e n - F a a u . ~}$ \\ \$ns XIX Capitel/}

IgI

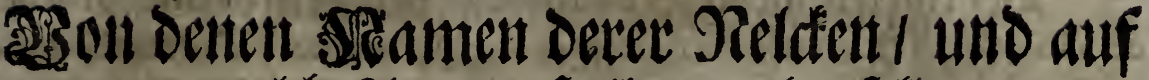 weldbe 2 (nt man fie ibnen geben forl.}

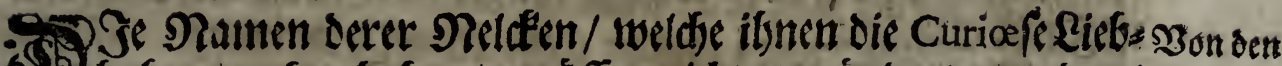

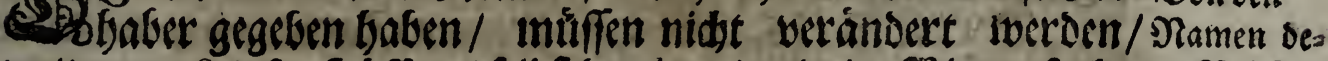

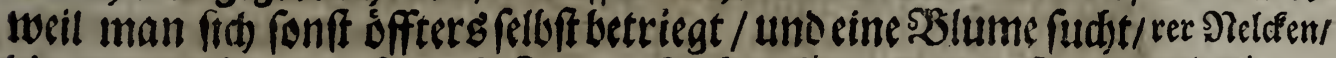

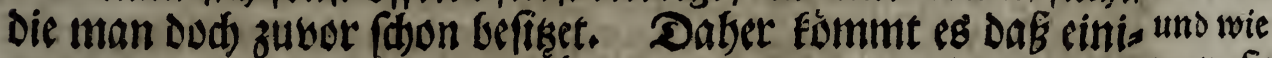

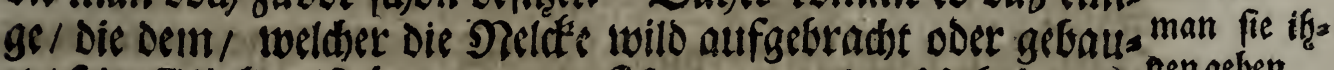
et / fein Elited misgonnet / uno fid) Autores boer Lutbeber cis nengeben ner foldten fósinen sBlumen zu werben angemafiet/ inoem fie fool. ifer'ben Vamen Dromadere, Beau Louis, \&c. bengelegt baben. Serr J. Laurent, Notarius bon Laon, giebt in finem Abbregé des Arbres nains. \&c. oDer furken $B e g r i f f$ won Denen 3twerd).

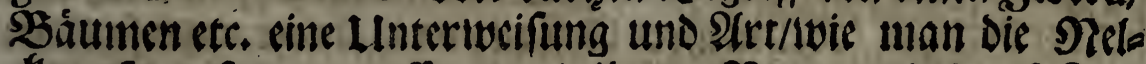
deen/ fo zu fagen/ tauffen / und ilsmen Vamen / dadurd fie in ibren Farben etc. unterídieden werden/ benlegen foul. Lund das

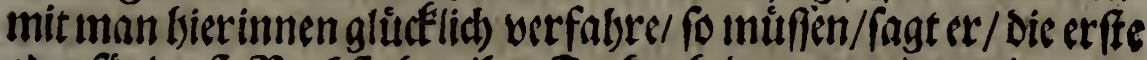
oder fót terffeßzudffaben iber Farben bedeuten und anzeigen.

Bum (Exempel: cine weife Nelde / Die roth gerprengt iff) (blanc pananché de rouge) folf man bon Roy, Baron Royal, Benedictin reformé, belle Rachel, bon Riche, beau Ruftique, bon Receveur, brave Roland ooer bien Rayé\&c. nennen; Der Buttdffated Des erffen 23orts B. bebeute alebann Blanc, tweí / Det erffe \$Bubo ftobe Dis andern $2 B$ orts $\mathrm{R}$, Rouge oder rotb.

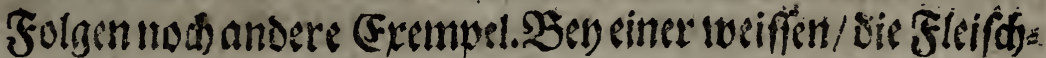
Fare gefprentye iff / (blanc panachéde couleur de chair) fénnen oié STamen fron/bon Chapelain, belle Charlotte, bonne Chalonnoife, beau Chapeau, bien Charitable oos r bon Chanoine \&c. nadisten

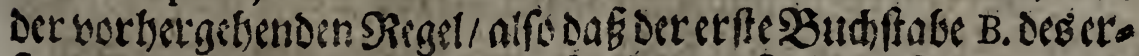

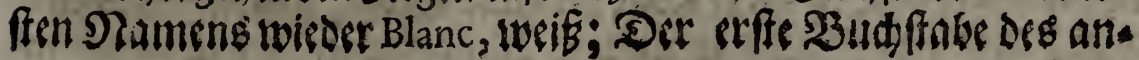


192

Reue Unteribeifung

Dern Namerisaber Chair, Sleifd/ ooer couleur de Chair, Sleifds= farbebedcute.

Zor cine 23 eiffécic Biolbraun gefprengt ift (blane panaché de Violet) fan mall neftmin/ bonne Voye, bonne Villageoife, bon vieillard, beau Vifage, bon Vice-Roy, bien Venu, bien Vif, \&c. Da B. ebenfalls Blanc oder die Wseiffe/ V. aber Violet ober die Ziolbraus ne'farbe anzeiget.

Bordie 'Sladgęaraut uno Purpur=-Sarfie(gris panaché de pourpre)fin,o oic Namen/grand Prieur, grand Pape, grand Prêtre, grand Provincial, grand Pompée, gros Paul, grand Préfident, grand Partifan, Greffier Prefidial, gros Pierre, grand Philippe, grand Pouffin, grave Philofophe \&c. Dą̧ wieder nad) obiger Siegel/ G. Gris, grau P. aber Pourpre, Purputfarb bedecutet.

Unter diefen Mamen fudbet eud nun bernus / Dser erfindet

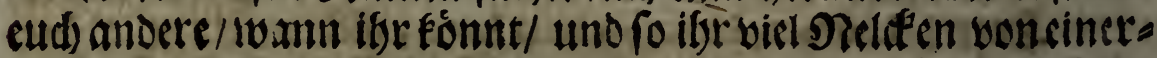

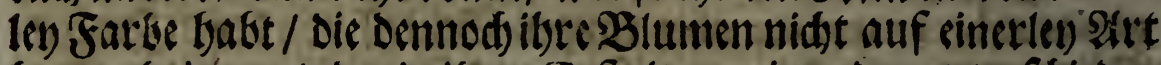
berbor bringen / oder in iferer (Beffalt von einander unterfdeieden fino / fo geber ifnen entweder von denen vorbergebenden doer nadf folgenden Slamen/ oder erdiditet cud fel(sf andere nad) cu=

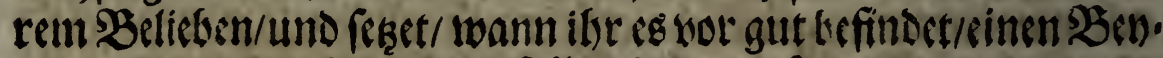
Namen Dar 3 ; Sietunten follen Extmpel folgen:

Zor eine weiffe und \&eilfarte (blanc \& incarnat) fennen Dir Namen fenn: Julie ober Julienne, bonne oder belle Jndienne, blanc Jacobin, brave Judith, bon Jardinier, belle coer bonne Infante, Bacha Ibrahim, bon Jofeph \&c.

Zor cine tweís uno Purpur geforengte; (blanc panaché de pourpre) belle Paule, bon Prince, beau Poupon, bon Patriarche, brave Prophete, beau prieur, bon Pafteur, bon Paroifien \&c,

Zor bie groffe weiffe (gros blanc) grand Berger, gros Benedictin,grand Bailli, \&c.

Bor einerotle und fladfoggraue (rouge \& gris de lin.) Rodomont Gaillard, General Role, grand Religieux, gros Rubis, \&c.

Zor sine Fladg:-graue und 2iolbraume/ (gris de lin \&Vio- 
let) General Wirtemberg, grand Vicaire, grand Varlet, grand Vaillant,gentil Vicomte, gai W:alon, Grand Vifir, \&c.

Zor sine rotbe und Fleif fof farbe (rouge \& couleur de Chair) le raviffant Confeiller,le Chanoine Regulier, rufe Commiffaire, Coeur Royal, chafte Roy, Rodeir changeant, Capucin reformé, \&c.

Solder Geffalt verfábret man aud mit Denen andern Sarten. Diefe Atet die Relceen zubenennen/madt toafiman

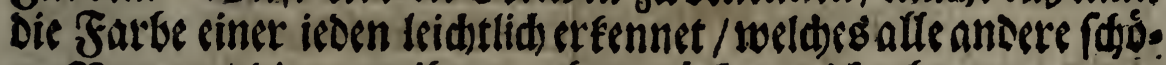
ne গRamen / Die man ibnen geben módte / nidst tbunt.

W3ann ifr von obgemeloten/ ooer fonft erfundenen פas

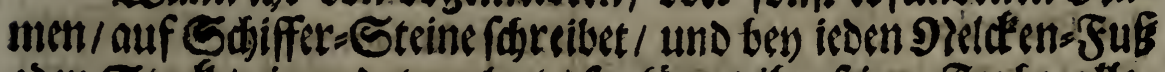

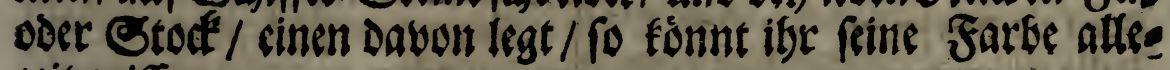
seit wiffen.

Stre fonnt aud bie Namen / fwelde man fatonetliden bengelegt/ belbalten/ und auf obenangezeigte 23 eifenur cine

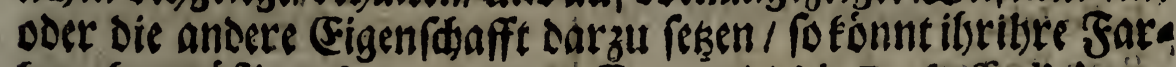
ben ebenmábig erfennen: zum Excmpel / Dic Ducheffe d’ Avaro iff tweiß und 2 ioltrautm gefiurengt (blanc panaché de violet) getbet ifr nod Diefen (Eigenffafftliden Namen Darzu / bonne veuve, Dab dá B. Blane, Das V. aber Violet, Bidloraun brdeutet / fobee baltet ifre auf befagte 23 eife die Farbe: alfo Die Sainte Agnesiff

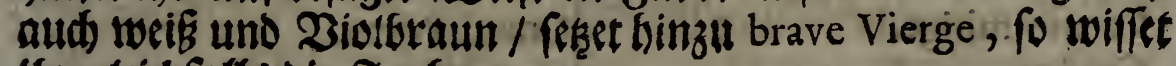
thr gleidffalls dis ?ararbe.

3u bem Commandeur, twelde weiß uno rotb gefprengt ift/ (blanc panaché derouge) Pe(set nod) Diefe $230 r t e ~ l i n i z u /$ bien reglé,und zu Der Juno: , tweldie aud locíf und roth iff / belle réveufe, fo bleiben aud) Die Farben und Namen: Mit Denen andern

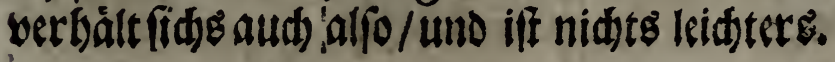

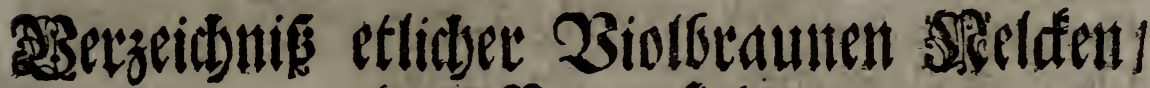 Deren Tamen find:}

A.

Apelles,

$\checkmark$ Alteffe:
Aftre du monde Violet. Archiducheffe. Bb

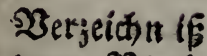
Derer $\mathfrak{B} 10 \mathrm{~L}$ braunen Neld́tat. 
Aftropole.

Archevếque.

Arcode triomphe.

Alidor.

Aurore naiffante.

Artamene.

Amiral Tromp.

Belle Déeffe.

B.

Bâton Royal.

La Brafarde.

Beau de nos jours.

Belle de jour.

BelleHortenfe.

Belle Agnés.

Belle Iris.

Beau Routier.

La Conquête.

\section{C.}

Conquête de Bacquelan.

Conquête dú Sautoir.

Carme mitigé.

Catalan.

Conquête d' Eftrées.

Comteffe.

Comteffed' Ether.

Cour Royale.

Charles d' Autriche.

Charles le Hardi.

Conquête Verdier.

Charmant d' Hongrie.

Conquête conftant.

Conquête del' Aube.

Conquête des prés.

Duc de Longueville.

Duc de Guife.

Disputé triomphant.

Le Dauphin.

Dorimene.

Ducheffe de Boheme

Duc de Candale.

Duc de Milan.

Duc de Duras.

Dauphin triomphant.

Eleué d'Eftrées.

Etendard du jour.

Excellente Bury.

Favory.

Florebertine.

S. Fouray.

F.

Grand Conquerant.

Grand Prieur.

Grand 'reaux,

La Gentille.

Grand Céfar.

Grande Beauté.

Grand Noir.

Grand Jupiter.

\section{$\mathrm{H}$.}

leHeros.

le Hardy.

Illuftre Pontoife.

Iditior. 


\section{- zubem}

\section{L.}

Loüs Conquerant.

Medor.

M.

Marquis du Quênois.

Morillon d'Artois.

Morillon Violet.

Morillon fivel.

la Majeftüeure.

Morillon le Fevre.

Maitre des Poltes.

Marquis d'Affentar.

Muftaphà Violet.

N.

Nompareil de Compiegne.

Nompareil Royal.

Nompareil de Rhodes.

Nouvelle Enfrol.

Nouvelle Enceinte.

Olidan.

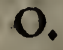

Orpheline.

Primo.

Paftorelle.

Polimor.

Perle Royale.

Paffe-role Violet.

Patriarche le grand.

Prince de Chimay.

Pâle mitigé.

Paon Royal.
Pourpre enfoncé.

Paffe-Croifette.

Princeffe.

Petit David.

Pourpre furpaffant.

Princeffe aimable.

R.

Raviffante Landouche,

Roy des Maures.

Reine d'Efpagne.

S.

Sans fouci.

Superbede France.

Scarbourg.

Superbe Verdier.

Souveraine Royale:

T.

Tertio Violet.

Tréforier.

Triomphe des oeillets.

Theatre du monde.

Tuton.

Unique de Flandre.

Unique Imperial.

Unique Royal.

Unique triomphant.

Victoire de Maftric.

Violet Choifi.

Unique des Couleurs.

Unique Dauphin. 


\section{6}

\section{greue Untertweifang \\ Serzeidinin Derer rotjen Peldêt.}

Serzecinnin Pugute.

Dercr rotf̧en Aimable Orphée.

Sheffen:- Aimable rouge.

A.

Agréable en beautév

Etendard Royal.

St.Felix:

France triomphante.

- B. B.

Balas.

Beau Cramoifi.

Baradas.

Beauté triomphante.

Bel 'inconnu,

Beau threfor.

Brifar.

Belle Ecoffoife.

Baltanie.

Charmant de nos juors,

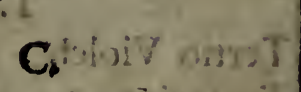

Conquête malin.

Couronne Royale.

Cloris.

Cramoifi Royal.

Cléapatre.

Conftantin.

Conquête rouge.

Cardinal de Boüillon:

D.

Dupe Philippe,

Duc d'Yorck.

Duc de Duras rouge.

Duc d'Anjou.

Elevè des Granges?

Druortian

\section{Géant.}

General de France.

Grand Chambellan.

Illuftre en beauté.

Loiiis triomphant.

$$
L_{i}
$$

M.

Morillon dela Croix,

Morillon Bellone.

Morillon d' Irlande:

Morillon magnifique.

Morillon hardi rouge.

Morillon de Gand.

Morillon d' Efpagne.

Morillon de Mont.

Morillon d' Hybernie.

Morillon dela cour mitigé.

Monfieur de la Ferté. 


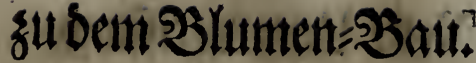

Nompareil le Grand.

N.

O.

Oriflamme.

Le Prince,

Le Prince d'Efpinoy.

Prince des Pais-Bas

Prince d'Orange.

Procris.

St.Paulin.

leRoy d'Alger. la Royale Poncet.

Roy d'Angleterre.

Roy de Flandres.

Rouge Sergent.

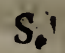

Soldat:

Sortie Royale.

Sophy de Perre.

T.

Tournoifien rouge,

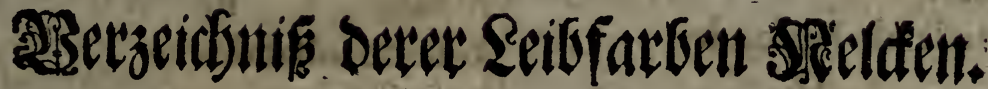

B.

Duc de Florence

E.

Eftat de France.

Flamboyant.

Feu de Ligny.

Feu de Rhodes.

Feu\& blanc.

Grand incarnat.

Grand Cyrus

Grand Etendard.

Grand Albartir.

Grand Turc.

\section{G.}

F. 
198

ఇeue Unterweifung

$\mathrm{M}_{\text {. }}$. $\mathbf{T}$

Monftre pâle.

Tertio de Paris.

Polyphile.

P.

Triomphe Imperial.

Souvage.

s.

v.

Victorieux.

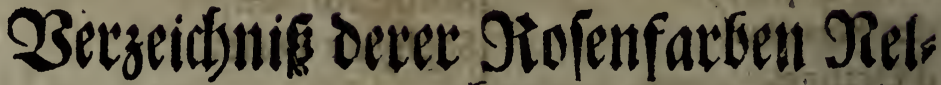

dfen.

C. Madamed'Orieux.

Celimene.

Charles d'Autriche rofe.

Celadon.

Comteffe de Hollande.

Doralife.

D.

$P$.

Pucelle de Flandres,

Rofe d'Hollande.

Rofe d'Intrie.

Rofe Royale.

Rofe permanente.

Rofe de Jericho.

Rofe triomphante.

Groffe Madelon.

G. ?

Reine en beauté.

Rofalinde.

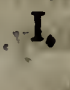

Indicrofe.

Ifabelle.

Madame d'Hunieres.

Monftrïeufe.

Thomas.

$$
\text { M. }
$$

\section{2erzeid)nis Dever weiffen deelden.}

Berzeidnníß Belle Douce. berer weif Blanc racine. fen Nieldén. Blanc de Paris.
B.

Blond de perle. Beaubilanc. Rofe bl'anche.
S.

Salmé. Sylvie.

Tour de Babel. 


\section{gubem Slumen=?au.

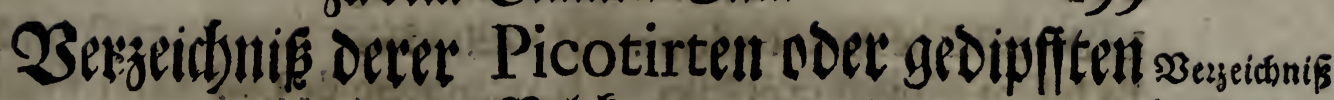 Naldén.}

berer gea

Dipffen

गelćen.
Augufte Triomphant. Aftre du monde. Aftre triomphant. Amiral de Frife. Amarillis. Agréable. Apollon, Alcidon. Augufte le grand.

Belle Aminte.

Beau piqueté.

Charles-Quint.

$$
\text { B. }
$$

Etoile de jour.

Eudoxia.

Eminentiffime.

Grospiqueté.

Indimion.

Jupiter.
Junon.

Lys Parangone.

$$
\text { L. }
$$

M.

Mars.

Mercure.

Maftricoy.

Piqueté Imperial.

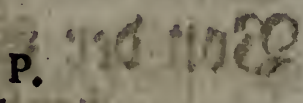

Piquete de Tournay.

Piqueté de Brinche.

Piqueté du Change.

Piqueté gagné.

Pulcheria.

Piqueté Briefmans.

Piqueté pourpre.

Reine Marguerite.

Roy d'Hongrie.

$$
T .
$$

Triomphe de l' Isle.
I.

$$
\text { V. }
$$
Verdure Luifante.
Venus.

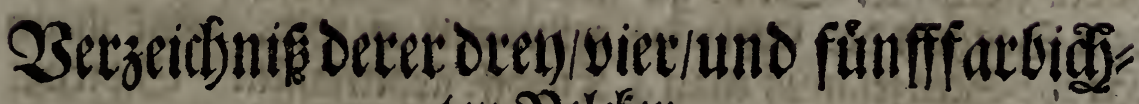

ten Nelcfen.

Tricolor de Compiegne. Tricolor Poncet.
Quadricolor d'Amiens. Quincolor d'Amiens.
Berjeictinl\$

Der 3.4.uno La farbiditen 
LaDiverfite des trois couleurs. Le Zelandois.

La Joliete des quatre couleurs La Conquête de Los, La chinoife.

?!:

Mian twill Durd Diefegegebene 23erzeidniffe diejenige Nela (fen / belde bein Autori entweder aus dem(sedadtnif gefallent odet nod nidt beeant fino/ nidht ausgefdolofen baben.

\section{2ก̋̉ XX. Capifell}

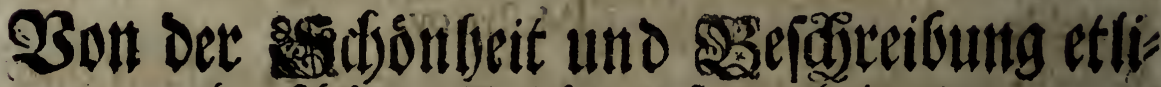
d)er fobonen Petlden infonderbeit. etc.

\section{Binloraune Relden.}

A.

Biolbzaune $A$ pelles, iff cine Duntel Bioloraume Dreltel auf cinct reis Delefen in: A nen Ibeiffen Sarbe / die ibre Blátter felyr ivobl uno fauber

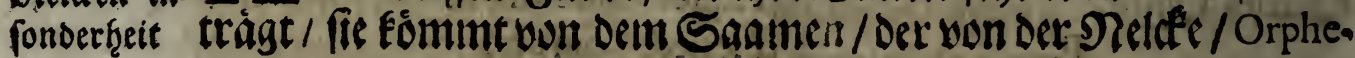
befdrieben. line genannt / gefamlet worden; ibre Pflanke iff zmar zart/ Dod trágt fie cine ziemlid) becite oder groffe Blume: aufibret Stengel mus man ibr 3. Rnopffe laffin.

Altefle, iff eben bon diefer Ssattung / Biolotatmet Farbel

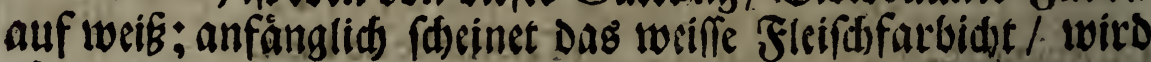
aber zulest volleommen weif / ifre Pflanke iff zart / tino das Sritne daran bleid); fie twiro grof I und ift breit gefprengt/ Das Berprengte doer die Flefen aber ffeben tweitlaufftig bon cin: ander zertheilet. Sie if zu Compiegne aufgetradit/ uno bon Dem Saamen Der Orpheline gewonnen worden. Suf ifrem Saupt=Stengel mub man 4. Snoppfe frebenlafent. Sie trágt Saauten; ibre (Finfalàge aber múfen bor Der Fáulung / Deren fie untertworffen fino / wertwabet werbell.

Aftre du Monde Violet, if bill=purpur-2Biolbraun/ 


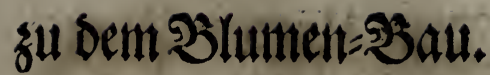

201

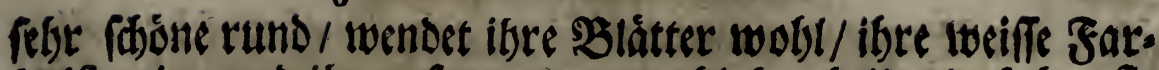
be if rein / und ibs gefiprengtes rooblabgettseilet; Dod bat fie him uno viecer fleine Flectén / die fie aber nidht broüillirt, oder wertwirtet und unordentlid madjen. Stbere 9oflanke iff fard"

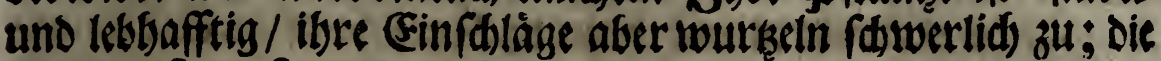
SBlume iff gro B / und muE man Dem Stengel über 3. Doer 4. Sinưpffe nidet laffen. Sonft swirb fie audd Iris pourpré genannt. Archiducheffe, if Biolbraun auf iveiB / fo nods mit bins

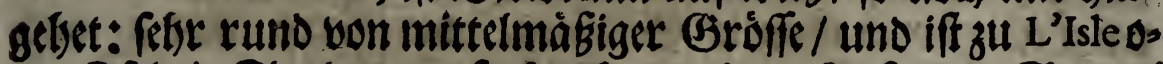
Der Sfel / in Flandern aufgebradts worden: Auf Dem Stenget Jâft man nur 4. Snópfe ferben.

Aftropole, if unvergleidlidf fhoin 2 Biolbraun / auf ciner

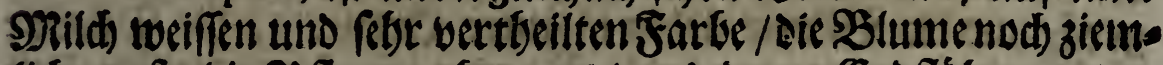
liid) gró : Dic Poflanize aber zart/ und Denen Groffibten unterworrfen: Sie trágt Saamen/ und ibre (Finfdaläge wourkêtin gerne. Sie iff zu L'sle auffgebradit oder gewonnen worbeny und foll nur 3. auf DaÉ Jjödffe 4. Rnúvife belsalten.

Arc, ooer Arche de triomphe, iff yon einer Dundefetin Pur.

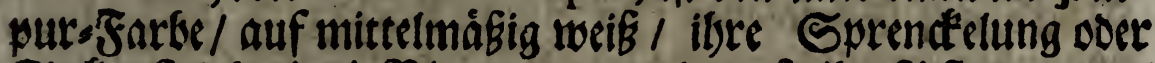
Flecten find breit/die B/ume rund und gro $B$; ibre? flanke zart/

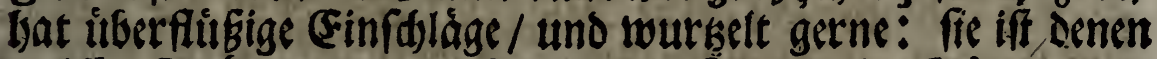
weiffen Flecten unterworffen / weldse fid soie cine siátude ober

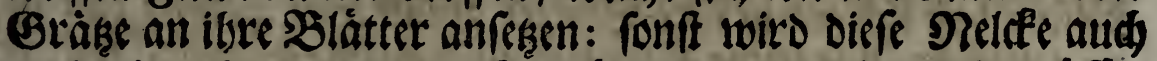
Archirtiomphant genennt: Sie fósmmt von L'sle; und múffen ibr sur 4. Rniveffe gelaffen iverden.

Artamene, if Dundécl Biolstaun / auf ciner rcinen lveifo fen Farte/ und if yon Der Orpheline gewornen lworden: Maan

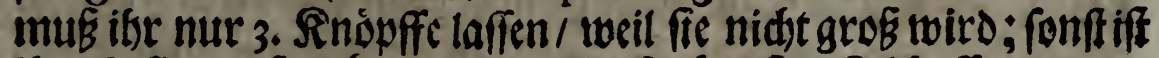

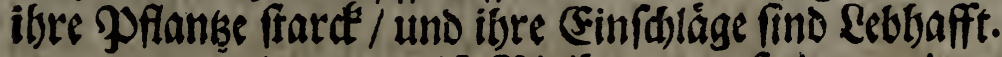

Amiral Tromp, if 2 Bidlbraun auf einer reinen tweiffen Farbe/ und fómumt von L'Isle; ither Blume if grob.

B.

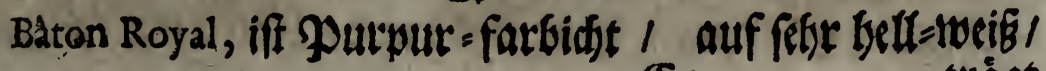
(E) trígt 
trágt eitte Blurite von mittelimábiger Grisfe/ aber felse voluer

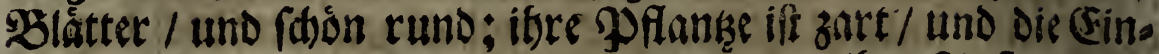
fd)láge fdurad) / befommen aud) gerne Den gelteren Sioft und die Grábe : Nan mué fievor denen lesteen Siegen des Sorbfts uno

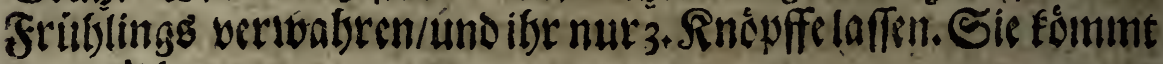
voin L'ssle.

Belle Agnes, ift eine alte Neldfe / bat wenig 2 Bolbraune auf einer mittelntábigen wociffen Farbe; fie fpringt gerne auf/ triagt aber Dord leidetlid Saamen/ Dannentsero man fie aud bebalten foll; Diefer musi ınan 6 . Rnopffe laffer.

Beau Routier, iff $\mathfrak{B}$ iolfraun auf einer rcinen weiffen Fur : be / und fómmt bun Amiens aug ter Picardie; itbre Blutne if grof / unD Die Blátter ffetsen in guter Oronung; die Pofianbe

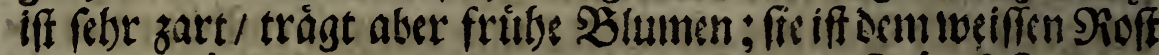
uno der Sáule unterworffen; man làft ibr 5. Rnópffeffebsen.

\section{C.}

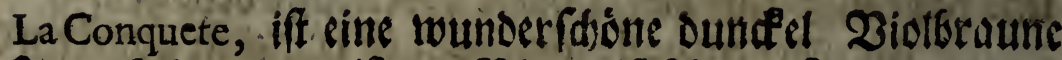

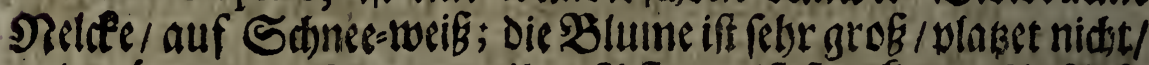

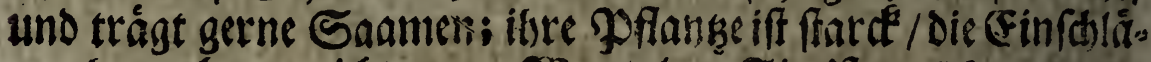
ge aber nebmen nidht getne 2sutheln: Sie iff zu Isle grtwon= nen worden. $23 a n n$ cin Fet)er an ilher Slume iff/ to iff is

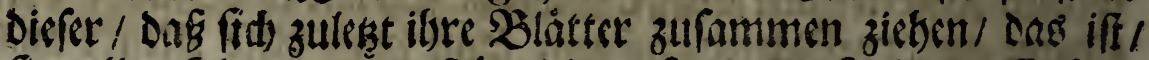

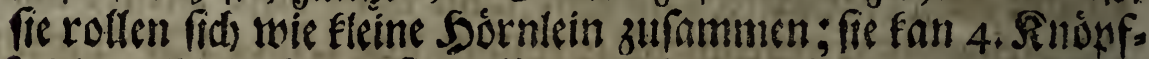

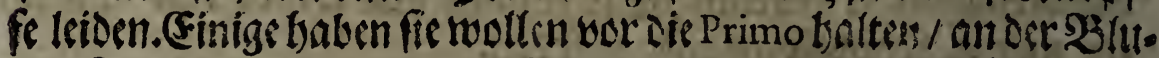

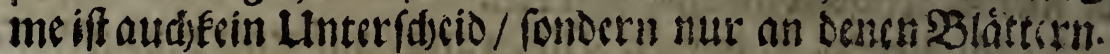

Conquête Bacquelan, if Purpurfartid)t uno iweí) aGer fethe zertbeilt und breit / Desn weiffen Sioff unterworffen; bie

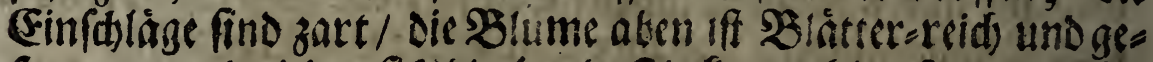
fprengt / und zieben fid) Dic bunde Flefern Iwohl auf denen SBlat= tern binauf: fie wiro zu L'sle gefunden. SRan láf ibs 4. o. Det 5. Rllipipfe.

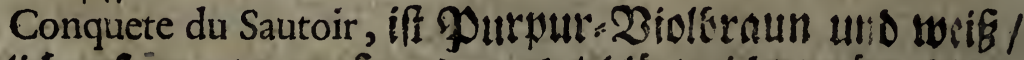

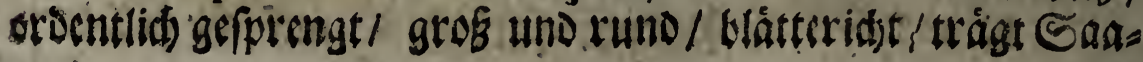




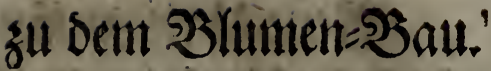

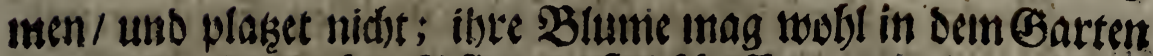

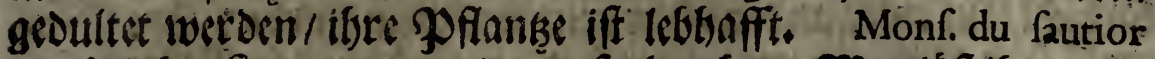

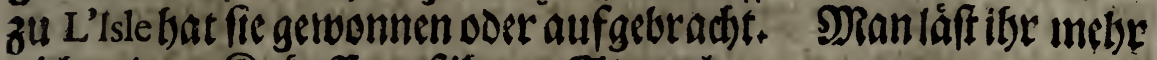
nid)t als 4. Snópffe auf itisem Stengel.

Carme mitige, if suncécllopurpurfarbbidt / auf einer init.

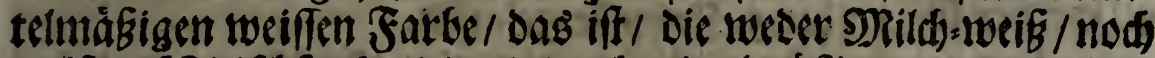

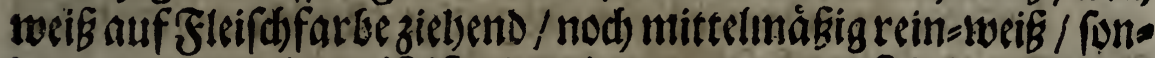
Dern nur gemein weis if / Damit / wann man fid Des 230 orts

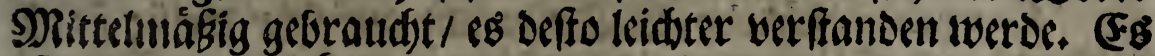

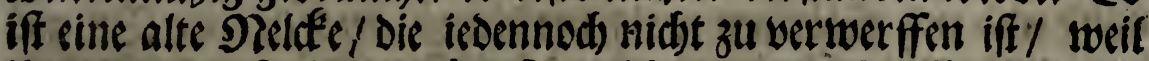
itber Pourpurf farbe oundetel iff / weldese man nidst allezeit ande. nen פReldéen findet.

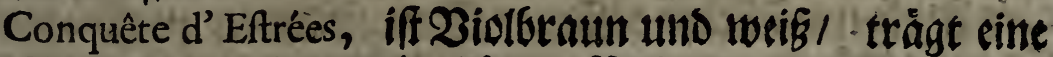

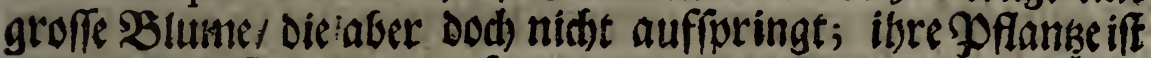
zart. Sie iff zu L'Tsle aufgetbradet roorden / und ean / waant fie twobl inadt genowmen toirt / Saamen bringen; man ın il)e 4. Inippfe lafien.

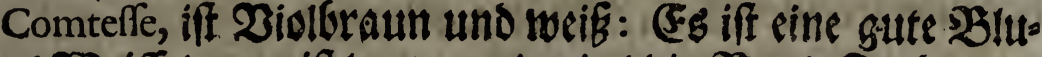
me/ Da\& 23eiffe daraniff lauter und rein/ Dic Sunde-Sarbe bDer

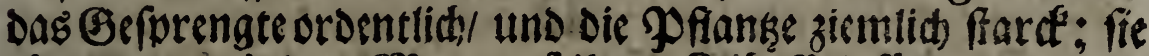

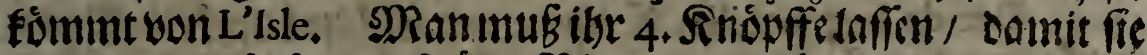
Gelegenbeit babe cine fdjome SBlume zu treibem/ und Eaamen fुu tragen.

Comtefe d'Ether, if won einer violbraunen uno mitte'máf:

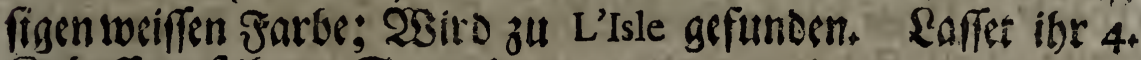
Sinjoffe auf ibrem Strmgel.

Conquête Verdier, if Domntéleviollbraun auf cinter reinem

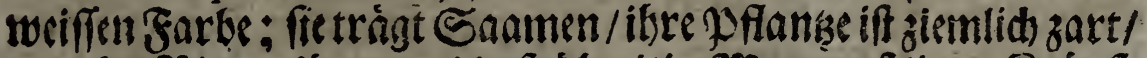

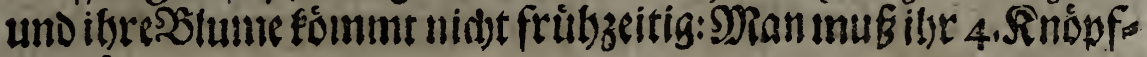
felaffer.

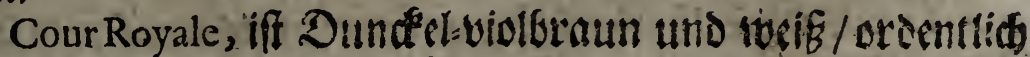

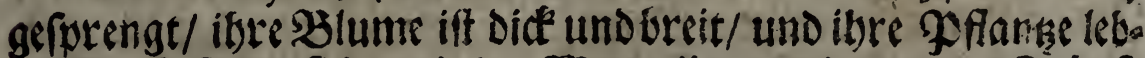
bafft: fie finser fid 3u L'Tsle: פ̧ann ibr weniger als 6. Sinopfs

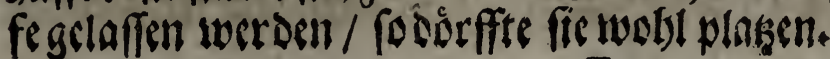




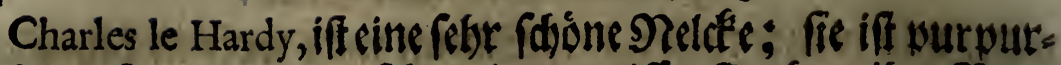

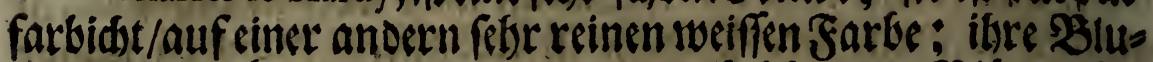

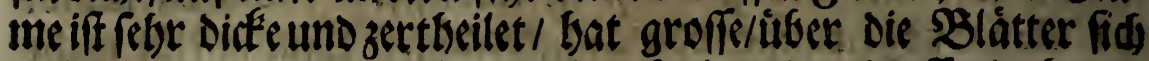
zietsende / uno mie ein Getwebe burds simanoer lauffende Gunde Fleeten: fie wird zu L'Isle gefunden; ; Auf Dem Saupt = Sten= get werden ibs 4.0Der 5. Snopyfe gelaffen.

Conquête conftant, ift ében bieienige / woldde man Medor nennt/ savon bernadi foll gebadit werben.

Conquête de L'Aube, iff 2 iolstbraun auf feftr tweis; fie if rund und mit sbtáttern wobliberfeben / autd if ibse Sblume

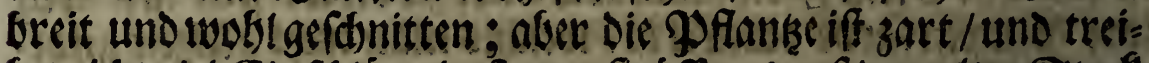

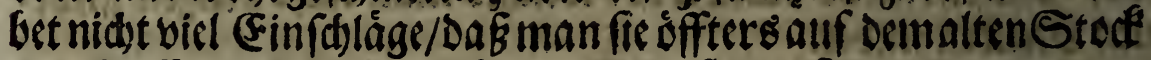

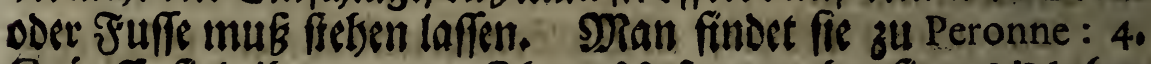
Rnópffe fine ibr genug. Stheren urfprung that fie zu L'Isle ben Monfr. L'Aube befommen.

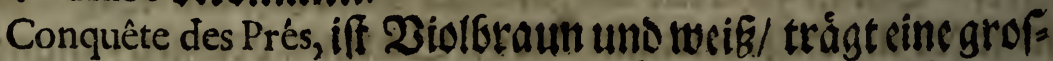

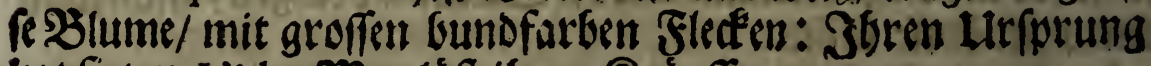

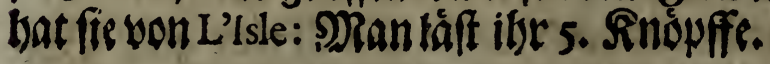

\section{D.}

Duc de Longueville, iff won ciner foldien suncefeln ఇours

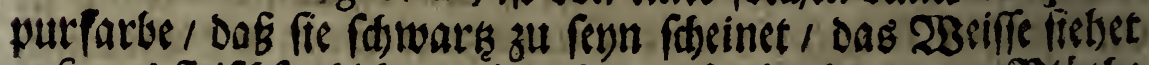
anfangs feifdffarbidft/ twird aber nadigelbense in Der SBiuttle

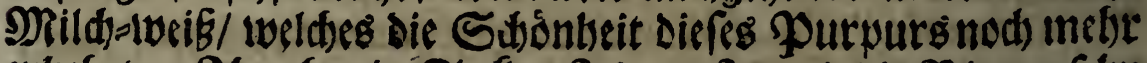

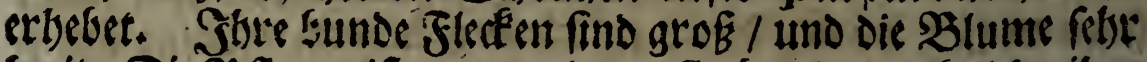
breit; Die DPfange iff zart/ und eas Grime Daran Gleit;; ibre.

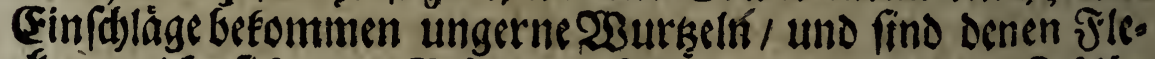

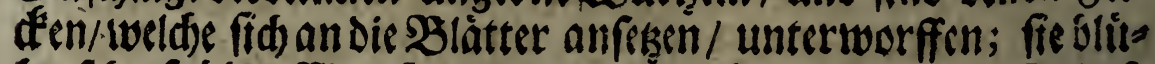

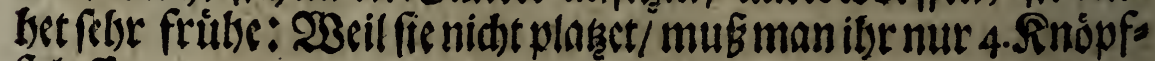
felafferi.

Ducde Guife, iff feftr fhón purpurfarbsidt/auf rein 23eif;

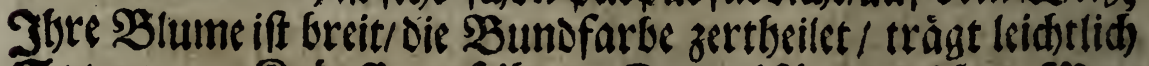
Eaamen; 4. Rnoppfe auf itfrem Stengel f findet fie zuL' Isle. 


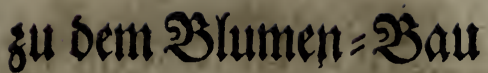

Difputé triomphant, iff von einer ziemlid) reinen 2 iolbralls nenefarbe / auf, foon tweis: ibre slume iff nidst grobi cero. wegen man ibr nur 3. Snopffe laffen mus.

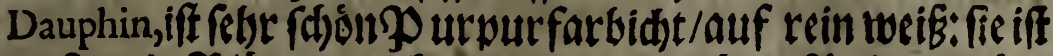

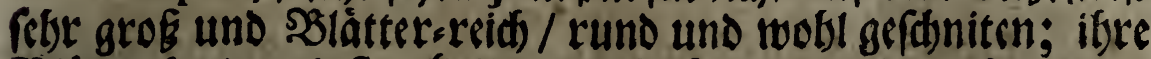
Blátter breit uno ftard" ; ibre (Finfdláge wourscln nidyt gernel und treiten ibren Stengel vor Der Beit: Die Bundfarbe zies bet fid woblauf die SBlátter binauf. Sian laft ibr nut s. Snopf fe.

Dorimene, if Purwurfarbidt / auf rein wcif / die fotre grof blutbet; ibre Sund farbe iff zertbeilet / Die Prianke aber

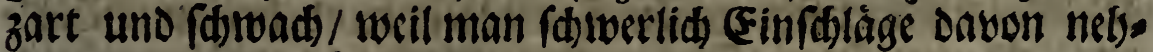
inen fan. Sie if bon Dem Saamen der Orpheline gezenget / uno won Compiegne gefommen. 2n 4. Rnópffen bat fie genug.

Ducheffe de Bolieme, iff oundel Biolbraun/ auf fojon weib. Sie iff in ibrer $\mathfrak{B}$ undfarbe nid)t felye zertheilet / aber

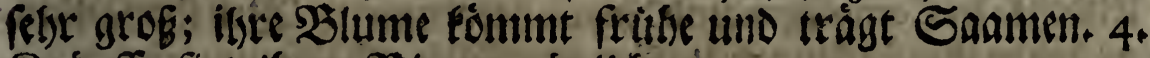
Snopffe find ibrer Blume nitslids.

Duc de Milan, ift entweder Duncfel Bioloraun/ oder lidst Ourpurfarbid) / auf fdón weif / ibre Blume ift grof uno rund / SSlatterreid) / uno bat groffe Bund farbidte Slecten; ils:

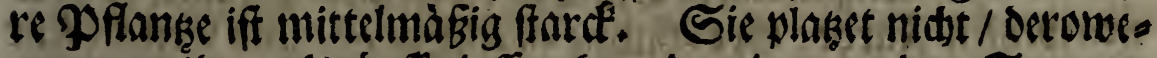
gen man ibr 4. Sinopffe laffen fan/ Dantit man Den Saamen Dabon befommen moge. Man finort fie gemeiniglid z"l L'Isle.

Duc de Duras, iff febr fajon Biolbraun uno Iveís ; ibre Blume iff gemeiniglid grofi; dic greffe bund farbidte Slect"ut ordentlid) gezogen/ und ivobl zertheilet: Die Pofinne ift faft zart/ Das Bruthe Daran aber fdón : Dic (stofiche uns ocr treiffe Roft greiffen fie leidttich an. Sian muf fie nor fádididion Re: gen vertwaben / abfonderlia Ioann man will bab fie Saamen bringen folf: Raffet ibr 4. Rnopffe.

Dauphin triomphant, if cine folle neue Mrelfe. Manfagt int2sciffes fen febr foon/ und dic Diolbraune Farte uberaus 
fieblid//fe rev iwobl gefdenitten / uno habe groffi gundfarbidste

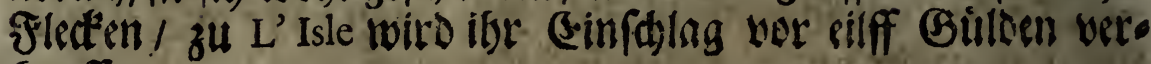
Eaufft.

E.

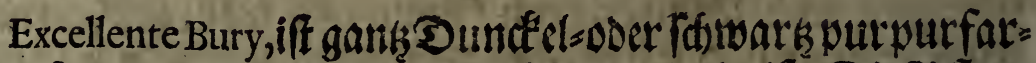

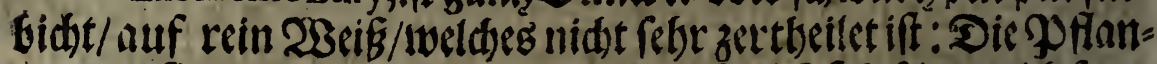

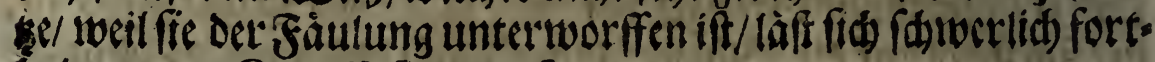
bringen: 4. Rnopffe find yor fie gemug.

\section{F.}

Florebertine, iff cine fefge fabone Duncelepurpurfarbidte

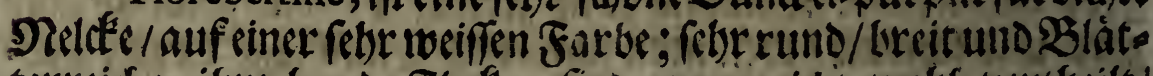
terteid); ifse bunde Flecten fins zwar nid)t wobs wertbeilt

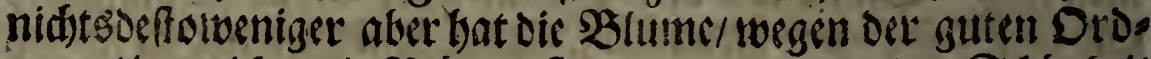
nung/in welder sie sblätter ffetyen / uno roegen ser Sdjónbeit ibrer Sarben / sinen groffen (Glants und Anfebn : SRan Ean fie leidtlid zu Compiegne und Noyon befsumen. 2Beil ifresp flan:

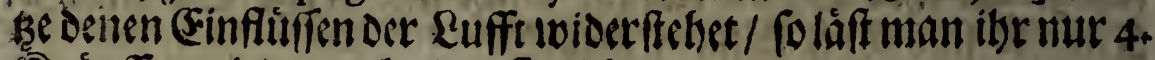
Sinowffe/ und dennod) plasetfie nidit.

\section{$\mathrm{G}$.}

Grand Conquerant, iff Oundelebislbtraum/auf einer faff reit nen weiffen Farbe; ibre SBlume iff fets grob/ und weil fie fegr

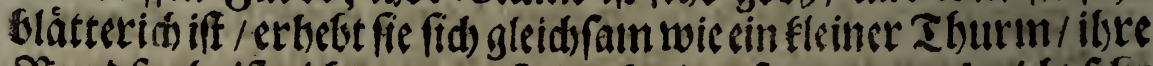
Sund farbe if nid)t gar grob boer Greit ge(prengt/audd nidst frbe gertbeilt/inderm fie lsin und wieder fleime Flecten Dar ztwifden auf benen SBlâttern bat / Die aber die Sdionbeit itser Slume nid)t

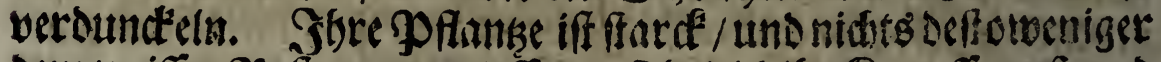
Dem weiffen SRoft unterworffen: Obgleids ibr snouff grog uno

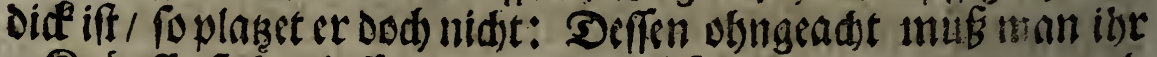
5. Intopfe frebenlaffen / zufeben ob fie Sanmen tragen wols li,

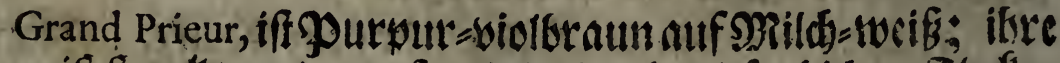

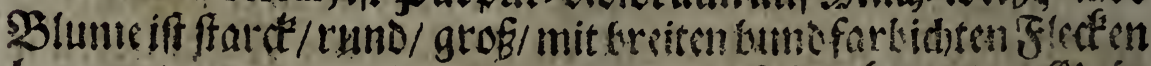

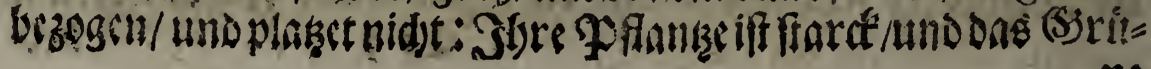




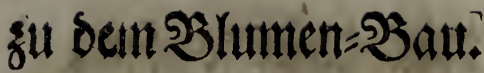

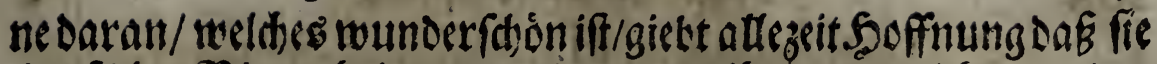

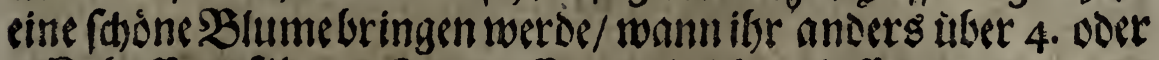
5. Snópfe auf itbrem Saupt=Stengel nidet gelaffen werben.

Grand Preaux, weldef fonft audd) Paon Royal genennet wires.

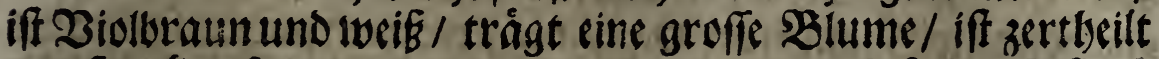

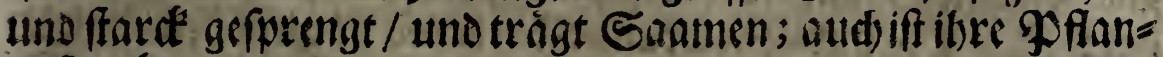

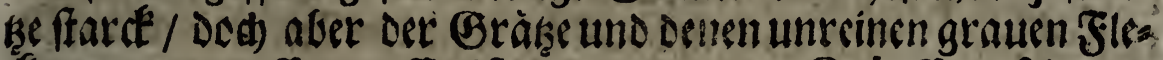

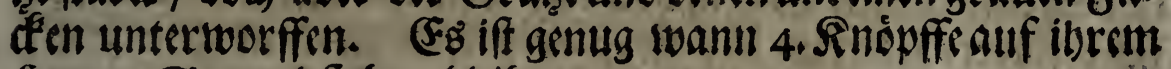
Saupt=Stengetl fitlen bleiben.

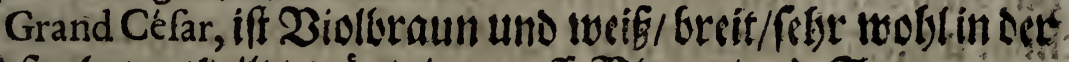
Sound farbecuertbeilt/ trágt eime groffe Blume/und Eaamen.

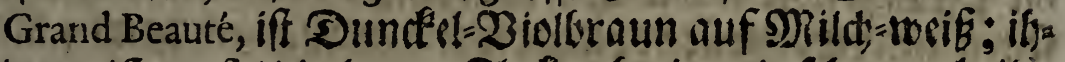

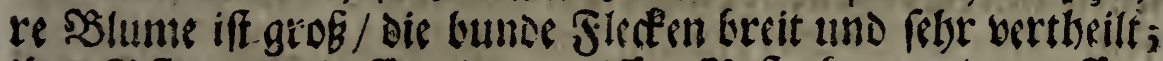
ibre Poflanke lebbafft / Denn weiffen SRoft aber unterwerffen.

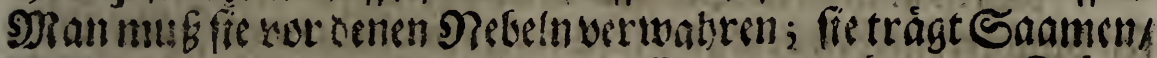

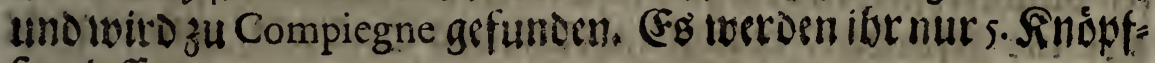
fegelaffen.

Grand noir, iff yon cincr ouncteftn \$ourpurfarbe / grob uns

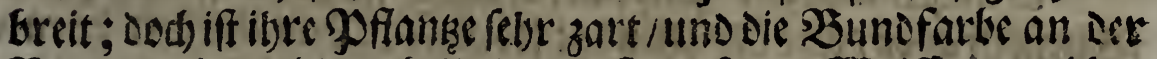

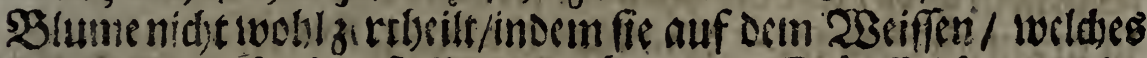

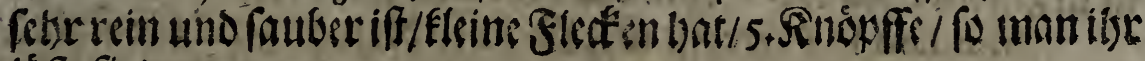
láft /fino genug.

\section{I.}

IIlustre Pontoife, fonft le beau de Verny gentrint) foumit

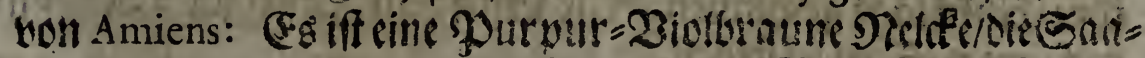

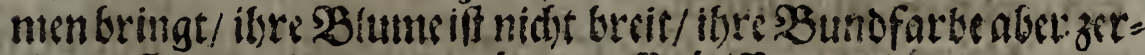

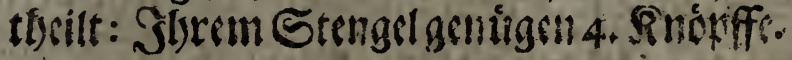

Iditiot, ifferen sicienige / melde man fonft Tertio Violet

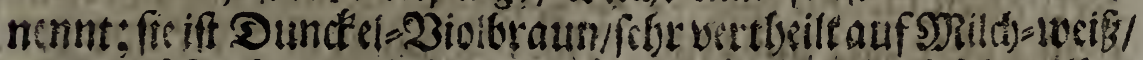

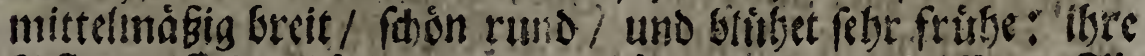

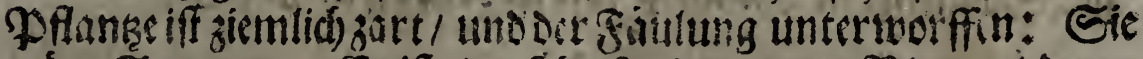

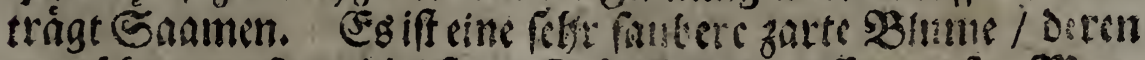

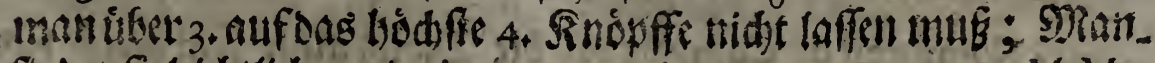
finder fietleidjtlid) ju Amiens. 
208

Neue Unterweifung

M.

Medor, if lidet ober bellwutrputrfarbiddt/ / wirb fonff Conquette Conftant genamnt/ Dierweit fie Monfr. Conftant yon Compiegne bondem Saamen Der Orpheline getwounen uno aufgecbradts hat; Shr Purpur=23iolbraune Tarbe/ ob fie gleidbetu/fo giebt

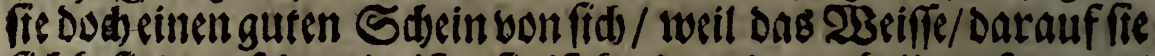
fid befindect / fethresein iff; fie if breit und zertheilt gefprengt/

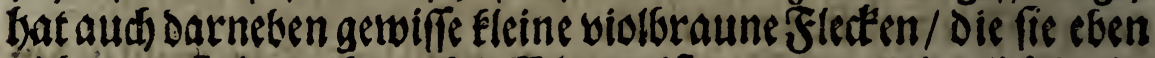
nidst ungeffalt madien: itbre ' $B$ lume iff tuno/ uno ziemlid breit/

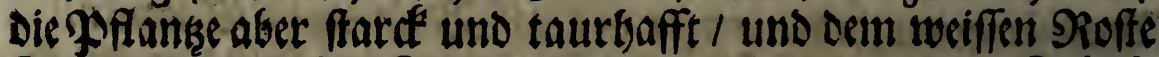

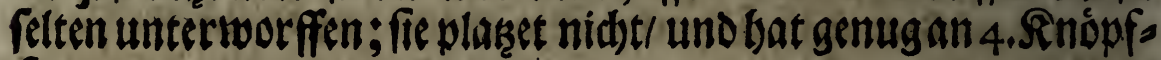
fen.

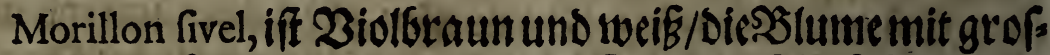

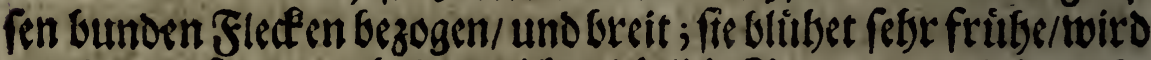
zuL' Isle gefunden / bringt nidft teidftlid) Saamem/, und braudbt mebr nidtat als 4. Sinópfe.

La Majeftüeufe, if Pourpurfarbidit/ auf rein weif ; SGre

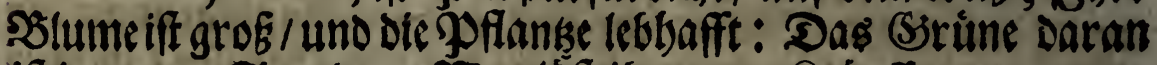
if ingutem Stande. RRanläft ibr nur 5. Rnépffe.

Morillon le Fevre, iff cine Nelle / Dieman zuL'Isle findet/ fie trágt fobon Diolbraun/auf einer zarten oder reinen tociffen Farbe; die bunde Fleden fetben febr zertbeilet aufifbrer Blumel welde breit und runo iff; Stgre Pflanke ift ziemlid) lebbafft/unt

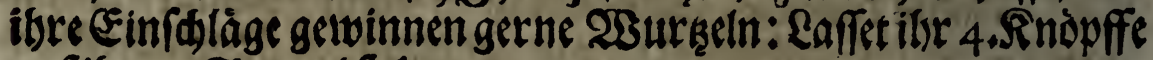
aufitgrem Stengel freben.

Maître des Poftes, iff 2 iolbraun und Iveig/ mo fetre breit.

Muftapha Violet, 'iff bell Biolbraun / aufeiner foonen und

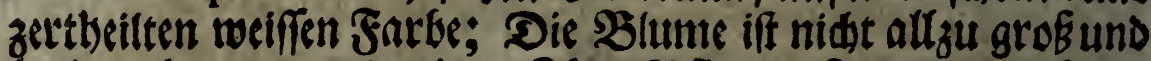
breit / aber zart und rein. Store Poflange if zart/ uns, Grin get Gaamen: fie bat an 3. Doer 4. Snópfien genug.

\section{N.}

Nompareil de Compiegne, bie Bioltbraume Farbe iff ferr betl 


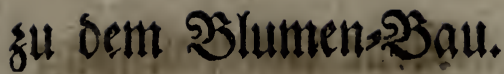

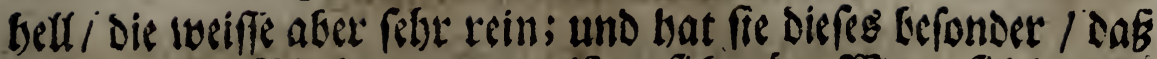
fie even foviel 3 iollbraun als wei

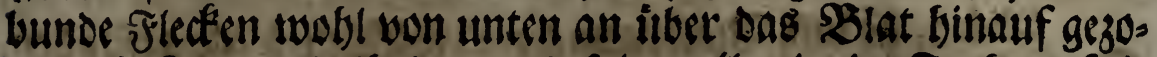
gen / fo find es die ibrige / und folget allezesit cine Sarbe auffoie andere / wann nemlid ein violbrauner J̈leféten geformmen / fo

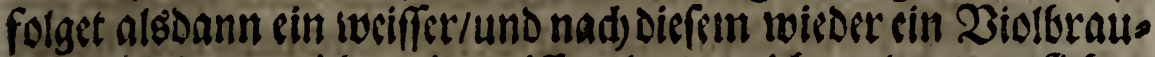

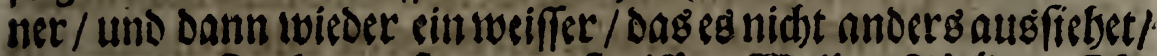

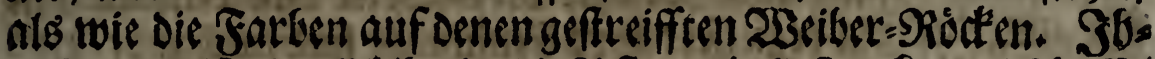

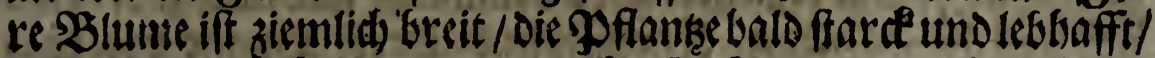

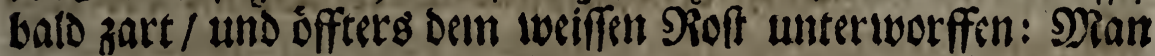
fónte ibr nidt unbitllig. Den פaumen Der Morillon geben / weil

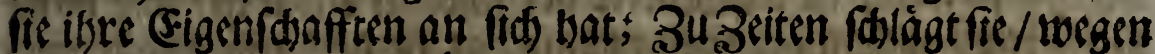

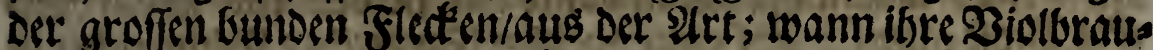
ne Farbe Pourpur oder oundéseler waire / als fie iff / fo wäre es

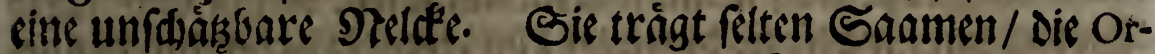
pheline iff itsre S) Sutter/ / orr Garten Des Serrn Conftant, Der Drt iferes Sereommene. 4. Snopffe find ibr genug.

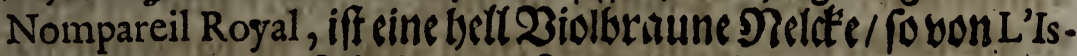
le gefoummen und auf Sdjncetweig grzogen iff/ bie bundec Farbe

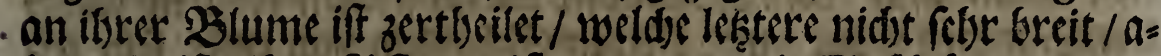

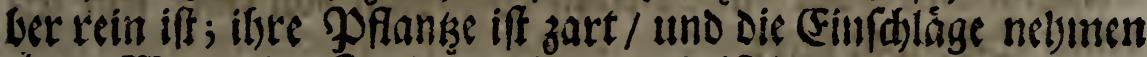
gerne 2Burkesen; fie Nlaget nidbe / und iff es genug twann man ibr 4. Snóviffe freben läft.

Nomparcil de Rhodes, if eine $\mathfrak{B}$ (tume von siner wunder fras

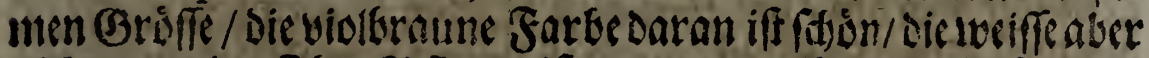

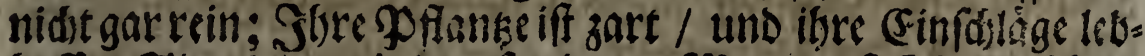

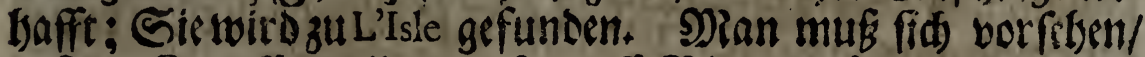

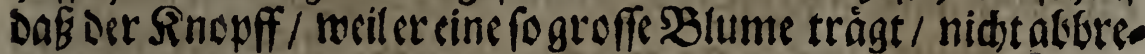

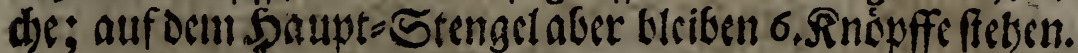

Nouvelle Enceinte, ibr פrame (Die ncue fosmangere Nets

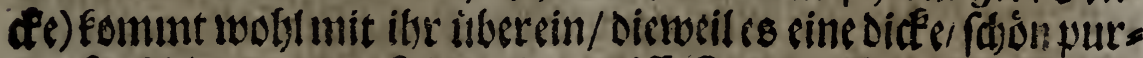

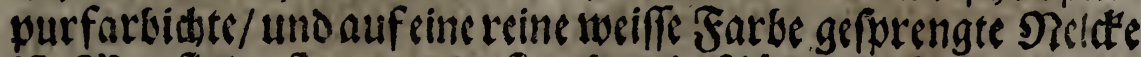

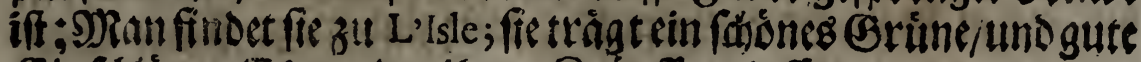

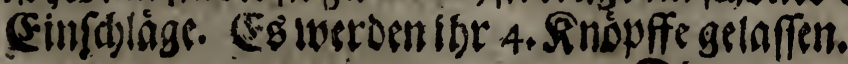

$$
\text { Do }
$$

o. Oli- 
Olidan, iff beft Biolbraum/ uno twird zu L'sle gefunber. Sie fidft auf Der Milds=lveiffen Sarbe / fo fie trigt / fetsr wobli

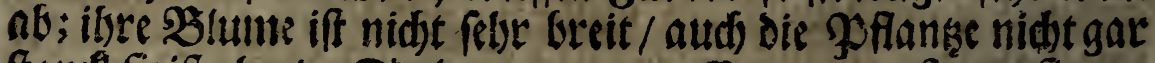

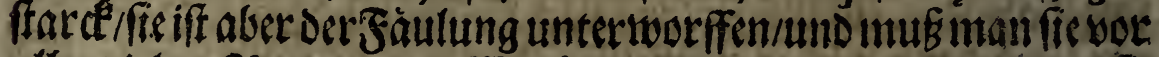
allzuvielen siegen oder Wraffer berwabren / in Dem nean fie

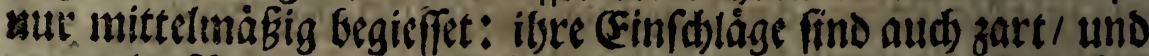
wurseln faswerlid; 4. Sinopffel fino ibrer solume vortrágs lid).

Orpheline, if bic SRutter ber fogonen Neldet! / uno ob fie

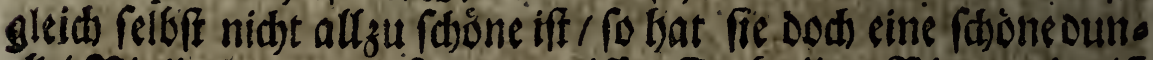
fiel 2iolbraune / auf einer weiffen Farbe/ibre Slume aber if

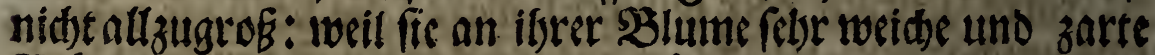

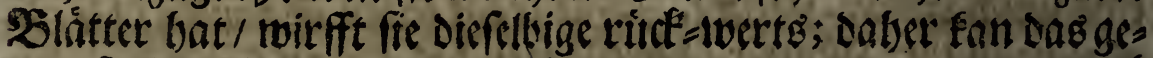

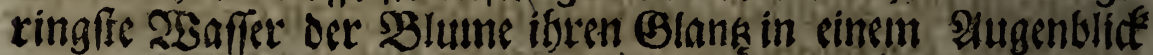

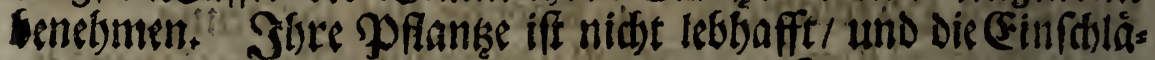
ge gewinnen feine 23urbeln / man zwinge fie dann durds s) Rits tel: Man láffet 7. biß 8. Snopffe baran ffeben/ weil fiel leidhts

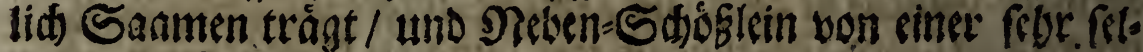
tenen Edisonbeit gisbt.

$$
\text { P. }
$$

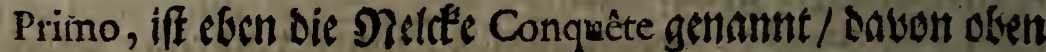
getmerdet worden / bat eben diefe Sarben/ eleen das weiffe / e ben Diefe Eigenffofften/ nur dab fie in Denen Slättern unters fojicden fino / der Lunterfdico iff aber fo flein/ Dak man feinen arimen madjen sarff.

Paftorelle, iff Dundel Biolfraun auf Yurpur zietend/uno

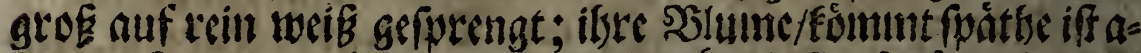

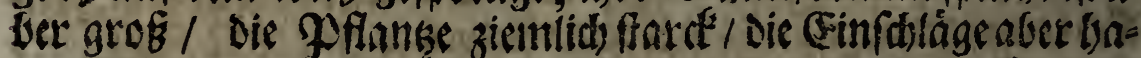

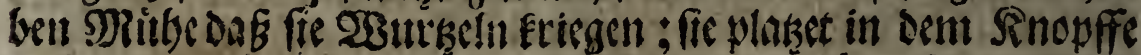
aufiwann man ifse oeten nidst 6 . läft; uns trágt felten Sas. 


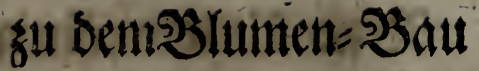

Itten. Dumit ibre Blume seffo eber blibe/musman fie zu Bcis. ten all die SMittags: Sonne fesen.

Polimor, Diefe blitbet eben um die Beit wie die Primo, if

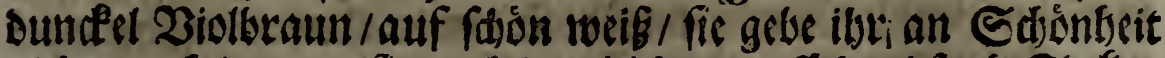
nidsts nad) / waun fie aud orrgleiden groffe bumofarbe Flecten batte / uno wate wobl nod fabner/ tocil fie nod breiter uno slátterider als die Primo iff iftere SBlume bridt wie sin Sburm lein betwor / if aber febr twenig gefprengt: es iff die rundeffe fo. main baben fan/ ible Spflanke iff zart / Das Brime Daran iff ztwar lebbaff / wird aber bon benen (5roflobenangegriffen / tund Die (Finfd)lăge berlieren meiftentbeils: ible Sirafft/weil fie Der Fáule unterworfen ift; of fie gleid nid)t plaset / fo werden ibs cod) 4. bif 5. Inopffe gelafien. SRan trifft fie zu L'sle an.

Perle Royale, fonft Tuton genannt 1 if voll eimer fotonett.

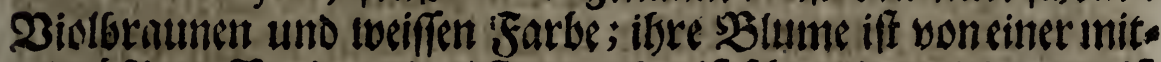

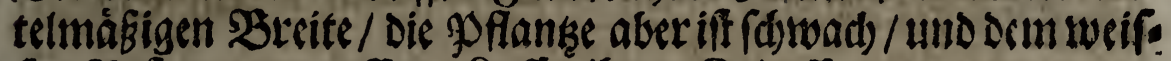
fen SRoft unterworffen. Saffer ilsr 4. Sinopff.

Paffe-Rofe Violet, iff fhón Diolbraun uno torifi / breit/ aber flads; Die bunofarbe Fleden netmen unter ifsen Lrs fortung/und zieften fid) wobl auf bas 2 lat binauf; fie platere

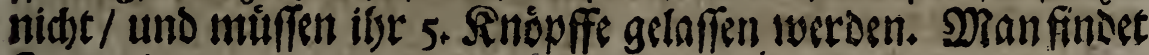
fie zu L'Isle.

Patriarchele Grand, lvelde fonft aud Grand Patrice gctuannt wird / ift Dundfel=2Biolbraun / coer bill = putpurfarbidbt/ auf felor foon tweif : Die Nelde iff febr grof / aud) breit gcfprengt; Die Pflanke if zientica) zart / und dem toeiffen sioft unter. worffen: An 4 Sinopfen bat fiegenug. Sie iff zu L'Isle aufges bradjt worden.

Pâle mitigé, iff cine Slule e/die der Carme mitigé ganth gleid

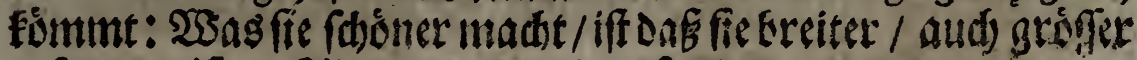
efferngtiff. Sie kiro zu L'Isle gefunden.

Prince de Chimay, if fell=purpurfarbidt auf Mild:twcif́; Sbre⿻上lume bat nuc cine mittelmásige Breite / ift aber gut

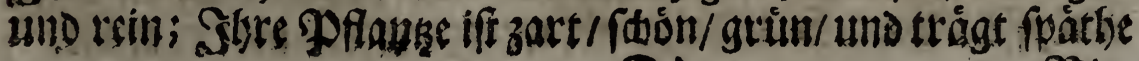




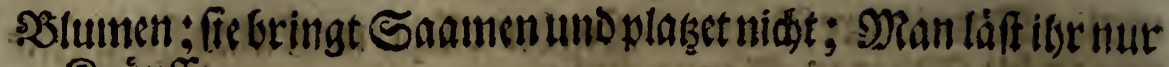
4. Rnupffi.

Pourpre furpaffant, iff febr fabin purpur farfidit nuf MR ilds.

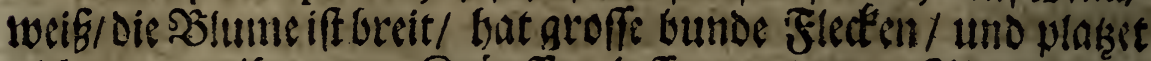
nidet / wann ilgr nur 5. Snopffe getaffen werten. Sie twird 34 L'Isle angetroffen.

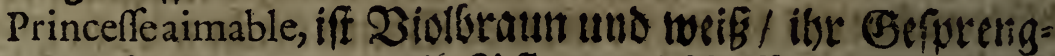

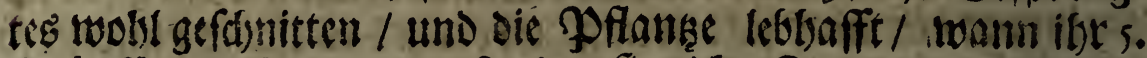

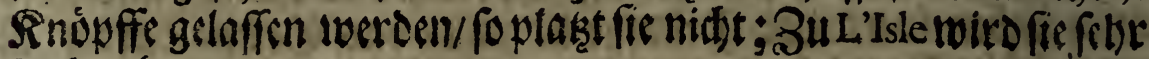
bod getyalten.

R.

Reine d'Efpagne, iff befr 2 Biolbraun auf fajón tweís; Dis SBlume ift mittelmábig breit / Das Befferengte grob / aber nidst wohl abgefondert woer zertheilt; Oie PPlanke if zart/tund wiro zut Amiens gefunoen. Salfet 4. Sropffeauf itzerm Stenget fiteben.

$$
\text { S. }
$$

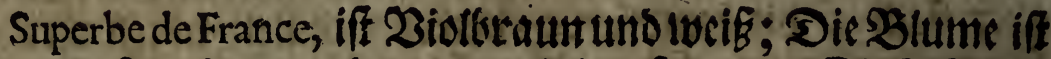
ztwar nidbe febr breit / aber ordentlid) gefprengt: Die SPFlanke

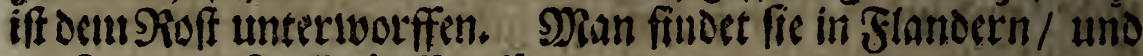
mus it)r 4. biB 5. Sinopffe laffen.

Scarbourg, iff fidon Dundelfat6idjt/ traggt eine freite/ auf

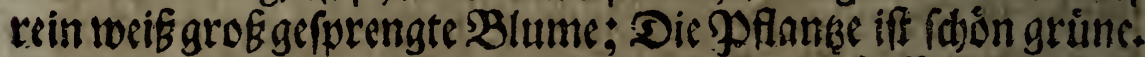
Sic plaset nid)t/man bat Saamen von ilbr zu boffen / uno láft ithe 4. bieis 5. Rnopffe.

Superbe Verdier, fat cine febr groffe dicfe S1ume / if $23 i v /=$

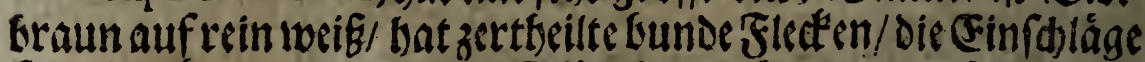

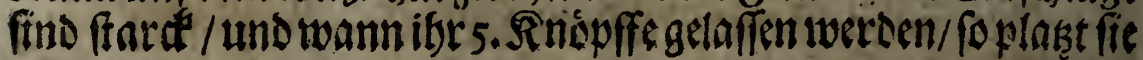
nidit.

Souverain Royal, ift cine groffe 2 iotoraun und rocißgge-

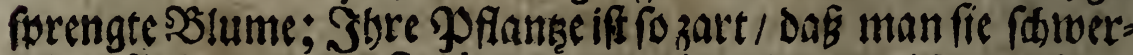
lidi) aufbringen fan; fit formme von L'Isle, plaket nidit an ifren Snopifen/woamn fie anders nict weniger als 4. ODer 5. tràgt. 


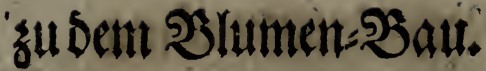 \\ T.}

$2 \mathrm{I} 3$

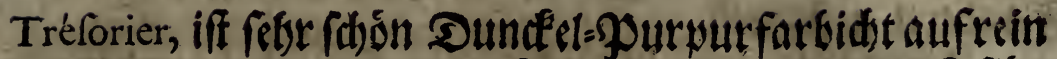
woik / und wiro zu Compiegne gefunden: Stgre SBlume iff febs breit/ oeren sunde Flede'en fid) woblauf diesBlätter binauff zies ben : V3ann 5.00er 6. Sinópfe alf ibrem Saupt-Etengelgse laffert toctDen/fo plakest fie nid)t.

\section{V.}

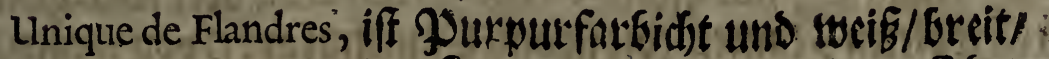
uns, roobl getbeilet; meu bat fie zu L'Isle aufgebradte. Stret

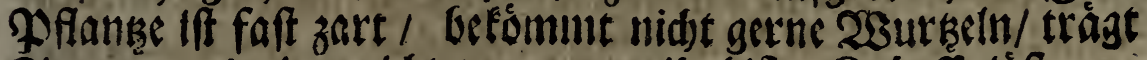

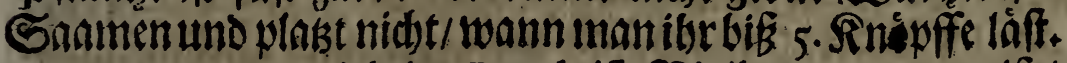

Unique Imperial oder Royal, if 2 ioltraun uno meiß / Der

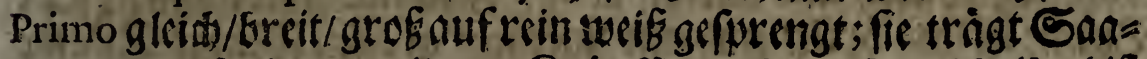
tmen/ uno foringt an ibren Sinipfoin nidst auf/melde ibr/bis auf 4. oder 5. nidst follen genommen werden.

Unique triomphant, iff $\mathcal{B}$ iolbraun uno rocif / grof uns or: Dentlid) geferengt/ uno twiro zu L'sle angetroffen: Stgre Pflan.

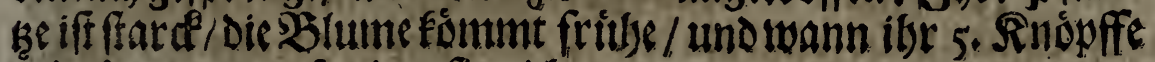

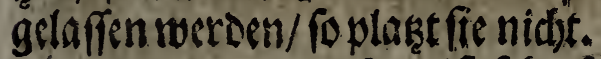

Victoire de Maftric, iff febr fidgón Putpurfarbidst auf rcin weib/ welde man neid Erobetung diefer Stadt aufgebradtet

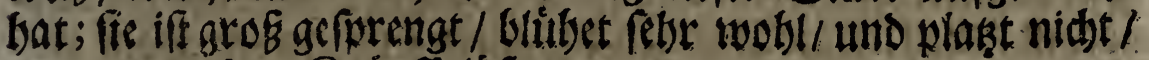

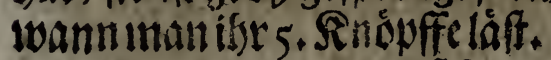

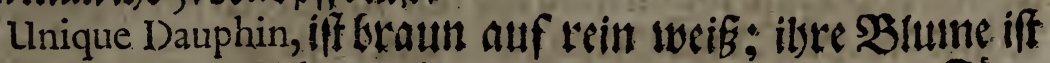
Eleinaber zart/ wie nid)t weniger aud Der Stengel/ Der Der Fauls lung und demen Erd = Floben untertworffen ift. Man imus ibe nur $3+$ Sinópffe laffen.

\section{Retie seeldert.}

A.

Diutfie Mel=

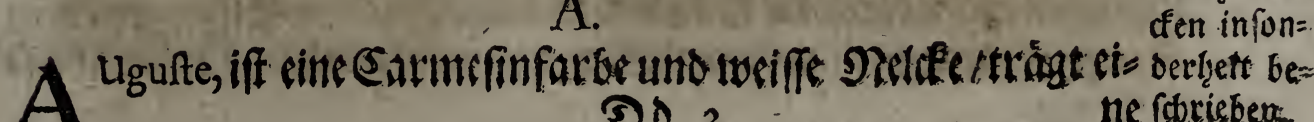
A DO $_{3}$ ne forricber- 


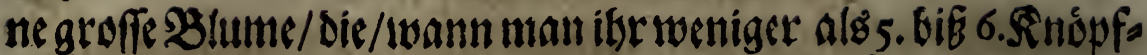

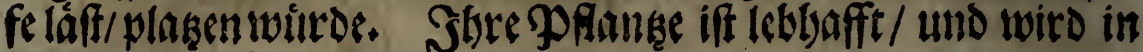
Ftandern gefunben.

Aimable Orphée, iff aud) Earmefinf fartidift tno woeiB; ititre

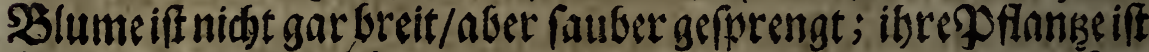

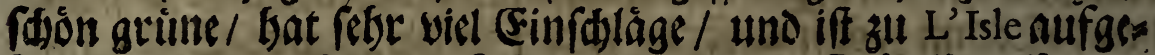

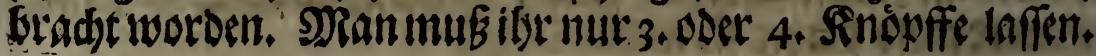

\section{B.}

Beau Cramoifi, fonft Grand Chambellan oder Balas genantut/

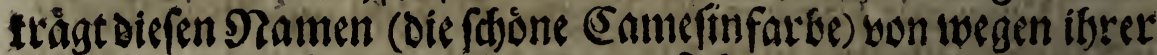
Farbe/ Dababer bat fie beronders/Dag ibre weiffe Farbe mit tem

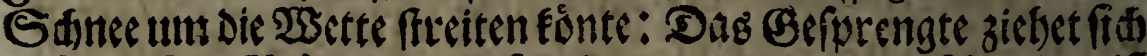

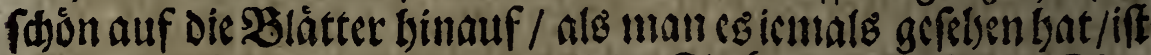

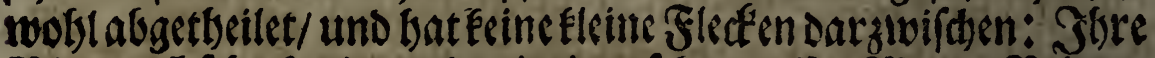
Bblume iff felse brcit/ und mit einer felog groffen Menge 2Blätter

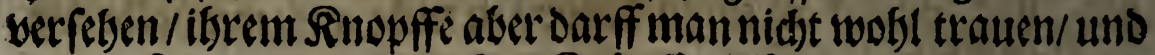

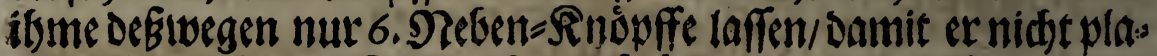

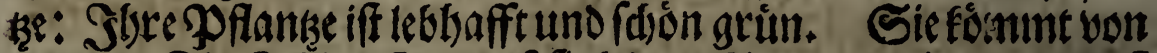

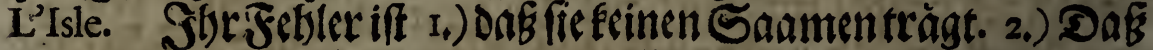

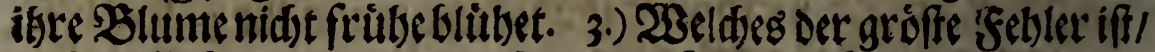

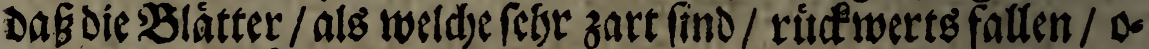

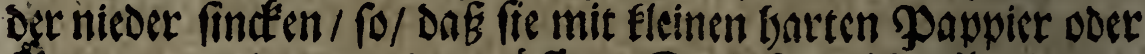
Sappe unterleget werden mirffen; Dod if es nidat allezesit yon:

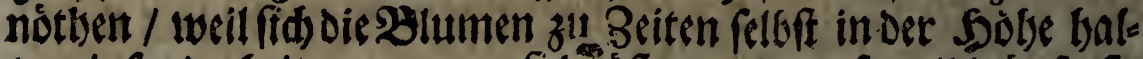
ten/ infonderbeit wann man fíd lẩf angelegen foun/ Die sauferffe

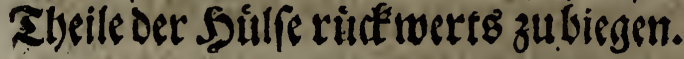

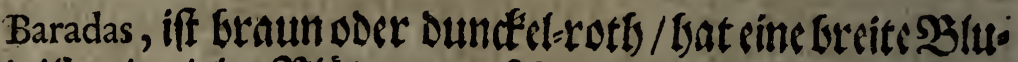

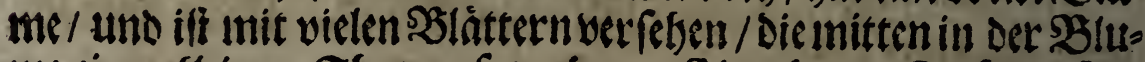
me cinen fleinen $\mathfrak{T}$ burn formitren: Store sunde Stecten find grob / ffeben aber nidbt ferbr zertbeilet: Das wesiffe saran iff

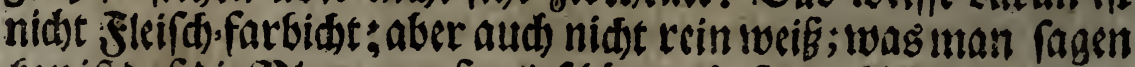

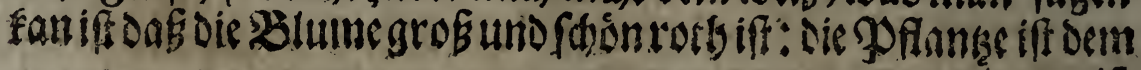




\section{รัน Den છlument:ริau.}

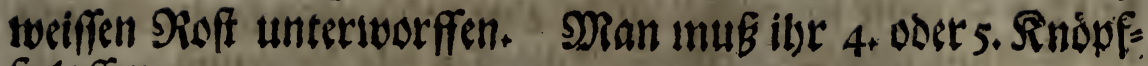
fe lafferl.

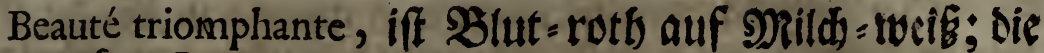
bunde Flecten find flein / wie aud) sie Blume / welde nidit gat biele Şlätter bat: Dod if sie Nelefe zurt / unb ibre Poflanke lebbafft. She milfen nur 3+ oder 4. Sinopffe gelaffen werden; manfinoet fie zu L'Isle.

Bell inconnu, iff befr roth auf fajon tweif; ifte PPflanke if zart / Denen gráultidten Slefeen unterworffen / uno genoinnt

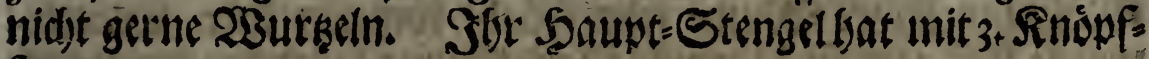
fen genug.

Beau Tréfor, iff belt=rotls auf febr tweib; ifte SBlume ift rund und breit / uno die bunbe Flectén zertbeilet; ffe bringt Saa= men/wlaks nidbt / und wird zu L'Isle gefunden. Sie bliilset frits

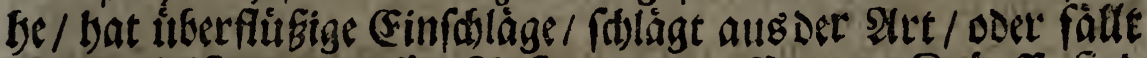
aus / und if dem weiffen Sioft untertworffen. 4. Rnowffe fins wor fie gentug.

Belle Ecoffoife, ift eben bis Bel inconru, unter sinem un: terfdicbenen Nanen.

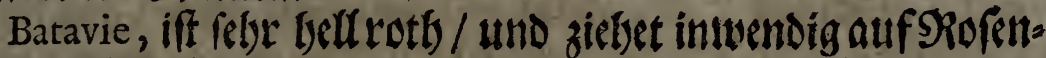
Farbe. Sie iff fest Greit / Das reeiffe batan aber iff nidte rein. 23ann man ife nid) auf Das wernigfte 6. Anepffeläf / fo plakst fie leidtlid). Stre (Groffe docr Breite madst die Sd)onbsit iffer Slume/Dabon fie getragen sie bis 14. Daumen oder Bolle breit gerwefen: Dod) if sie Pfianke fonwad) / und Dem weiffen

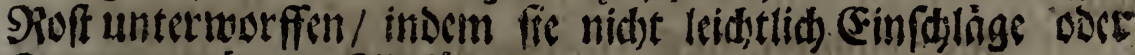
Saamen tragt. Sic fomme ban Noyon.

Conquête Malin, ift cine frutke sarmefin= Şarte gieldfe/auf

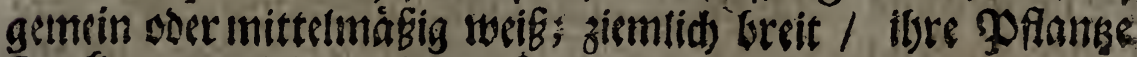
ffurd / und wiro zu L'Islegrfunden.

Couronne Royale, if Earmefinfarbiot aufrein-sveins; ibs

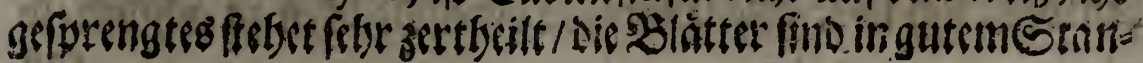


216

De / Der Rnopff iff grobs / giebt cine fritbe uno berite Blumel Die Samment trágr. Sin 5. Rnópfen bat fie genung. Cloris iff Earmeffufarbidt und gemtin weiß / Dic SBlume

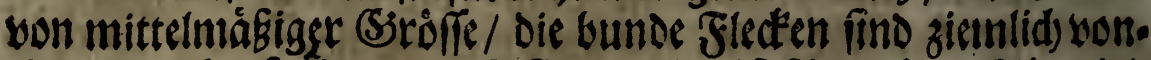
sinander abgefondert / Die 9 ) flanke aber iff fdread). Sie twiro zu L'Isle gefunden/ und bat getuig an 4. Doer 5. Rnópffen.

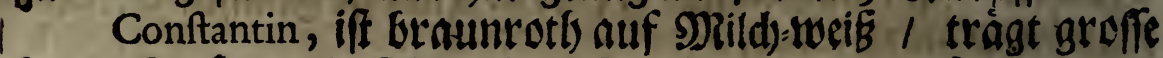

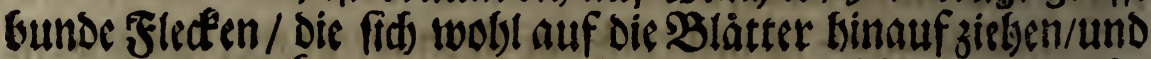

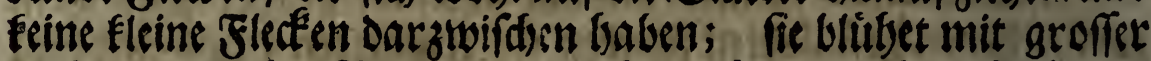

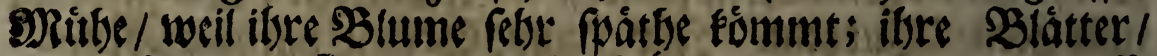

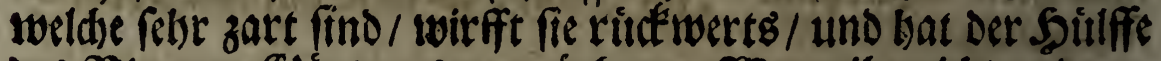

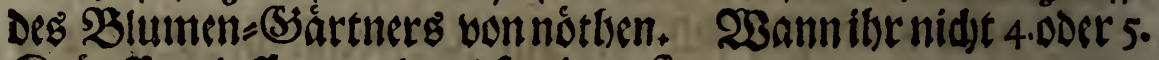
Sinopffe gelafien weeben/ fo plast fie.

Conquéte rouge, iff eben von Der Art wie de Bel inconnu do. Der Belle Ecoffoife.

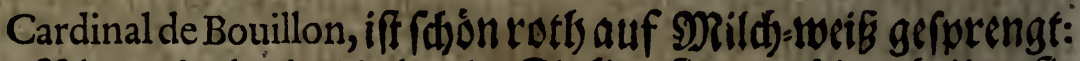
Sbre Sllume ift breit/ bie bunde Sleden fino wobl getteilt / fie trágt Saamen/ uns waann ibr 4. oDer 5. Rnitopfe gelaffen twers Den/foplaşt fienidst. Sielviro zu L'ssle angetroffen.

\section{D.}

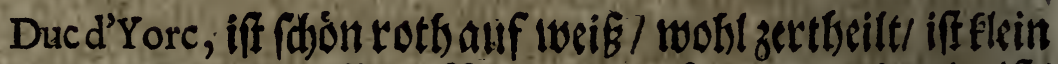
gefprengt/ und bat eine fleine 3 lume / oie aber zart und rein iff/

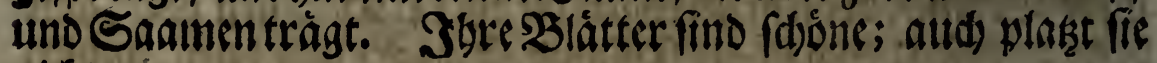
nidjt.

Dupe Philippe, Diefe Nelde / ob fie gleid unterfficesene Nafimen befommen / als Prince d'Epinoy, (wwelddes ifre redter Daabme iff) und Saint Felix, bat fre fidi Ded in ibrer Sart felloften

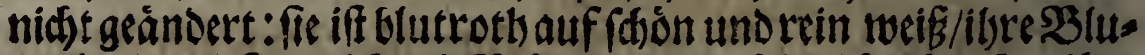

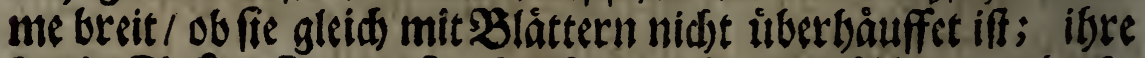

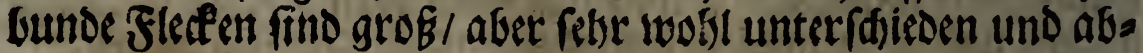
gettseilet; iffre Poflanke if lesthafft / und weeil fie Die Ebluse bad

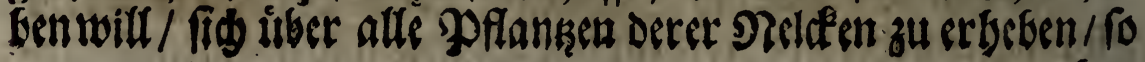




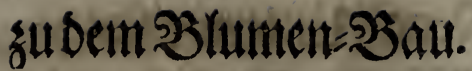

fan unan faum Stedeen vor fie finden'/ bie fod) genug find:

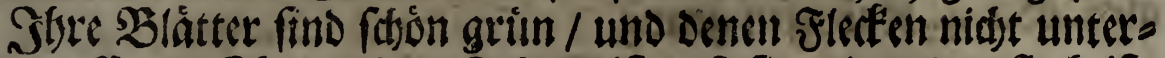

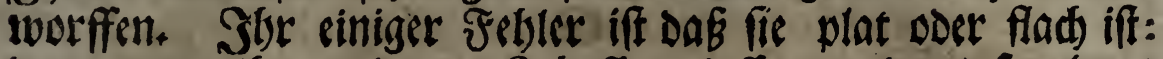
Dann wann ibst 4. DDer 5. Rnoppffe gelaffen twerden/ fo platęet fienid)t.

Duc d'Anjou, iff belt-rotb/auf siner fo ziemlids weiffen

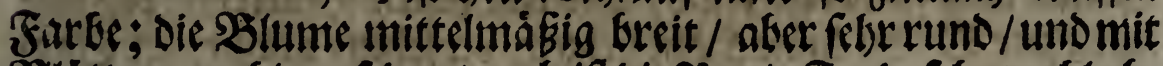

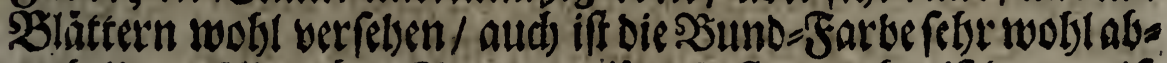
getbeilt. Sie trägt Saamen/ ifre goflangeaber if Dem weifa

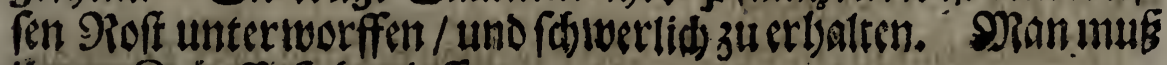
ilst 4. Rnöpffe freben laffen.

\section{E.}

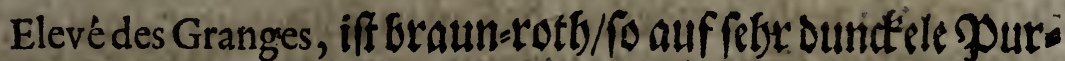

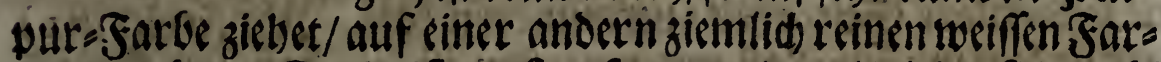

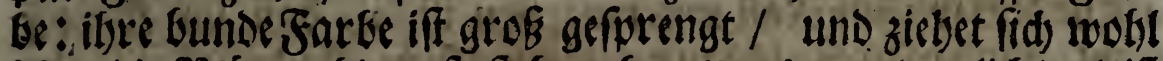
über bie SBlátter binauf / f feferet aber ettwas unordentlid/urdift init Eleinen Flecten vermifddet. Soerr Pat des-Granges bat fie

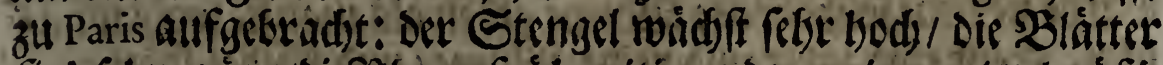

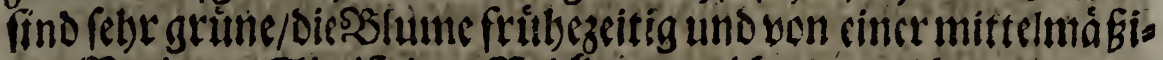

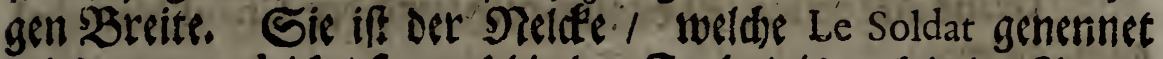

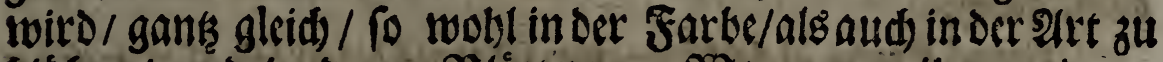
blíben / unt in Denen 2 lattern. WSann man ibr 4. oder 5 . Snôpffe läft / plaset fie nidst.

Etendard Royal, iff Earneefin-Farb auf meiB zichend; oie Gumbe Flecéen fino wobslgefdunitten / gro B / und zertbsilt/ die

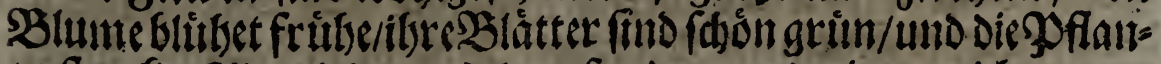
Be ffarff: Sie twird 34 L'sle gefunden / und plaket nidst twann ibr 5. Sinopffe gelaffer werden.

$\mathrm{F}$.

France triomphante, iff ferts fdojon Carmefint farlidit//auf

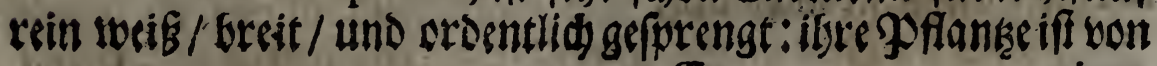




\section{$218 \quad$ Reue Untertweifung}

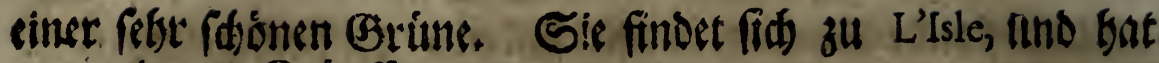
an 3. DOer 4. Inipipfen gentug.

$\mathrm{G}$.

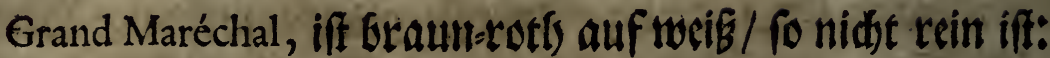

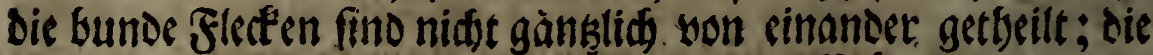

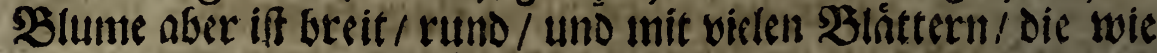

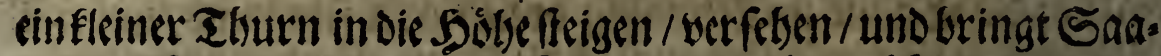
men. Sie wirs zuL' ssle gefunden/ uno plaşt nidet/wann man ibt' 4. bis 5. Inouffe lâf.

Guimberlin, iff cinMorillon, berMorillon deGand, oberT Tournoi-

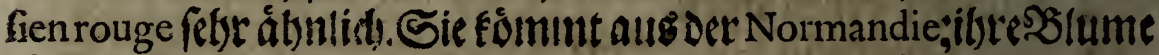

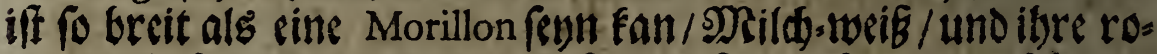

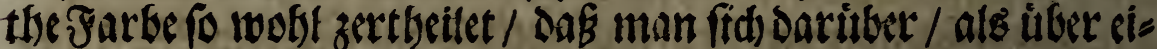
$\mathfrak{n e}$ fonderbarc Seltenbeit/ verwundern fan. Jor Selbler iff $\mathrm{x}$.)

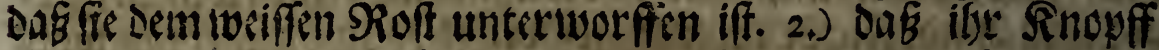

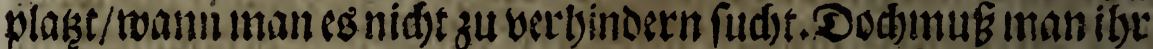

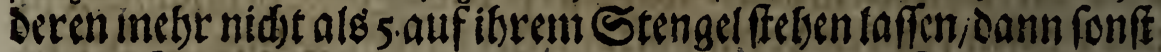

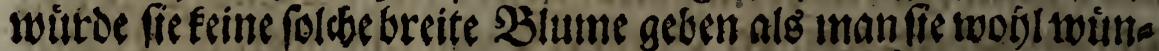

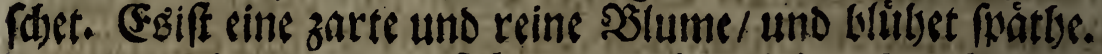

Grand Argentier, iff fraunnerotb/ und Der Grand Marechal gants glsid).

Grand Cramoifi de L'Isle, ibr Name (bie gloffe Sarmefins farbictete Neldee von L'sle) bringt ibte Farbe/ und oen Dort wo fie gezetget worden / mit fid): ilgre weiffe farbe iff forcin/ bafs

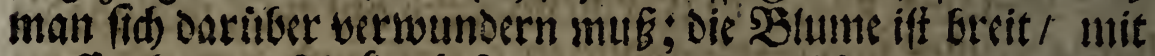
groffen bunden Fleffen Gerprengt / die Dod) nidte unerdentlit) o. Der verwirret ffelsen. Sie fringt Samen/und wann ifse 6 . Sinopfie gelaffen tortoen/ fo plaset fie nidst.

Grand Amiral de France, if aud Sarmefinefarkidt) $/$ auf

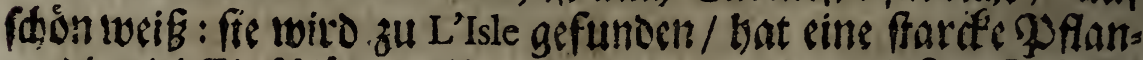

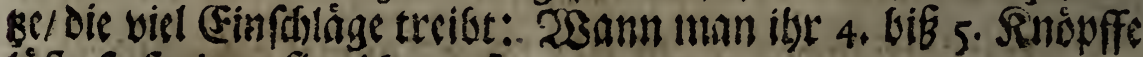
laft ' fo foringt fie nidyt auf. 


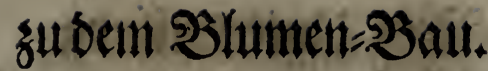
cramoifi netmet.

Grand Chambellan, ift eben die Neldfe / welde man beau

$$
\text { L. }
$$

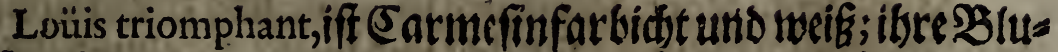

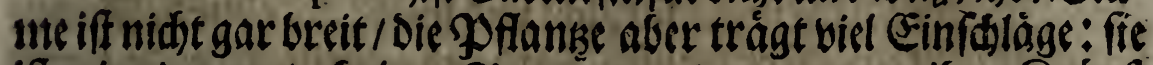
iff rein oder zart / bringt Saamen/ uno wann man ibr 5+ Snopf: feláf / foplakst fie nid)t.

\section{M.}

Morillon de la Croix, fyat eine groffe (S) (eid)beit mit ber beau Cramoifi uno Grand Chambellan; fie iff zwar in etwag/sod abet nidt in der Sdjonlecit und in de? Sarbe/davon unte? foieden; Dañ

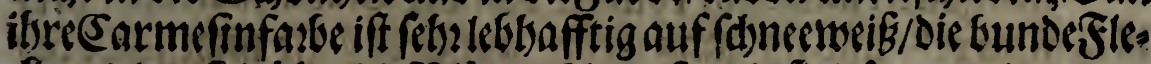
den zieben fid úber dieß latter binauf/ und find fo bon cinander abgetbeilet/wie inanes felsft tounforen mag;ibzeslume if breit/ und blatterid/ bie ssląter aber fino fáwad) und zart/sob fie fid

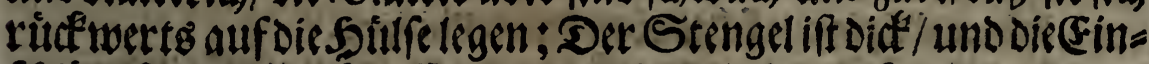

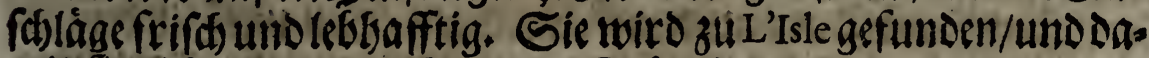
mit fie nidf plase/mitfen itst 6. Snopffe gelaffen tweroen.

Morillon Bellone, iberotbe Farbe bat was befonders/Dann esfind feine rotbe Sledeen / fondern nur fleine Dipfflein: Die

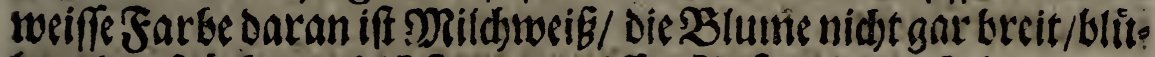
bet aber pátbe/auch iff fie dem tweiffen Sioft und decmplasen un= terworffen. Sie wird zu Amiens angetroffen / uno muß man ifkr zunt wenigften 6. DDet 7. Rnipffeloffen.

Morillon Magnifique, iff blutrotb auf MRildtwcifi; ifre Blt: Ime if nid)t gar breit/bat nud nid)t ubrig Blatter : Sic iff nidjt grof gefprengt / aber febr rund/und diefled"en mobl wertheilet/ audh iff fie fower zu tauen. Sielwito zuL'Isle gefunden/ imo bat an $4.00 \mathrm{er} 5$. Inopfen genug.

Morillon de Gand, oder. Tournoifien rouge, fino von oet

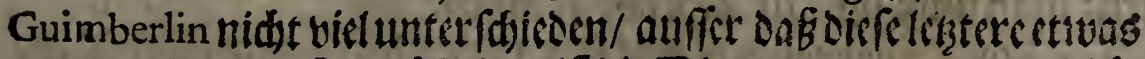
weniges breitet ift : im literigen iff oie SBlume denen andern gleid).

Morillon d'Efpagne, iff Earmefinroth/ nuf rein torif; die 
bunde Flecten fino grob/ bertbeilet/ uno zieben fid wobl tuser obe

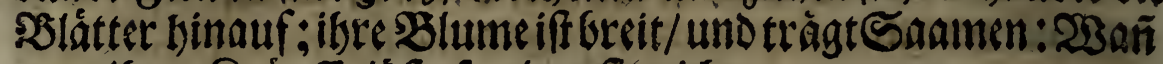

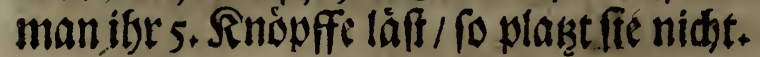

Morillon du Mont, Morillon d'Hibernie, fino ztwey fagine und gleide शelcfen / Carme finfarbidst und locif; ibre bunde Ftecten fino grob/auf siner fegr weiffen Farke abgetbeilt ffechenos/4no breit. Sie bringt Saanen/ und waim fie 6 . Rnowfe aufitserm Saupt = Stengel bat / iff fie dem \$Plaģen nidst untêtivorffer. Pan findert folde zu L'Isle.

Morillon de la Cour, iff sine fegr netie Eaimefinfarke uns waiffe Nitde.

Marquisd'Humieres, foinunt bon oer Grand Maréchal bet/.

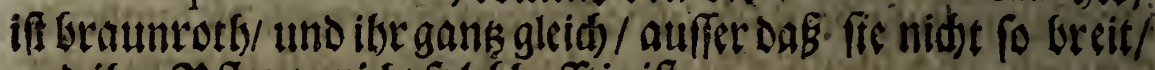

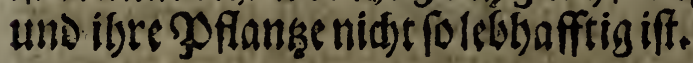

$$
\text { P. }
$$

Prince d'Epinoy, feftet ofen Dupe Philippe.

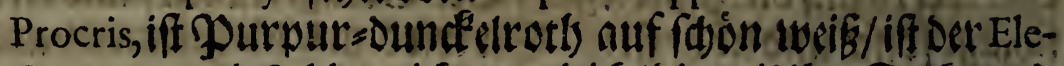
védes Granges, uno Soldat nidst ungleid)/ Dietweil ibre Satbe uno

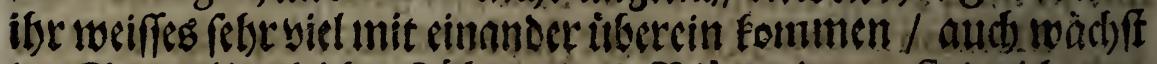

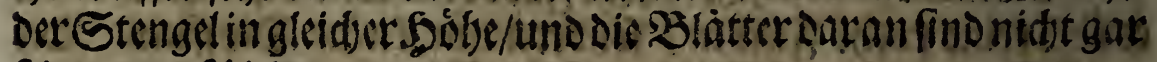
ferbe unterfdicoen.

Saint Paulin, ift cine ungetseure groffe Nele? / bat afer nidte gat viel bunne Sleffen / und diefe fols flein: fie Nlaz̧t getne.

$$
\mathrm{R} \text { : }
$$

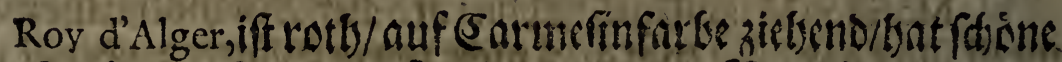
bunde Flecten auf rein weik / Die gants feine Zerwirrung ooer

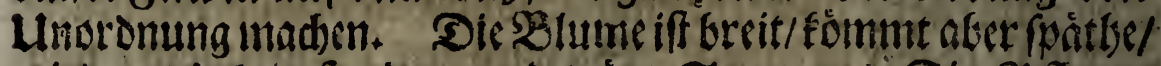
woird zu L' isle'gefunden/ umo trägt Ganmen. Die Bpfanke

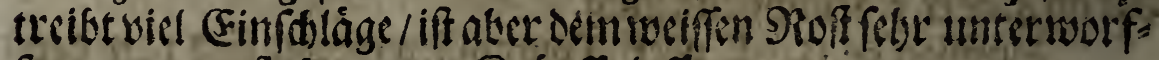

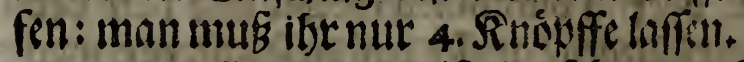

Roy d'Angleterre, iff eine febr rare Nilde pan cincr iber:

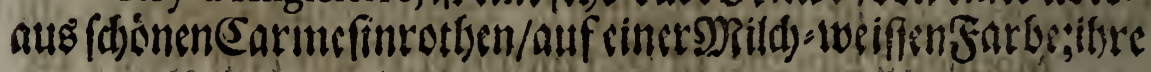

Blume 


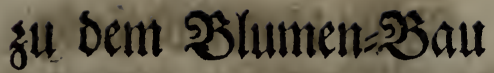

Blume if nod) fo ziemlid breit/ aber runb in bem fodeffen (Gras

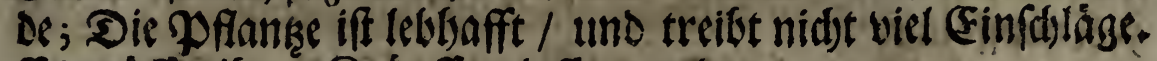

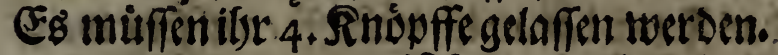

Roy de Flandres, if braunroth / aber vons siner ungefiseuren

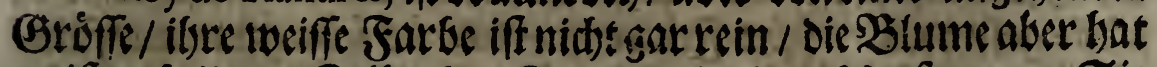

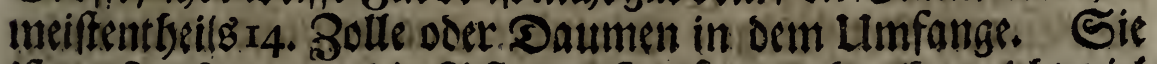

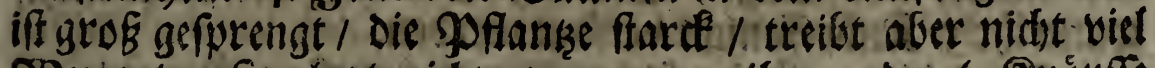

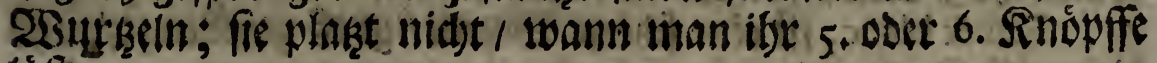
lâf:

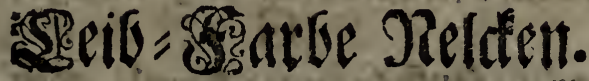

\section{B.}

Beau Daumont, iff eben Die Incarnat Laubinoy, und iff cg Eeilfat te

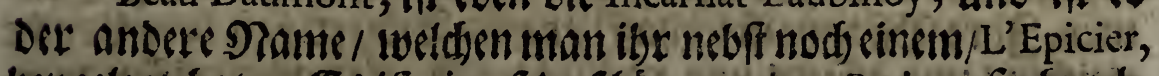

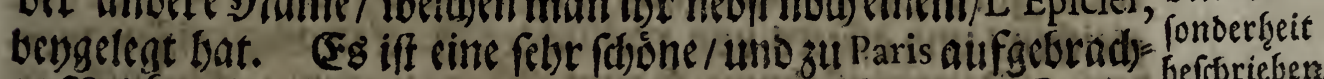

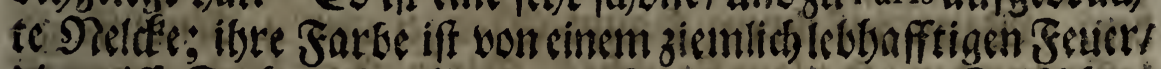

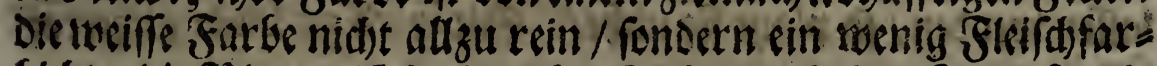
bidst; Die Sblume if treit/ aber flad); Dod bat fie biefes eis gen / Dab freleidetlid) Saamen bringt/ und imit groffen Fle.

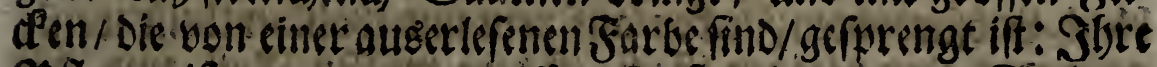

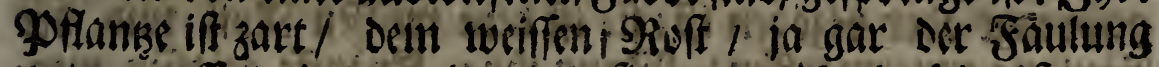

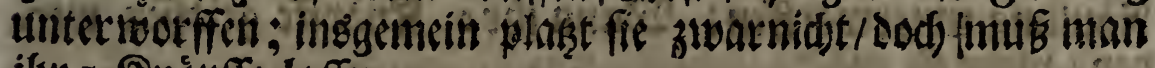
ibr 5. Rnowffe laffen.

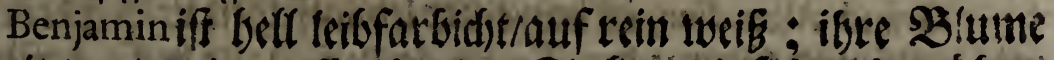
iff breit/ uno thit groffen bumben Flecten / Die fid didite ilber

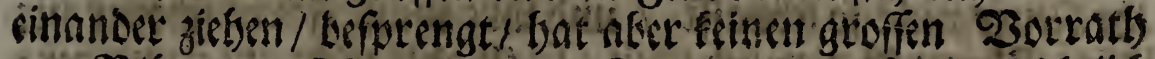

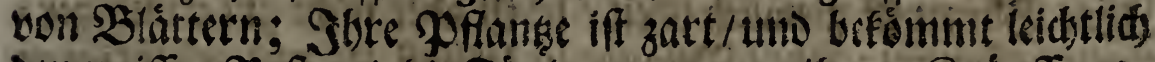

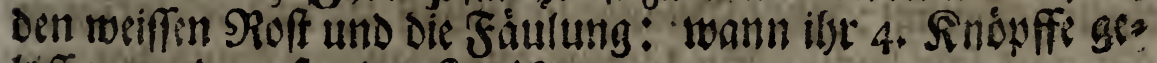
laffen toerden/ fo plaset fie nidds.

\section{D.}

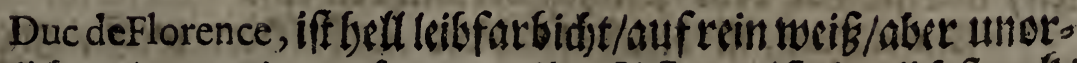

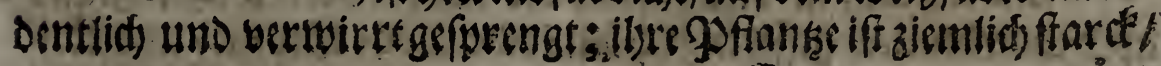

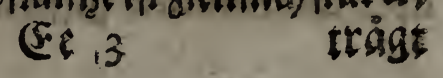




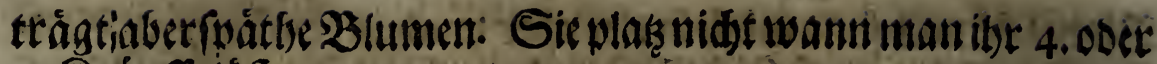
5. Sinópiffeláft.

Feu de Ligny, bas Jeture Daran ift lebbafft /auffelst weik/ Die slume if breit / ibre \$P flanke ater fobwath / uns fie wiro zu

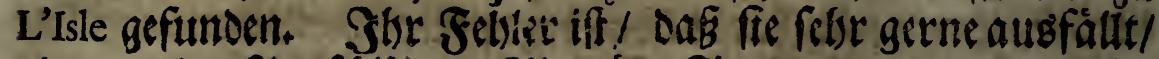
ober aus der 2lrt fálägt ; Sie triggt Saamen/uno plakt nidjt/ wann ibr 5. Inopffe nidit verfagt twerden.

Feu \& blanc, iff eine fdoone \$Bltume//grof gejurengt/ uno bie weiffe Sarbe rein; fe iff breit / ja gar ungebeuer.

Grand Incarnat, fonft Incarnat Royal, oDer Incarnat Impe-

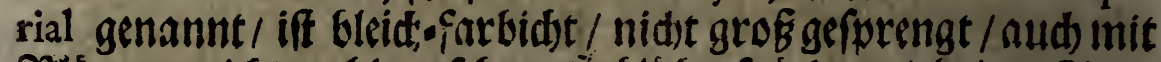

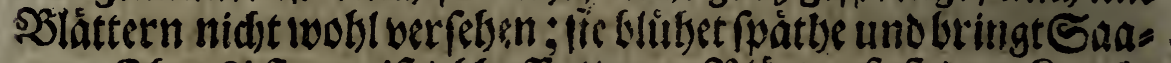
men. Jore Pflanke ift lebbafft / ceren Slatter faft Dem Eaudse gleidien / und offters von rotthlideten Fleffen angegriffen wer: oen. Waann auf ibrent Saupt= Stengel nut 4. Smopfe ge= taffen werden / fo plagt fie nidst. Sie wirs zu L'Isle antgetrof: fen.

Grand Cyrus, trágt cine fdjone SSlume I die mit groffen bleid)=Reibfarbidsten Slefe'en/auf rein uno woblvertbeilt meifi gefprengt ober bezogen iff; fie if Dem tweiffen sioff uno oet Sáulung unterworffen: $23 a n n$ ibr 2. Snopfe gelaffen twer. Den / plaset fie nid)t.

Grand Albardier, if bon einer lebbaffigen \&eib-garbe/auf

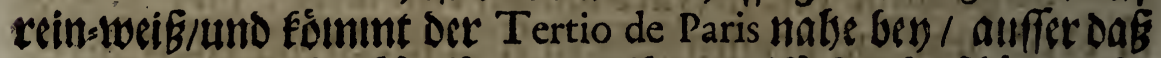

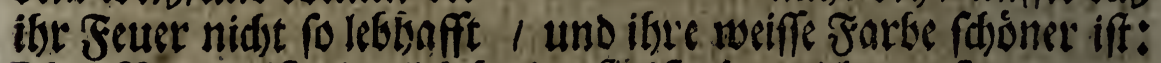
Shre slume if ziemlid oreit / fie if aber nid)t grof und zers theilt gefprengt; Sbre Pflanke iff lebbaffig / und crbertibren

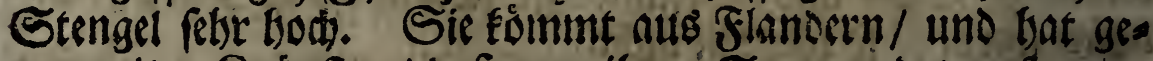
nug init 5. Sinopfen / dą man ibren Saamen davon famin: len / uno fie yor deill OPlaken berwabren fan.

Grand Turc, if bleid = farbidt auf foion weif / grof 1 afer unordentlid) gefprengt; bat feine breite SBlume / uno fothe 


\section{Znbein 2 hument $=53$ ait.}

223

te wor eine" Morillon pasfiren. SGre $P$ flangecif faft zart/ wann

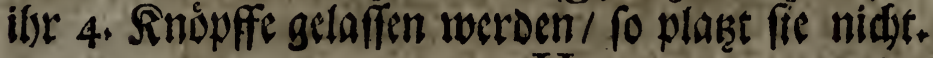

\section{$\mathrm{H}$.}

Hipolyte, if Geth Eeibfarbidgt/und Der Deränberung uts

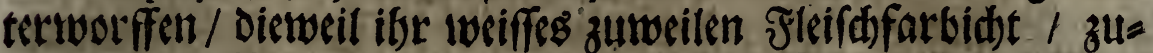
weiten aber Mildffarbidst; mit groffen/ zu Beiten aber aud) mit fleinen bunden Flecten Gezogen iff: wo iman ibs; nidft 6. bi 7. Snópfe láft / fo ptaģt fie gerne.

Incarnat Imperial, felset Grand Incarnat.

Incarnat Caron, ike warbafftiger :Rabime iff Incarnat Jan-: cille, fonft afer aud) Grand Etendard, uno fie formunt von L'Isle. Store ideiffe Farbe iff fetse rein / auds iff fie nod) ziemlids grof gefprengt/ fe felbft aber iff Elein / und febr runo ; ibre. OPflanke Die lebsafftig / und von eimer fdoonen Grime / ift denen Frofloben untertoorffen / bat aber gute grime Blatter. 4. Snopffe geben ifir eine fosone slume.

Incarnat de Gille, iffecine groffe Blsid):leib farbe Nelcte/bláte teridh / uno plast gerne; ifre weiffe Sarbeiff ziemlids rein / die Poflanke fo frarda al man eg begebren fan/ uno trágt febr viele

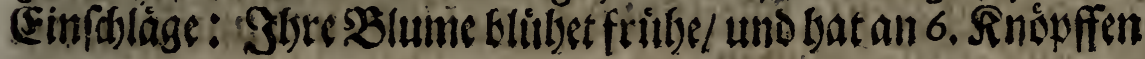
genug.

Incarnat des Fremnes, iff cime leibfarbe Nelde eifo bon L'sse

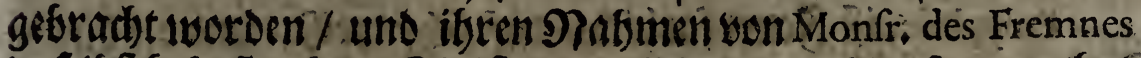
Dafelbff Gefomen bat. Sic ift orbentlide uno woblgeforengt/bat:

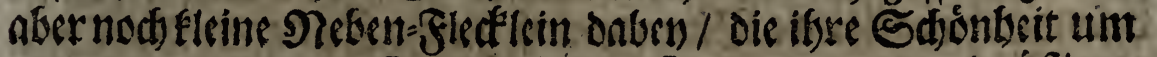
ctwas verminoern: Sbre Pflanbe iff von einer mittelmábigen Gtârce / uno tràgt (Finfablàge in oer Menge. Diefer muf man 4. Rinisufe frebsinlaffen.

Incarnat Railly, iff cinc groffe leibfarbid)te NRelde/auf rein

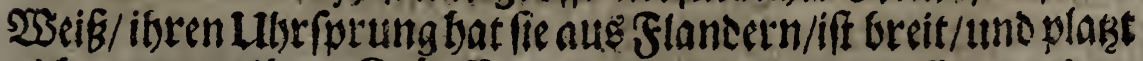
nidts t wann iler s. Snoveffe zu Dem Saament gclaffen werden. Dies Pflankelebbaffig. 


\section{4}

\section{Nette Unterfueifutitg}

Imcomparable, if Feuerfartsidtund weib / Die weiffe Far: be aber if nidbt febr rein/audb bie fumbe Fteden nidst wobl won

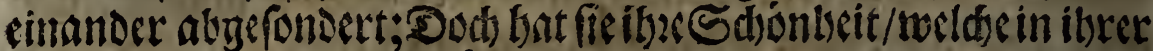
Sarbe / Siimber unt Didfe beffebet. Sluke goflamke/ sie robon grin iff/ if Dem wueffen SRoff/ und Dem Rrebfe/ orer Der fo gea nannten făulung untertworffen: Sic trágt Gaamen/uno murs fenifor 4. Doer 5. Rnopffe gelaffen werden.

Incarnat Blonne, iff bleidb = leibfarbidit / fot aber cine fefor reine tweiffe farbe / undoiefes bor fid) befonders / Daf feecine felse groffe uno blátterreidje Pildé / Deren S3undfarbe mobl yon einander abgerondert iff. Sic wird zu L' Isle gefundern/und

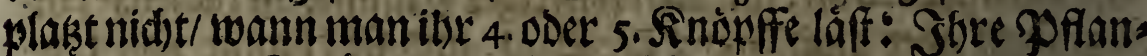

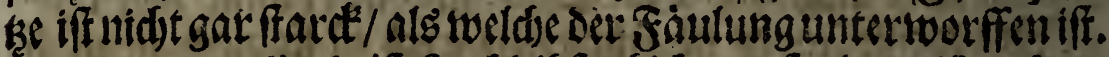

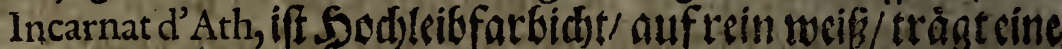
breite/ grofgefprengte/ und in Den gefprengten flectern wobst ber. theilte SBlume / und wird zu L' Isle gefunden; ifse Pplanke ift

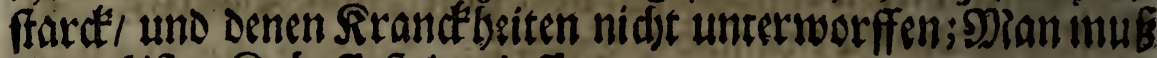
ift 4. bib 5. Sinopffeftebenlaffer.

$$
\text { M. }
$$

Monitre pâle, if bleidj farbid)t / bon einer ungebscuren Grofs fe/uno placet aerne; ONan findet fie zu L' ssle, und mirfen ilst 6 . inopffe getaffen werden.

$$
P \text {. }
$$

Polyphile, iff Seuterfarbidst/autf febr sweig \& und bie Gunde Farbe darauf febr wobl bon cinamber getbeilet : Diefes bat fie

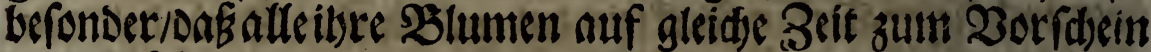
Doer Blútsen fommen / und die lekte eben ro breit als die crffe iff; manumbs fee in Der Sonne blüben laffen. Sie trägt Saamen/

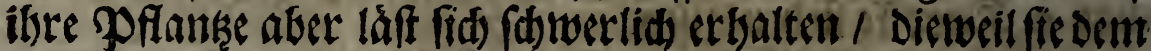
weiffen SRoft und oer Säultung untertworfen ift.

$$
S \text {. }
$$

Sauvage, if zuParis gezeuget worsen/ uns bat ifren Nakd men von oemienigen/ ber fie aufgebradet bat: (Einige baten fie

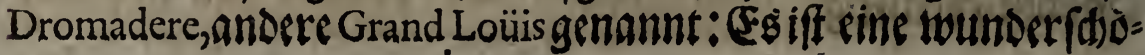




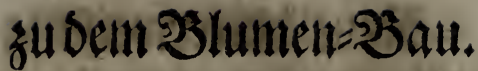

ne Nelefe; Die Reibfarbe Daran if zwar nimt lebbaffig / itse

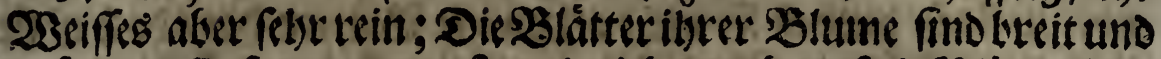

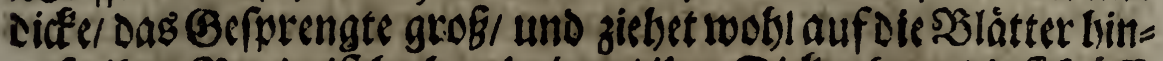
auf; ibre sRunde iff bod zu balten / ibre Didec aber / Die fid iff:

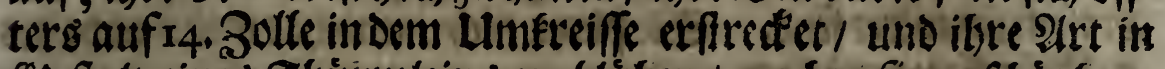

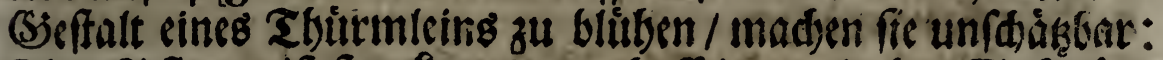

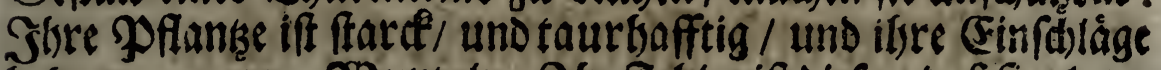

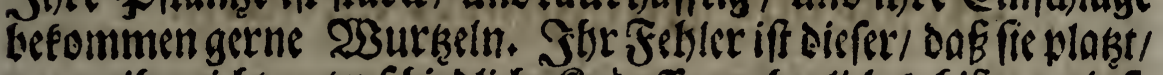

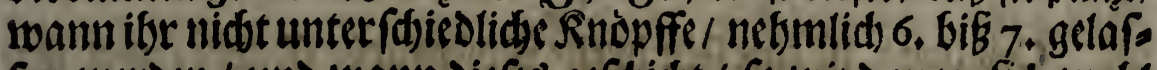
fen werden / und wann diefes geftidst / fo wiro man fig lwobl Dabey befindent.

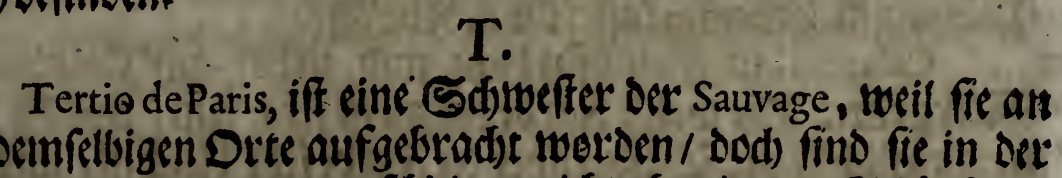
efendemfelbigen Drte aufgefbrad)t worden / Dod) find fie in Dot Diefe if von einer bortrefflid lebbafftigen duncéelen \&eib: Far: be/ Das iff / voneiner Duncécl=rotben Seuer-Farbe/ibr23eiffes if nidst rein/ fondern ein lwenig fleif farbidte / ibre Blume nidet fo berit als Der Sauvage; Die Gunde Flectenaber fino nidst Eleiner/ aud) nidst weniger von einander abgefonoert nls diefer ibre/uns

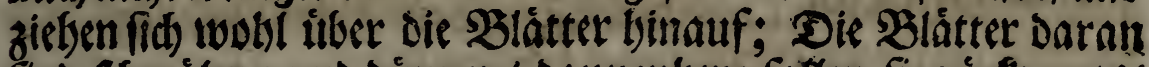
find fdimáler / und ditnner / Dannentero falden fie riteftwerts/ uno múf fen mit Pappen/ oder fonff ettvas bierzu Dienlides une

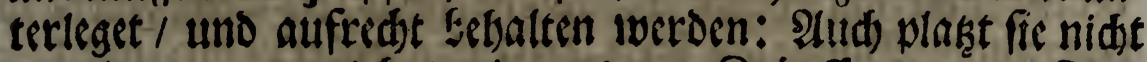
wie die Souvage, uno bat mit 4. oucr 5. Sinipffin geturg: Shre Polunke ift ftarte genug/ ob gleid) ifrer Brimes nidt von Dem

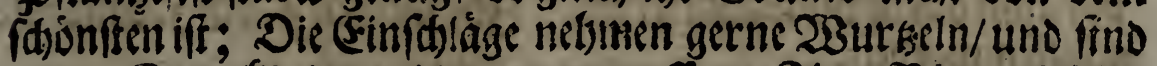
Denen Rrandéteiten nidst unterworffen: Shre Blume blibset nidts fo fritbe/ moie die SBlume der Souvage.

\section{$\mathrm{V}$.}

Victorieux, Ivirs altd Flamboiant, und yon amsecen Incarnat à doubles feïilles genannt / andere aber faben ibs ten Namen petit Sauvage gegeten : Sie iff bon einer friftiten uno lebtsaffen. Ecibfirbe / aufrein weiË/ mit groffen lumben Flefen / und oie 


\section{5 \\ Secue Unterweeifung}

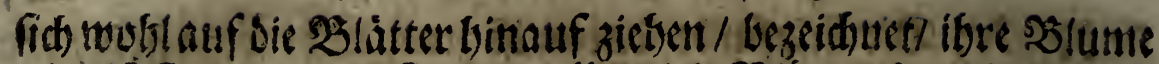

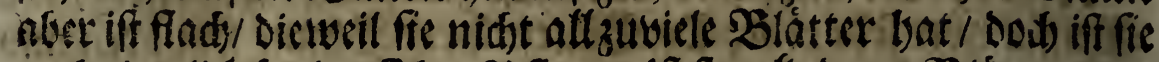

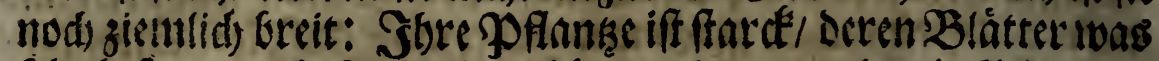

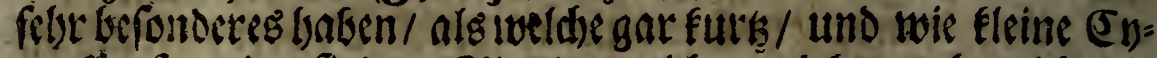

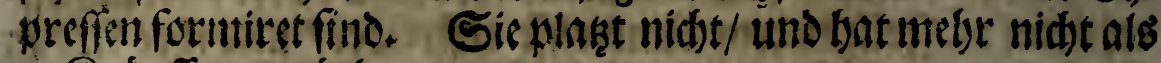
4. Inippiff bonnetbent.

\section{Tiofentund fleighfarte sedelen.}

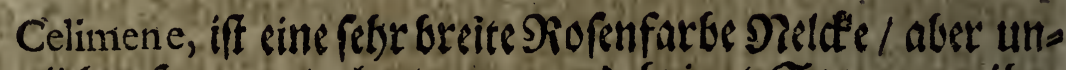

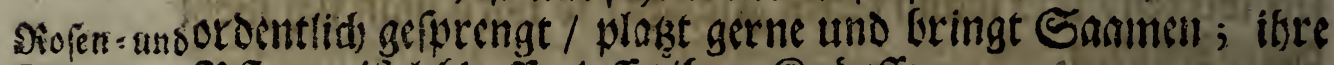

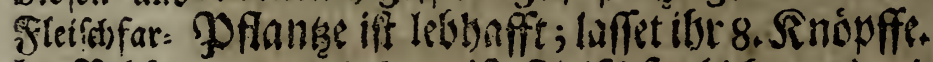

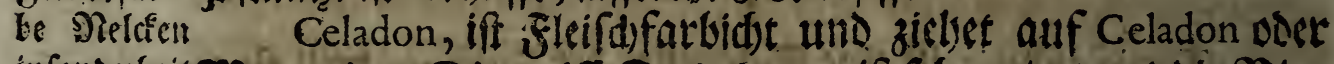

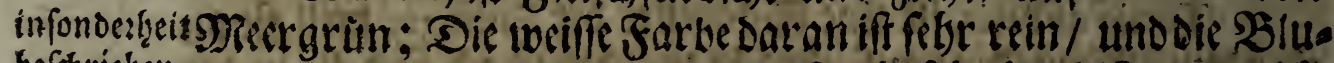

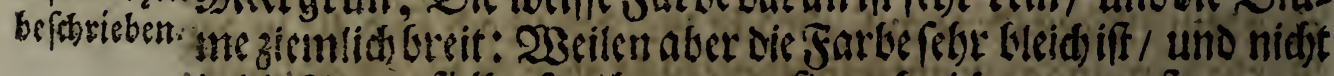

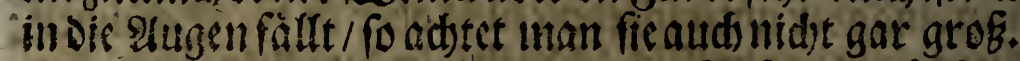

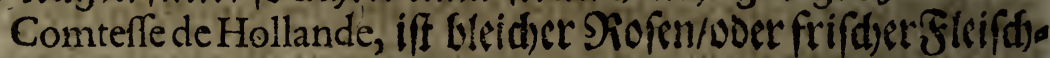

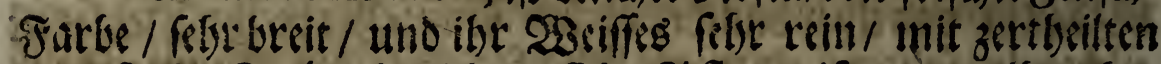

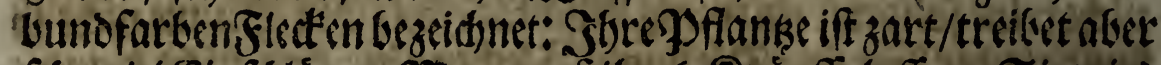

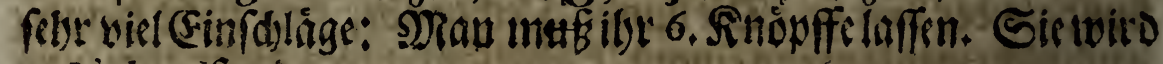
äL'sle gifumen.

\section{D.}

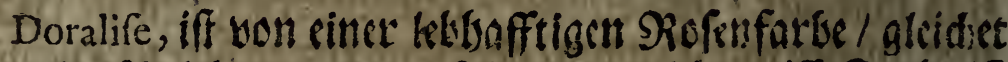

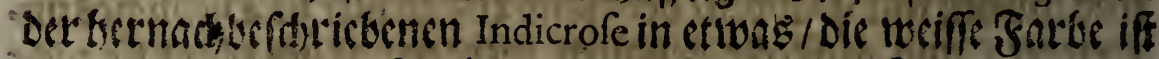

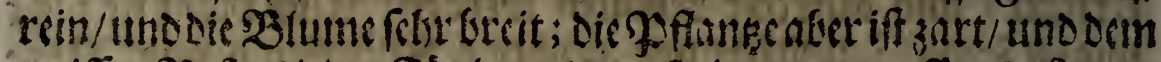

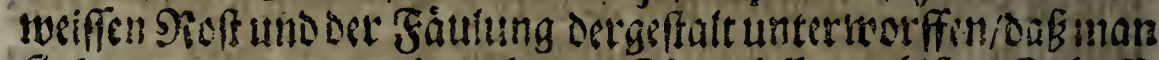
fic faum darur verbabren fant. Sly miffer 4. Gig 5. Rnopfe getaficn werestr.

\section{G.}

Groffe Madelon, boer nud) Tour de Babel, iff cinc Nitcese von ciner unnatirtliden (Groffe; ; Diefes ater if anch allie la:a fie

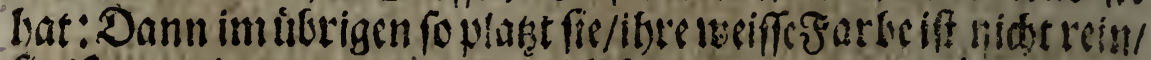

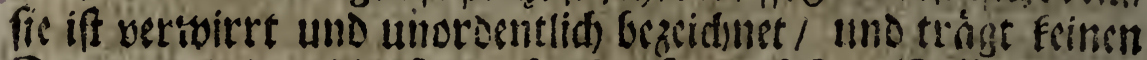

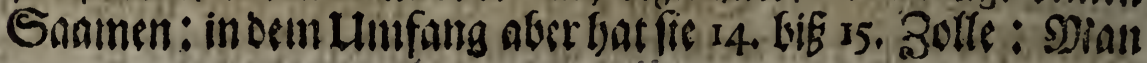




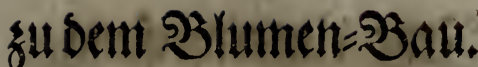

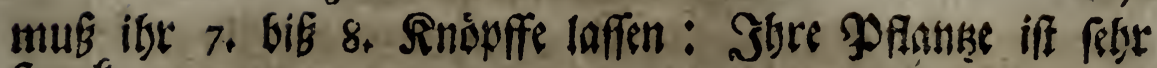
ftarce.

$$
\text { I. }
$$

Indicrofe oder Res Indique, if die allertiesffe uns ange. netsmfte Prelefe / tweldse man unter benen anmutbigen Fatben

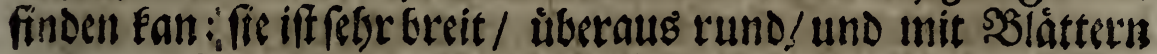

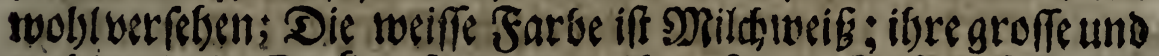

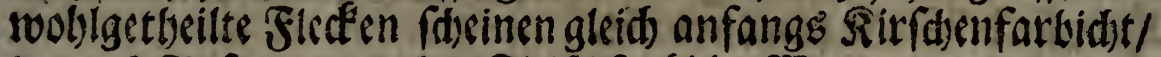

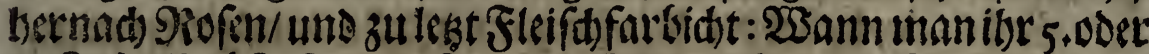
6. Sinovffe láft/ foplatat fie nid)t: Shre Pftanke trágt breite uno

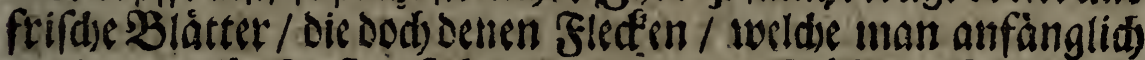

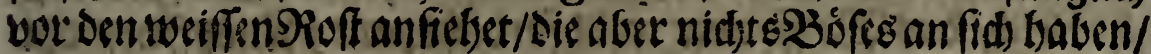
unterworffen find. Stree (Finfoläge befommen nidte gerne 2Burketrn/ und connenleidttide faulen: Sbre sBlunte blitbet in Dem fritsling / Derowegen manfieauds in Dem Serbfe pflan: Ben/ und vor oenen allzuftardésensegen vertwalsen foll. Sie wiro zu L'Isle, zu Amiens \&c. gefunden.

Ifabelle, if bleider Siofen oder Fleifdf farbidst / ibr $23 e$ eifs

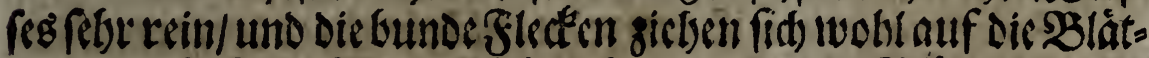

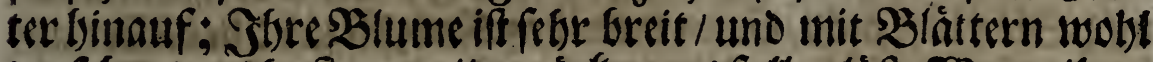

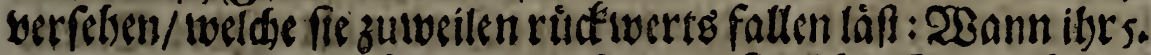
oder 6. Sinopffe gelaffen werden/ foplaks fie nid)t; Sie treift viel

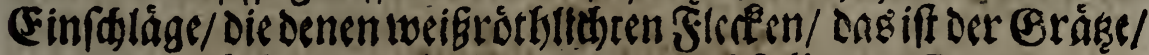

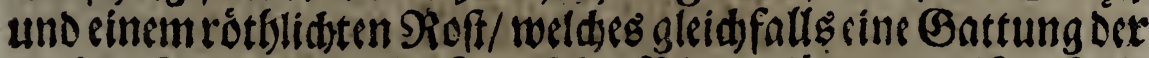

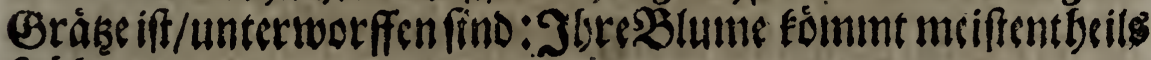
fribe.

\section{M.}

Madame d'Humieres, iff better Siorenfarbe ; ibre Blumel fo febr weiß / iff init groffen Sleden geforengt/ breit/ blübet as

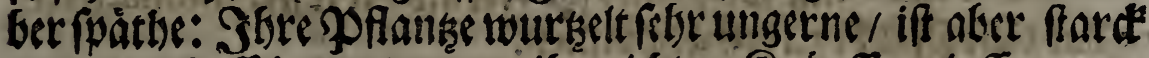

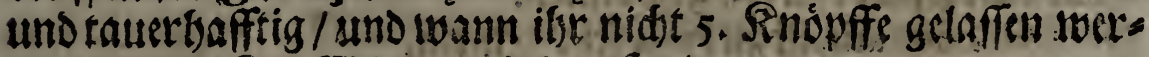
Den/foplaţeffe: 2Biro zu L'Isle gefumben.

Madame d'Orieux, if yon Det rorbetgebenden Nelde nidje unterficieden/aufer das iber Farbe Glcider iff.

$$
\text { Sf } 2
$$

R.Rore 


\section{$\mathrm{R}$.}

Rofe d'Ifrie, ift bleider SRofen oder Flei dofarbe/ auf roin

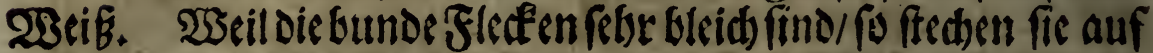
ciner fobedtweiffen Farbenid)t viel ab: ilbee SBlume iff treit und

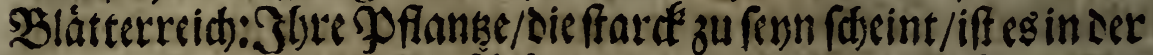

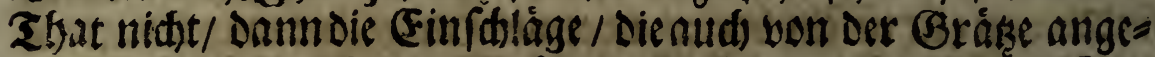
griffen wersen/ netmen gat faswerlid 23 urkecln : Wann fie 5. sinouffe tethàlt/fo plant ffe nidgt.

Rofalinde, fietbet der Ifabelle ganţáǵnlid)/ausgenommen/ Sabffe nid)t fo brcit uno toobl blublet.

Rofe d'Hollande, iff ebendic Rofe de Jerico, ifre Sarbe iff

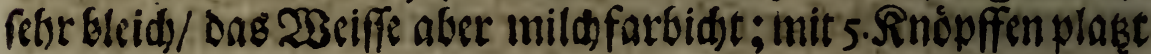
fir nidt.

Rofe Royale, if eine fefr groffe sBlume / voreiner fete rei. nen weiffen Sarbe / unb ordentlid gefprengt: Sbre po flanke ift

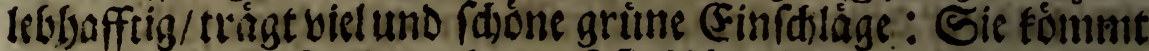
bon L'Isle, 5. Sinopffe madjen cấ fie fdơne $2 B /$ lumen bringt: Sie blitbet nidit fritbe.

Rofe Permanente, iff eine reine/nidjt Grcite/aber zarte Bitus me: Sie plaket nid)t/mamm manibrs s. Snóbiffeláft: fiebleibet als

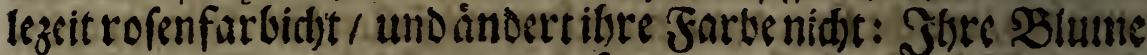
Gtibt lange / und wiro zu L'sle gefunden.

\section{Beiffe Melden. \\ B.}

Tiseifie Did= den infore Dertheit be $=$ fajricber.

Belle douce, if cine greffe / Greite uno blátterreide ssiu= me / Deren Poflanke ffarde uno lebbaftig ift: 23annibr 5 . ooer 6. Rnépfe gelaffen woorden/ fo plast fie nidbt.

Blanc Racine, iff toeíB/ /uno fo breit als die erfte. Monfr.Racine bat Diefe giclfé zu erff gctwonnen.

Blanc de Paris, iff zแ Paris feltr gemein.

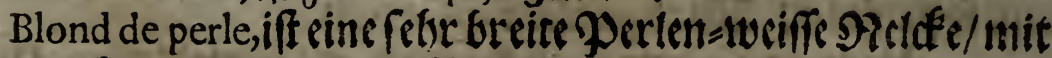

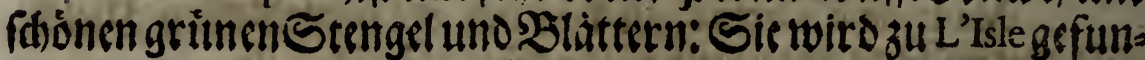
inn.

Rofe 


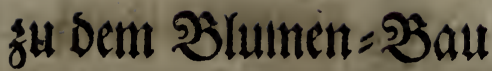

Rofe Blanche, iffeine wabrtbaffige weiffesore / oann fie if

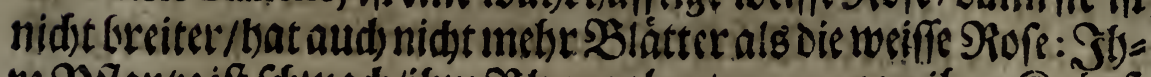
re Phanke iff fduad /ibre Slume aber/wann man ibr 5. Sinopf fefteben lâf / plak̨t nid)t.

\section{Picotirte oder gedipffte seelfett.}

Augufte Triomphe, iff cine der fdónffen picotirten Pelefen/ Picotirte

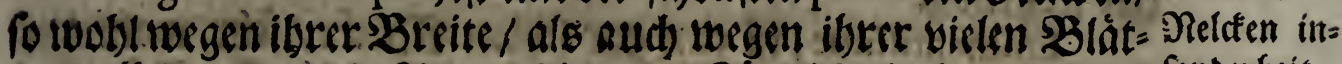

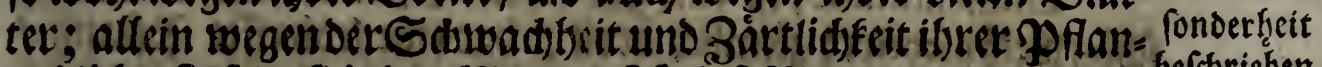

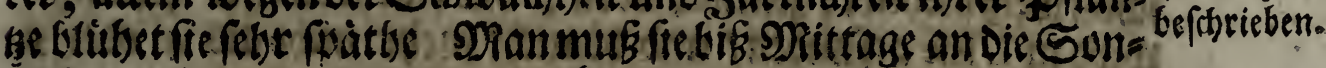

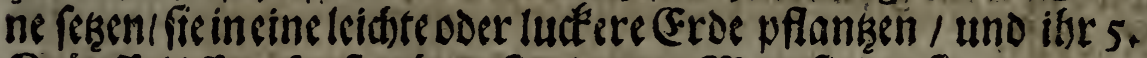
Snopffelafien/ fonft wirdefieplagen: .Ran findet fie zu L'Isle, Paris, \&c.

Aftedu Monde, if eine/ infonderbeit um Den sRang ifrer. Slatter/ ilteraug foldr picotirte Pelde : Sbre sblume if nidjt gar breit / aber fefr tund/ und alles twas fie an fid bat iff ordent= lid) uno tooblgeffalt/ ibre Pflanke aber iff nid)t gar ffard: Sie if Dein toeiffen Rof und Der Fáulung unterworffen/ und woiro zuL'Isle, Amiens, \&cc. gefundent.

Aftre triomphant, iff bteit uno felct farce picotirt: ifregoflan: ke iff von ciner mittelmábigen Stärefe/ wiro zแ L'Isle angetrof= fen/uno inus man ibr 4. Sinopffe lafen.

Amarillis, Agreable, Belle Áminte uno Etoile de jour, fino 4. faff gleid) picotirte Preldetn/ und beftebet ibr Lnterfoied nur in Der Farbe und in denen $B$ lättern / in Der S6reite und Sireffe oder

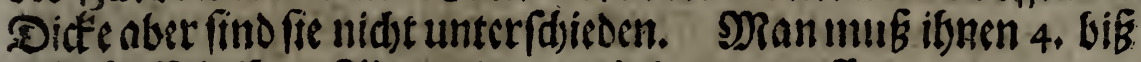
5+ Snopffelnffen: Sie twerdenzu L'Isleangetteffet!

Apollon, if Graun auf rein wrif picotirt: Die Nelde iff

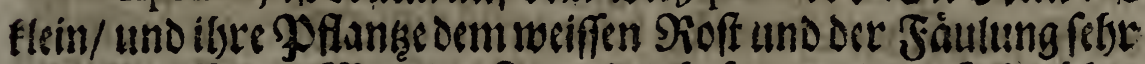
untertwolffen. SPanfanfeguL'Isle boten/ und mus ibr úber 4. oder 5. Rnóbfenictet laffen.

Beau piqueté, iff Dir Verdureluifante fefor álntidi: Sie if lidt $=$ purpur picotirt/ febr diff und breit/ unb Ibann ifor 6. big 7 . $5 f 3$ Ruipf 


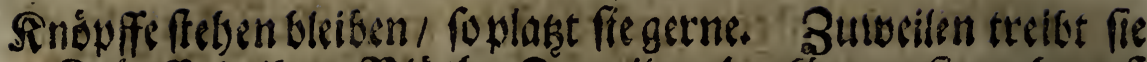

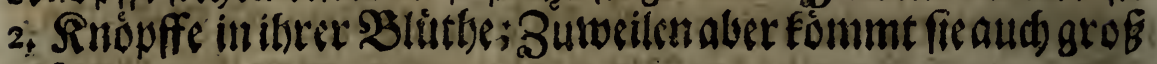
gefprengt.

Eudoxia, if cine febr flare uns reine Neldfe / Dag 2Beife

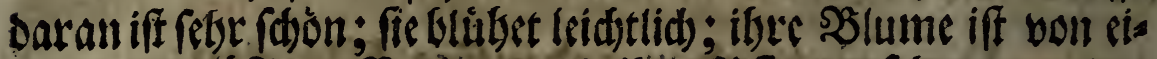
ner mittelmábigen Sreite / uno ifire Sp flanke feter zart/ Der

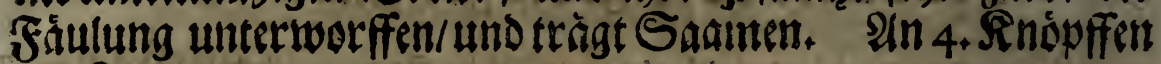
bat fie genulg.

Eminentifime, iff cine gar fdoone Nelefe / febr lwobl auf fajon weib picotirt; ziemlid breit ; bat cine lebhaffec Pp flankel

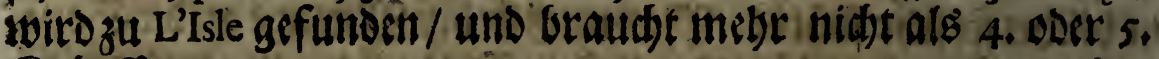
Sinepffe.

Gros piqueté, iff wegen ibrer (Broffer bie vor eine picotirte its bernatiurlid iff / und wegen ibrer fegr reinen weiffen Farbe / eine

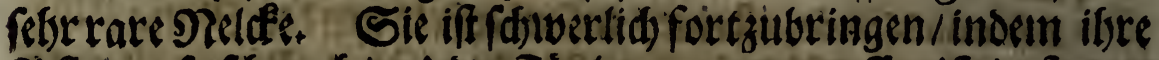

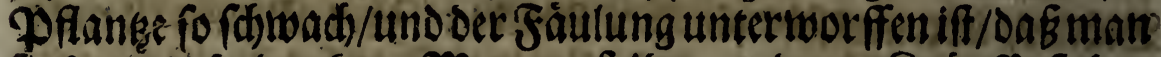
fie faum erkalten fan: Man muB ibt 4. oder 5. Snopffe fteben laffen.

Indimion, ift beutun auf trin toeis picotirt / freit / uno plast nidst: Sbre Poflanse iff fidon grime / uno Eeinen Rrancébeiten unterworffen: 23 iro zu L'Isle angetroffen/uno bat mit 4, Inopf = fen genug.

Jupiter,Junon,Mars, Mercure,Venus,find affe traume/aufrein

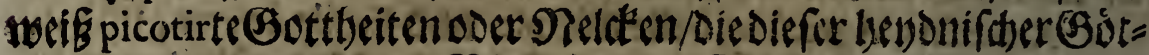
ter Paanen tragen ibere 2 lumen aber find Elein : Mann fan fie fu L'Isle baben.

Lys parangoné, diefe Neltée ift/wasi ibre Blumteanbelangt/: bolltoinumen; Dunn fie iff wobl picotirt/ Greit/ blâtecrreid/ / uno rein weif: Sbre DPFantse bingegen iff zart/ ber Fáulung unters

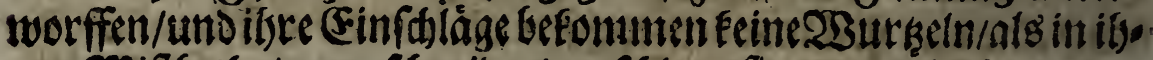

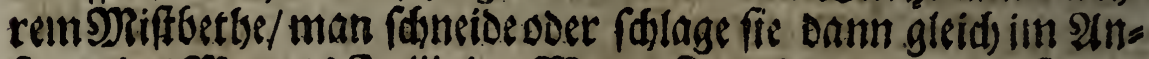
fange Deg Nonats Sulii ein; 23ann fie nidte zum wenigften 6 .

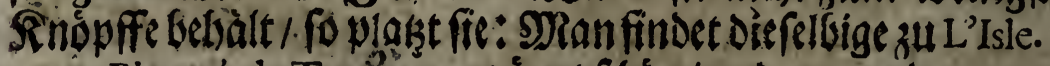
Piqueté de Tournay, grinet foun/ und wourgele gerne; ikre 


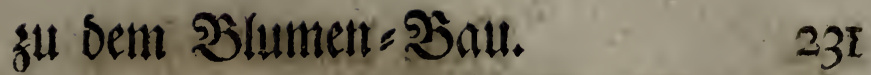

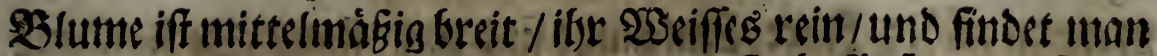
foldes getmeiniglid) in Der goicardie. 4. Inouffe fims wor fie ges nug.

Piqueté du Change, ibre Blumte iff fefre frartét picotirt/breit/

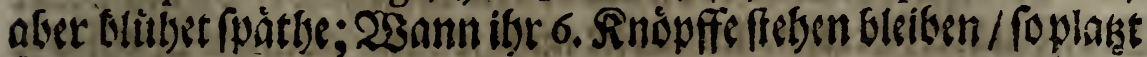
fienidist.

Pulcheria, if cine fot fffatde picotirte Slelde/ bon ciner mite

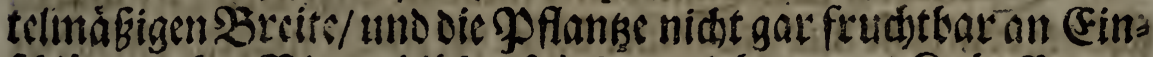
fd)ligen; ibre Blumeblibet patbe / uno bat an 5. Sinopfen ges nug.

Piqueté Briesmans, iff bicte uno brcit / ibre Pfanke febr zart / und oic (Finfolage fommen fatwerlid) und lang fam fort.

Piqueté pourpre, iff febr wobl picotirt/grimet fdon/unt wird zuL'Isle gefunden.

Triomphe de L'Isle, iff cine zarte / auf fobon tweis picotirte Nalde; itre Slumeift breit/ uno ibre Pplanke lebbaftig: Sic arfordert 4. Rnopffe.

Verdure luifante, oabon febet waǵ ficy oer Beau piqueté be= rilltet toorden.

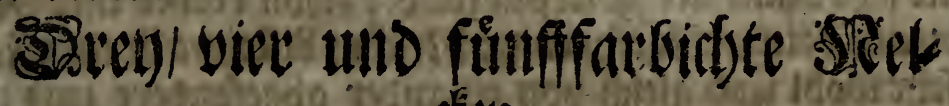
dén.

Tricolor deCompiegne, if pursurfarbidt/bleidher sober twel= detr Siofenfarbe / uno tweiß; ; Der Purpur iff oundet / uno Das weiffe febr rein : Aler wois an ciner Tricolor doer orenfatbidtern

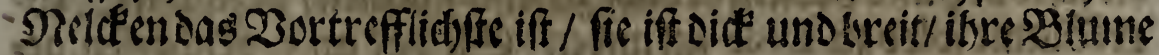

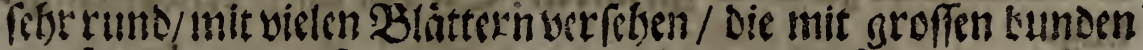

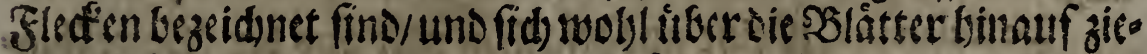

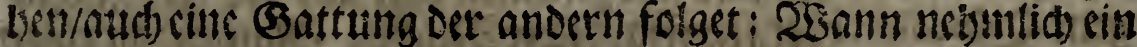
Flefécn von bleider Siofenfarbe auf rein weis borthergegangen fo folget sanne in Durpurfarber narauf/und fan Das reine?seifs ferser vor einen bunofarbidten Flceten/gleid) Den ondern / als vor Dag Felo oder den Grund/Dormuf oie antere gezcidinet fetsen/ gebalten werden: 2Sanndiefer Nelde 5. Rnópffe bleiben/foplabst

Drey/vier unb fưnff: farbidite פlelcfen itts fonderheit befatrisbea.?

\section{.}


232

\section{Meue Unterweifing}

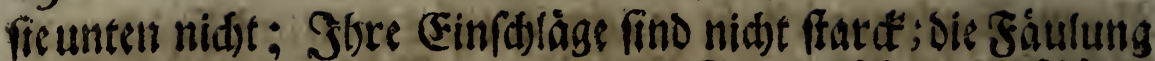
greifft bie Tricolor an/Derowegen inan fie vor befen uno fíádi: den Regen in ad)t nebmen mue.

Tricolor poncet, iff von der erffen nidft anders / als in ber

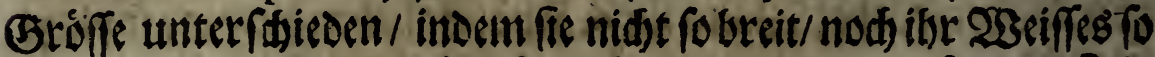
rein/ nod audibre Jarben fo toobl bon einander gefondert find.

Quadricolor uno Quincolor d'Amiens, Diefe Neteéen twáren fabone/ wann fe nur grok / und beffer vertbeilet wären/alfeine fie

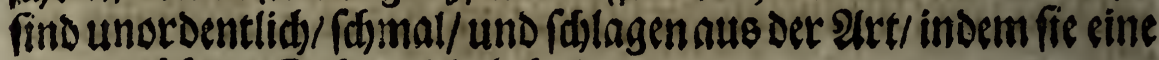
SBlume úber 2. Jabeenidbt betbalten.

La diverfité des troiscouleurs, Diefe Nelefe iff fehr unordent= lid) und verwirrt/ trágt aber eine groffe?slume / Die 7. febr uns

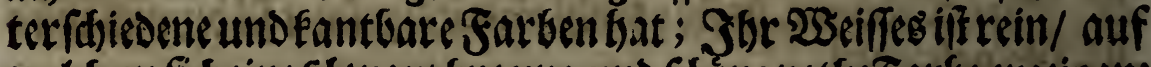
weldem fide cine rdswarkbraune und fajone rotbe?arbe erzeigen; Sbre Pflunze iff von mittelmáfiger Stárd"e/ urid fan man foldhe

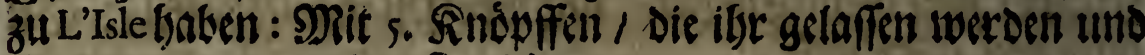
Saamen tragen/plakgt fie nid)t.

La Joliete ober Jolivete des quatre couleurs, iff cine von fobo: ner und febr Dundeler Purpurfarbe / fdjón rotber unt sRofen.

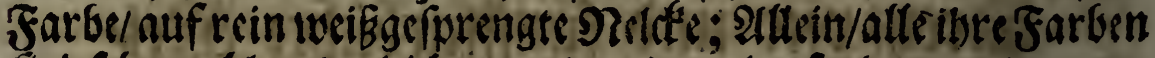
fino feftr wobl uno gleid) bon cinanter abgefondert uno unter= fdieden: : Man findet fie (eid)tlid) zuL'Isle.

La Chinoife, iff cine rare Tricolor woer brenfarbidite Nets

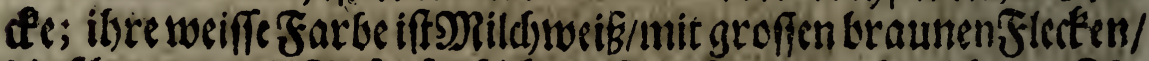

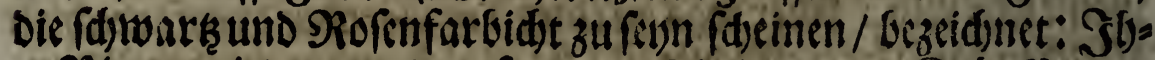
resslume wird zu L'sle gsfunden: Sic bat an 5. Sinopfen ge nug.

Le Zelandois, iff eine nusgefaltene ooer auts ser Art gefd)la gene Quincolor, oder fínfffarbidste Nedeee : NRan madde einen Staat von ibr/wegenibersatbe/bie febt ordentlid vermifast ilf.

La Conquête de Los, iff Sdjifferffrin = Tarbidit / und twir zu L'Isle gefunden. 


\section{รu Dem Sllumen= S3au. $\quad 233$ \\ Sonde?AuriculaUrfiodet

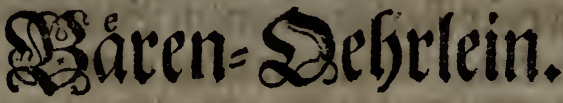 \\ 2aร̃ I. Enpitel|}

Gon dem atriptung noer Stertommen de: Sären-Debreteins.

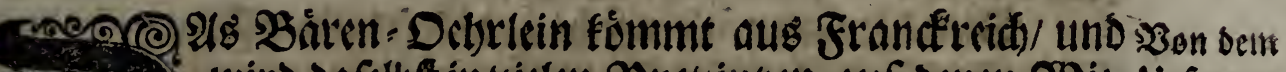

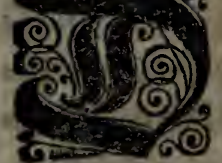
woird dafelbft in bielen Probinsen auf oenen 2 Bie = Urfprung fengefunden; Dod fino fie won senjenigen/twelde in bes 2 árent

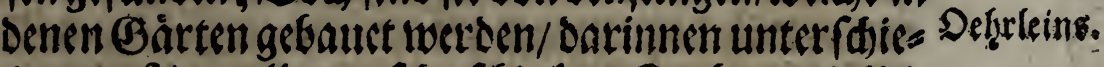
Den/ Daf jene alle bon febr fdsledten Farben und fleinen Gloden fins: Diefe lektere aber fo man in dentreatrten zeu= get/ und aus guten Saamen nusfudbet / alte fold)e (Figen/d)aff: ten an fid) baben / bie man an fdobnen uno angenebmen Blumen witniden fan.

Ob nun diefe Blume gleid) aus Franderd) fonmt/ fo fino oods die Frankefen die (Erften nidst/weldse ibre Sdjontseiten erfannt und angemerdfet baben / Die Flanderer oder Flamiman. Der baten fidh Diefelbige meble angelegen feun laffen als jent; Jann fie baben die erfe geforengte zu L'Isle in Flandern aufgetradt. Sienennendiefelbige Auricules, oder 2uriateln.

\section{(อุ}

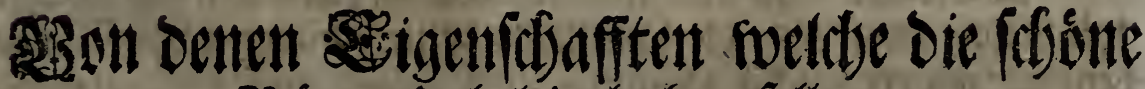
SBären=Debrtein baben follen.

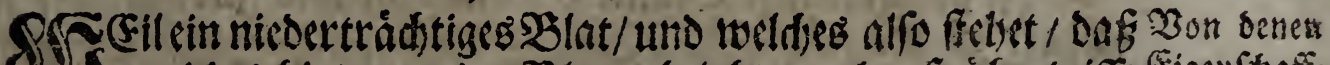

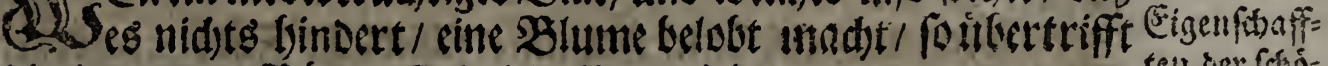
bierinuen das Sáren= Delorlein ibrer viele. 


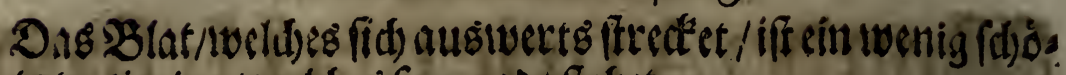

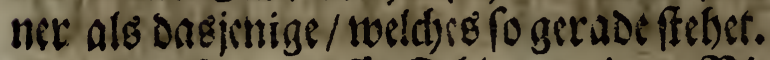

Egiff ein groffer Feller an cincin Blumen.Stengel/ wann er fo dinne iff / oas man itbn unterftisen inuf; attd) wann or fo fursiff / Dos manoen Straub faum feben fan: Snallen Din:

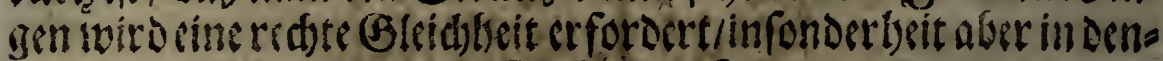
jenigen/ weldes zur:2ugenluft beffinmt fins.

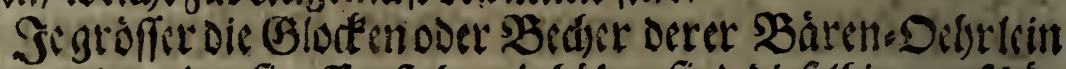

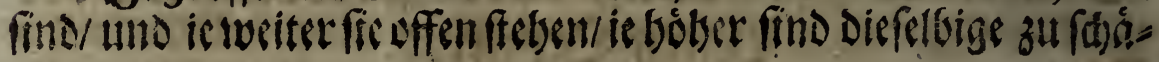
terll.

Biele darunter faltenfid/ und disfes iff ein Febler.

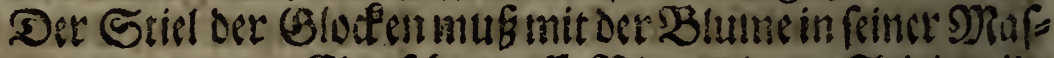
feitbercin fummen. Eine felgr groffe Blume/ Deren Stiel an ibs =

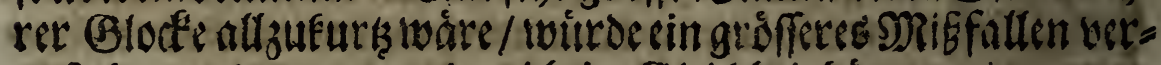
urfadsen / als wanner cineridstige (S) leiảbleit bàtte.

Das Aluge ant cinent Béren=Delstein foll gros uns wobl

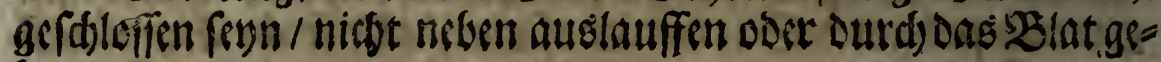
ben.

Das Ruge iff Dagienige runde Singlein/fo mitten in Det Blume ffelset/ uno faft allezeit gelb ooer (eitronen=farbidst iff. Zon dentri gefprengten madte man feinen groffen Stant.

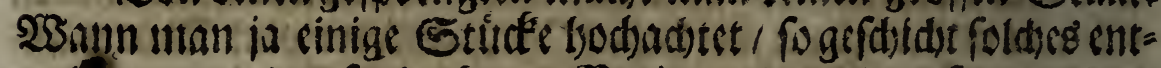
weont wegen Dec fonderbaren Breite. oder simce fo twumbers liđ) vermengtet uno bizarren Farbe/ Davon man . Sg finumy bat/

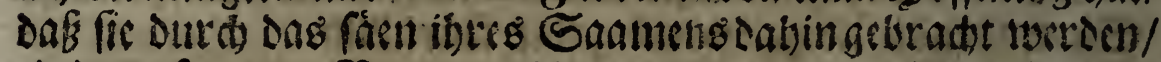
cinige gerpecngte \$lumen/ Die stwas von ibser atrt bebaltem/ mitzutbsitent.

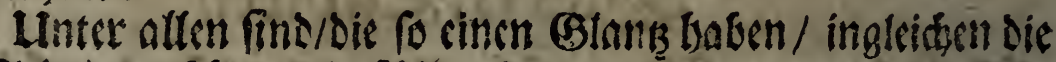

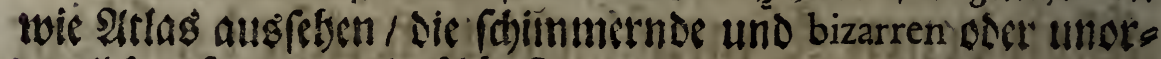
oentlid) geffrengte/sie fóomfer. fidioner iff fie.

Se gleider Diefe Blume gefprengt iff und Jarben bat / je

Man muf fid Gemibsen unterfatiedide) Farben ancenen Báren=Debrlein augzufinden / Damit man fie nemlid)ooncin= 


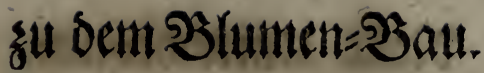

ander unter fteciben fònne/ Dann viel sarunter fersen einander

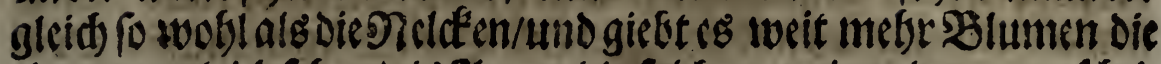

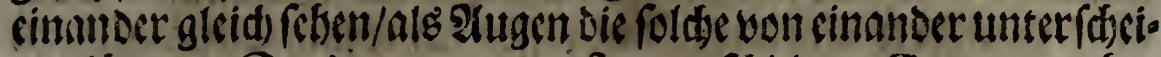

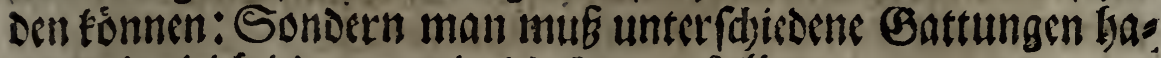
ber/ bie gleidf lederman in Die stugen fallen.

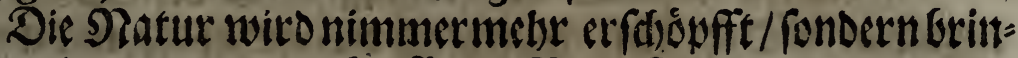

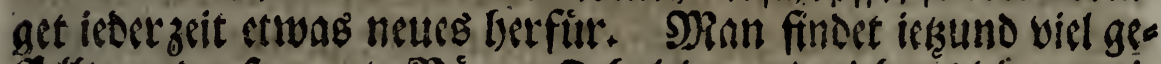

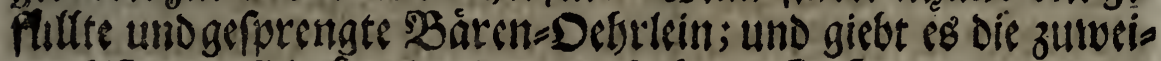
len GiE orrin Blodein in einander baben / fie find aber rar uns

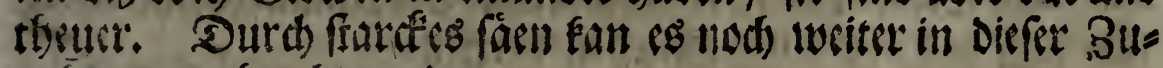
nebsumng geferadit werdert.

3e mebr dus 3 airen = Delbrlein fleine Glodecn auf cinem Stengel bat/ ie fdóner iffes. 23annes rings um ben Stenget

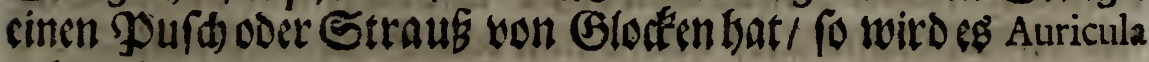
polyanthes genannt.

\section{2กหื III. Cnpitel|}

Som ber jutenen bintent:Selferteint tuidstigelt Eroe: ingleichem twie man biefe כilume in Dem Sopffe und in ibrer 2 luthe tractiren / und bie NebenEndóflein bavon abnebmen foll.

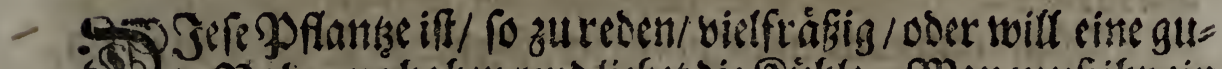

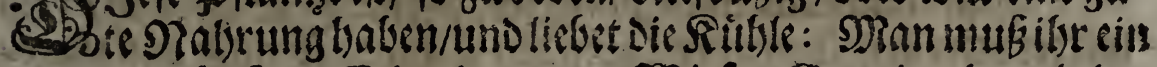

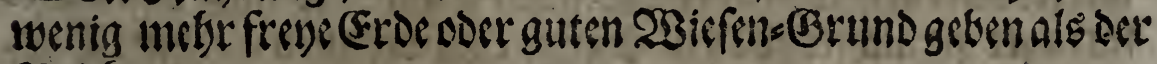
Neld tes. $^{2}$.

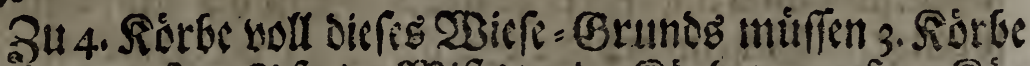

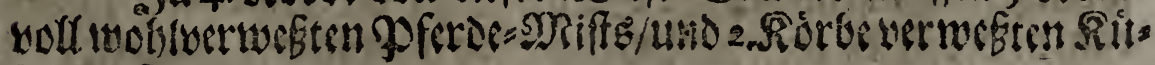
be $=$ Diffo fommen.

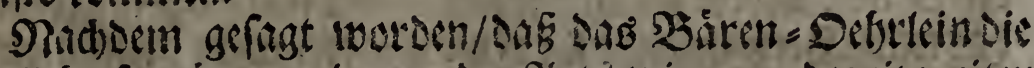

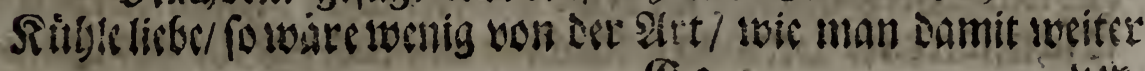




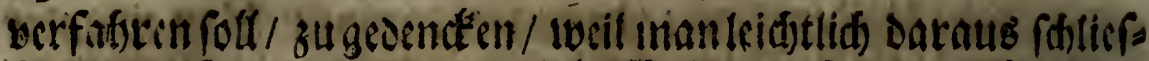

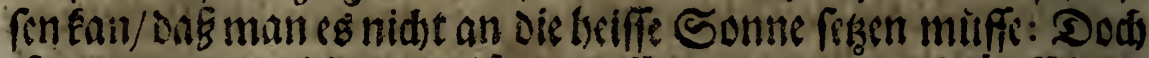

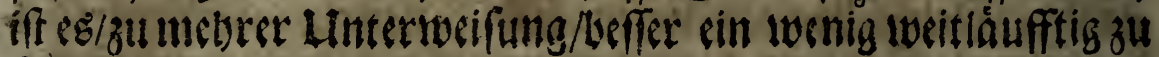
rovit:

(Gleid) 3u Rnfange ocs Friblyings/bur bein Blityen/ Fegst

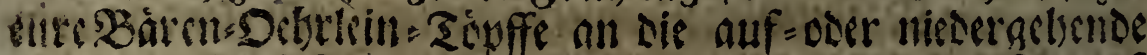

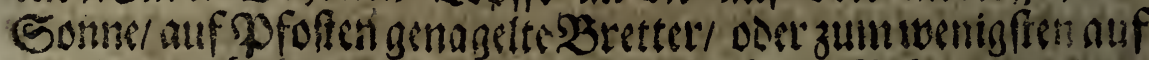

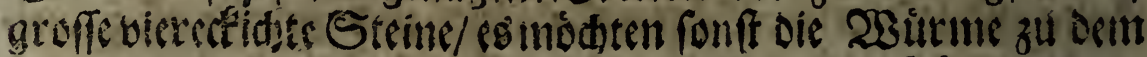

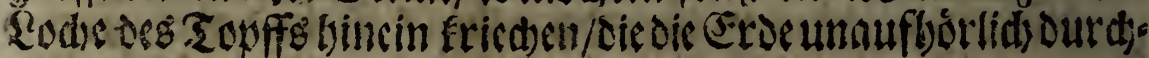
witglen / und uthe cinen Souffen werffen.

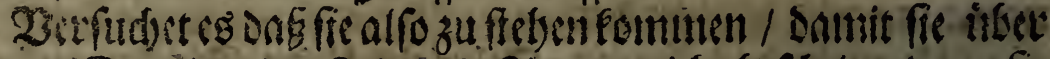

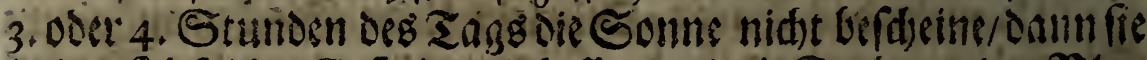
balten fid folder Geffalt tweit beffer/ und die Farbe an ber \$Blus me wiro vicl oundeflet/ unofómmt dem Sanmet gleider.

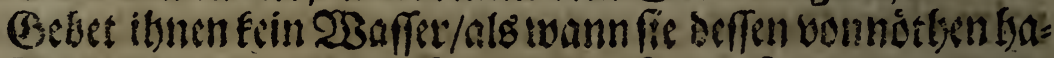

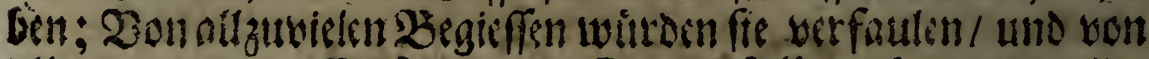
alizubenigen frafftiog twertoen: Darum faffer nidjt / indem ith siner Befalse entgetsen nollet / in bie andere.

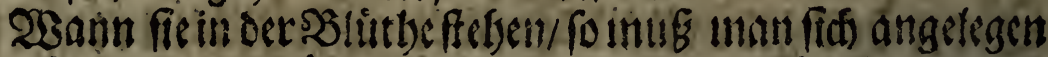

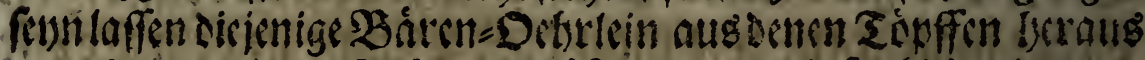

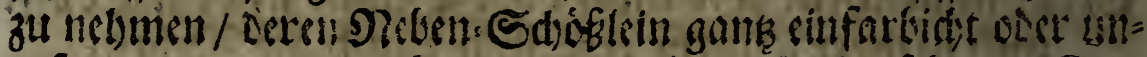

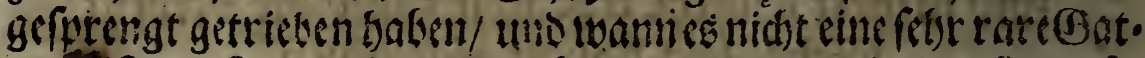

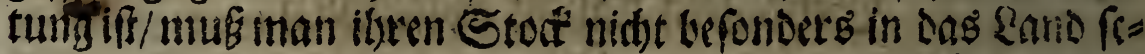

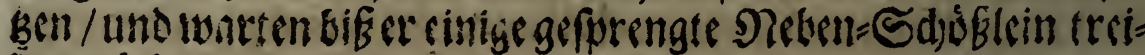
benmódite.

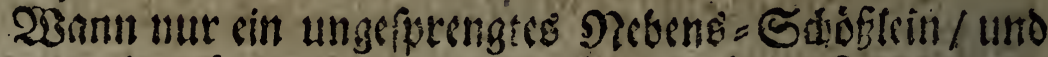

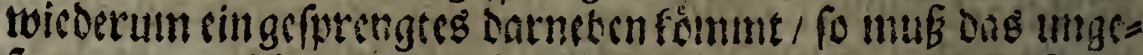
furengte zernid)tet / DaE gefprengt aber febalten wertem: Das= jenige/fo cimmal ungeriurengt gefoumen/miro nimmermelse geFrengt. Ein einfatbldt Sdjóblein zu verterien oser binzu= rid)ten Dorfft ifse cbensie \$of fankenidge nuenclymen/fondern reift

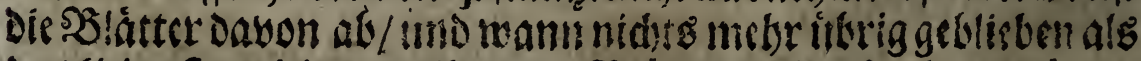

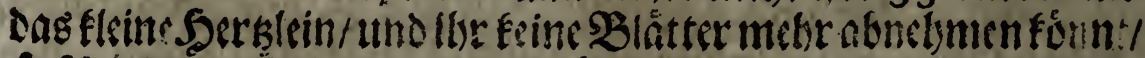

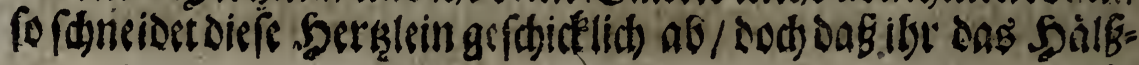




\section{รัดerniłlumen=}

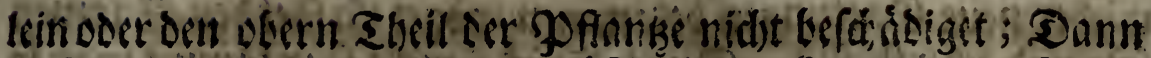

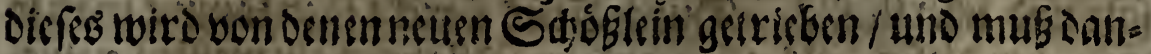
nenberoerbalten werten.

$28 a n n$ der in curcun Sapffefid be findendec Stenget untert

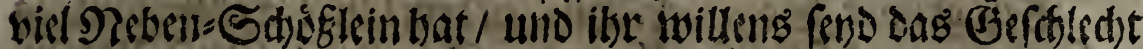

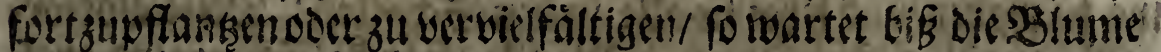

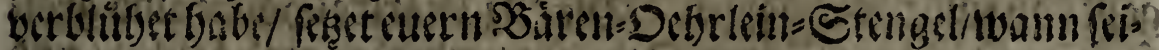

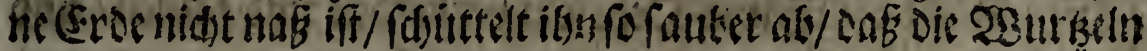
on-

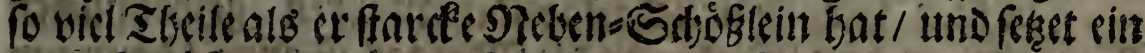

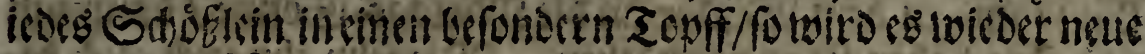

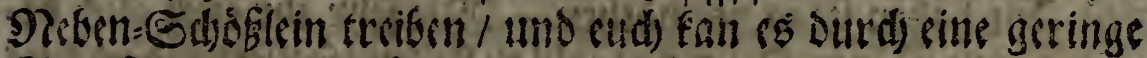
Sorgfalt nidbt an soflansirn mangefn.

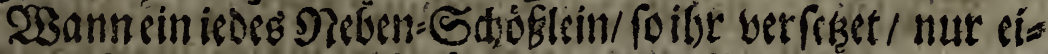

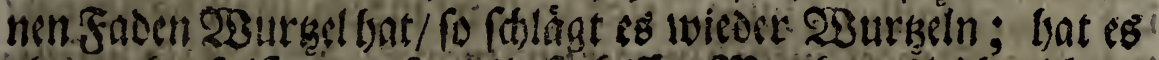

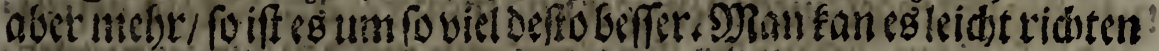

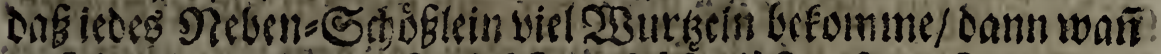

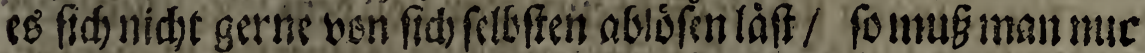

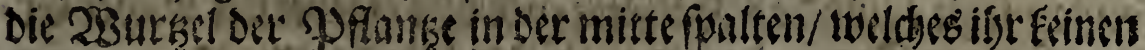

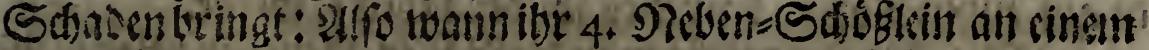

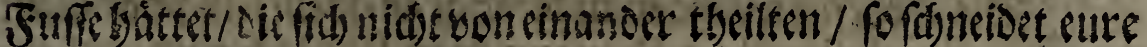

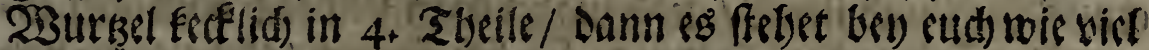
23urkern ibr cinem icden NeGen= Sadóblein laffen wolt.

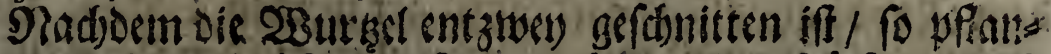

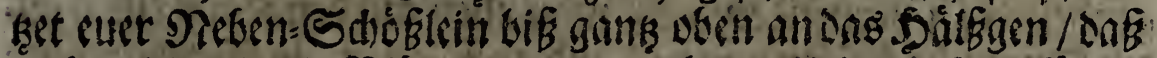

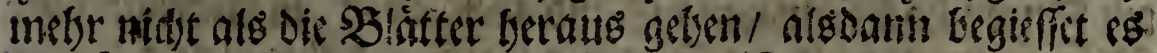

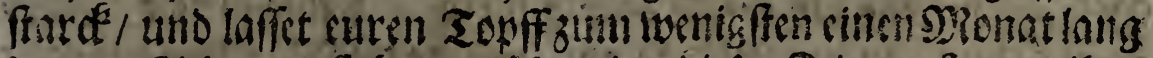

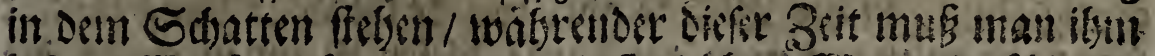

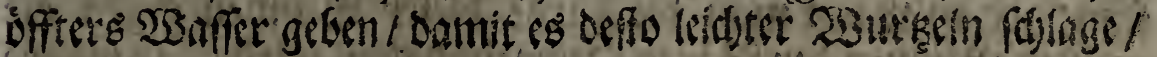
niemalš aber zu viel.

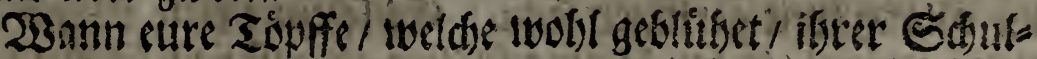

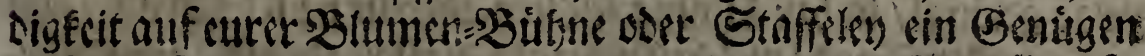

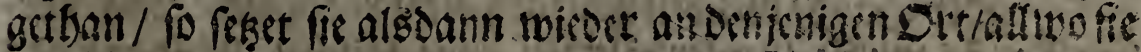

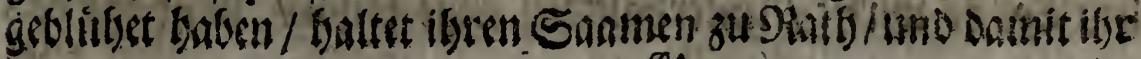


wieder netue Gattungen befomumen móget / fo fäet ben Saamen

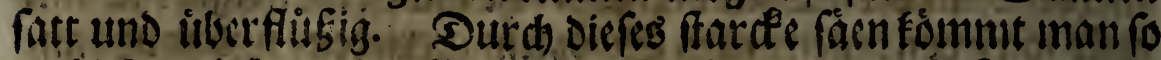

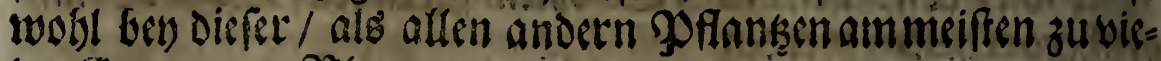
len Gattungen S3/umen.

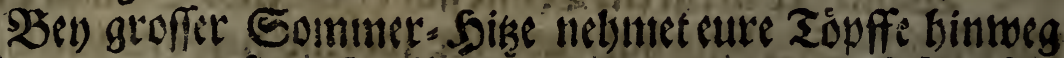
neo fie waren/uno feset fie alfe in Den Sdjatten: Diefe Zorfor-

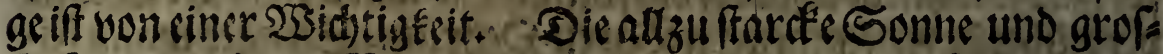

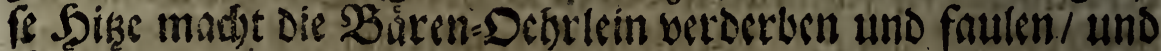
tobtet fie endididgat.

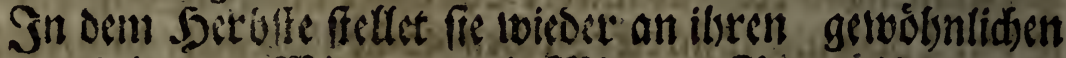

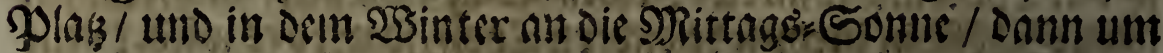

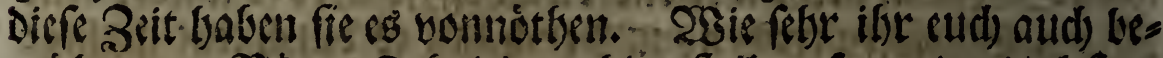

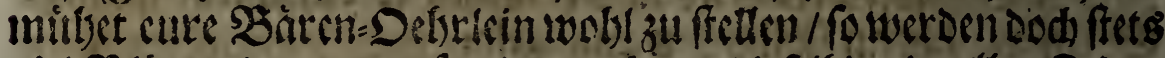
biel Blâtter Daran verfaulen / nelbmet Diffelbige in atten Beiten

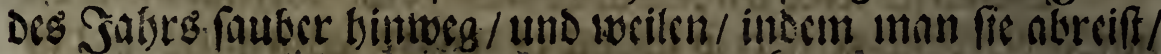

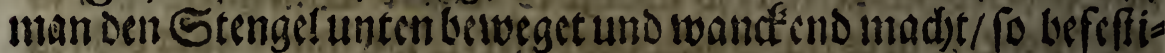

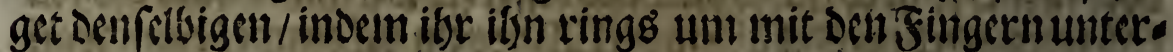

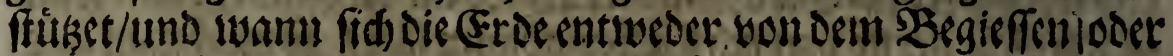

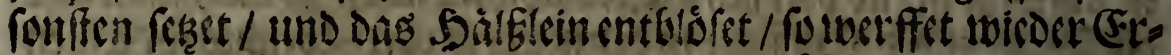

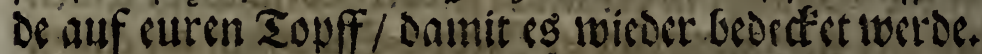

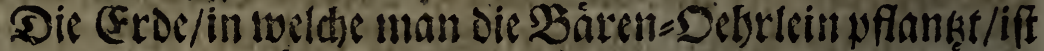

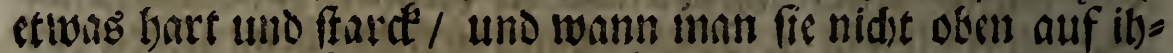

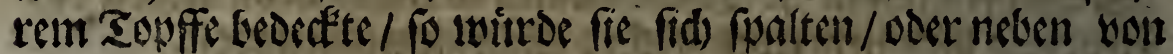

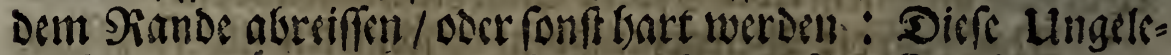

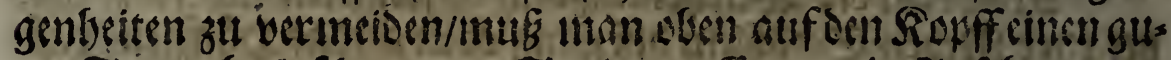

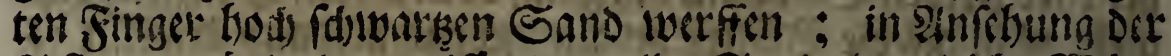
Poflange witrde der weiffe oocr gellbe Sand eine gle ide 23 sirs

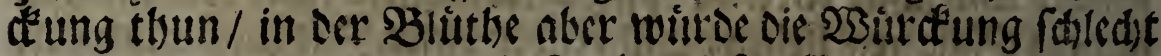
Fent: sann wamm man die Farbe diefer sblumen gegen die

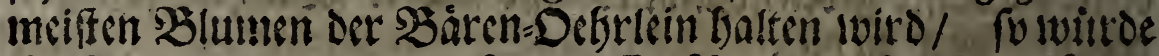

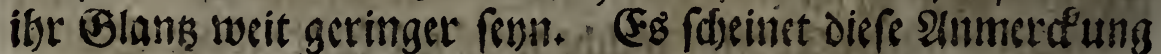

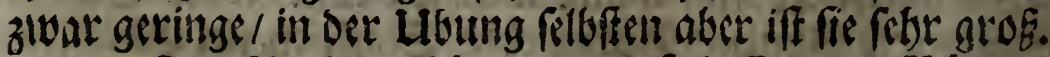

Der Sand/ weidsen man auf Dic Eroc des Bären:Deftr.

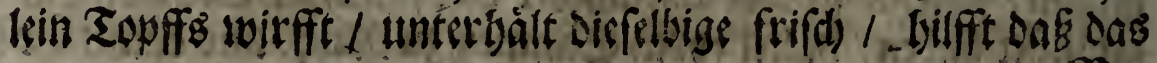
Be? 


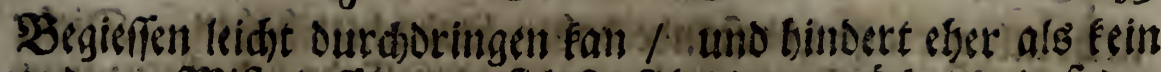

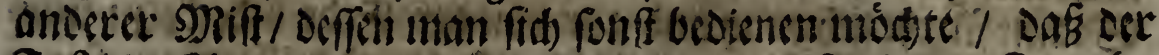

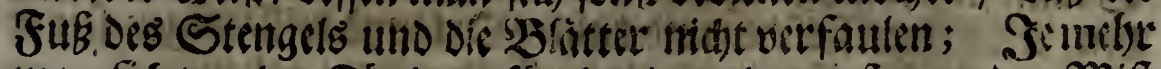

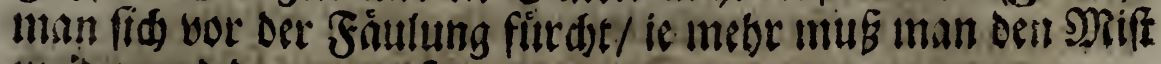
meiden und dakoin entfermen.

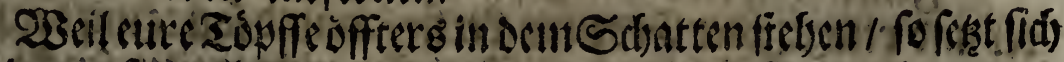

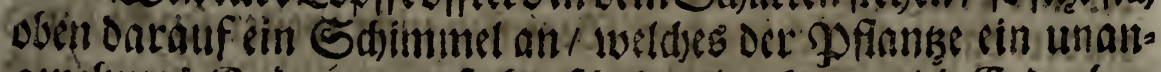

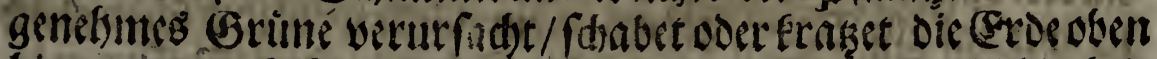
binueg/ und fdhittef frif(den Sand darauf. Die Sdjonbeit

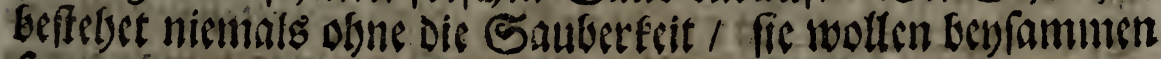
fring.

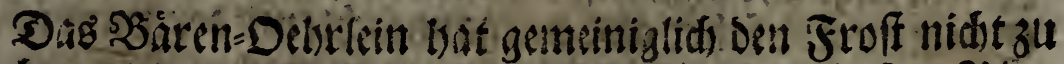

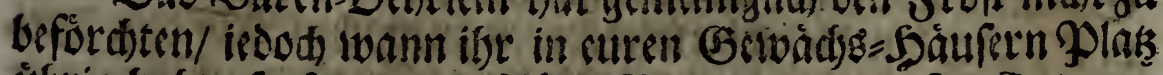

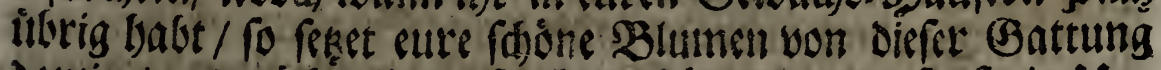

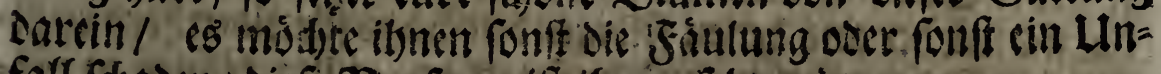

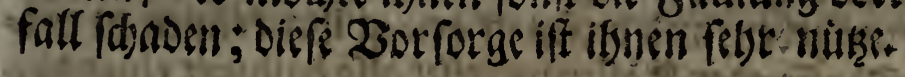

\section{2ns IV. Enpitel/}

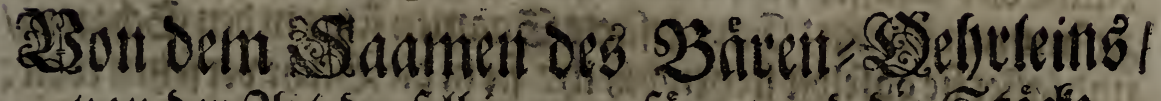
von ber 2lirt benfelbigen zu fäen / uns bie Stócte. oder'sgfaittsen Davon aufsubringen.

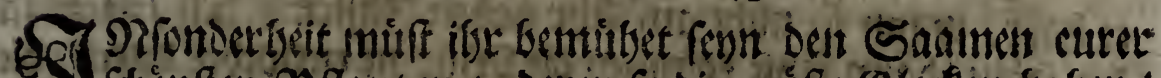

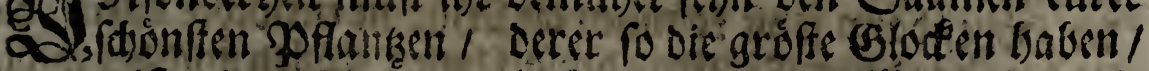
aum theifen Dent Sinmmet greid formmen/ hor allen andern bie

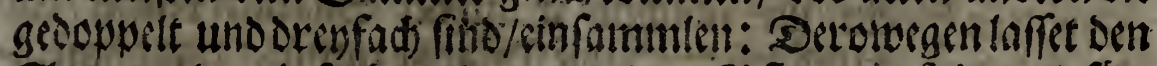
Saamen ber cinfatten ober gemeinen Moflangeir fablen/ faet liefer iveniger uno stivag gutts. werdeti.

Diefer Sgame ibif bu anfange des Septembris gefact

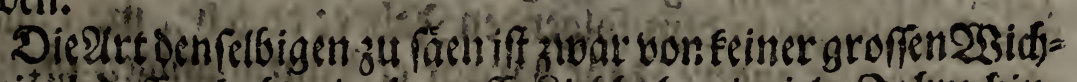

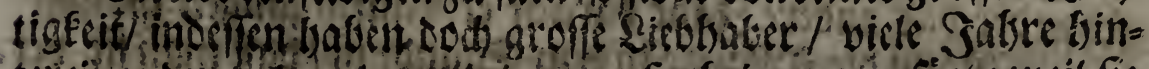

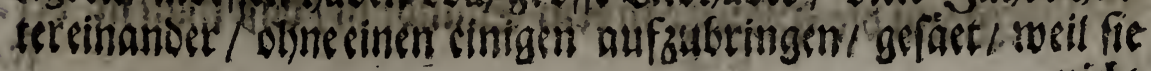
nidit 


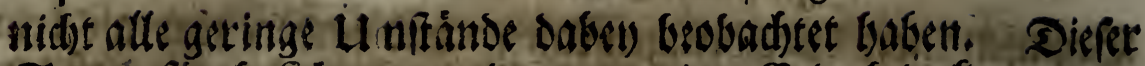

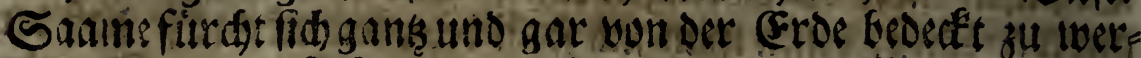

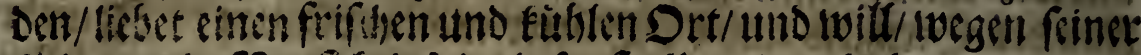
Eleine/intir 30 rfict)tigétitalö fonff alle andere baben.

Fitllet flade irroene Topoffeoder Ráften mit fobr guter leid)=

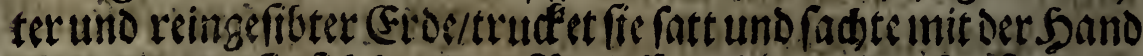

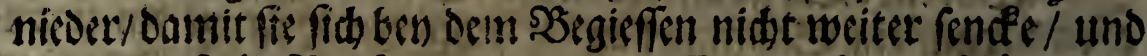
midet atf alle 3 orforge / wanneure (Erde wobl und fdjon gleid

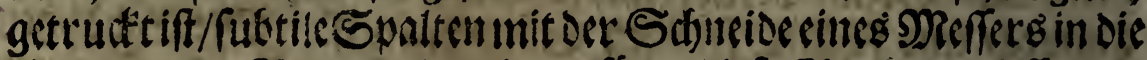
Eroe/ cuten Saanten Darein zu faien/Diefe Spaltenumuten as ber febrenge und nidst tieffeesn/ Darein faet etwas dimne curen

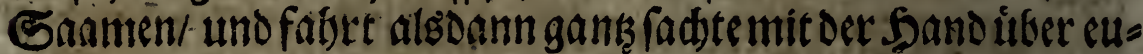

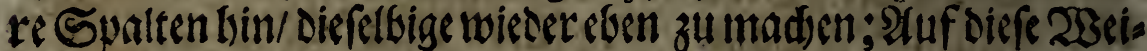
fe iff der Saamen entweder indie fleine Spalten gefallen/ oder bat fid) mit der aus oenen felbigen ourd bas faneiden beraus ge falleneneros ungeben/ unt diefes if genug ibn feimen zu mas d)en. Eute Topffe doer Ráften begiefet al fo balo mit siner elei=

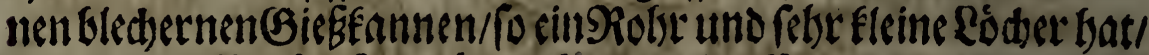
Damit Dag 23uffer foin dinne betaus lauffe/und die Froe nidst

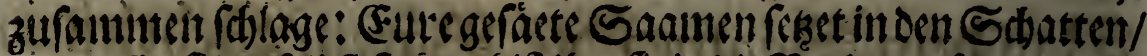

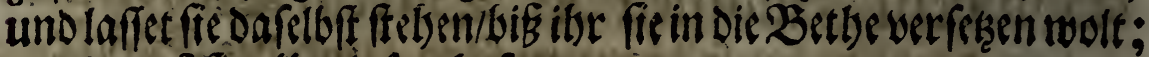
madet Dab́ fie allezeit feudit fentr.

Eure Topffe tind Ráften/ Darein ibr bên Samen gefä.

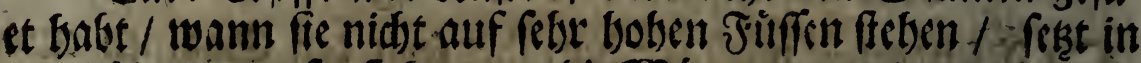

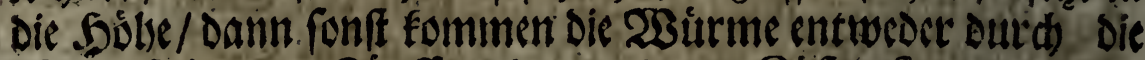

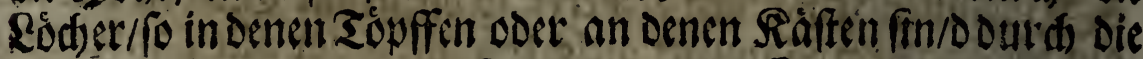
Epaiten bincin/ uno imaden/ wann oer Saamen feimet / bag

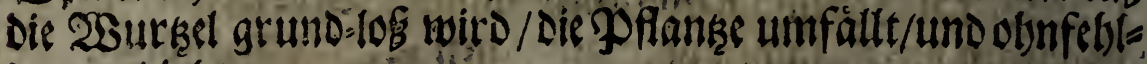
bar verbirbt.

Butweilen geber ber Saame / gleids das exifte Safit als et gefaet worden/auf: gemeiniglid aber gefdiddt-foldses zu (Finde DeE Sritblings/ in oent folgenoen Sabre; Dods lat man aud ge= felyen oer das andere Sabre darauf crft aufgegangen iff

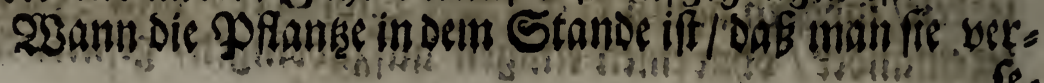




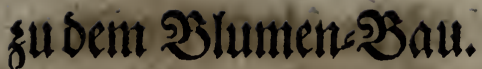

fegen fan/ mus fie alt cinen fublen ort dis Gartens/umzufe ben ob fie gefprengt fommen will/gefest werden/gefdjidjt bies fes leatere / fo thut man ibr gleids bery ber erffen sliutbe ober Sllume ibr redst / uno verseget fie in Towffe.

\section{Bon Det Orchis Serapias, Setapifahen} Stender-WBurs oder Snaben=-Sraut.

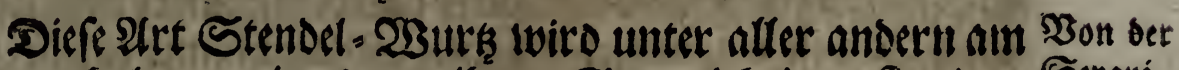
bódffen gebalten / rings üm ibren Stengel bringr fie cinen

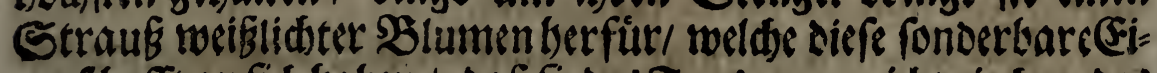

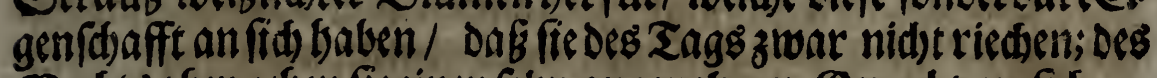

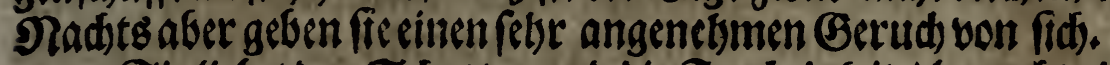

Sie lieber ben Sdjatten und die Fenddtigfeit / brautdit e eine fatte oder ffardée erde / uns muB 5. Finger tieff / und echen fo weeit boneinander Befeset werden. SRan nimumt fie febte felten aus.

\section{2un Dem Ornithogalo, aldols fitaut

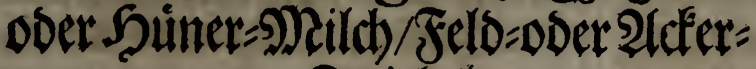 z̧wiebel.}

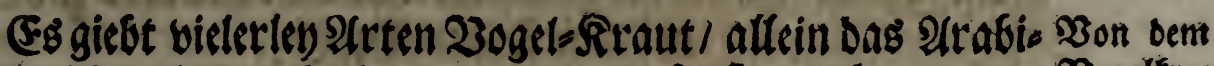
\{fe/ / Ornithogalum umbellatum maximum, fonffen aud Lilium Alexandrinum genannt / ingleideem Ornithogalum exoticum, ober Das auslánoifdec 2 ogelferaut / welddes aum Indicum ober Das Sndianifde gencent witrs/find am wertbeffen gethalten.

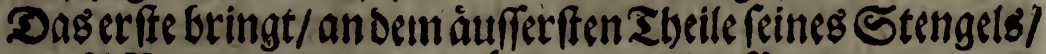

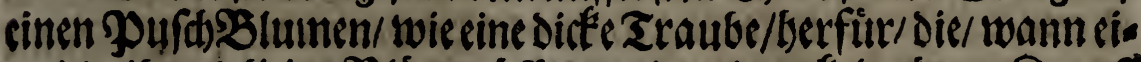

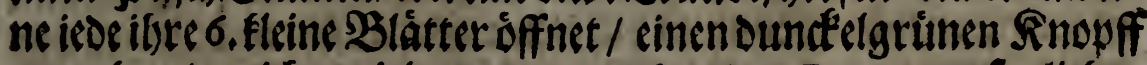
umgelven / weldden viele Les Larmes de Nôtre Dame, unffrr lieben Frauen TGgränen/ zu nennen pflegen: Sic fangen yon unten an

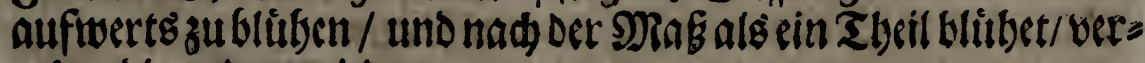
gelsen bie andere twieder.

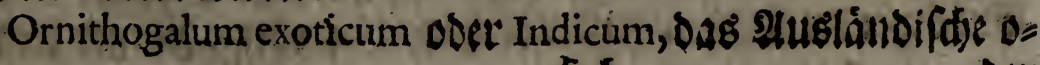
Dh 


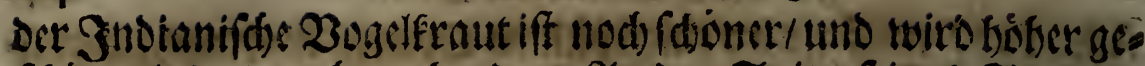

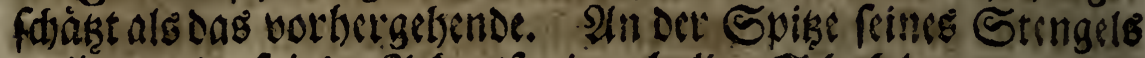

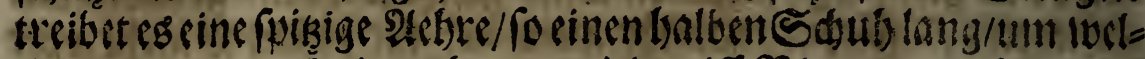

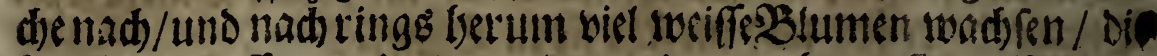
ben ibrer Deffinumg in Der mitten cinen grimen: Sinopfir entoce tén.

Dar Ornithogaluntoder 3 ogclfraut will Sonne/ und in

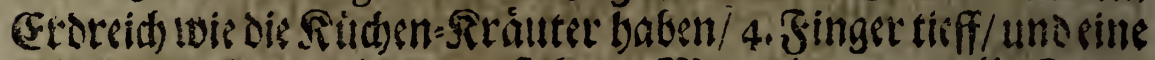
Spannc weit bon einnhoer fetben: Maan nimme eo alfe Sabje

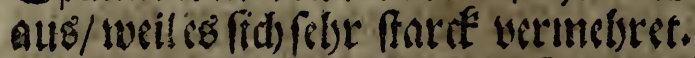

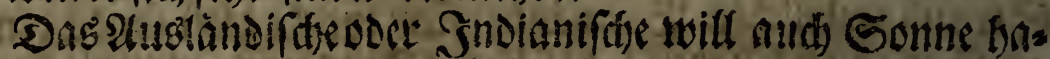

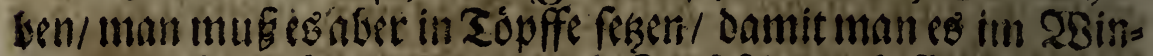

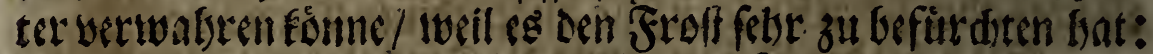
(EB braudets cine gute (FrDe/ Darff nut 2. Finger tieff/ und cine

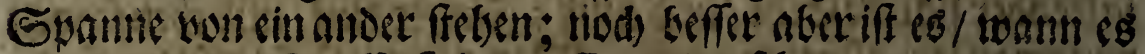

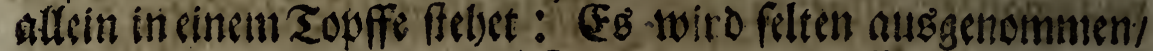
wannaber fecin Saame reiffiff/ mus man ibn faen: unan bers

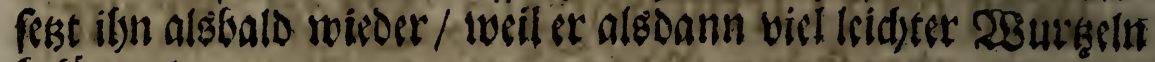
betémment.

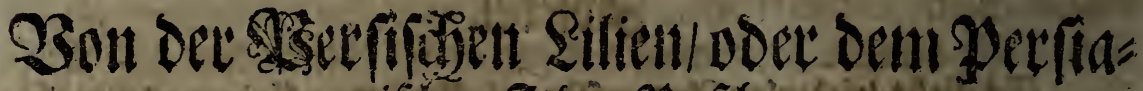

\section{nifiten Seder:PUif(d).}

Son ber Derfificent silien.
Sintwirs aud) Lilium Sufanum genennt / fright rîigs um

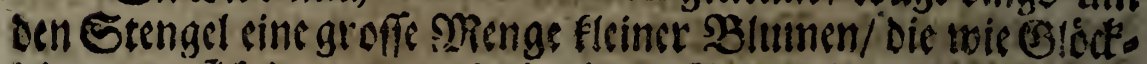

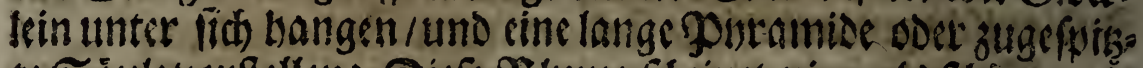

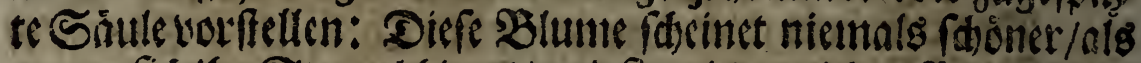
wann fï ithr Stengel bieget/ und fie swieder nicder fältt; Dann es formiren fid alsoann fo vict fleine Stráuffec uno freigen aus Dem (Grunde fo viel Eleine gitldene Fáferdien berfür. Dab es das

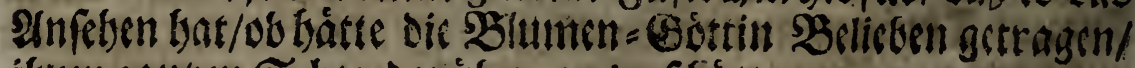

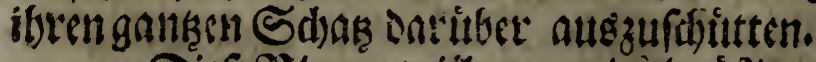

Dieferblume twill nur mitfetmábige Sonne/ uno sine

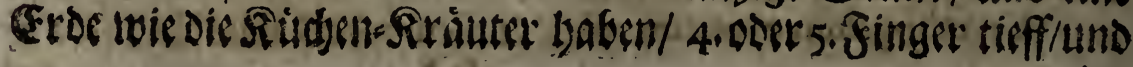




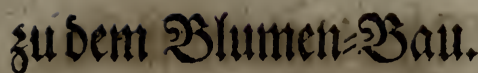

cine Spanne weit yon tinander ffeten / und weil ifere 3twiebel/ eben fo wernig als dert Räufer= STronen isre / mit ciner Edelelfien

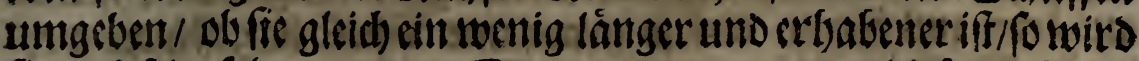

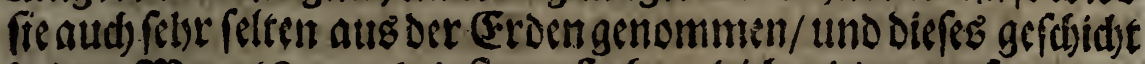

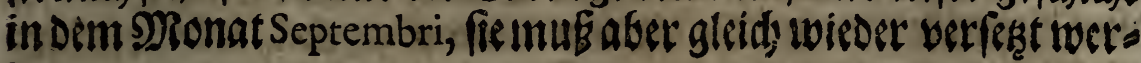
Den.

Bon bet Paralyfi,Serg: Sanidellodersetgs Sd)hiffet=-Slume.

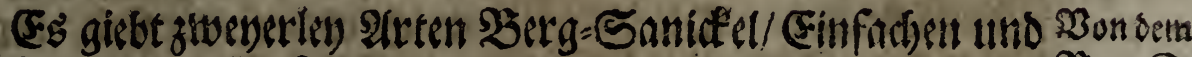
Gefittten: Der Einfade bat cinen hoben Stengel / an beffen Berg=Ga

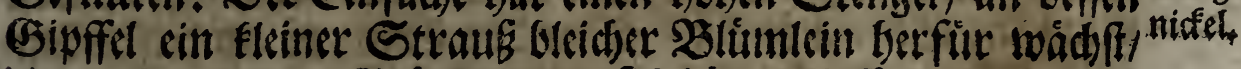

Die Den SRand íteres Blátter unter fid) bángen laffen.

Die gefuttle iff fo woblt wegen der Farbe/ als aud wegen

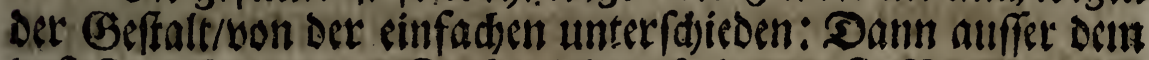
Daß fie auf Eitronen Sarbe ziebet / fo bringt fie BBlumen / De= ren eine inter andern ffebet / weldes dannenlyero ben denen Fran. Bofen den 9ramenL'un dans l'autre, (eine in Der andere) Gefolm: men baben.

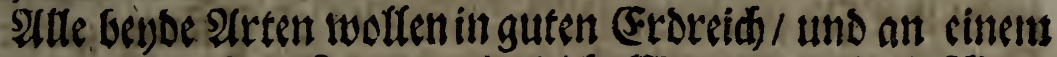

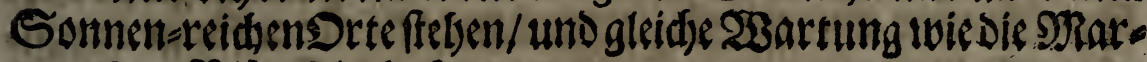
garetben=Sliunlein basent.

\section{3on Der Paffions-3zlume.}

Diefe Slume / twilde Die Sndianet Marocato, unfereneule Bon bee

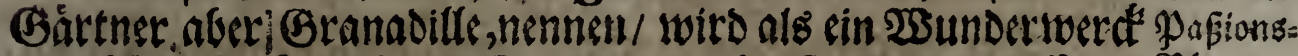

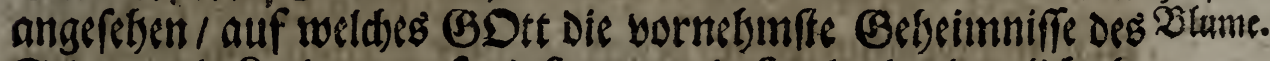
Todes uns \&endens unfers Serrn und Sevlandeg deutlich abs: gebilder bat: Dann wann wir Dic Blätter / welde diefe SBlus me umgetern / anfeten / fo feflen fee ung sas ficio vor/weldscs Sthme die Süben zum Spott nngezogen: Die fonatfs Spizen/

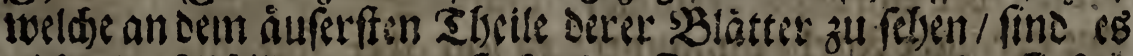

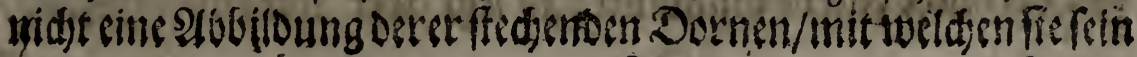


Saupt gefrònet baben? Luno diefe fleitue mit Blut = Farfe be: ficefte Báferlsin/ Die rings berum bängen/ zeigen dic Siutben an I mit welden er auf fo graufame wssife iff geffauwt wor: Den. Die fleineSáule/ de in Der BBlume bervor freigh / weifet uns dicjenige / an weldhe $\mathrm{Fr}$ ben Pilato ofye einige SBarmbers kigfeit angebunden worden. Der oben auf feebende Sut bils bet oen in Galle uno Egig getundeten Sdbwantm ab / Der ibme Dargereidt worben. Die 3. Doer 4. Eleine Pfálgen ooer Bapfs $\mathrm{fen} /$ fo itber oer Sáule binauf geten / formiren Die fpisige Nito gel / mit welden man ibme fo unmenfalid) die Sänoe und Stifs

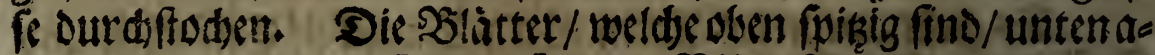
ber an Dem Stengel fteben / fino cin Bitsnif́ Der Rantse / lwelde itsm feine Seite geoffnet. Nur Das Ereuks ift an diefer Blu. ine nidbt eingsoridet / wiealle andere Inftumenten des Eendens/ zu rebent.

Diefe Blume will an sincm Sonnentreiden Drte / in cie ner fetten und feuditen Groe ffeben: Die 23urkel wobl zuptan. Benmus man fie biegen/3. Singer tieffe einlegen / uno wieder mit eben diefer Ersen zudcteen: fie formmt fo wobl in Towfen als in dem lande fort / man ınußs fie aber ringg un sen siano wobt mit Biegefn verwwabren / dienceil Diefe Psflanke gerne auge fdinecifft / uno ieberzeit dic Frevbeit fudbt; fo fie anfängt nuezus

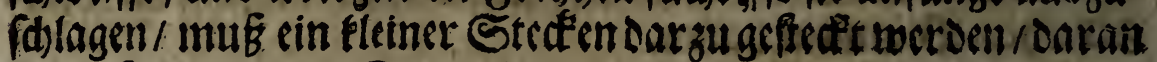
man fie mit einem Faden binde.

\section{Gon dein Sumach oder 23erber-82aum.}

Der Gerber:Saum / wectdermman Rhus nennet/ hat uns

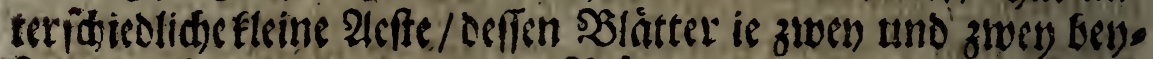
farmmen bàngen' und denen s3táttern des Spenerting b ocer Epreber=S3aums gleiden. Er blitset in Dem Majo: an sem Gipffet eines ieden Aeftleins formmt cine Traube ober Rolben

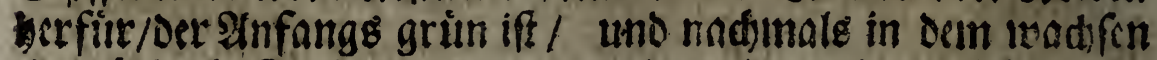
eine rotblide Farbe annimmt; zu lest aber wird diefe sStume/ 


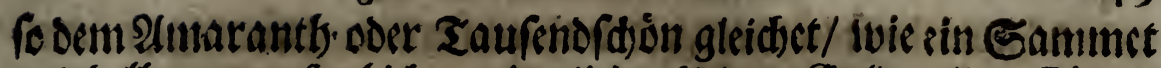
und bell-purpurfarbidst / mite etliden Eleinen Gollesgellben Sớrno lein untermenget / weldsee lie nod) fdósner inadjt.

\section{Bon denten seripolinifaben Sanunteln oder Samen=รup.}

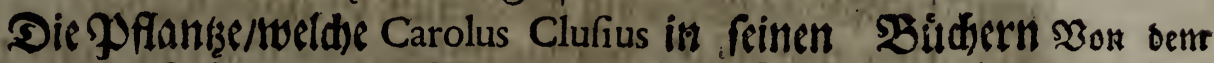
Ranunculum Afiaticum grumofa radice nennt / iff elen Derjenige/ triopolini= welden Die Frankofen Renoncule de Tripoli nennen. E\& giebt fden Sganen=

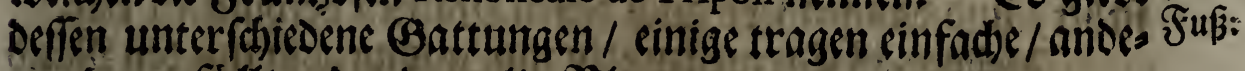
re aber gefiultete oder boppette SBlumen.

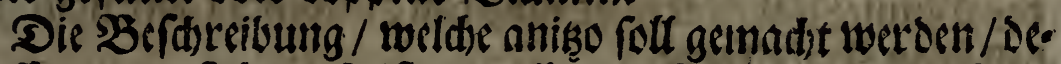

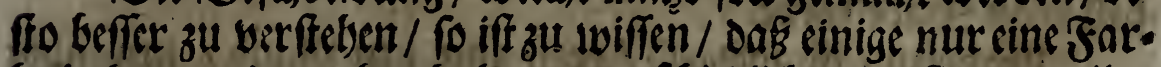
be baben / andere aber buber unterfofieslide / und find zutweilen

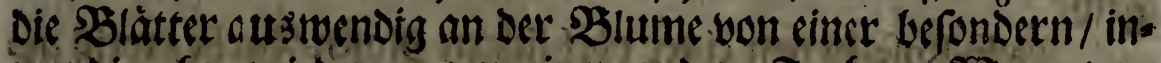

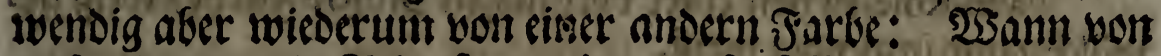
Diefen lestern die Siede feun wird 7 so rod die austwendige

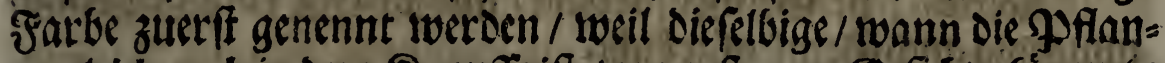

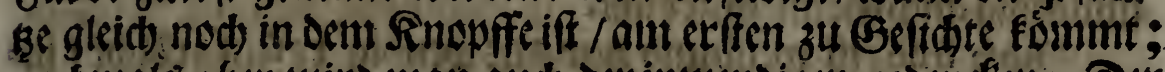
nadimals aber woirt man auth ber intwendigen gedencéen: Derr

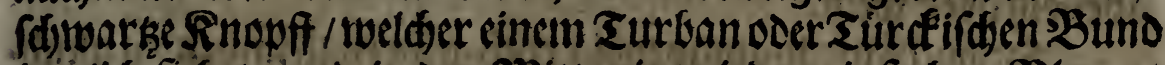

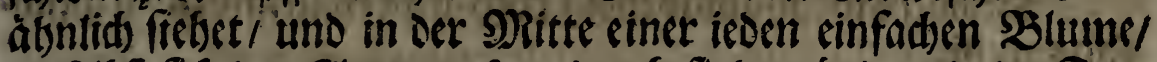
woofelloff fid, oer Saaume formiret/sefindet/andert in Der Fars-

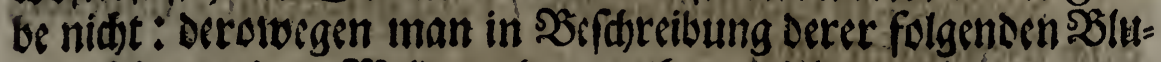
men feint weitere Meldoung davon thun ivird.

Der $\mathfrak{A}$ nfang fold mit senen sinfaden/ und die nur cine Far. be baben / gemadist werien.

Die cinfade tripolinifate SRanundétitu/fo aur sine Sarbe

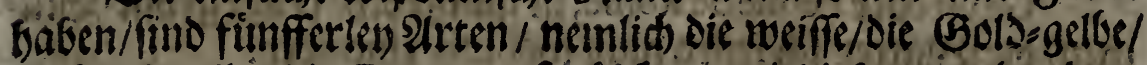

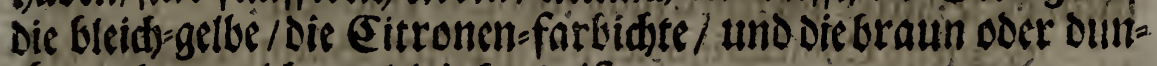
dfel rotbe / wellde wobliriedeno iff.

Die cinfade SRanuncé eln unit cincr gecoppesten Sarke fino folgendoc/als bic

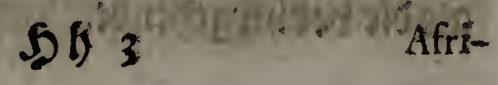




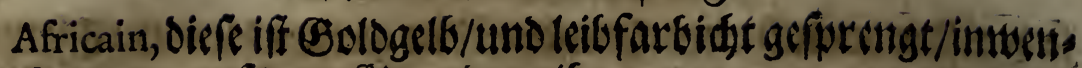
Dig aber ooer auf dem (Sirunde gel6.

Aurore, iff gelf ausibendig am Der SBlume/leibfarbidit ge= fprengt/ inwendig 2(urorfarbid)t/

Befançon, ift bleidjgetb / roth gefurengt/ intwendig getb.

Calabrois, iff rótblidft ooer von ciner Gemfen Jarke/rotg um Den Siano / intoendig gleidfalls Geemen farbid)t.

Drap d'or, iff 5010 -gelb/ und ausivendig mit rotb unterinengt/ fo daf fie simem Drap d'or ober gitbenen Stitefe gleid) fiefer / uno Dannentero audj diefen glamen. Gefommen bat.

Melidor, iff Earmefintotb/ nut augivendig uim Den Rano

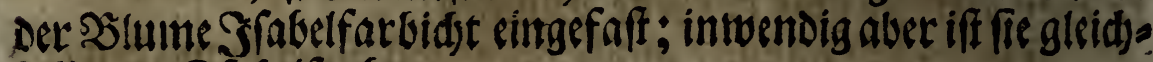
falls von Srabelfarbe.

Parmefan, iff gologelb / roth um den SRand / intoendig gellb.

Pafe-Rofe, iff won einer rotthlidtet Siofen=Sarbe / tweíß gee avollet $/$ und intoendig tweif.

Romain, iff Gemfenfarbidft/ ausewendig rotb gefwrengt/ Intwendig auds) (semfenfarbid)t.

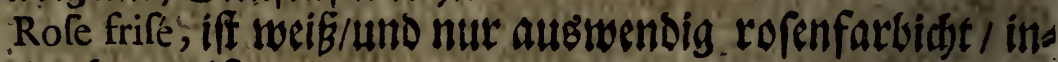
twendig aber weif.

falts weik.

Satiné, iffrweiß/austwendig rotb gefprengt/inneendig gleid.

Sydonien, if Gemfenfarbid)t / roth) geforengt / imuendig aud) Gempenfarbidt.

$\mathrm{ben} / \mathrm{fmo}$

Die gefúlte Sanundéln / fo nur cine cinfadje Farbe ba

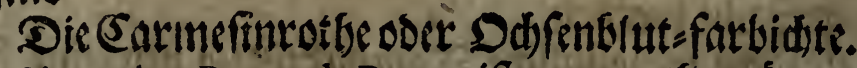

Geantodir Peone de Rome, iff gants rotb/trágt groffe 2 the

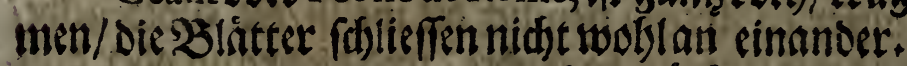

Géant de Conftantinople, hat gróffere Blumen alB bie vot: betgekenos/ aud ffeben ifre sE!ätter in Gefferer Oronung.

Die Gelbe init SRauten= Solättern / bat Eleinere SBlumen als die vorthergeternde. 


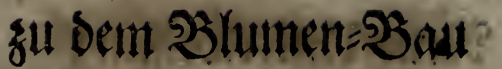

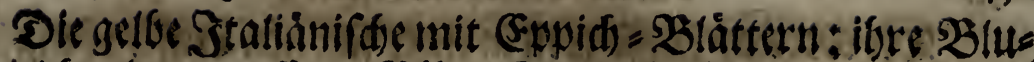

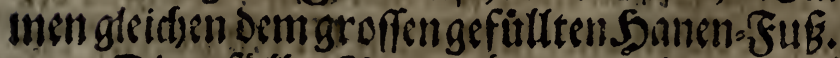

Die

Diegeffutte Ramundételn mit siner grcospelten Farber fino

Boluiel, biefé fómunt bon ber fleinen gemeinen poomerans Genfarbidten ber/ weldje gellee Streifenthat.

Geantober Jaune de Rome, iff gello geffrcifft/ aber wers

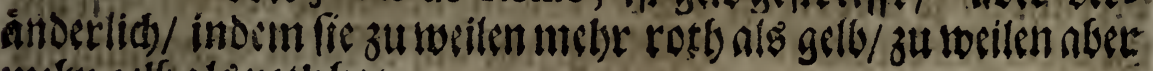
inebr gell bals rotb bat.

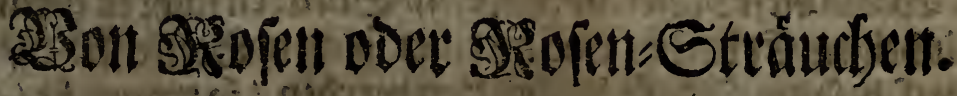

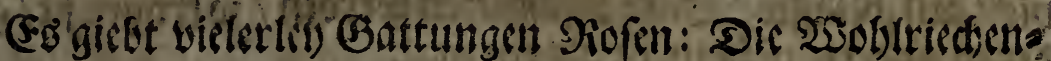

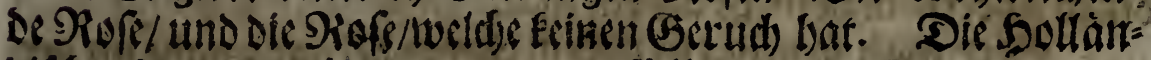

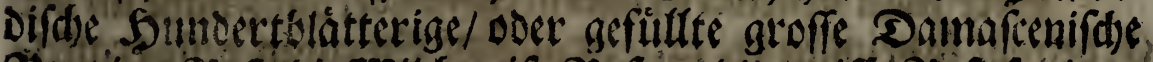

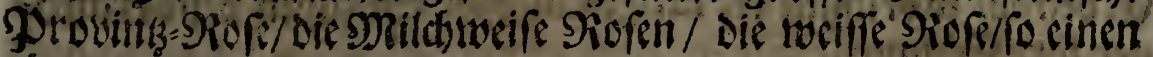

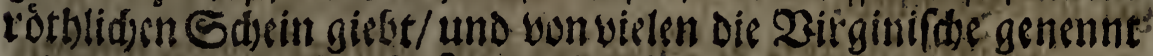

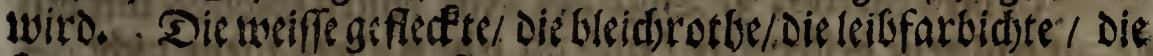
fattrothe Proving= Siofent genannt. Die Befprengte Siofen/

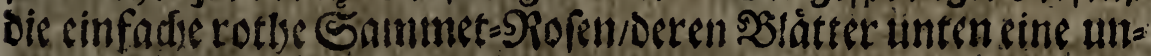

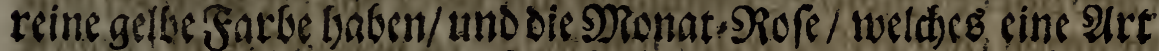

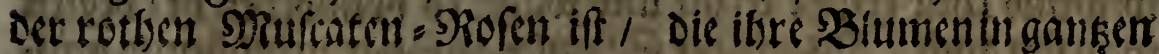
Eträuffen bringen. Dir gelbe Shofe/dieGroffegenannt/Dic Das: mafernifhe / oser SRufcatesRofen.

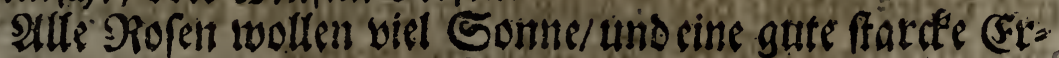

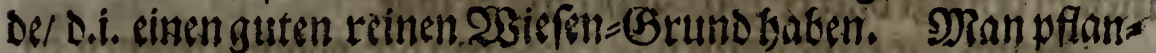

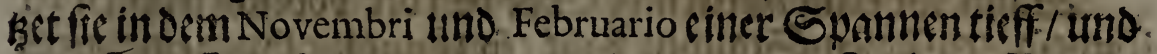
fiket fie 3. Sdubse weit cine von der andern: Sn Dem Mronat

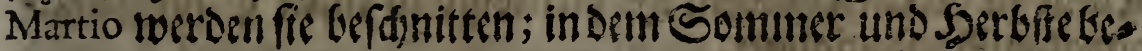

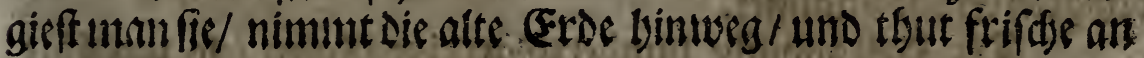
ifsere Stätte.

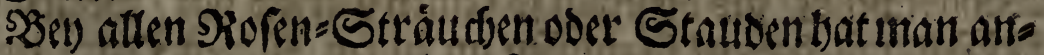

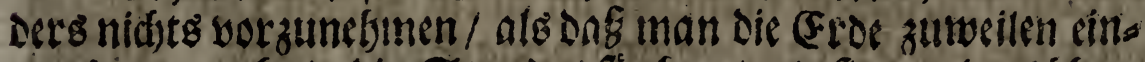

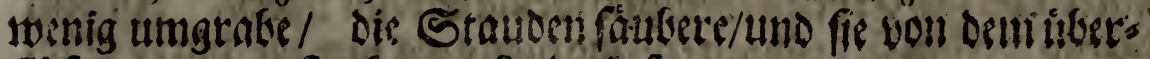
flubigen und erfiererenen solige befretse. 


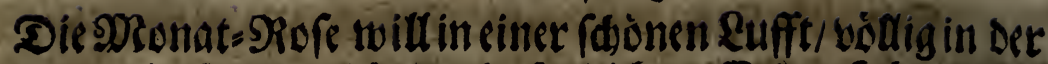

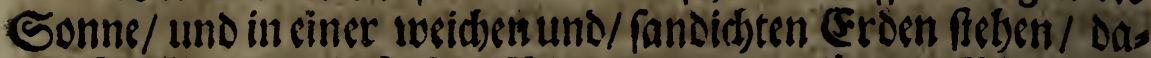
mit fie alle Mronat frifde $\mathfrak{B l u m e n}$ tragen fonne: $23 a n n$ die erffe Slumen vergatigen find/ fo fancider man fie unten an Dem Gleide ade: Rnotế unter senen be fagtểSlumenab/undwannibs

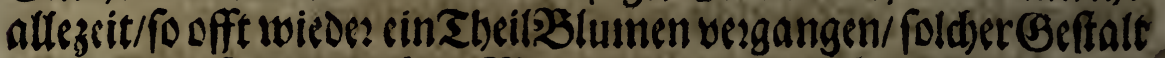

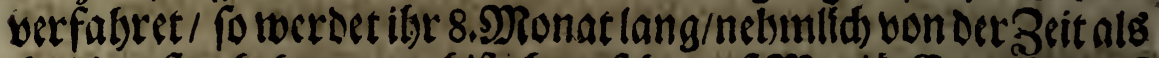
ilsr die etfen befommen/ biß obngefebr auf SRariá Empfängnif in Dem Decembri Siofen baben.

W3ann Diefe Piofen Doer $\Re$ Pofen=Stauben nidtetie einem fols wentuditigen Croreid/ uno an einer folden Stelle fechen/aud

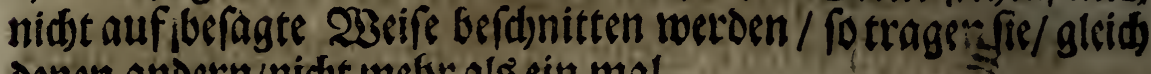
Denen andern/nid)t mefbr als ein mal.

Oder man fdnetidet fe in oem Novembri gank nabe-an oer Erden ab/ fouringen Die neugewadjfene Stauden defto erâffie ger iffre 2 lumen.

In Dem Martio, 3. Tage vor Dein bollen NRonde/ twerden fienuf bas neue Gefdritten / uno an iederm Drte imebre nidst als nur einoder zlven 2ugen fteben gelaffen / alsbann nimme man

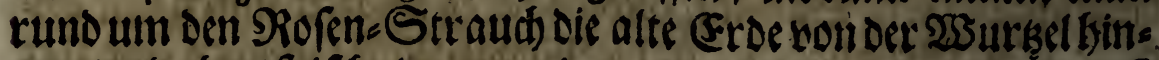
weg/und thut frifde bazu/ uno wann es vonnotben if / begieft man ibn aud). 23annoer Straud anfángt zu blîtenen/fo milsfen alle Rndopfe/ ebe fie fid nod offnen / abgenommen weroew

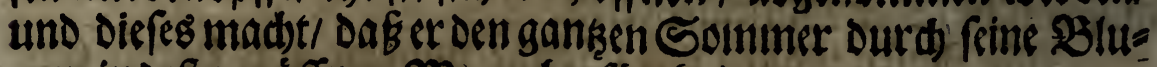
men in defto gróferer Nengeberfür bringe.

28ann ibr feine naturlid)e (sroe von ber obbefderiebenen zu

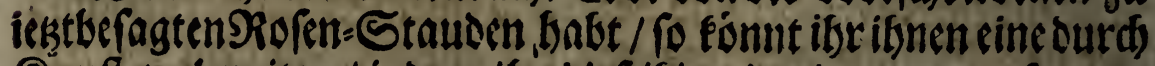
Runft zu bereiten / indem ibr diefelbige in cinen genugfamges Dingten Sand p flanket.

Die Sollandifde bunecrtblattrige Rofen / fo mobldie 25obltriedende/ als dicienige fo Eeinen Berud bat / wodken gleidewartung baben/ fie mutfen an einem futblen Orte/ und in guter 2siefen= Erden feben/uno wenig Sunne baken. Sn Dem Martio werden fie gefdnitten/ und nidts als nur bic Durte Spi. 


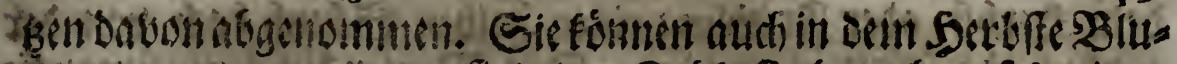

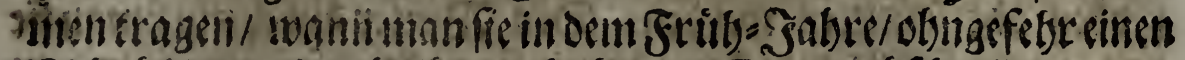

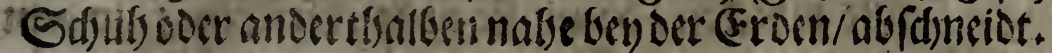

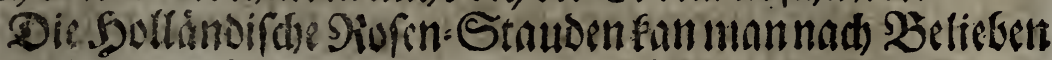

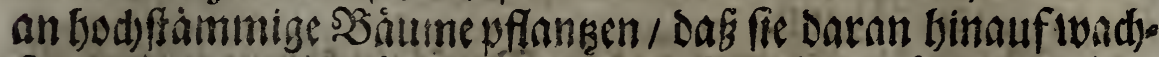

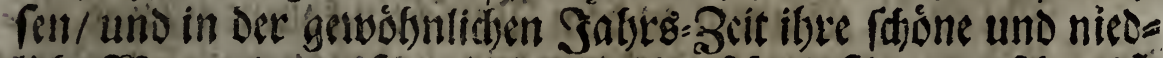

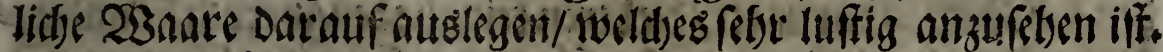

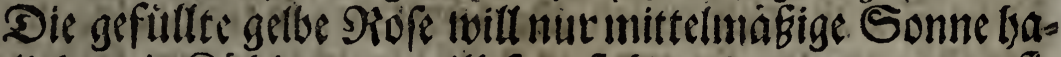

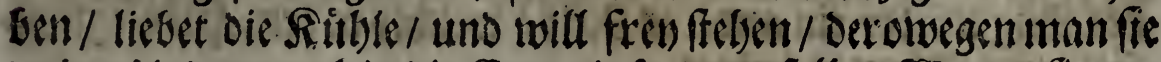

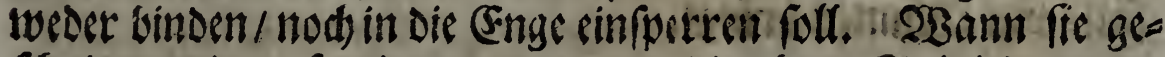

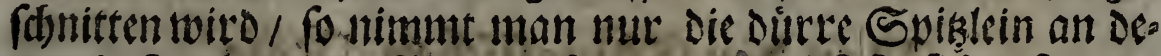

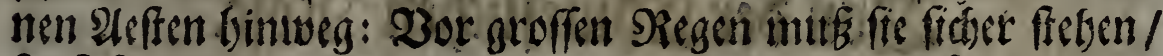

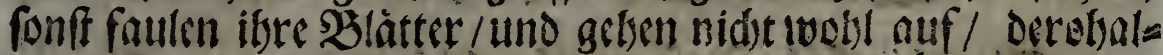

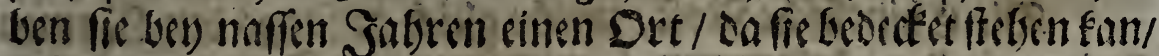

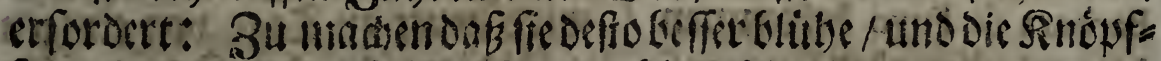

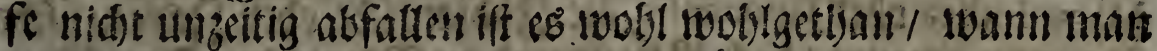

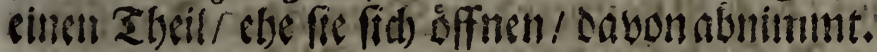

Damit fie alle Sabre tragen/ muş main fie/ roandoie

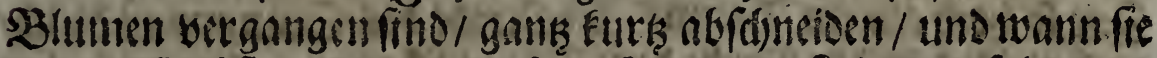

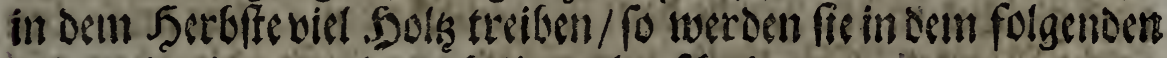
Febriario ober: Martio no dif cimmal gef d́n nittent.

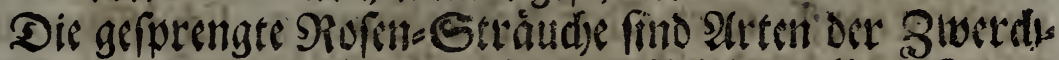

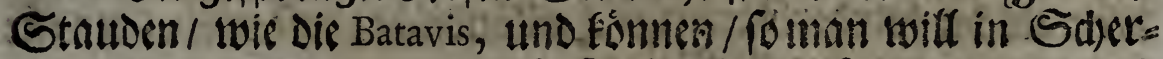

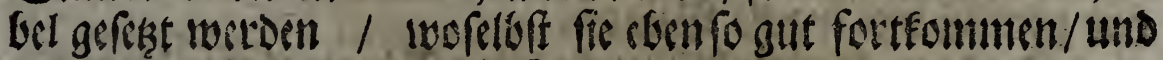
Das ibtige tfun / als indosin \&ande.

$20 n$ biefen und alidern Piofen = Etanden fan tuan aufgere meitive Siofen = Standen Sdjiltetweife probffen dDir oculiren/fo serben ffe / wann fie in Julio boer Augutfo oculiet werden/ Esines wiges untertaffen / sas folgende Gabir carauf soltumen

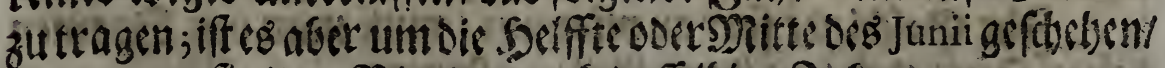

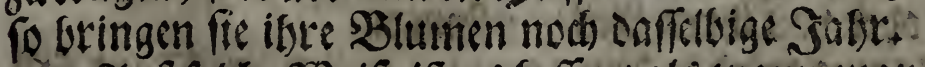

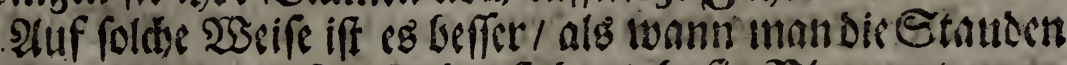

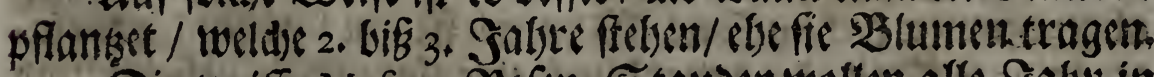

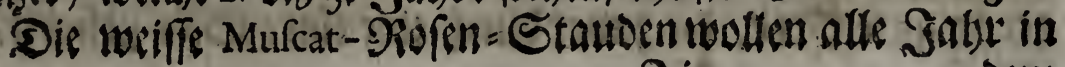
Si ocm 
Dein Serbffe oder Fritbling cinen balben Sdudd bod von ber (etden abgefdnitten twerden: Den 23 inter durd) mus manfie Imit langen MRifte zudecten / Daunit fie nidts erfrieten ; in oem fruthling aber / wann ibr den Diff twieder binweg nebme/ grabt ilse fie sin twenig um.

2Bann Die \$Blumen zu Dem 3 orfajein folminm / uno fin= oen fid) Siuthen Darunter / Dieberen feine baben/porden fie andert = balbe Sdubse tieff unten abgerdonitten / fo treibt alsosun sin is.

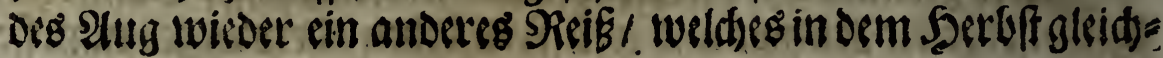
falls viel Stumen bringt.

\section{3on Der Seflinefithen Diofe.}

Son ber Eḩinefifdsen riofe.

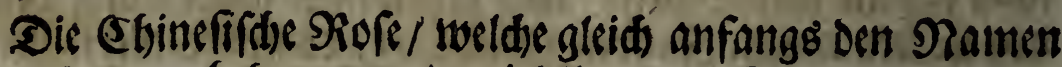
Barbara de Fuyo befommen / wiro beute zu Tage von sinigen Malva Indica oder Japonenfis, Die Sndianifde coer Snponeffifhe Pappelin genennt / Dod) iff fie unter dem Namen der Sinefifoten Doer Elsinefiffeen Rofe beffer befannt. Diefe twiro mit Der Beit fo bod) als sin Saum/ die Sinde Des Stamms ift bleid/ uno gleidet in oer Farbe sem Feigen=\$Baum / bat auth sben

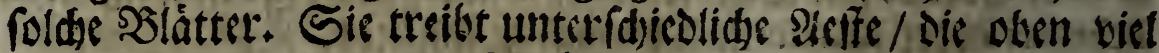
runoe Rnopffe ciner Nus dict befommen / fid) offnen / uno fo

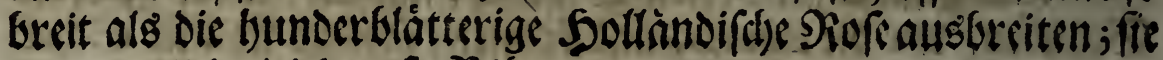
bat ziemlid vicl fraure slätter.

Sn Dem Serbffe blutbet fie / ibre Blume aber wábret nur

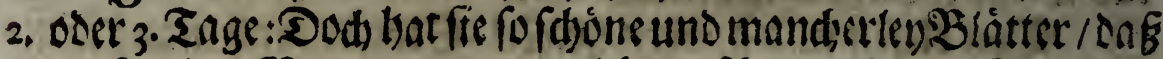

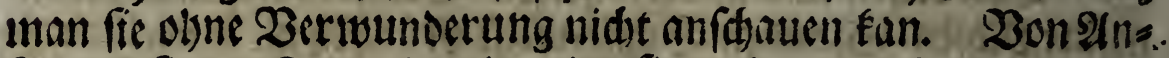
fung iff fie resif/ nadinals wiro fie rotly/ uno iberziebt fich

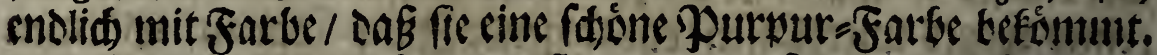

Stor (Befdeledt fort zu pflanken / mus man oen Saamen Davon fásm/ oser bou ibren Reffen pflangen.

Der Saame wird in Dem Martio, wann oer Mond fafi abgenommen bat/gefaet: :Man wirfft ibn febr weit voncin. oer in gute Eroe/ die zubor outd) eine flare Sibe gefiebet / uno 


\section{รั ธem Slumen=ริau.}

in Sdserbel zubereitet woorden / Darcin fómunt alshaum ber Saas me/ uno woird einen Finger bod mit gleidser (E rde zugseceft:

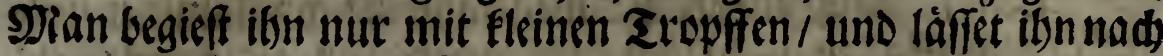
uno nad bie Sonme befdeinen / nad Berfieffung 30. Tazen fangt er an auf zugetsen/und wanm diefe fleine? flangsectrwas ines

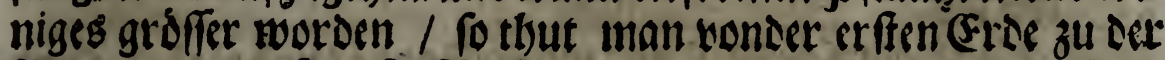

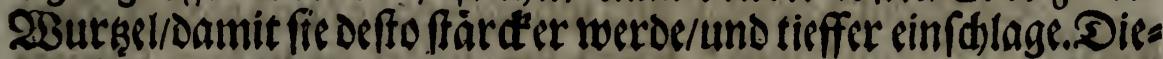

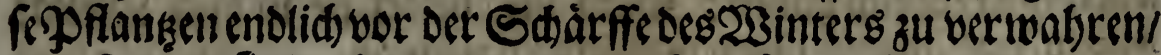
fotlieff tman fie in einen warmen/Dods lüfftigen Drt ein.

3u Ende des Sabrs nimmt man fie twiecer aus de nen zoppfen oder Sdeerbern beraus/ verfest diefellige in eas

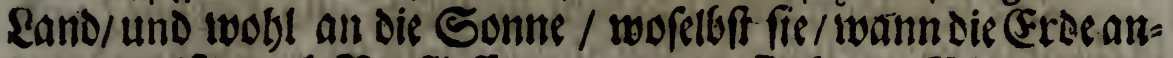
Ders gut iff / nad) 2erflieffiung 2, Doer 3. Sabern/ Blumen tras gen rwiro.

Dic Aeffe twerben in beın Majo gepflanket; und inuf man

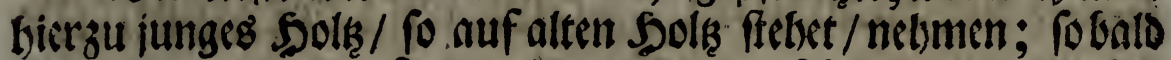

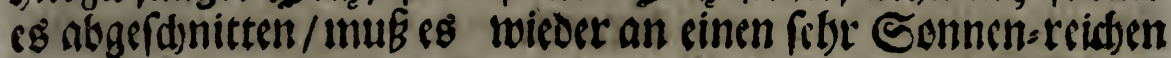

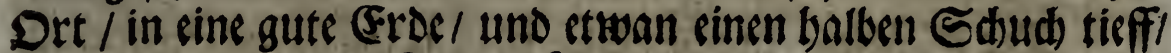

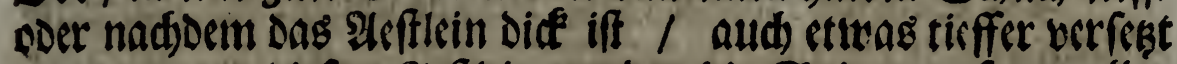
twerben; von diefem 2efftein werden dic Spigen zufamt allen

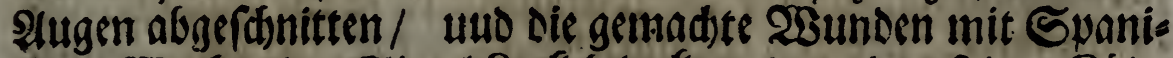

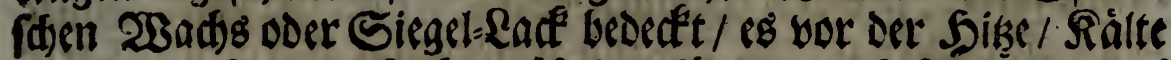

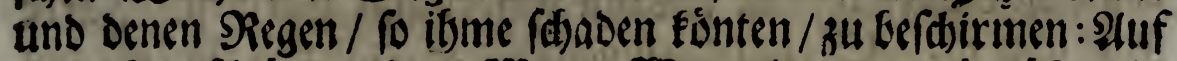

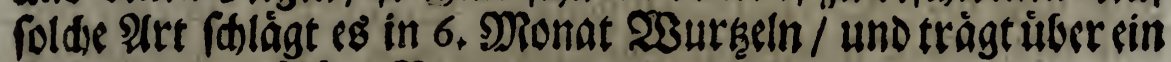

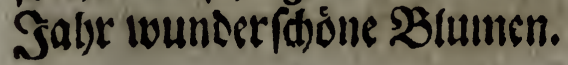

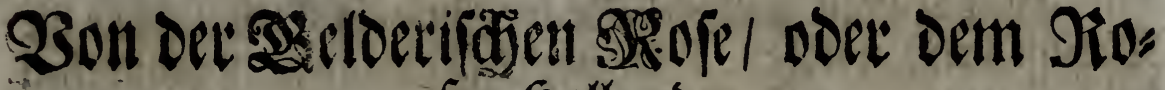 ren: Solllunder.}

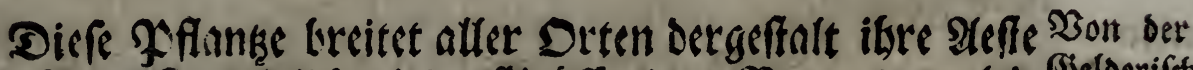

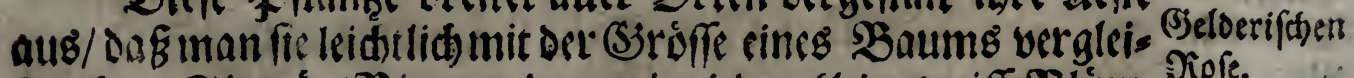

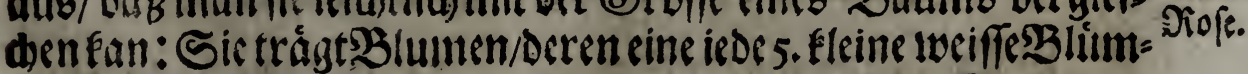
lein fat / und darunter zutweilen/entiveder aug der פTatur Der Si 2 . Pflan= 


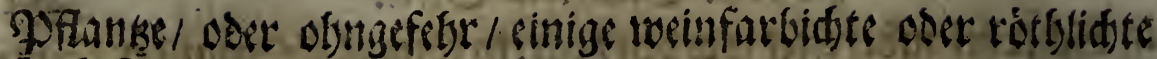
sidesefinocin.

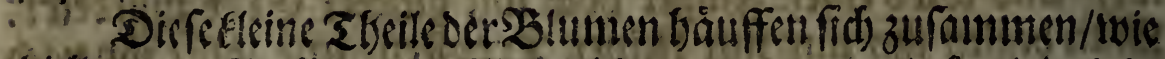

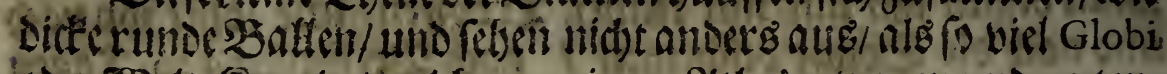

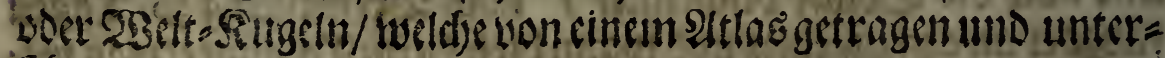
ffitser twirsch.

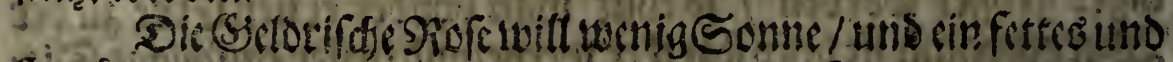

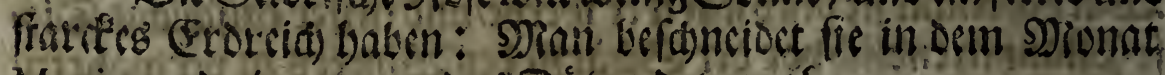
Martio, uno nimum nur Das Dirrs Davon ab.

\section{Reil oem seffratt.}

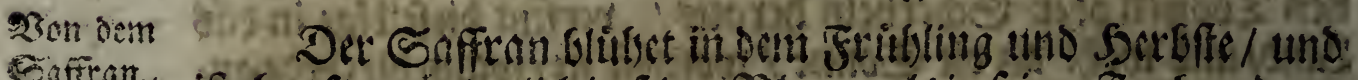
Saffram.

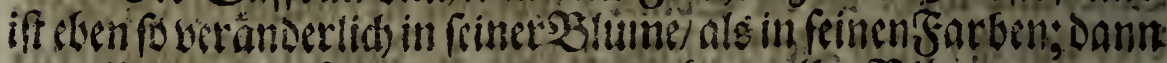

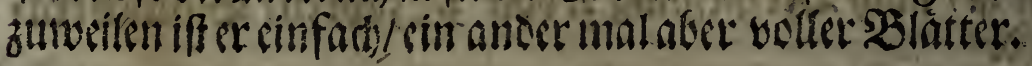

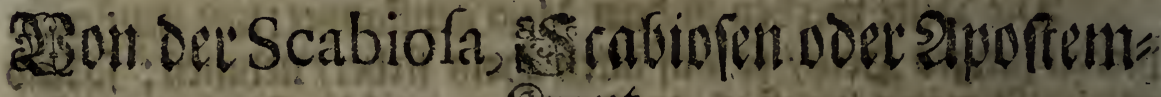

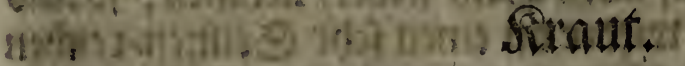

SBon ber Scabiafe:

Son Sgarza ótowatar.

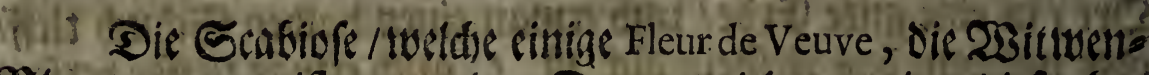

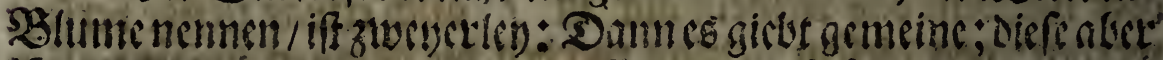

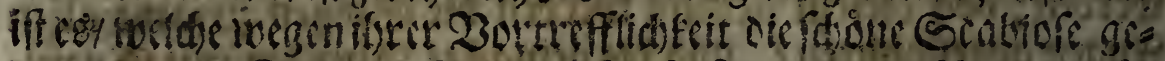

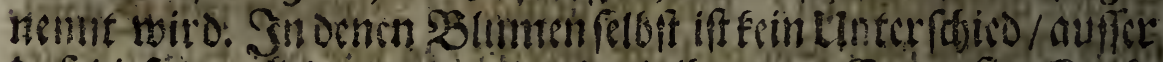

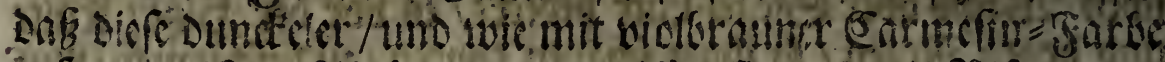

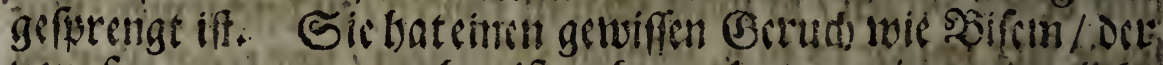

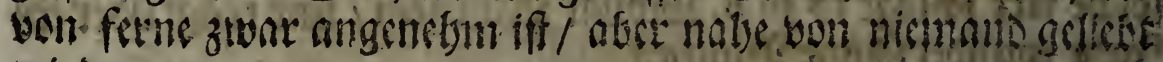
wits.

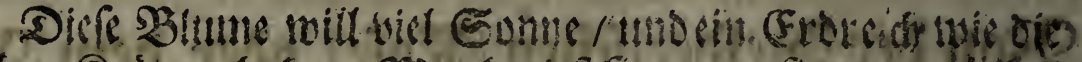

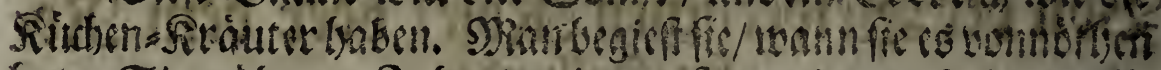

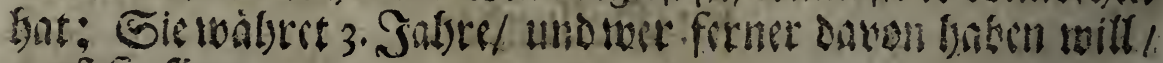

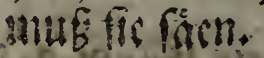

Wour ber Sgarza Odorata.

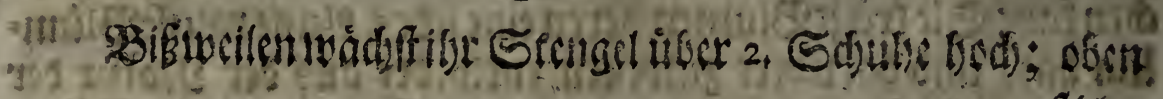

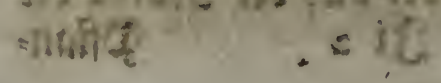
fidit $=*$. 


\section{รัดem}

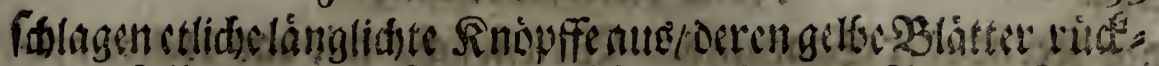

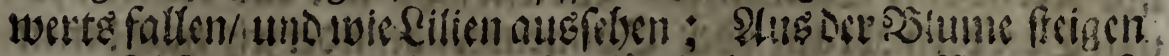

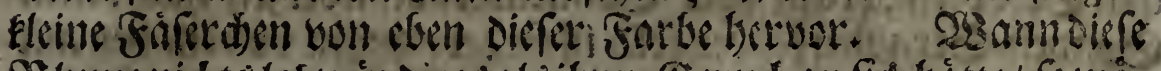

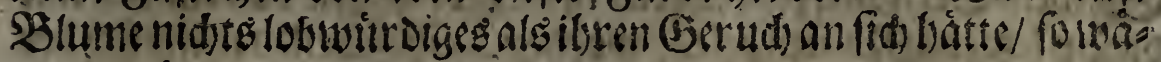

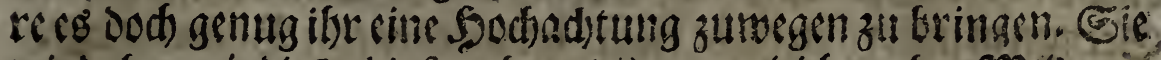

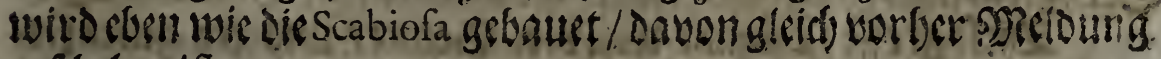
Befdechen iff.

\section{Zoun det Confolida Regali oder grittit ? \\ Spont.}

Dershitter: Swotm/ wont denen Jransofen Eperón deche-

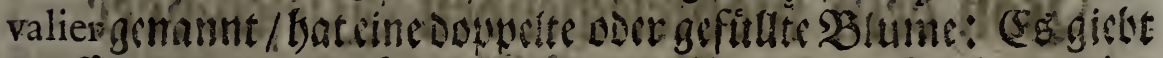

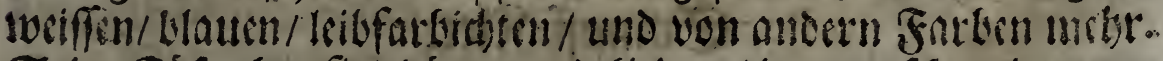

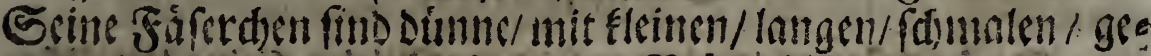

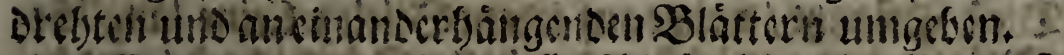

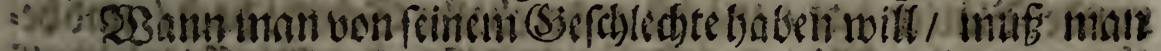

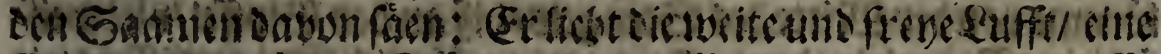

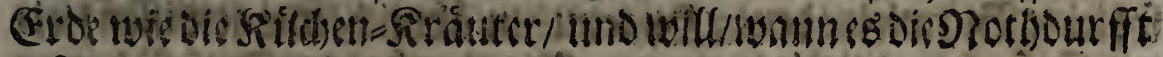
er fooert/reid)lidis begofientueroen.

\section{3on dev Planta maxima odet guffen Gn:

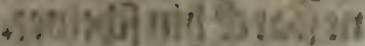

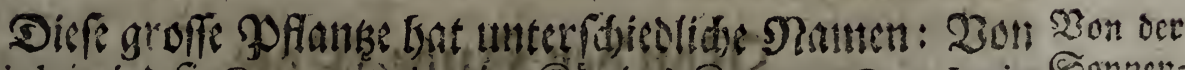

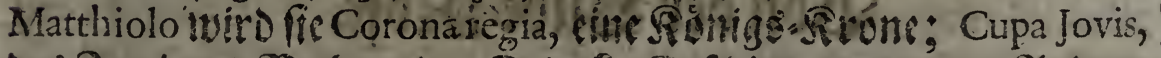

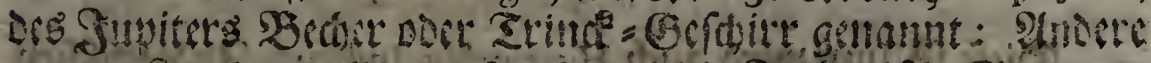

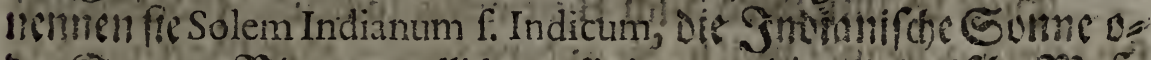

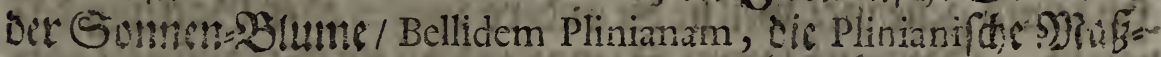

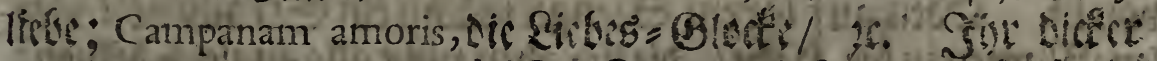

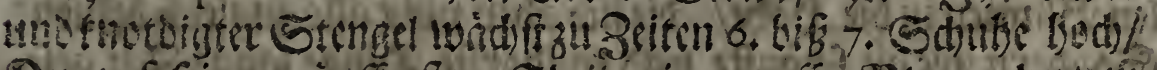

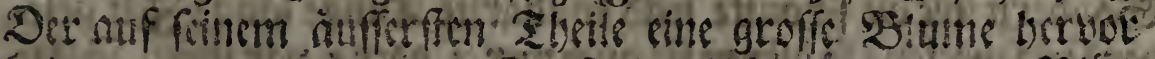

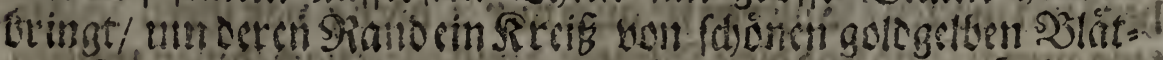

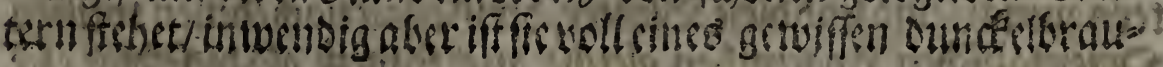


nen Rerns ober Saamens. Weilfiefid)/ wie das Heliotropium, Ecorpion=-Firaut oder Sonnentender iederzeit nadbenen Sonnen=Strablen filgren foll/ iff fie oerolwegen vonetlidsen mit

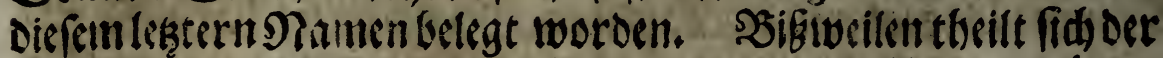

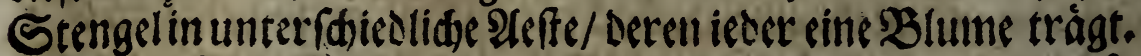

Diefe groffe Ppflanke will viel Sonne / und cin gutes fets. teg (Eroreid haben / uno weil fie vom Snamen gezeugt wiro / fo berfest man fis/nadbeen fie ein wenig aufgerwadfen und etroas ftaré toorden/ an sinen folden Ort / wo die Sonne. Die Dbers band bat/ und begieff fis/ toannfie es bonnotben bat.

\section{Son Dem wofleiedsenden Wiejensoder Sumpff= Iilee.}

Diefe Pflanke / welde auf iedern Stiell 3. Eleine länglidsts: runde SBlâtter bat / trádif andertbalbe Sdjube bow / und be:

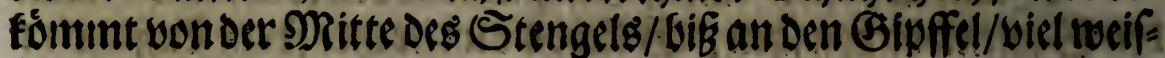
fe fleine Bliumlein/ Denen Syacintben ábnlid)/ mit getwiffen flei: nen Sáferdsen/ wiedie Rappern=Stauden baten; Diefeslumen riedben febr wobl / uno fino uiberaus luftig anzuleben.

Sndem Sdatten/ und an einem feudeten Orte / inag oic. RePrianke'lieber ffeben/alsan cinem fold)en Plake/ wo dis Son. ne frarde bin fdeinet.

\section{Bondersutes ofore.}

Diefe Blume mirb aud Hyacinthus Indicus, Sndianifder Syacintl) genennt/ tweil fie bie andere Species Doer Eattung das von iff. Dosen auf ibrem Stengel wàd ff ein Straus von vies len $\mathfrak{B l u m e n t i t}$ Die Sobbe/ Diefidh aber nid)t alle zugleid effnen: Sondern wie die fíonfte und foftharfte Dinge lange 3it gefes ben fenn wodten / fo offnen fie auds nur 4. 0Der 5. von ibren SBläts

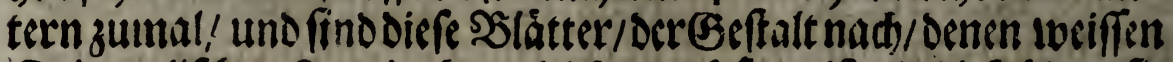

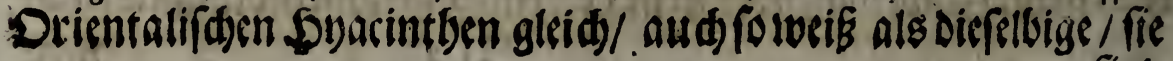




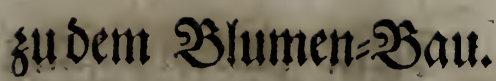

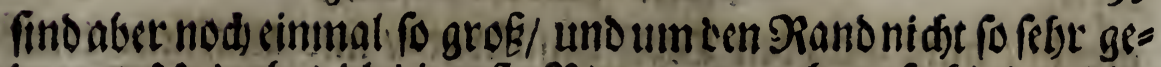

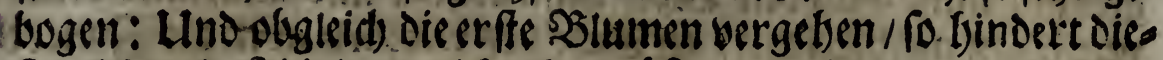

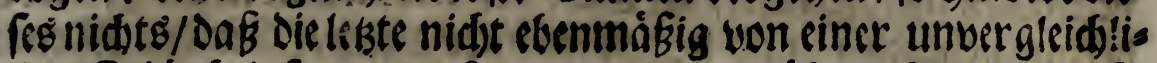

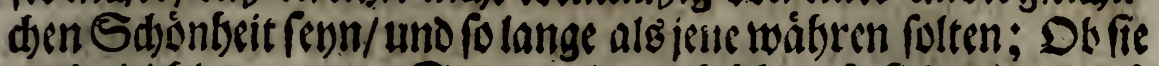

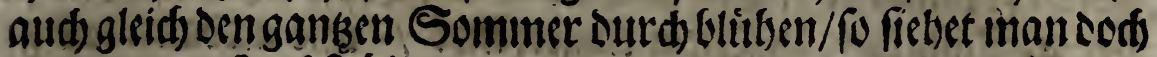

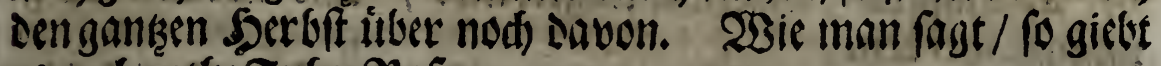
es aud rotbe Tubes Poren.

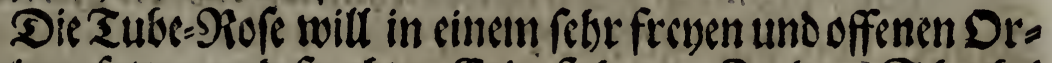
te/ in einer fetten und feudten (Erde freben: S In dem Sdaersel bălt fie fids beffes als in Dem \&ande. Man muË fie nidét üuer 3 .

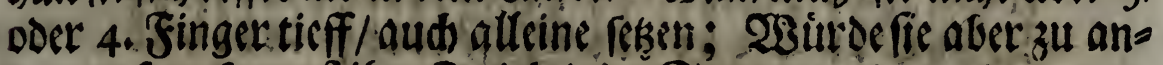

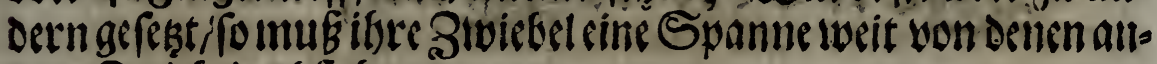
Derna Buicbelnabfietsen.

Den Soimmer itter muE fie ffets alle $\mathfrak{A}$ (bend (aud) twobl gar zu Mittage) ffartét (leg offism werden. In enem 23 inter aber

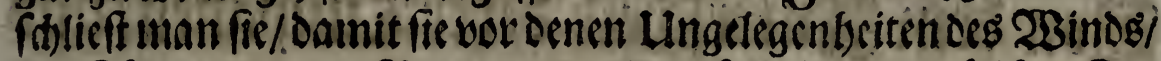
Der Rälte und derer Siegen vertwatseret fen/ in cinen foldten Ort cin / Der Dod lufftig fais / und da Die Sunne wobl bintemmen fan.

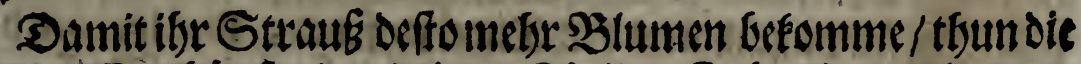
Serren Eartbăufer Den britten Theil 2. Sabre lang gelegenen uno vertwerfen Menf(dene-Sorl) unten in Den Sdjerbel.

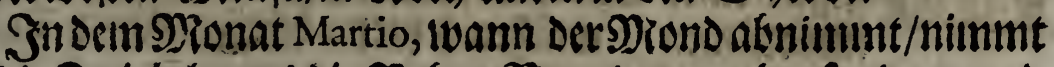

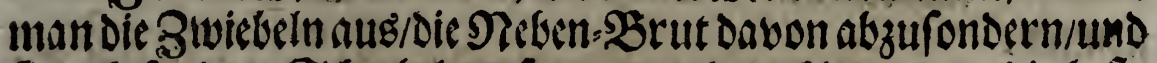
fie in befontere Sdertect at feren/ und nadjocm man Die keffe

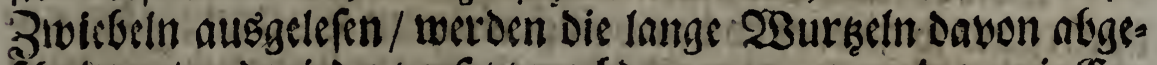

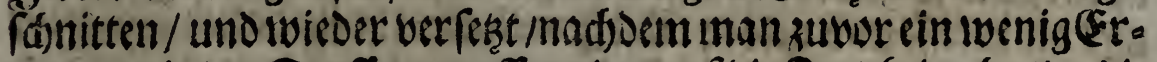

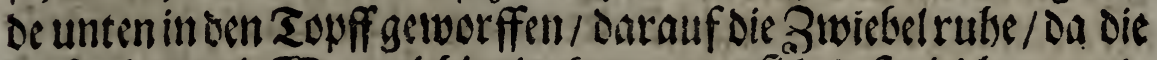

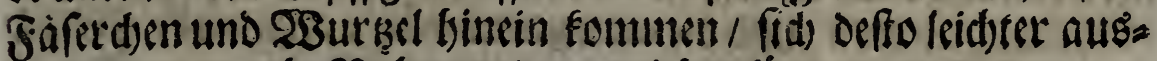
breiten/ uno melgr gatbrung Dowon bietsen fénnen.

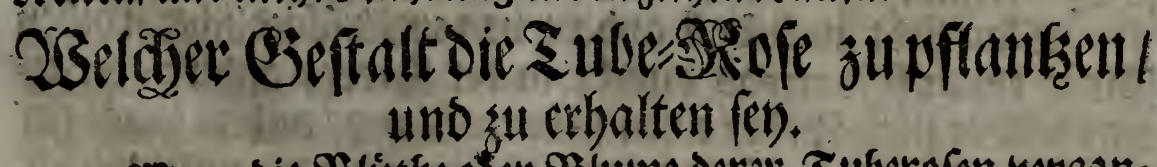

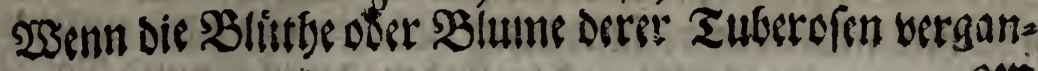


256

Reue Unterneifung

gen iff / mus man Den sopff tunffirtsen/ und ant einem trude

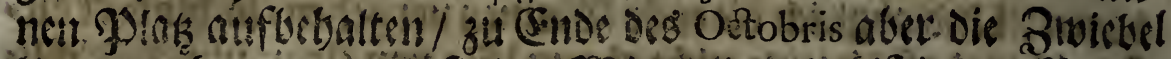

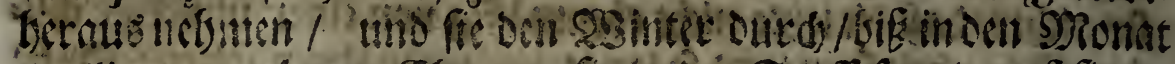

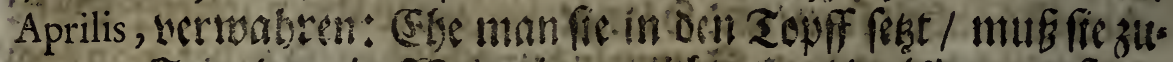
vor 4. Tage lang in 28 ein cingetweidet / und algbanu erft ge= phankt ivirdirn.

2แ(d) un Whinter viber nidit gefriers.

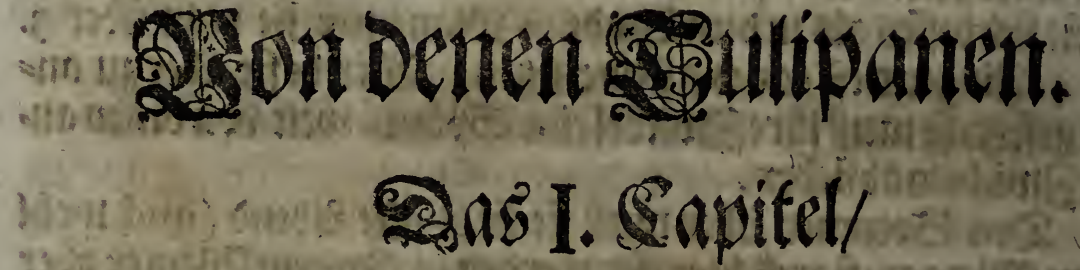

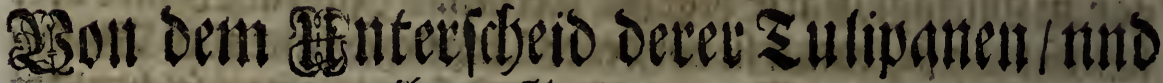
ibren Gattungem:

Bon Dem Linterichied Der ₹ulipa: nen.

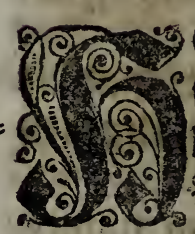

(5irk Menage fagt/ dafi Die Tulipanen ooer Tulipenut:

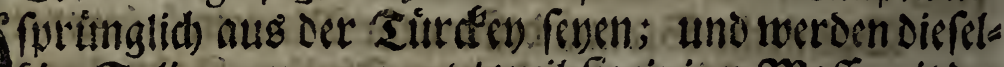

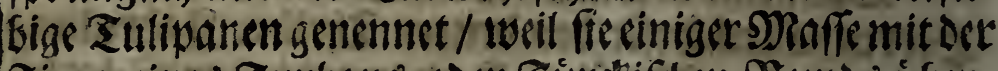

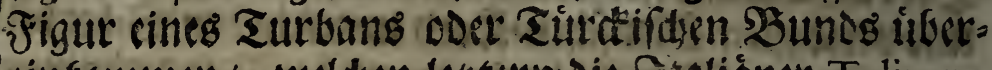
cinfoinunen/ weldjen lestern dic Sialiảner Tulipano

nenten.

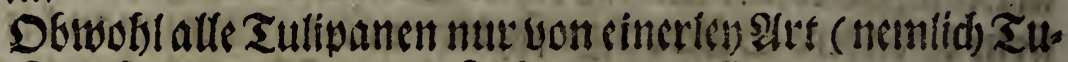
tipen) find fo giebteg bod) genviflid) vielettry (Sattungen sarune tev/ als tweiffe uno getbe; Die gemeine rotlge fino aud Sultipen/

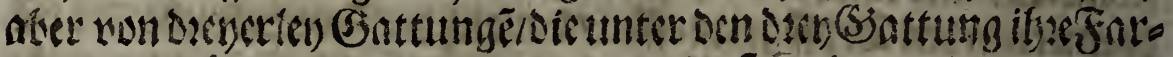
he nientalg ánoern / und die altergemeineffe/ aberaudb ole Bering. fdénigftefine.

Man fielst nud fonft andere von unterfdiedider rostent Farbe/ singe find etwas ouncest in der Farbe/ andere aber et=

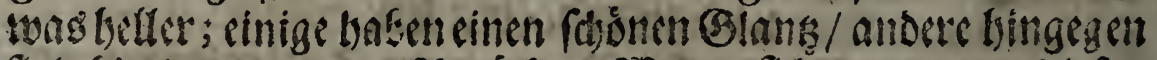

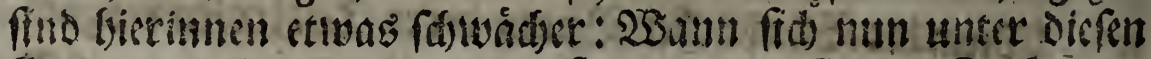
Gattungen einc oder die andere finder orren Erund-Sarbe vet= 


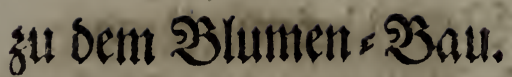

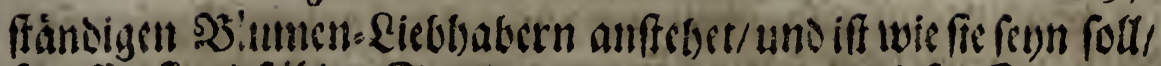
folaffen fie dicfe'bige Saamen tragen/ und yon diefen Saament fommen dic befte Farben ber.

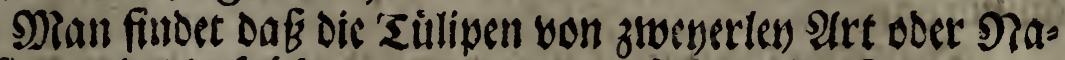
tur find / als die fritbe und Dann die finathe: (Es if audnod)

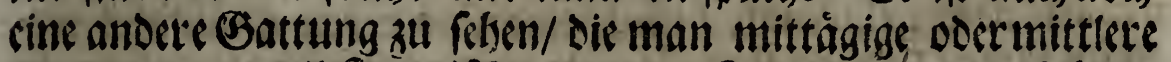

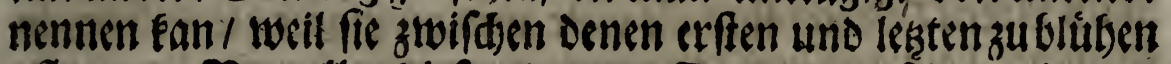
pflegen. Zon allen diefen oreven Gattungen feben soir von unter

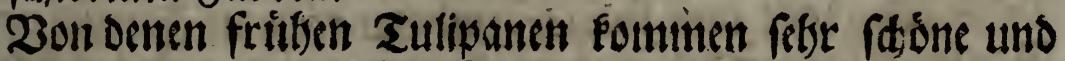

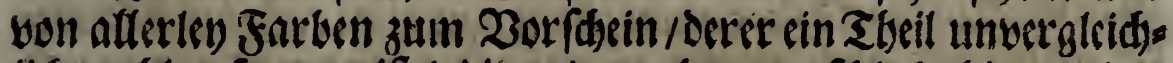

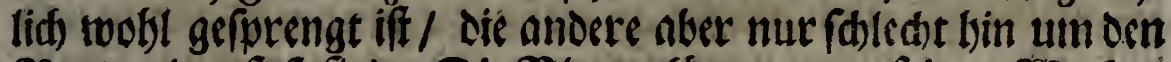

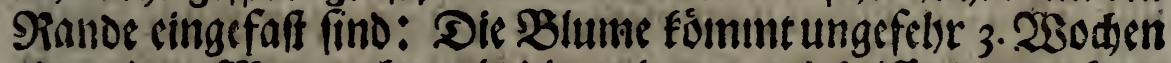
oder sinen Mionat eber ale die andere / und heiffer dannentero

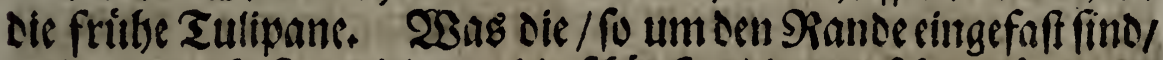

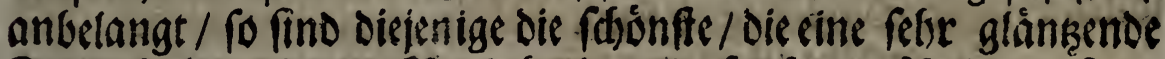
Farbe baben / Deren Fiand Gereit und fouber gefdenitten iff.

Zon denen fwattben / fo wobl als aud) von denen mifttlern ober mittágigen / giebe es bielerten Far ben / Beren die erfere nur

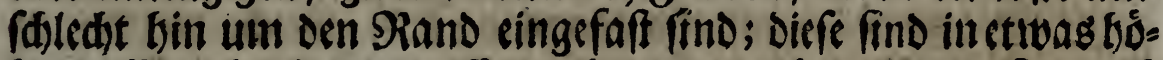
berm 2Betth als bie weeiffe/ gellee/ und rotbe: Einitge find roth und woieder roth eingeffaft; und Diefes madt fiesin wenig in 2 es

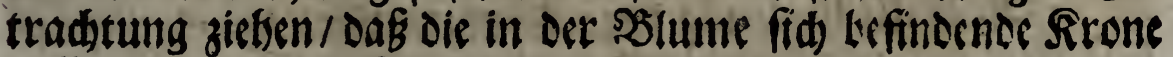
volffommen rund iff.

Die andere Gattung if won folden Farsen / bie ourd S5ülffe des Saaumens zu wegen gebradts werden / und finden fiut Darunter von fo viefertlen Farben / DaÉ es benen Mablern

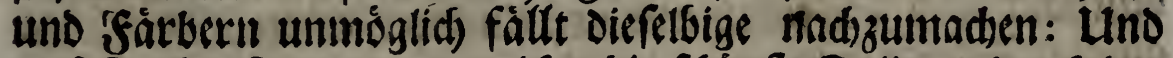

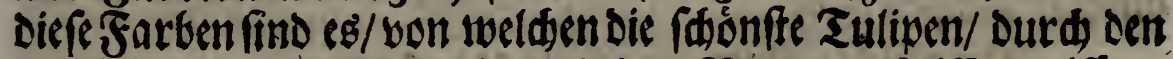

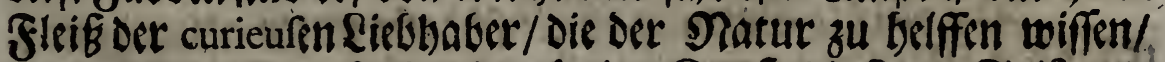

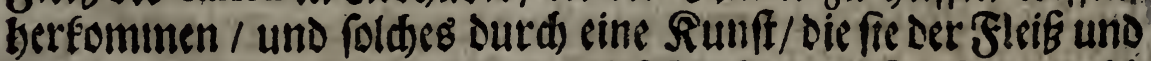

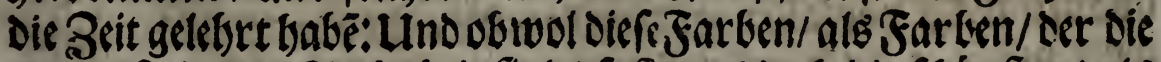

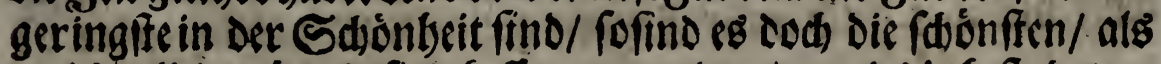

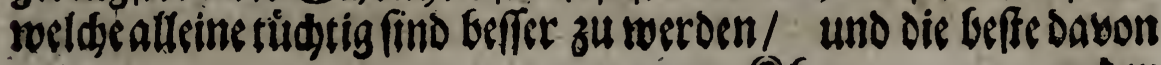


258

\section{Noue Untertweifung}

Ber Ename fan gefanumlet werben. Unter siefen Farben fine-

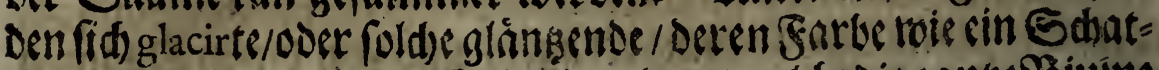

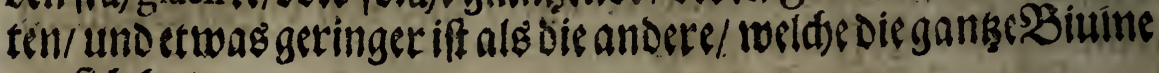
an fid bat.

Dic oritte Gattung beffetset aus Dencm/weldde man pannachirte ober gefiprengte nennt/ uno find oeren glcidffalles bie

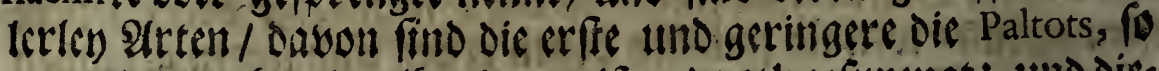
entweder roth and gell / oder weeí und reth gefipengt: und dire

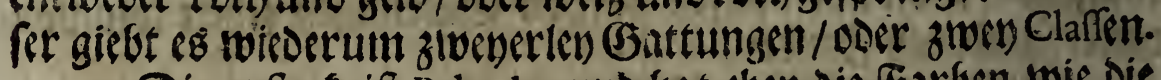

Die erfie Beift Paltody, uno hat eben die Furben wie Die Gattunig / fo man Paltot nennt/ fiet iff aber weitrciner und faubeo rer gefprengt/ autd suliffen an diefer / Die uinden Saamen und

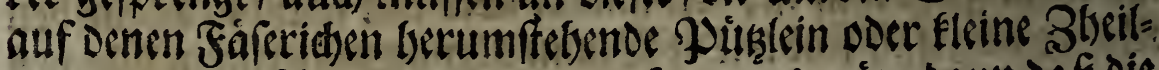

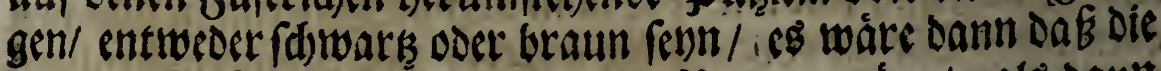

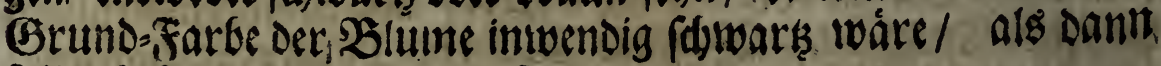
folden beragte poitglein gelb fenn.

Die andere Gattung oer panachirten oder gefwerengten wirt Morillon genennt / und Gat nur zwen Garben an ilyen

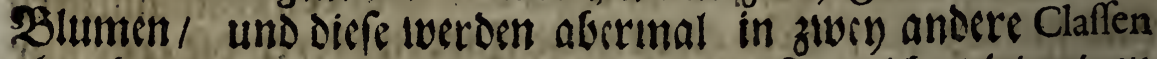
abgetbeitr/ Dalion oie andere Morillony beift/ weeldes viet reiner

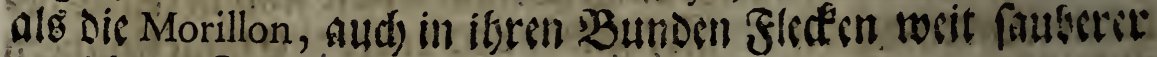
gezeidjnet iff.

Die Dritte Gattung Der gefiprengten wiro Agate genennt/

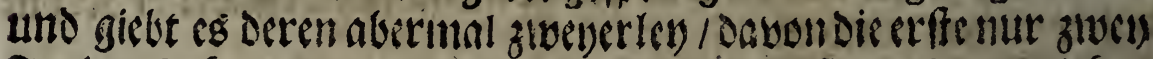
Farben baben; bie andere Battung aseer beiff Agatine, Ine bat Dren/zulweilen auds inchr Farben. Dic Agatine iff/olgne fic zu

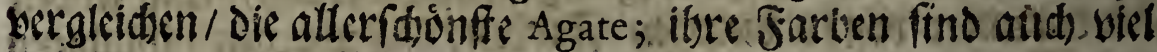

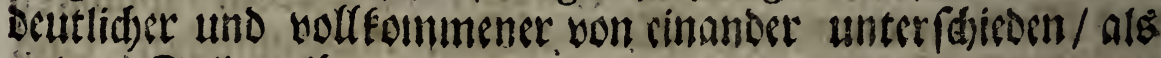
anderer Tulipen itser.

Die vierdite Gattung iff bie faibuffe unter alten / unb

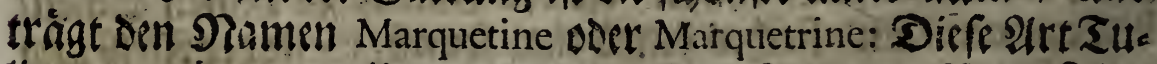
tipanen trägt vor alten andern ben goreí. Dowon: Man fietset

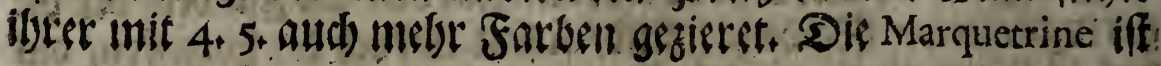


Die fdobnffe/ bie Gunde Flecten fino fo won cinander abgetbeilt/

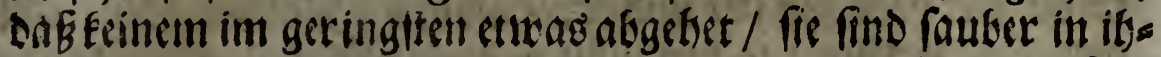

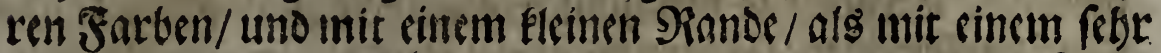
flaren und feinen Seíden : Saden umgeben: Lund diefse if Das Briden / woran man die fdionffe erfennen fan.

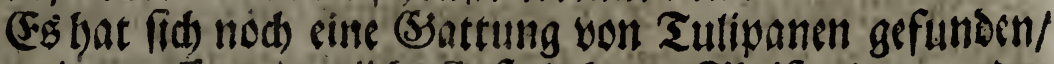
tweldese eine auffierovdentlide Geffalt yat: Sie if Bizarre, dDer

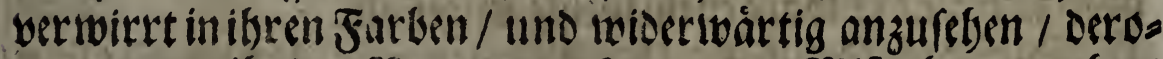
twegen man ibr den פiamenMonftrum, oder SMi gesburt gegefen:

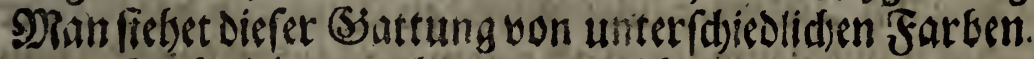

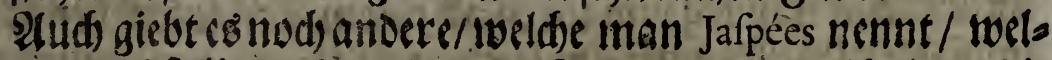
de żwar gleidffalles biele und unterfitiedene Farben faben/ Die

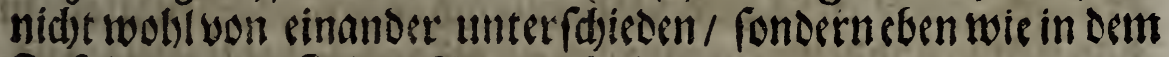
Safpis (Davon fie Den Nalmen Gaben) mit cinanoer wermengt ine.

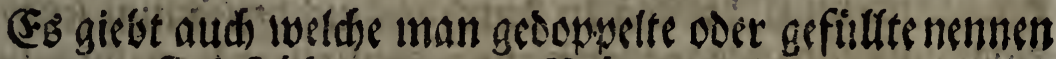

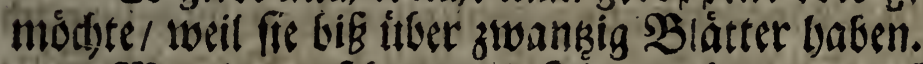

Man bat gefeben / und fielest nod / oeren'Blume grime Blätter wonl zwenen Farben baben; fie werden feuilles rayees, oder Tullipen unit geffreiffen SSlättern genennt / man find aber twenig föbune Darunter.

\section{2ub II. Capifell}

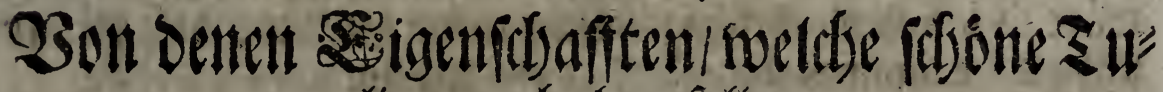
ripanen baben follen.

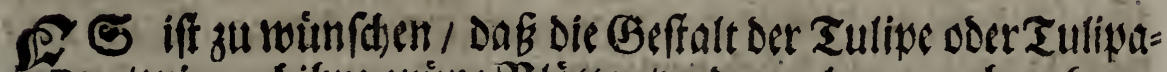

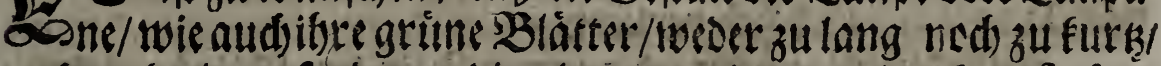

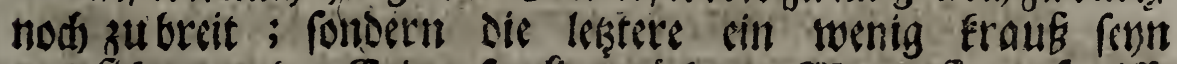

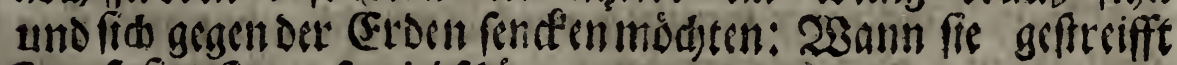
fins/ fo find fie um ro biel fadoner. origif?.

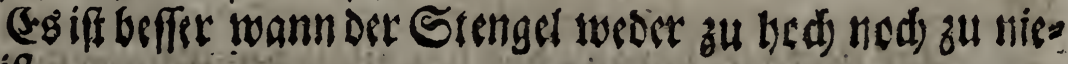




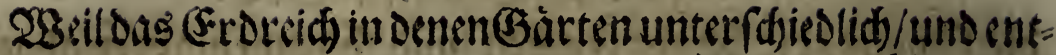
weder gut oder bós ift/ und derobalben die Stengel bofjer ooer niroriget twerden / fo fan man in diefen Stitce fein getwifis PRaß vorfarciben; fondern sie gròfte Zabloer fdónen Tulipen/ welde der Garten genteiniglid zubabenpflegt / mus bierinnen zur Siegel cienen. Der Stengel muB / in vergleidung feiner

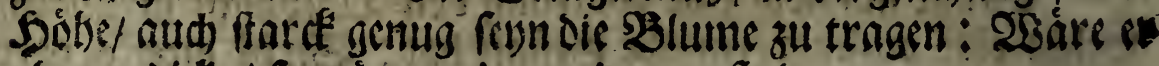
aber zusidee / fo wäe er ein wenig ungeffalt.

Die Form oder (Seffalt Der 3 Blume mus nid)t zugeswist fexn/ fonft iff fie gank Zerwerfflid): Wुer den Zerftano bat/ oaß er weif , wae twäroig uno felten an sinem Dinge zu feten iff, Dem ImuE folde? getwiffen Jarbe erträglid Imadien/ und tweil fid die szlätser/ in Dem fie ibre lunder farbe annebmen/ cin twenig in Die \&ángeaus:

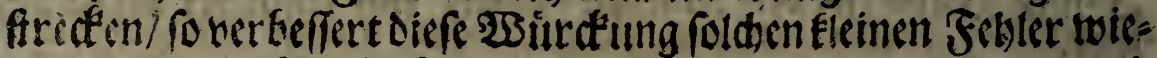

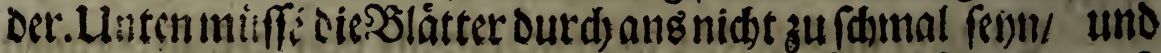
sinander ffetben/als twann fie auggefd)nitten ivären; foncern nad

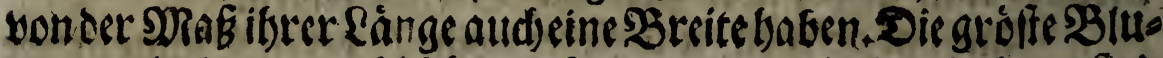

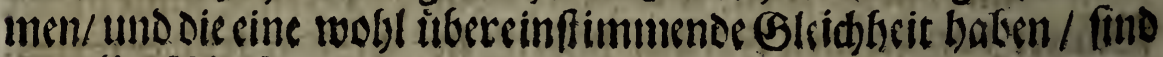
Die alferfdogntes.

Die Tulipen miffen 6. SBlâtter / 3, invendig und 3, autg:

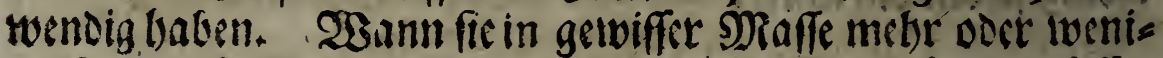
gerbuben/ fo ift es cin Febler; Dee intoentige Blátter milfen breitcr fevn als bie augivendige/ theten fie aber alle gleids/ fo

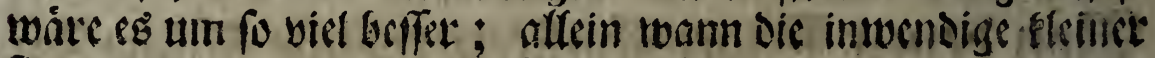
find als bie ausivindige/ ro ift cs cin Fethler.

Diejenige Imus man nid)t hod ndten / Deren Beffalt fíón ift wann fie zu blitben anfangen/ aber 2, ooer 3. Tage lees: nad) lang wiro und fid verliert.

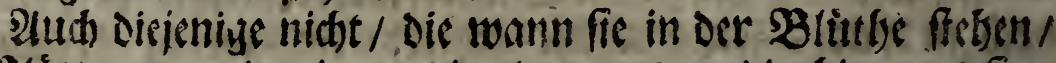

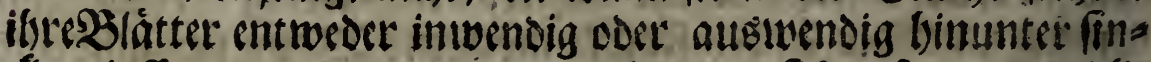
den laffen / Doer an cinander Eleben und fid) zufammen wict" len.

CE liegt viet Daran/ DaE Das Blat det Blume fatt uns 


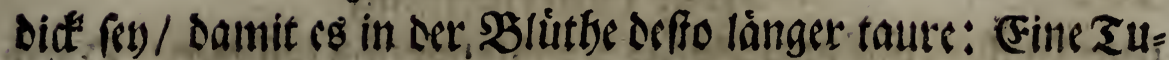

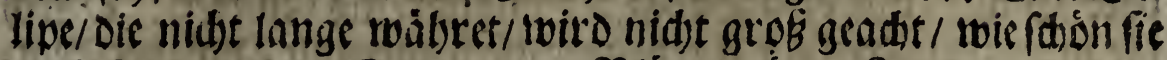

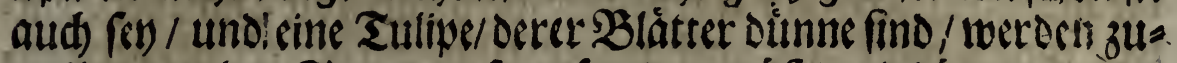
weilen bon der Sonnen/ fo zufagen/ / gerioff/ und Dorren aus es be fie blüben.

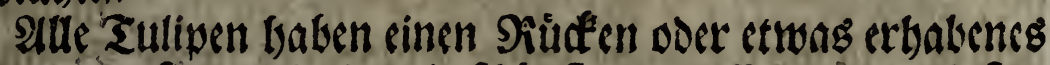
an fidi) und find dicjenige Die fitbonffe/ Dic beffen alu weenigften baben.

Dic bizarres bDer wertwitrte Far Gen find getwi Glid) bie fdojuffe. Luntir benen gefprengten fino Die fitattirte boer ges

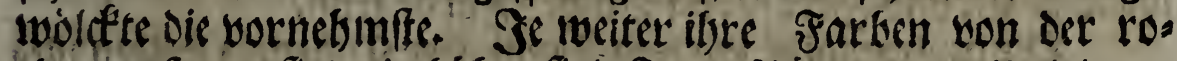

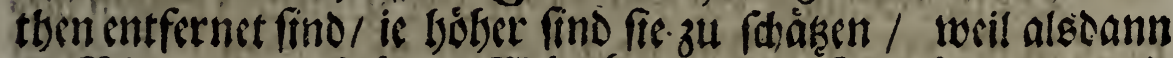

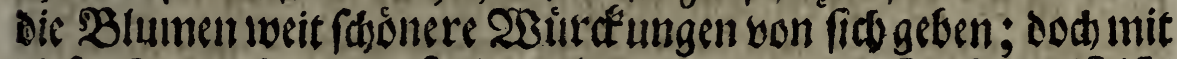

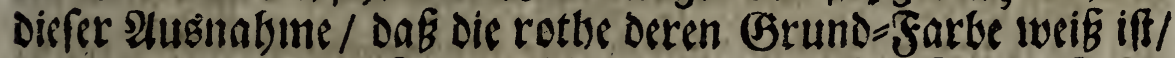

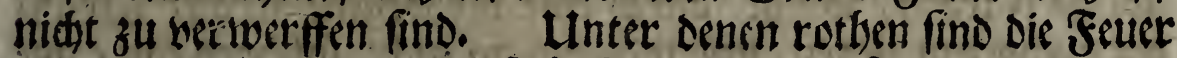

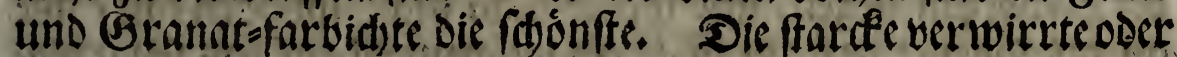
bizarren init siner weiffen Grunde. Farbe / und dis graute initcis

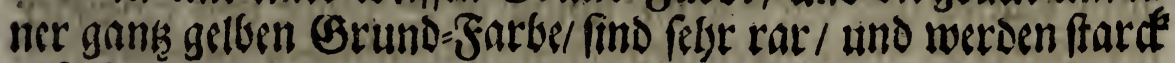
gefudt.

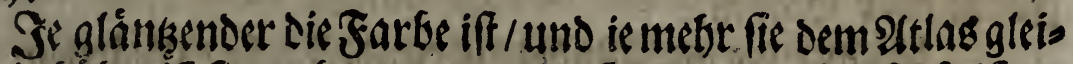

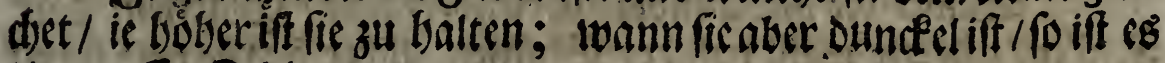
sin grofier Febler.

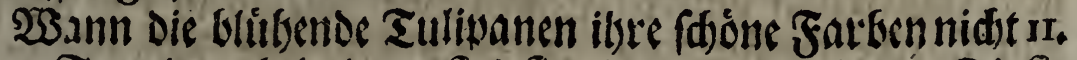
Doer 12. Tage lang betbalten / find fie nidtht viel zu adtern; Dief fie

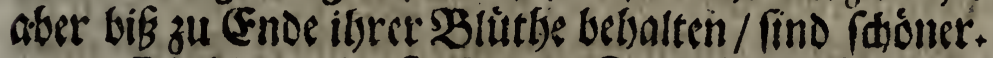

Dic Dic geringfete Grund-Sarke thaben find dic beffen fdón gefiverengt a w werten.

Dic Grund-Farben / fo ain fdónffen geiprengt fonumen' fino for wobt intwendig als ausivendig nur won einer Fatbe. Die-

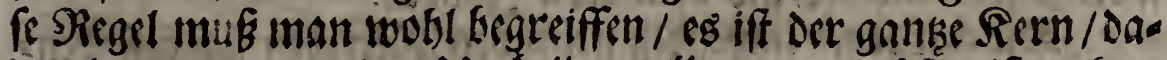
Durdh man / wann bag Lurtheil aun aller ungerwiffeffen iff / creene nen fan / twas aus benen Farben werben ivird. Die austwens Dige(Srund-Farbe nennt man/ Die twie Sterne doder runde Sreiffe

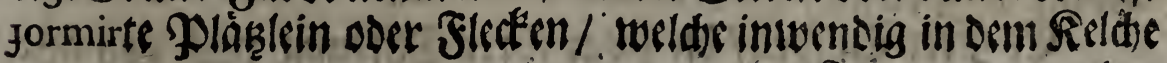




\section{2

ober Bedfer / auf dent Boben ber'Blatter/fid befinden: Durch

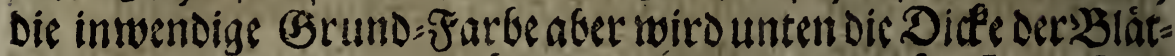

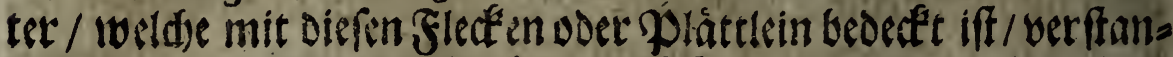

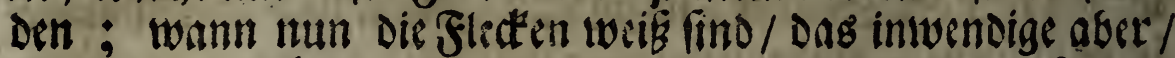

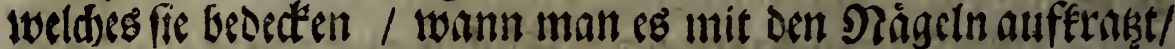

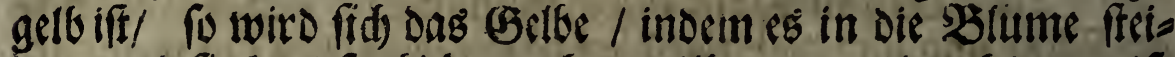

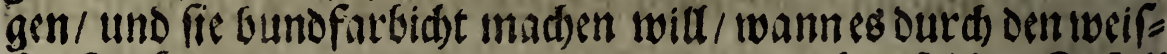
Fen Fleféten oringt / vertieren; Damit man afer folden 3ufalt

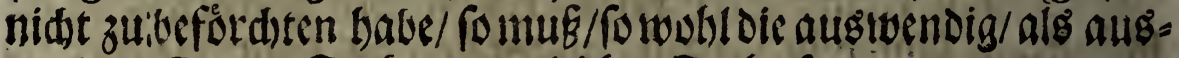
wendige Grumb-Sarbe/ven gleicfer Farbe feyn.

Die auswerndige (S3rund-Farbe oder goláttlein frtigen nices

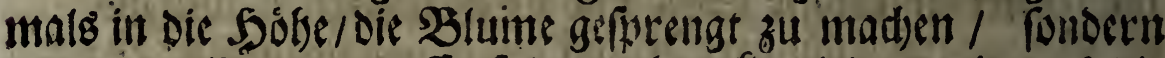

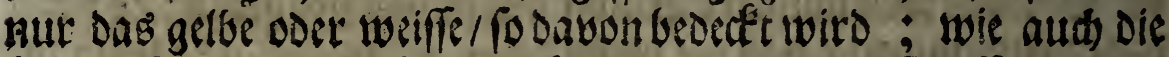
itbrige Farben / wo:ldes/ Durd cine verborgene Rraffe Darults

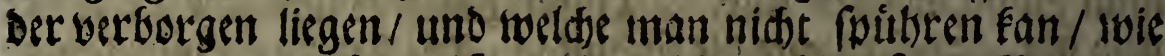
an oer Solitaire zu feben iff / als wellderwobs) auf oas B Blat binaufgerogene/ und Durd groffe fdjwarke Striedse non sinauder gefonderte Butto-Slecten bat/ Deren aus=und inwendige Bruno= Farbe aber weig iff.

23amn Die ausatwendige Grund-Gartbe / Plátttlein oder

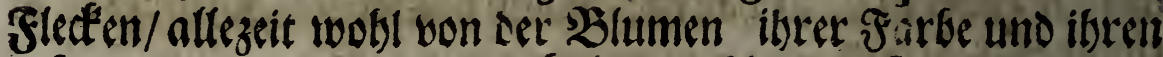
gefinrengten doer G Gundern Flectern unter fdiceen iff / fo hat man

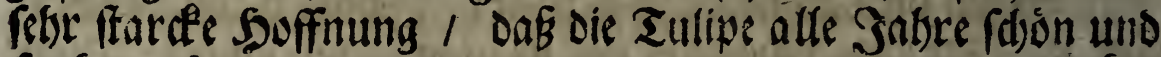

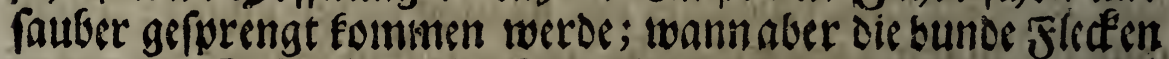

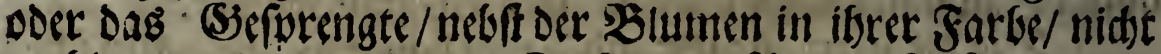

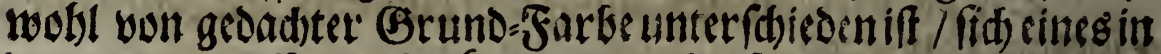

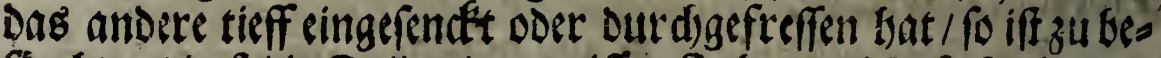

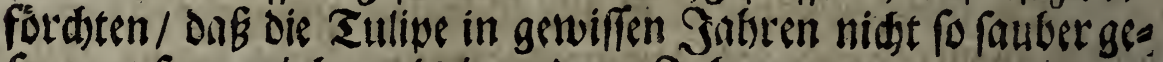
frerengt Penn muddite / als in andern Salbren.

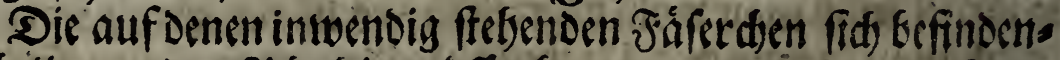

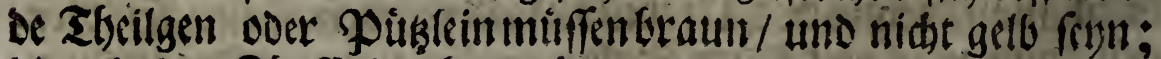
Die mittlere Bäpfflein aber mogen von siner Farbe from/ von weldere fie roollen.

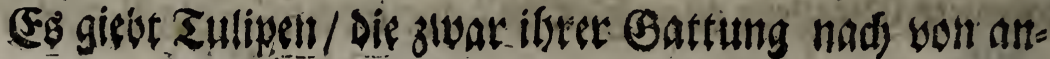




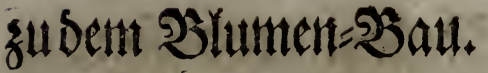

263

bern unterfdicben find/in oer Farbe afer cinander fo greidf folme

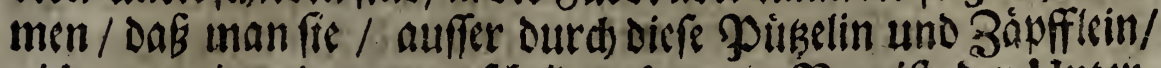

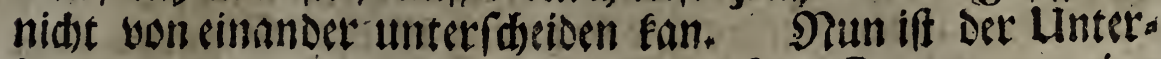

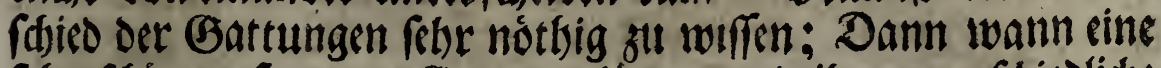

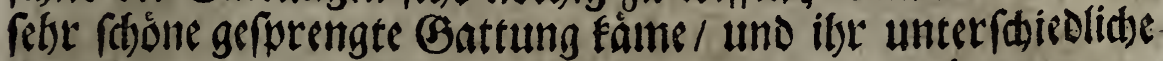

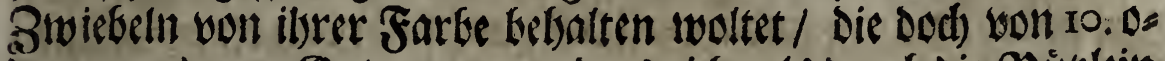
Der 12. andern Gattungen/anders nidte als Durd bie Poublein

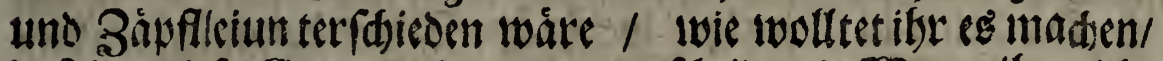

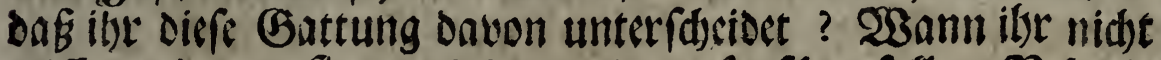
wwiffer / wie man fie examiniren und ausfor fden fol. Selbmet

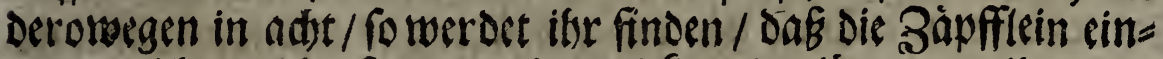

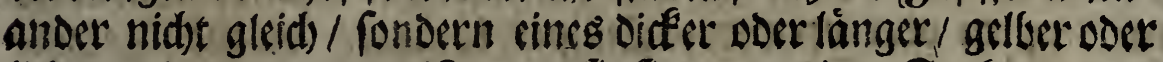

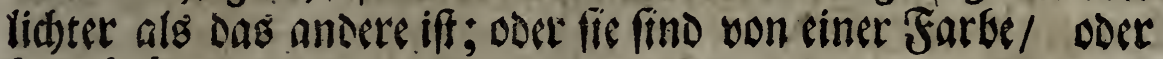
balb bráunlides/boer oben und unten braun ; poer fommen andere Beiden yod / Dadurd man fie wird voin

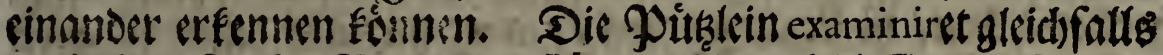

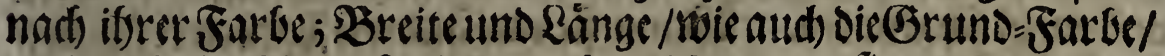

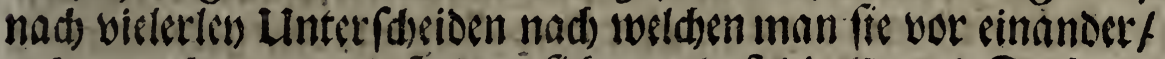

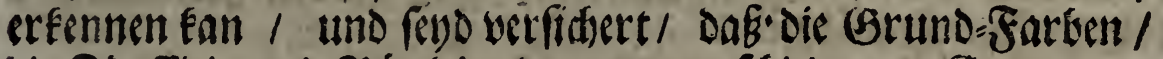

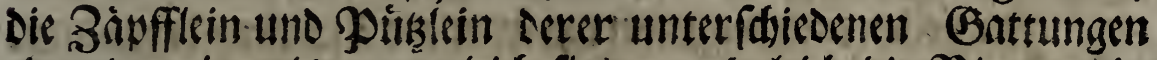
eitander niemals gank gleid' find $i$ obglesid) bie bilumen in nllen mit cinumber üsersinformmen.

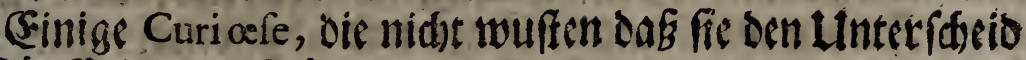
Derrer 3áufficin ober Poithlein/ Die Gattungen zu unterfdeciden/.

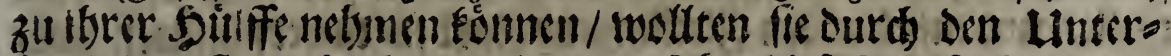

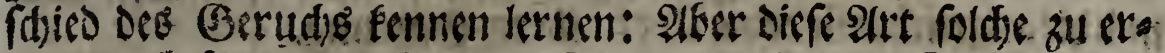

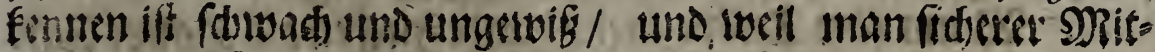

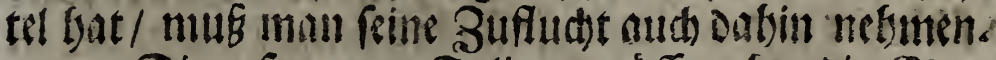

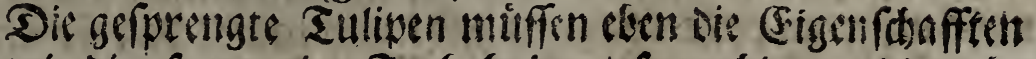

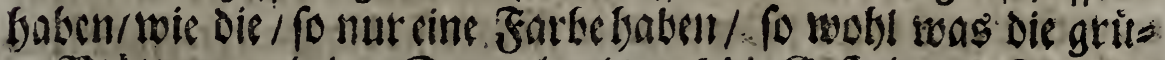

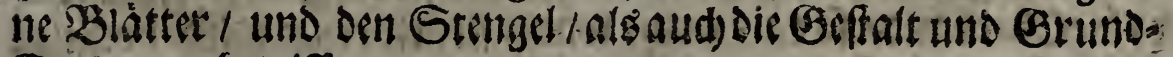
Farben anterrifft:

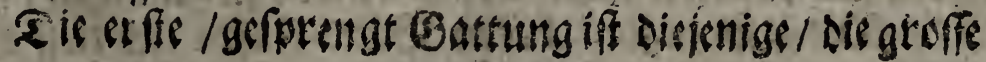




\section{Neuellnterweeifung}

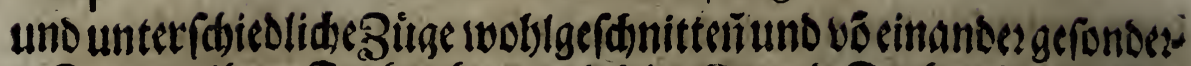
te Figurenilber Farben bat / und feinc(Grund-Sarben beétint.

Die andere gefprengte Gattung iff Die/ fo man à yeux

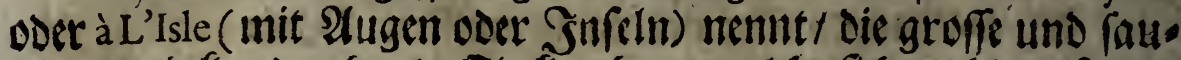

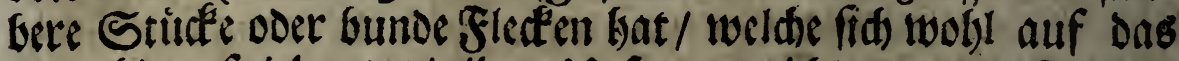

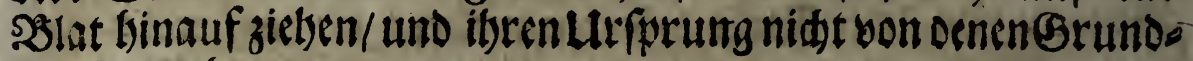
Farben netbmen.

Die oritte iff Diejenige / weldere groffe/ umb ber gefficeften $2(r=$ beit ábrntidese Siguren bat / Die won ibren farben wobbl unters

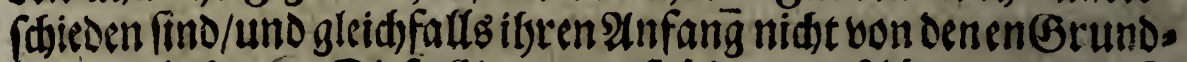
Sarben baben. Diefe Gsattung iff itberaus fdóne / wann fie

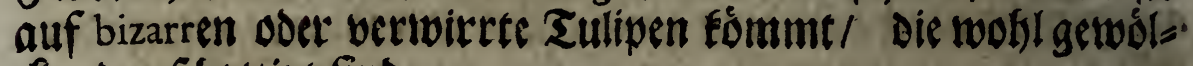
aft oder fifattitt fint.

Die vierte ift Die / beren Figuren ser fleingeffictéten $\mathscr{A r}$ -

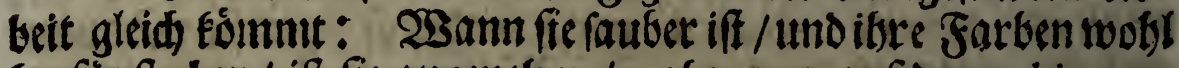
berfiurffedden / iff fie angenetsm / afer nur auf Denen bizarren

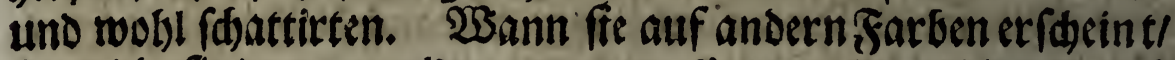
fo gleidet fie Dem Drapd'or coer Drap d'argent, Dem golloenen uno filbern Stidtée allüufert.

3uweeilen fino bie andere gefprengte Tuliwen/ Deren buns

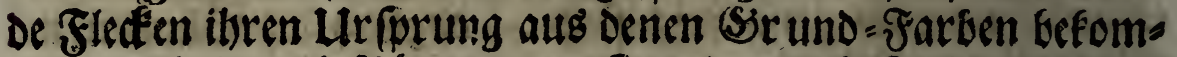

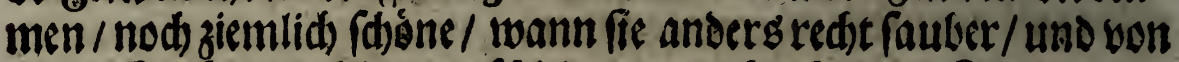
ibsen Farben wobls unterfatieden und abgefondert find.

Alte gefwrengte Tullipen / bie gleidjweit won einander abges

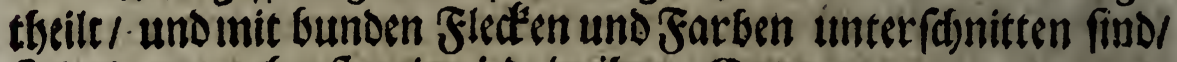
find die angenefsmffe / cine iede in ister Gattung.

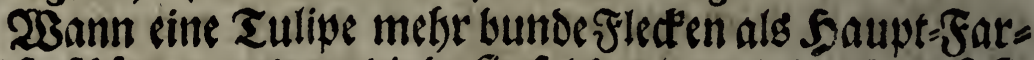

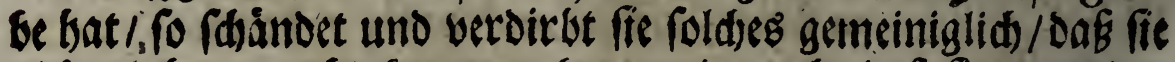

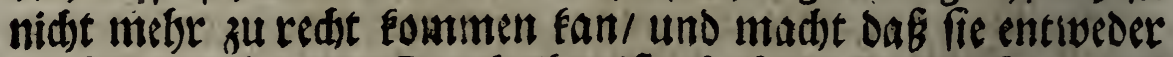

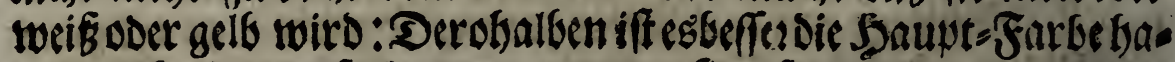

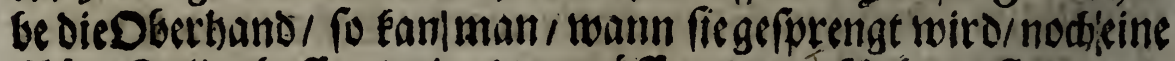

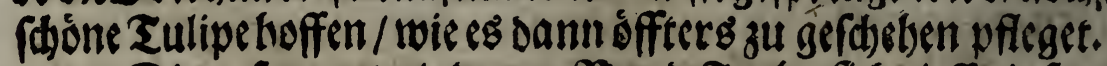

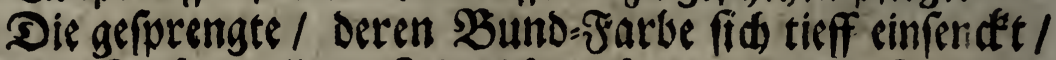

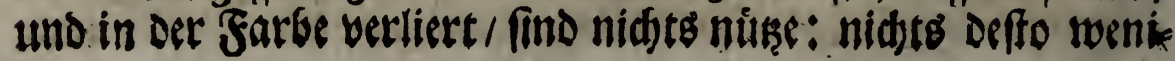




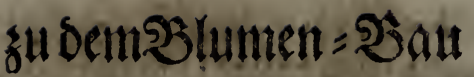

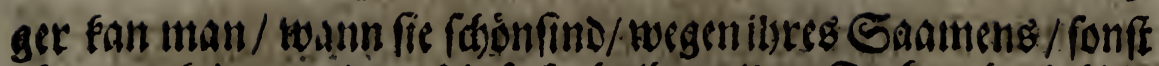
aber um feiner andern Lurfade balben/ ibre: Garben - benbebalo tent.

Die gefprengte Tulipen/ fo reid bon Farben fino / imus man Denen andern iederzeit vor zieben/ twann fe audi gleid, nid)t fo wobl gefprenge todern / toann fie nur bon einer fojouten Form. uno robl gefdinitten find dann nod) rarere uno fdobnerer das bon formmen fonnen.

Die verwirrt gefprengte oder bizarren/ Deten farben am beffen von sinander gefondert / und ain weiteffen von cinander. unterfácieden fino/ find die allerédjónffe.

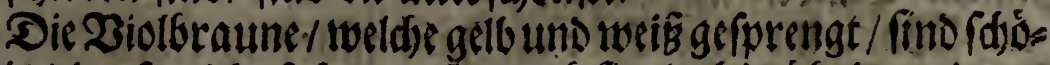
ner als die/ fo nidet fo braun find / ob fie gleide in itserigen einan: Der gants ábnlidó) Eomunen.

Eine iede gefprengte' Tulipe/ oie nemlid) gefprengt beiffen foll / iff nidots nike / wann fie unoroentlid) und berwirte iff.

Nan muf es eben nids alfo verifeben / alo ob mancine Tulipe / Die das crfe Sabr nid)t gleid) fauber gerprengt fómntt/ tweglverffen follt:/ oann es giebt gefpiengte die fidereinigen und

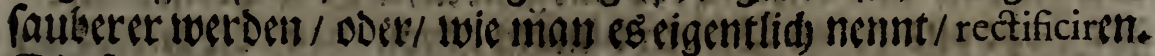
Die fo genannte Hazards, weidse ein twenig unordentlid oder vertwitrt fino / mulfen ben Seite gelegt wernen/ Danitman fie Das folgende 3 abje examiniren uno unterfuden fónne: Rectifi-

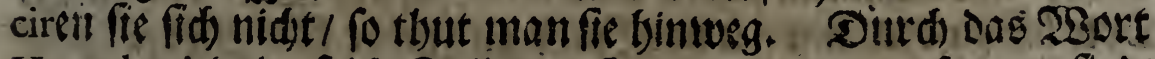
Hazard twiro eine foldse Tulipe berffandecn/sie mtan gefperengt fine/ Da fie es Dod das vorlyergetsenoe Salyr nod) nidt geivefen.

\section{อ}

Bon bet ju benen Sulipen oder tuichtigen Eroe.

Bon ber ju Denen?uit:

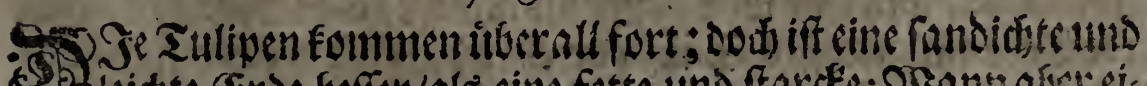

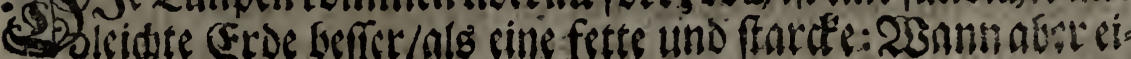
pent tidititige et 


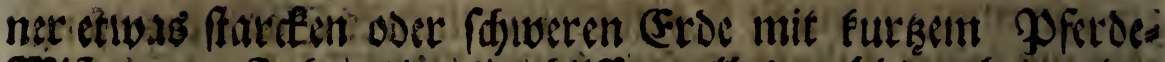

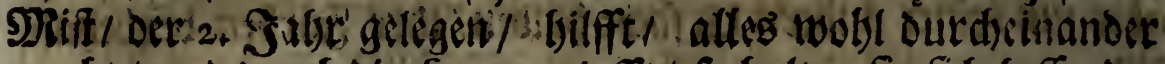
imadte / uno ourds bie Sorte wirfft/ fo balten fie fich beffer bae rinn als in feiner andeern Grde.

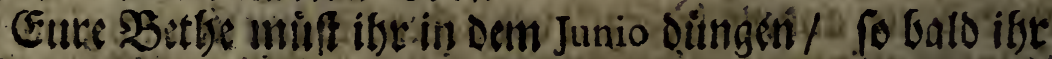

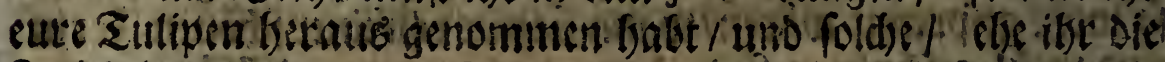

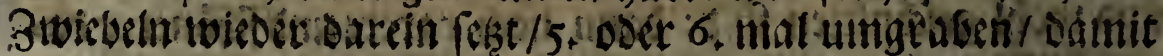
fiit) Der Miff unit oer Eroe Durd und ourd bermenge und ver:

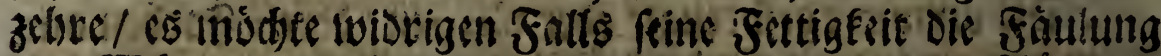

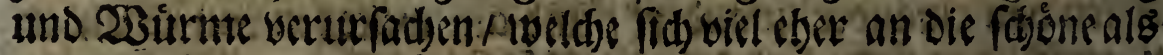
getuleine Zullipen antgingent

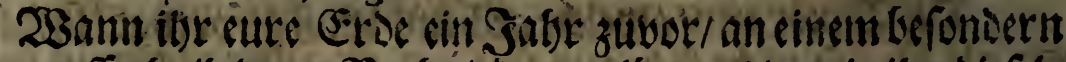

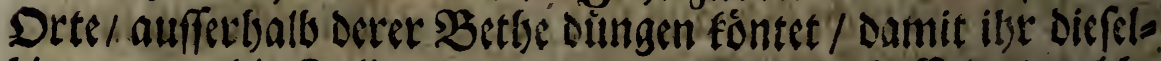

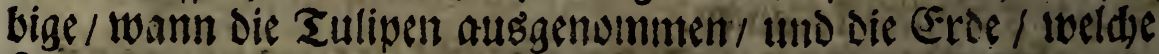

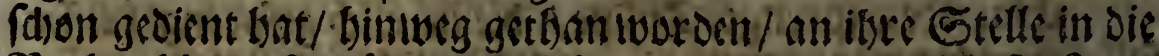

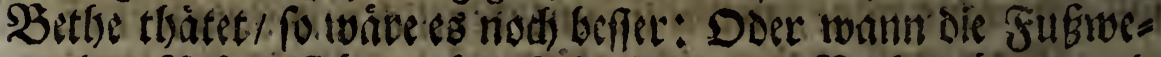

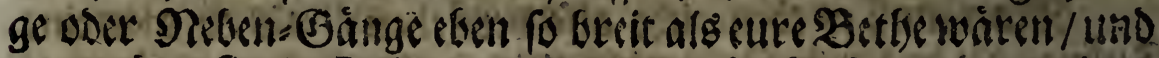

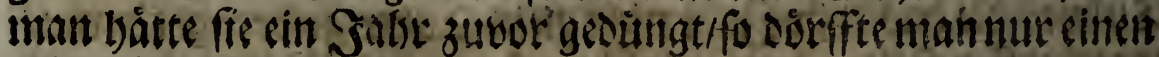

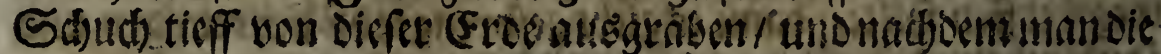

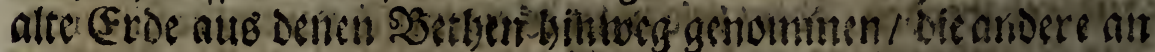

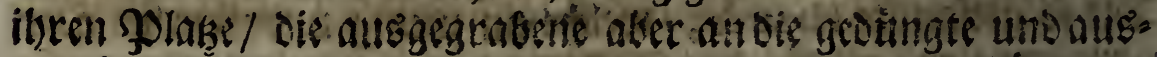

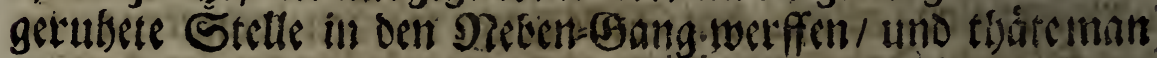

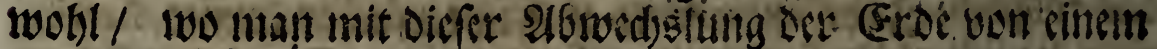

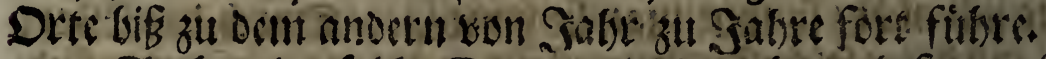

Sudjet sine foldec Erbe nuts/ bie sith aim beffen anfictset/

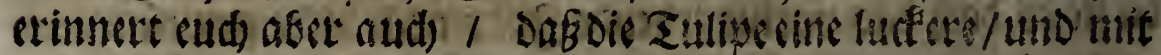

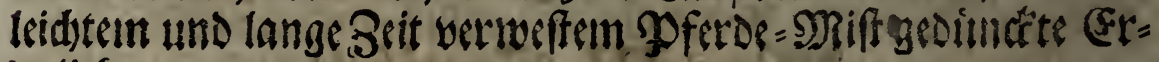
de lietre.

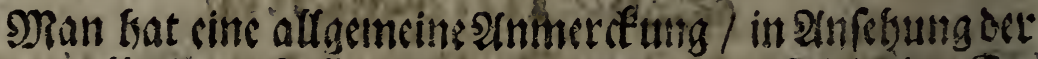

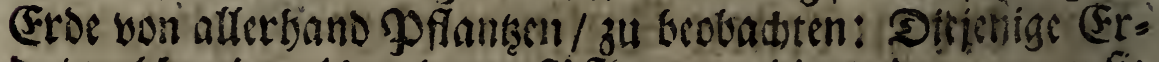

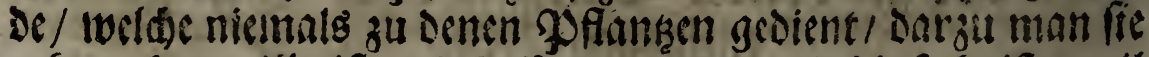

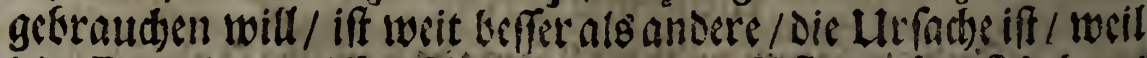
iede (Frde ein getwiffes Sälla vor cin iede goflenge beel fid hat f

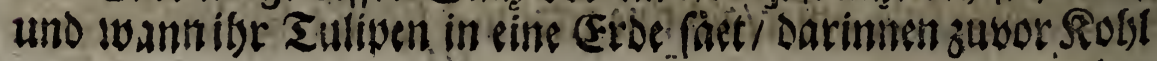




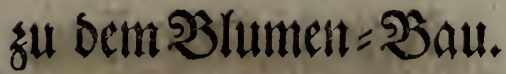

oder Rraut geffanden/ fo bat Das Sraut nur Das Salls/twels

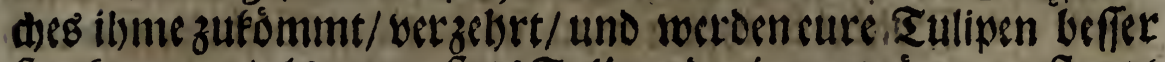

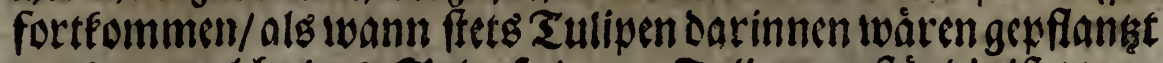

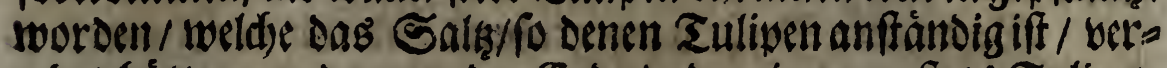
zebet bátten; uno waann Der ErtDe/ Darcin unan ffets Tullipen

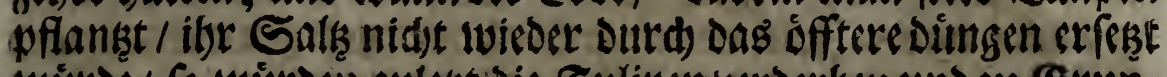

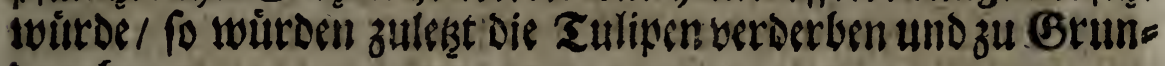
De gethen.

Stre móget nun cure Groe zu berciten twie ibe trotut/ fo unterlaff nidbt / gleid bon ber Beit an als ibe fie zubercitet / atl= Ie Limftänoe dicjer Zeit und oer Zubereitung aufzufderciben! Daunit/ wonn cure Pflangen geratben / ilse ing fimfftige alfío fémnet fortfallsen; ;ober aber wannibr in Dem Dimgen ser Sats de zu viel ooer zu wenig gettban/ oder eine geveiffe (erde oder

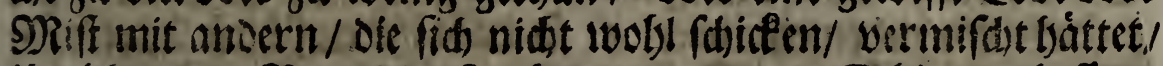

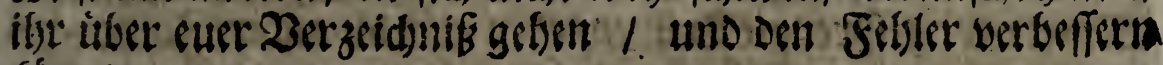
fónnt.

\section{2aร̃IV.Cnpitell}

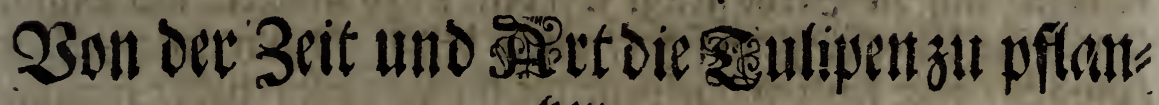
ken.

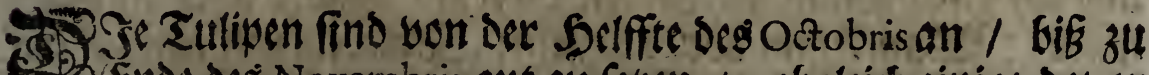

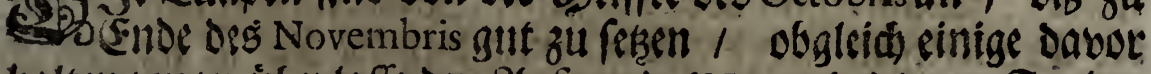
bulten / man itbertaffe den Anfang Deg Novembris Denen Fauten/

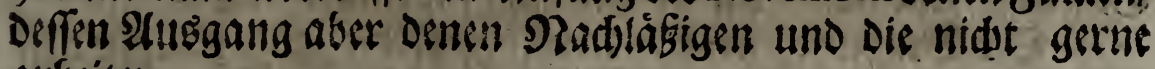
arkeiten.

2Banu man woul ber / in vorbergetbenden Eapitel gemelo=

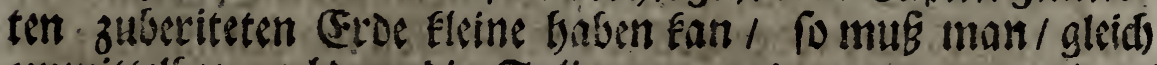

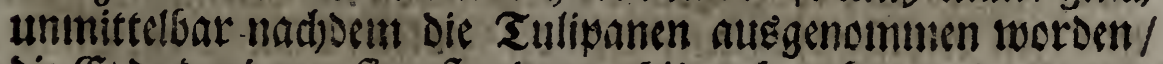
Dic Eroc Darinnen fie geffanden wobls dourdgraben/ und zum weses nigften oreumal lunter einander mengen/Dic Steine/wic audjoas

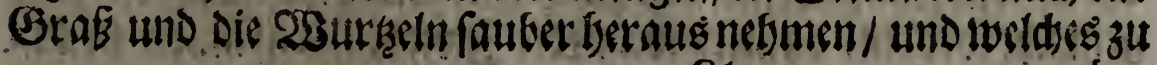


268 Mrue Untertweifung

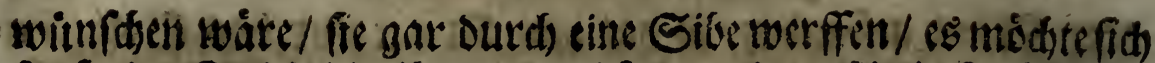

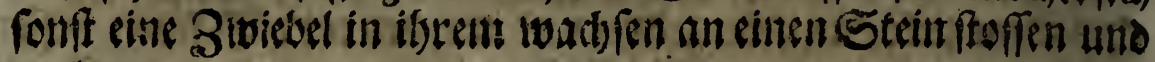
merlcken.

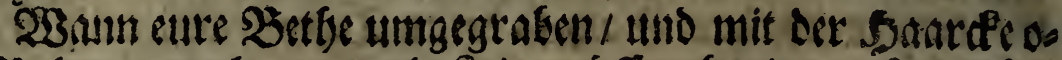

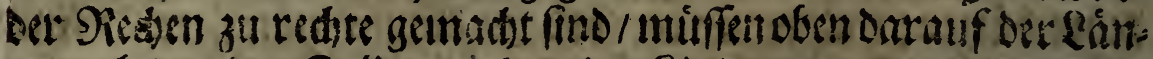
ge nad)/ und 5. Zolle voricinander Einien gezogen wertocin/und

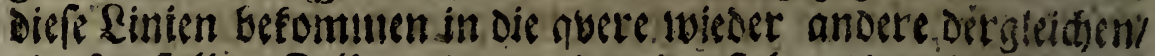

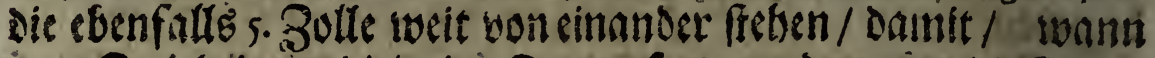

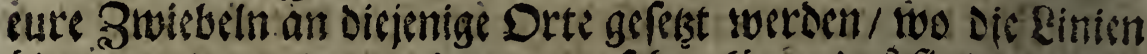

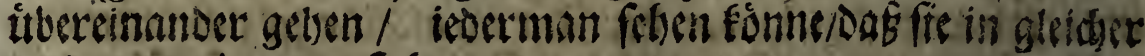
weite bon sinander fetsen.

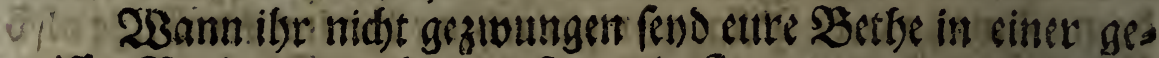

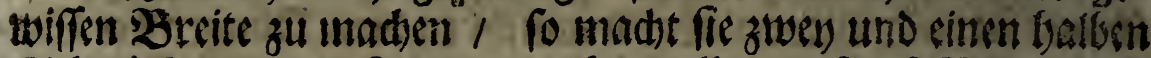

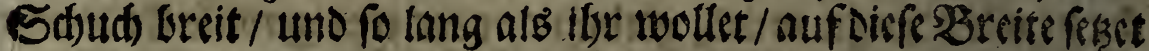

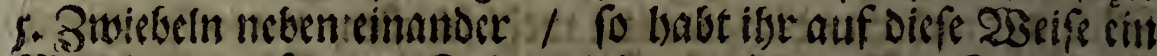

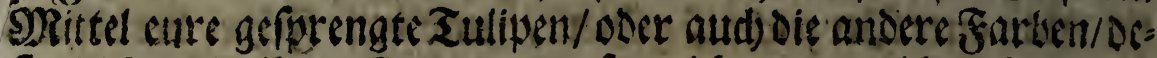

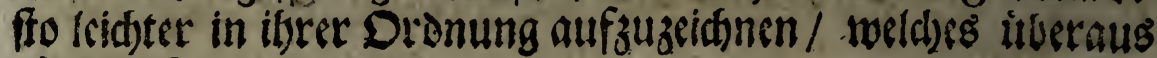
nitglida iff.

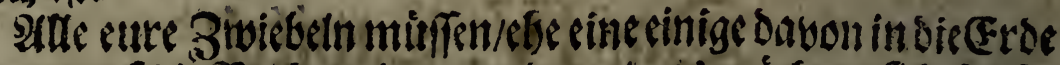

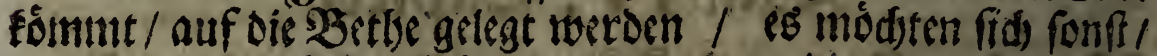

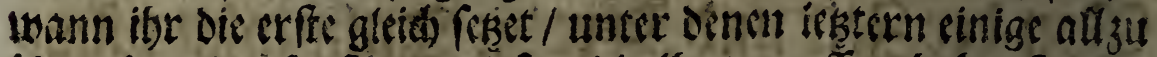

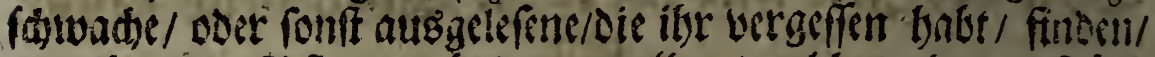

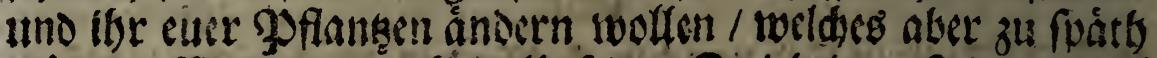

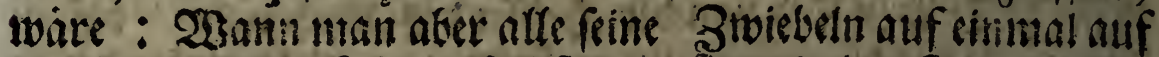

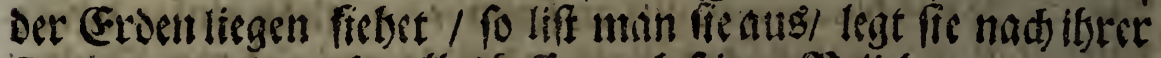
Gattung / mo madit alles beffer naw ferinenibellievert.

Die Euliparen muË man wenig itser s. gute Finger ticff

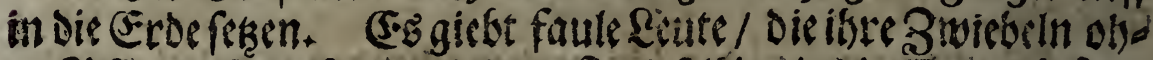

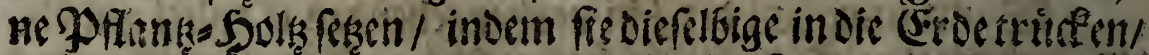

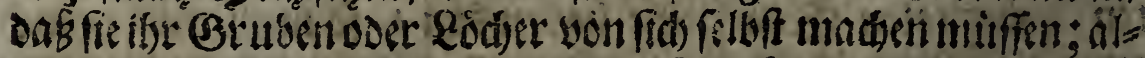

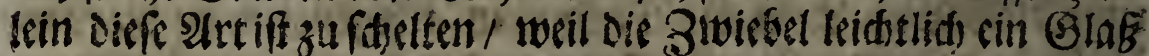

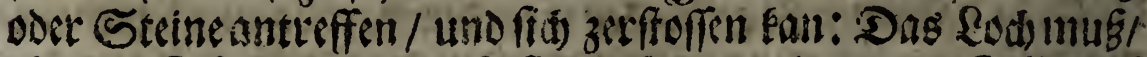

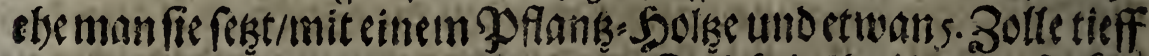

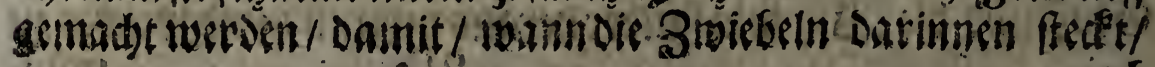
nod 


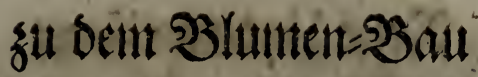

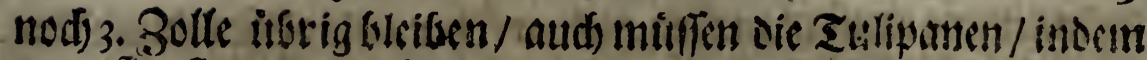

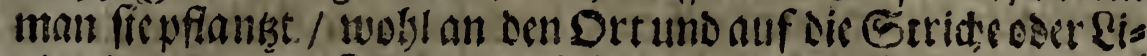
nien fommen/ wo fie frcustweife- iftercinanoer gsthen.

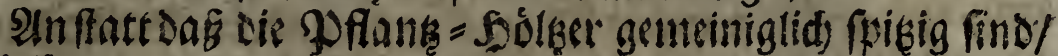

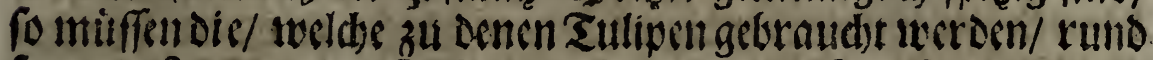

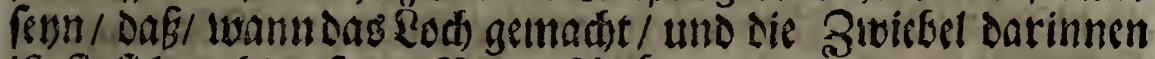

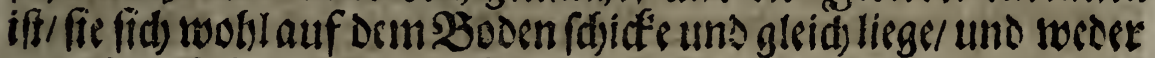

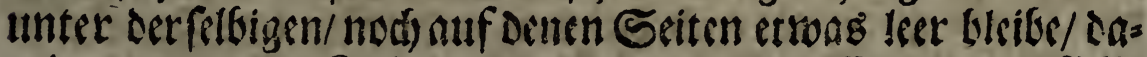
mit / wann sas \&od) mit flarer oder reimer (Erbe ausgeffittt

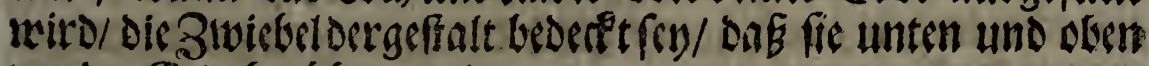
ven der Erie Geritbrtwerbe.

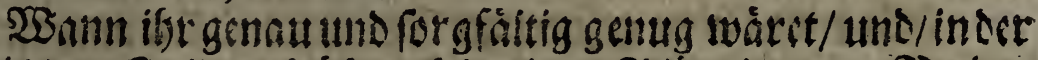

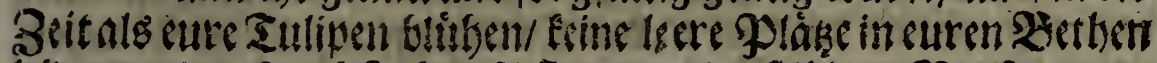

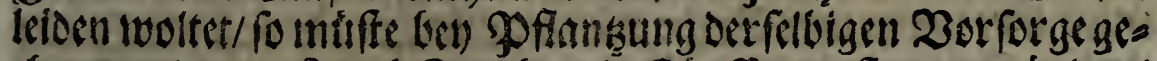

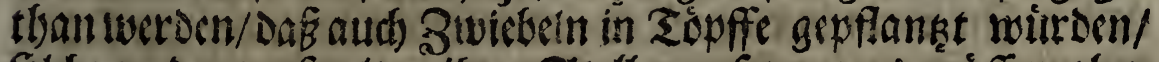

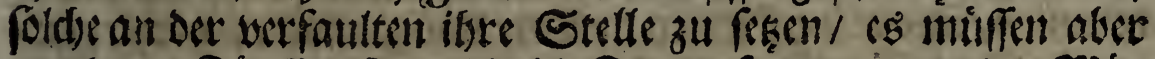

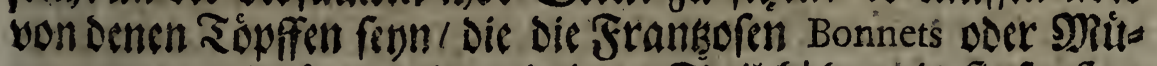
Gen nennen/ Dod um einen oritten Theil bobser als fie fonftent phlegen/audu muB Der בopf unten auf Dem Bocen fafe ganke

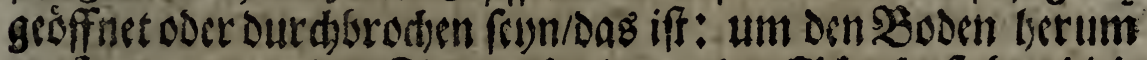

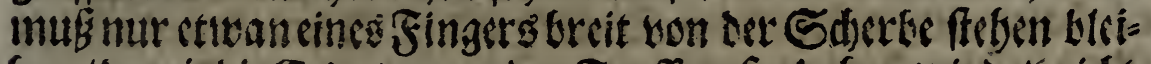

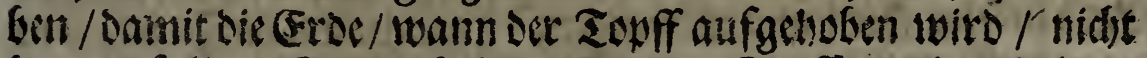

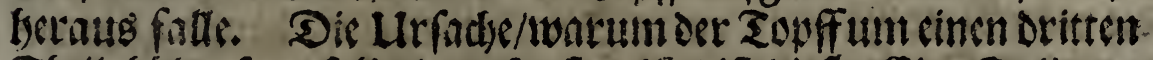

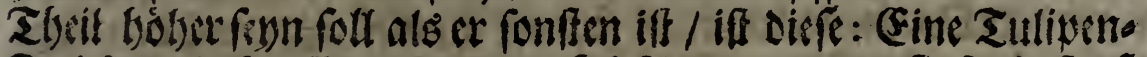

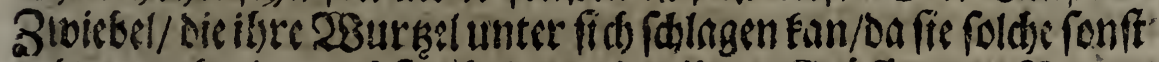

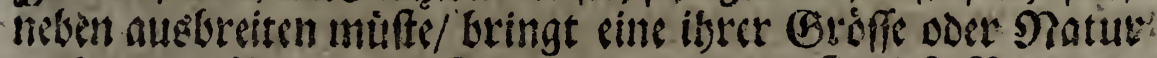

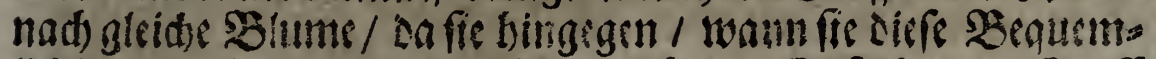

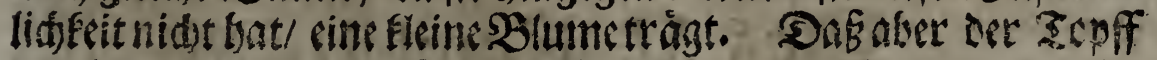

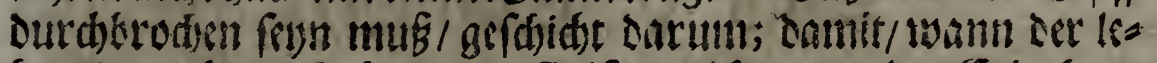

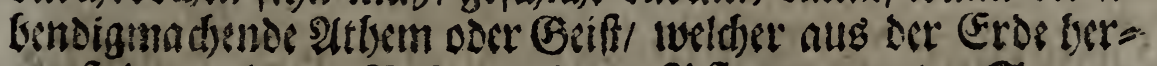

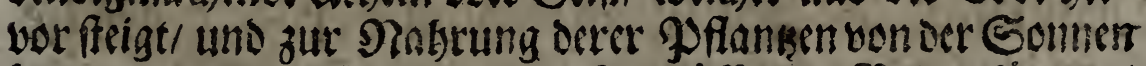

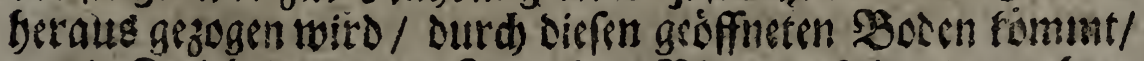

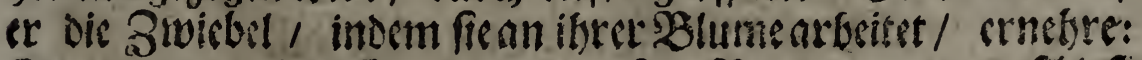
Dann wann im Ssegentbeil dirfer soden gante verfotiofs

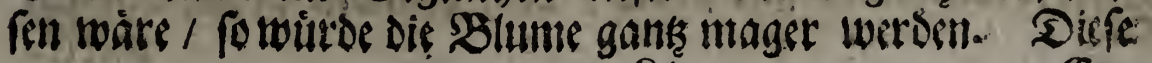
$\mathrm{Ql}_{3} \quad \mathrm{Er}_{2}$ 
Crinnerung inus imaneben nid)t anfeben / als ob fréetinen vitu Ben bätte / Dienweil man stwan 2(nemonen oder Sianund"eln fies bet/ bie in Denen Stherbeln ebenfog gros als in dem \{ambe werdert. DRit Denen Tullipen bat ss sine gants andere $\mathfrak{B} e$ fdaffenbeit/ Dann fie hat diefes lebendigmadenden (Geifts zu ibrem $23 a d)$ ge

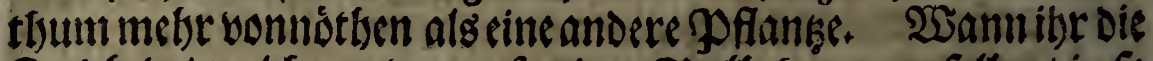
3twieseln/ weldes ander verfaulten Stelle fommen follen/ in fo wiel Topffe geferst als end beliebet / und zwar iese 3twiebel in

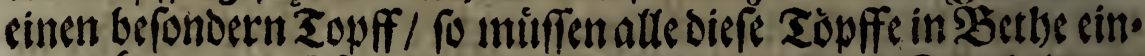

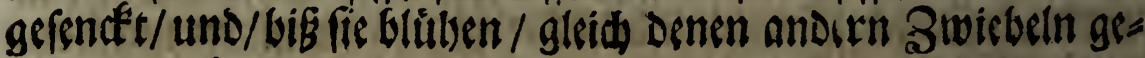
warter werden.

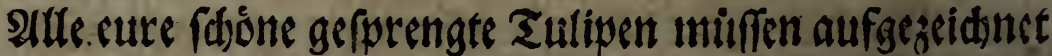
werden. Damit ife fie in Der Dronumg auf oie Eroe leget/

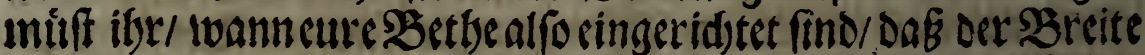
nad) 5. Bwieseln in siner PReibe oder nesen einanoer zu ffeten

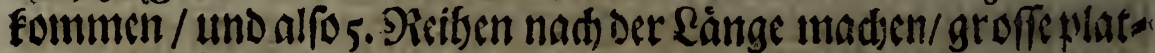
te ober flad)e Sdubladen baben/ Die in fimff Sieilsen fleiner viers ectidbter fád)lein abgetheilt / unz Der \&ánge nadh fo tweit vone einander unterfabieden find / als es vonnotbeniff. Saált euce Betb die \&ánge binunter 50. Qver=-Seiken / euere Sdublnden a.

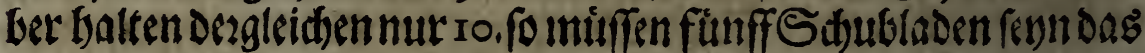
Beth in feine Dronung a ubringen. Zndem its die Zmiebeln in Die vieteffetgte Fád)lein eurer Sd)ubladenlegt / Damit fie in die

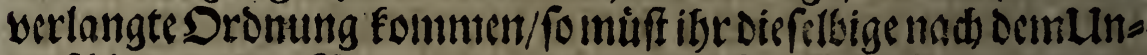
terfaico und der 2 ermifaung deter'Gartert auslefen und legen/. weldes/:wann fiebliulsen/febr luffig anzufdauen iff.

\section{2ab V. Eapifely}

2Bieman die

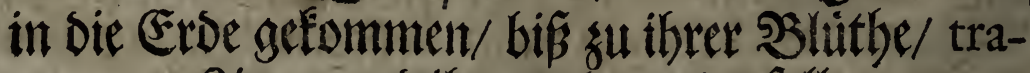
ctiten/und ibuten abswarten foll.

Co. Je Tulipanen fino ftarce / Dod befinden fie fid um cin 


\section{รu bem SBlument= Şau.}

inerdidges beffer/wann man fer toobl war tet und in adst nimñt:

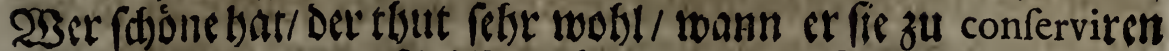
fudst. Solange bie Seiffen waren/múffen fie gleidh oben weg

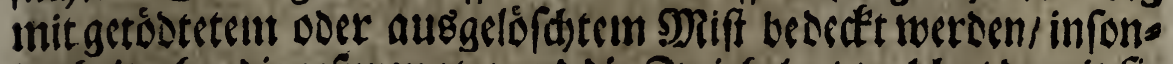
derbeit aber diegerprengte/ und die Zwoiebeln / woclde / Damit fie Dit berfaulten Stelle erfesen modten / in Sdjerbel gepflanst morden.

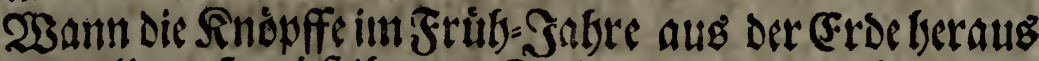
Gommen wollen / fo muff ifor cule Sulipen/woann es nidbt reguen

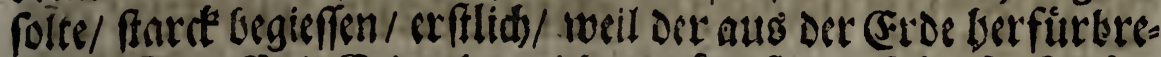

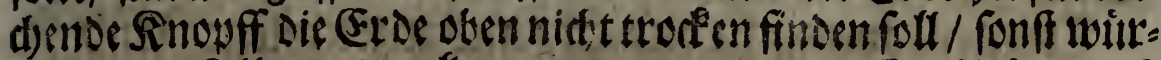
Dect gleidfoutre austrodenen uno verdotren. So fdiagt auds ferner diefer 3 egieffen die von denen Sieiffen leid)t und ludeter gemadte Floe wirder nicoer / und bringt die Pofianke Ivieder in Den red)ten Stand : Lber diefer befenditet cs aud Die Pflan= Be in Det Beit/ Dafie an ibere slume befdafftiget ift / uno reidjet

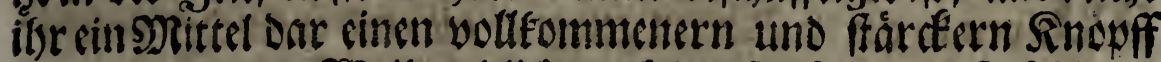

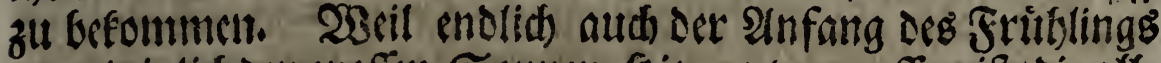
gemeiniglid) Der grofien Sonten=SDike unterworffen ift / bie alle

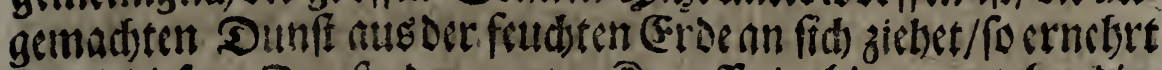
fie mit dicfenn sumfe oen zarten Sllopff/ da bingegen/obne die?

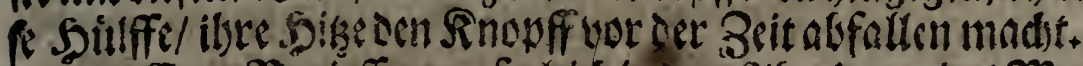

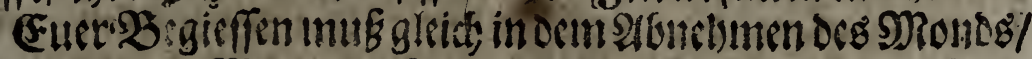

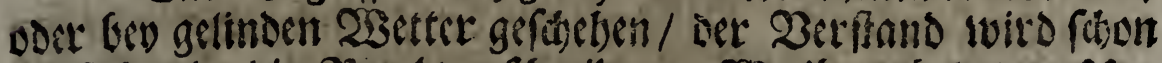
felbft bierin die Siegel vorfarsiven. 230 ibe rourdert zur Lin

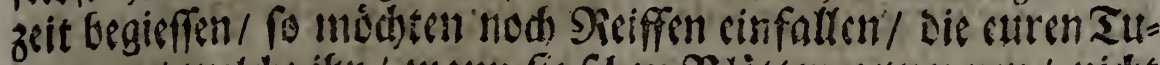
lipanch / welds iffr / twann fie fdoon Blatter gelwonnen/ nide

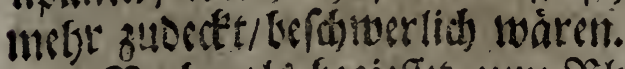

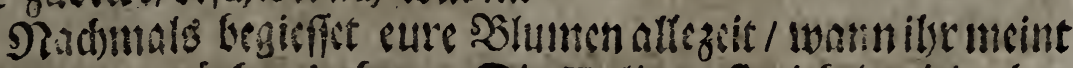

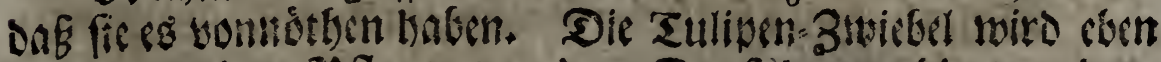
wie cine ansere gofanke von Dem Durf kcumrubiget/ unseu=

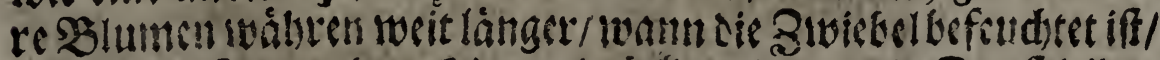
ale wann fie bon ber Sige georudt wird/ und Durff leisen muş. 
Bebor ibe cure Tulipen bas erffemal begieff / fonetwet

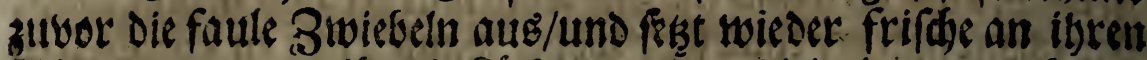

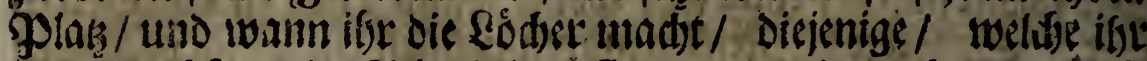
zuIII Vhadfegen in Sd)erbel gevflange / Darein zu bringen/ fo

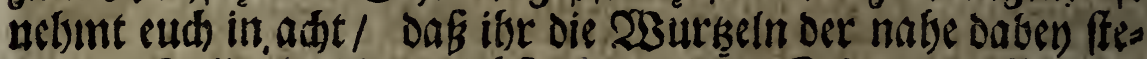
benden Tulipen nidte cntbloff / Doer ifsnen Srbaden zuftiget.

\section{2ab VI. Capitel/}

Qon benen notfoigen Snmetcungen / foie bie

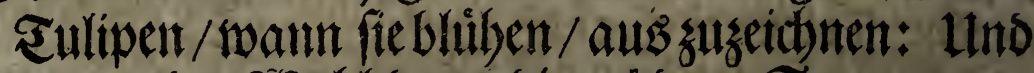
von Der 2 Babl Derer/Die sul Dem Saamen/ und Denen Theatris Doer $B l u m e n=$ Silbmen tuidstig finto.

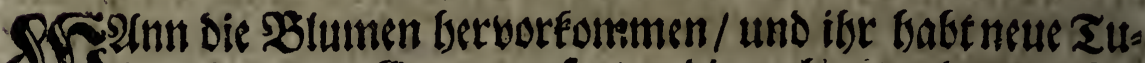
Wlipen in curen Garten gefest / die cud) entweder berebert worden / ober afer die ifte bon ettrem cigenen Saamen gezeuget babt / fo muft ifte diejenige Zlviebeln/ Deren Blumen die obens befdriebene Eigenfdafften Det Sdjonbeit nidet baben/, fleigig ausrciffett.

Die einfade Fritbersarben/bie Fritbs gerprengte und die Hazards parfaits, oDer volffolnmene Hazarden muifen / cine iroe Gattung befonders / bezeidnet twetden / uno geboren in sas

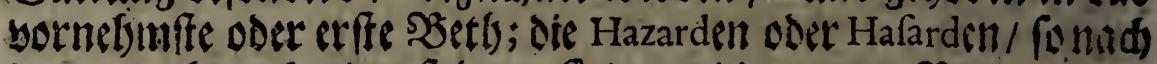
Denen yorbergebenden folgen / find ror Die andere Bethe; sare auf folgen die auggefegte ober auserle fene Fatben / wie aud bie zun Saanen beftinme Sulipen/deren icde art ein befonderes Setth baben muE.

Diefis find nun fed) ferley) (Enttungen Tulipen / weidje man mit oreyserlen Farbe wolfe zeidjnen fan. SGier zu bat man fein

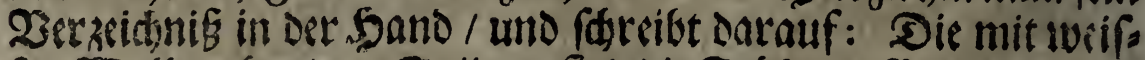

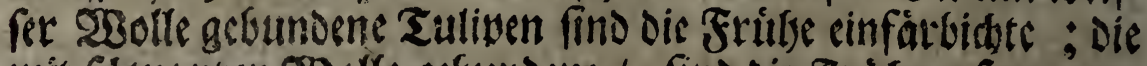

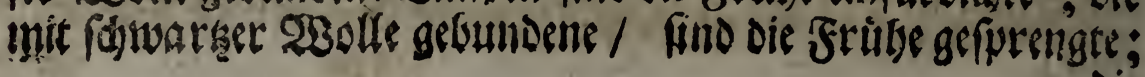


Die mit rother 230 olle gebundene / find dic vollfoumuene Hazar-

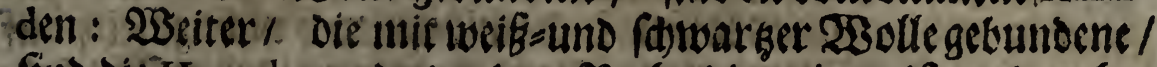

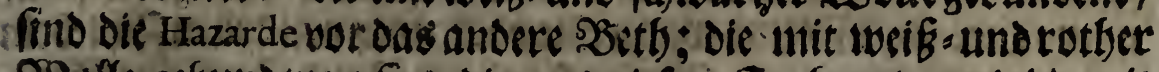
230 de gebundente / fino die nusertefene Fart:en / und bie mit

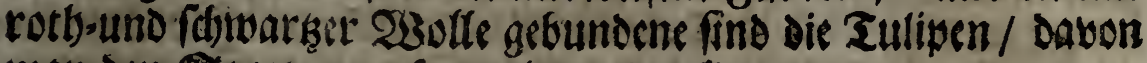
man ben Saamen zu faummien gedenetet.

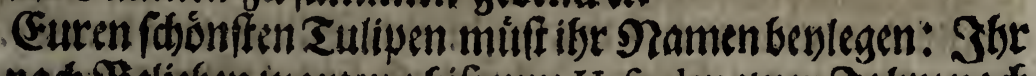

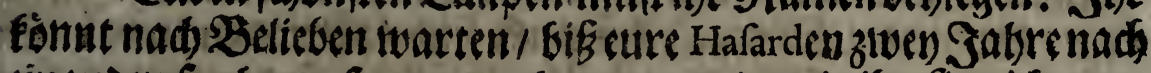
einander fauber gefurengt gefoummen/ damit ibr fie nidfet vers gesblid, benennet: Eure vornetbmfre Hafarden aber miffen auf-

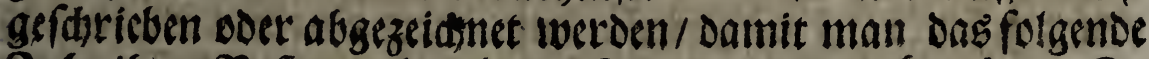

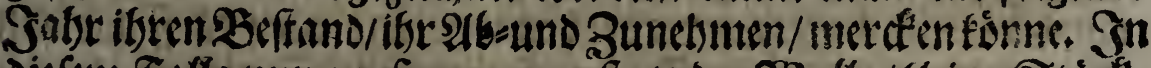

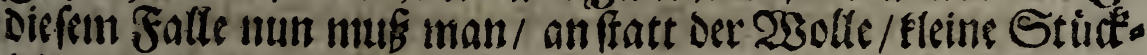

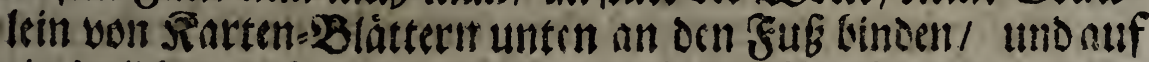

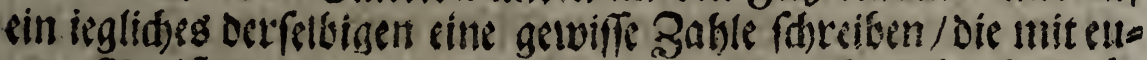

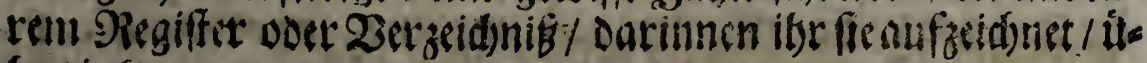
bercinfoimme.

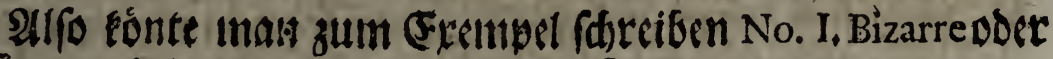

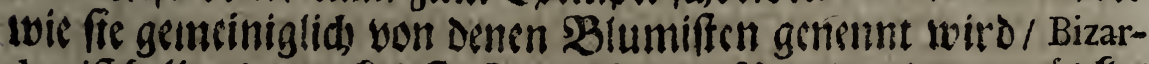

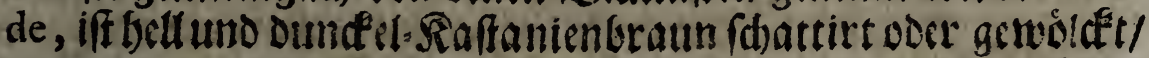

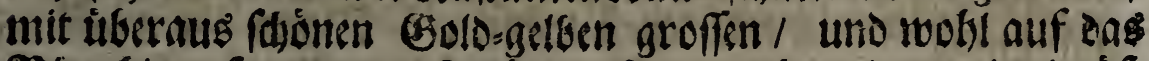

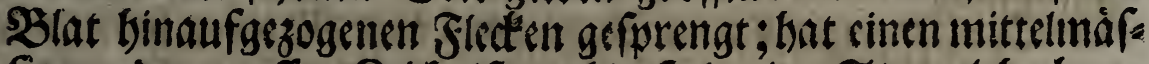

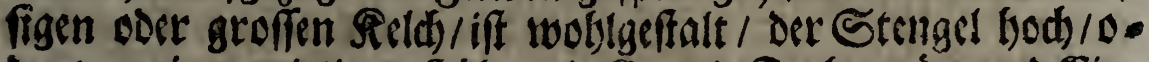
Der von einer mittlern Soble; die Grund-Sartie griut und Eir-

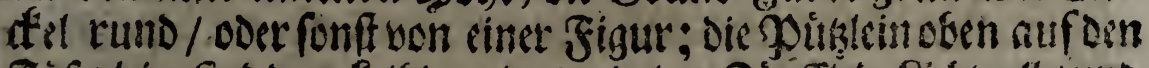

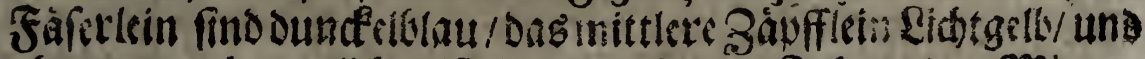

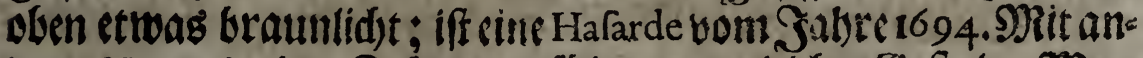

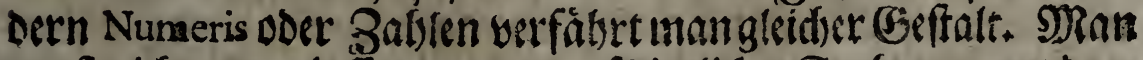

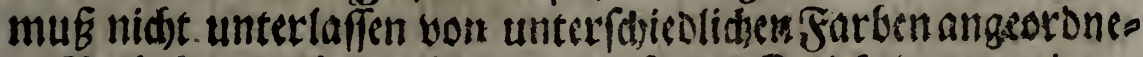

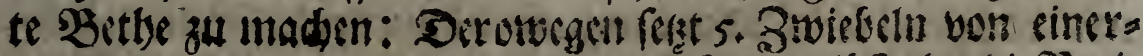

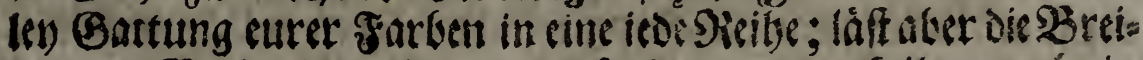
tc Derer \&etbe ein methrers zu / fo fan unan auds ibrer meht in

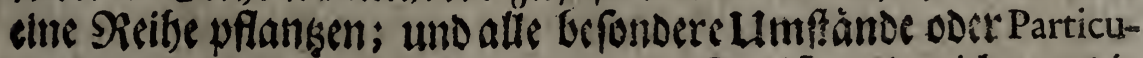
laritxeten der Gattung in Dag babende Siegiffer cinzcidnen; Die Min

Lilit 


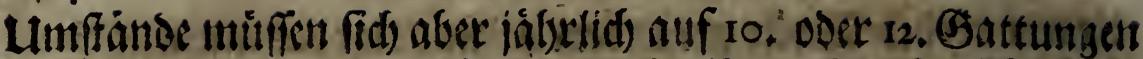

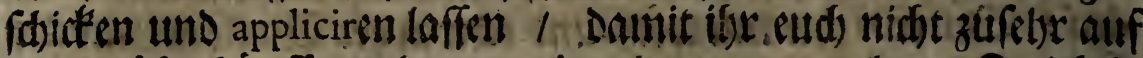
eininal úterbäufft/ uno twanneine ober ztweb bon senen S wiebeln geforengt werden / fo felset nad) / ob die soutmo- Farbe volfeom=

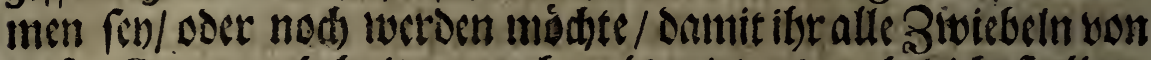

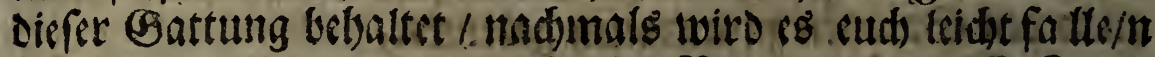

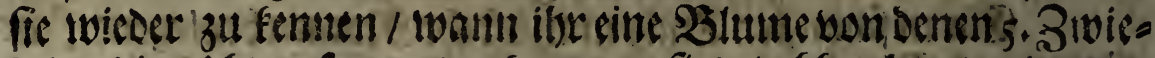
beln / Dic uidot gefprengt grfolnmen fino / abbredsen / uno gegen

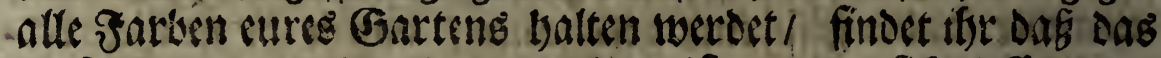
Gefprengte broïillirt oder vertwirtet iff / oder fid tieff in sas

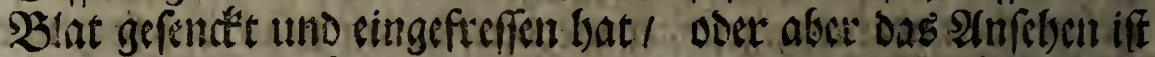
Durd) Die Bume=Farbe burdorben worden / DDer es findet fí cin anderer wefentlider Felsler / fonelsmt alle Btwiebelh / bie itse von biefer bofen Gattung babt / uno fabaffe fie auts curent

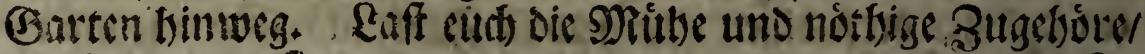

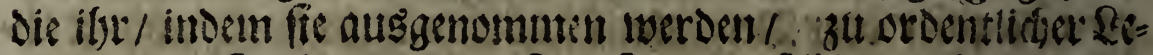
gung ifser Farten / und dabi ithe fie in derfelbigen crbattet / ant

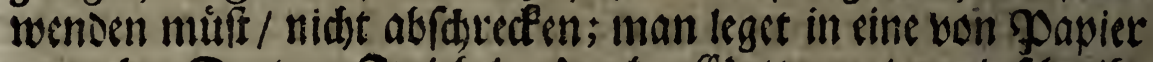

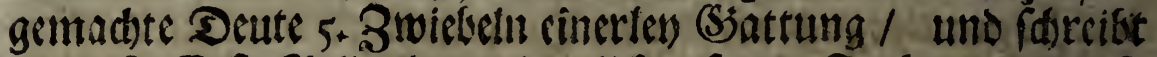

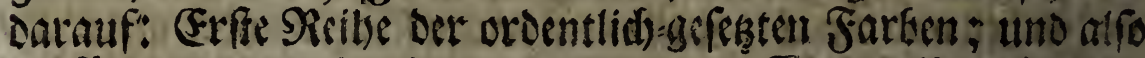

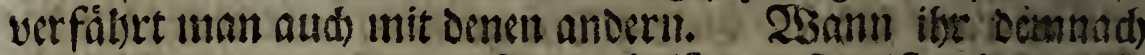
Diefe Oronung gegen cucr 2 erzeidinib oder SRegiffer baltec/ fo

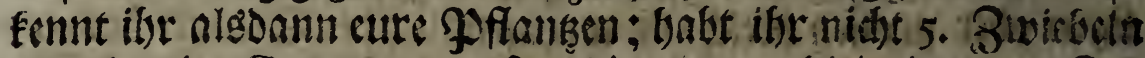
von cinerlen) Gattulig I fo jeidsenet nur Dicienige zur Beit

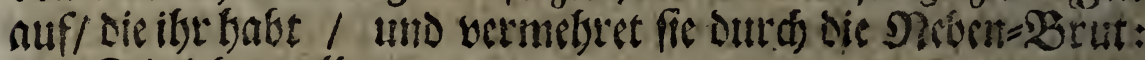
Die Beit letret nifes.

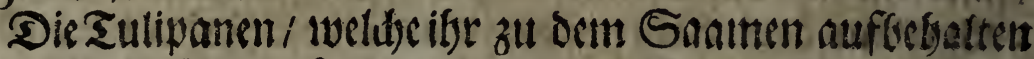

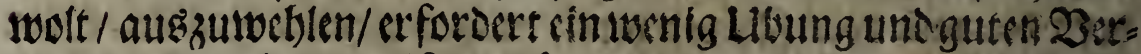
ftano: Die Unterweifung / fo man saven geten fan/ iff Das

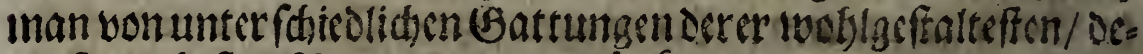

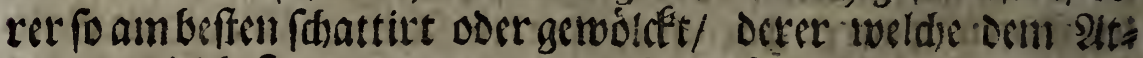
lag aut gleid)effen fommen/ und infonderbeit derrer Bifarren oder Bizarden/ weldeam meifen verwirtt in ibren Farbenfind/aus: 


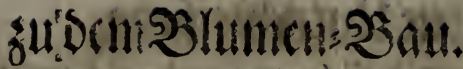

zeidnte; Die Silufortidte fino chen fo notbig alb sie Durdedel und die Huilée iff einegctboldt'te Bizarde, die nidts duntelel iff.

Padseem ibr cure Sulipatien zu Dem Snanten ausgezcid). net babt/ fo fredt denen andern allen oben die Roppfeab/ Damit fie nidt ferner bergeblid fort arbeiten / uno viel Samen bringen/ Dern man bernad) binweg loerfen múffe: Sndeffen lâft fid Die 3wiebel ibre cigene (srbaltung angelegen fern/ und rendet die

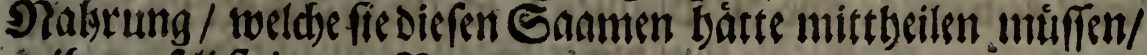
ă ibrem felbfteigenen Nusen an.

Wann diefer gefdelyen / fo läf man die Zwieleln reiff twet: Den/ indem ibnen (eroe zu fafien erlaubet/ bib fie gerng baben: und diefe Beitigung fan man metefen/ swann neinlid) our Sten:

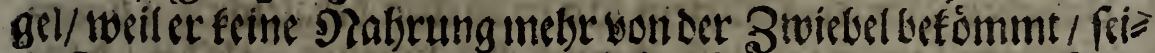

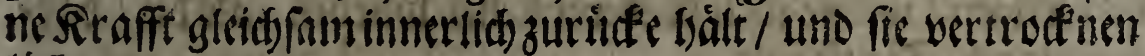
lâft.

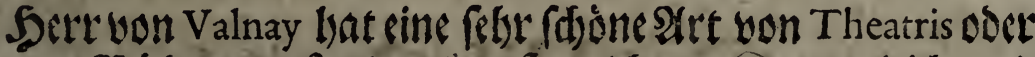

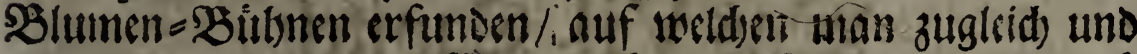
gank bequem cine ganke Denge gefprengte Sulipanen / die nad ilsern unter fdiedenen Farben vermifor / und ordentlide eine hes ben dic andere gefest fino/fan bor Augen frellen; alfo taf ibr in

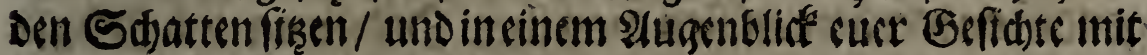
allem oemienigen/was ein groffer Barten Seltenes berfur zu bringen bermag/ ergösen fonnt.

Mitten in einem Saal fifte ex cinen febe groffen Sifd/

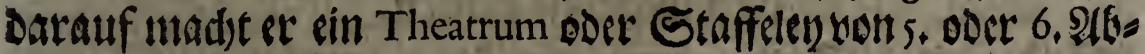

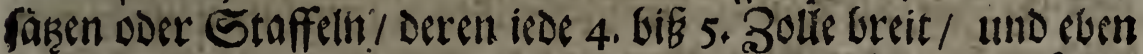
fo bod bonder andern erlyaben ift: Diefe Gtaffeley bedect et mit einem grunen Seppidte / fammlet feine boffemmen =ge forengte sulipen / und thut / nadjoen ot fie gants geoffnet / eine iede beronders in ein BJlấ / Dấ cinen engen Sals bat / tuno mit

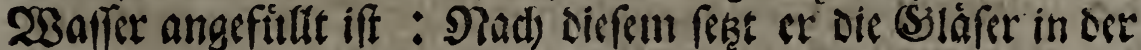
Dronung auf die 2 bläge ober Staffeln. Die Tulipen/ fo ct bierzu nimmt / fammlet er/ wann fe fdon eine zritlang geblitbet/

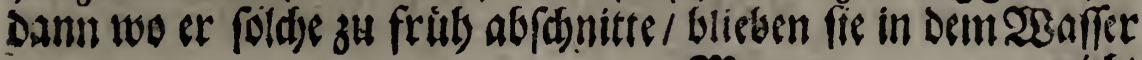




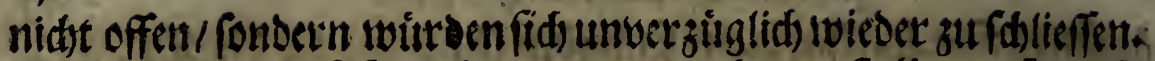

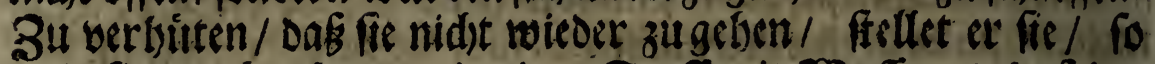

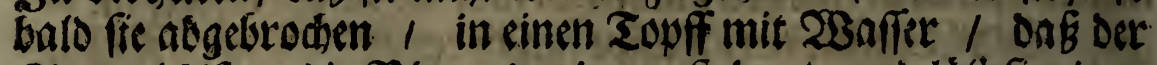

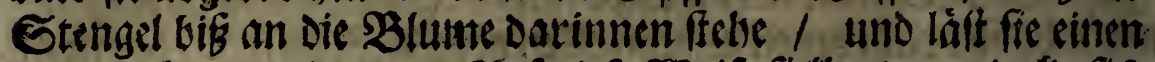

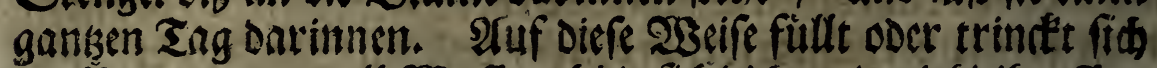

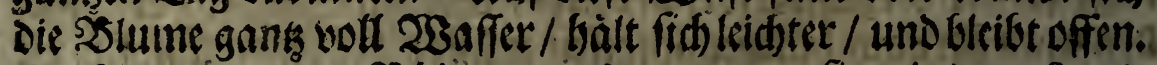
Diefe Theatra oder Bitbinen maden / loann fie mit Der Samo

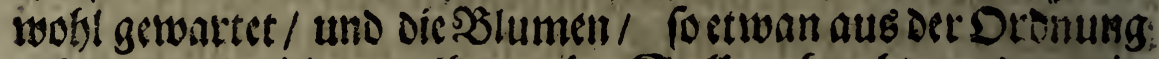

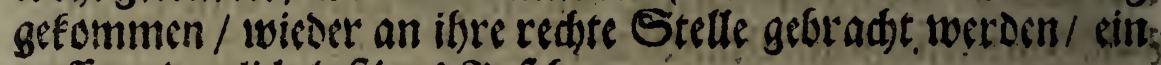

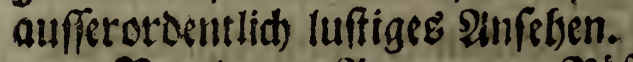

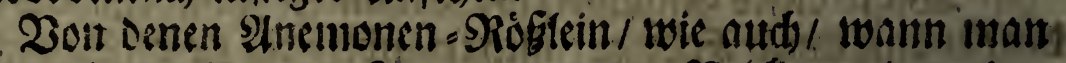

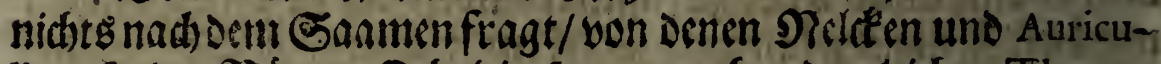

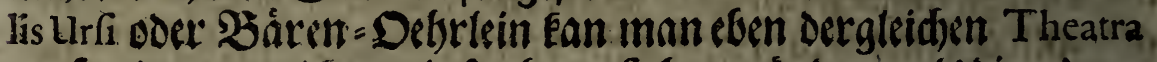

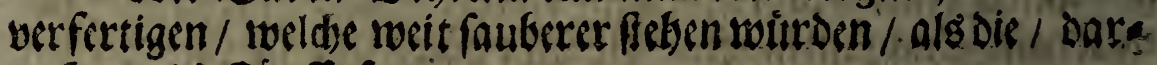

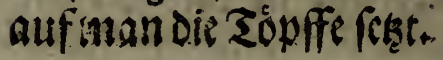

\section{2å̉ VII. Eapifell}

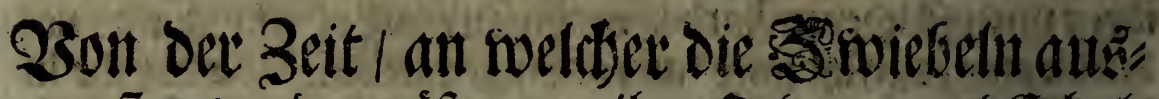
genoinen werben mifien/von ifrez Dronung underlyale tung/von benen Snamen uno ibrer Erbaltung: 2onder Zeit Differtbige zufáen/ uno wie Diefrlbige zu bauten.

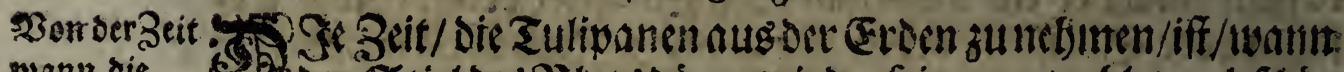
wann die

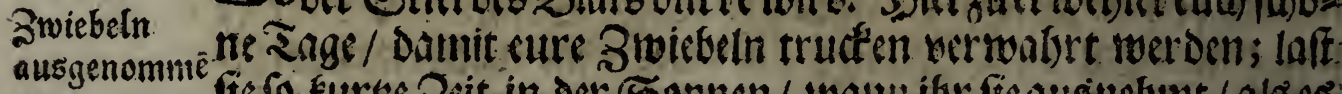
werden.

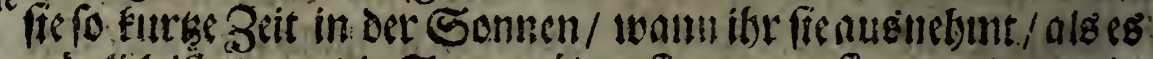

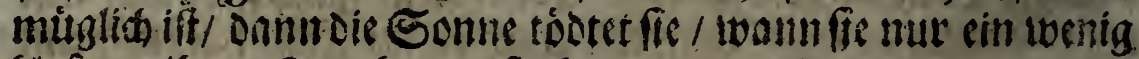
Wlog wenthrin Strablen geffoden wercen. Derolvegen / wann

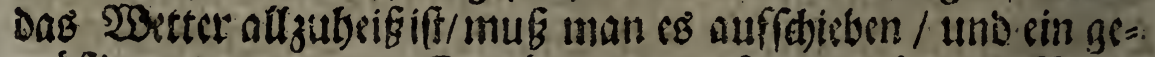

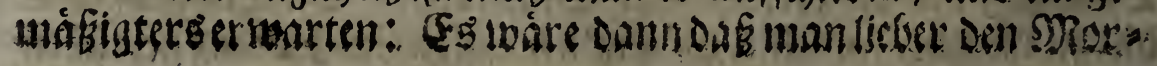




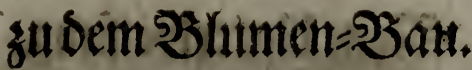

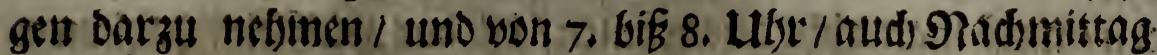
obngefelys gegen 5. Lllse wieder anfangen / und arbeiten woulte.

Eure ausgenommene Brwiebeln legt in eine Rainmer auf:

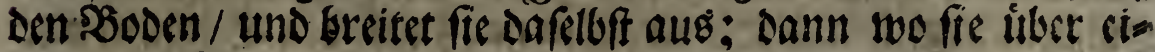

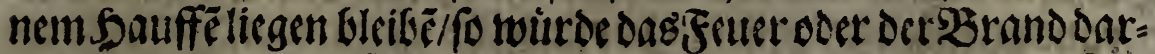
ein eoumen / und fie verderben. Derotwegen laft fie nufges

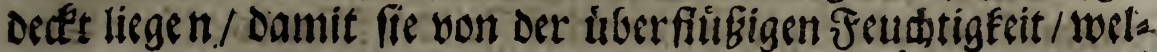
de fie nods von Der (Erde bers fids Gebalten/augtrodenen / unD auf folde 23 eife balten fie fids folse wobl. Dods Imit man von Beit zu Beit Darnads fesen/ und fie fadste ummenden/Damit/ wann fids stwon eine verleste oner frande sarunter befinten foltte / manauf ein Mittel ibr zu be!ffen modste beradte fern / in Dem inan neinlid) die SRince doer Sdelffen/ soer vielunebr die

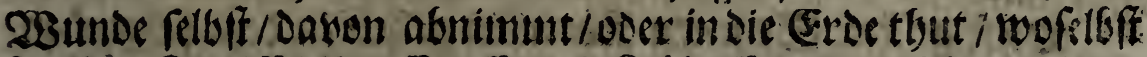

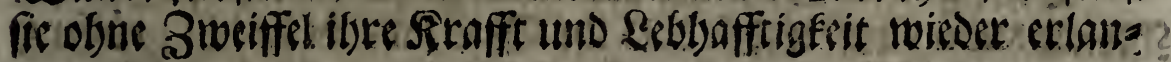
gen wirt.

Die Dromungen eurer gemadten Segiffer ocer Bciden. netmt allegeit in adts: fondert eine icec Gattung Swievein yon ber andernab/ uno legt zu ieder (Battung eingefdorichenes Siar.

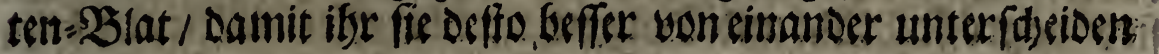
fennt.

Phadeem fie cinen Mionat oder ziven gelegen / und wookl: ausgetrodfnet fins/mus man fic faulern uno rein madben; man?

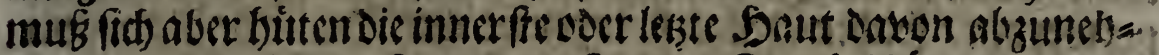

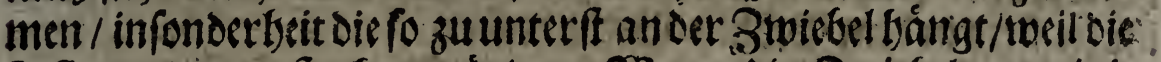
Pflanke Daben freten wirtoc. WBann dic Stwisegh gercini= act fins/ fo legt fie lieber in Rơrbe / als in Sctjadteth/ weil bie

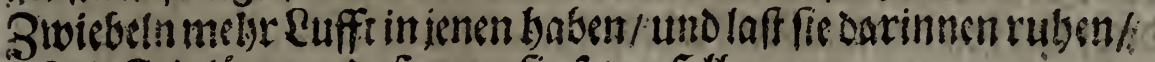

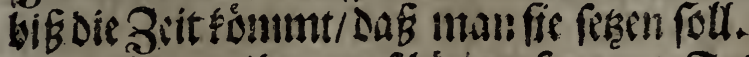

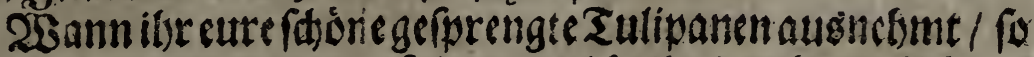

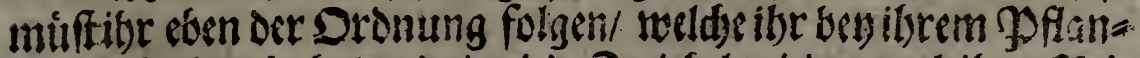

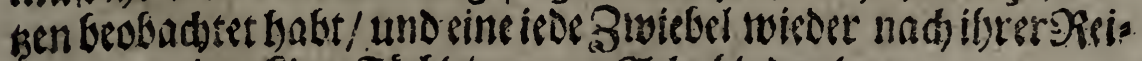

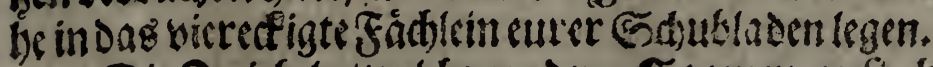

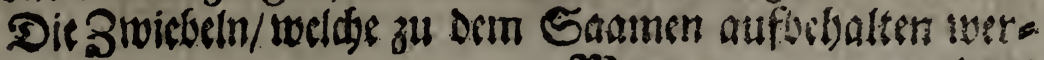
Rim 3 ICN. 


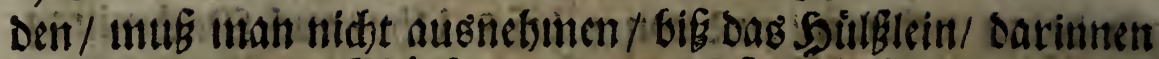

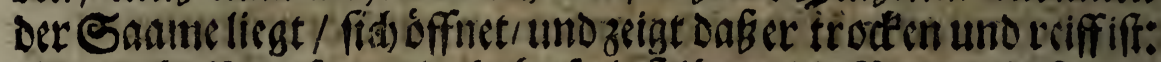

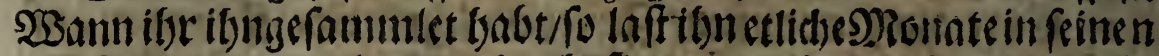
Soillglein liegen/ algbam bred)t fiegantsauf/ ben Saamen afle beraus zu nebunen/ utid ifonzu reinigen.

Guren Tulipanen= Saamen folt ifor in Dan Monat Se-

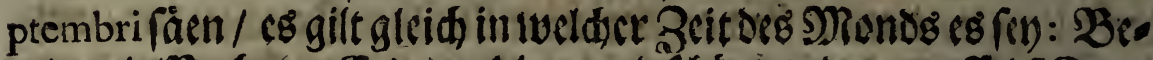
reitet cin'Betb) won (Ero w wobl zu/und fdutttet oocr werfft te Saaimenfo dunne darauf als ibr vermòget; Dann Die förnlein mîf fen zum wenigfen 2. Saftre in Der erde tiegen 7 bie fie grof toers Den/ ofme das inan fie beraus nebme. Curen Saanen bectet cines fleinen Fingers hod) mitelen der Eroe twieder z Befäet iff.

Diefe gefăete Saamen= Rọtnlein geten in dem folgenden Mionat Martio auf/ und fo bals iftriblat (1weld)es, nidit gróffer/

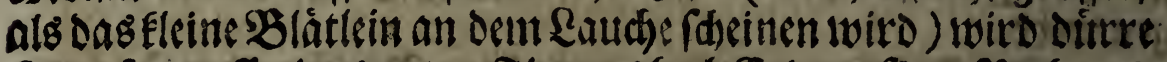

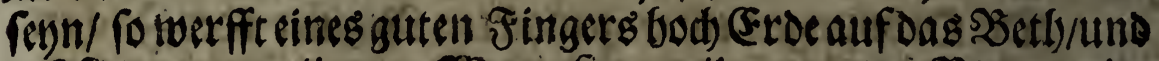
laff fie darunter liegen. 2Bann fe nun ibr ztocytes 2 lat gezeige basen/und ifse febt dab die - Btwichelngrof genug find / und ibe fe of ne groffe Meitbe uno Sorgewegen ibrer Rleinigfeit aus Der Grde nebmen uns wieder verfezen fonnt / fo nebint fie aus ibs= rem Pflank=:Betbe teraus/ uno feket fie alsdann wieder Seth= weife/ Damit fie alle Sabre/gleid) denen andern wieder berpflan. Bet werben / folder Geefalt bringenfie eber Blumen/ als wann

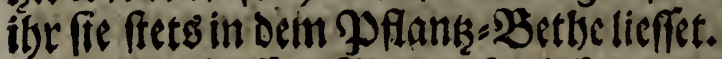

Ben beiffem 28 etter begiefle curen Snamen feigig / wann et eg vonnotben bat; Saltet itn bon dem Lnfraut rein / uno Defét ibubey barten Bieiffen oten au. 


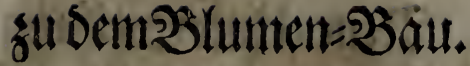

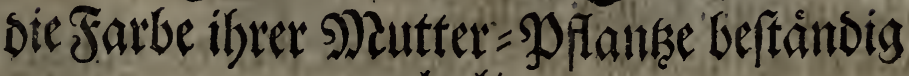 erbalte.}

Son ben Saut bet Pedentsitutl Into wie fie

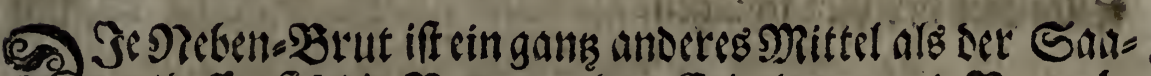

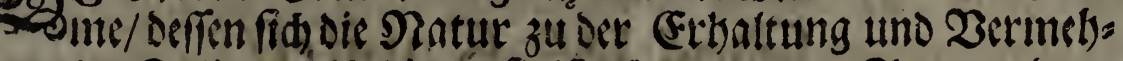

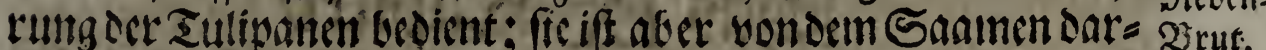

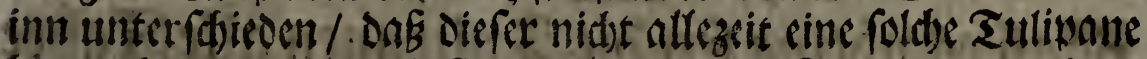

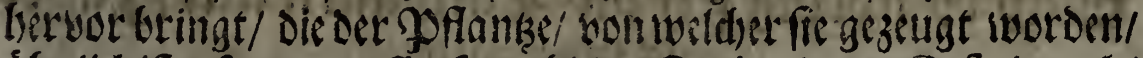

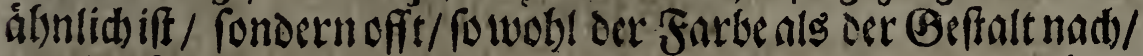
von Der relbigen unterédjiesen: Da in Gegentbsil Dic Micbents

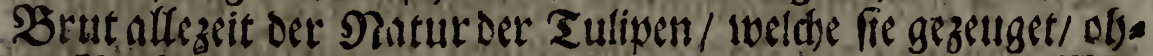
ne Beraindertung nad)atumt/ und feines woegg andert. Woer

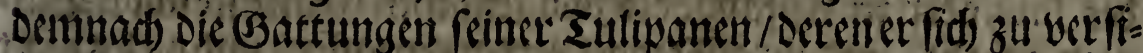

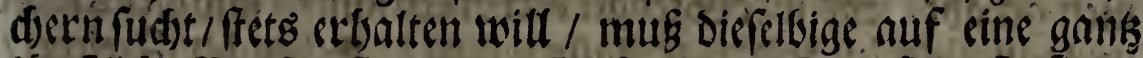

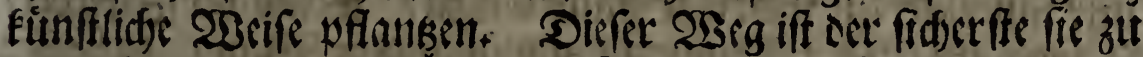

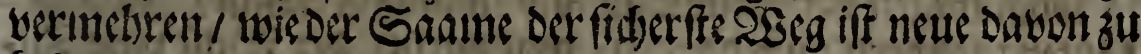
beEvinunert.

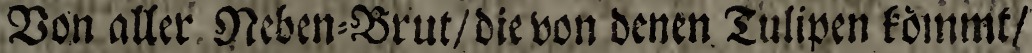

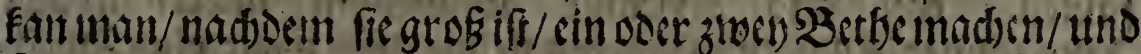
fie etrwas nabe an cinamber pflanken/ fo find fie gleidfaran die

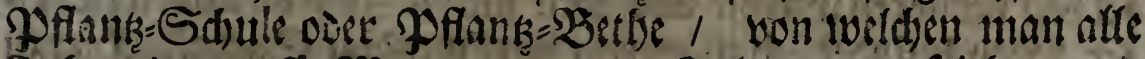

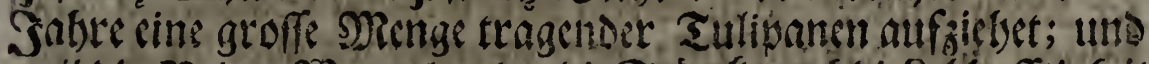

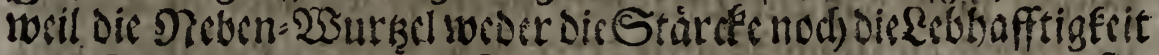

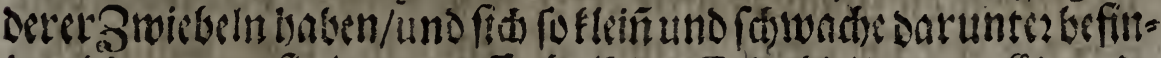

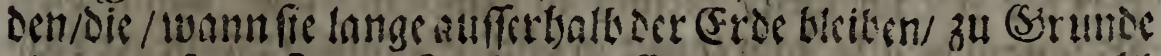

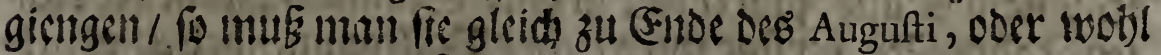
gar 14. Enge nadidecul fit aus der Erde genommen worten/

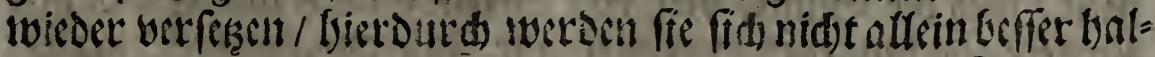
ten/ fondern auds claer tragen/ als isann iman fie erff um die

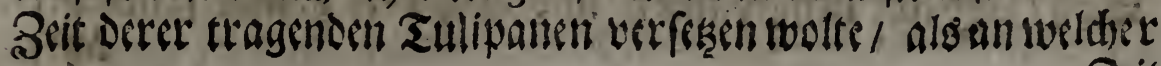


Beit man fie thetles vertwedeft / viele aber gar erfforben finsen

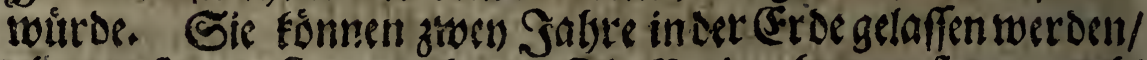

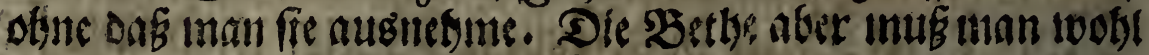
umidblieffen / uno fiubsek balten.

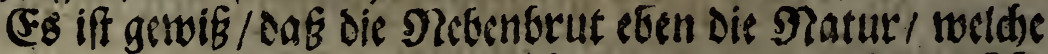

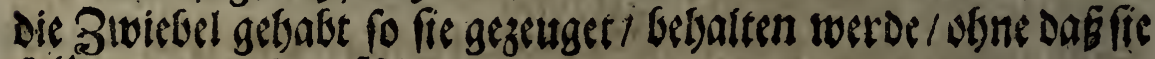
foulte alts ber ant fófligen.

\section{2ns IX. Snpitel/}

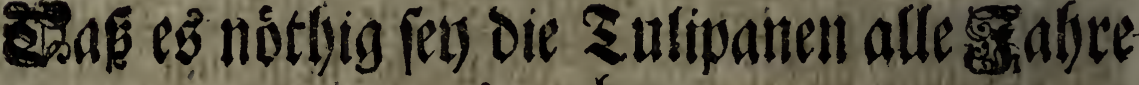 auszunthimen.}

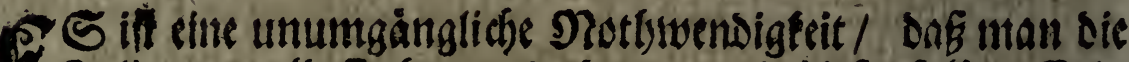

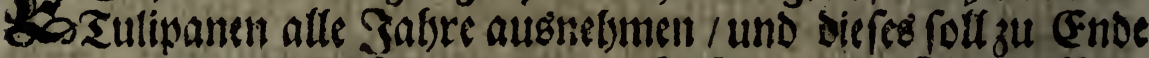

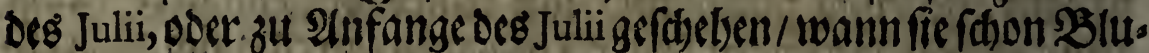

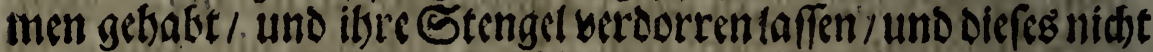

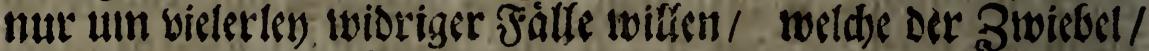

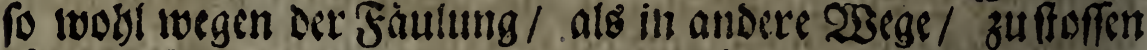

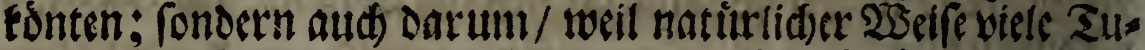

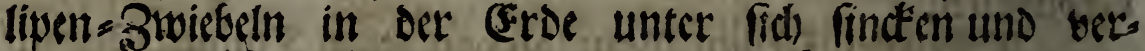
faulen / Dä́ alfo Derrienige welderer fie unserfadicolide

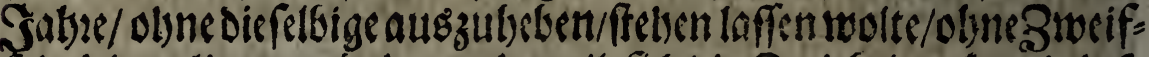

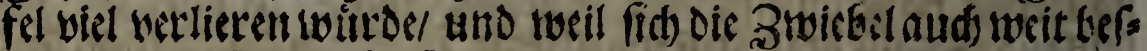

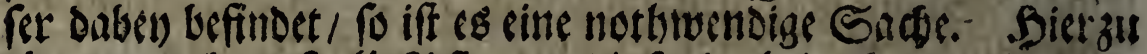

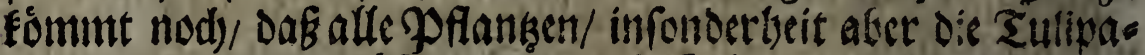

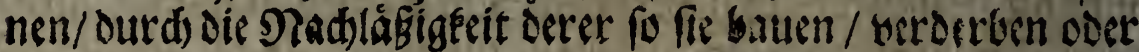

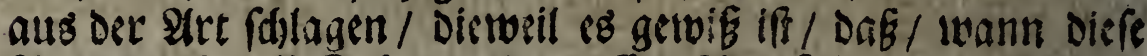

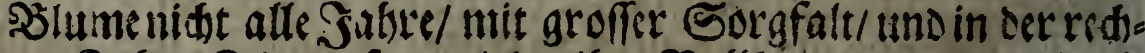

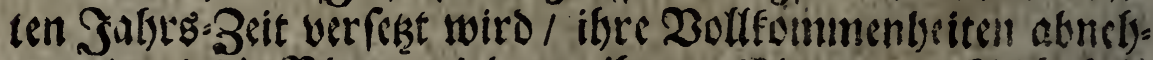

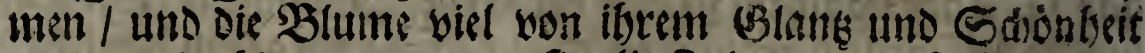

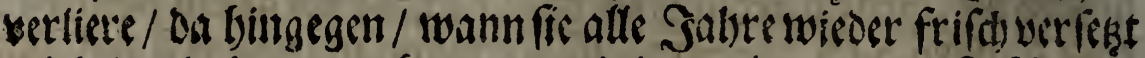

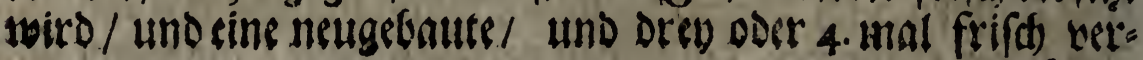




\section{รui Dem}

281

ànderte uns ungearbeitete (Frde findet/ 18 z 23 ermetrung ibret Sdjonbetr cin groffes bentràgt.

\section{X $\mathrm{X}$.}

23on Denten Rrandffeiten Deter und Dem פndttel ibnen wieder zu belffen.

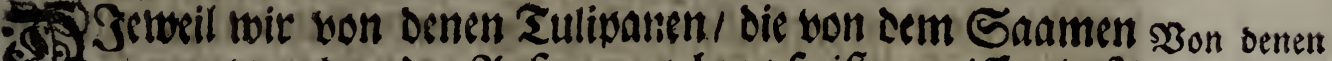
gezeuget werden/ Den 2(nfang maden / fo iff zu wiffen/ Dak/ Srand heitē wann die Zlwiebeln nod) flein und fdwadh fins / fie Die Rrafft. Derer Suli=

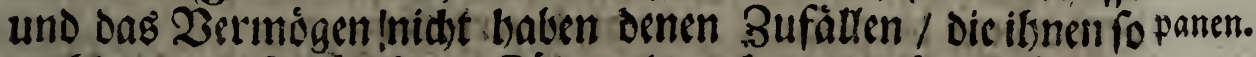

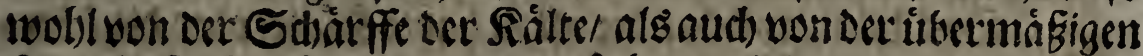
Shise zufteffen fénnen/zu widerfethen/wic dann obne Bwweiffel biel ourd bic Alteration oder Zerinderung/ welde fie ibnen ver. urfaden/ dabon umfominen. 23eil man Denmnad diefem Felbe

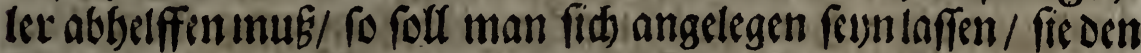
Winter ourd) mit Srettern oder Matten zu verwabren/ Damit fievor gar ftardfen Siciffen / Sdjnee / S3latt=0oer Spiegel = (ciik/ fo auf Die Siegen zu folgen p flegt/ja vor Der 23 inter= Sonne fellbft

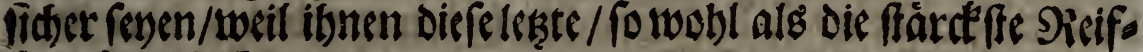
$\mathrm{fen}$ / todtlid iff.

Mit Der Eleinen Neten = Brut muB man elen auf folde

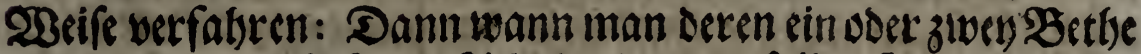
boul bat/ bie zur PPflang:-Sdule dienen / follen fie mit gleider Sorgfalt bedecett werden/ Damitibmen oergleiden Bufälenidet begegnen módteten.

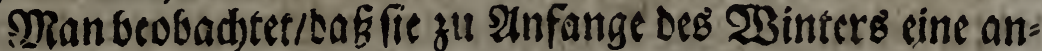
fectende Rrandelbeit befalle / une diefes gefdidst folgender Ges

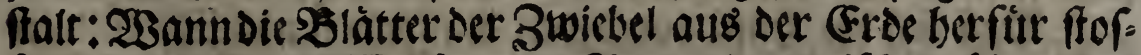
ren / fo lauffe Ealt waiffer oder SRegen Darzwifhen binunter,

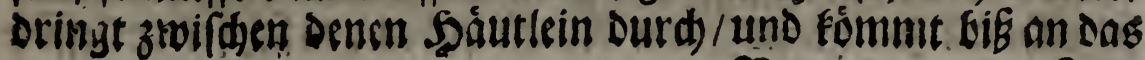




\section{2}

\section{Neue Unterweifung}

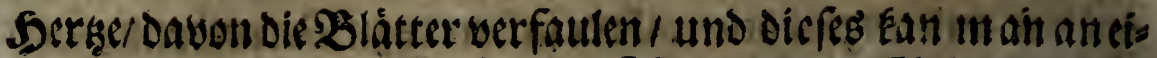
ner Eleid)-rotblidten Farbe / Die fid) an benen Spiklein Derer Blätter zeigt/wabrenelymen / Dergeffalt / Daß / waann man an

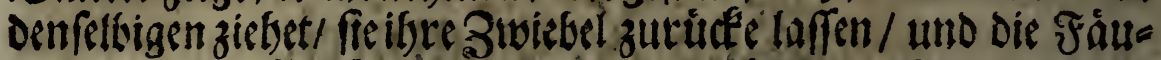

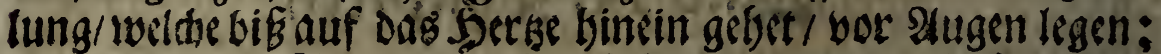

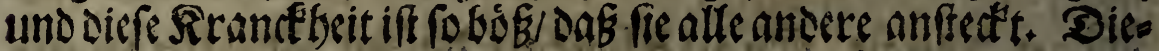
fem ourd cin Nittel bor zu biegen / fo if vonnotleen / Daf man Die Zwiebel mit einen Seter / twie man bein. Denen Melonen braudst / ausinelsme/ oamit / wann fie zu fammet ifrereroe bers

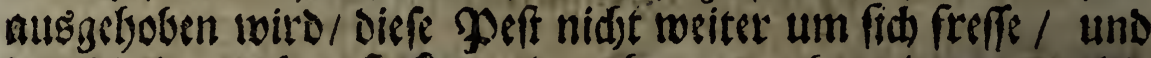
Das itbrige auds anffecte : oder, aber man fan rings um cie Btwicbel cinten fleinen (Graben futfren / Der cinen balben Sdjud)

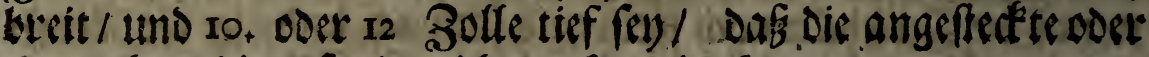
vercorbene die gefunde nidt nuds berberfe.

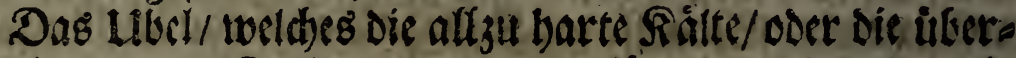
mábige Sişe Denen Tulipen zugezogen / fömunt aud/ /ind oer af Beit alg fie aus Der Froen genonumen toerden/ zuแn Dorfdeill; Dann man findert alsoann fleine Pleben= Bwieteln / sie gank the

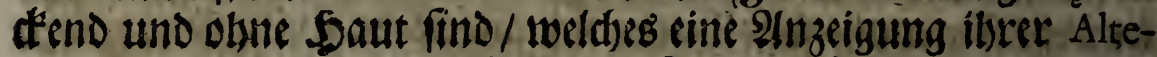
ration uno Sdubad)beit if / Dabon fie abgeloft oder abgetrentet werden/ und utmeommen.

Diefem LGel abzubeffen / muEmandie Presen-DBrutoder

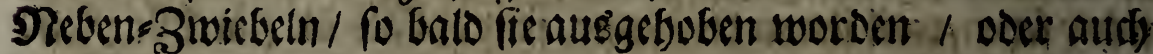

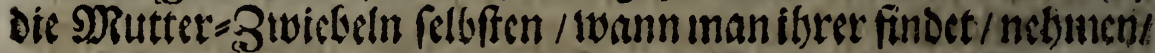
uno unberzuglide in sen Sand / oder an einem andern fasattids. ten Ort / in Die Eroe legen / Daf fre ourd) cimenngenebme Silts=

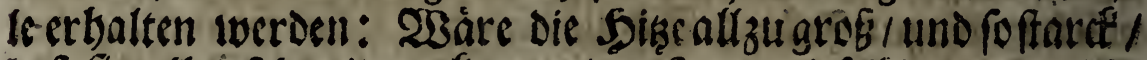
Dak fie alzz felbr sintrudf'neten / mus man oiefelbige gans leid)t oder nur twenig begieffen / und forner init Zerftand uno 23or: frutigfeit auf befigte 23 eife / bif in Den NRonat Septembris, vers fabren / Da fie alsoann anders wobin verfeket iverden.

Daß́ fich Die Saut bon Denen Tullipanen ablóft / fómme Daker / weil man fie nidte tief genung in sie (Erde fegt; und weil fie nidgt allezeit genumb fame Siraffe baben von fidd felber tieffer 


\section{צu bem Slumen= Saut.}

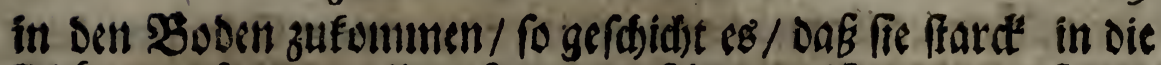

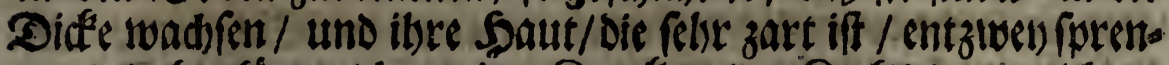

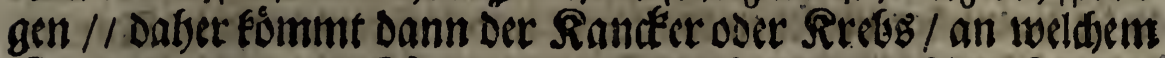

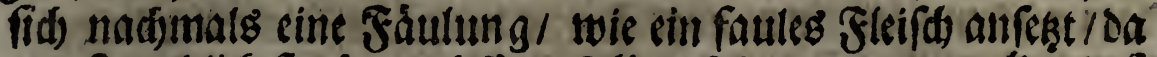

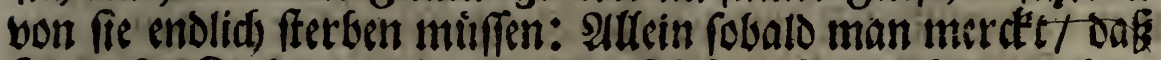

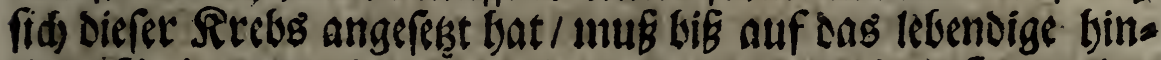
ein gefdonitter werben $I$ und wann nur sas Unterffe an ser

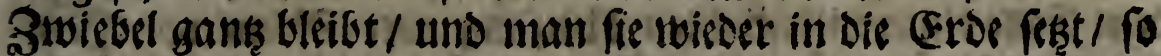
Ean fie fich erbalteri uns wieser auffemmen.

280 man Die Tullipanen inbeim Februario und Martion nidft

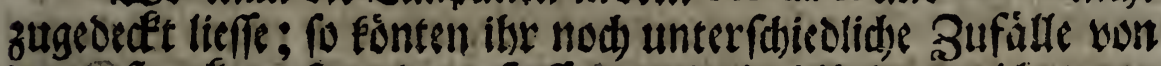

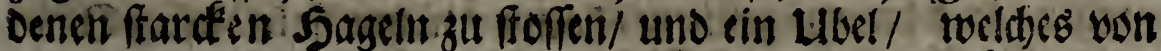

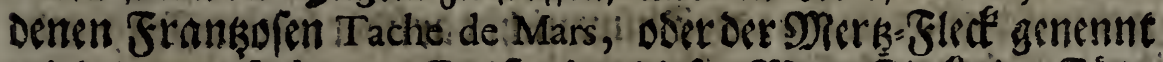

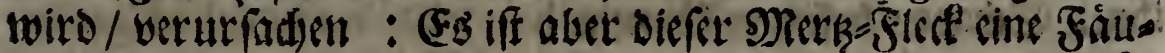
lung/ Die ibre erffe Blätter gleid unten an der Erocenangreifft'

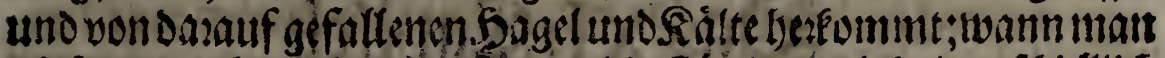

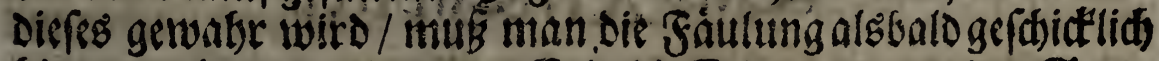

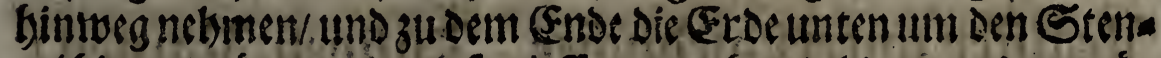
gel binuweg ráumeni/ und fo tieff ausgraben / als manes vor nóa

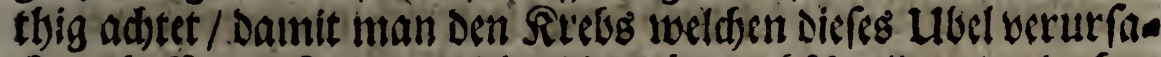

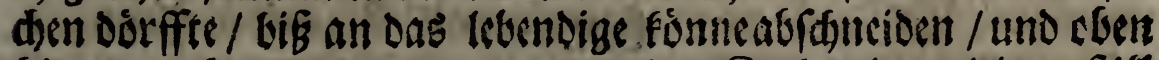
binwerg nefgmen : Dann wo man Den Rrebs cine zcitlang fith

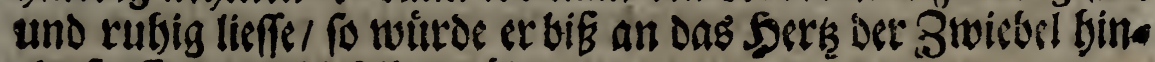
ein freffen uno biefellige tóoten.

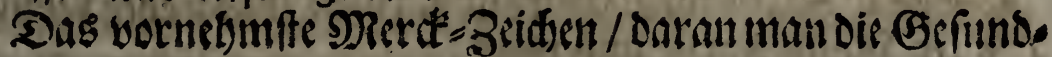
beit berer. Tutlipanen erfennen fan / iff wann man bert itreem

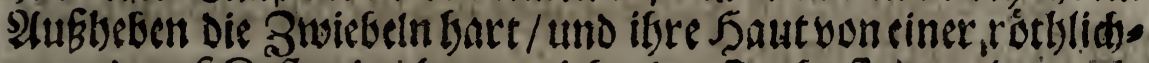
en unto auf Raffanient:uraun zieffenden Fartue fintert; Bann cie

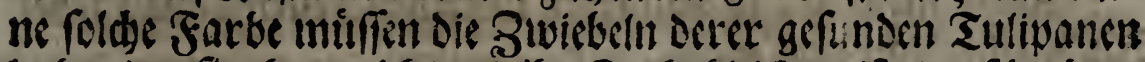

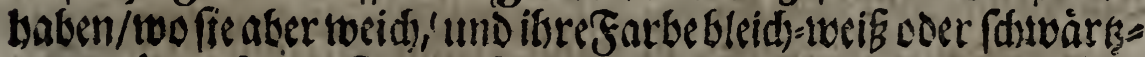

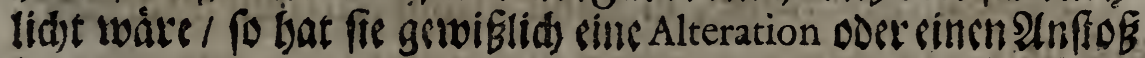
befoummen.

Die beritfmetefte Blumen=Eiesbaterbaben cin Mittel ges

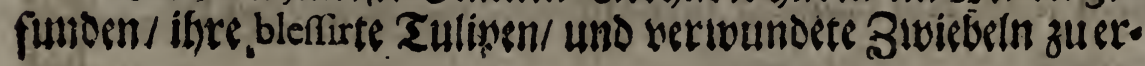

\section{Nin ?}

bato 
284

balten. Unmittellsarinadoem fie diefelbige aus der Eroegenotinett legen fie folde ordentlid) neben cinander in Den. Sdatten/-als

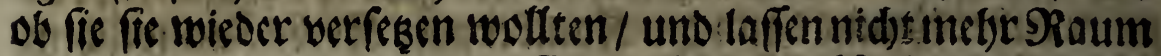
Durzwifden / als sinen quet Finger breit; auffoldse Art befom. men fie fige Rrafft und vorige Zolleommenkeit wieder:

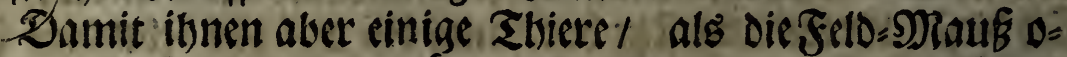

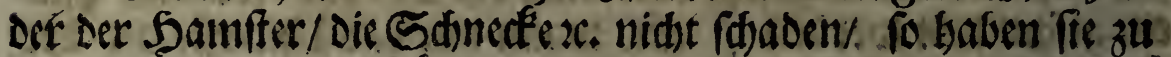

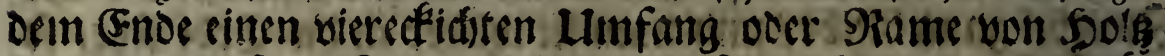

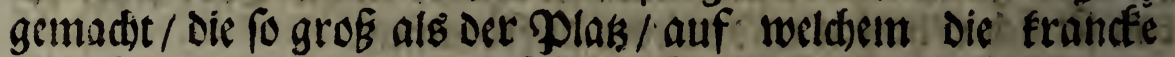
Btwiebeln liegen/ uno obngeféts 4. Bolle hod) if / Daruber wiro ein bon (Fifen=Drath gefloditenes (siegitter mit engen Róchern: gezogen / uno Darauf geffitrst / Dam / wann ffe in Diefen Dins: ge cingefdloffen liegen/ Die Shure nid)t ouruber binlauffen / uno ibnen Sdjaden zufügen fónnen.

\section{2å̉ XI. Capitel!}

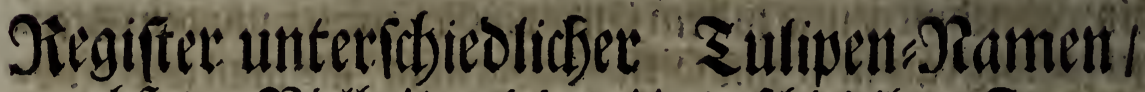

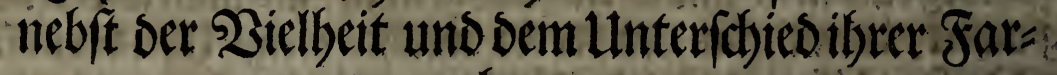

bert.

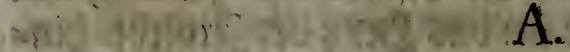

A.

$\Delta$ gate d'Aft, if roth/Pourpur-farbidt/ / bleid oder verweld"s A ter siofen. Fatbe uni reig.

Agate Amirale, iff Flad) gr,grau / Das iff / bell-23iolfarbidit/ beth-Jcuer-rotb uno meib.

Agate Armand, iff von cimer unreinen beden 2Biol-gantbe/ Tauben=farbid)t uno weib. und twcif.

Agate d' Arquelaine, if Dunctel=uno betl=taubenfarfictit:

Agate Royale, bat nut sren Farben/ Dic aber bolfkom= men wobl von einander unterfdieden und abgetlgeile find: Sie 


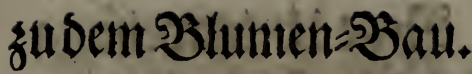

bat cine befle Purpur. Farbe und rotb/ Die fid in bundef fe

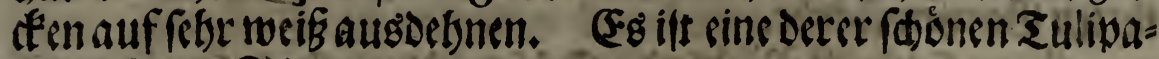
nen iekgiger Seit.

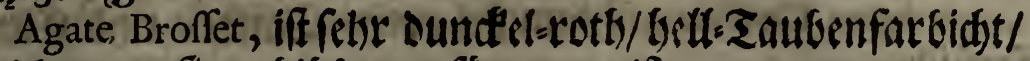
uno gleid) wann fie zublítyen anfängt / weib.

Agate Brillet, if Tauben=farbidtt und tweib/und cine frù = be Tulipane.

Agate. Brabanfonne, iff Dundel-rotb/ betliauben=farbiditl und ouncell-seif.

bidit.

Agate Brune, if roth auf braun/ unb bell=sauben=far:

Agate Chapelle, if bon rotber anthen=?arte uno sueig.

Agate Cofte, iff fatt $\mathfrak{B}$ iol=bliu / bell=totb und stlag-lweib.

Agate de Cointe, if Dundeler tauben=Sarbe/bell: Saubene farbidht uno dundelesmeiß.

Agate Chon, if Rauben-farbid) / oundel-grauy - tho von sundéter Sitronen= Sarbe.

Agate Caftelain, if Tauben=farbidft / bleidd)=rotb und tweib.

Agate Dentelée, bat eine Sauben=Sarbe 7 die fattstoth) uno weif bezeid)tict iff.

Agate duDru, ift Sofenfarbidtt / mit \&eib : Sarbe unters

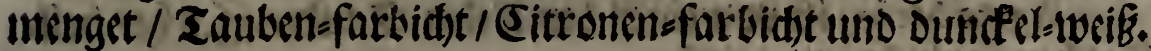

Agate Datte, if Ravendel-grau/und Pourpurefarbidjt auf Carmefin ziebent.

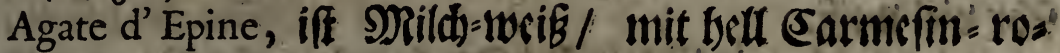
then Flecten gerperngt.

Agate Ferrans, iff ouncfel - Purpur $=$ farbid $)$ t $/$ Vice - Royfarbid)t / und cin lwenig tweif.

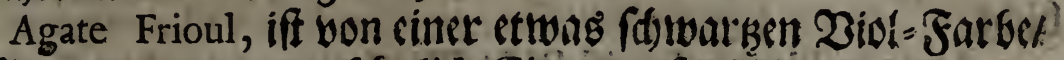
Dunefelegrau uno unanfergnlid) (Sittonen-farbid)t.

Agate Guerin, iff oleid)=gelb uno toeiß. und geib.

Agate Gobolet, ift (Sarmefin=toth)/ Saubent-farbidit/ weif

Agate Goblin, if mit fünff Farben gezierct / nemlid) mit

$$
\text { Vin } 3 \text { Reile }
$$


Reib-Sarbe / rotf gellb und Rafe boer. Sourpur-totg / und einer fatten Gemirem Sarbe.

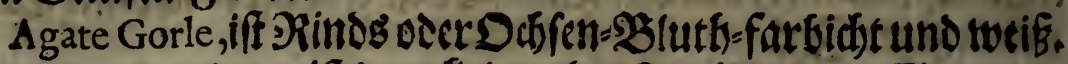
farbiditst.

Agate Govion, if Dundel-rotb/ Tauben und Eitronen Agate la Deferte, if Tauben-farbicht und cintwenig weibl uns cine frútbe Tulipane. sceí̈.

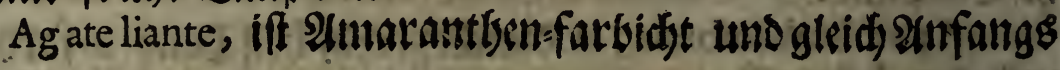

Agate Lionnoife, if Biigel=toth / Tauben= farbidst uns tweiß/ aber alles vertwirrt und unordentlido.

Agate Lorney, if Tauten-farbidt und weif / Dods nidt in oer erffen 2 liutbs:

Agate Minime, bat vier seutlidbe uno fantbare Farfen! als Rid)t=Purpur / gelb / O(maranth uno roth.

Agate Monfieur de Chartres, iff bon ciner Dunfeelen zalls ben = Sarbe / Ravendel grau uno rocis.

Agate Magnin, iff von ciner Dundéfen Tauben.Sarte / mit

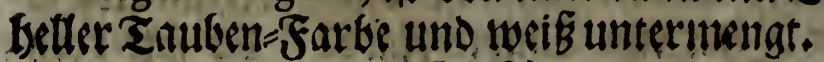

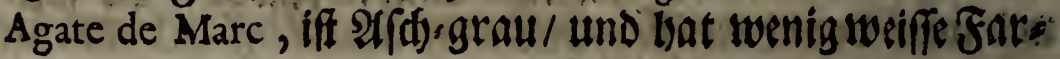
be.

Agate Mole, iff von einer Dunde elen Tauben-Sarber bells Tauben=farbidt uno weif.

Agate Morin, ift Purpurfarbidt/uno unrsingrau auf felse biel tweís.

Agate Morad, iff Dundel-Fauben-farbidtt / Ravendel-gratt uno toris.

bidit.

Agate Ochée, iff Dundéllgrau / rotb uns Gemren-far.

Agate la Piemande, iff Ridjt ßiolbraun / tauluen=farbidit/ rotb uno weif.

Agate Proferpine, iff fotwarkgratu/gelb/ unb voll ciner Dundelen Sitronen=-Farbe.

Agate Patin; if Profensfarbidte 1 Tauben-farbidit uns

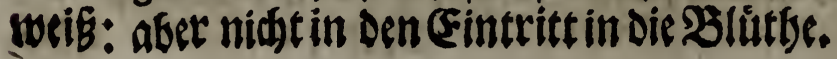




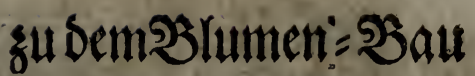

Agate Picot, iff bon ciner buucferern / und bann wor sincr

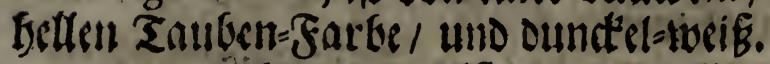

Agate de Quibly, iff yon einer lideten 2 iol-Sartbe/ Dun.

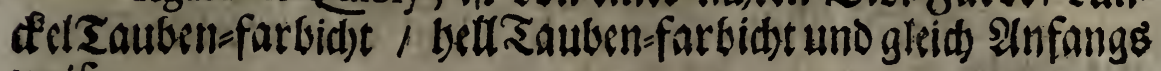
weik.

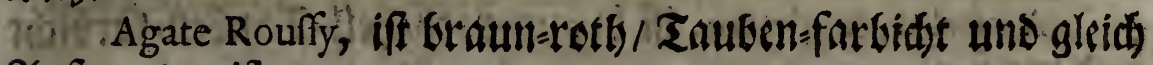
Anfangs weik.

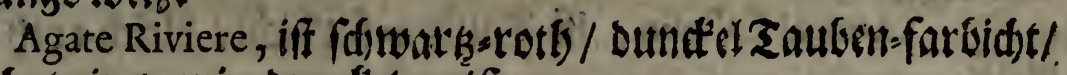
uno bat cin wenig Dundécl: weiß̧.

Agate Robin, iff Pourpur-farbidte / roth und tweiB; the

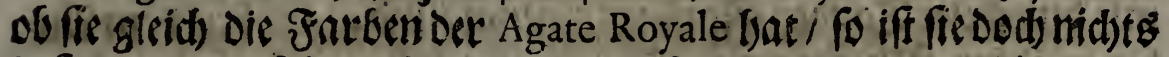

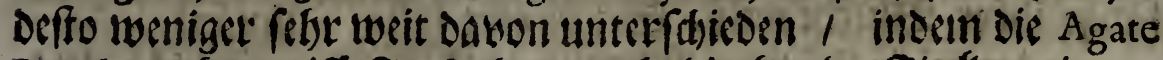
Royale mebbe weiffe Trarbe bar $/$ aud bie Gunde Glecten sinane Der nidst gleid) fetsen.

weib:

Agate Romaine, if Taltben-farbidft / und hat ein wenig weib.

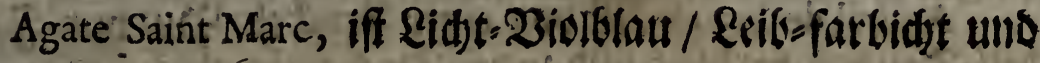

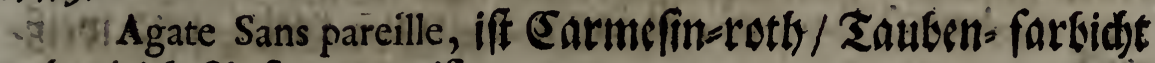
und gleid $\mathfrak{A}$ nfangs tweíf.

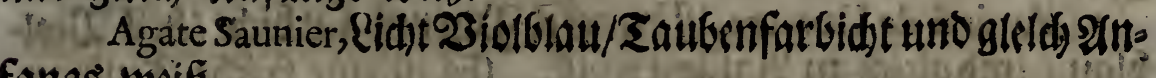
fangs weib.

Agate Sauvage, if 2 Bidlebraun / won einer bunátelen Pourpure Farbe und wei í.

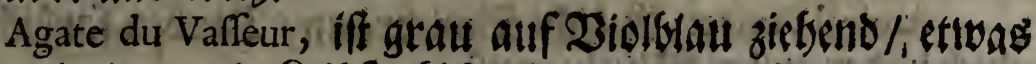
weiE / und ein wenig Reibfarbidt.

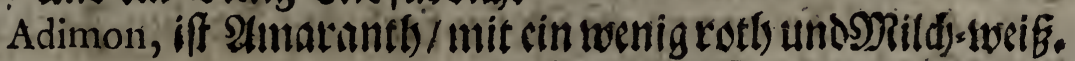
Albertine, Gat Eleine Pourpurfarbididte Striemen / Düne gefiprengt / mit Ridids=3iot=blau uno weig.

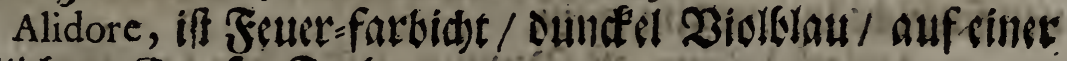
wibilidften (Gemfent-Sarbe.

Alquite, iff gelb umb roth gefirengt.

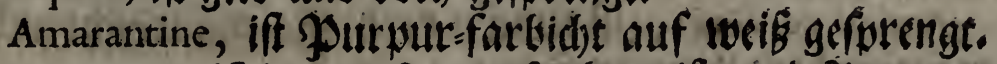

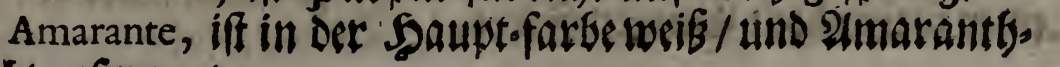
farbiditt gefprengt. 


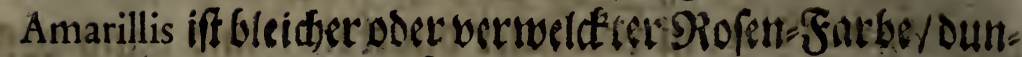
fel Durpurfarbidt und tweif.

Ambrife, if Tauben=forbidt / rotb und torif. met= Farbe.

Amiable, iff Mrildstoeis / uno von braumrotber Sam.

Amiral d'Angletere, iff Graunarotb/betf = sauben: farbidt und tweís.

weib.

Amiral Caftelin, iff Tauben=farbidt/ blcidf=rotb uno

Amiral Chrétien, iff won ciner bleiden Tauben=Farbe/

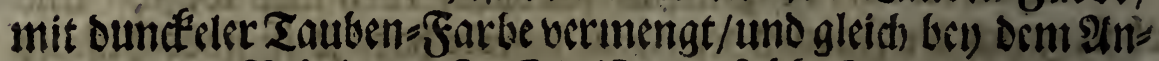

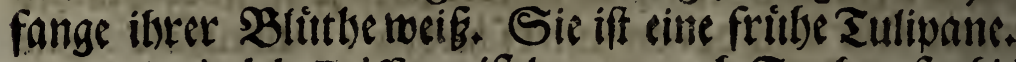

Amiral de Boiffere, if braunstoth/Sauben=farbidit gleid Snfangs und weif.

Amiral de Delf, iff yon rottere Rofen-Farte uno tocib.

Amiral Fruy, iff Ravendel=grau / fditwark=grau uno toeif.

Amiral de France, iff von einer ound"eln Purpur= Farbe/ betl= sauben=farbidt und weif: Ded) nid)t gleid Sinfangs. gelib

Amiral Fournier, iff oundel=grau $/$ rotb $/$ uno weifs

Amiral de Heverte, iff ound el purpur farbidft / bed . Siol blau / uno gleid) zu Anfang weib. (Fr iff cine frube Sulipan. Amiral de Hollande, iff rotfb uno weif.

Amiral de Mars, iff Glutt) trott) unotreif.

Amiral Poncet, iff sid)t Diolsbraun / Sauben-farbidt uns gleid) in Der erften $\mathfrak{B l i n t b e ~ w e i ß ̧ . ~}$

Amiral Triverman, if SRofen=farbid)t / Sauben=Sarb uno Ibeif:: Dod) nid)t gleid)| (2nfangs.

Amiral Vallier, iff Pommeranken=farbidt / Siofen / Sitro = nen-farbidt uno unrein to iff.

Amiral Villiers, if Purpur / Tauben-farbidst / uns gleid) Infangs weißi.

Amiral de Vènes, iff oundell:rotb/SRofen=farbidt uno von sintr tociblidten (Sem ene Farbe. 


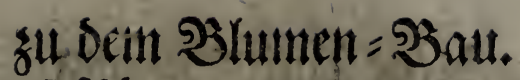

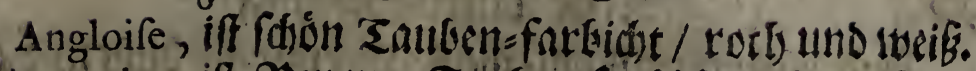

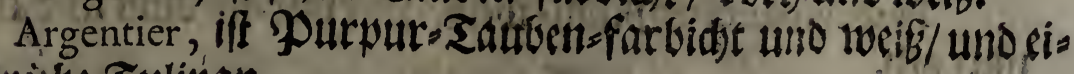
Mi srible Tulipant.

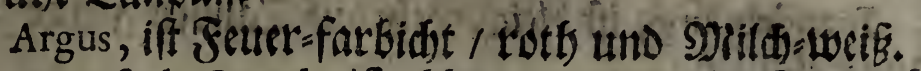

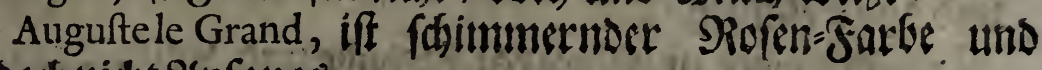

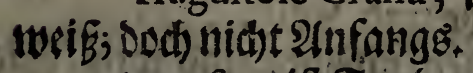

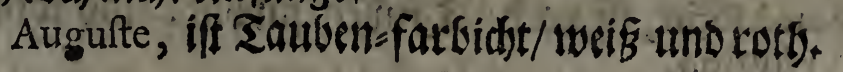

B.

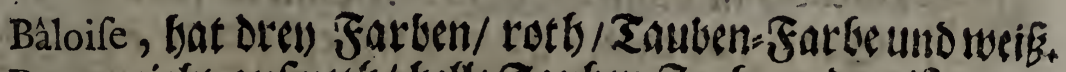

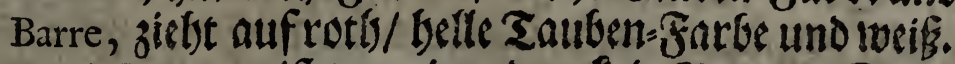

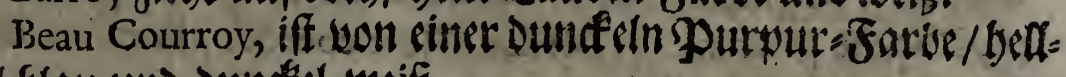

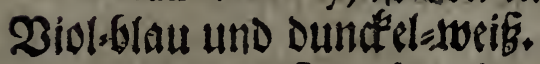

Beaupré, iff roth und twi is.

Belin ordinaire, iff roth / Tauben $=$ farbidt und wecie.

Bellin Trelon, iff 2Biolbraum/ sin menig rotls und weeiE.

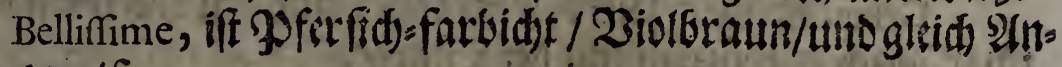
fangs tweiß.

Belled" Anvers, iff Biel6raun/Pourpur-farbieitums weib.

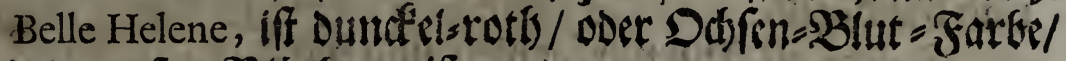

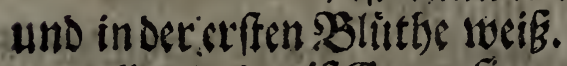

Belle Morine, iff

Belle la Barre, fJat Der Brabanfonne ifbre fGarken / memlid)

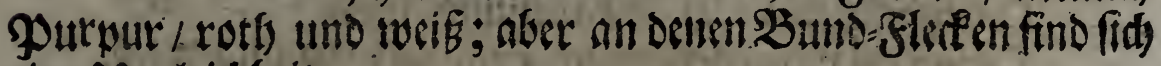
cine Lungleidfbeit.

Belle Perlee, iff tod scis-fatbidt und petso tocib.

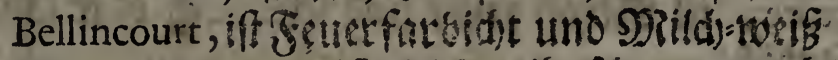

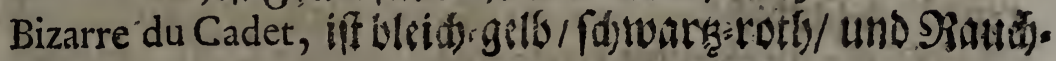
gills.

Bollhuert, iff scibfarbidst und weif.

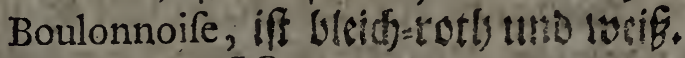

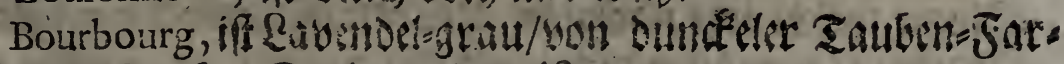

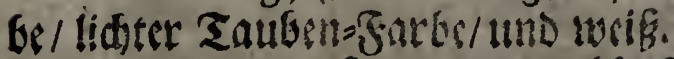

Bourgeoife, if von einer lethaftigen Siotgen Fatte / auf

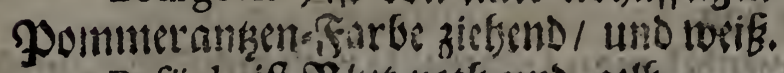

Bofiuel, if SBluteroth und gelb. 


\section{2yo. Teetue Unterweifung}

nig rotk.

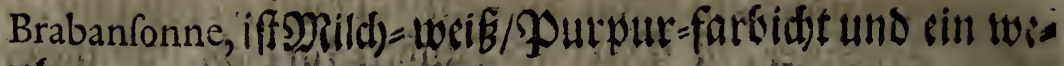

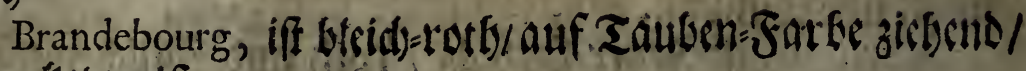
und burréctleseif.

Brantinot iff Nacarnt farside uns toeib.

Brantion Morin, ift roth / Saubin- farbidt und Iweif. Sit flibst imfritling.

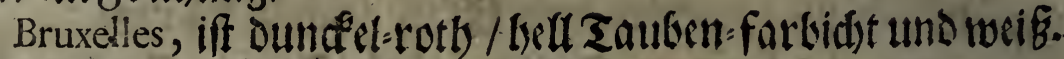

:" Sonft hat Iman auth nod) folgende/als: Beautéde Chartres, Belle Mignonne, Belle Cailite, Belle Tragene, Belle Mariniere, Blanche printaniere, Bordée into Rebordée, Brantion de Boh. Brantion de L'Aube-épine.

\section{C.}

Cadette, iff Purpurfarbid)t / uno hat vicl 23 siffe:

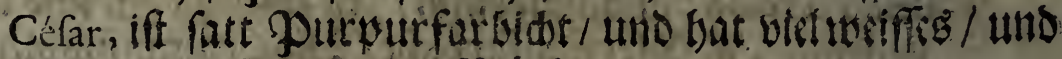
flwar gleid) in Dcmanfäng Ler \$littlis.

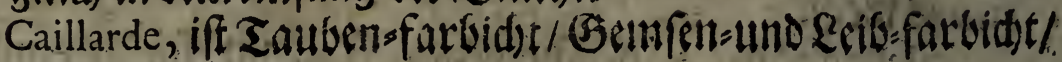
und Boldogellb.

Califte, iff Purputfarbidt uno IvesE.

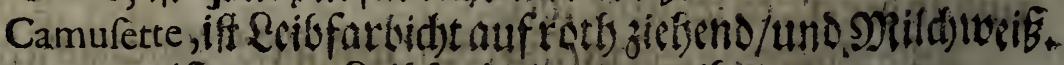

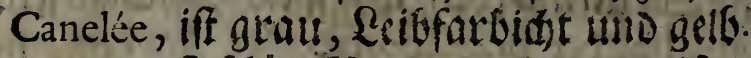

Canette iff fabon Ziolbratm uno twsif.

Catine, iff Eavendelograu / Secis=farbidst uns tweig.

Carlée, if rotblidt: grau uno Gemfen-fartidt:

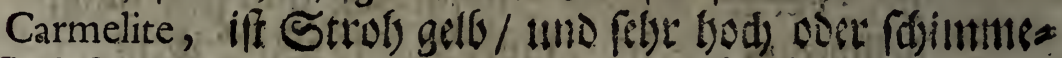
reno $\&$ eib $=$ farbidit.

Cartie, iff eben Die Carlée.

Cadenulle, bat cinen Namen der mit iffer Saóntscit

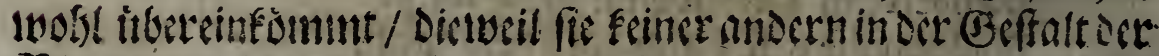

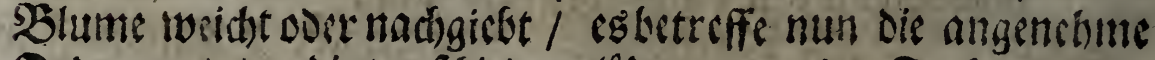
Oranung/voer Die verf́diedene Sartungen ber Farben : Sie bat aber cine gourpule=Farbe sie auf Biolbraun jiebet / wenig. roth / und virl wosíbat.

Celefte, iff Ravenorl-graul sintwenig rotiound NRilds=lwcif. 


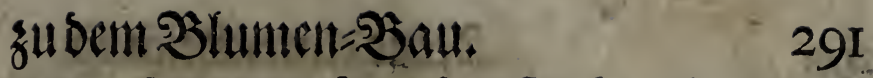

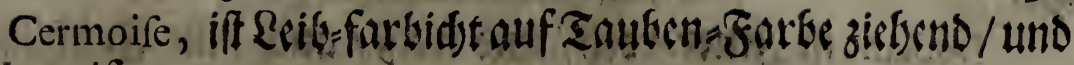
Milld=tacif.

Chanceliere, iff $\mathfrak{B}$ iololau und weik. faft.

Chamois, if um ocn Shano mit Sdjurlad)= Farfe cinge:

Chartreufe, iff Sid)t=2iololau / cin wemig sourput-farbid)t/

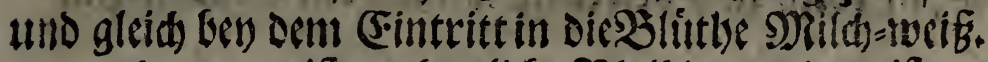

Chameau, if rotb / sidst=2iol(blau und weís.

Chinoife, iff graulidter Tauben= Sarbe/ roth uno Germ: rent:farbid)t.

Citadelle, iff goutpur-fartidt / Sidt:=23iol-blau uno tocip.

Colombin \& blane à grand bord pritaniere, oic fruble oDer Tauben=farbidte uno weiffe mit Detn groffen SRande.

Colombin \& blanc à grand bord tardive, Die fwatlle Suluben. farbidste und weiffe mit deut groffen sianos.

Columelle, if Rafin Sarbidst rotb uno weig.

Concubine, if sausen-farbidt uno twis.

Couronne ardente, iff usei unomitten z!wifden iffern Far: Gen fdowarklidht uno eine fribe Sulipan.

Corinthie, iff Goldgelo / weig und rotb.

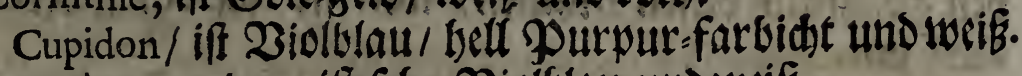

Curél printaniere, iff fegr $\mathfrak{Z}$ iolflau uno weib.

Curétardive, iff gleidf falles febr Gleid) 2 iolblau uno weif.

Unter biefen Budffaben C. geforenaud nod) Confidente, Couronne Royale und Gardinale.

\section{D.}

Dalepon, iff Birgef-roth / mit ciner fduwarken Srunb=Sar:

be.

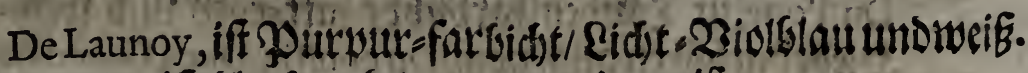
Dentelée, ift Gleid)rotb/ uns unrein tweís.

Devifee, iff tweis und rotb.

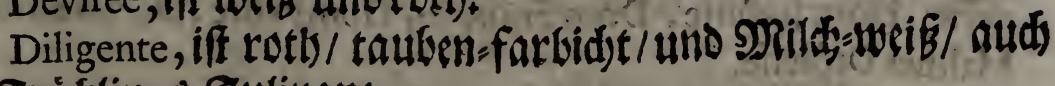
cine Frublings:=Sulipane. 
Sulipane.

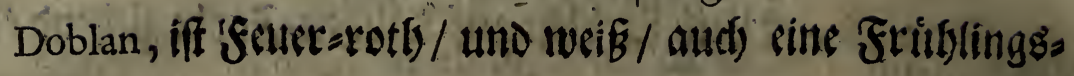

Dom Chateâu, Biol-braun / Earmefin/Pourpur-farbidst/. uns rwsi.

Dolincourt, if \$urpur =farbia)t uno wele.

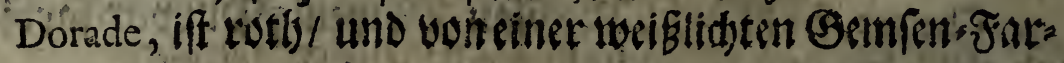

Ui. gelf.

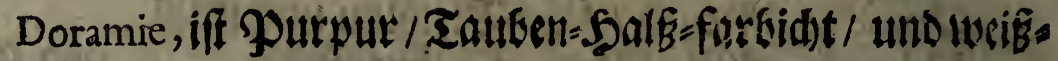

Dorilée, if 2 Biolblau und SRild)-woip.

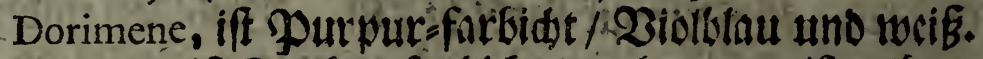

Dorinde, iff Tauben=farbidte / rotls uno tosib-gels.

Doris, iff Mrild)=rweig /mit einer fefre lebbaffigen rothen

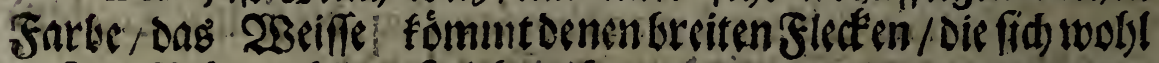
auf sie Blatter binauf zieben/ben.

Drap d'ord'argent, panache, if cinefrúbe Tulipone/ oie sent

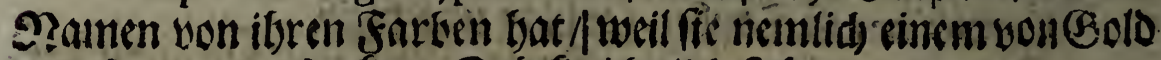
und Silber getwutcteten Stitfe älonlids fiebt:

Drapd' argent de Valencienné; Drap d'argent duBerger, bat ben gleidffalls diefen Vtamen/'weillfie wie cin ffilberer 3eug. ausfeten. und weif.

Druide, if sundebtotf / won oundelet sauten = Furbe/

Ducale, iff fabon uno tweif.

Du Chêne, iff Purpur =farbidtt / roth unt tocig.

Bidft.

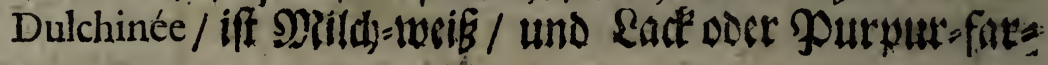

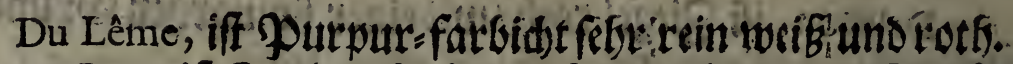

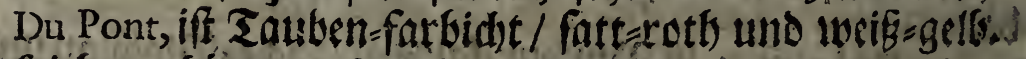

Sieber gebóren audis nodb/Dupouffin, Ducá Grand bord printaniere, Duc a grand bord tardive, Ducápêtit bord tardive, DomFrederic, Dom Jerôme, Dom François, DomPedre, De Clermont, de Malines Drôleffe. 


\section{'su dem Slument=: Baut' \\ $\mathrm{E}$.} Ivisís.

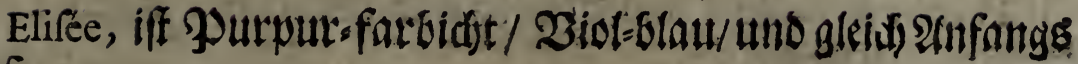

Erimante, iff rotly/ bleid)=gelf uns getb.

Eriftie, iff Surpur = farbidst und toris.

Efperance, iff ounctel =grau / rotb unogelf:

Eftampe, if Tauben=farbid)t/, weifi uno gelf:

Etoilée, bat faft eben die Farben twie die Dorilée, die fón Didiblau uno weif fino.

Eufrafque, iff rotb uno Ottlasencib.

Eugene, if braun-rotb uno tocib.

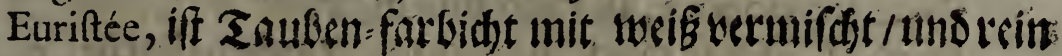
gefprengt.

Eufébe, iff Tauben=farbid)t / roth / uno Gem

$$
\text { F. }
$$

Fauftine, iff bon ciner rotblid)ten Tauben=รatbe / Stlaa Iocib auf cinem blauen=\$Doen / uno iff fei)r woblgerprengt.

Felicité, if Gleid)=roth uno gelb/um ocn Sand mit sinent rotben Fodorn singefaft.

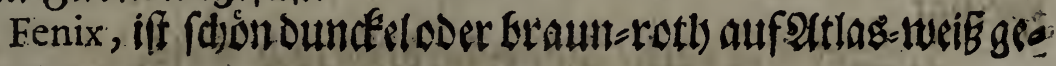
fprengt.

Feüille d'Esdine, iff fiton Nacatat=uno Duncel-rotf.

Filandre', iff won ciner foonen Purpur= Farbe/. fehr telit und zart aut tweifi gefprengt.

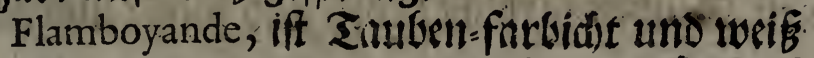

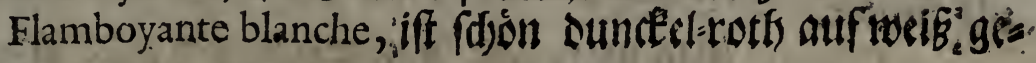
prenger.

Flamboyante Colombine, if won sinter fdonten sauben Fat: be uno lociff.

Flamboyante Maximis, iff ffitwar $=$ grau / bleid = gelb / tutb Sittonen=farbidt: / allesaber ffibt berwirer und unordents liff.

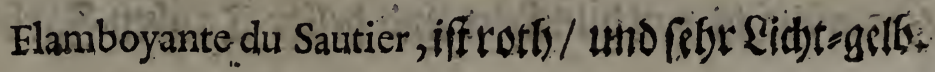


294

\section{Neue Unterweifung}

Flamboyante de Tuder, ift rotf uno orsinar=gsl6:

Flamboyante de Tunis, iff rotb uno unanfebntid gelb/ auf Eitronen= Sarbe zielend.

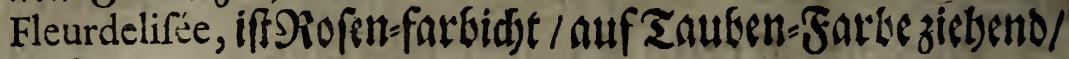
uno wociß̧.

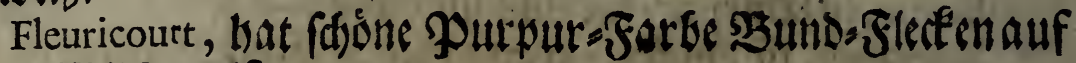
fauber $\mathfrak{M}$ ildb=lweiE.

Fleurimont, if bodt)=Purput=fartidst tund weif.

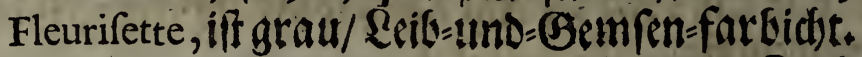
wei

Florentine, iff von einer lidten Tauben= Sarbe und pebr

Forte à connoitre, iff rotti uno tocib.

Frangé, if von einer weiblidten Tauben= Satbe / uno brallmitoth.

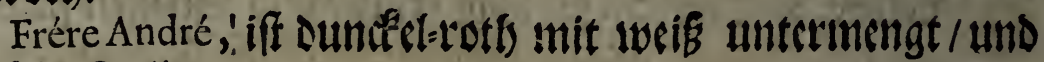
cine frible Tulipane.

Frere Claude, iff Bofen=Farkid)t / rotb uns Glau/aber als leg untordentlid.

Frére Jean, ift yon ciner lidien Purpur=Farbeund weif.

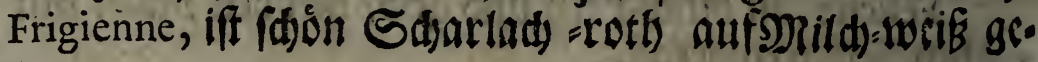
fprengt.

Fronteval, if rotb/. SRofentfarbidft und weif.

$\mathrm{G}$.

- Galatée, iff meibegelf auf Bold-gelb gefprengt.

nig Febler.

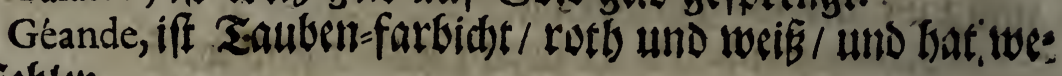

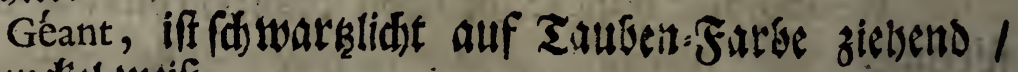
und Dunctel-meif. woviß.

General Gouda, iff won ciner fefte glänzenden \&eibfarbe und

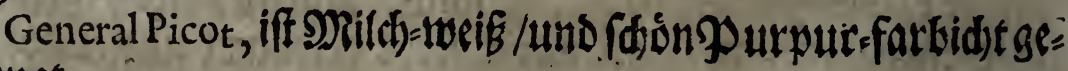
fprengt. weif.

Genevoife, ift yon dundeter und befter Tauben= Sarbe/ uno 


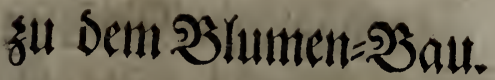

Genoile, iff yon siner rótbliden grautn Farbe und 295

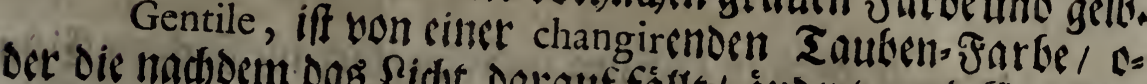
farbidts.

Gentilly, iff roth / feuetfarbidst und weib.

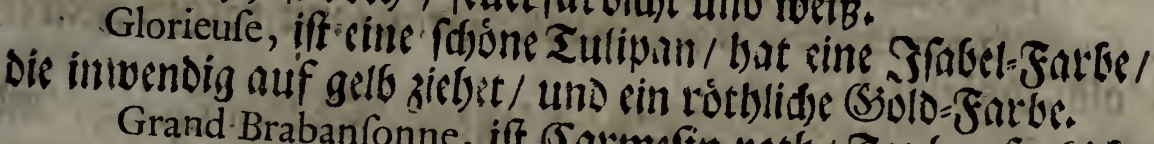

Grand Brabanfonne, iff (Earmefin rotl)/ :aubern-farbidet uno $\mathfrak{m e} i \bar{B} /$ Dodj nidbt glesids anfangs.

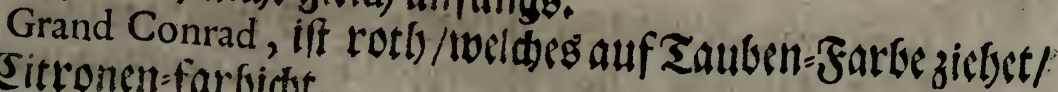
uno (sittonen-farbidt).

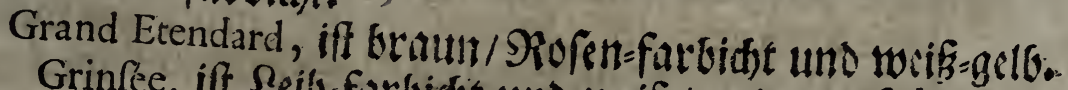
lipun.

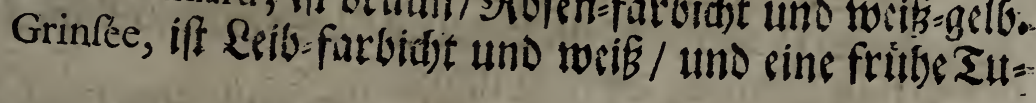

Grife Orientale, oder Agate Orientale, iff won ciner fojouncent

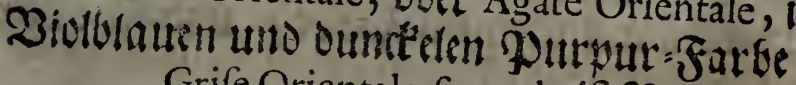
farsid)t undivib.

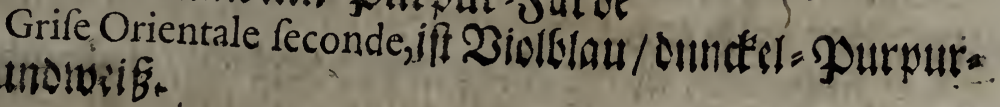

\section{$\mathrm{H}$.}

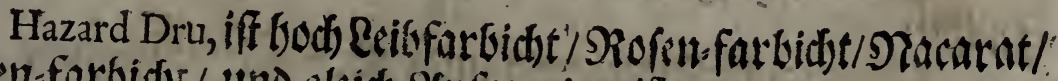
toulbern-farbid)e / und gleids senfange weis.

Hazard Rubin, iff rotts/ (Earmeffin-farbiddt uns weib. und weik.

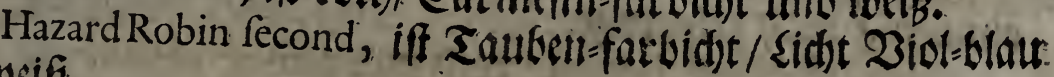

Helene bat faff chen sie Garken iwic sié Géande, nemlidid: roth/ Faubenth =Farbe und tweiE.

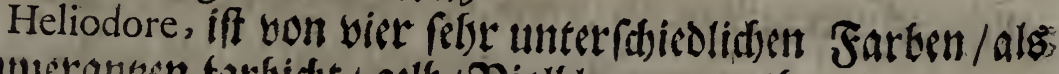
Poommetrangen farbidst/ getle/ $/$ Biolblau und totth.

Hercan, iff Duncécl-rotb uno Bemfen=fartidet gefprengt// Die abir in 2. oocr 3. Tagen weif wird.

Herculée, iff Gluts-roth und Dilds) tweiß gefiprengfo 
296

Peueduterweifung

I.

Iacobé, if rotb/ froun uno von ciner weiblidfen (Se) fent Farbi.

Iafpe Angloife, if ounefel-grau / rotb uno weiś-gelb. Iaspin Harlan, iff felir Dundefl=grau / mit rotben Fleden als Thränen gefprengt. weif.

Iaspe Marceau, iff \&avendel =gran / Tauben=farbidit und

Iaspe premiere, iff bleidf)=roth und Gem (ent-fartsidft.

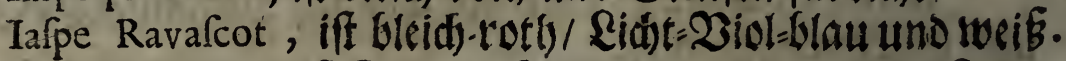
Iaspe Saine Jean, ift Sauben-farbidt/ grau und tweif.

Iaspe Truder, iff Dunctell=grau Gleid=roth) uno weib=gelb.

Jean le Fevre, ift roth) und gellb.

Iean Gueret, iff fdón $\mathfrak{B i o l b r a u n ~ u n b ~ t w e i g . ~}$

Ignace, if bleid)=totb auf Gemfent= Sarbe / und febe rein und flar gefwrengt.

Imperiale, iff Dunfel-purpur=farbidft / sintwenig rotbund Mild):veif. zeidunet.

Infante, if $\$$ fabell farbsidt uno mit weiffen Striemen si:

Iolicourt, if Biegel=-roth und gells.

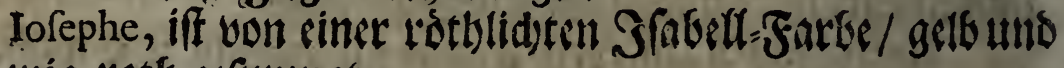
einwenig roth gefprengt.

Iris, if Dunct? : graut / roth uno getb.

Iuliane, if Tauben=farbidbt / weiß̈ uns grau.

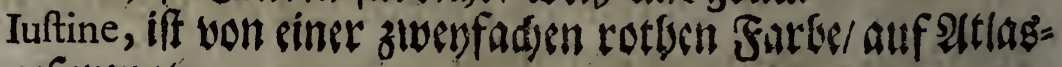
aveiß gefprengt.

\section{L.}

Lactance, iff Fetuer =farbidtet / weis uns rotls.

La Blin, if foson 2iol=blau/ ourd cin wenig rotg won siner berfürffedenden weifien Farbe afgefondert.

LaDucheffe, lyat Der Brabanfonne ifire Farken unt daf 


\section{su bemร̧lumen= 3 au.}

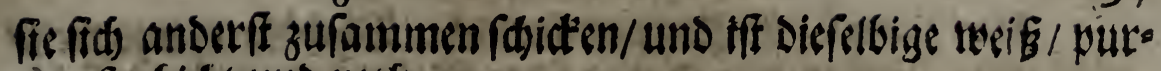
pimf-farbidtet und rotf.

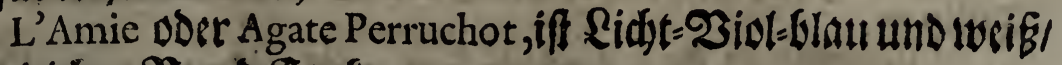
mit gleider $\mathfrak{B}$ unto.Farber.

Lapponie, iff Tauben=fartsidst $/$ weis und rotb.

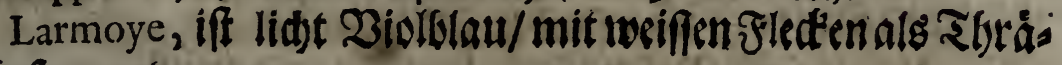
nen ferprengt.

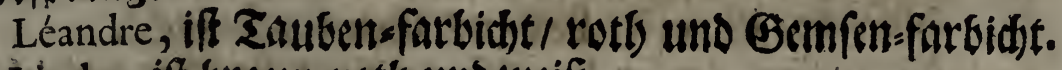

Lindot, if braun=rotb und tweis.

Lionne, if geib-farbid)t / roth uns weik.

Lifa, ift rott/ $/$ Domerankstn farbidst und gets / mit glcidsen Bund = Sletten/

Livie ober Livia, iff fefr fdjón 2 iol-blau auf weiß ges forengt.

L'Oeuf de Pàques, if dunctel-roth / uno im stnfang tweí.

Lucque, if lid):-2iol=blau auf fdjön tweiß gersrengt.

Lyante, if Smarantlen=farbidst $/$ fo auf 2 iol-braun zice bet/ und weib.

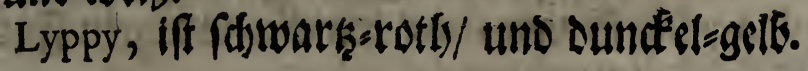

\section{M.}

Marbrée de Bôtre, iff wön cincr unteffánbigen lidłt 2 iolo blauen Sarbe / und fäon roth / Deren Sdein won ciner hoben uno

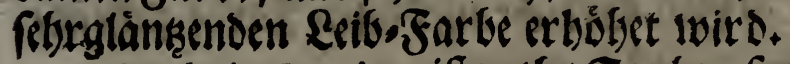

Marbrée Grenier, iff roth 1 Tauben=forbidit une tweib.

MarbréeSaint Germain, iff bleidf=grau/ Esib-farbidst und rott).

Maniffere, bat sine beffándigerotbe / cinwernig fatt-rotbe/ und eine fetre weiffe und faubere Farbe.

Marquife, iff rotb/ bleids=rotb/ oner verwelatter Sofern= Jarbe/und weif $=$ gelfo.

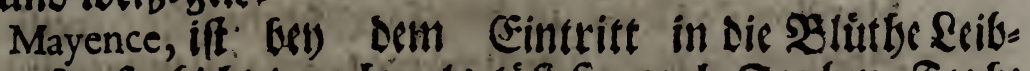
und Gemfen=farbidit / nadjmals láft fie aud Tauken = Farter und roth anfid fergen.

Pp $\quad$ - Me- 
Meridionelle, if Purput:-farbidit / Biol-blau / uns meig/

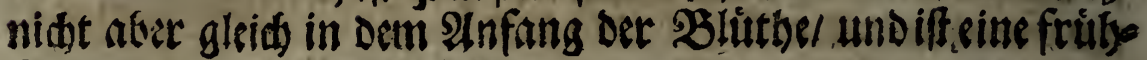
Tulipan.

Melidor, iff Eeibs farbidit auf weis gefurengt.

Melinde, ifore Farben fins fajon Pourpur / fefor lidat/os. Der kobafftig rotón uno fauter SMild)=meißs.

Meliffé, iff SRofen/Reibs farbidt und weif.

Mercure, iff rottj/Reib-und $\mathrm{Bem}$ (s) =farbidst.

Merveille d' Amferdam, if von ciner ffarce'en und lebbaff tigen 2 iol=blateen Farbe und weif.

Merveille de Camp, if Sauben-farbidtt/ fhrwarklid)t / uno weib. Es ift eine frithe blume.

Merveille de Harlem, iff bon ciner surdfin und bsllen Tauten=farebe.

Meftre de Camp, iff Tauben = farbidst / fhtwargshlitits und rosib/ aud cime fribe ₹ulipe.

Morillon d' Anapes, ift ven ciner meiflidten Bemfen-Sar Ge/ ourauf eine woblwermengte Reib:Sarbe zu feben. und sweif.

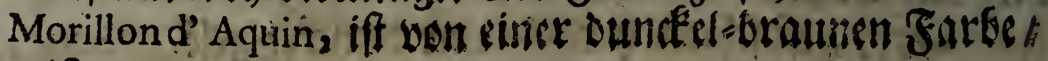

Morillon Brun, iff fdoon fraun-roth uns rweiE.

Morillon Brun Robin, iff fdiwark-rath uno iweif.

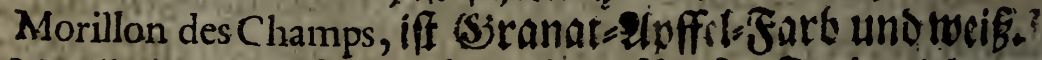

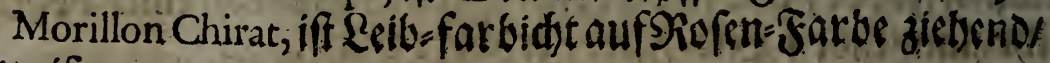
and weif.

Morillon Cloutier, iff fdoon Nacarat uno bod \&eib = fare Hid) auf tweiß gerprengt.

Morillon Dru, iff Sranatapffel-farbid)t/gelb/Cittonen= fursidet und weib.

Morillon Dry, if Rcib farbidt auf SRofen=Farbe Jiebers

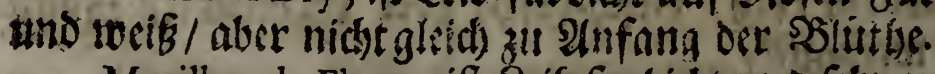

Morillon de Fleurs, iff \&eib-farbid)t uno fobr weif:

Morillon de Flien, iff Eavilndelegrau/ yon dundesterund vider Tauben-Sarbe und weif. 


\section{รัแ}

Morillon Jacquet, iff Rofen=farbidt uno tweif. fangs.

Morillon Madame, iff roth uno iveif; Dod nid) gleid 2H:

Morillon Medional, ift Sarmefin:roth/Sauben-farbidt uno tweif.

Morillon Nacarat, if SRacarat uno Iveif.

Morillon parfait, iff Earmefin=toth uno tweib.

Morillon Pafcal, iff von siner ounde eln Sauben=Farts/fonuf totb jiebet / und weif. weif.

Morillon Picard, iff rotb auf Reib=Farbe ziebeno / und felst

Morillon Rofan, iff von Ridtststwarker Fatte / auf Po: meranken= Sarbe ziebeno/ uno meib.

Morillon Sang de Boeuf, if Duncelesarmefin= roth / unt

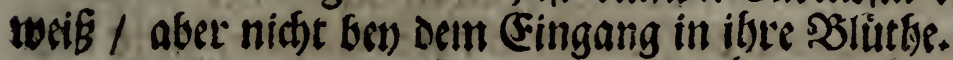

febr tweif.

Morillon Studer, iff von ciner Dundt in Sofen=Farbeunt

Morillon fur brun, iff Sarmefinatotl) / Rindsadde Dd: fen-SSlut=farbidt uno febt lebbaffig=tweiß

Morillon fuperlatif, le petit Augufte genanne / if $\mathfrak{b o d}=$ seib faroidgt uno febr weif? aber nidt gleid wann fe zubluben anfängt.

Morillon Tournay if bon einer Dunctelen Diols blatten/. und oundeln Tauben=Farbe / uno bat nid)t biel weiß an fids.

Morillon Zuret, if rotg / Rofen=farbidt/ und voneinet ananfebnlidben ooer cundfeln sitronen=-Sarbe.

Morinette, if won ciner leblyaftigen \&eib= Farbe and weif.

Morine, bat cine zientids fasme und auf fauber tocif/ weldes fie gleid bet) Dem (sintritt in Die Blitthe befommen/ gefprengte fatte seibs Farbe.

Montfort, iff mit einet fatten 2 iol=6lauen und mit roth bermengten Farbe auf fhon tocib gerprengt.

Monitereille, iff init sinet lebbaffigen Sarmefin = rotben Sarbe auf fegt wiel wosis gefprengt.

$$
\text { pp: Mon- }
$$


Monftre fimple, Niefe wiro alfo (Die cinfade Mriggefurt) wegen oer Gróffe ithrer $\mathfrak{B}$ lume genannt: Sie if rotb uno gelle/ wie ein Drap d'or ober góloenes Stitckes.

Monftre Double, iff eine ₹ulipan / Die wenig Zergnitgen

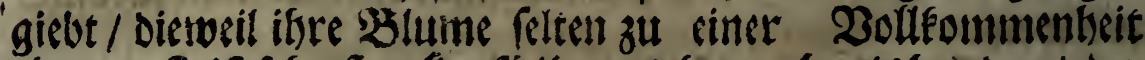

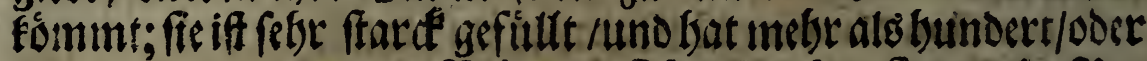
bundert und żwantsig Slátter; Stge Jarben finorotb / SPo: merankęn-fatbidft uno gelb.

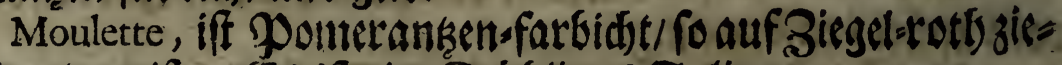

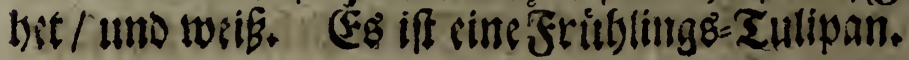

\section{$\mathrm{N}$.}

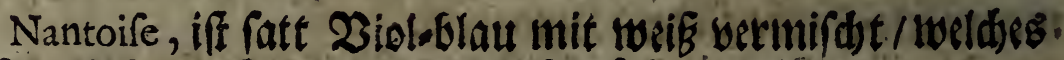
fid febr fason auf tweis in Bunse Flefen auretbeitt.

Nevers, bat efen die Farben wie die Nantoife, nut dag

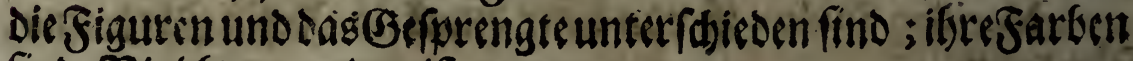
fino Bioleblau unolveiB.

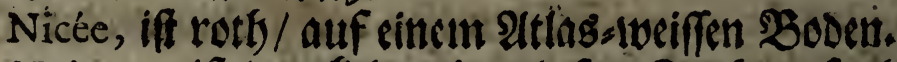

Noiron, if sundetlectly und fatt Bauben = farbidt auf Gemien= Sarbe.

St.. Noirlis, iff rotb/ Zioleblau uno tweis.

Dipfft.

Nouvelle dè Hollande, ift toriB / und Ridt =\$Purpur ges

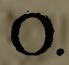

Oculus, iff fobon braun-rotb uno Mniltbiveif.

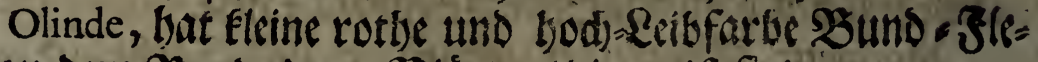
fen an bem Sande Lerer Blâtter / Die wotiB find.

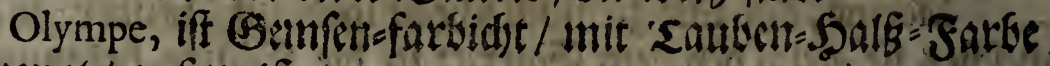
vermengt / nuf meis.

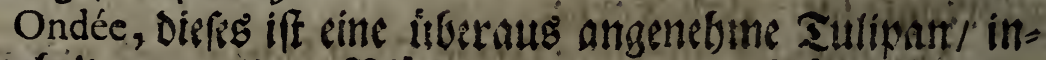
fonderbseit wegen ibrer $\mathfrak{B}$ lätter / bie von einer fdönen 3 reitc;

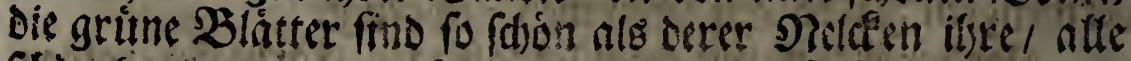
fojon frous/ uno ringsberum nit siter (Einfoffung). fo meis

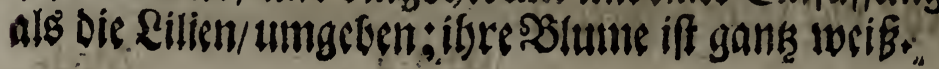




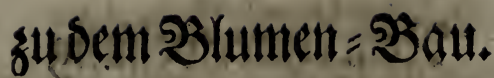

Opale, bat vier Farben / sine fatte Tauben-Sarbe / gole= gello / rotb uno weif.

Orientale Morin, iff won orey unterfobicbenen Sarben/ Biol=blau / rocif uno Purput: farbidtt.

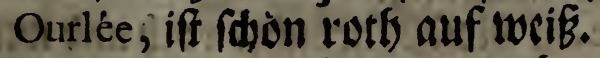

Ourlee rectifié, iff braun=rotb) / fo auf Earmefin zichet/

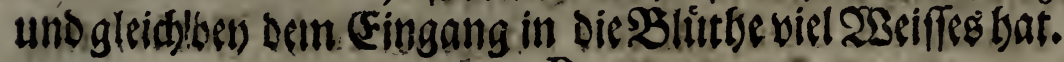

P.

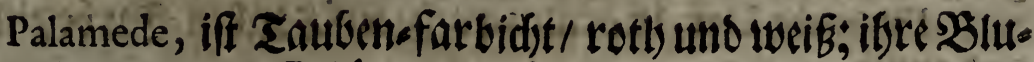

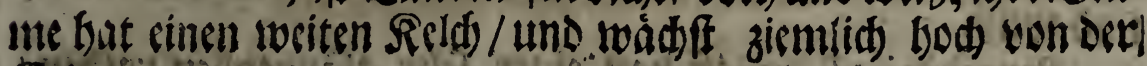
Eroen.

79. Palas, iff Pourpure farbidit uno iveiE. Sultipe.

Paltot Cadons, iff ouncteleroth und gells / und cine fribe

Paltot de trois Couleurs, iff vons siner bleiden Zauken=Fat: be/ Sditweffel=gelf / und roth:

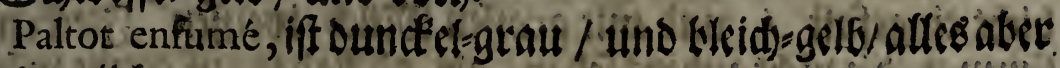
unordentlid.

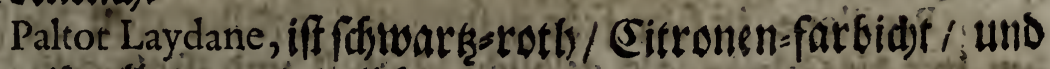
tweif́gels/aties unorechtlids.

Paltot Ledanus; if - von "ciner pekt frifden roflsh

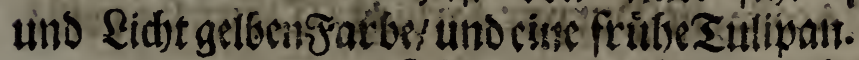

Paltot Pluton, iff foswarkerotb uno gells. 1 .

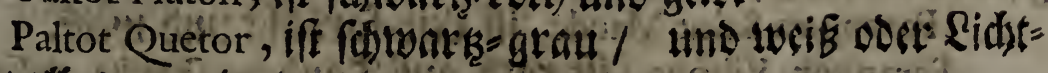
gets / altes nertwiter.

PaltotRobin, if mangelfaffe tipatt.

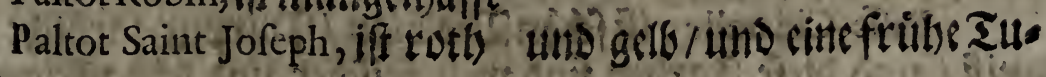

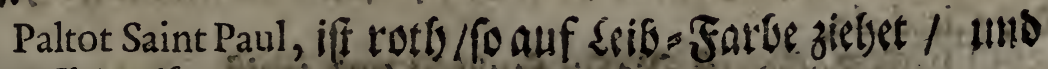
Sd)iveffel

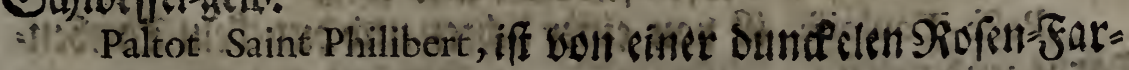
be $/$ rotb tho verwirrt Eitronen = farbidts.

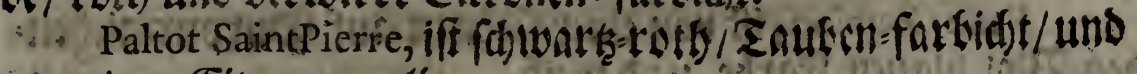
virwirrt Eitronen=gel6. $\therefore-i$

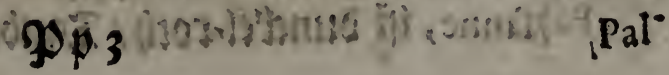


302

Paltot Tenebreux, ift idswark-totb/uno gelb/ weldes leştes re auf (Bem/en= Sarbe ziehet.

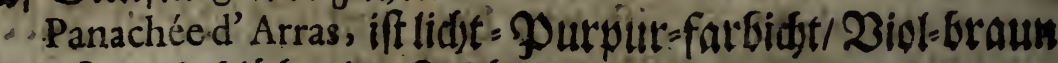
ano weiß / uns bliber im Jtübling.

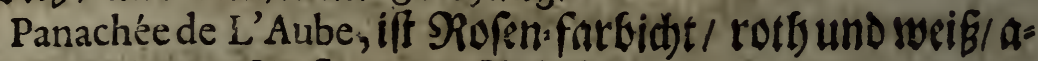
bet nidit gleid) antenfang oer Bblittbe.

Panachée de Caen, hat eine glanisende rotlye, Jarbe i, mit gorfen weiffen $\mathfrak{B}$ uhn $=$ Slede'

Panachte Lief, iff braun=rotb/auf Zauben=-Farbe zieflend/ und tocif.

Panachee de Paris, if bout einer felte glänesenden rotten! uno fdowen weiffen farbe / Die fie gleid) bey dem (Eintritt in

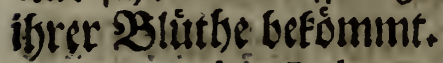

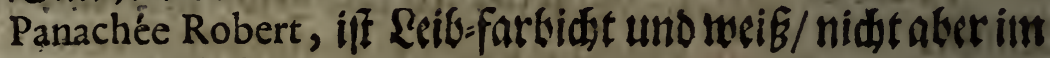
Anfang Der 3 little.

Panfilie, iff fajon 2Biol blau/ um oen Siano Surpur=fars bidet cingefaft / und mit groffen Mrild) - meiffen Jiefen ge fprengt / bie nidtanders feben / als of fie darauf gelegt wáren.

Papillone, iff febr fein gefwrengt / uno hat esen die Far: ben twie die Galatée, alś gelblidot Sfabell uno Gologello / nur

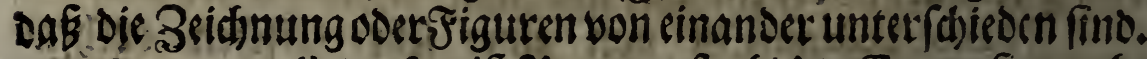

Parangon d' Acofte, if purpur-farbidt/ / Earmefin=roth)! grau und rocif.

Parangon Saint Maudé, if Rcib-farbidtt tuto twsif.

Parangon Viltons, iff rdtb auf Tauben = Farbe ziebeno/, uns fód iveís.

Paffe-Cidatelle, iff fión 2iol(clau / Purpur-farbid)t uno weis / und Diefe Jarken fino tweit frifher und lebbaffiger als Der Citadelle,

Paffe-Rofee, if Siofen-fargidit und incib.

Paffe-Touloife, iff von cimer lideten und Dundetn Taubent Farbe uno weif.

Paffe Zaiblon, iff von siner fabonen auf PurpureziebenDen 2 iol =blauen - Earbe und ineiz.

Payfanne, if Dunceel-totb , Tauben-farbid)t uno weif.

Pein- 


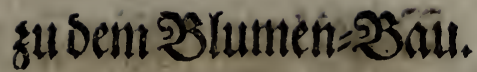

Peintre, if wonsinet frifdensauben= Farbeuno toei $/$ fie Glibet in Dem Jrubling.

Penfee bork Belle Penfee, ift Der Gedancfent oder Dren: faltigecit Blimlcin farbe uno SDild)=tweib.

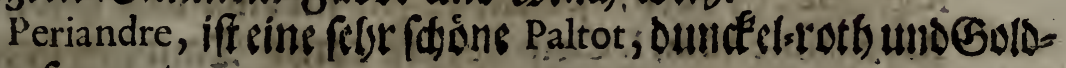
gite gefprengt. tocifi.

Petit Alexandre, if von lidjer ₹auben-Farbe uno Spildf=

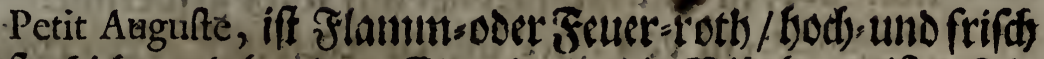
Reib: farbidt uno ber) bom (Fintritt in Die slutbe weif. Sis Estmint filst fuatles.

Petit Suife, iff rotb/ braun unto gelo. fprengt.

Picarde, if lotb und cin tocnig 2iol a blau auf tosib ges

Plumerolle, ift trid)=rotb uno Bemenf farbidt.

Pommce, iff scib=farbidst und rocíb.

Prevôtale d'Abbeville, iff sauben-farbidht/uno bon cinez fat: ten uns unreinen Eeib: 5 Sarbe.

Prefidente, if Siofen=fartidt auf Raib-Sarbe Jieteno / uns bey Dem sintritt in die Blithe locí.

Predentuë, if fobt toobl mit ciuter foonen qurpttrs Sars be / auf tocifi gefwrengt.

Princeffe, iff bod Beib-fartidit / bleids sctb / sitronen=far:

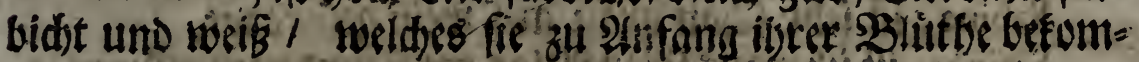
men.

Proferpine, if rotb / Bemfen-farbidt uno siolo-gelft?

fin Pucelle Nichon, ift Sdbarladb-roth/Tautern-farbidt und weib / nidt abet Eet) Dem (Eintritt in Die Slutbe. weifi.

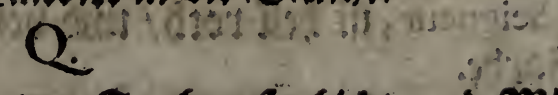

Quirinus, ift Sammet L Tauben=farbidt uns Mild)=

Quatricolor, bat vier Sritben / inemlid) / Senet=Farbe / fate te Tauben Farbe / Oemfon=Farbe / mo unrein tocif.

R.R 2 


\section{git}

Ramonneufe, if von simer lideten uno ountefeln sauben: Farbe/ underin twenig tweip.

Raphaële, iff rotb/ Poomerankent=farbidtt uno gelfe.

12d Ravennoifenum, 1. Chapelle, iff rotb/ Tauben=farbidit /. und Lveiß̧.

Raymonde, if tobis uno rott).

Recrodee, if anuben-farbid) auf wsib gefprengt. pegr weis.

Reguliere, if von siner lideten Tauben=sarbe/roth uns

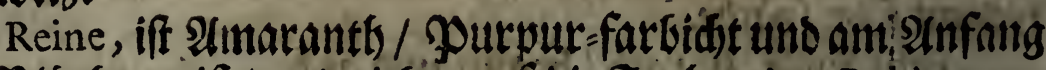
Der Bluttbe weik / uno zieket auf die Jarken Der Robinette.

Richemont, iff fojon Biol blau uno tweif gefprengt.

Richeval, iff febr reid, 2iol = blau auf weí gefprengt.

Robine, if dimarantlentefarbidte uno cimbenig tweib.

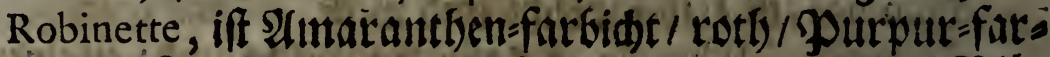

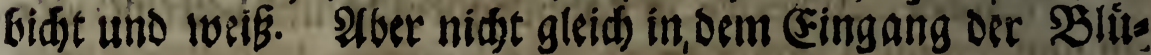
the?.

Roclyefort, if rotb / S(abefl- farbidjt / unt gratt.

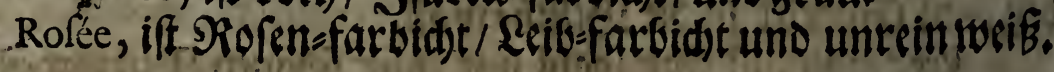

S.

Sabine, if fegr fojon'grau auf toeis gefprengt.

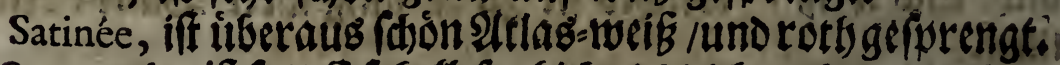

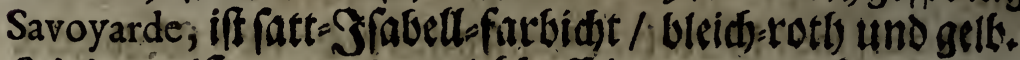
weikisegelb.

Scipion, iff bon einer lebbaftigen rotben Jarbe / und

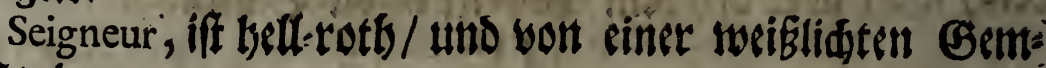
fen= Farbe.

Sergent, if gelo tuns roth / uns Glibet febr fwattbe. Solimene, iff nidt grob; iber Farben fino fojon Purpur uns weib. 


\section{ร̆แ bem}

305

Specieufe, iff bon einer ftomen 2 iol= broumen ober buns

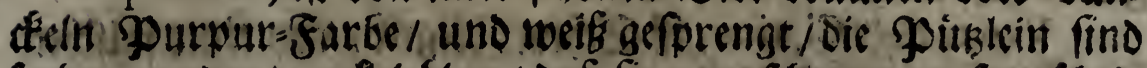

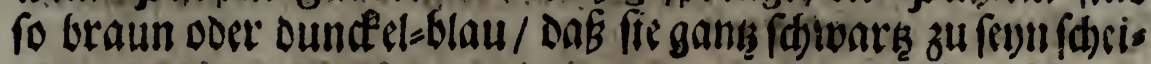
nen.

Specieufe d, Huard, iff purput-farbid)t / half-roth) / Taus ben-farbidt uno weib. Sft cine Fritblings Tulipc.

Suiffe du Château, ift oundell-rotl) / uno blcidds ge(b.

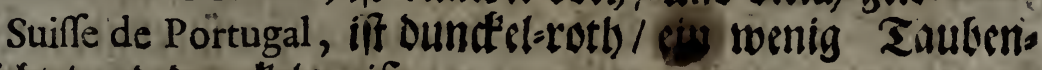
farbid)t / uno Dunctet-rocif. worik.

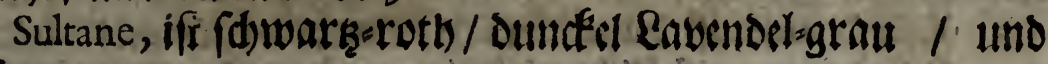

$$
T \text {. }
$$

Tamife, iff Purpur=farbid)t / Biolsbraun und weiß gcfprengt.

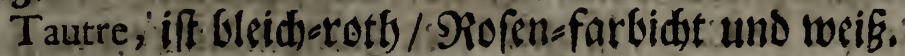

Tarante, iff weif und rothgefprengt.

Tenebreufe, iff cine Gattung Der Paleots, rotb und gelf ge. prengt.

Toûjours belle, dicf sulipe if vergnitgt / Daß itbre Far: ben nidte andern; Dann ifere berworfateinende weiffe und bleids. rotbe Farbe nebinen / von oer Beit ale fie berborgetwadjen bifi fie twieder abfäflt / in geringften nidte ab.

- Travêti, if voll einer bleiden Eavendel grauen farbel Dundfel-roth uno weis; alles aber if verwirrt.

Tüilloife, if Tauten=farbid)t / roth und tweif.

Tulipe de Candie, iff von einer lideten Tauten=Sarbe / uns formirt ibre SBlume wie dag Colchicum Trojanum.

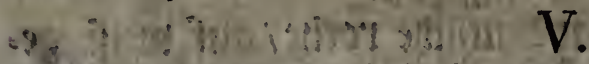

12. Valee, if foisn Purput-farbidt auf weif.

Veuve commune, iff bleidjstotb uns weif.

Veuve de Vignes, ift von eincr Duncétn Purpurt Farbel

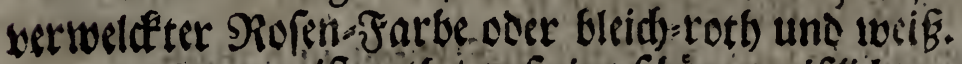

Venitienne, if rotb/auf cine fajone losiblidite $B \mathrm{em}$ en.

$$
\text { QI }
$$

Far 
Farb: Beferengt.

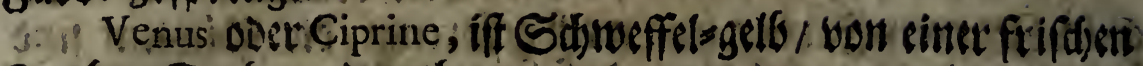
Saubene Farbe uno rotb.

Dundeletweifis.

Vernois, iff lidet Taubsh-farbidst/ Siofen-farbidtet unt

Viceroy, if won ciner auf 2 iol-Graun giefenden Purpure. Farte / und fetsi tweif.

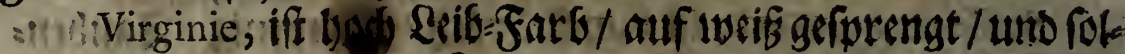

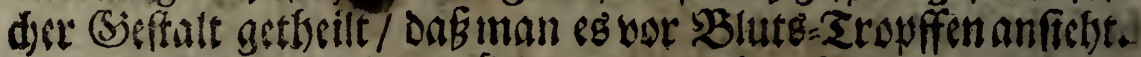

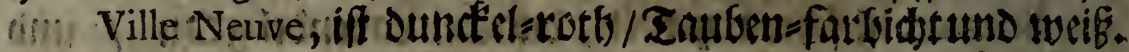

Ville Marets, iff \&id)t viol=blau/ctwas Spurput=farbidt/. und febre lckbafftig weib.

Vigni, ift bell Talben=farbidte / rotb und gelf.

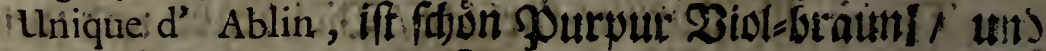

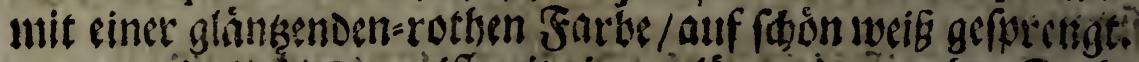

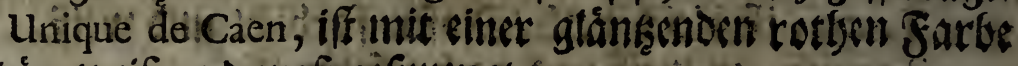
auf foron tweiß unogrob gefprengt.

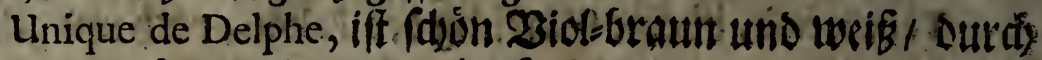
sin Lenig rotf yon einander abgefondert.

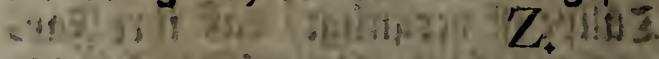

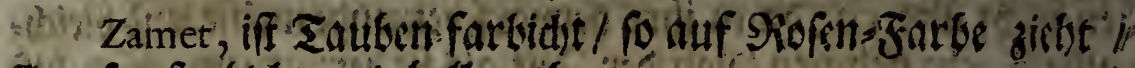
Gemren farbidte uns bettetotls.

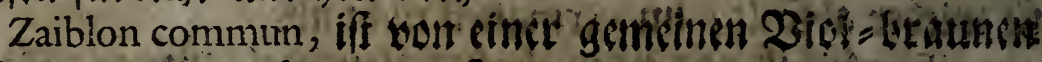
Farbet inwentig roth) uno tweif.

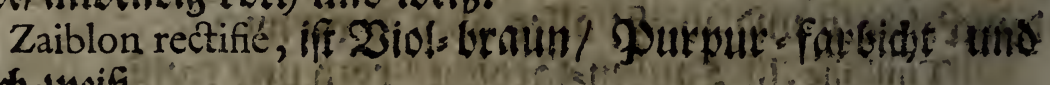
Mild)=1weig.

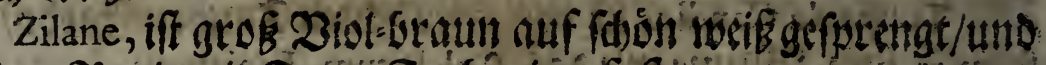

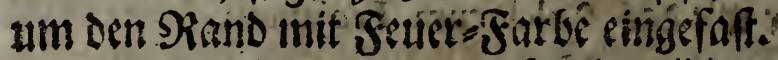

Zurandale commune, bot Doutlidse rotbs / ouf wsif gea

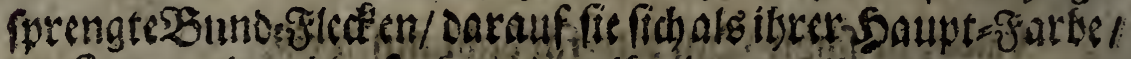

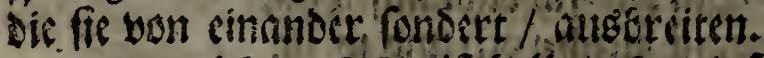

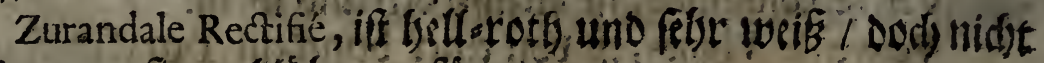
gleid wann fie, zu biutien anfongt.

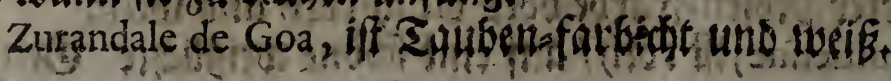

1.2

Bott 


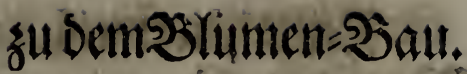 \\ Son der Viola Martia multiplicifiore, ober gefiullen Merk=-2iole.}

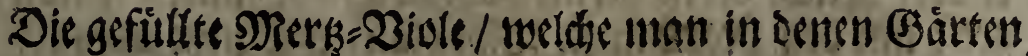

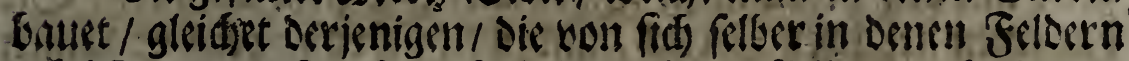

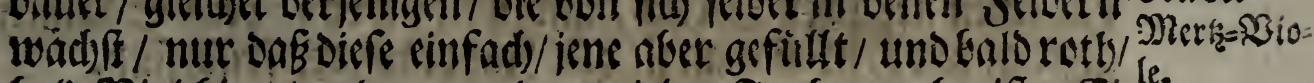

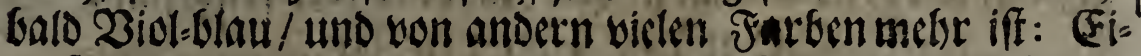
ne fo wobll als ofe andere friedt and Der Erden bin und fresitet fidi) alts.

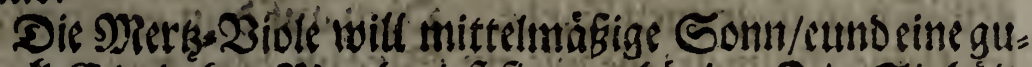

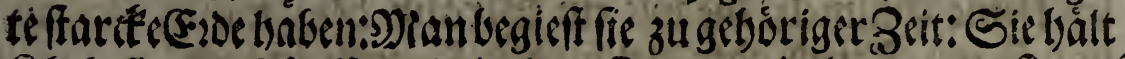

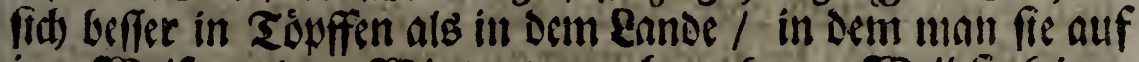
iene 23 eife an dem 23 inter vertwabren fan. 2Scil fie feinen

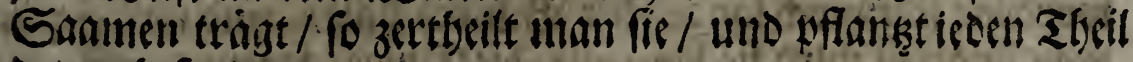
Davon befonters:

\section{Bont oer Viola Pyramidali.}

Sie wird aud fonff Viola arborefcens oder erecta getiannt/

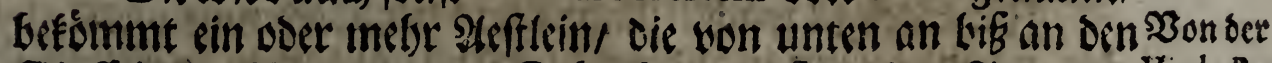

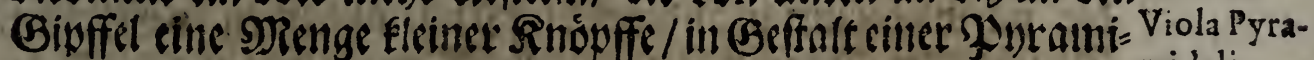

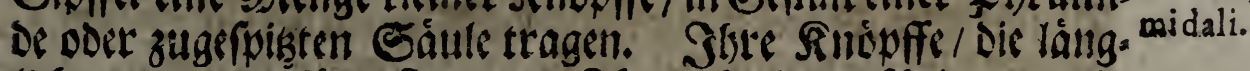

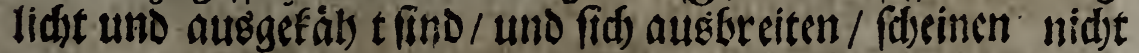
anders / als ob es fo viel Glaue Sterntein wären / auts bercin

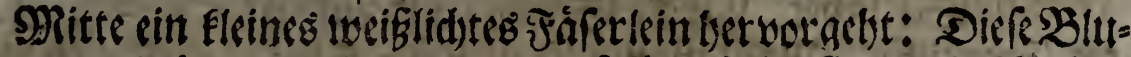

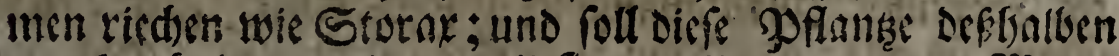
twerth gethalten werben/ weil fie zutweilen 6 , gankset' Menat in Flor fretset.

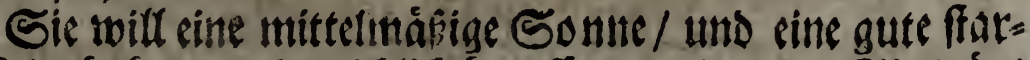
dee Eroe baben uno reidslid begeffen tucrden. Sie tráge feinen Saanten; fortbern man vermelset fie Durd) Dic 28 ura

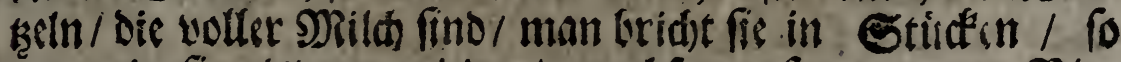

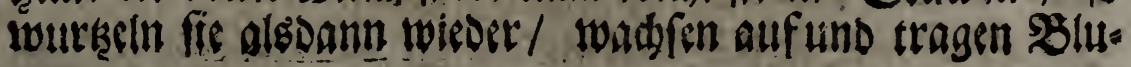
men. 
308

\section{secuetunterweifung \\ Zon Der Cornette.}

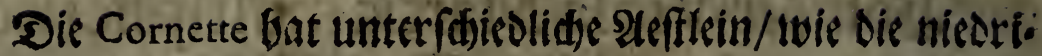
ge Batume ober Stauden/die fely biel Blumen / wie die Bect) er oder Relde ceren gefitften Glodeen=Blumen geftult/ tra. gen; uin ben SRant iff fie Biolsblau / und zieltt auf toth: Sie bat einen liebliden Geruds / uno tweil fie bon ten Snamen gegeugt twiro/ mus man fie afte Sabre wieder frifd faen.

\section{Bon Det Eternelle.}

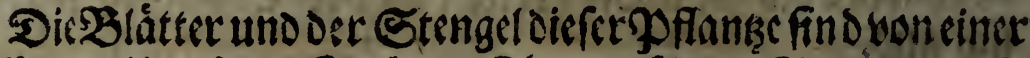

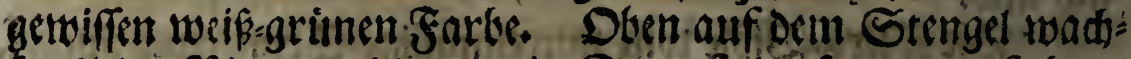
fen fleine SBlumen/ die wie sin Straus bernfanmen fielsen/ uno fo vicl Strob oder blcidogelbs Snopffecin find / und treil Diffe Blume/ob fie gleid) unten an Demt Stengel atgefdinitten worden; iedennod lange Beit Beffand băle, und ifse Jurbe nidbt ámocrt / wiro fie Eternelle, oir Ewoige / gimennt. Sis it= fordert nut eine gemesine uno gemodfnlide 23artung. Bon der Farnefiana odet Triefen:\$2lume.

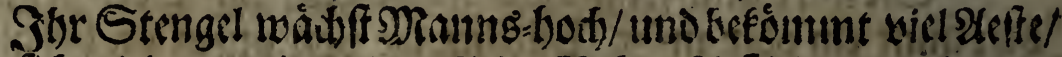

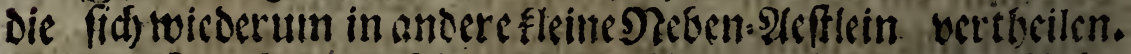

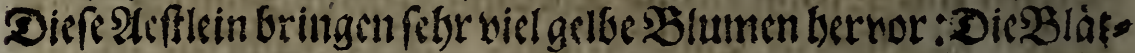

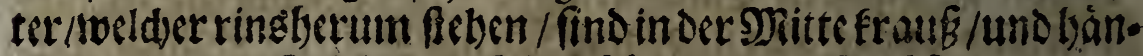
gen an fleinen Gtielen. Sie blibet in Dem Sorfifs.

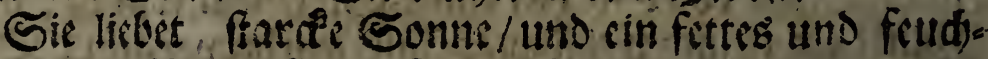
tes (Erorcid): Man pflantht fie 4 - biE 5. Finger tieff / umo

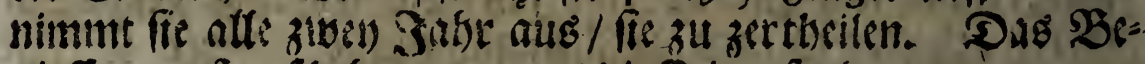
gieffen mus geichetsen/woann es die Bcit erfordert.

\section{QBon oer Plumelle.}

Es gisbt Daren cinfadse uno gefutte / tenter dench cinfa =

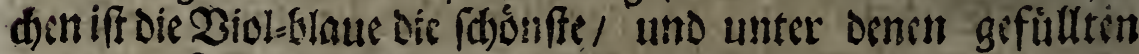

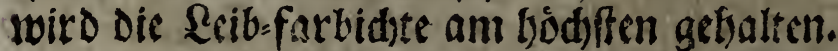

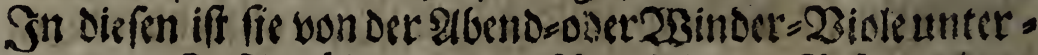

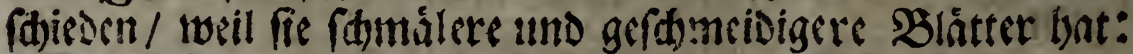
(od) will fie in allen gleide SBartung twie jene baben. 


\section{Bon bem Melonen=:Sau}

\section{Reuer

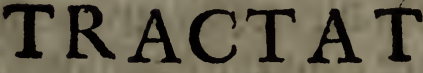 \\ 2on dem}

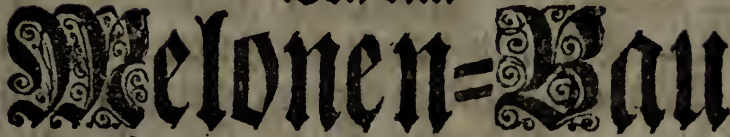

\section{wie detfelbige foll gefülutetwerden.}

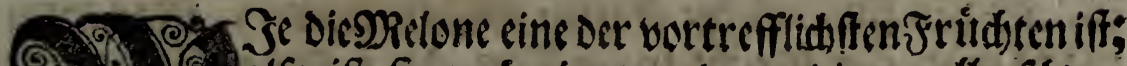
alfo iff fie auds cine bon oenen die nm allerfatwe. -.) 6 greften zu bauen find. Sie muß griwiffe Gradus

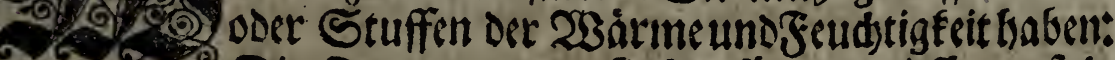
Die Orte / wo man fie bin fáct / / minfen aufeis ne gank befondere Wzeife zubercitet werben. Zunveilen will fie zugeoesft ferm / zumeilen aber \&ufft baben. Rurk / man

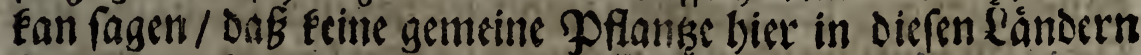
fer / Die incbr Sorgfáltigfeit uno 23artung crfordern / oder oenen jenigen / weldse ibre Ruft an dem Garten=23efen baben/ melbr ubung gebe / ale eben die Melonte.

23eil Diefe futwere Sade / Die Melonen zu bauten / ings gemein befannt iff / bat man Dubor gebalten / Dabes bencn crrieufen Riebbabern fetir angenebom fenn lwerde / wann fie bier bie Aet / Deetn man fid infondertsit in biefigen Prowinsen/

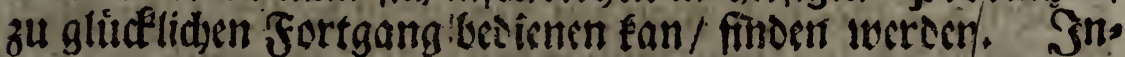

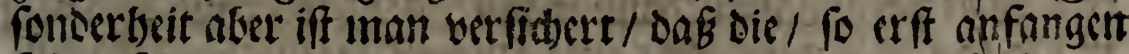

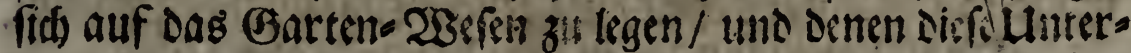

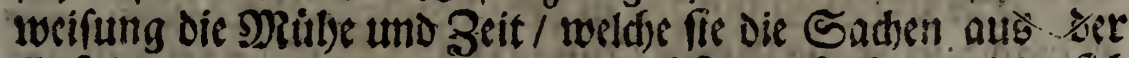
Erfabrung zu lernen/antbenden mirfern/erfpabren iwito / fid erfreuen worren cin leidjtrg Mittel anzutreffen / Dadurd) fie

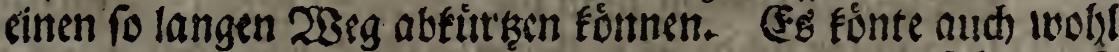

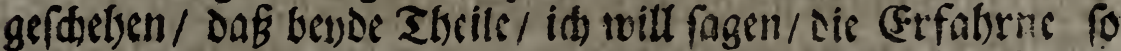

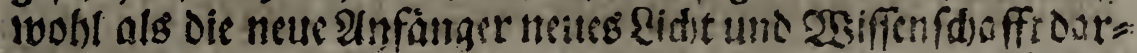

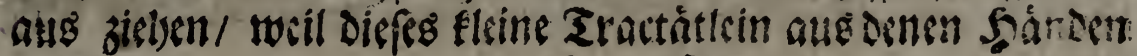


310

Won bem Melonen=:Bau.

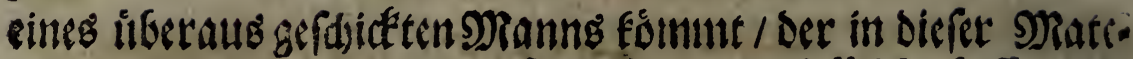

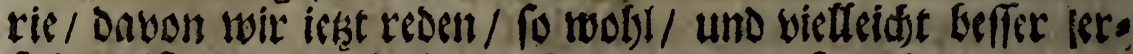
falfsen iff / als simer in denen Dicberlanden fenn Ean.

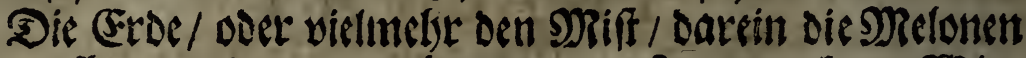

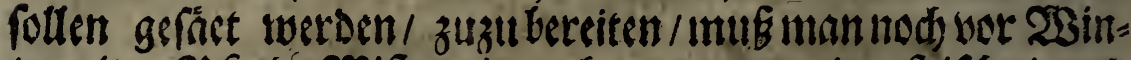

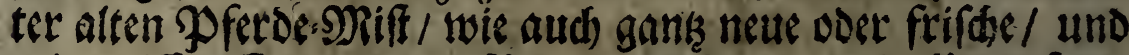

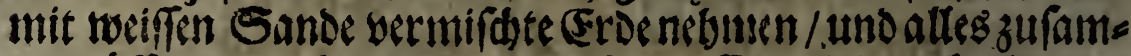
men siffers surds einatoer lwerffen. Es wird aud ein von Brettetn zufaummen genagelter Raffen ver fertiget / Der To lang

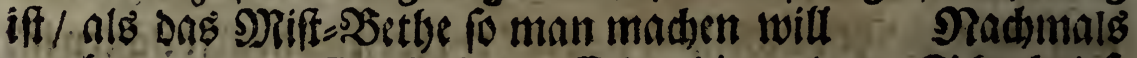

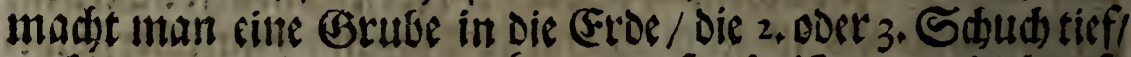

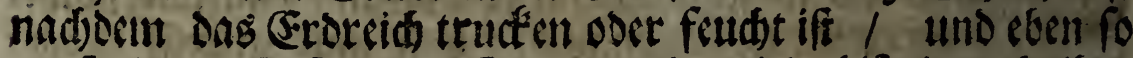

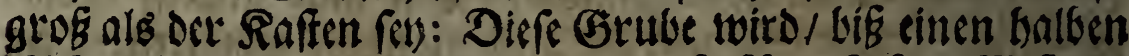

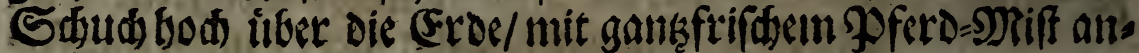

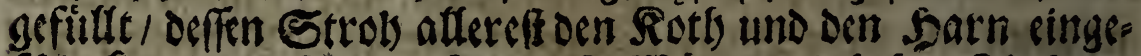

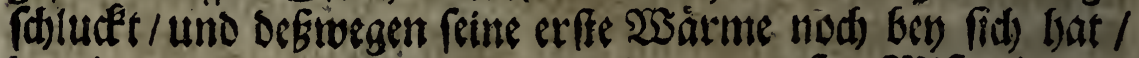
Damit wann er Demf urisen oder alten vertwe fen פRiffe viel bon reiner $23 a$ árme inittlseilet / er Den Saamen feimen / und Die SPflanke aufoeben inadse.

SRad Dem Dic Grube gemadts iff / uno Der Raffen und

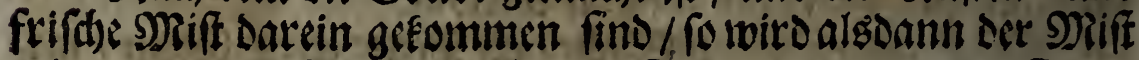
mit 8. oder ro, Buttent woll vertwe ffem und zubersiteten Dung

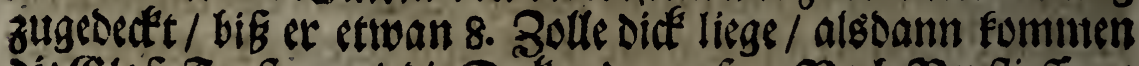

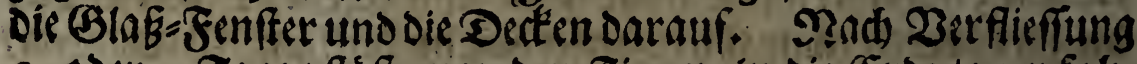
2. oder 3. Tage/ fiboft man Den Finger in Die Erde/zu crfatbs ren / ob fie fich erivártme: Dann wann Dag 23 etter raulb und bart

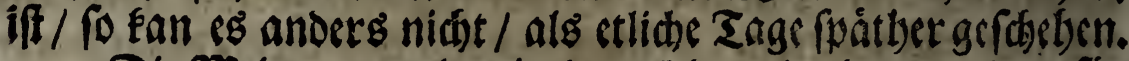
Die Mielonen werden in Dem Februario DDer Martio gefäs

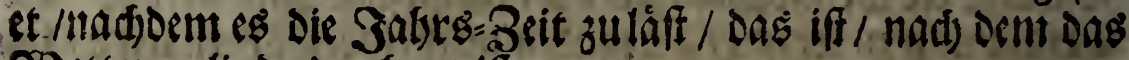
23 etter getind Doer bart iff.

Der Saaune/ Deffen man fids Gebienet / mag fenn wis or

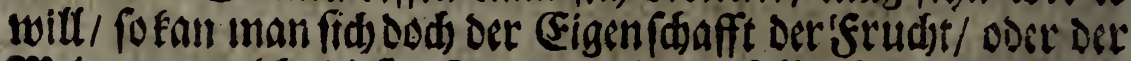
Melonen/ welde diefer Saame bringen forf / ifrer Gattuneg nidjt 


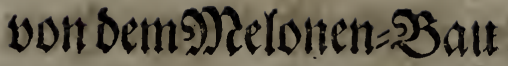

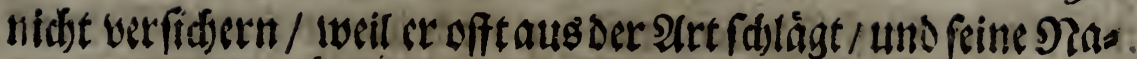
tur in etwas verandert / fo iff audb) Dei Saame / Der an Denen

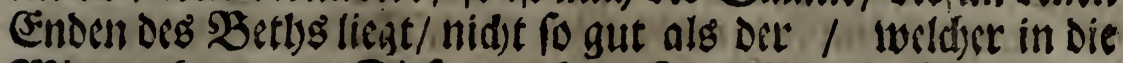

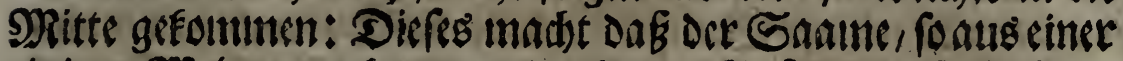

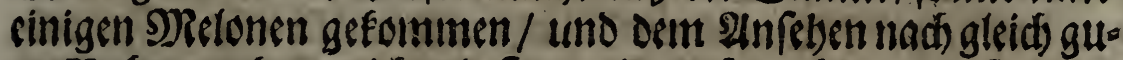

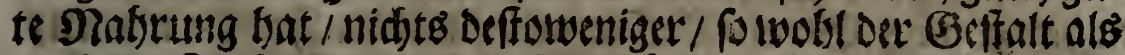

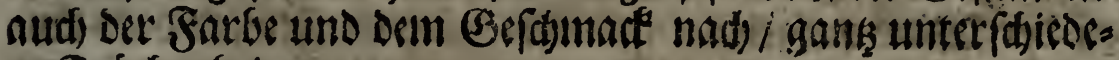
ne Sritutete fringt.

Der Stame uiro gemeiniglid fo tief / als bic Didéc cis

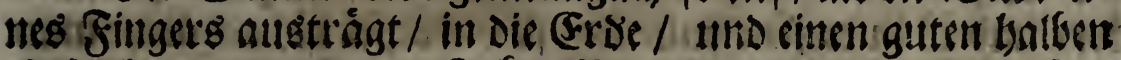
Sditud von cinander geffectet: Man bat nod sine gans fone:

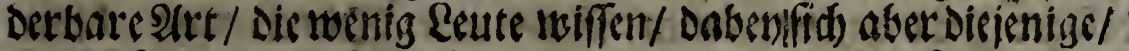

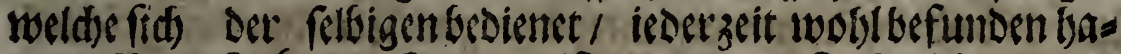

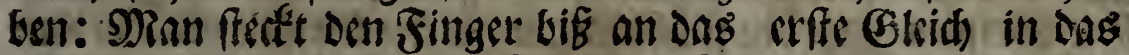

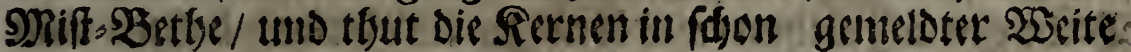

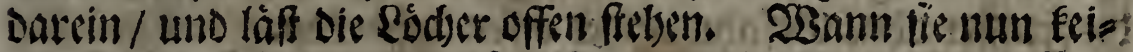

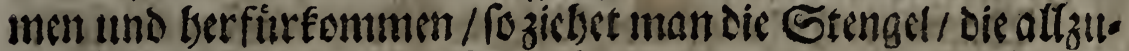

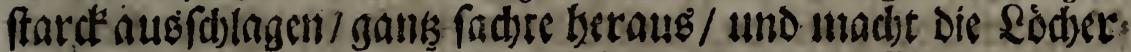

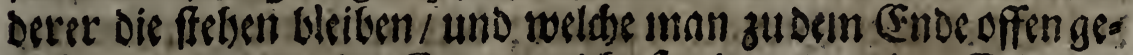
Inffen 1 doumit Die Rernen nidet faulen 1 . thit Eroe zut

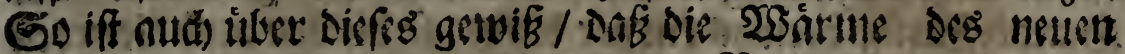

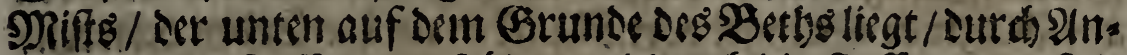

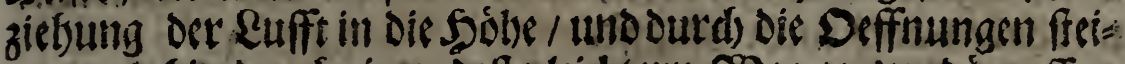

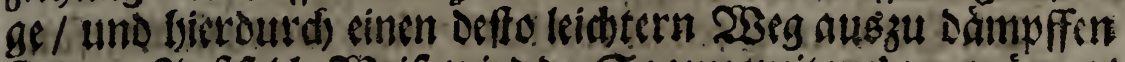

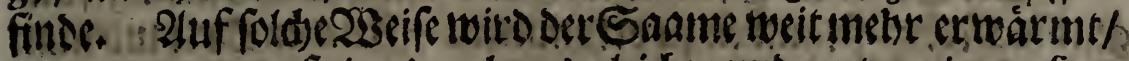

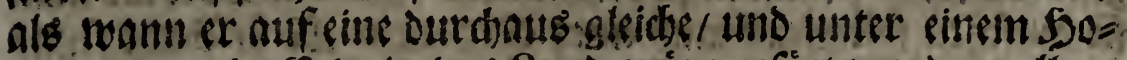

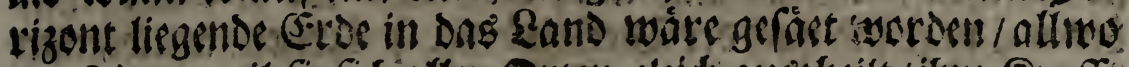

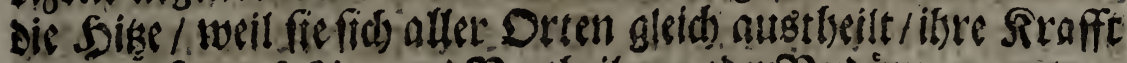

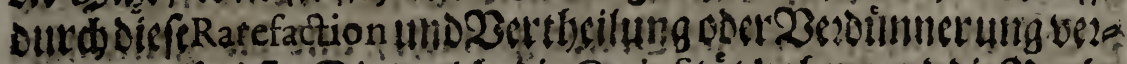

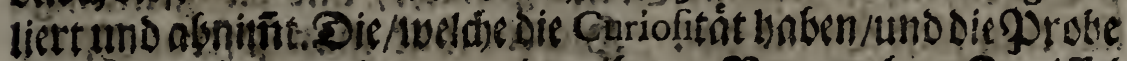

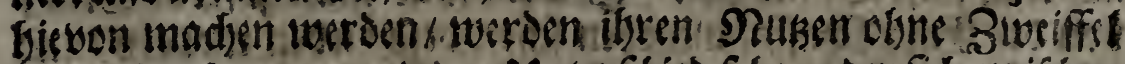

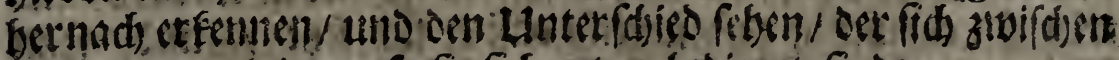

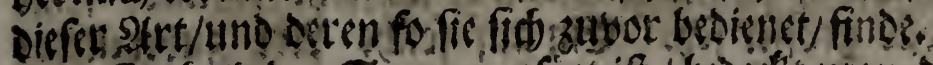

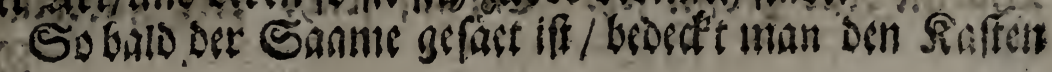




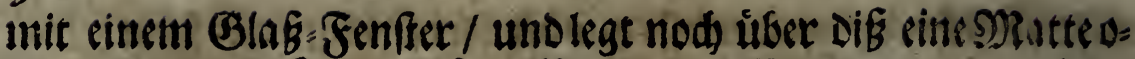

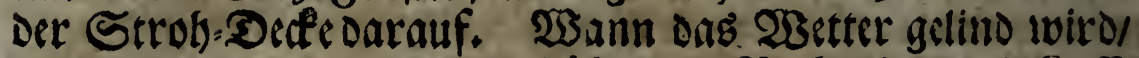

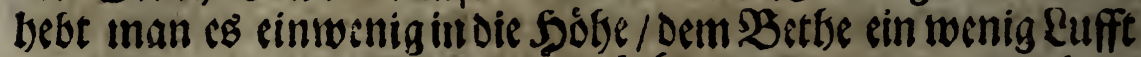
zu geben / Damit Der Stengel zuructée bleibe / und zu bertsins

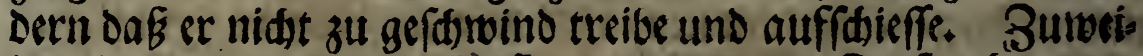
len bänt unan Strob= Decfen neben um die Senfifer berum/ DaE Der $23 i n$ aufgetbalten werde/ und die Fenfter Defto láns ger offen bleiben dorffen: Dann weil die Rufft / wann fie bon.

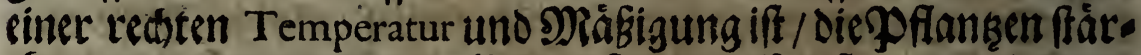

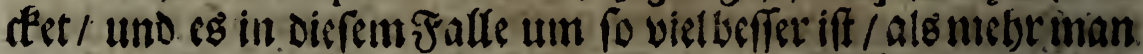

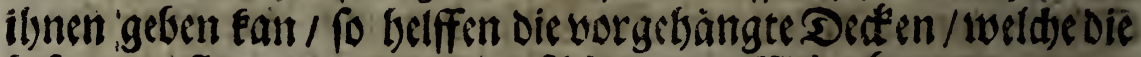

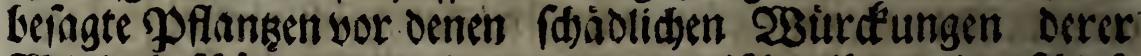

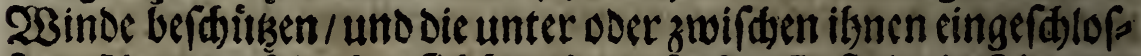

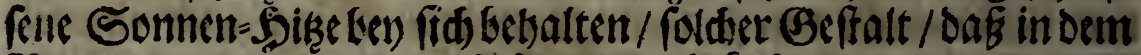
Betbe eine angenebmere 2Barme zuritefe bleibe / Dabero mant die Fenfter obne Gefabr länger offen laffen fan.

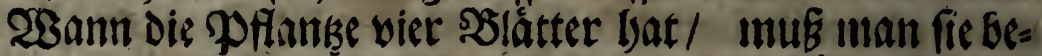

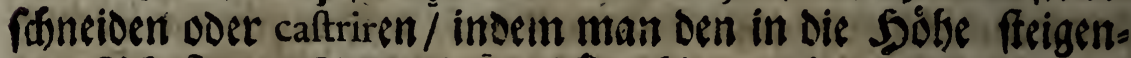
Den Sdjos oder Stengel abjzwidt; bierourd wiro verthinderty

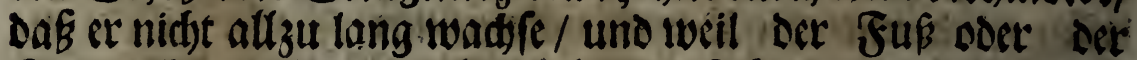
Shaupt=Stengel etwas fint ker bleibr / fo bleiben audb die necben ausidalagende Stengel oder Siancét an der Froen beflebent unobaben auds mebr Rrafft.

Die Meclonen=Stenger iverden werfest/ wann fie angefan:

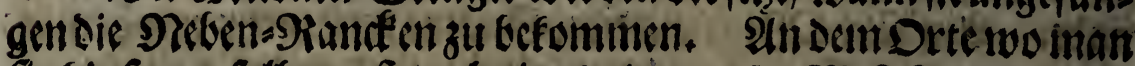

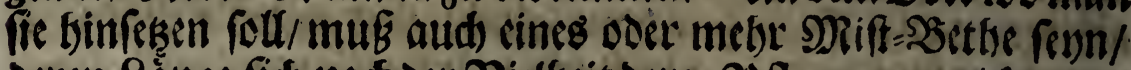

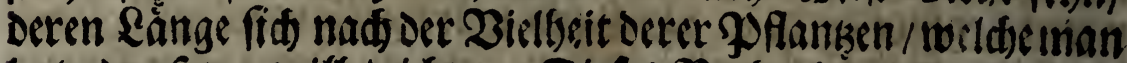
bat oder feren will / ridte. Diefes Betb twiro in cine 2. Doer 3. Sdud) tief gegrabente Grube gemadst / tuno die geineinigs

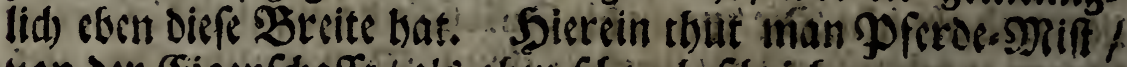
von der (Figenfdafft / als oben foson befabrieben wooroen / und tritt ifn!l ein Ibinig zufanumen / DaE er fids feßse / uns feine Wárme Deffo grofler fey (sin auf foldse art zubercitetes 


\section{won bem Mclonen=?}

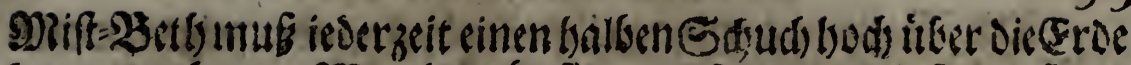

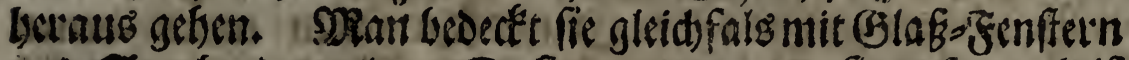

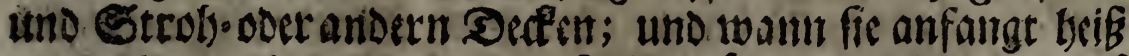

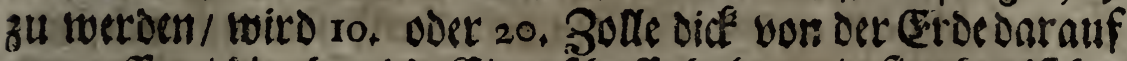
genourfen / sie eben die Eigenfabafft babe/ als fie oben if bre fratieben worben.

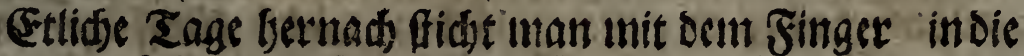
erbel zu erfatien ob fie anfange fid zu erivármes / und wann man finder / DaG fie Den rediten Grad ooer Stuffen der

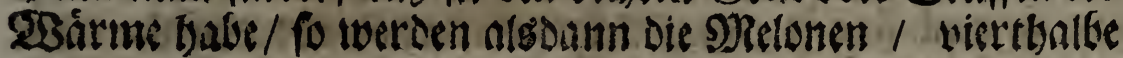

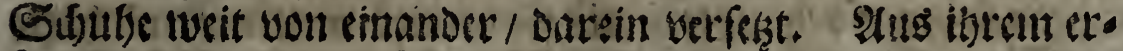

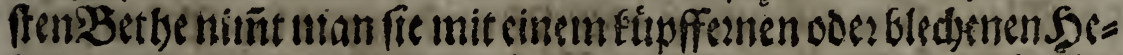

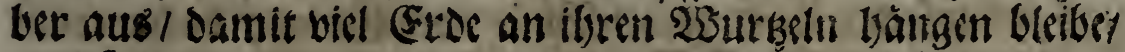

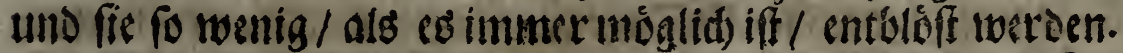

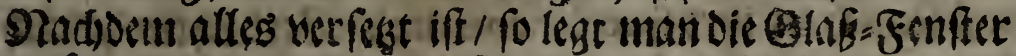

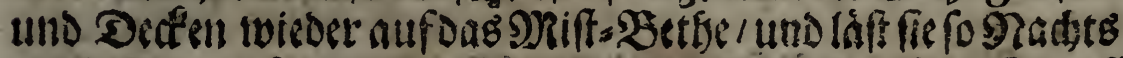

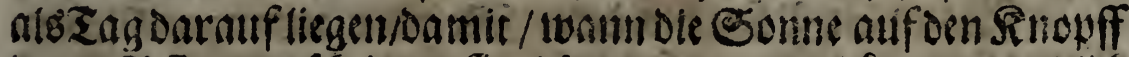

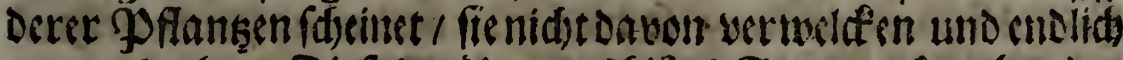

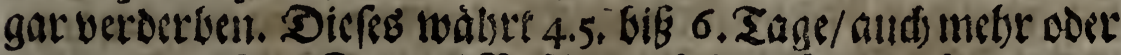

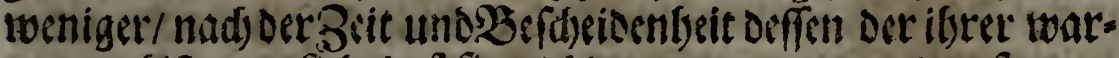

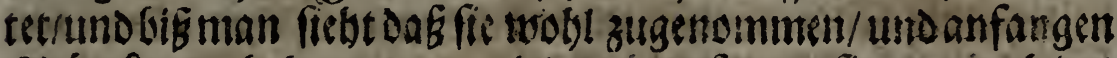

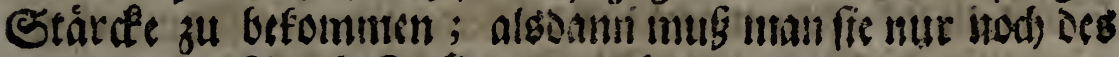
Nadefs init Strols: Dideen verwatretn.

$23 a n n$ man furs nad) Der Beit/ alo bie ostelonen fino

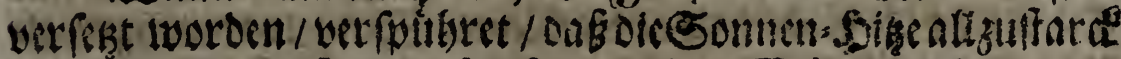

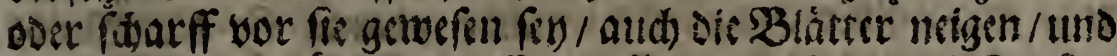

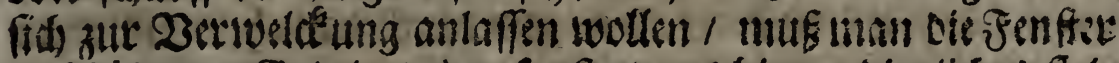

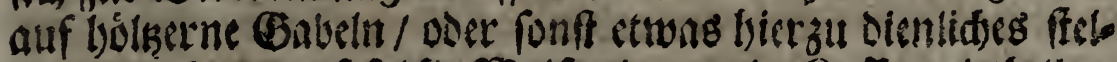

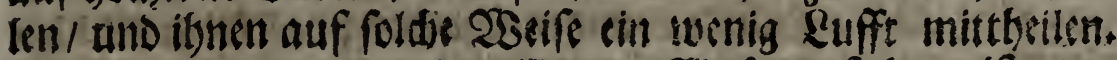

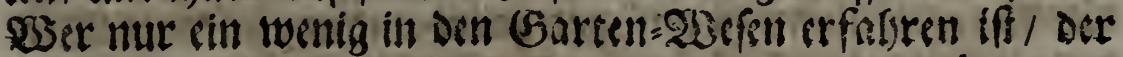

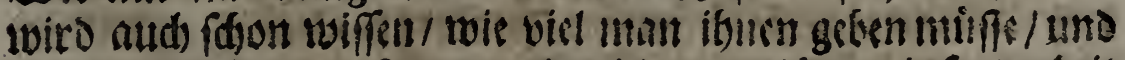

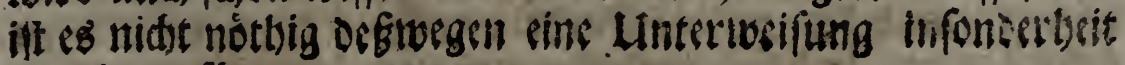
biert beysufufigen. 
Die SR:tonen getwinnen ilgre Rnoppfis / ober zeigen/want Die SBlitt): vergangen/ ibre Frudbt febr felten unter benen

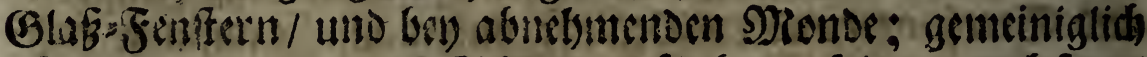

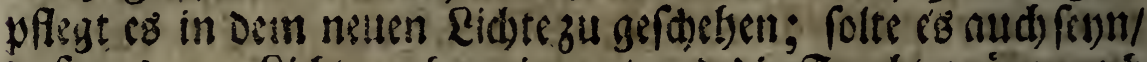

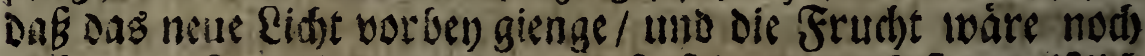
nidbt zum $30 r$ fdein gefoumenen / fo folte man faft getwislid

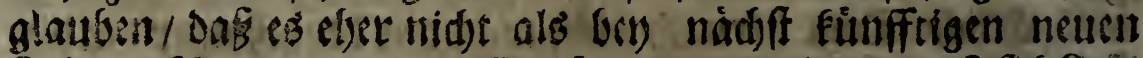

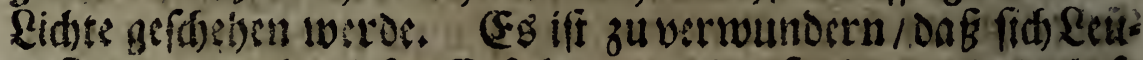

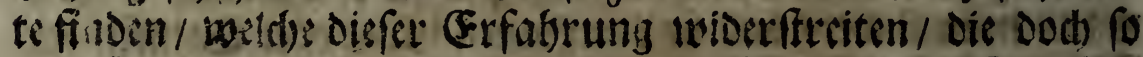
gemis / aud) fo offe gemad)t uno weicbattholt worben iff. Sit

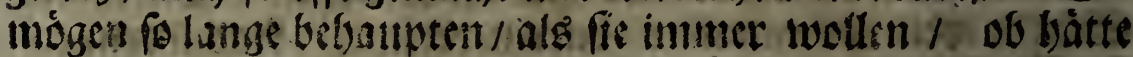

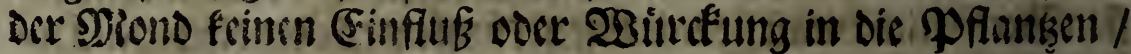

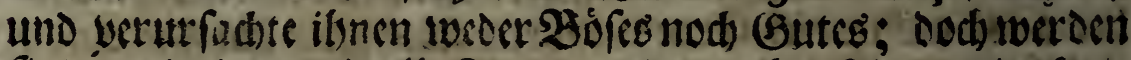

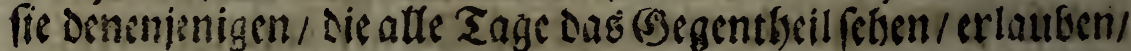

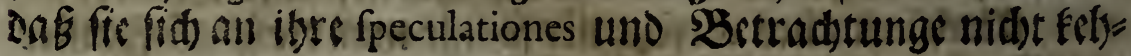
ren.

23ann die \$f fanken derer Relonen anfungen Rebens Stengel zu biépinmen/ fo muß man notthwendiglia) ocn Frefs fer / oder den Nesen=Stengel/ser dic Oherband bat/ aud) ges

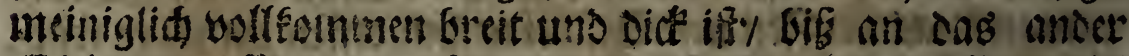

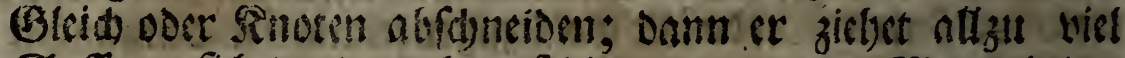

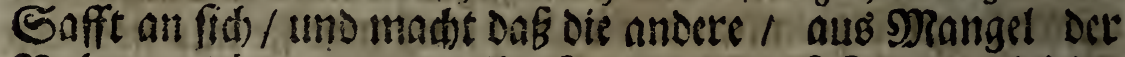

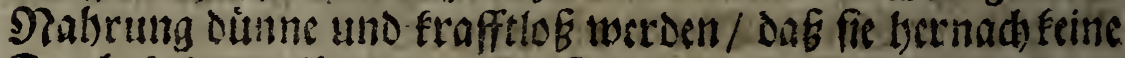
Frudte bringen fénnen. (Fo iff auth gut / waun stan fleine

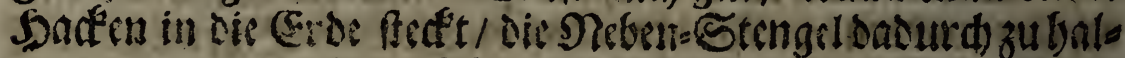

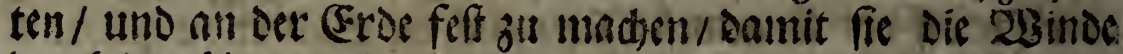
Durón Das bin=uno bertreiben / und Durd) Das berumbalsen auf Derm Betles / nicht vertderben.

Gegen die Stiffte Doer Den 24uggang Deg Denats Maii nimutut Han / toenn cs anfängt gelino uno angenebmer 2Set=

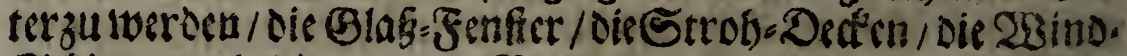
Sdirme und die un Die Betbe gemadte breterne Ráffent

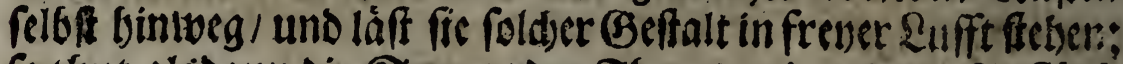
fo thut alebann die Sonne/ Der Thau/ und andegt sinfliffi 
von bem 2) Relonen= 3 au.

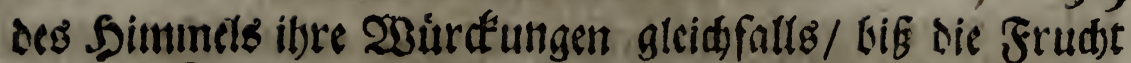

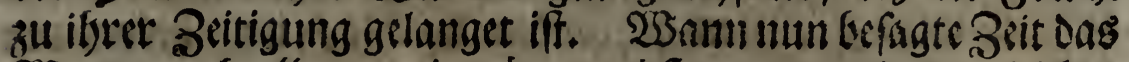

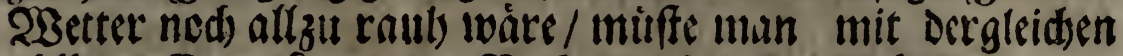
volligen Entoedfung Derer'Betbennod) mebr innebalten; Dann man mus fid bierimnen nad) Der (Figenfdafft trs wsetters oder oer Sabts=3eit/ nidst aber nad) einem getwiffen Tagedes Monats ridtetr.

Man bat fid wobst worzureben / das der Plantze nidbt zu biel Neben = Stengel/und Denen Neben=Stengelmnid)t zu viel Fritd)te getaffen werroen; diefes wird bier generaliter und insgentein gefagt: Dann waต sie Sadse particulariter uns in=

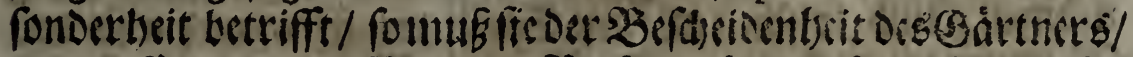

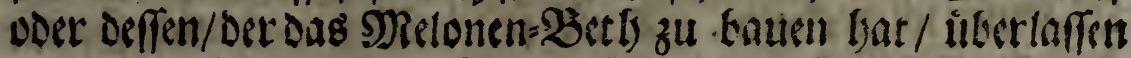

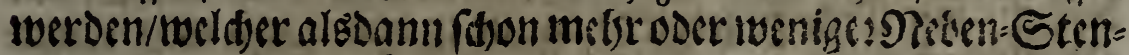

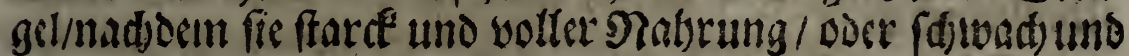
Diune fino / weiro frelsen laffen.

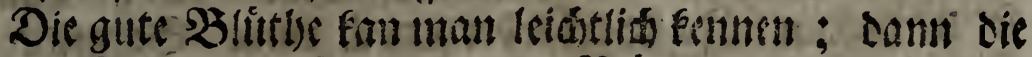
Frudtet erfidseint eben fo beto als die sblittle/ nuth fo gar else Diefe fid nods oben offit. 233ann nlestanit tas 23etter gut

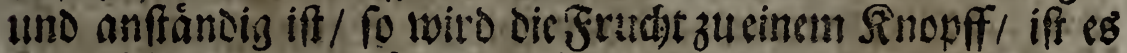
nber bób und widertwartig/ fo faulet bingegen bie Frudbt / und bilfftétein MBittel Davor. Damit Die Fruát an Der guten Blit= then/uno ing fümftige andenen/Dicnod) nidet blittern/ Deffo elser

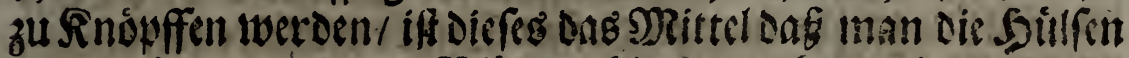
Der tauben oder leeren Blitteen binneg nelyms/ inoen man fie mit benen Vágeln / fo weit unten als es megglid) iff / ats

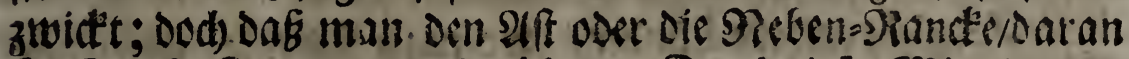
fid) Frud)t findet/ nidst bertilbre. Durd oicfer Dittel / wer = Den die Srudbte Rrafft befommen/ uno in Dem 2Bndsitgum

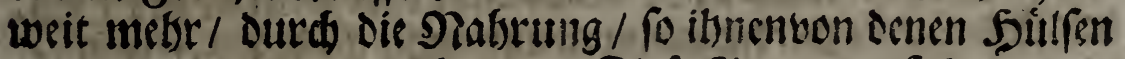
entzogentworden/ zunefomen. Diefe Ant za berfaleren ver: firkst die ârbeit/ und man thut mels in siner Stunte / als man fonft in vielen Tagen zu tbungerwobnt iff: und dicfes $\operatorname{Rr} 2$

ve $=$ 
feremint der frudtet viel beffer / als alle erfinnlidie Sorge und 283 artung/fo man antwenden modjte / ibr frefommen Ean.

Tann Das Mifts gen als is wial / falt gefunoen loiro / muf man nidit unters Infien Daffetsige wisder zu ertwármen. Zu cem Endegróbt man anderthalbe Sdube tieff bie Eree um das Beth at: 1 und thut friften \$frrbe=Miff bincin: Sonft doufften die

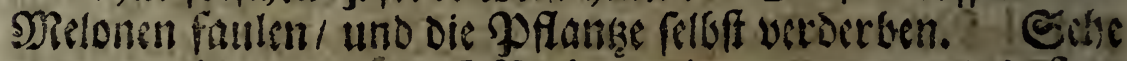

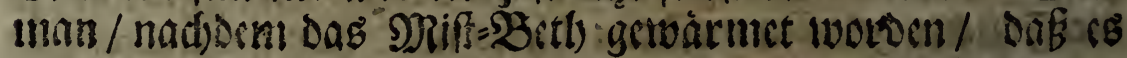
ofermal falt willde / milfe/ man Den vorigen S2)iff bimweg nebsten / uns frifiten an feine Stedte twerffin / und alfo ons

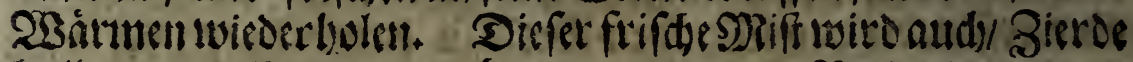

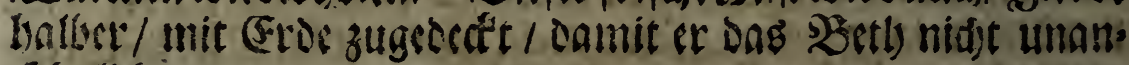
fibulidis madi.

Dit Gurden oder Rufuncen twirden ket) nale aufois fe 2utt gebaut: Jafie erfortern nod mebr Sorgfolt uns Flcißß / abfonderlid) wann iman friths zcitige boben will; woil

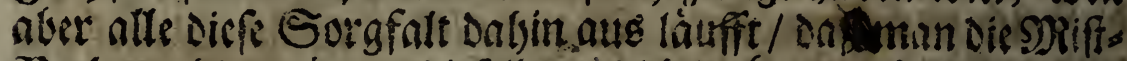

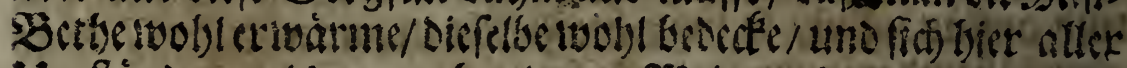
Lumfande / welde man ben Denen Delonen in ads nimint mit nod) grofferer-Zorfidtstyesit bediene/ aud Diefe 20rfids=

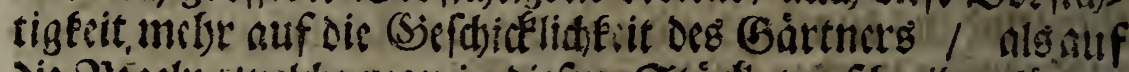
Die Piegeln/lvilde man in biefern Stride borfdireiben fontel anfomint / fo ift es unmotbig nod weiter von sicfs Materie zu reden.

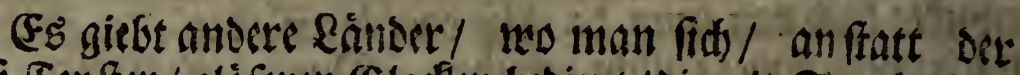
Glabs: Fenfter / glâerer Glocen broient / Dir mit Strob ztige-

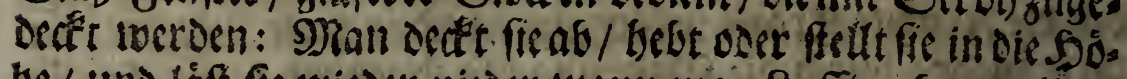
be / und läff fie wieder nieder/wann man Eufft geben wila /

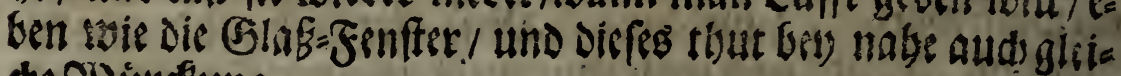
d) 23imcteung.

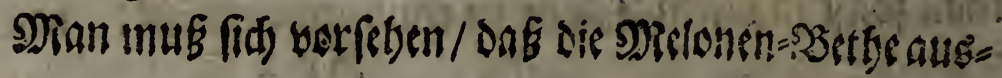




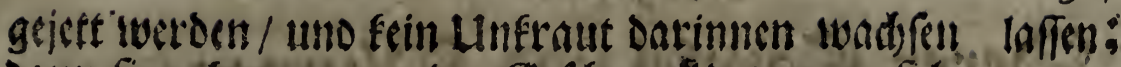
sann fie netbinen gerne dert Gefdomad Bavon an fid.

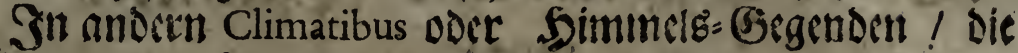

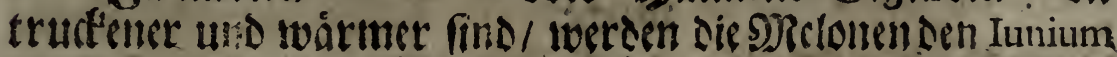

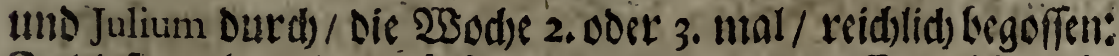

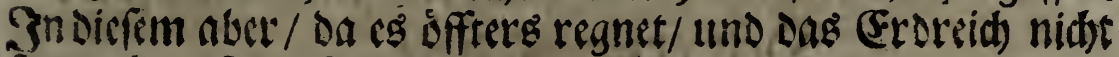
fo tructisn if / gefddidtediefes gar felten.

Sil Diffen Dreen faet man aud) Dit Mitunen= Rerne in fleine runbe Brutsen/Die sitren doer ziwen Sajube tieff find/ unb Darcin man unten friftesen / oben Darauf aber alten פMift gertban/ uno mit guter (Erbe bermengt hat. 238il man fie

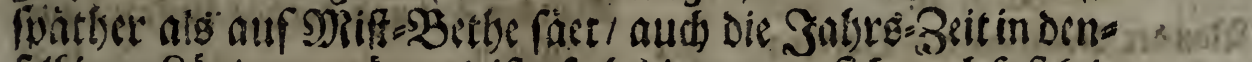

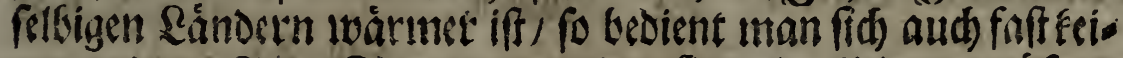
ner andern art: Büweiten werden fie mit fleinen glásern

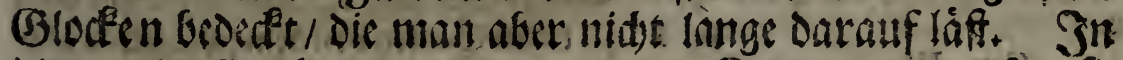
iese runde Gribe thut man 5. DDer 6. Sernen / und fegetfie

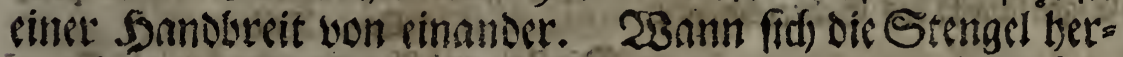

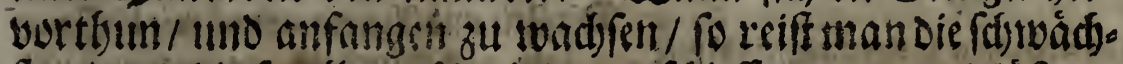

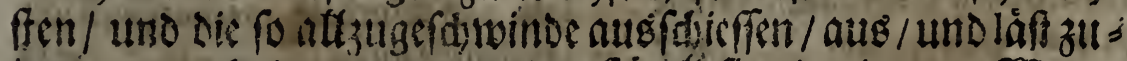

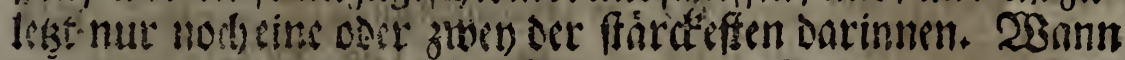

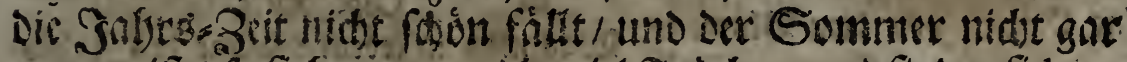

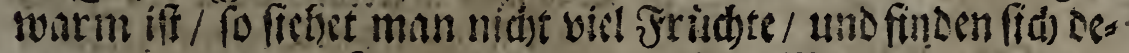
rer werig sis gut find: 23aun aber Das WSerter gencigt iff/ fo gicue siefe art zu bauten/ faft bbite einige Rumft/ Die bethe

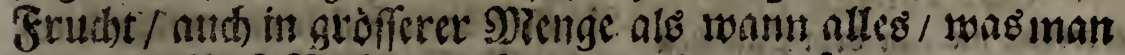

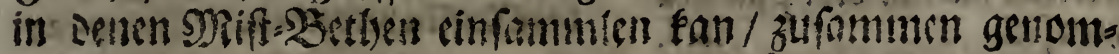

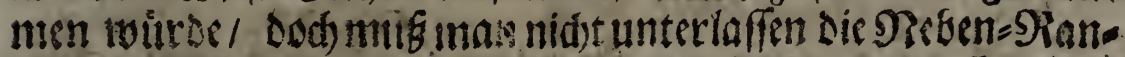

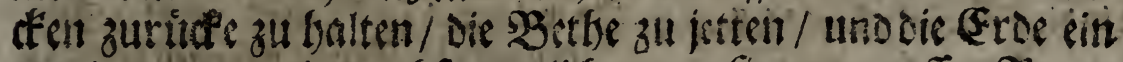

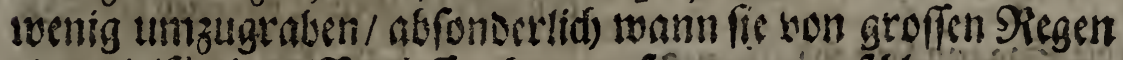

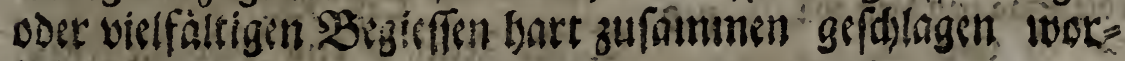
ber.

\section{It 3}




\section{giegifter. \\ 2eter Snpifel und \\ iveldee}

in benen bet)den sheilen diefes 2 Betefisentbalten fino.

\section{Der erife selull.}

Cap. I.

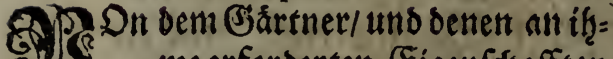
meerforberten Eigenlififferen

$$
\text { Pag. I. }
$$

\author{
Cap. II.
}

Bon ber Situation bes G3artens

\section{Cap. III.}

Son ber Figur und 2Abtheilung des Gar: tens.

Cap. IV.

3on ber Eigenfuafft bes EroreidjE. p.4 V.

Bon benen Blumen insgemein/uno wie man fie foll fennen lernen.

$$
\text { Cap. VI. }
$$

2Alfgemeine Niegeln von bem 3 lumen: $\mathfrak{B a u}_{\text {. }}$

\section{Cap. VII.}

Wann in dem Barten zu arbeiten p. 6 Cap. VIII.

Die Negel tweldie man in bem-Pfinthen beobactiten foll. ibid.

\section{Cap. IX.}

Wie man in die Sherbet pflanţe folle. p.8

$$
\text { Cap. X. }
$$

sorsie man die Gaamen fäen foll. p. p

$$
\text { Cap. XI. }
$$

W3amm/ uno wie man fáen fol. p. so

$$
\text { Cap. XII. }
$$

Sil weldher Zeit des Jaf̧rs man sie Dlu= men verferzen foll.

\author{
Cap. XIII.
}

Sont der Stunde und 2frt ble PPflantsen zu begieffen. P.I2

Cap. XIV.

Bon ber Zeit und 2frt Das Linfraut aus: zujeten.

$$
\text { Cap. XV. }
$$

Bon ber Zeit und 2(rtivann uno wie mant einen Esarten von sem fodadichen Ungejieffer reinigerr fool.

$$
\text { Cap. XVI. }
$$

p.14

Die Zeit und 22rt/mann und wie bie Zwies

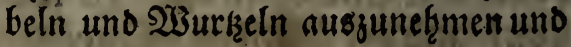
zucrigalten fino.

p.16

\section{Cap. XVII.}

Was man in iebem Monat bes Saf̧rs vor 2(rbeit in Dem 23 lumen=-S5arten ju verridsten frabe.

$$
\text { Càp. XVIII. }
$$

p. 18

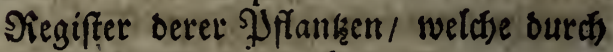
Demisieiffen verderben.

$$
\text { Gap. XIX. }
$$

In welduemAfpect oder@iegend der Son= ner man oie Blume pflanken foll. p.29 Cap. XX.

Welaje Zeiten in oem Safire bie befter renen oie Saamen zu fáen.

P.3I

\section{Cap. XXI.}

Niegiffer derer Yaąrs:Seiten/ an weld)en cin iedes fajone తెendabfe in feinem Flor 


\section{Piegilter.}

Slor fieleget/ nadd Detten 12. Miunaten Des Sabgrs abgethecilt.

Cap. XXII.

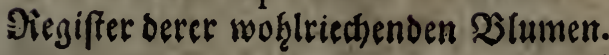

p. $4^{6}$
Diefem ift beygefiggt

Eine Xuslegung etlider Terminorum o:

4. Der 230 orter/oerer fid) die Franizofen bey dem Rlumen=:Bau beotenen.p. 48

\section{Det alldete $\mathbf{z}$ leil.}

Bon ber 2fffobill:Wurk

p. 58 Bon der Sammet:23lume oder aufeno= fojóne. ibid. Don Dencn Inemonen=Sidflein. Cap. 1.

Bon ber Gabonteit berer 21nemonen= Niōblein.

$$
\text { Cap. II. }
$$

Bon ber zu bem 2(nemonen=23au túd)ti= gen Eeden.

Cap. III.

Bon ber Zeit uno 2(nt bie Znemonens Sióblein zu pflankzen.

$$
\text { Cap. 1V. }
$$

p. 66

2Bie man die 2(nemonen Siózlein/von ber Zeit als fie in die Eroe gefommen/biß

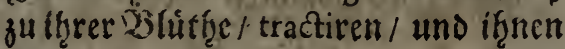
abtoarten múffe.

\section{Cap. V.}

P. 68

Bon der Zeit/wann die 2anemunen-Dió Ietir aligfunef̧men; in welcher Dro= nung es gefónehen for /und wie fie ju er= halten fegcin.

\section{Cap. VI.}

P.70

Bon Denen Sramen/von ber Zeit/wann Diefelbige jufácn/uno wie fie zu bauen fino. p. 72 Diegifter ber haarigen 2(nemonen:Dió $\beta=$ leill.

$$
\text { Cap. VII. }
$$$$
\text { p. } 76
$$

Bon demVerbafco Confantinopolitano, oter Conftantinopolitan. S\$Buffraut
Bont oer Bellide Hifpanica, Epanifden Margrethgen ober Mlaß̧lieben. ibid. Bon benen Campanulis luteis, oder getsen B̉locfen DZhumen. p. 83 Bon dem Sameel $=$ Shal $/$ / oder Der weif fen Fron:? ?arciffe. P. 84 Bon dem Rapuntio Americano, ober ber Cardinals=28lume. P. 85

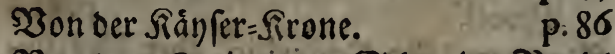
Bon dem Cyclamine, Stjweit = 23root oder Erd =2Apffel. p. 87 Boll dem Dictamno oder Diptam. P. 88 Bon dem Hormino, Stharlact) oder Ŝtit: ter: Sieur.

p. 89 Bon oer Fritillaria uber Fritillerie. ibid. Bon ocm Digitali, Singerḩut oder Şanto. fưur.

अonoer Ge po son der Genifta alba, oder weiffen Ein= ffer. ibid. Bon der Viola Matronali, 2(6endo=oder Mutter= $=$ Biole. p.gI Bon Sagacintigen. Erfte Dromm gerer Syyacinthen. p 92 2fnoere Dronung Derci: Salyacinthen, p.93

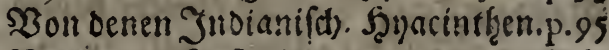
Bon benen Jefminen. Bon Denen Jenquilden/ oder Italiåni: faben Narciffen-Dioglein p.ror Bon denen Taffeter. $\quad \mathrm{P}_{3} \mathrm{OO}_{3}$ Bon ber Iride, oder Biol:SMurk. P. 13 Niegiffer derer Iridum bulbofarum, o oet jwiebelichten SBiof-S23urł. . P. p. 105 Bon 


\section{Fieşifter.}

Won betm Lauro Indicä, ober Jnoiani= furen forber $=$ D aum.

Bon bem weiffen Lilac obet Gpamifaen Enrings: 23 aum.

s2on dem blauen Lilac, coct Gpanifaen Syringsb.

Son Denen siliett.

SBon der Sdywertet=Rilien.

ibid.

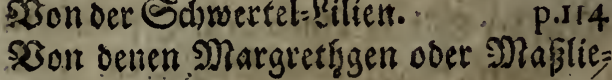

bent.

P. I-15

Bon denen Martagis, oder 5eyduifínen silien.

ibid.

Bon Den Lentifco Indica, ober Inoiani= (f)en Maftix - Daum.

ibid.

SOn demMufcoGreco, oberबiriedsifben M200в.

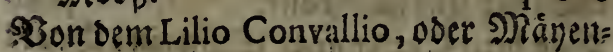

Blituiein.

Bon ber gefútten Mijrte.

$$
\text { Cap. I. }
$$

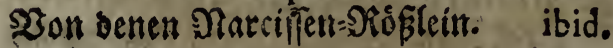
Cap. II.

Bon ber groffen Narciffe/Nompareil ge: nannt.

$$
\text { Cap. III. }
$$

p. 120

Won benen Indianifben Narciffett.p.122

\section{Zon Denen Nelcéten.}

Cap. I.

Bon benen Eigenfwaffin / welche die fbone Nelaten bavien follet. p.126 Cap. II.

20n bem Sopffe oder Scherbel/ barein man die Relcie pflanizen foll. p.129 Cap. III.

Rott ber Erbe/Die fu Dem Nelden= 3 au erforbert wirt.

Cap. IV.

23on ber 2art/ bie Nelden eimblalagen - oper einzufactueiden.

p. I3i

p. 135
Cap. V.

Pon oer Art uno 2 Seife / wie die Deben =

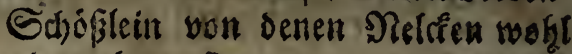
abzunetgmen fino.

$$
\text { Cap. VI. }
$$

p. 138

SOn ber 21rt uno Weife/ wie bie פlelde in oen 3opif gebradit / uno gepflankst merdent foll.

Cap. VII.

p. $14^{2}$

In weldjer Zeit man Die NRe?cte in oas

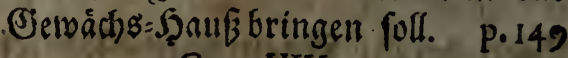
Cap. VIII.

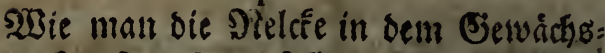
Saufe tractiren foll. ibid. Cap. IX.

Wann man die Tielfe wieder aแ1 ifrem Sietorichs: \$̧aufe nefmen foll.

Cap. X.

p. 154

S2Beld)en Drt/Oegeno uno Situation man Der Nelden geben foll.

$$
\text { Cap. XI. }
$$

p. 157

Irbelaber Sieftalt die síelcfe foll begofien werden/ oder was inall bey dem Eie= gieffenzu beobachtent liabe.

Cap. XII.

p. 160

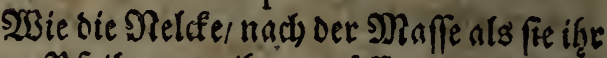
Pfeilgen treibet / milfe gebauet wer= ben.

$$
\text { Cap. XIII. }
$$

p. 165

Daß man ber Delce dic ubcrflibige Snopffe benefimen múfie.

p. 170

$$
\text { Cap. XIV. }
$$

Sie man ber Diclde helffen folle dafi fie blithe.

$$
\text { Cap. XV. }
$$

p.175

23ie unan bie Relde vor bem fajabliçen Ungezieffer verwafiren foll:

$$
\text { Cap. XVI. }
$$

P.178

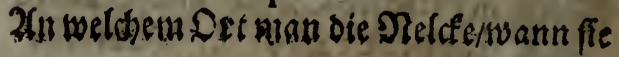


blühet/ftelten foll; infonderbeit aber/ Daß̧ fie vor dem Dhrewurm uno der $2 A=$ meife múffe verwaliret werdent. p. 182. Cap. XVII,

Bon bem Nelsen:Saamen/von ber Zeit/ wann man ifgn fíen foll / und von feí nem Btot oder Staude.

$$
\text { Cap. XVIII. }
$$

Bon denen Sirancf f̧eiten / bie ber. Nelffe zusufolfen pfiegen.

$$
\text { Cap. XIX. }
$$

p. 187

Bon benen Nanen oerer Deldét / uns auf weldbe Art man fie iḩner geben foal.

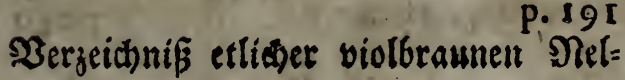
cfen.

P.193

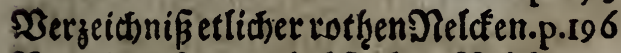
Bergeidniß berer leibfarben Nelefen. p.

Berzecianí̧ berer rofenfarben Nelefen.

197
cten.
.198

Berzeiđaníß berer weiffen Delefen. ibid. Berseid)ni iß berer picotirten ober gebipff= ten פeldén.

Bergeidhniß̄ berer orey/ viet/ uno fúnff= farbidten Nelafen.

\section{Cap. XX.}

SBont ber Sdjónheit und Defétreibung ett.ffhonen Dieléen infonderheit.p. 200 Boiolbraune Delfen infonberheit be: fobriebert.

Niothe Melfen infonberh. befitor. p.2 I3 Seibfarbe Melden infonderf. befars.p.221

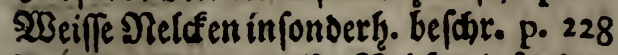
Picotirte ober gedipffte Dielden infonder: Geit beforteben.

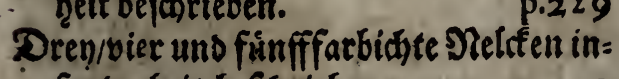
fonderfieit befostieben. Son Der Auricula Urfi oDer SBären $=$ Debrlein.
Cape I.

Bon dem Urjprung oder.jerfomnten des Báren:Dehreteins.

$$
\text { Cap. II. }
$$

Bon Denen Eigenfîfaffen/, weldhe bie f̧̧ơne Bären=Def̧rlein ţaben follen.ib. Cap. III.

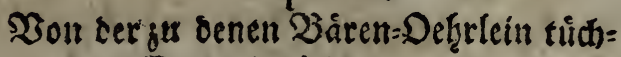
tigen Evle: ingleiden roie man biefe SBlume in oem Fopfie uno in itgrer -Bluttre tractiren / uno bie Neben= Sabó̈́tein dabon abneţmen foll. p. 235

$$
\text { Cap. IV. }
$$

Bón Dem Saamen deg biáren:Def̨zleims: von der 2 trt senfelbigen ju fáen/und oic

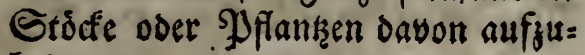
bringen.

P.239

Bon Der Orchis Serapias, Serapifaten Stendel=283ut oder Rnaben=Staut.

p. $24 \mathrm{r}$

Bon bem Ornithogalo, $\mathfrak{B}$ ogel= Rraut os

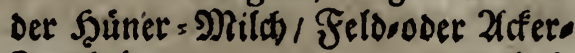
Zrwiebel. ibid.

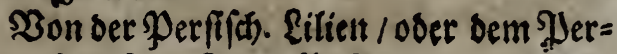
fianifben Feder:\$ufth.

Bon oer Paraly fi, 2 erg $=$ Sanicfel $/$ oder Berg=Salliffels: lume. Bon der \$apítong=2Blume. ibid. Bon denen Eripolinifanen Panundelir ober Şanent= Fư

$\mathfrak{B}_{\text {onIo }}$ (en obersiofen= Etráud)en.p.247 Bonocr Efrimefiften Diofe. p. 250

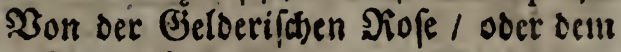
פio jen-Şollunder.

p. 251

3on dem Saffran.

p. 252

Bont der Scabiofa, Erabiofen ober 2ípo= ftemt=Siraut. ibid. Bonber Sgarza Odorata. itid. Bour ber Confolida Regali ober Sitter= Sporn. 


\section{Siegifter.}

Bon der Planta Maxima, oder groffer. Sonnent-23lume. ibid. Moit bem wohtriedsenden Biefen:ober Sumpff: STlee.

20on Der ₹uberofe.

P. 254 ibid.

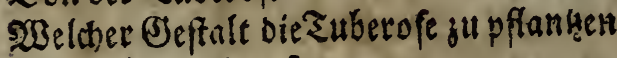
uno ju erḩalten fen

P. 255

\section{Won benen Suliparen.}

\section{Cap. I.}

Bon dem Unterfshied derer Zulipanen/ und iţren Ẻattungen. p. 256

Cap. II.

Bon benen Eigenf(d) afferen/beldde (d)ơne Zulipanen ḩaben follen.

$$
\text { Cap. NI. }
$$

Bon ber ju denen Zulipen ober Zulipa= Cap. IV. nen tiitstizen Eroe. son der Zeit uno 2art bie Zulipen ju plankzen.

$$
\text { Cap. V. }
$$

2Sie ntan bie Zulipanen/yon ber Zeit als fie in bie Eroe gefommen / bi is zu iherer Şlüthe/traêtiren/ uno ighnen abwarten forl.

Cap. VI.

p. $270^{\circ}$ Bon denen nóthigen Ainmercungen/ /wie oie Eutipen / wann fie blühen / augzu= jeidjnen; und yon der 2 Bathli berer / oie ju dem Samen uno benen Theatris ooer Blumen = Butifnen túchtig fino.

p. 272

\section{Cap. Vm.}

Bon ber Zeet / an woeldyer ble alviebeln ausgenommen sverden múffen/sont tḩ rer Dronung und Errhaltung/von Des: nen Saamen und ifrer Erryaltung Bon ber Zeit biefelbege ju /ăen/ uno wie fie gu bauen.

\section{Cap. viri.}

p. 276

Bon denn Bau der Deben=2rut/und wote fie die Sarbe ihter Mutter-sp flanķe be= fáñoig erţarlte.

P. 279

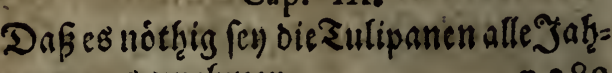
pe ausjunetgmen.

p. 280

\section{Cap. X.}

Bon denen Sirancflfeiten derer Sulipa= nen/ und bem Mittel iḩnen wledcr zu hielffen.

Cap. XI.

P. 281

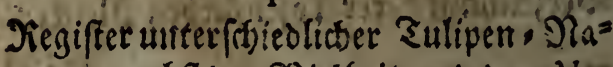

men/nebft der şielf̧eit und dem Un terfotied ilfrer Farben. p.284 Bon Der Viola Martia multiplici flore, os Ser gefúlten S)erk=-SBiole.

P.307. Bon oer Viola Pyramidalio .... ibid. Visa der Cornette. $\quad 50$ P. 308 Zon der Eternelle. Son der Farnefiana poer Qhiefen: Shlume Szon ber Plumelle. ibid? ibid.

DeuerTractat von sem Plelonen2s attzó. (E) ก

C ORR I G E N D A

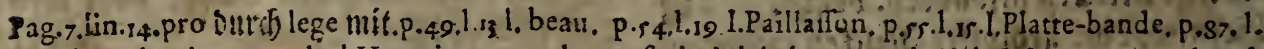

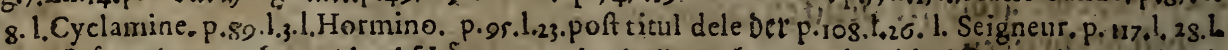

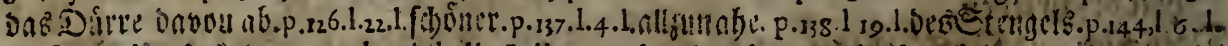

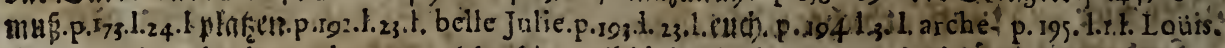

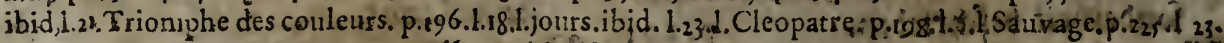

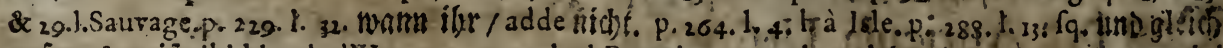

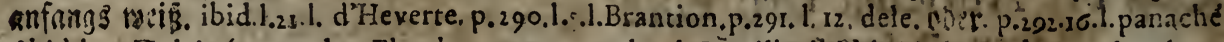

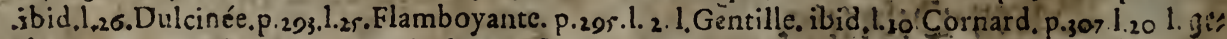

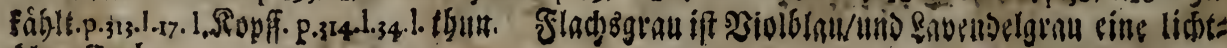
blategarbe. 


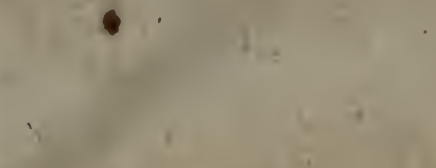

$+1$

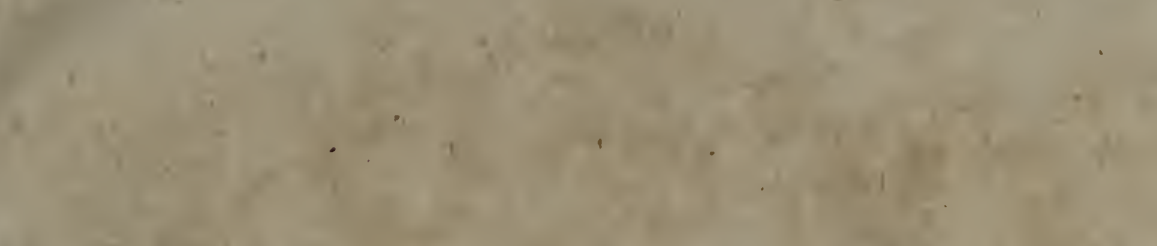

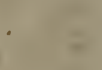

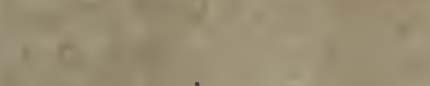

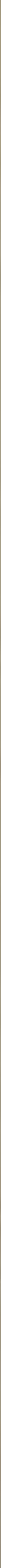




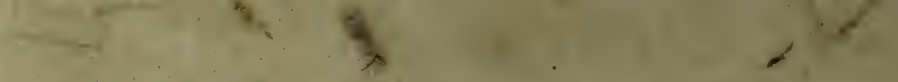

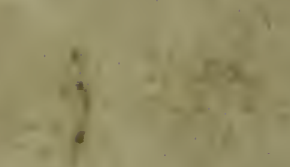

$$
\text { *3: }
$$

i.
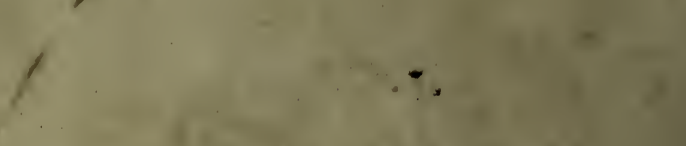

$145 x+6$

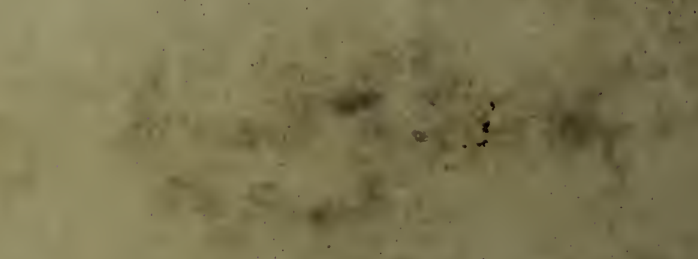

s.

s.

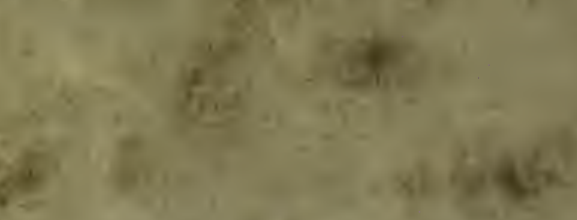

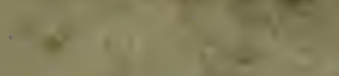

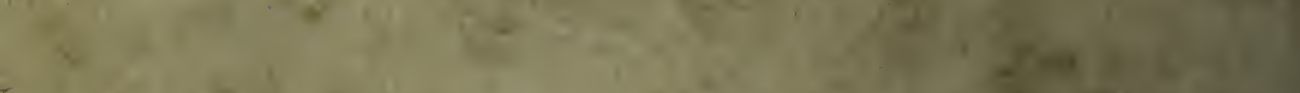

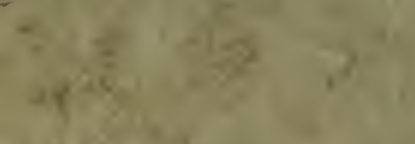

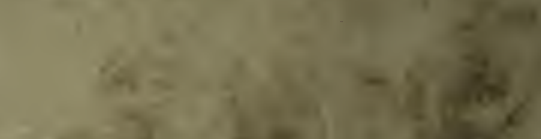
de s.

in

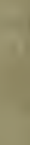

$\left(x^{4}-x^{2}+2 x^{2}+3 x\right.$

$$
x^{2}+x^{2}
$$
$\sin ^{2} \mathrm{~A}^{\mathrm{t}}$ $28=$ का
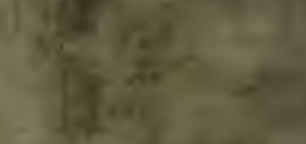

$+8=$

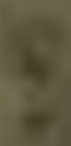

